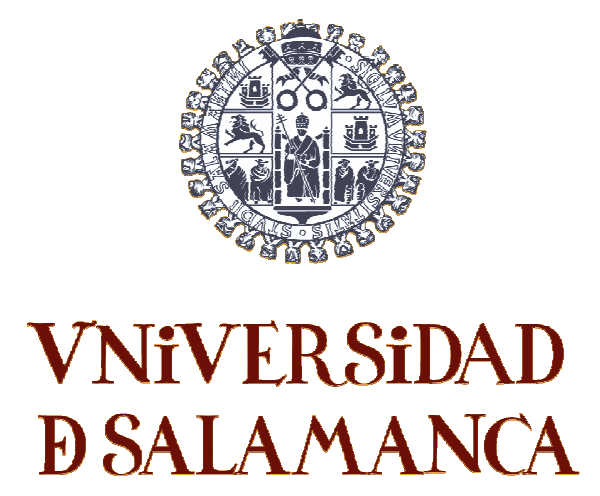

FACULTAD DE PSICOLOGÍA

DePartamento de PSicología Evolutiva Y DE LA EduCACiÓN

Tesis Doctoral

Características psicosociales, calidad de vida y

necesidades de las personas que ejercen

prostitución

Ruth Pinedo González

2008 
El Dr. D. Félix López Sánchez, Catedrático de Psicología de la Sexualidad del Departamento de Psicología Evolutiva y de la Educación de la Facultad de Psicología de la Universidad de Salamanca, y la Dra. Dña. María Begoña Orgaz Baz, Profesora Titular del Departamento de Psicología Básica, Psicobiología y Metodología de las Ciencias del Comportamiento de la Universidad de Salamanca,

\section{CERTIFICAN QUE:}

El presente trabajo de Tesis Doctoral, titulado "Características psicosociales, calidad de vida y necesidades de las personas que ejercen prostitución", realizado por Dña. Ruth Pinedo González, licenciada en Psicología y en posesión del Título de Grado de Universidad de Salamanca, se ha desarrollado bajo nuestra dirección y supervisión, reuniendo, a nuestro juicio, los méritos suficientes de originalidad y rigor científico para obtener el Doctorado Europeo.

Para que conste, firmamos la presente certificación en Salamanca a 22 de Julio de 2008.

Fdo.: Dr. D. Félix López Sánchez
Fdo.: Dra. Dña. María Begoña Orgaz Baz 
La gratitud es una de las virtudes mas sublimes del ser humano y sin ella, todo lo que uno hace, perdería su verdadero valor. Por ello quiero agradecer su apoyo a todas aquellas personas que me han acompañado en este largo camino, en el que más que un logro intelectual, he alcanzado una experiencia verdaderamente humana.

En primer lugar gracias al Dr. Félix López por su dirección, su apoyo y su confianza, y a la Dra. Begoña Orgaz por su trabajo incansable, sus consejos y su ánimo constante.

Gracias al Dr. Neil McKeganey y la Dra. Marina Barnard por permitirme una estancia tan acogedora en la Universidad de Glasgow y todas sus aportaciones a este trabajo.

Gracias a mi familia porque lo que soy y donde estoy se lo debo a ellos. A César por su comprensión en mis ausencias, su inestimable ayuda y por estar siempre presente. Gracias a María por estos más de veinte años de amistad, sus críticas y por todas esas horas que me ha regalado. Gracias a Rafic y Mario por sus aportaciones lingüísticas.

Gracias a María Gutiérrez-Cortines y Manolo por permitirme trabajar estos años en el Programa LUA donde he aprendido la verdadera esencia del trabajo con las personas que ejercen prostitución.

Gracias a todos mis amigos por escucharme, darme su apoyo y quererme tal y como soy (Rosa, Fernando, Elena, Eliza, Lina, Marta, Paz, Ma Jesús, Sara, Javi, Pedro, y un larguísimo etcétera).

Gracias a todos mis compañeros de doctorado y de la Universidad, en especial a Elena por sus buenos consejos y por contar conmigo, a Eva por su presencia, a Rodrigo por esas largas conversaciones y su experiencia, etc.

Finalmente agradecer a las verdaderas protagonistas de esta historia, las personas que ejercen prostitución, su participación, su paciencia y todos esos buenos momentos en los que me han enseñado tanto la sensibilidad como la fortaleza del ser humano.

\section{GRACIAS A TODOS}




\section{Una canción para la Magdalena}

$\mathrm{Si}$, a media noche, por la carretera que te conté,

detrás de una gasolinera donde llené,

te hacen un guiño unas bombillas azules, rojas y amarillas, pórtate bien $y$ frena.

$\mathrm{Y}$, si la Magdalena pide un trago,

tú la invitas a cien que yo los pago.

Acércate a su puerta y llama si te mueres de sed,

si ya no juegas a las damas ni con tu mujer.

Sólo te pido que me escribas, contándome si sigue viva

la virgen del pecado,

la novia de la flor de la saliva,

el sexo con amor de los casados.

Dueña de un corazón, tan cinco estrellas,

que, hasta el hijo de un Dios, una vez que la vio,

se fue con ella.

Y nunca le cobró

la Magdalena.

Si estás más solo que la luna, déjate convencer,

brindando a mi salud, con una que yo me sé.

$\mathrm{Y}$, cuando suban las bebidas,

el doble de lo que te pida

dale por sus favores,

que, en casa de María de Magdala,

las malas compañías son las mejores.

Si llevas grasa en la guantera y un alma que perder,

aparca, junto a sus caderas de leche y miel.

Entre dos curvas redentoras

la más prohibida de las frutas

te espera hasta la aurora,

la más señora de todas las putas,

la más puta de todas las señoras.

Con ese corazón,

tan cinco estrellas,

que, hasta el hijo de un Dios,

una vez que la vio,

se fue con ella,

Y nunca le cobró

la Magdalena.

Joaquín Sabina

19 Días y 500 Noches (1999) 


\section{ÍNDICE}

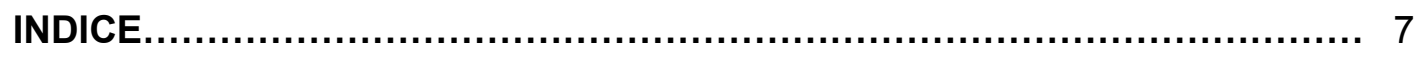

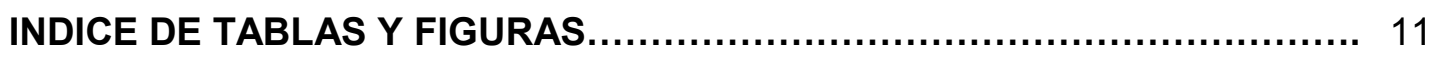

INTRODUCCIÓN......................................................................... 17

MARCO TEÓRICO.

CAPÍTULO I EL FENÓMENO DE LA PROSTITUCIÓN.

1.1. Dificultades metodológicas y éticas en el estudio de la prostitución

1.1.1. Difícil acceso a este grupo de población

1.1.2. Difícil estimación del tamaño y los límites de la población

1.1.3. Representatividad muestral y asunción de homogeneidad

1.1.4. Bibliografía escasa, poco científica, estigmatizante y prejuiciosa

1.1.5. Dificultades asociadas a los lugares donde se realiza el estudio

1.1.6. Dificultad en la publicación de estudios

1.2. Trata de personas con fines de explotación sexual Vs. Trabajo sexual o

prostitución

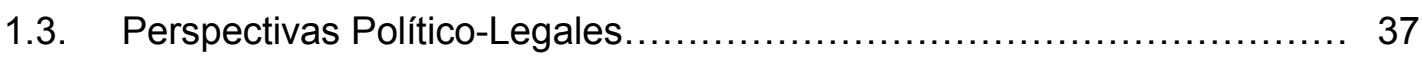

1.3.1. Perspectiva Prohibicionista

1.3.2. Perspectiva Abolicionista

1.3.3. Perspectiva Reglamentarista

1.3.4. Perspectiva Laboral: reconocimiento de derechos

1.3.5. La prostitución ¿violencia de género o fenómeno vinculado al género?

1.3.6. Perspectiva político-legal adoptada en España

1.4. Características y condiciones en las que se ejerce prostitución 56

1.4.1. Factores relacionados con la entrada en la prostitución

1.4.2. Tipología de la prostitución: calle, club y pisos

1.4.3. Riesgos y prácticas abusivas en el ejercicio de la prostitución

1.5. Perfil de las personas que ejercen prostitución. 88

1.5.1. Binomio drogodependencia-prostitución

1.5.2. Binomio inmigración-prostitución

1.5.3. Binomio transexualidad/travestismo-prostitución

1.6. Dimensiones del fenómeno 103

1.6.1. Estudios realizados a nivel nacional 
1.6.2. Estudios realizados en Castilla y León

1.6.3. Evolución del fenómeno de la prostitución

1.7. La prostitución en Internet: una nueva visión

CAPÍTULO II. LAS NECESIDADES INTERPERSONALES

2.1. Teoría de las Necesidades Humanas. 129

2.1.1. Teoría de las necesidades de Maslow (1954)

2.1.2. Teoría de las necesidades de Mandfred Max-Neef (1980)

2.1.3. Teoría de las necesidades de Doyal y Gough (1992)

2.1.4. Teoría de la autodeterminación de Ryan y Deci (2000)

2.2. Teoría de las Necesidades Interpersonales.

2.2.1. Teoría del apego de Bowlby (1958)

2.2.2. Teoría de la soledad de Weiss (1973)

2.2.3. Teoría SPF (Social Production Funcions) de Steverink y Lindenberg (2006)

2.2.4. Teoría de las necesidades interpersonales básicas de López $(1995,2008)$

2.3. Las necesidades interpersonales en las mujeres que ejercen prostitución.

2.3.1. Necesidad de establecer vínculos afectivos incondicionales y duraderos: vínculo del apego

2.3.2. Necesidad de disponer de una red de relaciones sociales

2.3.3. Necesidad de contacto corporal placentero e intimidad sexual

CAPÍTULO III. LA SALUD Y LA CALIDAD DE VIDA. 171

3.1. La calidad de vida relacionada con la salud. 171

3.2. La calidad de vida y la salud de las personas que ejercen prostitución.

3.2.1. Salud física

3.2.2. Salud psicológica

3.2.3. Salud social

3.3. Relaciones entre calidad de vida, salud y necesidades interpersonales. 
6.3.1. Perfil sociodemográfico de las personas que ejercen prostitución

6.3.2. Formación e historia laboral

6.3.3. Vida familiar y social

6.3.4. Estado de salud física, sexual y psicológica

6.3.5. Necesidades interpersonales básicas: el sentimiento de soledad

6.3.6. Calidad de vida

6.4. Procedimiento.

7.1. Perfil de las personas que ejercen prostitución en Castilla y León.

7.1.1. Formación e historia laboral

7.1.2. Vida familiar y social

\subsubsection{Estado de salud}

7.2. Necesidades interpersonales básicas: necesidades emocionales, sociales y sexuales, de las personas que ejercen prostitución.

7.3. Calidad de vida de las personas que ejercen prostitución.

7.4. Predictores de la calidad de vida de las personas que ejercen prostitución... 275

7.4.1. Predictores relacionados con la salud y el mundo de la prostitución que explican la calidad de vida

7.4.2. Predictores relacionados con la salud y el mundo de la prostitución que explican las diferentes subescalas de la calidad de vida 7.4.3. Predictores relacionados con las necesidades interpersonales básicas que explican la calidad de vida 
7.4.4. Predictores relacionados con las necesidades interpersonales básicas que explican las diferentes subescalas de calidad de vida

CAPÍTULO VIII. DISCUSIÓN.

8.1. Perfil de las personas que ejercen prostitución en Castilla y León.

8.1.1. Prostitución de exterior

8.1.2. Prostitución de interior

8.2. Necesidades interpersonales básicas de las personas que ejercen prostitución

8.3. Calidad de vida de las personas que ejercen prostitución

8.4. Factores explicativos de la calidad de vida de las personas que ejercen prostitución.

8.4.1. Factores de salud relacionados con la prostitución explicativos de la calidad de vida en las personas que ejercen prostitución

8.4.2. Factores relacionados con las necesidades interpersonales básicas explicativos de la calidad de vida en las personas que ejercen prostitución

8.5. Implicaciones prácticas

8.5.1. Propuestas de intervención

8.5.2. Propuestas de investigación futuras

8.6. Limitaciones del estudio.

CAPÍTULO IX. CONCLUSIONES.

REFERENCIAS BIBLIOGRÁFICAS.

ANEXOS. 


\section{INDICE DE TABLAS Y FIGURAS}

\section{TABLAS}

Tabla 1. Tipología de la prostitución femenina (Dirección General de la Mujer, 2001).

Tabla 2. Tipología del trabajo sexual 'directo' e 'indirecto' (Harcourt y Donovan, 2005, p.202).

Tabla 3. Respuestas jurídicas posibles (López y Mestre, 2006).

Tabla 4. Tipos legislativos/ Modelos sobre prostitución en los 25 Estados miembros de la UE (Di Nicola, Orfano, Cauduro y Conci, 2005, p. 8).

Tabla 5. Posturas feministas sobre la prostitución (Elias, Bullough, Elias \& Brewer, 1989, p. 321).

Tabla 6. Factores explicativos recogidos en el trabajo de campo (CIMTM, 2003, p.48).

Tabla 7. Factores estructurales recogidos por los organismos internacionales (CIMTM, 2003, p.49).

Tabla 8. Tipo de inmigración de mujeres colombianas y ecuatorianas (Solana, 2003, p.188).

Tabla 9. Necesidades y satisfactores (Max-Neef et al., 1986, p.42).

Tabla 10. Necesidades y satisfactores de la teoría de las necesidades humanas de Doyal y Gough (19994, p.202).

Tabla 11. Diferencias según el estilo de apego en la historia de apego, los modelos mentales y las experiencias de amor (Feeney y Noller, 1996, p.31).

Tabla 12. Similitudes entre la teoría de la soledad de Weiss y los hallazgos de Rubenstein y Shaver (1982).

Tabla 13. Riesgos asociados a la resolución inadecuada de la necesidad afectiva.

Tabla 14. Riesgos asociados a la resolución inadecuada de la necesidad social.

Tabla 15. Riesgos asociados a la resolución inadecuada de la necesidad sexual.

Tabla 16. Principios básicos en la conceptualización, medida y aplicación del concepto de calidad de vida (Verdugo, 2006, p.31).

Tabla 17. Dimensiones de calidad de vida e indicadores de calidad (Verdugo, 2006, p.34).

Tabla 18. Variables e instrumentos de medida utilizados en el estudio.

Tabla 19. Situación laboral actual e ingresos económicos mensuales en euros de las personas entrevistadas.

Tabla 20. Causas de entrada y motivos de salida de la prostitución en función del tipo de prostitución.

Tabla 21. Costearse las drogas como causa de entrada y motivo de salida en función del tipo de prostitución.

Tabla 22. Precios $(€)$ de los servicios y tiempo contratado en función del tipo de prostitución.

Tabla 23. Frecuencia de movilidad en función del tipo de prostitución.

Tabla 24. Satisfacción con la prostitución en función del tipo de prostitución. 
Tabla 25. Motivos para legalizar la prostitución en función del tipo de prostitución.

Tabla 26. Agresiones físicas en función del tipo de prostitución.

Tabla 27. Interrupciones voluntarias de embarazo en función del tipo de prostitución.

Tabla 28. Agresiones sexuales durante el ejercicio de la prostitución en función del tipo de prostitución.

Tabla 29. Puntuaciones en depresión, ansiedad y autoestima en función del tipo de prostitución.

Tabla 30. Agresiones psicológicas en función del tipo de prostitución.

Tabla 31. Descriptivos de sentimientos de soledad en función del tipo de prostitución.

Tabla 32. Descriptivos de calidad de vida en función del tipo de prostitución.

Tabla 33. Matriz de correlaciones entre las variables de salud relacionadas con la prostitución y la calidad de vida de las personas que ejercen prostitución.

Tabla 34. Matriz de correlaciones entre las variables de salud relacionadas con la prostitución y la calidad de vida de las personas que ejercen prostitución de interior.

Tabla 35. Matriz de correlaciones entre las variables de salud relacionadas con la prostitución y las diferentes escalas de calidad de vida (salud física, psicológica, social y ambiental) en la muestra general.

Tabla 36. Matriz de correlaciones entre las variables de salud relacionadas con la prostitución y las diferentes escalas de calidad de vida (salud física, psicológica, social y ambiental) en las personas que ejercen prostitución de interior.

Tabla 37. Matriz de correlaciones entre las variables de necesidades interpersonales básicas y calidad de vida en la muestra general.

Tabla 38. Matriz de correlaciones entre las variables de necesidades interpersonales básicas y calidad de vida en el subgrupo de personas que ejercen prostitución de interior.

Tabla 39. Matriz de correlaciones entre las variables de necesidades interpersonales básicas y las diferentes escalas de calidad de vida en la muestra general.

Tabla 40. Matriz de correlaciones entre las variables de necesidades interpersonales básicas y las diferentes escalas de calidad de vida en el subgrupo de personas que ejercen prostitución de interior.

\section{FIGURAS}

Figura 1. Relación entre prestigio y lucro en trabajos tradicionalmente masculino y femeninos (Juliano, 2004a, p.163).

Figura 2. Cuadro resumen de los factores relacionados con la exclusión y marginación social de las personas que ejercen prostitución

Tabla 3. Necesidades humanas según Ryan y Deci (López, 2008). 
Figura 4. Modelo de los cuatro estilos de apego adulto de Bartholomew (Bartholomew y Horowitz, 1991).

Figura 5. Teoría de las necesidades sociales de Steverink y Lindenberg (López, 2008).

Figura 6. Las necesidades humanas en el desarrollo de los seres humanos (López, 1995, p.14).

Figura 7. Necesidades interpersonales básicas de López (Carcedo, 2005, p.29).

Figura 8. Cuadro resumen de las tres partes principales del estudio.

Figura 9. Distribución de la muestra en relación con la variable género.

Figura 10. Distribución de la muestra en función del tipo de prostitución.

Figura 11. Distribución de la muestra en función de la nacionalidad.

Figura 12. Distribución de la muestra en función de la nacionalidad y el tipo de prostitución.

Figura 13. Distribución de la muestra en función del género y el tipo de prostitución.

Figura 14. Nivel de estudios de las personas entrevistadas en función del tipo de prostitución.

Figura 15. Historia laboral anterior a la prostitución en función de la prostitución.

Figura 16. Horas de trabajo al día y número de clientes al día en función del tipo de prostitución.

Figura 17. Porcentaje de personas con movilidad para trabajar en función del tipo de prostitución.

Figura 18. Necesidad de más protección en el trabajo en función del tipo de prostitución.

Figura 19. Unidad de convivencia en función de la nacionalidad.

Figura 20. Con quien viven los/as hijos/as en función del tipo de prostitución.

Figura 21. Dónde se encuentra la familia de origen en función del tipo de prostitución y la nacionalidad.

Figura 22. Dónde se encuentran tus amistades más íntimas en función del tipo de prostitución y la nacionalidad.

Figura 23. Porcentaje de personas consumidoras de drogas y media de años de consumo en función del tipo de prostitución.

Figura 24. Frecuencia de consumo de drogas en función del tipo de prostitución.

Figura 25. Agresiones físicas durante el ejercicio de la prostitución en función del tipo de prostitución.

Figura 26. Edad media de los primeros contactos sexuales no coitales en función del tipo de prostitución.

Figura 27. Edad media de los primeros contactos sexuales coitales en función del tipo de prostitución.

Figura 28. Número medio de parejas sexuales en función del tipo de prostitución.

Figura 29. Porcentaje de mujeres con un embarazo a término antes de ejercer prostitución. 
Figura 30. Porcentaje de mujeres cuyo primer embarazo no fue deseado en función del tipo de prostitución.

Figura 31 Porcentaje de personas con infecciones de transmisión sexual y personas seropositivas al VIH/SIDA en función del tipo de prostitución.

Figura 32. Frecuencia media de agresiones sexuales en función del tipo de prostitución.

Figura 33. Porcentaje de personas diagnosticadas en el pasado de depresión o ansiedad en función del tipo de prostitución.

Figura 34. Medias en salud mental en función del tipo de prostitución.

Figura 35. Puntuación media en autoestima en función del tipo de prostitución.

Figura 36. Agresiones psicológicas en función del tipo de prostitución.

Figura 37 Sentimientos de soledad en función del tipo de prostitución.

Figura 38. Puntuaciones medias en satisfacción sexual y depresión sexual en función del tipo de prostitución.

Figura 39. Dimensiones de la calidad de vida en función del tipo de prostitución.

Figura 40. Resumen del modelo de regresión lineal para la calidad de vida considerando las variables de salud relacionadas con la prostitución en la muestra general.

Figura 41. Resumen del modelo de regresión lineal para la calidad de vida considerando las variables de salud relacionadas con la prostitución en las personas que ejercen prostitución de interior.

Figura 42. Resumen del modelo de regresión lineal para la salud física considerando las variables de salud relacionadas con la prostitución en la muestra general.

Figura 43. Resumen del modelo de regresión lineal para la salud física considerando las variables de salud relacionadas con la prostitución en las personas que ejercen prostitución de interior.

Figura 44. Resumen del modelo de regresión lineal para la salud psicológica considerando las variables de salud relacionadas con la prostitución en la muestra general.

Figura 45. Resumen del modelo de regresión lineal para la salud psicológica considerando las variables de salud relacionadas con la prostitución en el subgrupo de personas que ejercen prostitución de interior.

Figura 46. Resumen del modelo de regresión lineal para la salud social considerando las variables de salud y el mundo de la prostitución en la muestra general.

Figura 47. Resumen del modelo de regresión lineal para la salud social considerando las variables de salud y el mundo de la prostitución en el subgrupo de personas que ejercen prostitución de interior.

Figura 48. Resumen del modelo de regresión lineal para la salud ambiental considerando las variables de salud relacionadas con la prostitución en la muestra general. 
Figura 49. Resumen del modelo de regresión lineal para la salud ambiental considerando las variables de salud relacionadas con la prostitución en las personas que ejercen prostitución de interior.

Figura 50. Resumen del modelo de regresión lineal para la calidad de vida considerando las variables de necesidades interpersonales básicas en la muestra general.

Figura 51. Resumen del modelo de regresión lineal para la calidad de vida considerando las variables de necesidades interpersonales básicas en el subgrupo de personas que ejercen prostitución de interior.

Figura 52. Resumen del modelo de regresión lineal para la salud física considerando las variables relacionadas con las necesidades interpersonales básicas en la muestra general.

Figura 53. Resumen del modelo de regresión lineal para la salud física considerando las variables relacionadas con las necesidades interpersonales básicas en el subgrupo de personas que ejercen prostitución de interior.

Figura 54. Resumen del modelo de regresión lineal para la salud psicológica considerando las variables relacionadas con las necesidades interpersonales básicas en la muestra general.

Figura 55. Resumen del modelo de regresión lineal para la salud psicológica considerando las variables relacionadas con las necesidades interpersonales básicas en el subgrupo de personas que ejercen prostitución de interior.

Figura 56. Resumen del modelo de regresión lineal para la salud social considerando las variables relacionadas con las necesidades interpersonales básicas en la muestra general.

Figura 57. Resumen del modelo de regresión lineal para la salud social considerando las variables relacionadas con las necesidades interpersonales básicas en el subgrupo de personas que ejercen prostitución de interior.

Figura 58. Resumen del modelo de regresión lineal para la salud ambiental considerando las variables relacionadas con las necesidades interpersonales básicas en la muestra general.

Figura 59. Resumen del modelo de regresión lineal para la salud ambiental considerando las variables relacionadas con las necesidades interpersonales básicas en el subgrupo de personas que ejercen prostitución de interior. 


\section{INTRODUCCIÓN}

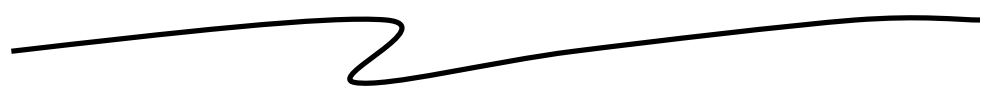

Instituciones como la Dirección General de la Mujer o Médicos del Mundo (López y Mestre, 2006; Solana, 2004) estiman que hay entre 300.000 y 500.000 personas ejerciendo prostitución en cerca de 200.000 locales de alterne repartidos por toda la geografía española.. Se calcula que esta actividad genera hasta 18.000 millones de euros al año y que España es uno de los principales destinos de tráfico de mujeres de América Latina y Europa del Este para el ejercicio de la prostitución.

Mientras, en Castilla y León se calcula que ejercen prostitución aproximadamente 3.000 personas (Asé-Psiké, 1997), en más de 100 clubes de alterne de las que cerca del 90\% son inmigrantes (Guardia Civil, 2000). Las cifras relacionadas con el mundo de la prostitución son impactantes, desde la aparición de Internet la industria sexual ha cambiado adaptándose a las nuevas tecnologías; y a la inversa, las nuevas tecnologías se han adaptado a la industria del sexo. Se calcula que casi el $70 \%$ de las ventas realizadas por internet son de carácter sexual. Por ejemplo en 1998 los ingresos en la industria del sexo a través de la Red superaron los 1.000 millones de dólares al año. En cuanto a los clientes de esta gran industria no se sabe mucho, pero se estima que cerca

de 1.000.000 de hombres compran servicios sexuales cada día en España, gastándose aproximadamente 50.000 .000 de euros diarios en prostitución. Se calcula que la industria del sexo mueve al año en España cantidades de dinero similares a las que factura el Corte Inglés (Salas, 2004; Solana, 2004).

La prostitución es uno de los fenómenos sociales más controvertidos de la historia de la humanidad, ha estado rodeada de sentimientos tales como repugnancia, asombro, incomprensión y fascinación, siendo calificada eufemísticamente como la profesión más antigua del mundo. Tenemos constancia de la existencia de esta actividad en diferentes 
épocas y civilizaciones. De hecho, una de las formas más antiguas de prostitución de la que existen registros históricos es la prostitución religiosa, supuestamente iniciada en Sumeria y Babilonia.

En la actualidad asistimos a un creciente interés social y científico por el estudio de la prostitución tanto a nivel internacional como nacional. Este esfuerzo realizado por gobiernos, instituciones no gubernamentales y las propias asociaciones de personas que trabajan en la industria del sexo se ha iniciado en las últimas décadas y tiene una importante repercusión en Estados Unidos y en Europa. El gran número de personas dedicadas a esta actividad, las condiciones precarias en las que muchas de ellas trabajan, la lucha por sus derechos, la inmigración ilegal con fines de explotación sexual, la existencia de mafias que controlan la actividad, etc. han suscitado un creciente interés.

La mayoría de los estudios científicos realizados en este campo se han centrado en investigar el estado de la infección del VIH/ SIDA y otras infecciones de transmisión sexual en las personas que ejercen prostitución en la calle y son drogodependientes, facilitando en muchos casos la generalización y la creación de estereotipos sobre el colectivo en general. En la actualidad, el fenómeno de la prostitución y las personas implicadas en ella presentan características muy diferenciadas a las de hace dos décadas, por ello es necesaria la investigación objetiva de esta nueva realidad, para conocer e intervenir de forma eficaz y adecuada en la mejora de sus condiciones sociolaborales y calidad de vida.

Por ello, consideramos muy importante investigar sus necesidades, como afirma Sue Metzenrath (1998), trabajadora sexual, refiriéndose al personal científico e investigador "Ellos deberían intentar apoyar las necesidades de investigación de los/as trabajadores/ras del sexo" (p.11), puesto que es el mismo colectivo el que ve la necesidad de estudiar su situación, sus necesidades, etc.

En la actualidad en España, la inmigración esta íntimamente asociada con la prostitución, siendo en la mayoría de los casos inmigración femenina. Encontramos numerosos factores asociados a la inmigración que influyen en las condiciones en las que estas personas trabajan y viven. La inmigración ilegal es uno de los mas perjudiciales, ya 
que, por una parte favorece la proliferación de grupos organizados dedicados a captar, trasladar y controlar personas para la industria sexual; y, por otro, favorece la entrada de estas personas al mundo de la prostitución, ya que no pueden optar a trabajos regularizados.

La inmigración, si además es ilegal y realizada mayoritariamente por mujeres con grandes cargas económicas, genera un contexto en el que la persona se encuentra más vulnerable a riesgos como la explotación, malas condiciones laborales, aislamiento, soledad, conductas de riesgo, etc. Por todo ello, vemos la importancia de estudiar objetivamente las condiciones en las que este colectivo vive y trabaja, cuales son sus necesidades y como es su calidad de vida.

En resumen, este colectivo está rodeado de numerosos estereotipos relacionados con el hecho de ejercer prostitución, ser inmigrantes, ser mujer o transexual, etc., que genera la aparición del estigma y con ello la exclusión social. Las personas que ejercen prostitución constituyen uno de los grupos sociales más marginados y excluidos a lo largo de la historia y en la sociedad actual, por todo ello es necesario intervenir en este aspecto ya que conlleva numerosos riesgos de salud para el colectivo.

Con este estudio pretendemos conocer, en primer lugar, las condiciones sociales, laborales y sanitarias de las personas que ejercen prostitución y ver las diferencias existentes entre los diferentes tipos de prostitución (calle, de club o piso); en segundo lugar, evaluaremos qué grupo satisface mejor sus necesidades interpersonales básicas y presenta mejor calidad de vida; y finalmente, analizaremos qué factores influyen en su calidad de vida.

Para ello, hemos dividido nuestro estudio en dos partes, una primera teórica compuesta por tres capítulos, y una segunda parte compuesta por ocho capítulos donde desarrollamos todo el progreso y resultados de la investigación.

La parte teórica está compuesta por tres núcleos temáticos que orientarán el posterior análisis de datos: un primer capítulo, sobre los aspectos y las características principales del fenómeno de la prostitución (dificultades en el estudio de la prostitución, 
definición del fenómeno, perspectivas político-legales, características y condiciones en las que se ejerce, dimensiones del fenómeno, perfiles del colectivo y la prostitución en internet). Un segundo capítulo, donde realizamos una revisión de las teorías más importantes sobre las necesidades humanas e interpersonales y su aplicación al estudio del colectivo de personas que ejercen prostitución. $Y$ finalmente, un tercer capítulo, donde comentamos el concepto de calidad de vida y las implicaciones que tiene su estudio sobre este colectivo.

La segunda parte, en la que desarrollamos el estudio realizado, está compuesta por los siguientes capítulos: en primer lugar, el planteamiento del problema. En segundo lugar, los objetivos e hipótesis planteadas en el estudio. En tercer lugar, describimos el método que hemos seguido para llevar a cabo el trabajo que presentamos. En cuarto lugar, presentamos los resultados obtenidos. El quinto capítulo, hace referencia a la discusión de los resultados obtenidos. En sexto lugar, planteamos brevemente las conclusiones más importantes a las que se han llegado a partir del trabajo de investigación realizado. El capítulo séptimo, desarrolla las propuestas de intervención derivadas de los resultados obtenidos. Y finalmente, se exponen las limitaciones que hemos encontrado en el estudio, la bibliografía consultada y los anexos.

Consideramos nuestro estudio de gran interés científico y utilidad social y profesional ya que nuestros datos proporcionarán una visión completa del fenómeno de la prostitución en la actualidad. Además arrojará luz sobre las características y diferencias existentes entre los diferentes tipos de prostitución existentes en Castilla y León, las cuales desterrarán multitud de estereotipos y falsas creencias sobre este fenómeno. Pero la aportación más novedosa de este estudio se centra en el análisis del estado de las necesidades interpersonales y la calidad de vida de cada uno de los tipos de prostitución, finalizando con el análisis de los factores que explican cada una de las subescalas que componen la calidad de vida de estas personas. Estos datos orientarán las intervenciones a realizar con las personas que ejercen prostitución si nuestro objetivo es mejorar su bienestar y su calidad de vida. 


\section{MARCO TEÓRICO}

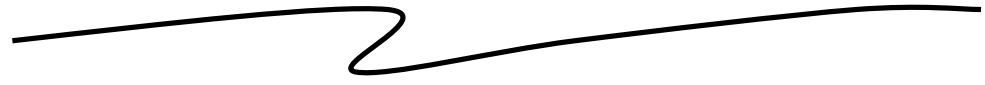

\section{CAPITULO I: EL FENÓMENO DE LA PROSTITUCIÓN}

Según Ebbinghaus la prostitución tiene un largo pasado pero una corta historia (Potterat, Rothenberg, Muth, Darrow y Phillips-Plummer, 1998). Esta observación deriva de las dificultades para obtener información objetiva de muestras representativas de personas que ejercen prostitución.

Se trata de un tema de investigación muy controvertido, por lo que en primer lugar realizaremos una revisión de las dificultades metodológicas existentes en el estudio de este fenómeno, de las definiciones existentes, de las perspectivas político-legales, de las características y condiciones en las que ejerce esta actividad, los diferentes perfiles de las personas que ejercen, las dimensiones del fenómeno y el papel que juegan las nuevas tecnologías en el mismo.

\subsection{Dificultades metodológicas y éticas en el estudio de la prostitución}

Nos encontramos con numerosas barreras a la hora de diseñar, llevar a cabo y publicar estudios de investigación con un carácter científico y objetivo. Estas dificultades se deben a la naturaleza y características del objeto de estudio que nos ocupa.

\subsubsection{Difícil acceso a este grupo de población}

Las personas que ejercen prostitución son un grupo de población de difícil acceso, debido fundamentalmente a la clandestinidad en que se realiza esta actividad y el estigma 
que tiene asociado, como bien lo refleja Regina de Paula Medeiros en su libro (2000) "Hacer entrevistas a una prostituta es más difícil que vender enciclopedias" (p.41).

Las personas que ejercen prostitución sienten miedo y desconfianza ante aquellas personas que quieren conocer esa parte de su vida que ellas se empeñan en esconder. Su mayor miedo es que se conozca su identidad y se sepa la actividad que realizan (especialmente en las españolas) o que se conozca su situación ilegal y sean deportadas a su país de origen (principalmente en las inmigrantes ilegales). Por esto se esfuerzan en mantener una doble vida en la que su vida privada no se mezcle con su vida laboral (Sanders, 2006).

Las personas propietarias o encargadas de los locales donde se ejerce esta actividad también sienten gran desconfianza hacia las personas ajenas a este mundo. Por ello, en la mayoría de los estudios realizados, el personal investigador ha tenido que recurrir a terceras personas para que mediaran en las presentaciones o primeros contactos y superar así las reticencias iniciales (Sanders, 2006).

Como afirma Shaver (2005), "debido a que los miembros de poblaciones ocultas a menudo están involucrados en conductas estigmatizadas o ilegales, los temas relacionados con la privacidad y la confidencialidad son de gran importancia. Esto (...) puede llevar a muchas personas a rechazar la cooperación o a dar respuestas falsas para proteger su privacidad. Alternativamente, los participantes pueden decir lo que se quiere oír de ellos" (p.298).

La gran movilidad que presenta este colectivo, tanto dentro como fuera de la actividad, es otro factor que dificulta su accesibilidad. Suelen cambiar con frecuencia de local (hasta una vez al mes cuando realizan la actividad en régimen de plaza ${ }^{1}$ ), de ciudad e incluso de país para trabajar (Vandepitte, 2006).

\footnotetext{
${ }^{1}$ Hacer una plaza consiste en trabajar en un local durante 21 días seguidos; suelen hacer coincidir la semana de descanso y cambio a otro local con los días en los que la mujer tiene la menstruación.
} 
Las diferencias lingüísticas y culturales también pueden convertirse en una importante barrera de acceso a la hora de llevar a cabo un estudio con un colectivo en el que más del 90\% es población inmigrante (Agustín, 2001; Solana, 2003).

Por último, como otros autores han señalado (Medeiros, 2000), las mujeres que ejercen prostitución valoran la satisfacción inmediata y su libertad de tiempo de manera que pueden comprometerse con el estudio y luego no aparecer a las citas o hacer esperar al investigador/a el tiempo que ella necesite. Así lo refleja Regina de Paula Medeiros (2000), "esperaba a que la prostituta llegara, a que comprara ropa u otras cosas, la esperaba cuando salía de la peluquería, cuando recogía al hijo en la escuela, cuando esperaba para atender a un cliente. En su casa, la esperaba mientras terminaba de comer, a que ella despertara, esperaba mientras terminaba de ducharse. Desde luego, mi destino era esperar, pero esperar sin mal humor y sin rabia, pues entendía que esto formaba parte de su realidad" (p.44).

1.1.2. Difícil estimación del tamaño y límites de la población

Como afirma Shaver (2005), "el tamaño y los límites de la población son desconocidos, por lo que es extremadamente difícil conseguir una muestra representativa" (p.298).

En primer lugar, es difícil estimar la población involucrada en esta actividad debido a la clandestinidad con la que se realiza. Las personas involucradas suelen ocultarlo, debido, principalmente, al estigma y rechazo asociado (Agustín, 2001; Sanders, 2006).

Un segundo aspecto que dificulta la estimación del tamaño poblacional es la falta de definiciones claras sobre el objeto de estudio, por lo que en función de la definición en la que nos basemos se incluirán unos sectores u otros. Por ejemplo, la Industria sexual indirecta ${ }^{2}$ no suele cuantificarse en los estudios debido a que es aún más oculta y desconocida que la

2 Cuando "La prostitución no es siempre la única o primaria fuente de recursos para las personas que la realizan" (Harcourt y Donovan, 2005, p.203) 
directa ${ }^{3}$. Por otro lado, como afirma Agustín (2001), "los métodos de recuento varían sobre cuestiones de género; generalmente no clarifican si se ha incluido a los trabajadores masculinos y cuando han citado cifras de mujeres si se han incluido transexuales" (p. 127).

En tercer lugar, las ideologías e intereses que subyacen a muchos estudios pueden hacer que se subestime o sobreestime la magnitud real del fenómeno. "Las organizaciones antiprostitución pueden producir estadísticas inexactas, ellos tenderán a sobreestimar el número de trabajadoras sexuales. Mientras, los gobiernos pueden tender a subestimar los datos debido a un punto de vista más restrictivo del trabajo sexual" (Vandepitte, 2006, p.23). Las organizaciones (ONGs, Asociaciones, etc.) que llevan a cabo programas específicos dirigidos a personas que ejercen prostitución y no se apoyan en perspectiva ideológica alguna, más que la prevención de riesgos, son los que poseen una estimación más exacta de la magnitud del fenómeno y de las personas involucradas en él.

Como afirma Ronald Weitzer (2005b), “ningún área de las ciencias sociales tiene una ideología que contamine más el conocimiento que los trabajos sobre la industria del sexo. Demasiado a menudo este área de investigación está sesgado deliberadamente para servir a una agenda política en particular" (p. 934).

Finalmente, también debemos mencionar la dificultad para estimar los datos reales sobre tráfico de seres humanos con fines de explotación sexual, fenómeno confundido en multitud de estudios y escritos con el de la prostitución. Según un estudio realizado por el Parlamento Europeo únicamente un $24 \%$ de los 25 Estados miembros de la UE presentan bases de datos adecuadas y fiables sobre el tráfico de seres humanos con fines de explotación sexual (Di Nicola, Orfano, Cauduro y Conci, 2005, p. 9). Como consecuencia de esta falta de rigor en la recogida de datos y la confusión terminológica, encontramos que hay un cambio continuo del número estimado de personas traficadas y/o explotadas sexualmente, tanto en Europa como en España.

3 Cuando "Es claro que el propósito principal de la interacción es intercambiar sexo por dinero" (Harcourt y Donovan, 2005, p.201) 
1.1.3. Representatividad muestral y asunción de homogeneidad

El uso de muestreos aleatorios de las trabajadoras sexuales en la mayoría de los casos es imposible debido a las características de la actividad y de la población implicada. Por ello, "demasiado a menudo los hallazgos y conclusiones se trazan desde la conveniencia y se usan muestreos por bola de nieve que ni son adecuados ni generalizables" (Weitzer, 2005b, p.939).

Recoger los datos en muestras incidentales que sólo hacen referencia a subgrupos de población específicos crea importantes problemas para la generalización de los datos. Muchos estudios únicamente se han centrado en aquellos grupos de población más accesibles (desde los servicios sociales, médicos, judiciales, etc.) por lo que sus conclusiones estarán sesgadas o únicamente pueden hacer referencia a esos grupos específicos, sin posibilidad de generalización de los datos.

En los estudios sobre prostitución hay una presencia excesiva de las personas que la ejercen en la calle, que presentan problemas de adicciones, problemas legales, etc. (Elias, Bullough, Elias \& Brewer, 1989; Jessen, 2004; Vandepitte, 2006), y se presta poca atención a otros sectores de la industria sexual como la prostitución ejercida en clubes, pisos, etc. y la ejercida por hombres y transexuales. Los grupos que mayormente se han estudiado son también los más vulnerables y a los que se les aplica el estatus de víctima (e.g. grupos que no sólo trabajan en el sexo sino que también tienen otros problemas, como la pobreza, vivir en la calle, la victimización y el consumo de drogas) oscureciendo así la realidad de otras muchas personas que ejercen prostitución.

Por todo esto, como afirma Gail Pheterson (1990), “los artículos científicos por lo general hacen inferencias sobre 'La prostituta' o sobre las prostitutas en general desde muestras que no son representativas y que tienen poco en común o nada con la población real” (p.398). Así se llegan a conclusiones erróneas a partir de las cuales se toman medidas que afectarán a todas las prostitutas en general. Y "aunque la imagen de la prostituta como 
desviación patológica parece haber desaparecido gradualmente, la imagen de la prostituta como una víctima sigue aún prevaleciendo" (Vanwesenbeeck, 2001, p.276).

En resumen, la característica definitoria del fenómeno de la prostitución es la heterogeneidad, es decir, hay una gran variedad de tipos y de circunstancias en las que se desarrolla esta actividad (Jessen, 2004). Agustín (2001) lo expresa claramente: "La 'metodología' de hablar sólo con los que trabajan en la calle omite a todos los demás que trabajan en burdeles o casas de citas, clubes de alterne, bares, cervecerías, discotecas, cabarets y salones de cóctel; en líneas telefónicas eróticas o en sexo virtual por Internet; en sex shops con cabinas privadas; en casas de masaje, de relax, de desarrollo del 'bienestar físico' y de sauna; en servicios de acompañantes (call girls, chicos de alquiler) y en agencias matrimoniales; como actores en cine, video y revistas pornográficos; en restaurantes eróticos, servicios de dominación o sumisión, en complejos turísticos y en pisos particulares" (p.112).

Por todo ello, los estudios deben conseguir la mayor representatividad muestral para superar así las asunciones erróneas de homogeneidad adoptadas por muchos autores. "La clave (...) se basa en diseños de investigación que expresen comparaciones estratégicas" (Shaver, 2005, p.307) y que ayuden a comprender las características definitorias de cada grupo.

1.1.4. Bibliografía escasa, poco científica, estigmatizante y prejuiciosa

Muchos autores afirman que parte de la bibliografía existente sobre el fenómeno de la prostitución ayuda a mantener los prejuicios y el estigma que recae sobre este colectivo, en vez de ayudar a combatirlo (Agustín, 2001; Elias, Bullough, Elias \& Brewer, 1998; Perkins, 1991; Vanwesenbeeck, 2001; Weitzer, 2005a). Según Weitzer (2005a), "la bibliografía sobre prostitución es deficiente en varios aspectos importantes. Ha habido pocos avances teóricos en los últimos años. En cambio, un gran número de escritos cuasiteóricos y polémicos realizan reivindicaciones sobre la naturaleza y las consecuencias de la 
prostitución y otros tipos de trabajos sexuales. La mayor parte de este trabajo ideológico ha estado motivado por una obvia política antiprostitución" (p.211).

Pocos son los autores que informan adecuadamente sobre las cuestiones metodológicas relacionadas con este tema (Sanders, 2006). Muchos estudios sobre prostitución pueden ser criticados por asuntos metodológicos "algunos autores fallan al describir cómo y dónde contactaron con los sujetos de investigación. Otros fallan en la inclusión de grupos de control, etc." (Weitzer, 2005b, p.937).

Otra de las críticas realizadas a la literatura científica sobre temas relacionados con la prostitución, es que ha ayudado a mantener los estereotipos y el estigma asociado a esta actividad en vez de trabajar por eliminarlo. Pheterson (1990) afirma que "la investigación científica social está infectada con prejuicios contra las mujeres etiquetadas como prostitutas. Incluso la categoría 'prostituta' está basada más sobre representaciones sociales y legales sobre una mujer mala o puta que sobre un conjunto de características actuales dentro de una población de personas" (p.397).

Temas como la infección por $\mathrm{VIH}$, el consumo de drogas, los abusos sexuales y los malos tratos plagan la gran mayoría de los estudios científicos realizados, olvidando otras áreas de estudio como son sus condiciones labores, su salud, sus demandas y necesidades, etc. (Agustín, 2001; Medeiros, 2000). "Desde los inicios de los años 80 en adelante, la mayoría de las investigaciones han estado relacionadas con los riesgos laborales relativos al VIH. Muchos estudios médico-epidemiológicos se han focalizado en las prostitutas como una supuesta vía de la epidemia, pero el acercamiento a menudo moralizante, categorizante, unificador y estigmatizante a las prostitutas desde la investigación del SIDA se ha probado empíricamente que es erróneo" (Vanwesenbeeck, 2001, p.245).

Otro punto donde la investigación se ha mostrado sesgada y prejuiciosa es en referencia a las causas que motivan la entrada en la industria sexual. Son muchos los estudios que concluyen como motivo principal de entrada en la prostitución la victimización temprana, pero como afirma Vanwesenbeeck (2001) "el problema principal con la 
victimización temprana, el no tener hogar, y el consumo de drogas como factores explicativos en el trabajo sexual es que nos llevan a ser investigados entre grupos muy específicos de prostitutas (e.g. jóvenes sin techo, prostitutas encarceladas, y/o mujeres que trabajan en la calle). Estos grupos definitivamente no representan a todas las trabajadoras del sexo" (p.260). De nuevo volvemos al problema de la generalización de datos a la población a partir de muestras poco representativas.

Finalmente, como afirma Agustín (2001), "en España durante la década de los años 90 se han producido diversos trabajos referidos al tráfico de mujeres, (...) con una orientación muy marcada: identificación del tráfico con redes mafiosas, de la migración para la prostitución con explotación sexual, y de mujeres prostitutas a víctimas engañadas. Este tratamiento reductivo ignora la diversidad de modalidades, así como las amplias implicaciones económicas de los servicios sexuales, y fomenta la estigmatización del sector y la xenofobia respecto a las prostitutas inmigradas" (p.160).

Como resume Weitzer, "más investigación sobre prostitución de hombres y transexuales, como también estudios mejor diseñados e ideológicamente más neutros de prostitución femenina, contribuirán a un entendimiento comprensivo más sofisticado y matizado sobre la prostitución contemporánea" (2005b, p.946).

1.1.5. Dificultades asociadas a los lugares donde se desarrolla el estudio

El contexto y las características de los lugares donde se desarrollan las actividades sexuales comerciales generan una serie de dificultades a la hora de llevar a cabo un estudio científico sobre el fenómeno.

En primer lugar, se debe invertir grandes cantidades de tiempo en el desarrollo del trabajo de campo para conseguir el acceso y la confianza de las participantes y poder recoger datos más fiables. Conseguir el acceso a un local donde se ejerce prostitución requiere una fase previa de negociación con las personas encargadas de los locales, donde 
se intenta mostrar claramente los objetivos e intenciones del estudio y que no se perjudicará ni al negocio ni a las personas involucradas en el mismo (Sanders, 2006).

Después, se debe conseguir la colaboración de las propias personas que ejercen prostitución, por lo que debemos invertir de nuevo mucho esfuerzo en conseguir su confianza. Se llegan a emplear muchas horas en el trabajo de campo por lo que el/a investigador/a llega a ser amigo/a, confidente, experto/a en salud sexual, etc. de las participantes, esto mejora notablemente la veracidad de los datos pero en ocasiones difumina los límites de los roles entre investigador/a y objeto de investigación.

También debemos mencionar los posibles riesgos a los que se expone la persona encargada de realizar este tipo de estudios. En ocasiones se deben afrontar ambientes hostiles que necesitan ser controlados con cuidado, poniendo en práctica habilidades de negociación y manejo de conflictos, donde mantener la calma es una parte esencial del trabajo de campo (Sanders, 2006). Pero el trabajo emocional por parte del investigador es el mayor riesgo al que se enfrenta, es lo que Melrose (2002) denomina el dolor del trabajo de investigación que se da cuando se trabaja en áreas sensibles como la prostitución. Como afirma Sanders (2006), "aunque no siempre es el caso, las conversaciones informales y las entrevistas (...) con las mujeres que trabajan en prostitución pueden hacer salir datos poco placenteros consistentes en historias de abuso, explotación, desesperación, consumo de drogas y desesperanza" (p.484).

Finalmente, otra dificultad relacionada con el contexto en el que se lleva a cabo la investigación es el conocimiento del mundo de la prostitución y la sexualización del ambiente donde se trabaja. Lleva un tiempo conocer y acostumbrarse a las características y normas de funcionamiento de los locales donde se ejerce esta actividad. Es más fácil acostumbrarse al ambiente de los pisos donde se ejerce prostitución que a los clubes o la calle. En los clubes te mezclas directamente con los clientes y tienes que saber manejar las diferentes situaciones que se presentan (Sanders, 2006), mientras que en la calle sientes mayor desprotección. El setting, el lugar donde se realiza la entrevista, suele ser la habitación donde se llevan a cabo los servicios sexuales por lo que no es el lugar más 
adecuado para realizarla (sentadas en la cama, sin mucha luz, si llega un cliente hay que interrumpir la entrevista, etc.).

1.1.6. Dificultad en la publicación de estudios

Para terminar con este punto, no podemos dejar de mencionar la dificultad que en ocasiones supone publicar estudios realizados sobre temas relacionados con la prostitución que no se adecuan a lo políticamente correcto.

En primer lugar puede ser muy difícil conseguir subvención económica para llevar a cabo estudios de investigación en este ámbito. Como escribe Agustín (2001), "la necesidad de investigar (...) es urgente, pero los gestores de fondos se resisten a financiar investigaciones que no encajen en alguno de los marcos teóricos actualmente aceptables: 'prevención del sida', ‘violencia contra la mujer' o 'tráfico de mujeres'” (p. 105). Mientras que en otras ocasiones, tras invertir grandes esfuerzos económicos y personales en la realización de un estudio, éste se queda cogiendo polvo en alguna estantería perdida de alguna institución debido a que lo encontrado no gusta o es políticamente incorrecto. 
1.2. Trata de personas con fines de explotación sexual Vs. Trabajo Sexual o prostitución

Como hemos visto anteriormente, la conceptualización de la prostitución varía mucho en función del autor al que nos refiramos, por lo que es importante definir con claridad el ámbito de investigación al que nos dirigimos (Agustín, 2001). La falta de definiciones claras y generalizadas sobre los diferentes tipos de prostitución o trabajo sexual provoca que haya confusiones entre los diferentes estudios, ya que cada uno hace referencia a aspectos diferentes del fenómeno.

De hecho, una de las principales dificultades metodológicas en el estudio de la prostitución o el trabajo sexual es la confusión conceptual que impera en esta área de estudio. Esta confusión en las definiciones se da principalmente entre los siguientes conceptos: tráfico ilícito de migrantes, trata de personas con fines de explotación, y el fenómeno de la prostitución (Agredano, 2005).

Durante la última década, tanto a nivel nacional como a nivel europeo e internacional, se han realizado diversos trabajos referidos al tráfico y trata de personas; sin embargo, todavía existe confusión entre estas diferentes realidades. En primer lugar, según el Convenio Contra el Crimen Transnacional Organizado de las Naciones Unidas (2000), el tráfico ilícito de personas hace referencia a "la facilitación de la entrada ilegal de una persona en un Estado parte del cual dicha persona no sea nacional o residente permanente con el fin de obtener, directa o indirectamente, un beneficio financiero u otro beneficio de orden material" (CIMTM, 2003, p. 24); mientras que la trata de personas se refiere a "la captación, el transporte, el traslado, la acogida o la recepción de personas, recurriendo a la amenaza o al uso de la fuerza, al rapto, a la superchería, al engaño, a la incitación, a la coacción o al abuso de poder, recurriendo a la concesión o recepción de pagos o beneficios para lograr el consentimiento de una persona que tenga autoridad sobre otra, con fines de explotación, independientemente del consentimiento de la persona”. (CIMTM, 2003, p. 24). 
Como vemos, ambos conceptos implican el traslado de personas de un país a otro, pero se diferencian fundamentalmente en los elementos de engaño, coerción y sometimiento. Las redes de tráfico ilícito se limitan a introducir personas extranjeras de forma ilegal en un país cobrando elevadas sumas de dinero, pero una vez traspasada la frontera el extranjero busca trabajo por su cuenta. Mientras que en la trata internacional con fines de explotación la víctima, una vez introducida en el país de destino, será sometida a condiciones de esclavitud, a fin de obtener de ella un elevado lucro económico (Agredano, 2005).

No se puede identificar sin más prostitución y trata de personas ya que hay que tener presente que no todos los casos de trata se dan para la prostitución, también se dan para el servicio doméstico, matrimonios serviles, la agricultura, talleres textiles, etc. Y por otro lado, no todas las personas que ejercen prostitución han sido víctimas de redes de trata de personas, sino que muchas personas han decidido realizar esta actividad con algún grado de voluntariedad, entendiendo esta voluntariedad como ausencia de una tercera persona que obliga o coacciona a ejercer prostitución. Ya que consideramos que en la gran mayoría de las ocasiones son las circunstancias y necesidades de la persona las que la obligan a ejercer esta actividad, como veremos a lo largo de este estudio (Agredano, 2005; Agustín, 2001; Butcher, 2003; Kempadoo, s.f.).

Como vemos, traducir directamente desplazamiento por tráfico, o prostitución por trata, sería simplificar y totalizar realidades demasiado complejas y diferentes. Si realizásemos tal simplificación estaríamos pasando por alto la posibilidad de la elección voluntaria de migrar desde el país de origen, o la elección voluntaria de la prostitución como actividad económica. Es decir, "las decisiones personales de las trabajadoras sexuales se pasan por alto" (Butcher, 2003, p.1983).

Dentro de esta confusión conceptual, vemos cómo cada uno de los grupos ideológicos usa el lenguaje para luchar por sus reivindicaciones. El término trabajo sexual o trabajador/a sexual fue definido durante los años '70 en EEUU, en los movimientos que tuvieron lugar por los derechos de las prostitutas. Fueron las mismas personas que ejercen 
prostitución quienes acuñaron esta denominación para destacar su estatus de trabajadores/as y luchar por sus derechos sociales y laborales (Agustín, 2001; Bindman y Doezema, 1997; Kempadoo, s.f.). Mientras, los grupos de corte abolicionista, luchan por usar términos como el de explotación sexual para referirse a esta actividad o personas prostituidas para referirse a las implicadas en esta actividad. De esta forma definen a la persona que ejerce prostitución como víctima.

Por lo tanto, el tráfico y la trata de seres humanos con fines de explotación sexual serían delitos a perseguir, juzgar y erradicar; pero el fenómeno de la prostitución en sí mismo no es un delito, por lo que debemos diferenciar tales conceptos. "Estas realidades pueden darse a la vez o pasar de una a otra, pero aunque asociadas son diferentes y conviene tratarlas como tal, de lo contrario nos arriesgamos a confundir y desenfocar el problema y esto nos llevaría a dar una respuesta equivocada" (Agredano, 2005, p.4). En el presente trabajo de investigación la realidad que estudiamos es la prostitución y las personas que realizan esta actividad, no el tráfico ni la trata de seres humanos.

Hemos encontrado multitud de definiciones para el término, y cada una de ellas destaca diferentes aspectos, pero manteniendo los elementos comunes a todos ellas hemos formulado una propia sobre la que hemos basado nuestro estudio.

Al definir esta actividad tenemos que ser conscientes que la dificultad radica en la gran variedad de tipos de prostitución resultantes de la combinación de factores como: el lugar donde se ejerce; el grado de libertad con la que se ejerce; el sexo, la identidad sexual y la orientación del deseo tanto de quien vende como de quien compra el servicio sexual; los horarios o grado de disponibilidad; la clase social; etc.

Pero, haciendo un esfuerzo sintetizador, podemos definir la prostitución como la negociación y prestación explícita, directa y a corto plazo de servicios sexuales a cambio de dinero, bienes u otros beneficios, con o sin intervención de una tercera parte. Esta actividad implica como mínimo a dos personas mayores de edad (la que vende y la que compra) que realizan la negociación y la prestación del servicio sin coacción por terceras partes, ya que si la hubiera hablaríamos de explotación sexual. 
Ante esta gran heterogeneidad de definiciones y clasificaciones hemos seleccionado algunas de las clasificaciones más completas; en primer lugar la realizada Barahona (2001) que establece diferentes criterios clasificatorios en su obra titulada Tipología de la Prostitución Femenina en la Comunidad de Madrid (ver Tabla 1).

Tabla 1. Tipología de la prostitución femenina (Barahona, 2001)

\begin{tabular}{|c|c|c|}
\hline & CRITERIO DE CLASIFICACIÓN & TIPOS \\
\hline 1 & Por el género de quien ejerce & $\begin{array}{ll}\text { - } & \text { Prostitución “Masculina" } \\
\text { - } & \text { Prostitución “Femenina” (Mujer y } \\
& \text { Transexuales) }\end{array}$ \\
\hline 2 & Por la edad de quien ejerce & $\begin{array}{l}\text { - } \quad \text { “18 y } 25 \text { años” } \\
\text { - } \quad \text { "26 y } 35 \text { años” } \\
\text { - } \quad \text { "36 en adelante" }\end{array}$ \\
\hline 2 & Por el lugar donde se ofrece el servicio & $\begin{array}{ll}\text { - } & \text { Medio “Abierto" (calles, parques, etc.) } \\
\text { - } & \text { Medio "Cerrado" (club, pisos, etc.) }\end{array}$ \\
\hline 3 & Por la procedencia de quien ejerce & $\begin{array}{ll}\text { - } & \text { "Nacionales" } \\
\text { - } & \text { "Extranjeras" }\end{array}$ \\
\hline 4 & Por adicciones de quien ejerce & $\begin{array}{ll}\text { - } & \text { "Drogodependientes" } \\
\text { - } & \text { "No drogodependientes" }\end{array}$ \\
\hline 5 & $\begin{array}{l}\text { Por los ingresos obtenidos en el } \\
\text { ejercicio de la prostitución }\end{array}$ & $\begin{array}{ll}\text { - } & \text { "Alto standing" } \\
\text { - } & \text { "Bajo standing" }\end{array}$ \\
\hline 6 & Por su dedicación & $\begin{array}{ll}\text { - } & \text { "Profesionales" } \\
\text { - } & \text { "Ocasionales" }\end{array}$ \\
\hline 7 & Por las condiciones de trabajo & $\begin{array}{l}\text { - } \quad \text { "Por cuenta propia" } \\
\text { - } \quad \text { "Por cuenta ajena" }\end{array}$ \\
\hline
\end{tabular}

Y, en segundo lugar, presentamos la clasificación realizada por Harcourt y Donovan (2005), en la cual dividen el trabajo sexual en dos categorías: directo (cuando la venta de servicios sexuales es la fuente de ingresos principal con la que se gana la vida la persona) e indirecto (cuando el sexo comercial es una fuente suplementaria de ingresos) (ver Tabla 2). 
Tabla 2. Tipología del trabajo sexual ‘directo’ e ‘indirecto’ (Harcourt y Donovan, 2005, p.202)

\section{Tipología del trabajo sexual 'directo'}

Calle: los clientes son captados en la calle, parques u otros lugares públicos. Y los servicios realizados en las calles, en coches o locales de corta estancia

Burdel: lugares explícitamente dedicados a proporcionar sexo. Mejor seguridad que en la calle. A menudo con licencia de las autoridades.

Escort: El cliente contacta con la trabajadora sexual por teléfono o mediante los trabajadores/as de hoteles. Es lo más discreto en el trabajo sexual. Relativamente caro debido a la baja movilidad del cliente. El servicio se realiza en la casa o el hotel del cliente.

Privado: El cliente contacta con la trabajadora sexual por teléfono. Es similar a la Escort excepto que los servicios se llevan a cabo en el establecimiento de la trabajadora sexual. Una variante en Londres y en otras grandes ciudades es 'la prostitución de pisos' -servicios de gran coste.

Ventana o Entradas (Doorway): los burdeles con trabajadoras sexuales a la vista del público. Las ventanas son habituales en climas fríos y las Entradas en lugares más cálidos.

Club, pub, bar, karaoke, lugares de baile: los clientes se captan en los locales donde se vende alcohol y son llevados a cabo los servicios allí mismo o en otros lugares.

Otros locales de hombres: los clientes se captan en barberías, baños, saunas, y en zonas mineras. Los servicios se realizan allí o en otros lugares.

Hoteles: hombres solos son abordados en sus habitaciones de hotel o pensiones.

Transportes (barco, camión, tren): Las trabajadoras del sexo pueden alojarse en los vehículos para dar servicio a la tripulación o a los pasajeros, o captar clientes en las estaciones o terminales.

Radio: las trabajadoras del sexo circulan por las autopistas usando una radio para intercambiar mensajes con clientes potenciales camioneros. Los servicios se llevan a cabo en los camiones o en las áreas de aparcamiento.

Otros métodos de captación de clientes: a través de varios medios incluyendo tablones de anuncios, anuncios de prensa, 'catálogos de trabajadoras sexuales' con número de teléfono móvil, mediante internet, etc. Los servicios se llevan a cabo en burdeles o en otros locales.

\section{Tipología del trabajo sexual 'indirecto'}

Sadomasoquismo: fantasía sexual a través del role playing. Puede conllevar inflingir dolor, pero el contacto genital no es lo habitual.

Danza erótica: puede darse un contacto muy íntimo pero sin llegar a un contacto sexual

Salón de masajes: los locales se dedican fundamentalmente a dar masajes, pero también se pueden dar algunos servicios sexuales. En el sudeste asiático los mismo se puede aplicar para las barberías.

Espectáculos ambulantes: Actores, bailarinas, y otras personas de los espectáculos pueden proporcionar servicios sexuales.

Chicas de la cerveza (Beer Girls): mujeres jóvenes que trabajan para grandes compañías 
promocionando y vendiendo productos en bares y clubs. Los servicios sexuales son un complemento a sus ingresos

Vendedores de calle y comerciantes: normalmente en mercados rurales complementan sus ingresos con servicios sexuales.

Oportunistas: una persona captada en un local social puede ocasionalmente elegir cobrar por servicios sexuales si el cliente parece lo suficientemente rico.

Mujeres libres: mujeres, normalmente solteras o divorciadas, que intercambian servicios sexuales por regalos.

Acuerdos individuales: la madre soltera que puede tener sexo con su casero en lugar de pagar una renta. Trabajadores sexuales mayores que únicamente tienen relaciones sexuales con un número reducido de clientes, mediante citas. Concubinas. Mujeres o hombres 'mantenidos'.El número de posibles acuerdos es muy grande.

Clubes de Swingers: algunos clubes de 'swingers' emplean (de forma oculta) a trabajadoras del sexo si hay escasez de clientes femeninas.

Geisha: mujeres ocupadas principalmente en proporcionar compañía social, pero el sexo puede ocurrir

'Sexo por drogas': mujeres que realizan felaciones por cocaína en las 'casas del crack'. Jóvenes homosexuales en los países occidentales pueden ocasionalmente proporcionar servicios sexuales a cambio de drogas

Chicos de playa y gigolós: hombres y chicos se ocupan para mujeres normalmente para propósitos sociales pero el sexo a menudo también se da. Algunos chicos de playa son menores y muchos se ocupan con hombres

Sexo para sobrevivir: donde la miseria u otras deprivaciones serias son inminentes, sobre todo para personas dependientes. La comida y la seguridad pueden ser la moneda de pago más que el dinero.

Como vemos la prostitución presenta una gran heterogeneidad, tanto en las personas (nacionalidad, género, edad, definiciones, motivaciones, etc.), en los escenarios (lugares donde se ejerce, forma de captar clientes, grado de contacto, etc.), como en las condiciones laborales (permanencia, continuidad, tipo de servicios, precios, horarios, movilidad, etc.). 


\subsection{Perspectivas Político-Legales}

A lo largo de la historia, los Estados han desarrollado diferentes sistemas para tratar el tema de la prostitución y estos sistemas influyen a su vez en su legislación, que consecuentemente determina las condiciones de trabajo y vivencia de las mujeres implicadas en esta actividad.

No existe un consenso en la forma jurídica con la que tratar el tema de la prostitución y las personas implicadas en ella. No hay un consenso ni a nivel mundial, ni internacional, ni siquiera a nivel nacional, ya que como ocurre en España, hay legislaciones diferentes entre las autonomías. Todo esto es un fiel reflejo de la situación en la que se da la actividad, de la gran diversidad de opiniones, decisiones y tratamientos del fenómeno.

A modo de resumen de las respuestas jurídicas posibles o modelos legislativos sobre el tema de la prostitución presentamos la Tabla 3, donde se refleja el concepto sobre la prostitución que tiene cada modelo, la relación subyacente entre hombre y mujer y finalmente, algunas características y ejemplos de cada sistema (López y Mestre, 2006). 
Tabla 3. Respuestas jurídicas posibles (López y Mestre, 2006)

\begin{tabular}{|c|c|c|c|c|c|}
\hline & PROHIBICIONISMO & $\begin{array}{c}\text { REGLAMENTARISMO } \\
\text { DECIMONÓNICO }\end{array}$ & $\begin{array}{c}\text { REGLAMENTARISMO } \\
\text { ACTUAL }\end{array}$ & ABOLICIONISMO & TRABAJO SEXUAL \\
\hline $\begin{array}{c}\text { Relación } \\
\text { hombre- mujer }\end{array}$ & Puritanismo & $\begin{array}{l}\text { Ganapán / Cuidadora y } \\
\text { 'puta' }\end{array}$ & $\begin{array}{l}\text { Globalización } \\
\text { Modelo patriarcal } \\
\text { Migraciones ordenadas }\end{array}$ & $\begin{array}{l}\text { Mujeres dominadas por } \\
\text { hombres sexualmente } \\
\text { (como sexo y mediante } \\
\text { el sexo) } \\
\text { Tráfico / Trata }\end{array}$ & $\begin{array}{l}\text { Entramado complejo de } \\
\text { relaciones de dominio y } \\
\text { espacios de igualdad } \\
\text { Migraciones autónomas }\end{array}$ \\
\hline $\begin{array}{l}\text { Concepto de } \\
\text { prostitución }\end{array}$ & Delito & Mal menor & Libre profesión & Esclavitud sexual & Trabajo \\
\hline $\begin{array}{l}\text { Ejemplo País, } \\
\text { ciudad o 'petición' }\end{array}$ & EEUU & Grecia & $\begin{array}{l}\text { ANELA } \\
\text { Tribunal Europeo de } \\
\text { Justicia }\end{array}$ & Suecia, Estado Español & Holanda \\
\hline $\begin{array}{c}\text { Medidas } \\
\text { características }\end{array}$ & $\begin{array}{l}\text { Todo prohibido: venta y } \\
\text { compra de servicios }\end{array}$ & $\begin{array}{l}\text { Zonificación } \\
\text { Control Sanitario } \\
\text { obligatorio }\end{array}$ & $\begin{array}{l}\text { Reconocimiento de la } \\
\text { actividad sólo por cuenta } \\
\text { propia. } \\
\text { Dos adultos consienten } \\
\text { una relación. } \\
\text { Empresario } \\
\text { reglamentarista } \\
\text { (zonificación y control) } \\
\text { Alterne } \\
\text { Tipificación } \\
\text { proxenetismo }\end{array}$ & $\begin{array}{l}\text { Intervención policial: } \\
\text { Perseguir responsables } \\
\text { (proxenetas y clientes) } \\
\text { Intervención social: } \\
\text { Salvar /rescatar } \\
\text { mujeres. } \\
\text { Intervención Jurídica: } \\
\text { Tipificación } \\
\text { proxenetismo, } \\
\text { rufianismo }\end{array}$ & $\begin{array}{l}\text { Reconocimiento } \\
\text { derechos trabajadoras. } \\
\text { Regulación actividad por } \\
\text { cuenta ajena } \\
\text { Cooperativas de } \\
\text { servicios sexuales }\end{array}$ \\
\hline
\end{tabular}


Dependiendo de cada autor, o de la perspectiva teórica, podemos encontrar algunas variaciones en la clasificación de los diferentes modelos legislativos existentes sobre la prostitución, pero normalmente todos se reducen a los siguientes: Reglamentarismo, Abolicionismo, Prohibicionismo y Reconocimiento de derechos laborales.

El estudio llevado a cabo por Di Nicola, Orfano, Cauduro y Conci en 2005 desde la Università degli studi di Trento y Università Católica del Sacro Cuore con el apoyo del Parlamento Europeo, ha hecho posible determinar que, aunque las políticas sobre prostitución en la Unión Europea son diferentes, es posible agruparlas en cuatro modelos, dependiendo de la aproximación adoptada por cada Estado en relación tanto con la prostitución de interior (apartamentos, burdeles, hoteles, clubes, pubs, saunas, salones y ventanas) como con la de exterior (calle). En la Tabla 4 exponemos las diferencias existentes en cada modelo y en qué países podemos encontrarlo.

Tabla 4. Tipos legislativos/ Modelos sobre prostitución en los 25 Estados miembros de la UE (Di Nicola et al., 2005, p. 8).

\begin{tabular}{|c|c|c|c|c|}
\hline MODELO & $\begin{array}{c}\text { PROSTITUCIÓN } \\
\text { EXTERIOR }\end{array}$ & $\begin{array}{c}\text { PROSTITUCIÓN } \\
\text { INTERIOR }\end{array}$ & $\begin{array}{l}\text { ESTADOS } \\
\text { MIEMBROS }\end{array}$ & $\begin{array}{c}\text { \% DE LOS } \\
\text { ESTADOS } \\
\text { MIEMBROS }\end{array}$ \\
\hline ABOLICIONISMO & No esta prohibida & No esta prohibida & $\begin{array}{c}\text { España, República } \\
\text { Checa, Polonia, } \\
\text { Eslovaquia, } \\
\text { Eslovenia. }\end{array}$ & $24 \%$ \\
\hline $\begin{array}{c}\text { NUEVO } \\
\text { ABOLICIONISMO }\end{array}$ & No esta prohibida & $\begin{array}{l}\text { No está prohibida } \\
\text { (sólo en burdeles) }\end{array}$ & $\begin{array}{c}\text { Bélgica, Chipre, } \\
\text { Dinamarca, Estonia, } \\
\text { Francia, Finlandia, } \\
\text { Italia, Luxemburgo }\end{array}$ & $32 \%$ \\
\hline PROHIBICIONISMO & Prohibida & Prohibida & $\begin{array}{c}\text { Irlanda, Lituania, } \\
\text { Malta, Suecia }\end{array}$ & $16 \%$ \\
\hline REGLAMENTARISMO & $\begin{array}{l}\text { Regulada y no } \\
\text { prohibida si } \\
\text { cumple la } \\
\text { regulación }\end{array}$ & $\begin{array}{l}\text { Regulada y no } \\
\text { prohibida si } \\
\text { cumple la } \\
\text { regulación }\end{array}$ & $\begin{array}{c}\text { Austria, Alemania, } \\
\text { Grecia, Hungría, } \\
\text { Letonia, Países } \\
\text { Bajos, Reino Unido }\end{array}$ & $28 \%$ \\
\hline
\end{tabular}

Como podemos ver, el modelo más extendido en Europa es el nuevo abolicionismo y el reglamentarismo. A continuación explicaremos cada uno de los modelos legislativos 
existentes en Europa y en cada uno expondremos las características legislativas de un país en concreto que se rija por ese modelo.

\subsubsection{Perspectiva Prohibicionista}

Los países que siguen políticas prohibicionistas, son aquellos en los que se intenta reprimir la prostitución penalizándola. Se sanciona a toda persona involucrada en esta actividad, a las que se dedican a ella, a las que la organizan o las que la explotan, incluso a quienes hacen uso de ella (ASE-Psiké, 1997).

Se ha argumentado que esta situación es la más perjudicial para las personas que ejercen prostitución, ya que al negarse tal actividad deben mantenerse en una clandestinidad total sin que el negocio desaparezca, dejándolas en una situación de total dependencia respecto a las terceras personas que se lucran de su trabajo (López y Mestre, 2006; Juliano, 2004a). Según Marjan Wijers y Lap-Chew (1997), los sistemas prohibicionistas en lugar de proteger a las mujeres o trabajar a favor de sus intereses, genera ganancias considerables para cualquier persona (proxenetas o intermediarios) menos para la prostituta; facilita y sanciona el control y el abuso de ellas por parte de terceros y deja a las mujeres sin defensa legal alguna para defenderse contra la violencia, la coerción y el abuso.

En la actualidad Suecia es el país europeo que mejor representa este sistema. A continuación presentamos algunas de sus características:

Se prohíbe tanto la prostitución de interior como la exterior si bien solamente son criminalizados los clientes, no las prostitutas, ya que son consideradas como víctimas de violencia. El 1 de Enero de 1999 Suecia reguló la compra de servicios sexuales, donde la persona que mediante pago obtiene una relación sexual es penalizada.

- La ideología subyacente a esta ley es que la prostitución es una forma de violencia masculina contra las mujeres y niños. 
- El Código Penal penaliza a cualquier persona que promueva o explote relaciones sexuales casuales mediante pago, y también se penaliza el uso de cualquier local para este tipo de actividad.

- $\quad$ Es ilegal comprar un servicio sexual de alguien menor de 18 años.

- $\quad$ En 2002 se introdujo un nuevo delito: el tráfico de seres humanos con fines de explotación sexual. (Di Nicola et al., 2005, p. 39).

\subsubsection{Perspectiva Abolicionista}

Las posturas de corte abolicionista tratan la prostitución como un fenómeno incompatible con la dignidad y el valor de la persona (Convención para la represión de la trata de personas y de la explotación de la prostitución ajena, ONU, 1949).

Es el enfoque esencial de todos los instrumentos internacionales, incluso antes de 1949. Para esta postura toda prostitución constituye una violación de los derechos humanos. Desde la Organización de las Naciones Unidas (ONU) se han creado diferentes instrumentos cuyas funciones son: denunciar, sancionar y tratar de proteger a las víctimas (CIMTM, 2003).

Desde esta postura se establece que la represión debe ir dirigida contra toda aquella persona que fomente o se lucre de la prostitución ajena. Sus objetivos se dirigen hacia la protección y rehabilitación de las víctimas, y consideran que la prostitución nunca puede ser reconocida como un trabajo ni se puede distinguir entre prostitución libre y forzada (Convención para la represión de la trata de personas y de la explotación de la prostitución ajena, ONU, 1949). La convención de la ONU de $1949^{4}$, fue un intento por terminar con las posturas reglamentaristas, pero mostró múltiples puntos débiles que intentaron ser paliados con el "Protocolo adicional de la Convención de la ONU Contra el Crimen Transnacional

\footnotetext{
4 Año en que la ONU celebró la Convención para la Represión de la Trata de Personas y de la Explotación de la Prostitución Ajena
} 
Organizado para prevenir, reprimir y sancionar la trata de personas, particularmente mujeres y niñas/os" del año 2000.

"Las abolicionistas piensan que legalizar o descriminalizar la prostitución sólo sirve para empeorar el problema, y que para una completa erradicación del trabajo sexual, criminalizar a toda persona involucrada en el trabajo sexual (aunque no suele ser a la prostituta) es la forma más efectiva para conseguirlo" (Sanders, 2006, p.4)

Francia sigue un modelo Abolicionista y estas son algunas de las características de su modelo legislativo en materia de prostitución:

- La prostitución de exterior (calle) no está prohibida, pero la prostitución de interior está prohibida cuando es ejercida en burdeles (Art. 225.10).

- El Código Penal prohíbe el proxenetismo (i.e. ayudar, asistir, o proteger la prostitución de otras personas; beneficiarse de la prostitución ajena; y atraer, tentar, inducir o coaccionar a una persona hacia la prostitución)(Art. 225.6).

- La pena por proxenetismo se agrava cuando se realiza contra un menor o una persona especialmente vulnerable.

- $\quad$ El Código también prohíbe mantener una casa de prostitución (Art. 225.10).

- El Art. 18 (de la Ley sobre Seguridad Doméstica, 2003) criminaliza tanto el ofrecerse o buscar clientes como a aquellos clientes que paguen por sexo con una persona particularmente vulnerable; el Art. 28 permite la retirada del permiso de extranjeros a aquellos que se encuentren buscando clientes.

- El delito sobre tráfico de seres humanos con fines de explotación sexual se introdujo en el Código Penal en 2003. 


\subsubsection{Perspectiva Reglamentarista}

Las posturas de corte reglamentarista consideran que la prostitución es una realidad social universal imposible de erradicar (Mestre, 2004). Reconocen su existencia y la regulan, estableciendo así una serie de disposiciones que intentan controlar, de alguna manera, esta actividad. La reglamentación supone siempre un control, pero también un reconocimiento de la actividad. Algunas medidas reglamentaristas, como la zonificación y el control sanitario de las mujeres implicadas, fueron las más extendidas en el siglo XIX y están aún vigentes en algunos países.

Las políticas reglamentaristas, según sus partidarios, surgen de la escasa eficacia de las perspectivas abolicionistas empeñadas en liberar a las mujeres víctimas. Como Covre (2004) afirma, "a pesar de que el ejercicio del meretricio haya estado siempre muy marcado por la violencia, la degradación y la explotación, las prostitutas se han opuesto siempre de distintas maneras a las políticas que prometían liberarlas sometiéndolas a una disciplina (...) La prostitución ha sido (y es) para muchas mujeres un recurso, a menudo el único posible" (p.242).

Magdalena López y Ruth Mestre (2006) denominan esta postura Reglamentarismo decimonónico para diferenciarla de las nuevas formas de reglamentación que están surgiendo en diferentes puntos europeos, como Alemania y Países Bajos.

Las cartillas sanitarias especiales para prostitutas implican la elaboración de censos o de registro de las personas que ejercen la prostitución. Los problemas de las revisiones obligatorias y los registros son variados. Por ejemplo, se ha dicho que dificultan el acceso a los servicios para las personas que no están registradas; además, suponen un instrumento de control sobre las personas registradas y, finalmente, como denuncian las prostitutas, este control sobre ellas les quita el control que ellas pueden ejercer sobre su trabajo y las aboca a situaciones más peligrosas (López y Mestre, 2006).

La zonificación puede hacerse de diferentes formas; por un lado puede prohibirse la prostitución de calle, admitiéndose únicamente en clubes que pueden ser controlados; por 
otro lado, la zonificación puede corresponderse a espacios públicos, para situarla fuera o al margen de las zonas con vecindario (López y Mestre, 2006). La zonificación, a pesar de ser una medida reglamentarista, es practicada en España en ciudades como Bilbao en 1999 o Barcelona en 2003. Esta medida, generalmente, está dirigida a eliminar la prostitución de calle, ya que es la más visible y molesta para el vecindario donde se encuentra ubicada.

En este modelo "de reconocimiento de derechos no se habla, de negociación con las prostitutas, tampoco. La prostitución es sobre todo un problema de orden público, aparece siempre vinculada a otras formas de criminalidad y rodeada de actos delictivos" (López y Mestre, 2006, p. 79).

Entre los países de la UE con sistema reglamentarista Grecia es el país con medidas más similares al reglamentarismo decimonónico, y sus características son:

- La prostitución de exterior es considerada un delito, y el único lugar legal donde trabajar como prostituta es en un piso.

- Para trabajar legalmente las mujeres necesitan un Certificado de profesión. Solamente las mujeres que no están casadas y con permiso de residencia válido pueden obtener este Certificado.

- Los pisos donde se ejerce prostitución no pueden estar en edificios cercanos a escuelas, guarderías, bibliotecas, etc.

- Las mujeres que ejercen prostitución deben registrarse en el Departamento de Sanidad y llevar a cabo chequeos médicos regulares. Ellas no pueden ser forzadas a hacer el chequeo médico, pero si no lo realizan y ejercen prostitución comenten un delito.

- El Código Penal prohíbe el proxenetismo, la prostitución de menores y lucrarse de la prostitución ajena. 
1.3.4. Perspectiva Laboral: reconocimiento de derechos

Durante la última década surge un sistema más liberal, en el sentido de excluir la intervención del Estado en la moralidad de los individuos, que defiende la postura de la prostitución como negocio privado que necesita ser regulado (Mestre, 2004). Desde esta perspectiva, se lucha por otro tipo de regulación, como es el reconocimiento de los derechos y obligaciones, sociales y laborales, de las personas que ejercen prostitución, como cualquier trabajador/a.

Esta nueva postura reglamentarista, que defiende los derechos humanos y laborales de las personas que ejercen prostitución, ha surgido con fuerza en los últimos años y es promovida desde una parte del movimiento feminista.

Desde este movimiento se ha planteado el cambio de terminología a la hora de tratar esta actividad, ya que consideran que es más adecuado el término Trabajo Sexual o Trabajadores/as del Sexo en vez de prostitución o prostituta. Según Bindman y Doezema (1997), "toda ley nacional, (...) cuyo resultado sea poner a las/os trabajadoras/es sexuales fuera del marco legislativo, debería ser rechazada. La redefinición de la prostitución como trabajo sexual es propuesta como condición previa para que las/os trabajadoras/es sexuales disfruten al completo de sus derechos humanos y laborales" (p. 2).

Los términos trabajo sexual y trabajadora/r del sexo han sido acuñados por las mismas trabajadoras del sexo para redefinir el comercio sexual, no como una característica social o psicológica de una clase de mujeres, sino como una actividad generadora de ingresos o una forma de empleo para mujeres y hombres (Lean, 2004). Como Bindman y Doezema (1997) defienden, "la falta de protección internacional y local hace vulnerables a las/os trabajadoras/es del sexo a la explotación en el lugar de trabajo, y al acoso o violencia por parte de los jefes, los agentes de la ley, los clientes y el publico el general. La necesidad de protección laboral, incluyendo la salud laboral y el material de seguridad, es de particular importancia en la situación actual del VIH/SIDA". (p.3). 
La OIT (Lean, 2004) declara que aunque está fuera de sus competencias definirse sobre si los países deberían o no legalizar la prostitución, ofrece algunas recomendaciones para la toma de una posición política, derivadas de un estudio realizado en 1998 en algunos países del sudeste asiático, y son: a) proponer la erradicación de la prostitución infantil, b) reconocer la variedad de circunstancias que se dan entre las prostitutas y eliminar las abusivas, c) centrarse en las estructuras que mantienen la prostitución, no en las prostitutas, d) realizar análisis macroeconómicos oficiales para evaluar, por ejemplo, la problemática sanitaria del sector, decidir el alcance y la magnitud de las políticas de mercado necesarias para tratar con quienes trabajan en él y estudiar las posibilidades de extender la fiscalidad a muchas de las lucrativas actividades asociadas al sector del sexo y e) examinar el aspecto sanitario, no sólo de las prostitutas, sino también entre los clientes, teniendo en cuenta que la cadena de transmisión desde el sector del sexo a la población incluye personas que practican el sexo sin protección alguna con sus esposas o con otras personas (Lean, 1998).

Una de las principales críticas de este modelo es que mantiene en la ilegalidad a las personas inmigrantes que no tienen una situación administrativa regular. Es decir, en la actualidad como hemos visto la prostitución va unida inexorablemente a la inmigración, y aquellas personas que migran ilegalmente o se encuentran ilegalmente deben seguir ejerciendo prostitución sin ningún derecho laboral.

Esta perspectiva política ha sido llevada a cabo por algunos países europeos como Holanda a finales de 1999 y Alemania en el 2000. Las características del sistema legislativo de los Países Bajos son las siguientes:

- Desde 2000 en los Países Bajos la prostitución de interior y de exterior no está prohibida siempre que cumplan las normas requeridas.

- Los Países Bajos ven el mercado sexual como parte de la sociedad y debe ser aceptado. La regulación permite la prostitución dentro de ciertos límites. Estos límites incluyen, por ejemplo, la aprobación de las autoridades los locales de los burdeles que deben ser inspeccionados en términos de salud y seguridad para obtener la licencia municipal. La prostitución es considerada oficialmente una profesión legítima 
$\mathrm{y}$, por tanto, las prostitutas tienen los mismos derechos y deberes que otros trabajadores. Sin embargo, las prostitutas están obligadas a llevar un documento identificativo que deben mostrar si se les requiere y si no lo llevan cometen un delito. Pero no hay un registro de prostitutas, ni obligación de controles médicos ya que violaría la privacidad individual.

- Las personas que residen fuera de la llamada área económica europea no pueden trabajar como prostitutas a menos que tengan permiso de residencia válido para estar en los Países Bajos, mientras que los ciudadanos de países con los que la UE ha firmado un acuerdo (por ejemplo Bulgaria o Rumanía) pueden trabajar solamente como autónomos.

- La prostitución exterior es regulada en algunas ciudades, donde el gobierno local ha designado una zona controlada (Tippelzonen).

- Se prohíbe y penalizan delitos como la explotación sexual, la prostitución de menores y lucrarse de la prostitución ajena.

- Desde 2005, los Países Bajos tienen una nueva ley anti-tráfico que cubre todas las formas de tráfico de personas (Di Nicola et al., 2005, p. 40).

\subsubsection{La prostitución ¿violencia de género o un fenómeno vinculado al género?}

Tomando en cuenta las diferentes definiciones y posturas político-legales sobre el fenómeno de la prostitución, encontramos que en ellas subyacen dos posturas teóricas de corte feminista radicalmente enfrentadas. Ni siquiera encontramos un consenso entre los diferentes movimientos y teorías feministas en relación al abordaje de la prostitución.

Para analizar las diferentes posturas feministas en relación al fenómeno de la prostitución vamos a recurrir a la Tabla 5, propuesta por Elias, Bullough, Elias y Brewer en 1989, en la que se recogen los diferentes posicionamientos de cada tipo de feminismo. En esta tabla podemos encontrar seis tipos de feminismo los cuales podrían ser divididos en dos grandes grupos a partir de su postura en relación con la prostitución. En primer lugar 
encontraríamos las posturas prohibicionistas o abolicionistas (Radical, Socialista y Marxista), y en segundo lugar las posturas reglamentaristas y de reconocimiento de derechos (Existencialistas y Liberales). 
Tabla 5. Posturas feministas sobre la prostitución (Elias et al., 1989, p. 321)

\begin{tabular}{|c|c|c|c|c|c|c|c|}
\hline Tipo de feminismo & $\begin{array}{c}\text { Origen de la } \\
\text { opresión de la } \\
\text { mujer }\end{array}$ & $\begin{array}{c}\text { Efectos } \\
\text { coercitivos de la } \\
\text { prostitución }\end{array}$ & $\begin{array}{c}\text { Solución a la } \\
\text { presencia social } \\
\text { de la prostitución }\end{array}$ & $\begin{array}{l}\text { Papel de la mujer } \\
\text { como prostituta }\end{array}$ & $\begin{array}{c}\text { Efectos } \\
\text { degradantes }\end{array}$ & $\begin{array}{c}\text { Postura sobre la } \\
\text { descriminalización }\end{array}$ & $\begin{array}{l}\text { La prostitución } \\
\text { debería ser } \\
\text { erradicada }\end{array}$ \\
\hline Radical & $\begin{array}{l}\text { Las prácticas } \\
\text { reproductoras y sexuales. } \\
\text { El hombre es socializado } \\
\text { para tener deseos } \\
\text { sexuales y la mujer para } \\
\text { ser sumisa. La opresión } \\
\text { es cultural no biológica, } \\
\text { por lo que se necesita un } \\
\text { cambio de actitud. }\end{array}$ & $\begin{array}{l}\text { La prostitución se iguala } \\
\text { a la violación. La } \\
\text { prostitución es esclavitud. } \\
\text { Toda mujer está afectada } \\
\text { por las tendencias } \\
\text { coercitivas, explotadoras } \\
\text { y opresivas de los } \\
\text { hombres hacia las } \\
\text { mujeres. La coerción es } \\
\text { cultural más que } \\
\text { biológica. }\end{array}$ & $\begin{array}{l}\text { Erradicar la opresión } \\
\text { masculina. Cambio de } \\
\text { actitudes y promoción del } \\
\text { cambio social hacia una } \\
\text { mayor igualdad entre los } \\
\text { sexos. Si la prostitución } \\
\text { es ilegal el cliente debería } \\
\text { ser igualmente } \\
\text { perseguido por la ley. }\end{array}$ & $\begin{array}{l}\text { La prostituta es una } \\
\text { víctima de un sistema de } \\
\text { opresión masculino. La } \\
\text { prostitución no es una } \\
\text { transacción privada } \\
\text { inofensiva. Afecta a todas } \\
\text { las mujeres. }\end{array}$ & $\begin{array}{l}\text { La prostitución es } \\
\text { degradante para la } \\
\text { prostituta y para todas las } \\
\text { mujeres. La prostitución } \\
\text { es igualada a un tipo de } \\
\text { violación. }\end{array}$ & $\begin{array}{l}\text { En contra. } \\
\text { La descriminalización no } \\
\text { resolverá el problema. } \\
\text { Cambiar las actitudes de } \\
\text { los hombres y buscar la } \\
\text { igualdad social es más } \\
\text { importante. }\end{array}$ & $\begin{array}{l}\text { Si. } \\
\text { Erradicar la desigualdad } \\
\text { entre los sexos } \\
\text { desalentando cualquier } \\
\text { acción que degrade a las } \\
\text { mujeres. }\end{array}$ \\
\hline Socialista & $\begin{array}{l}\text { Origen social y } \\
\text { psicológico incluyendo las } \\
\text { prácticas sexuales y } \\
\text { reproductoras. Para } \\
\text { erradicar la opresión es } \\
\text { necesario un cambio en } \\
\text { la estructura social y } \\
\text { económica. }\end{array}$ & $\begin{array}{l}\text { Las mujeres son } \\
\text { coaccionadas a papeles } \\
\text { degradantes para la } \\
\text { construcción de sistemas } \\
\text { sociales de clase. Sin la } \\
\text { presencia del capitalismo } \\
\text { la mujer elegiría otros } \\
\text { papeles. }\end{array}$ & $\begin{array}{l}\text { Intentar remedios no } \\
\text { legales como cambiar la } \\
\text { estructura social. Cuando } \\
\text { sistemas económicos } \\
\text { explotadores, como el } \\
\text { capitalismo, } \\
\text { desaparezcan, lo hará la } \\
\text { prostitución. }\end{array}$ & $\begin{array}{l}\text { La prostituta es una } \\
\text { víctima del sistema. }\end{array}$ & $\begin{array}{l}\text { La prostitución es una } \\
\text { corrupción del sistema } \\
\text { capitalista. }\end{array}$ & $\begin{array}{l}\text { En contra. } \\
\text { Es más importante } \\
\text { cambiar la estructura } \\
\text { social que causa la } \\
\text { prostitución en primer } \\
\text { lugar. Los socialistas no } \\
\text { buscan un remedio legal } \\
\text { para la prostitución. }\end{array}$ & $\begin{array}{l}\text { Si. } \\
\text { Erradicar los sistemas } \\
\text { económicos explotadores } \\
\text { tales como el capitalismo. } \\
\text { Centrarse más en las } \\
\text { necesidades humanas de } \\
\text { forma más solidaria. }\end{array}$ \\
\hline Marxista & $\begin{array}{l}\text { Las distinciones de clase, } \\
\text { la corrupción del trabajo } \\
\text { asalariado, y el } \\
\text { capitalismo. }\end{array}$ & $\begin{array}{l}\text { La coerción es } \\
\text { económica en su origen. } \\
\text { El trabajo asalariado es } \\
\text { esclavitud involuntaria y } \\
\text { subordinación de la } \\
\text { dignidad de los seres } \\
\text { humanos, exacerbada } \\
\text { por la definición de las } \\
\text { clases sociales laborales. }\end{array}$ & $\begin{array}{l}\text { Intentar remedios no } \\
\text { legales. Cuando sistemas } \\
\text { económicos } \\
\text { explotadores, como el } \\
\text { capitalismo, } \\
\text { desaparezcan, lo hará la } \\
\text { prostitución. }\end{array}$ & $\begin{array}{l}\text { La prostituta es una } \\
\text { víctima del sistema } \\
\text { económico. }\end{array}$ & $\begin{array}{l}\text { La prostitución es } \\
\text { degradante para la } \\
\text { dignidad humana dentro } \\
\text { de una esclavitud } \\
\text { involuntaria de un } \\
\text { sistema que explota a la } \\
\text { gente. }\end{array}$ & $\begin{array}{l}\text { En contra. } \\
\text { Es más importante atacar } \\
\text { las causas subyacentes } \\
\text { de la prostitución } \\
\text { eliminando el capitalismo. } \\
\text { Los marxistas no buscan } \\
\text { un remedio legal para la } \\
\text { prostitución. }\end{array}$ & $\begin{array}{l}\text { Si. } \\
\text { Erradicar sistemas como } \\
\text { el capitalismo y la } \\
\text { prostitución } \\
\text { desaparecerá. }\end{array}$ \\
\hline
\end{tabular}




\begin{tabular}{|c|c|c|c|c|c|c|c|}
\hline Existencialista & $\begin{array}{l}\text { La desigualdad en las } \\
\text { libertades sociales. Es } \\
\text { necesario mejorar las } \\
\text { libertades y los derechos } \\
\text { individuales. }\end{array}$ & $\begin{array}{l}\text { Las mujeres no son } \\
\text { coaccionadas hacia la } \\
\text { prostitución. La } \\
\text { prostitución puede ser } \\
\text { una experiencia } \\
\text { liberadora y } \\
\text { empoderante. Donde hay } \\
\text { poca libertad o pocas } \\
\text { elecciones, la prostitución } \\
\text { es una buena opción. Las } \\
\text { diferencias biológicas son } \\
\text { importantes. }\end{array}$ & $\begin{array}{l}\text { Fomentar acciones que } \\
\text { liberen a las mujeres } \\
\text { como seres humanos. } \\
\text { Necesarios mayores } \\
\text { niveles de igualdad entre } \\
\text { los sexos, }\end{array}$ & $\begin{array}{l}\text { La mujer competente } \\
\text { elige ser una empresaria } \\
\text { y encuentra métodos } \\
\text { para mantenerse a sí } \\
\text { misma. }\end{array}$ & $\begin{array}{l}\text { Las mujeres de toda } \\
\text { descripción y ocupación } \\
\text { tienen a favor poderes } \\
\text { para vencer la } \\
\text { adversidad. La } \\
\text { prostitución no es } \\
\text { degradante, es } \\
\text { empoderadora para las } \\
\text { mujeres. }\end{array}$ & A favor & No. \\
\hline $\begin{array}{l}\text { Liberal (Libertades } \\
\text { incondicionales) }\end{array}$ & $\begin{array}{l}\text { La desigualdad en las } \\
\text { libertades sociales. La } \\
\text { necesidad de educación y } \\
\text { razonamiento son las } \\
\text { mejores soluciones. } \\
\text { Mejorar la sociedad } \\
\text { promocionando la } \\
\text { igualdad entre los sexos. }\end{array}$ & $\begin{array}{l}\text { La prostitución deriva de } \\
\text { un impulso biológico. La } \\
\text { prostituta actúa por } \\
\text { elección libre. Esta } \\
\text { decisión puede verse } \\
\text { como un negocio } \\
\text { ordinario. }\end{array}$ & $\begin{array}{l}\text { Las condiciones de las } \\
\text { prostitutas pueden } \\
\text { mejorarse mediante la } \\
\text { educación y la búsqueda } \\
\text { de mayor igualdad entre } \\
\text { los sexos. }\end{array}$ & $\begin{array}{l}\text { La prostituta es una } \\
\text { empresaria que contrata } \\
\text { su trabajo como un } \\
\text { derecho. Como con } \\
\text { cualquier negocio su } \\
\text { habilidad para evitar el } \\
\text { peligro depende de su } \\
\text { conciencia sobre el } \\
\text { mundo. }\end{array}$ & $\begin{array}{l}\text { La prostitución es un } \\
\text { negocio. En todos los } \\
\text { negocios hay aspectos } \\
\text { degradantes que deben } \\
\text { ser superados. }\end{array}$ & A favor & $\begin{array}{l}\text { No. } \\
\text { La prostitución es un } \\
\text { derecho civil. }\end{array}$ \\
\hline $\begin{array}{l}\text { Liberal (Libertades } \\
\text { con restricciones } \\
\text { morales) }\end{array}$ & $\begin{array}{l}\text { La desigualdad en las } \\
\text { libertades sociales. La } \\
\text { necesidad de educación y } \\
\text { razonamiento son las } \\
\text { mejores soluciones. } \\
\text { Mejorar la sociedad } \\
\text { promocionando la } \\
\text { igualdad entre los sexos. }\end{array}$ & $\begin{array}{l}\text { En teoría la postura } \\
\text { liberal debe oponerse al } \\
\text { efecto excesivo de la } \\
\text { persuasión cultural sobre } \\
\text { las mujeres poco } \\
\text { educadas interfiriendo en } \\
\text { su búsqueda de } \\
\text { autonomía, teniendo } \\
\text { entonces una influencia } \\
\text { coercitiva sobre su toma } \\
\text { de decisiones. }\end{array}$ & $\begin{array}{l}\text { Esta postura cuestiona la } \\
\text { posibilidad de que una } \\
\text { prostituta pueda hacer } \\
\text { una elección informada } \\
\text { dados ciertos niveles de } \\
\text { educación y cultura. }\end{array}$ & $\begin{array}{l}\text { La prostituta es una } \\
\text { empresaria con el } \\
\text { derecho de ofrecer sus } \\
\text { servicios. La prostitución } \\
\text { tiene problemas } \\
\text { asociados con esto y no } \\
\text { deberían ser fomentados. }\end{array}$ & $\begin{array}{l}\text { La educación, el } \\
\text { razonamiento, y la } \\
\text { igualdad entre los sexos } \\
\text { podría mejorar las } \\
\text { condiciones de la } \\
\text { prostitución. Los liberales } \\
\text { insinúan que hay } \\
\text { probablemente mejores } \\
\text { elecciones para las } \\
\text { mujeres. }\end{array}$ & A favor con reservas & $\begin{array}{l}\text { No. } \\
\text { La prostitución es un } \\
\text { derecho civil pero no } \\
\text { debería ser alentada. }\end{array}$ \\
\hline
\end{tabular}


Los tres primeros tipos de feminismo se caracterizan por considerar la prostitución como una forma extrema de violencia de género, equiparándola a una nueva forma de esclavitud o violación hacia la mujer. Consideran que el origen de la opresión de la mujer es una consecuencia de la dominación masculina y el sistema capitalista, y que toda mujer que ejerce prostitución es una víctima que debe ser rescatada, ya que la prostitución degrada a la mujer y a la dignidad humana. Las propuestas de actuación que se plantean desde esta perspectiva son la abolición o erradicación de la prostitución, el rescate de las víctimas y la penalización de delitos tales como el proxenetismo o la trata de personas con fines de explotación sexual. Para eliminar la prostitución consideran que debe erradicarse los sistemas económicos explotadores (como el capitalismo) y la desigualdad entre los sexos. Algunas autoras partidarias de este modelo son Andrea Dworkin $(1981,1997)$, Catherine MacKinnon (1987, 1989), Kathleen Barry (1995) y Sheila Jeffreys (1997).

Mientras, los tres últimos tipos de feminismo creen que la opresión de la mujer tiene su origen en la desigualdad de las libertades sociales y que la educación y la igualdad entre los sexos mejorarían la sociedad. Consideran la posibilidad de la elección voluntaria de la prostitución, incluso que puede ser una experiencia liberadora y empoderante para la mujer. La prostitución es considerada una actividad económica en la que la persona implicada es una empresaria que ofrece unos servicios, por lo tanto se lucha por conseguir los mismos derechos sociales y laborales que el resto de trabajadores/as. Las propuestas de actuación que se plantean desde esta perspectiva son luchar por la igualdad entre los sexos, por la legalización de la prostitución como una actividad laboral y la penalización de actos delictivos como la prostitución de menores, el proxenetismo y la trata de personas con fines de explotación sexual. Algunas de las autoras más importantes partidarias de este modelo son Gail Pheterson (1992, 1996), Paula Medeiros (2000), Raquel Osborne (2004), Jo Doezema y Julia Bindman (2004), Dolores Juliano (2002, 2004, 2004a) y Laura Agustín (2001). Estas, entre otras muchas personas, "luchan por defender los derechos de las personas que ejercen prostitución como trabajadores/as del sexo, y afirman que el estigma 
de puta es el rasgo que imposibilita la consideración de la prostitución como un trabajo" (Juliano, 2002, p.12).

\subsubsection{Perspectiva político-legal adoptada en España}

Como en todos lo países europeos, la historia española muestra un vaivén de políticas respecto a la prostitución. Durante el siglo XX se pasó de un sistema abolicionista (1935) a uno reglamentarista (1941) y, de nuevo, al abolicionismo con el Decreto-Ley del 3 de Marzo de 1956 sobre Abolición de Centros de Tolerancia y otras Medidas relativas a la Prostitución. Finamente, la adhesión del Gobierno Español (1962) al Convenio de la ONU de 1949, sobre Represión de la Trata de Personas y de la Explotación de la Prostitución Ajena, implica una ratificación y reforzamiento de la política abolicionista de la prostitución.

El código penal de 1995 trata únicamente la prostitución infantil o de personas incapaces, penalizando actividades que induzcan, promuevan, favorezcan o faciliten la prostitución de estas personas; respecto a los adultos sólo es considerada cuando existe coacción, violencia, etc., para conseguir su ejercicio. El ejercicio de la prostitución individual está despenalizado pero se encuentra sumido en una situación de alegalidad en cuanto no se prohíbe, se tolera pero no se le reconoce los derechos laborales.

El cambio fundamental de este Código es que el bien jurídico a tutelar es la libertad y la indemnidad sexuales y no, como antes, el honor, la moralidad o las buenas costumbres. Desde esta perspectiva no se penaliza el proxenetismo en sí sino su desempeño referido a menores, incapaces o adultos coaccionados. Esta situación permite a los propietarios de establecimientos dar de alta a trabajadores sexuales en la Seguridad Social como camareros especiales, aunque es bastante infrecuente que lo hagan, por lo que la reducción del proxenetismo o la ampliación de los derechos de los trabajadores distan de ser prácticas extendidas" (Agustín, 2001).

"Aunque en España no existe un sector formal de la industria del sexo, los Parlamentos de dos comunidades autónomas (País Vasco y Navarra) han presentado 
proposiciones para conseguir el reconocimiento de los derechos sociales de las personas que ejercen prostitución. Ambas propuestas están directamente vinculadas con la aparición e incremento del fenómeno de la prostitución de migrantes en dichas áreas" (Agustín, 2001, p.182).

En 1999 el Parlamento de la Comunidad Autónoma Vasca crea una Ordenanza local sobre establecimientos públicos dedicados a la prostitución (BOE, Núm. 104, Junio de 1999) con el objetivo de regular la localización de los locales de alterne y señalar los requisitos mínimos de orden higiénico sanitario de dichos establecimientos. De esta ordenanza quedó totalmente excluida la prostitución en domicilios o viviendas particulares por lo que ha recibido numerosas críticas, ya que ha propiciado una tendencia de cierre de clubes y un aumento en el número de pisos.

Por su parte, en el caso de la propuesta de ley al Parlamento Foral de Navarra, el informe del letrado mayor del mismo indicó que la proposición excedía las competencias del Parlamento de Navarra por lo que la propuesta no fue admitida a trámite parlamentario (Agustín, 2001).

En España, algunos propietarios de grandes clubes han creado una asociación profesional (ANELA, Asociación Nacional de Empresarios de Locales de Alterne) que lucha por la regulación de la prostitución. Quieren presentar una imagen limpia y se distinguen de los propietarios de clubes que no cumplen las normas y los derechos de los/as empleados/as" (Di Nicola et al., 2005, p. 74).

Además de lo comentado hasta ahora hay que tener en cuenta que el número de mujeres extranjeras que trabajan en el mundo de la prostitución es cada vez mayor, por lo que no podemos dejar de hablar de la Ley Orgánica 4/2000, de 11 de Enero, Sobre Derechos y Libertades de los Extranjeros en España y su Integración Social; y de los posteriores Reales decretos $178 / 2003$ y $2393 / 2004$.

Esta ley regula la inmigración ya que es un fenómeno cada vez más frecuente dentro del Estado Español. En ella se regula tanto derechos como deberes de las personas 
extranjeras; los apartados que resultan de mayor interés para el tema que nos ocupa son los relacionados con la sanidad, el trabajo y la residencia en España.

En cuanto al tema sanitario toda persona extranjera tiene garantizada la asistencia sanitaria gratuita siempre y cuando se empadronen en alguna ciudad española. El problema de las personas que ejercen prostitución es que muchas veces viven en los mismos lugares donde la ejercen y los dueños/as de los locales no siempre permiten el empadronamiento en los mismos, aunque hay muchos casos en los que así ha ocurrido y la persona disfruta de tal derecho (Consejo General de la Abogacía Española, 2005; Emakunde, 2001).

El tema laboral puede ser el más interesante aunque en temas de prostitución tratarlo es una incongruencia debido a que la actividad no está contemplada como actividad laboral en España; pero igualmente es interesante si lo tratamos como un factor favorecedor de la entrada de personas en la prostitución. Un porcentaje importante de mujeres que ejercen prostitución viajan a España como turistas, esto implica que a los tres meses de estancia su situación pasa a ser ilegal; estar ilegal supone no poder trabajar en ningún trabajo regulado ya que está prohibido por el Art. 50 del Reglamento de la Ley Orgánica 4/2000 (Consejo General de la Abogacía Española, 2005). Esta situación administrativa hace que muchas personas únicamente puedan desempeñar trabajos de baja cualificación (servicio doméstico, cuidado de personas mayores o niños/as, etc.) con bajos ingresos económicos y sin contrato laboral, por lo que cuando valoran cada una de las opciones disponibles muchas se decantan por la prostitución como una mayor y más rápida fuente de ingresos.

Según el nuevo reglamento de extranjería las personas extranjeras pueden permanecer en España con una estancia (no más de tres meses) o con un permiso de residencia, la cual puede ser temporal o permanente. La residencia temporal puede ser de dos tipos, que permita el ejercicio de una actividad laboral o no. Muchas de las personas que ejercen prostitución están legalmente en España puesto que tienen permiso de residencia, pero si no tienen permiso de trabajo vuelven a encontrarse en la misma situación del párrafo anterior. Están legales en nuestro país pero no pueden desempeñar un trabajo 
regulado, teniendo que elegir entre diferentes trabajos no regulados, mal pagados, con malas condiciones, etc. De nuevo la prostitución puede verse como un mal menor en el que conseguir mejores ingresos económicos.

Los medios de comunicación nacionales informan de noticias relacionadas con la prostitución diariamente, donde la mayoría de ellas hacen referencia a delitos contra los derechos de los ciudadanos extranjeros en vez de relativos a la prostitución.

En el año 2000 se incluyó en el Código Penal un delito general de tráfico de seres humanos (Art. 318 bis) y un delito específico de tráfico de seres humanos con fines de explotación sexual (Art. 188.2). Una reforma en el 2003 integró los dos artículos en el mismo (Art. 318 bis), y afirma que "las penas serán impuestas a aquellas conductas que entran dentro de cualquiera de los párrafos anteriores con ánimo de lucro o mediante violencia, intimidación, engaño o abuso de una situación de superioridad o de especial vulnerabilidad de la víctima poniendo en riesgo su salud o integridad personal" (Di Nicola et al., 2005, p. 38).

Se han llevado a cabo diferentes comisiones en el Parlamento Español para tratar el tema de la prostitución, las dos últimas se han llevado a cabo en 2004 y 2007. En 2004, debido al cambio de gobierno se paralizó la comisión de expertos designada para debatir y buscar soluciones al tema de la prostitución. Esta comisión fue retomada en 2007, donde el Parlamento rechazó la legalización de la prostitución porque no creen posible separar el ejercicio de la prostitución del tráfico y la explotación de seres humanos. 
1.4. Características y condiciones en las que se ejerce prostitución

Partiendo de la definición dada en el punto anterior pasamos a explicar algunas de las características más importantes del ejercicio de la prostitución y a describir las condiciones en las que se ejerce esta actividad (heterogeneidad, movilidad, normas de funcionamiento, causas de entrada, etc.).

En primer lugar, debemos destacar la gran heterogeneidad de este fenómeno, encontramos gran variabilidad en el género, la nacionalidad, la edad, etc. de las personas que ejercen prostitución y también gran variabilidad en los lugares donde se ejerce (calle, macroclubes, whiskerías, pisos de relax, etc.). No podemos generalizar sin tener en cuenta esta variabilidad ya que se han encontrado diferencias significativas en base al género, en base al tipo de prostitución, en base a la nacionalidad, etc. (Sanders, 2005; Vanwesenbeeck, 2001).

Existe gran coincidencia al considerar que la magnitud del fenómeno de la prostitución o la industria sexual, tanto en España como en Europa, es enorme pero difícil de cuantificar debido a la clandestinidad con la que se desarrolla y el estado de alegalidad en el que se encuentra. El término de industria sexual incluye burdeles, casas de citas, clubes de alterne, ciertos bares y discotecas, salones de cabaret, líneas telefónicas eróticas, sexo virtual por internet, sex shops con cabinas privadas, casas de masaje, saunas, servicios de acompañamiento (call girls), agencias matrimoniales, algunos hoteles y pensiones, pisos de contactos, cines, películas y revistas pornográficas, restaurantes eróticos, servicios de dominación-sumisión (sadomasoquismo), prostitución callejera y una proliferación inmensa de formas de pagar por una experiencia sexual (Agustín, 2001).

Cuando analizamos el alcance de la industria del sexo aparecen diferentes segmentos que no suelen ser tomados en cuenta; normalmente pensamos en las personas que ejercen prostitución y como mucho en los/as dueños/as de los locales donde se lleva a cabo, pero hay más: 
- Personas que realizan tareas de apoyo directo: taxistas, camareros, porteros, encargados, personal de seguridad, personal de limpieza, etc.

- Personas que realizan servicios de apoyo a la estructura empresarial de la industria del sexo: abogados, contables, médicos, propietarios de inmuebles o pensiones, etc.

- Personas que viven de la industria auxiliar que suministra los instrumentos de trabajo: ropa, maquillaje, pelucas, tabaco, bebidas, preservativos, sábanas deshechables, etc.

- Y los sectores económicos que sin participar directamente se benefician de la industria: el sector hostelero, de turismo, del espectáculo, de las finanzas, de las telecomunicaciones y medios de comunicación como la prensa e internet. (López y Mestre, 2006)

Cuando analizamos los servicios que se comercializan también encontramos una gran variabilidad, algunos son genéricos, mientras que otros más especializados deben ser buscados en locales o espacios específicos. Podemos hablar de francés, masturbación, besar, penetración vaginal, cubana, masaje erótico, lésbicos, griego, sadomasoquismo, tríos, lluvia dorada, etc.

Algo que puede no parecer obvio a primera vista es la gran organización con la que se da esta actividad a pesar de la alegalidad en la que se desarrolla. Como afirma Sanders (2005), "se da un nivel sustancial de coherencia y continuidad en la organización interna de los establecimientos sexuales, las prácticas relacionadas con el trabajo sexual y las relaciones entre las compañeras" (p.159). Esta organización interna se mantiene debido a la existencia de una serie de normas, las cuales son más sociales que individuales ya que son diseñadas para fomentar el interés colectivo no sólo el individual. Normas tales como el uso consistente del condón y los precios (Sanders, 2005).

Estas normas hacen que cuando un cliente decide comprar sexo, aunque la interacción es una experiencia privada, el cliente compra dentro de un conjunto de expectativas y prácticas que son similares en otros lugares o con otras personas tanto a nivel local, como nacional e incluso internacional. El manejo de las normas puede aumentar 
o socavar la seguridad en el ambiente de trabajo, por ejemplo, si todas las personas que ejercen prostitución deciden utilizar el preservativo en todos los servicios sexuales que realizan, los clientes no se plantearían pedir sexo desprotegido ya que ninguna persona lo realiza. Sin embargo, cuando un grupo comienza a incumplir esta norma la seguridad de todo el colectivo se ve influida, ya que muchas se verán obligadas a no usar preservativo si quieren conservar a sus clientes o si necesitan ganar más dinero. Las personas que tienen la capacidad de poner sus propias normas y pueden elegir las condiciones en las que trabajan (precios, tipos de servicios ofrecidos, elección de clientes, etc.) serán las que mayor seguridad y control tienen en el ejercicio de la prostitución. Pero las normas sociales de cualquier grupo no son estáticas sino que están sujetas a los cambios sociales, culturales y políticos. Por ello, ha habido determinados momentos, como con la entrada de mujeres toxicómanas, mujeres inmigrantes o mujeres transexuales, que han hecho cambiar estas normas. Con la entrada de mujeres toxicómanas se vivió una bajada de los precios, mientras que con la llegada de colectivos inmigrantes o transexuales aparecieron nuevos servicios sexuales como el griego o sexo anal (Medeiros, 2000; Sanders, 2005; Shaver, 2005).

Otra de las notas características de la prostitución contemporánea es la gran movilidad de las personas que la realizan. Esta movilidad se da tanto dentro y fuera de la prostitución, como entre los locales, las ciudades y los diferentes países. Las personas que ejercen prostitución entran y salen de la misma con gran frecuencia, ya que un importante porcentaje de este colectivo utiliza esta actividad económica únicamente en los momentos en los que no tiene otra fuente de ingresos o necesitan dinero con urgencia. Igualmente, suelen cambiar de local, de ciudad e incluso de país para realizar esta actividad aprovechando momentos temporales (e.g. zonas turísticas en verano) o eventos (e.g. un mundial de fútbol) que propician mayores ingresos económicos. También existe movilidad entre los diferentes tipos de prostitución (calle, club, pisos de relax, etc.) ya que algunas personas los compaginan buscando diferentes cosas en unos y otros (e.g. más ingresos en un club y descansar en un piso de relax). 
Esta movilidad se da especialmente en la población migrante y se puede entender en el marco de los procesos de globalización aunque tiene rasgos especiales. Si atendemos a las causas del porqué buena parte de este colectivo cambia continuamente de lugar donde ejercer prostitución, encontramos las siguientes: para esquivar los controles policiales, porque algunos locales estipulan el trabajo durante un tiempo limitado, porque existe la cultura de andar buscando situaciones mejores, porque el cambio continuo genera más ingresos al ser novedad en un local, porque también quieren viajar y conocer otras ciudades y países de forma cosmopolita, etc. (Agustín, 2001; Sanders, 2005; Van der Helm, 2004).

Normalmente, son las propias personas que ejercen prostitución las que buscan los lugares donde acudir, a través de los anuncios de contactos o por otras compañeras van conociendo diferentes clubes, pisos, etc. donde se trabaja bien, el local es tranquilo, los dueños/as son majos, se gana más porcentaje por servicio sexual, etc. Ellas mismas se dan las direcciones y teléfonos y conciertan la realización de plazas. Las personas que realizan plazas suelen tener su propio piso o habitación alquilada donde van a descansar cuando terminan la plaza y antes de comenzar la siguiente (Emakunde, 2001). Trabajar en este régimen en un piso de relax supone estar disponible para los clientes durante las 24 horas, es decir, durante el día y la noche, disponiendo de un par de horas al día para salir del piso a realizar sus compras, llamadas, enviar dinero a sus países, etc. (Bindman y Doezema, 1997; Solana, 2003). En España "las rutas que las mujeres (...) nos han señalado como las más habituales (...) son Valladolid, Zaragoza, Sevilla, Málaga y Coruña parecen que son todos enclaves fundamentales de la prostitución (...)" (CIMTM, 2001, p.61).

Esta movilidad también tiene una serie de desventajas, la más inmediata y perjudicial es el desarraigo y el aislamiento que sufren estas personas. El cambio constante de ciudad o incluso de país provoca que no lleguen a conocer el entorno donde se encuentran ni a establecer una red social de apoyo. Por ello, ante un problema estas personas se encuentran desprotegidas y más vulnerables (e.g. si se rompe un preservativo no saben dónde acudir para pedir ayuda). "El conocimiento de la zona donde se ejerce es vital (...), le da pie a conocer los peligros y las zonas de socorro, la existencia de recursos, el desarrollo 
de lazos afectivos con compañeras, el establecimiento de clientes fijos, un ritmo de vida, un horario, (...)" (CIMTM, 2001, p.61). Si tenemos en cuenta el estigma asociado a la prostitución que hace que este colectivo se esconda y niegue la actividad que realizan, vemos que el aislamiento se potencia dificultando la búsqueda de ayuda cuando ésta es necesaria.

Debido a estos factores, el número de personas que ejercen prostitución cambia constantemente en el tiempo y en el espacio dificultando la atención sociosanitaria de este colectivo y el estudio de esta realidad, ya que la realidad de hoy puede no ser la misma en un breve espacio de tiempo (Vandepitte, 2006).

\subsubsection{Factores relacionados con la entrada en la prostitución}

Los factores relacionados con la entrada en la prostitución han sido ampliamente estudiados desde diferentes perspectivas (sociopolítica, antropológica, histórica, etc.) pero como afirma Vanwesenbeeck (2001) son muy difíciles de establecer adecuadamente en las investigaciones empíricas ya que nos encontramos con una mezcla de factores individuales y estructurales que se entrelazan e influyen en la decisión de ejercer prostitución. Dado que a partir de los estudios realizados no se pueden establecer relaciones causales entre los factores estudiados y la entrada en prostitución, hablaremos en todo momento de factores relacionados con la entrada en la prostitución, no de causas.

Como decíamos, al intentar explicar la entrada en la prostitución, nos encontramos con factores económicos, educativos, sociales, familiares, etc. que se entrelazan y dificultan la comprensión del fenómeno. Además, al referirnos a una actividad tan estigmatizada como la prostitución, nos podemos encontrar con los efectos de la deseabilidad social. Cuando los/as investigadores/as tienen dificultades para entender racionalmente las razones por las que se elige esta actividad, encuentran más fácil pensar en las prostitutas como víctimas; además es entendible que ellas mismas acentúen su estatus de víctima y las motivaciones negativas para trabajar (Vanwesenbeeck, 2001). 
En la actualidad el ejercicio de la prostitución tiene una fuerte base económica. No es la única causa pero parece la más influyente, ya que posibilita el acceso a ingresos económicos no sólo para la persona que la ejerce sino también para sus hijos/as, familiares, etc. (Carter, Harry, Jeune y Nicholson,1997; Elias et al., 1998; Harcourt y Donovan, 2005; Jordan, 2005). Pero nuestro análisis debe ir más allá, ¿Qué es lo que hace que una persona tenga tal necesidad económica que decida ejercer prostitución para conseguir los recursos económicos que necesita? ¿Qué factores influyen en el proceso de decisión? y finalmente, ¿Por qué ante condiciones socioeconómicas similares unas personas deciden ejercer prostitución y otras no?

Puede que desde nuestra perspectiva la decisión de ejercer prostitución cobre especial dramatismo y sea difícilmente entendible. Pero si contextualizamos esta toma de decisiones podremos entender la situación en la que se ven miles de personas (Jessen, 2004). Como afirma Dolores Juliano (2004a) "el trabajo sexual no se realiza en un mundo abstracto. Las personas que se dedican a él no lo hacen en medio de un vacío social o valorativo, sino que se encuentran presionadas por un determinado horizonte de posibilidades reales, en cuyo marco toman sentido sus opciones y donde éstas se concretan en medio de presiones más o menos determinantes. Sólo si conocemos el marco de posibilidades alternativas podemos redimensionar mentalmente nuestra visión de la prostitución y (...) permite entenderla como una opción entre otras posibles o incluso como una estrategia de supervivencia o de autoafirmación" (p.162)

A continuación presentamos un resumen de los diferentes factores explicativos recogidos en el trabajo realizado por la Comisión para la investigación de malos tratos a mujeres (CIMTM) en 2003 (ver Tabla 6). Como vemos, distinguen entre factores económicos, educativos, psicosociales y familiares. 
Tabla 6. Factores explicativos recogidos en el trabajo de campo (CIMTM, 2003, p.48)

\begin{tabular}{|c|c|c|}
\hline$\overline{\text { Económicos } y}$ & Paro & Discriminación laboral \\
\hline educativos & Falta de integración en el mercado de trabajo & Precariedad laboral \\
\hline & Explotación laboral & Pobreza \\
\hline & Irregularidad documental & Falta de acceso a la educación \\
\hline & Escasez a nivel formativo & Existencia de redes de captación, tráfico \\
\hline & Falta de información y recursos para emigrar & y trata de mujeres \\
\hline & & Desconocimiento del idioma \\
\hline Psicosociales & $\begin{array}{l}\text { Incidencia de abusos y violencia: interiorización del } \\
\text { rol de víctima y la culpabilidad }\end{array}$ & $\begin{array}{l}\text { Falta de autoestima y habilidades } \\
\text { sociales }\end{array}$ \\
\hline & Falta de redes de apoyo sociales y familiares & Falta de intervención de servicios \\
\hline & Desconocimiento y falta de información sobre & sociales y asistenciales \\
\hline & recursos & Falta de mecanismos de integración \\
\hline & Espiral de situaciones de marginalidad y & social \\
\hline & automarginalización & Estigmatización y autoestigmatización \\
\hline & Adicciones y/o consumo de drogas & \\
\hline Familiares & Violencia física y psicológica: maltrato durante la & Incesto \\
\hline (de la familia & infancia y/o adolescencia & Falta de seguimiento y apoyo familiar \\
\hline de origen) & Repetición de modelos familiares & Ruptura de lazos familiares \\
\hline & $\begin{array}{l}\text { Huída de la familia o independencia y modo de } \\
\text { vida no aceptada por la familia de origen }\end{array}$ & $\begin{array}{l}\text { De la familia propia: maternidad en } \\
\text { solitario }\end{array}$ \\
\hline & Prostitución inducida por un familiar & Compañero o marido en paro \\
\hline & Cargas familiares sin apoyo y/o recursos & Abandono \\
\hline & Falta de ingresos suficientes & Pareja y/o hijos con adicciones (ej. \\
\hline & Malos tratos & Ludopatía) y/o abuso de sustancias \\
\hline & Prostitución inducida por el compañero & (alcoholismo y drogadicción) \\
\hline
\end{tabular}

De la misma manera, la Unión Europea y el Alto Comisionado de Naciones Unidas para los derechos Humanos consideraron los siguientes factores estructurales como agentes explicativos de la prostitución (ver Tabla 7). Vemos que dan especial importancia a los factores relacionados con la desigualdad de género, la feminización de la pobreza y las migraciones. 
Tabla 7. Factores estructurales recogidos por los organismos internacionales (CIMTM, 2003, p.49)

\begin{tabular}{ll}
\hline Unión Europea & $\begin{array}{l}\text { Alto Comisionado de Naciones Unidas para los } \\
\text { Derechos Humanos }\end{array}$ \\
\hline La pobreza y la feminización de la pobreza & $\begin{array}{l}\text { Demanda de la industria del sexo y el turismo sexual } \\
\text { La discriminación contra las mujeres }\end{array}$ \\
El desempleo & $\begin{array}{l}\text { Escasez de información sobre los canales y el proceso } \\
\text { migratorio }\end{array}$ \\
La falta de educación & Discriminación en base al género \\
La imposibilidad de acceso a los recursos & Estatus desigual de mujeres y niñas en los países de \\
La demanda de la industria del sexo & origen y tránsito en la migración y el tráfico \\
& Estereotipos de la mujer como mercancía, sirvientas y \\
& objetos sexuales \\
Falta de promoción de los derechos humanos & Falta de implicación de los gobiernos \\
& Falta de control fronterizo en las migraciones \\
& Desarrollo de redes criminales transnacionales
\end{tabular}

Como vemos, la prostitución es un fenómeno que en su explicación no podemos dejar de tomar en cuenta la perspectiva de género. ¿Por qué la gran mayoría de las personas que ejercen prostitución son mujeres? ¿Por qué la gran mayoría de las personas que compran servicios sexuales son hombres? A continuación vamos a analizar los diferentes ámbitos en los que podemos contextualizar la entrada en la prostitución. Creemos que, en vez de distinguir el ámbito del género como un factor explicativo independiente, es más correcto hablar del género como algo transversal que influye en cada uno de los ámbitos que vamos a explicar a continuación (Van den Borne, 2003).

A partir de la literatura consultada vamos a distinguir dos áreas en las cuales podemos contextualizar la entrada en la prostitución, y son: el área social y el área individual. Estas dos áreas se entrelazan e influyen en diferentes momentos temporales, y su conocimiento permite entender el proceso de entrada en la prostitución.

- Área social o estructural

Nos referiremos a todos aquellos factores relacionados con el entorno de la persona. Dado que la mayoría de las personas que ejercen prostitución en la actualidad son 
inmigrantes muchos de estos factores influyen en primer lugar en la decisión de migrar y en segundo lugar en la decisión de ejercer prostitución.

Probablemente uno de los factores con más peso sea la mala situación económica y social del país de origen debido a guerras, desastres naturales, gobiernos dictatoriales, inseguridad ciudadana, etc. Especialmente en los países en desarrollo la mujer es más vulnerable que el hombre a vivir en la pobreza. Se trata del fenómeno denominado feminización de la pobreza (Declaración de Beijin, 1995), como afirma Junco (2003), "donde hay precariedad y desigualdad socio-económica, las mujeres son susceptibles de verse abocadas al ejercicio de la prostitución, como único remedio del que dota la sociedad para intentar salir de la precariedad más absoluta" (p.7).

Queremos hacer referencia a la existencia de sociedades patriarcales y machistas que asignan a la mujer roles que la sitúan en una posición desigual respecto al hombre. Estas circunstancias se dan en mayor medida en los países en desarrollo, pero el machismo es una lacra que podemos sentir en toda sociedad actual. Una sociedad machista es la que no educa a la mujer de la misma manera que al hombre, es la que ofrece a la mujer trabajos de segunda o con peor remuneración o condiciones laborales que al hombre, es la que pone las cargas económico-familiares sólo en manos de la mujer, es la que no ofrece apoyos y/o ayudas sociales para aliviar estas cargas familiares, es la que oprime y pone límites tanto a la esfera social como a la privada de la vida de la mujer, y un largo etc. (Agustín, 2001; López y Mestre, 2006; Pheterson, 2000; Kempadoo, s.f.).

Como afirma Juliano (2002), "en un mundo en el que las mujeres cubren las dos terceras partes de las horas trabajadas pero tienen acceso solamente al diez por ciento de los recursos, se produce una acumulación de recursos económicos en manos masculinas. Este es un fenómeno generalizado que se materializa en el hecho que, al contabilizar a los más pobres del mundo, encontramos que las mujeres alcanzan el $70 \%$ de este grupo" ( $p$. 143).

En cuanto a factores estructurales relacionados con el país de destino podemos encontrar las estrictas leyes migratorias y el racismo. En la actualidad vivimos un 
endurecimiento de las fronteras de los países denominados del primer mundo para dificultar las migraciones provenientes de los países en vías de desarrollo. Este endurecimiento de las leyes sobre migración tiene dos consecuencias muy relacionadas con la entrada en la prostitución. En primer lugar, al endurecer las leyes sobre migración se propicia que las personas que quieren migrar deban recurrir a redes de tráfico de personas con su consiguiente endeudamiento; esta deuda, generalmente cuantiosa, propicia que muchas personas decidan ejercer prostitución para pagarla en el menor tiempo posible. Además, una ley más restrictiva dificulta la estancia legal en el país de destino, y como se da en España no se puede trabajar regularmente si no se dispone de documentación legal, por ello, muchas personas optan por la prostitución como actividad económica que pueden realizar sin necesidad de tener permiso de trabajo (Harcourt y Donovan, 2005; Perkins, 1991).

Otro factor que puede facilitar la entrada de una persona inmigrante a la prostitución es el racismo, muchas personas encuentran muchas dificultades a la hora de encontrar trabajo cuando su color de piel, su nacionalidad o su raza no es la adecuada. En otras ocasiones hay personas inmigrantes que se ven obligadas a abandonar trabajos regulares pero mal pagados y realizados en condiciones de explotación debido a que son inmigrantes.

- Área individual

Nos referimos a todos aquellos factores relacionados con la persona y sus circunstancias personales que hacen que sea más vulnerable a entrar en el mundo de la prostitución.

Una mala situación socio-económica de la familia de origen o la creada puede favorecer la entrada en la prostitución. Una familia pobre, con muchos/as hijos/as, desestructurada o con antecedentes relacionados con la prostitución puede favorecer la entrada en esta actividad de alguno de sus miembros.

También encontramos factores relacionados con las características del ejercicio de la prostitución que van más allá de las razones puramente económicas. Varios estudios han encontrado que hay personas que además de las causas económicas optan por el ejercicio 
de esta actividad porque les proporciona otros beneficios como afirma Jordan (2005), "libertad para trabajar las horas que quieren; la autonomía y la independencia que en general experimentan en su trabajo; mayor flexibilidad de horarios para adaptarlos a sus responsabilidades y cuidado de sus hijos/as; y los altos niveles de camaradería que experimentan en sus relaciones con sus compañeras" (p.39).

De la misma forma, una red social vinculada con la prostitución también facilita la entrada en esta actividad, diferentes estudios han encontrado que tener un/a amigo/a o familiar ejerciendo prostitución facilita el comienzo de esta actividad (Di Incola et al., 2005; Herrera, 2000; Jordan, 2005; Juliano, 2004a; Montgomery, 1999). Como afirma en su estudio Perkins (1991), "Para la mayoría de las mujeres una gran necesidad económica o una inclinación psicosexual no es suficiente (...) Parece que tan importante como estos factores es la necesidad de que una mujer esté vinculada con la industria primero, o tener algún conocimiento sobre ella, antes de que de el paso de ejercer prostitución “(p.88).

A continuación vamos a comentar factores relacionados con la sexualidad y las diferencias en las conductas sexuales vinculadas al género que pueden influir en la entrada en la prostitución.

Debemos preguntarnos por la libertad sexual y el vínculo entre placer y sexualidad que tienen o han tenido las personas que ejercen prostitución. Muchas han podido tener experiencias sexuales tempranas y poco satisfactorias, matrimonios precoces realizados a veces como consecuencia de embarazos no deseados, violencia sexual dentro de la familia o la pareja, etc. Estos y otros elementos hacen que muchas personas tengan una idea menos dramática del hecho de tener una relación sexual esporádica, contractual e insatisfactoria. (Juliano, 2004a; Perkins, 1991).

También se ha encontrado que muchas personas entrevistadas en países latinoamericanos han tenido relaciones breves en sus países de origen con turistas extranjeros a los que consideraban novios temporales o una forma de salir de la rutina, de conocer cosas nuevas, satisfacer caprichos, etc. pero nunca como una forma de prostitución (Agustín, 2001). O como afirma Juliano (2004a), "para las mujeres pobres, una sexualidad 
sin goce puede ser una experiencia vivida desde mucho tiempo atrás y no forzosamente la prostitución les implica menos capacidad de negociación que sus relaciones de pareja previas" (p.168).

Hay varios estudios en los que se ofrecen datos sobre la victimización temprana (abusos sexuales y malos tratos) que han sufrido las personas que ejercen prostitución (Elias et al., 1989; Farley, 1998; Perkins, 1991). Como el realizado por Perkins en Sydney (1991) donde se encontró que un $15.63 \%$ de las 128 mujeres entrevistadas habían sufrido abusos sexuales por algún familiar o personas conocida. $\mathrm{O}$ el realizado por Melissa Farley en 1998 en San Francisco, donde se encontró que el 49\% de las entrevistadas informaron de haber sufrido abusos sexuales en la infancia. Probablemente el tipo de prostitución que estudiemos (de interior o exterior) influirá en este tipo de hallazgos encontrándose tasas mayores de victimización temprana en aquellas personas que ejercen prostitución de calle. Diferentes autores coinciden en afirmar que es necesario tomar con cautela ésta hipótesis ya que en primer lugar no se han llevado a cabo estudios que concluyan la relación causal entre ambos fenómenos, y por otra parte la población de personas que ejercen prostitución están más acostumbrados a tratar temas relacionados con su vida sexual por lo que puede ser más fácil para ellas hablar sobre los abusos que sufrieron en la infancia en comparación con el resto de la población (Jordan, 2005; Juliano, 2004a). Autoras como Jordan (2005) consideran que si la victimización temprana estuviera relacionada con la entrada en prostitución podría ser posibles por diferentes vías, por una parte "el abuso está relacionado con una baja autoestima y con conductas auto-lesivas, rasgos evidentes en algunos estudios sobre trabajadoras sexuales" (p.41) y por otra, "una respuesta común al trauma es la disociación psicológica, que puede facilitar la entrada en la prostitución y proporcionar un mecanismo de afrontamiento hacia las experiencias de la prostitución" (p.41).

La trascripción de un testimonio realizado por una persona que ejerce prostitución citada en el estudio realizado por Jordan (2005) nos ayuda a clarificar el tema que nos ocupa: 
"Muchas chicas que trabajan han sufrido abusos sexuales -no todas, pero sí

muchas. (...) Si tus primeras experiencias sexuales fueron preciosas, cálidas, entonces tendrás un punto de vista positivo sobre el sexo, pero si has sufrido abusos o violaciones de joven, entonces esto no será del todo un infierno. Tu puedes desconectar fácilmente en el trabajo porque ya lo hiciste en el pasado. Esos mecanismos de desconexión son esenciales para poder estar en este trabajo" (p.42)

También nos encontramos el caso de las mujeres transexuales, las cuales parecen presentar factores relacionados con su sexualidad diferenciada de las mujeres biológicas que influyen en la entrada en prostitución. Según un estudio brasileño, para las personas transexuales "la prostitución fue la única esfera de la vida que las proporcionó una autoimagen positiva, (...) la prostitución las dio un sentido de valía personal, autoconfianza y autoestima (Kulick, 1998). Ellas vendían sexo no sólo por dinero sino también por autorrealización" (Weitzer, 2005a, p.222). Según Harcourt y Donovan (2006) la distinción entre trabajo y placer para las mujeres transexuales en el mundo de la prostitución era a menudo borrosa.

Finalmente debemos mencionar otro aspecto vinculado a las diferencias en las conductas sexuales basadas en el género que influyen en el hecho de que las mujeres sean el grupo principal de venta de servicios sexuales y los varones el grupo principal de compra de estos servicios. Nos referimos a la mayor disposición de los hombres a tener sexo ocasional en comparación con las mujeres (López, 2004). Como afirma Félix López (2004), "detrás de este hecho universal (la prostitución) hay, sin duda, un doble patrón: la mayor disponibilidad del varón para tener actividad sexual ocasional, aún sin afectos y compromisos $\mathrm{y}$, por otra parte, la mayor facilidad de las mujeres para encontrar pareja sexual, si así lo desean, sin tener que recurrir a estos servicios" (p. 162). Por este y otros factores culturales, económicos, etc. a día de hoy las mujeres son el grupo mayoritario en el mercado del sexo, como vendedoras y no como compradoras.

Como ya hemos mencionado en el área social y estructural, los roles de género sitúan a la mujer en una posición más vulnerable que el hombre en cuanto a la entrada en la 
prostitución, ya que son las que mayores cargas económico-familiares soportan, las que menor formación académica, menos opciones laborales rentables tienen y por tanto más pobres (Jessen, 2004; Juliano, 2004a; van den Borne, 2003).

Es interesante comprobar como los trabajos tradicionalmente femeninos difieren de los tradicionalmente masculinos. Según Juliano (2004a), "mientras los trabajos masculinos pueden imaginarse progresando en un eje continuo, desde los mal pagados y con poco prestigio a aquellos que reúnen buenos sueldos y buena consideración social, en el caso de los trabajos tradicionales femeninos esta relación no se cumple e incluso se invierte" (p.163). En la Figura 1 mostramos la relación existente entre prestigio y valor económico en trabajos tradicionalmente masculinos y femeninos.

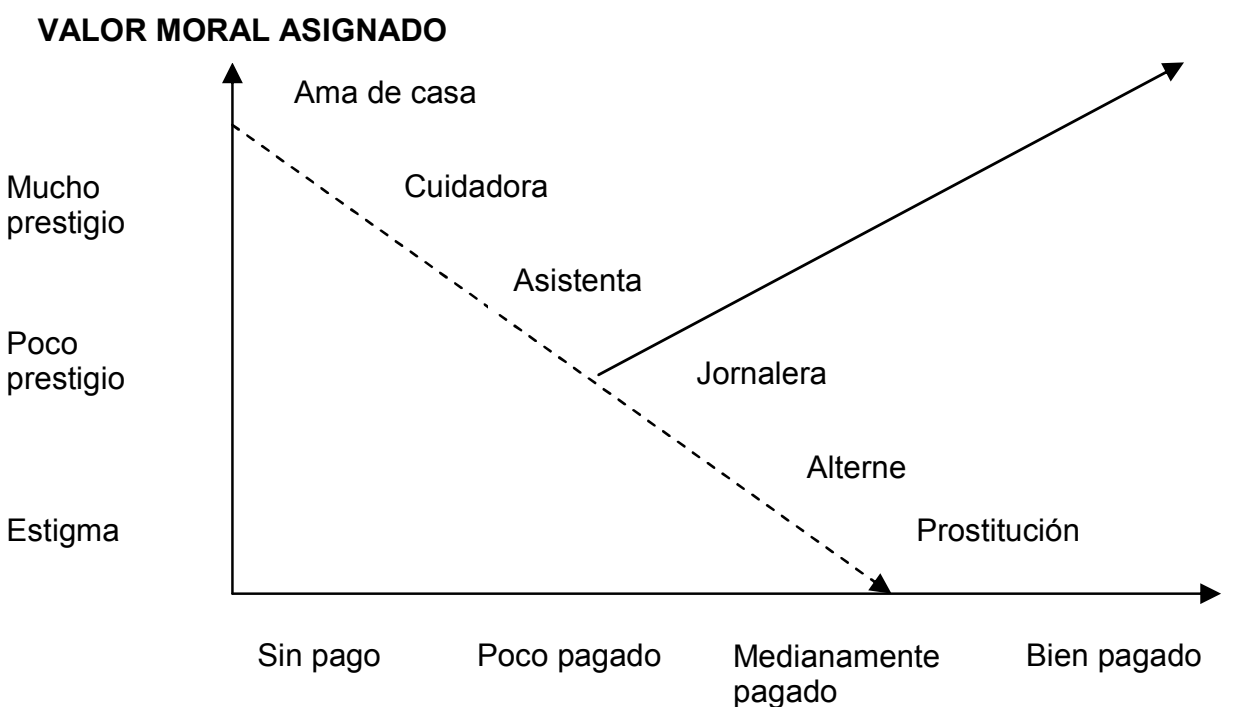

VALOR ECONÓMICO

Trabajos masculinos

Trabajos femeninos

Figura 1. Relación entre prestigio y lucro en trabajos tradicionalmente masculino y femeninos (Juliano, 2004a, p.163)

La única actividad femenina que otorga prestigio a quien la ejerce es el trabajo de esposa y madre, pero se trata de un trabajo gratuito y obligatorio. Los otros trabajos al alcance de las mujeres de los sectores populares (limpieza, cuidado, etc.) están mal pagados e implican menor valoración social. Vemos como un trabajo femenino tradicional y 
medianamente bien pagado, como es la prostitución, acarrea no sólo menos prestigio sino la estigmatización más absoluta (Juliano, 2004a).

Debido a la desigualdad entre hombres y mujeres, y ahora a la desigualdad entre el primer y el tercer mundo, vemos que las mujeres migrantes procedentes de países pobres se encuentran en la peor situación social y económica. Ellas sufren discriminación por ser mujeres inmigrantes, muchas de ellas ilegales, por lo que tienen serias dificultades para encontrar un trabajo. Los trabajos a los que pueden optar suelen ser precarios, sin protección legal, sin contratos, basados en relaciones personales, con escaso prestigio y nulas posibilidades de promoción. Como vemos estas características son similares a las que se dan en el ejercicio de la prostitución, pero presentan una importante diferencia y es que ésta última proporciona mayores ingresos económicos.

En el caso de las mujeres transexuales y travestis encontramos mayores dificultades a la hora de ocuparse en otras opciones laborales ya que sufren aún mayor discriminación laboral que las mujeres biológicas debido a que su papel es visto por la sociedad como de desorden. Se considera que estas personas desorganizan los sistemas de valores y las estructuras familiares, y están rodeadas de multitud de estereotipos que las estigmatiza ya no sólo por ejercer prostitución sino también por el hecho de ser transexuales o travestis (Medeiros, 2000).

A partir de las áreas analizadas podemos resumir el proceso de entrada en la prostitución. En primer lugar comentaremos el proceso de entrada de las mujeres inmigrantes, en segundo lugar la de las mujeres transexuales y finalmente la de las mujeres autóctonas.

Para las mujeres inmigrantes una mala situación económica, la inseguridad en su país de origen, las escasez de alternativas laborales económicamente rentables, las cargas familiares (hijos/as y otros familiares), etc. las lleva a plantearse el proyecto migratorio. Para migrar desde países del tercer mundo a países del primer mundo se necesita dinero e información sobre los pasos para llegar al destino, superar el control de extranjería, etc. Estas circunstancias, derivadas en parte de las restrictivas leyes de inmigración existentes 
en el primer mundo, facilitan la proliferación de redes de tráfico de personas que prestan el dinero y dan la información necesaria para llegar al país de destino sin dificultad. Las propias personas migrantes ven en ocasiones estas redes como un mal menor al que recurrir si quieren finalizar con éxito su proyecto migratorio (Agustín, 2001; CIMTM, 2003). No todas las personas inmigrantes recurren a las redes de tráfico para migrar, muchas costean su viaje con sus ahorros o con la ayuda de sus familiares (generalmente hipotecando su casa). Exceptuando las personas que viajan con sus ahorros, el resto contrae una deuda económica que deben devolver en la mayor brevedad posible, por ello muchas vienen con el conocimiento y la decisión tomada de ejercer prostitución. Sin embargo, otras personas deciden llevar a cabo otras opciones laborales (cuidado de niños/as y ancianos/as, limpieza, hostelería, etc.) las cuales se realizan bajo condiciones laborales muy duras y no están bien pagados. Tras un tiempo, deciden cambiar estos trabajos mal pagados por la prostitución ya que a través de ella pueden satisfacer sus necesidades económicas más rápidamente.

La vía de entrada de las mujeres transexuales es similar aunque presenta algunas características propias. Entre los factores estructurales no sólo tenemos la pobreza o inseguridad de sus países de origen, también encontramos una mayor dificultad para encontrar otras opciones laborales debido a la discriminación por ser transexual. Además, se ha documentado un rechazo muy hostil y grandes sentimientos de homofobia y transfobia hacia este colectivo (Agustín, 2001; Andía, 2006) en países Latinoamericanos, de manera que son víctimas de numerosas agresiones e incluso asesinatos por su condición de transexual. Como podemos leer en el Informe de ILGA (2007), la Asociación Internacional de Lesbianas y Gay, en países como México o Brasil son asesinados impunemente más de quince gays y transexuales por mes. Muchas de estas personas ven en la migración no sólo opciones laborales o mayores recursos económicos, también ven una vida mejor con mayor tranquilidad donde poder vivir sin miedo a ser víctimas de agresiones o sin que corra peligro su vida. Las transexuales tienen otro factor propio que influye en la decisión de la prostitución como fuente de ingresos. Ellas no suelen tener hijos/as aunque en ocasiones 
suelen ayudar a sus familias económicamente, pero necesitan grandes cantidades económicas para costear las operaciones de cirugía de cambio de sexo. Son personas que se hacen múltiples intervenciones para crear su ansiado cuerpo femenino, poniéndose prótesis de silicona en los pechos, en las caderas, en los glúteos, etc. se operan la nariz, los labios, la nuez, etc. y en algunos casos llegan a realizarse una vaginoplastia. Las vías a través de las cuales las transexuales migran son las mismas que anteriormente hemos comentado para las mujeres por lo que encontramos también mujeres transexuales endeudadas con las redes de tráfico de personas. La mayoría de ellas viajan con la prostitución como destino, de hecho, la mayoría ya ejercieron prostitución en sus países de origen. (Elias et al., 1989; Harcourt y Donovan, 2006; Medeiros, 2000)

Finalmente, vamos a comentar la vía de entrada de las mujeres españolas en el ejercicio de la prostitución. En la actualidad encontramos dos perfiles de mujeres españolas ejerciendo prostitución, las consumidoras de drogas y las que no consumen. Las mujeres que no tienen problemas de adicción a drogas suelen recurrir a la prostitución en momentos puntuales de su vida en los que tienen mayores necesidades económicas o se encuentran en situación de desempleo. Son las mujeres que mayor movilidad presentan entrando y saliendo de la prostitución cuando su situación financiera las obliga. Suelen sen mujeres con bajo nivel económico, cargas familiares, separadas de sus parejas y que no tienen los recursos económicos suficientes para cuidar de sus hijos/as. (CIMTM, 2001; Emakunde, 2001; Meneses-Falcón, 2003).

Por otro lado nos encontramos a las españolas que ejercen prostitución para costearse su consumo de drogas. Debemos decir que son muy pocas las mujeres que en la actualidad se encuentren en esta situación, pasaron de ser el grupo mayoritario hace una década a ser una minoría en la actualidad. Estas mujeres presentan características propias ya que su principal problema es la adicción a drogas, una serie de circunstancias en su vida les llevaron a consumir drogas y debido a su adicción comenzaron a ejercer prostitución. Hemos encontrado que son mujeres que han crecido en familias desestructuradas donde podían ya existir antecedentes de consumo de drogas o incluso de prostitución. Son 
mujeres que han sufrido victimización temprana relacionada con los malos tratos y los abusos sexuales en la infancia y/o adolescencia (Emakunde, 2001; Perkins, 1991). Muchas de ellas han tenido embarazos precoces y han sido madres solteras que en ocasiones han sido rechazadas tanto por la familia como por la pareja. Algunos de estos factores, o su combinación, han llevado a muchas mujeres a una adicción a drogas, la cual es soportada mediante el ejercicio de la prostitución (Cáritas de Zaragoza, 1996; McKeganey, 2006; Meneses-Falcón, 2003).

Es interesante ver como cada uno de los colectivos se corresponde con los diferentes lugares o tipos donde se ejerce prostitución calle, club y pisos. Las mujeres toxicómanas ejercen en la calle, las mujeres transexuales en pisos y las mujeres se reparten igualmente entre clubes y pisos.

Pero antes de pasar a describir las características y las diferencias de los diferentes tipos de prostitución vamos a volver a considerar las preguntas realizadas al comienzo de este punto, ¿Qué es lo que hace que una mujer tenga tal necesidad económica que decida ejercer prostitución para conseguir los recursos económicos que necesita? Como hemos visto los factores sociales e individuales se conjugan para crear un entorno de necesidad económica que genera que muchas personas deban decidirse por soluciones drásticas y/o rápidas ¿Qué factores influyen en el proceso de decisión? Consideramos que factores de género, económico-laborales y sexuales generan una situación de vulnerabilidad en la que una persona en determinado momento de necesidad pueda optar por esta actividad económica. Y finalmente, ¿Por qué ante condiciones socioeconómicas similares unas personas deciden ejercer prostitución y otras no? Es difícil contestar a esta pregunta ya que deberíamos comparar mujeres que encontrándose en las mismas circunstancias socioeconómicas unas han optado por la prostitución y otras no. No hemos encontrado ningún estudio de estas características debido fundamentalmente por la dificultad de encontrar un grupo control adecuado. Pero como resumen podemos quedarnos con la afirmación de Laura Agustín (2001): "Es también importante señalar que entre los que sufren la pobreza, malos matrimonios y todo el abanico posible de factores causantes, no todos 
optan por el trabajo sexual como no todos optan por migrar. Ningún tipo de determinismo explica por completo el fenómeno humano de la elección. Toda opción es intervenida por cuestiones de clase, género, etnia, nivel económico y las condiciones sociales del momento en su país (guerra, dictadura, hambruna, violencia, paro)" (p.26). La diversidad humana entra en juego en esta decisión, su naturaleza, sus deseos, sus pasiones, su curiosidad, su capacidad para arriesgarse, etc. (Perkins, 1991; Sanders, 2005).

1.4.2. Tipología de la prostitución: calle, club y piso

Varios autores han señalado la importancia de realizar investigación comparativa entre los diferentes tipos de prostitución ya que hay diferencias entre unos tipos y otros y ayuda a analizar la diversidad existente dentro del fenómeno de la prostitución (Emakunde, 2001; Harcourt y Donovan, 2006; Medeiros, 2000; Perkins, 1991; Shaver, 2005; Vandepitte, 2006; Vanwesenbeeck, 2001; Weitzer, 2005). Como afirma Weitzer (2005), "la estratificación de la prostitución tiene implicaciones en las condiciones de trabajo, la autoestima de los/as trabajadores/as y el ajuste psicológico, y su impacto sobre la comunidad circundante" (p. 215). Parece ser que el tipo de prostitución es el mejor predictor de las experiencias del/a trabajador/a. En este punto analizaremos los tres tipos de prostitución más importantes, y son la calle, los clubes y los pisos.

- Calle (Prostitución de exterior)

La prostitución de calle es la más conocida y practicada a lo largo de todo el mundo. Es la tipología más estudiada aunque sea la menos utilizada en la actualidad, ya que a pesar de su gran visibilidad supone aproximadamente un $10 \%$ de la actividad total. En las ciudades más pequeñas de España no existe prostitución callejera o se reduce a los grupos más marginales, como las mujeres mayores (de hasta 80 años de edad) y las mujeres toxicómanas (Agustín, 2001; Medeiros, 2000).

Las prostitutas callejeras utilizan la calle para captar a su clientela, cuando hablamos de calle hacemos referencia a parques, a polígonos industriales, a carreteras, etc., aunque 
los servicios sexuales se pueden llevar a cabo en diferentes lugares (en la misma calle, en el coche o casa del cliente, en habitaciones alquiladas por horas, etc.) (Emakunde, 2001; Medeiros, 2000). En la calle cada prostituta establece sus precios y éstos varían en función de la zona y del ambiente, aunque muchas confiesan que nunca saben exactamente cuánto cobrarán, ya que todo depende de la negociación que establece en privado con el cliente (Medeiros, 2000). En la actualidad, las mujeres que ejercen en la calle no suelen tener chulo como hace unos años, la mayoría son independientes aunque en ocasiones comparten sus ganancias o su droga con sus parejas (Shaver, 2005).

Ejercer prostitución en la calle, donde la mayoría de los servicios se hacen en los coches de los clientes, hace que éstos sean rápidos y limitados a las características del espacio (la mayoría de los servicios son francés y masturbación). Debido a que en la calle ejercen prostitutas toxicómanas, en ocasiones la clientela las busca y paga únicamente para que ellas les consigan drogas y consuman con ellos.

Las características del trabajo en la calle conllevan una serie de ventajas. El gran movimiento de clientes y la rapidez de los servicios generan mayor número de ingresos en un breve espacio de tiempo. Además las mujeres sienten más autonomía en cuanto a los precios de los servicios y la flexibilidad en sus horarios, no teniendo que compartir sus ganancias con nadie. Finalmente, los gastos generales que conlleva el ejercicio de la prostitución en la calle son ínfimos.

Pero también conlleva desventajas, se ha reseñado en multitud de estudios la falta de seguridad y los riesgos que se corren desempeñando esta actividad en la calle. Las agresiones físicas y sexuales, las humillaciones, los robos, etc. que soportan las prostitutas de calle son más elevados que en el resto de tipos de prostitución, y no sólo por parte de los clientes sino también por parte de los transeúntes, vecinos, policía, pareja, otras prostitutas, etc. La exposición pública que supone ejercer prostitución en la calle y llevar a cabo el servicio en el coche del cliente facilita las agresiones (Harcourt y Donovan, 2005; McKeganey, 2006; Perkins, 1991). Finalmente, las prostitutas señalan que trabajar en la calle no es muy cómodo debido a que están expuestas al frío, al calor y a la lluvia, no tienen 
lugares donde poder llevar a cabo su higiene íntima, se pasan muchas horas de pie, etc. (Medeiros, 2000).

Como consecuencia las personas que ejercen en la calle presentan niveles altos de estrés psicosocial, menor calidad de vida, son más jóvenes en su inicio en la prostitución (Shaver, 2005), mayor exposición a enfermedades de transmisión sexual, baja autoestima y mayor consumo de drogas ilegales (Weitzer, 2005a).

- Club: de ciudad y de carretera (Prostitución de interior)

En cuanto a los clubes, encontramos diferentes tipos. Por un lado el club de ciudad tradicional, el cual es pequeño, funciona como un bar y suelen tener habitaciones o reservados donde se llevan a cabo los servicios sexuales, aunque a veces se trasladan a pisos o pensiones cercanas (Emakunde, 2001). Funcionan de forma similar a un bar ya que los ingresos de las personas que ejercen en ellos no sólo se derivan de los servicios sexuales, sino también de un porcentaje que ganan con las copas a las que los clientes las invitan, esta actividad se denomina copeo o alterne. El club no funciona como vivienda y las personas permanecen en él durante el horario de apertura del local, que oscila entre las 9 de la noche y las 3 de la mañana. Los precios suelen ser fijados por las propias personas que ejercen esta actividad, los cuales dependen del tiempo (servicios de 20, 30 o 45 minutos) o del tipo de servicio (francés, completo, etc.).

El otro tipo de club, denominado macroclub o hipermercado del sexo (Salas, 2004), es relativamente moderno, comenzando a desarrollarse en los 90 , y su régimen de funcionamiento es similar a un hotel. Suelen estar ubicados en las carreteras principales cerca de las ciudades o pueblos grandes. Algunos de estos locales son espectaculares, albergando no sólo una discoteca y las habitaciones, sino también gimnasio, peluquería, restaurante, spa, tiendas de ropa y artículos de higiene, con cajeros automáticos en el interior, etc. En estos locales se pueden encontrar hasta 100 personas ejerciendo prostitución y supone alrededor del $35 \%$ del total, aunque este porcentaje puede variar en función de las zonas y las ciudades (Fernández, 2004; López y Pinedo, 2007; Salas, 2004). Estos locales cuentan con múltiples habitaciones en las que no sólo se ejerce prostitución 
sino también viven las personas que la ejercen. El régimen de funcionamiento de este tipo de locales suele ser de plaza, cada persona paga una cantidad diaria en concepto de alojamiento, la cual oscila entre 30 a $60 €$, y tiene derecho a vivienda, alimentación y lugar de trabajo. Las ganancias que cada persona obtiene vendiendo servicios sexuales suelen ser íntegras para ella, pudiendo ganar más dinero con las copas a las que los clientes las invitan (normalmente los dueños ganan un 60\% de la copa y las chicas el resto). Dado que los servicios sexuales se llevan a cabo en una habitación, éstos son diversos y los precios varían en función del tiempo y el tipo de servicio contratado. En los clubes las personas suelen tener libertad para elegir sus propios precios y los clientes con los que ocuparse, por lo que tienen más control sobre las condiciones en las que desarrollan la actividad (Agustín, 2001).

Actualmente en los clubes, tanto de ciudad como de carretera, casi el $100 \%$ de las personas que ejercen prostitución son mujeres extranjeras, es muy raro encontrar mujeres españolas, transexuales o varones. Las nacionalidades son variadas aunque los grupos mayoritarios son latinoamericanas, de Europa del este y africanas (Emakunde, 2001). La forma en la que los clientes son captados es a través del cartel luminoso situado en el exterior del local que anuncia la palabra club, aunque los clubes más selectos y modernos cuentan también con páginas web para anunciarse.

Los clubes presentan mayor seguridad que la calle ya que suelen tener personal de seguridad y encargados/as que velan por la misma. Además, aunque suele tratarse de un acuerdo verbal, los clubes tienen una serie de normas que deben ser cumplidas por las personas que ejercen prostitución y cuyo objetivo es aumentar la seguridad. Algunas de estas normas son: prohibido tomar alcohol y/o drogas en el establecimiento, o negociar y cobrar el servicio antes de subir a la habitación. Aunque los locales son muy visibles las personas que ejercen prostitución en ellos conservan mayor anonimato que las que trabajan en la calle (Shaver, 2005).

Según diferentes estudios realizados en Australia, Gran Bretaña, Canadá, Nueva Zelanda, España y Estados Unidos, las personas que trabajan en clubes no difieren mucho 
en su estado de salud de las personas que ejercen en pisos. En ambos tipos de prostitución las personas que ejercen esta actividad presentan mejor estado de salud mental, mayor autoestima, menos episodios de violencia física y sexual, tienen mayor acceso a los sistemas de salud y menor consumo de drogas (Fernández, 2004; Harcourt y Donovan, 2006; López y Pinedo, 2007; Shaver, 2005; Weitzer, 2005a). Las personas que trabajan en prostitución de interior (clubes y pisos) tienen mayor control sobre las condiciones en las que trabajan y mayor seguridad, por lo que sienten mayor satisfacción con la actividad que realizan en comparación con las personas que la realizan en la calle. Una mayor satisfacción con la actividad que realizan puede influir en el hecho de tener mayor bienestar psicológico y calidad de vida (Weitzer, 2005a).

Las personas que ejercen prostitución en un club encuentran como aspecto ventajoso el hecho de disponer de alojamiento, comida y trabajo sin tener que pagar grandes cantidades de dinero y con facilidad de acceso. Suele ser la opción elegida por aquellas personas recién llegadas de sus países de origen, ya que soluciona los principales problemas de integración al llegar al país de destino (alojamiento, recursos económicos, etc.). Dada la libertad que existe para poner sus propios precios y ganar el $100 \%$ de las ganancias, los clubes aseguran buenos ingresos económicos sin perder otras garantías como la seguridad.

Sin embargo los clubes también tienen una serie de desventajas, en primer lugar las personas que trabajan en ellos se quejan del aislamiento en el que viven, ya que su vida gira en torno a ejercer en el club durante la tarde-noche y dormir el resto del tiempo, no teniendo vida social ni tiempo libre para otras actividades. Además, algunos locales se encuentran alejados de ciudades o poblaciones por lo que no pueden salir con facilidad a realizar otras actividades, entre ellas su control sanitario. Algunas mujeres también se quejan de lo cansado que es permanecer de 8 a 10 horas diarias de pie, con tacones, en un ambiente cargado de humo con música muy alta, atendiendo a los clientes. (Fernández, 2004). 
- Pisos (Prostitución de interior)

Son denominados pisos de relax o de masajes, todos presentan características similares aunque difieren en el régimen de funcionamiento, es decir, dentro de esta categoría podemos encontrar, pisos donde ejercen prostitución un grupo de personas que se conocen pero son independientes; pisos regentados por una madam la cual es responsable o dueña del negocio; y pisos donde únicamente trabaja una persona de forma independiente.

Este tipo de prostitución se encuentra en expansión y en la actualidad supone el $60 \%$ de la prostitución total, pero es la tipología más invisibilizada y discreta (Ibbitson, 2002). Debido a su discreción encontramos mayor número de personas españolas ejerciendo en esta modalidad, ya que encuentran mayor seguridad para ocultar su doble vida y no ser descubierta por familiares o amistades (Emakunde, 2001). El número de personas que podemos encontrar en cada piso oscila entre una y diez personas, en ocasiones se llevan a cabo turnos de trabajo para cubrir las 24 horas de servicio (Agustín, 2001; Fernández, 2004; López y Pinedo, 2007).

Los pisos captan a su clientela a través de los anuncios clasificados de la prensa local. Dado que es su principal vía de acceso al cliente los anuncios suelen ser muy explícitos (en ocasiones con fotografía) y llamativos. En estos anuncios se proporciona un número de teléfono (normalmente móvil para un mayor anonimato) a través del cual el cliente se pone en contacto con la prostituta y pide información sobre el tipo de servicios que realiza y los precios. Cada piso dispone de varios anuncios en prensa con números de teléfono diferentes ofreciendo gran variedad de personas y servicios, es la forma de abarcar mayor mercado. Cuando el cliente llega al piso pasa a una habitación donde entran y se presentan cada una de las personas que se encuentran en el piso, de esta manera selecciona a quien es de su agrado o realiza el servicio que busca (Agustín, 2001; Perkins, 1991).

Dada la discreción de esta tipología los servicios ofrecidos presentan algunas diferencias, no ciñéndose únicamente a los servicios sexuales. El tipo de servicios 
demandados por el cliente suele ser afectivo y sexual, buscando también compañía, conversación, etc. (Agustín, 2001). Los precios de los servicios se basan en el tiempo, existiendo tarifas de 20,30, 45 minutos y una hora; también se pueden contratar servicios especiales porque el tiempo requerido es mayor o porque se pide un tipo de servicios sexual fuera de lo común (sado, lluvia dorada, griego, etc.). Son los/as dueños/as del piso quienes establecen las tarifas ya que las ganancias suelen ser un $50 \%$ para la casa y un $50 \%$ para la persona que ejerce prostitución. El dinero que queda para el piso sirve para pagar el alquiler, las facturas (luz, agua, calefacción, etc.), los gastos de comida y en ocasiones los anuncios en prensa (Fernández, 2004; López y Pinedo, 2007; Perkins, 1991).

En cuanto a las ventajas de ejercer prostitución en un piso se encuentra la discreción, la seguridad y la tranquilidad. A través de la mirilla de la puerta o mediante cámaras de circuito cerrado las personas que se encuentran en el piso pueden visualizar al cliente antes de que entre, por lo que se aseguran de no ser reconocidas y evitar a clientes con los que hayan tenido malas experiencias. Las personas que trabajan en este tipo de prostitución reconocen como ventaja la flexibilidad horaria ya que cada persona elige el horario que mejor le conviene en función de sus necesidades o responsabilidades. Son el grupo que mejor estado de salud presentan y tienen un mayor acceso a los sistemas sanitarios y sociales, por lo que no se encuentran tan aisladas como sus compañeras de club. Como desventajas aluden a una menor rentabilidad de la actividad ya que pierden un $50 \%$ de sus ganancias que quedan para el piso. 


\subsubsection{Riesgos y prácticas abusivas en el ejercicio de la prostitución}

La prostitución siempre ha estado asociada a diferentes riesgos como la infección por VIH/SIDA, el consumo de drogas, los episodios de violencia, etc. Como hemos visto anteriormente son las personas que ejercen prostitución en la calle las que peores condiciones laborales presentan, mayores riesgos corren y más vulnerables son a ciertas prácticas abusivas. Aún así queremos hacer una breve revisión de la literatura existente sobre estos factores tan relacionados históricamente con la prostitución, aunque en la actualidad en la prostitución de interior son infrecuentes (Church, Henderson, Barnard y Hart, 2001; Raphael y Shapiro, 2004; Surrat, Inciardi, Kurtz y Kiley, 2004).

- VIH/SIDA y otras ITS

Cuando pensamos en prostitución automáticamente pensamos en VIH/SIDA y enfermedades de transmisión sexual. Cuando comenzó la epidemia del SIDA en la década de los 80 y no se conocía demasiado sobre la enfermedad, se establecieron los denominados grupos de riesgo, donde entraban los homosexuales, las prostitutas y los drogodependientes. A partir de ahí el estigma se cernió sobre estos colectivos, y aún hoy, cuando ya no hablamos de grupos de riesgo sino de conductas de riesgo, a las personas que ejercen prostitución se las sigue considerando un foco de infección de enfermedades de transmisión sexual (Church et al., 2001; Day y Ward, 2004; Ibbitson, 2002; Medeiros, 2000; Vanwesenbeeck, 2001)

El VIH/SIDA está vinculado al mundo de la prostitución cuando hacemos referencia al grupo de personas drogodependientes que ejercen esta actividad para costearse su consumo de drogas. Cuando desvinculamos la prostitución de la adicción a las drogas las tasas de infección encontradas en estudios realizados en diferentes países han sido bajas, entorno al $1 \%$ en todos los estudios (Belza, Llácer, Mora, de la Fuente, Castilla, Noguer y cañellas, 2000; Day y Ward, 2004; McKeganey y Barnard, 1996; Medeiros, 2000; Sanchez et al., 2003; Sanders, 2005; Solana, 2003; Surrat et al., 2004; Vanwesenbeeck, 2001; Ward et al., 2004; Ward, Day y Weber, 1999; Uribe y Hernández, 2000; Uribe-Salas, Conde- 
González, Juárez-Figeroa y Hernández-Castellanos, 2003; Warr y Piett, 1999; Williamson y Folaron, 2001; Wolfers, 2000).

Las personas que ejercen prostitución están muy concienciadas del uso del preservativo en sus relaciones comerciales, el cual es usado por diferentes razones: para la prevención de enfermedades de transmisión sexual y de embarazos no deseados, como una forma de separación física entre su propio cuerpo y el del cliente y a la vez como una distinción entre las relaciones sexuales comerciales y las privadas (Belza et al., 2000; Cwikel, Ilan y Chudakov, 2003; Day y Ward, 2004; Jackson, Sowinski, Bennet y Ryan, 2005; McKeganey y Barnard, 1996; Vanwesenbeeck, 2001; Warr y Piett, 1999). Son los clientes los que presentan menor percepción de riesgo e intentan conseguir sexo desprotegido mediante el ofrecimiento de mayores cantidades de dinero, situación muy poderosa aceptada por aquellas personas con mayores presiones o cargas económicas (Jordan, 2005). En el estudio realizado por Rao, Gupta, Lokshin y Jana (2001) se encontró que las personas que usaban sistemáticamente el preservativo en sus relaciones sexuales comerciales perdían una media de un $44 \%$ de los ingresos económicos por cada cliente.

El buen uso del preservativo por parte de las mujeres puede deberse a las diferencias existentes basadas en el género, ya que como afirma López (2004) "Las mujeres tienen mayor percepción de los riesgos, están más interesadas y dispuestas a prevenirlos (...) Están más dispuestas a mejorar su salud y a contribuir a la salud de los demás. Los varones tienden a asumir más riesgos en las relaciones sexuales y están menos dispuestos a prevenirlos" (p.158). Pero también se dan diferencias educativas, los estudios llevados a cabo muestran que las personas que ejercen prostitución presentan buenos conocimientos sobre la transmisión del $\mathrm{VIH}$, mientras que los clientes tienen menos formación que la población general (Chetwynd y Plumridge, 1993; Jordan, 2005)

Pero son las relaciones sexuales privadas, con sus parejas, donde mayores riesgos corren las personas que ejercen prostitución ya que son más frecuentes las relaciones sexuales desprotegidas, y en algunas ocasiones ésta se convierte en la vía de infección de enfermedades de transmisión sexual (Albert, Warner y Hatcher, 1998; Ward et al., 1999). 
Tanto ellas mismas como sus parejas afirman que usar preservativos en sus relaciones sexuales está fuertemente vinculado al sexo comercial, por lo que no usan preservativos para diferenciar el ámbito comercial del privado, incluso es considerado como un intento de recobrar su respetabilidad (Warr y Piett, 1999). Como concluyen Warr y Piett en su estudio, "usar condones en una relación privada redujo sustancialmente la capacidad de las mujeres para experimentar amor e intimidad a través del sexo. Para sus parejas también, el uso del condón podía ser interpretado como una falta de confianza” (1999, p.301).

En cuanto a los datos obtenidos en el estudio de otras enfermedades de transmisión sexual diferentes al VIH/SIDA se han encontrado resultados similares en los estudios realizados en distintos países. Las enfermedades de transmisión sexual más frecuentemente encontradas fueron herpes genital (hasta un $85.7 \%$ en algunas muestras), el virus del papiloma humano (HPV) (hasta un $48.9 \%$ ), clamidias (hasta un $23.7 \%$ ) y hepatitis B (hasta en un 19\%) (Baltazar, Rivera, Cruz y Hernández, 2005; Camejo, Mata y Díaz, 2003; Sánchez et al., 2003; Touzé et al, 2001; Uribe y Hernández, 2000; Uribe-Salas et al, 2003; Ward et al., 2004; Ward et al., 1999). Entre los trabajos consultados cobra especial interés el estudio comparativo realizado por Touzé et al. (2001) sobre diferentes tipos del virus del papiloma humano. Este estudio comparó un grupo de población general con un grupo de personas que ejercían prostitución y éste último mostró mayores ratios de infección tanto para el tipo 16 como el 18 del HPV, que son los dos tipos de virus más vinculados con la presencia de cáncer de cuello uterino.

- Consumo de drogas

Como hemos comentado anteriormente hace unos años el consumo de drogas estaba fuertemente vinculado al ejercicio de la prostitución, y concretamente a la prostitución de calle, pero en la actualidad es la inmigración el factor vinculado a la misma (Brewis y Linstead, 2000; McKeganey y Barnard, 1996; Vanwesenbeeck, 2001).

Entre el colectivo de personas inmigrantes que ejercen prostitución encontramos, sin embargo, un pequeño grupo que consumen drogas, pero este consumo suele ser de carácter esporádico y el tipo de drogas consumidas suelen ser las mal denominadas drogas 
blandas o suaves, como alcohol, tabaco, hachís y pastillas. Mientras que no se encuentra un mayor consumo de cocaína y heroína en comparación con la población general (Brewis y Linstead, 2000; López y Pinedo, 2007; Pinedo y Martín, 2006; Sanders, 2005).

Las drogas pueden ser usadas por múltiples motivos en el mundo de la prostitución, "algunas veces para mantener a las trabajadoras despiertas durante largos días y largas noches, (...), algunas veces para relajarlas y aliviar la sensación de lo poco placentero que es el trabajo. Algunas veces esto también ayuda a jugar el papel requerido en el trabajo, para llegar a ser el producto que los clientes demandan" (Brewis y Linstead, 2000, p.86), ya que existen clientes que demandan a las propias personas que ejercen prostitución que consuman drogas con ellos como parte del servicio que contratan.

El hecho de consumir drogas durante el ejercicio de la prostitución, sea con el cliente o no, es paradójico en cuanto a que muchas lo consideran una estrategia para incrementar su confianza, su control, su fortaleza psicológica, etc. pero sin embargo, puede conllevar el efecto contrario: pérdida del control, menor percepción de riesgo, etc., factores que las colocan en una situación de mayor vulnerabilidad hacia riesgos de carácter sexual y episodios de violencia (Ribeiro y Sacramento, 2005; Vanwesenbeeck, 2001).

- Violencia física, psicológica y sexual

Otro de los aspectos mayormente vinculados al mundo de la prostitución es la violencia que sufren las personas que realizan esta actividad, la cual puede provenir desde diferentes ámbitos como la sociedad, la familia, los clientes, las parejas, la policía, etc. y puede ser física, psicológica o sexual (Vanwesenbeeck, 2001). Aunque la violencia es uno de los riesgos más citados en la literatura consultada, debemos, de nuevo, distinguir los estudios que hacen referencia a la prostitución de calle y la de interior, ya que esta última refiere menor número de episodios violentos (Church, Henderson, Barnard y Hart, 2001; McKeganey y Barnard, 1996; Surrat et al., 2004; Ribeiro y Sacramento, 2005).

En cuanto a la violencia que sufre este colectivo durante el ejercicio de la prostitución, se ha encontrado la misma tendencia en estudios realizados en diferentes países, hallándose diferencias significativas al comparar los niveles de violencia sufrida por 
las personas que ejercen prostitución en la calle con la que sufren las personas que ejercen prostitución de interior. "Un estudio Británico entrevistó a 115 prostitutas que trabajaban en la calle y 125 en saunas o en pisos y encontraron que las chicas de calle tenían más probabilidad que las trabajadoras de interior de informar que habían sufrido un robo (37 vs. $10 \%$ ), habían sido golpeadas (27 vs. $1 \%$ ), abofeteadas/empujadas/pateadas (47 vs. $14 \%$ ), violadas (22 vs. $2 \%$ ), amenazadas con una navaja ( 24 vs. $6 \%$ ), o secuestradas (20 vs. $2 \%$ ) (Church et al. 2001). Un estudio canadiense encontró diferencias similares entre trabajadoras de calle y chicas de compañía - robos (37 vs. $9 \%$ ), secuestro (32 vs. 5\%), abuso sexual (37 vs. $9 \%$ ) palizas (39 vs. $14 \%$ ), estrangulamiento (31 vs. $5 \%$ ), e intento de asesinado (10 vs. 0\%) (Lowman y Fraser, 1995). Tales disparidades en cifras de victimización para prostitución de calle o de interior son apuntadas por otros estudios en Australia, Gran Bretaña, Canadá, Nueva Zelanda, y Estados Unidos (Decaer, 1979; Perkins, 1991; Perkins y Lovejoy, 1996; Perkins y Bennet, 1985; Plumridge y Abel, 2001, Prince, 1986; Whittaker y Hart, 1996; Woodward et al. 2004). Claramente, las prostitutas de calle son mucho más vulnerables a la victimización que las de interior" (Weitzer, 2005a, p.216).

Parece ser que debido a las condiciones en las que ejercen prostitución, las chicas de contactos, las chicas de compañía y las trabajadoras de salones de masaje están en mejor posición para rechazar clientes peligrosos y también tienen mayor proporción de clientes regulares de bajo riesgo. Además el trabajo en los locales puede estar organizado de forma que incrementa en gran medida la seguridad de los/as trabajadores/as (cámaras y personal de seguridad, trabajar con otras personas, etc.) (Weitzer, 2005a). Mientras que las condiciones en las que trabajan en la calle (solas, realizando el servicio en el coche del cliente, en calles oscuras y apartadas, etc.) generan mayor vulnerabilidad a episodios violentos (Perkins, 1991).

Aunque los clientes y las parejas son las personas que en mayor medida ejercen violencia sobre las personas que ejercen prostitución (Kurtz, Surrat, Inciardi y Kiley, 2004), también se enfrentan a agresiones por parte de la policía y la sociedad en general. En ocasiones las mismas personas que ejercen prostitución se quejan de ser víctimas de las 
leyes antiprostitución, las cuales atentan contra ellas y las personas que las rodean (familia, pareja, etc.) y sin embargo no se sienten amparadas por las leyes antiviolencia que en teoría deberían velar por su protección (Pheterson, 2000). De hecho, la prevención y protección ante agresiones es una de las necesidades por las que lucha este colectivo y desde diferentes ONGs internacionales, como SWOP-USA (Sex Workers Outreach Project) y SALLI (United Sex Professional of Finland), se estableció el 17 de Diciembre como el día internacional del final de la violencia contra las trabajadoras sexuales (SWOP-USA, 2007).

Finalmente, no podemos afirmar que exista una violencia significativa por parte de proxenetas o los comúnmente denominados chulos. En los estudios consultados las personas entrevistadas afirmaban no ser controladas por ningún chulo, y los beneficios eran exclusivamente para ellas (Agustin, 2001; Medeiros, 2000; Perkins, 1991), pero en ocasiones, las condiciones en las que ejercen esta actividad pueden ser consideradas como violencia. Tal y como Ribeiro y Sacramento definen violencia "cualquier acto o episodio (...) cuyo objeto es restringir o reprimir el desarrollo o integridad física, psicológica, intelectual y/o emocional de una persona" (2005, p.62) situaciones como trabajar 24 horas, vivir en el mismo lugar donde se ejerce prostitución, el aislamiento o desarraigo al que se ven sometidas por el trabajo bajo régimen de plaza, etc. pueden ser considerados actos de violencia, aunque en la mayoría de los casos son condiciones aceptadas voluntariamente debido a la necesidad imperiosa de recursos económicos (López y Pinedo, 2007; Medeiros, 2000; Perkins, 1998; Ribeiro y Sacramento, 2005).

Pero, aunque en la mayoría de los estudios se considere a la prostituta la víctima de su cliente, "las trabajadoras sexuales no son receptoras pasivas de agresiones masculinas en su lugar de trabajo, sino que controlan activamente el riesgo de la violencia" (Sanders, 2005, p.72). Tanto las que trabajan en las calles como las que trabajan en locales tienen sus propias estrategias para minimizar todo riesgo de violencia durante el ejercicio de la prostitución (McKeganey y Barnard, 1996). Como concluye Sanders "las trabajadoras sexuales responden a los daños potenciales de tres formas diferentes: tomar precauciones, medidas disuasorias y protección reforzada" (2005, p. 75). En cuanto a la toma de 
precauciones hay una serie de reglas en el desarrollo habitual del trabajo para prevenir la violencia o los robos. Algunas de estas reglas son: cobrar antes de hacer el servicio, controlar la postura en la que se realiza el servicio sexual ya que hay posturas más peligrosas, no quitarse toda la ropa por si se tiene que salir corriendo, actitud amigable y jovial para prevenir reacciones violentas en los clientes, trabajar con otras personas, no trabajar en la calle, hacer salidas sólo a hoteles no a casa privadas, hacer salidas a zonas tranquilas no conflictivas, etc. Entienden por medidas disuasorias aquellas medidas en las que las trabajadoras sexuales intentan convencer al cliente de que los costos por romper el contrato son mayores que los beneficios. $\mathrm{Y}$ finalmente, la protección reforzada hace referencia a todos aquellos dispositivos que aseguran su seguridad (puertas, cerrojos, cadenas, cámaras de seguridad, etc.). (Shaver, 2005).

En aquellas situaciones en las que a pesar de las medidas adoptadas el cliente consigue realizar la agresión, encontramos que en general este colectivo no suele denunciar tales delitos. "La investigación sugiere que la realidad es que la mayoría de las trabajadoras sexuales no van a la policía cuando son víctimas de un crimen violento y raramente informan de los incidentes. La hostilidad hacia la policía no es infundada, ya que la policía, los juzgados y el sistema de justicia tienen una historia de discriminación contra las mujeres que ejercen prostitución" (Sanders, 2005, p. 89). 
1.5. Perfil de las personas que ejercen prostitución

A continuación vamos a comentar las características de los tres perfiles existentes entre las personas que ejercen prostitución en Castilla y León en la actualidad.

\subsubsection{Binomio drogodependencia-prostitución}

Durante la década de los 80 aparece en España un perfil nuevo de mujer que ejerce prostitución. Se trata de mujeres consumidoras de drogas ilegales (heroína y cocaína fundamentalmente) que ejercen la prostitución para costearse su consumo (Barahona, 2001).

La figura de la drogodependiente cambia radicalmente el mundo de la prostitución y provoca un rechazo radical por el resto de personas dedicadas a esta actividad. La motivación principal de estas mujeres era conseguir los medios para continuar su adicción. Eran pocas y aisladas en un principio, sin embargo el fenómeno fue evolucionando y la proporción prostitutas clásicas/drogodependientes se invierte rápidamente. De esta manera, prácticamente desaparece la prostitución clásica, siendo desplazada de los lugares tradicionales de prostitución, "en un contexto donde la drogodependiente podía alcanzar niveles de agresividad extremos y que además se veía rodeada de hombres más violentos que también era dependientes del consumo de drogas" (CIMTM, 2003, p.52). La prostitución se transformó, se deterioraron los espacios, los precios cayeron y el tiempo que se debía dedicar al ejercicio aumentó, empeorando la situación de las mujeres.

En el estudio realizado por Cáritas de Zaragoza en 1996, encontraron que un 50\% de las mujeres que ejercían prostitución en la calle se mantenían en la misma por la dependencia a drogas. Según un estudio de ACLAD realizado en Valladolid en 1997, un $64 \%$ de las mujeres que ejercían prostitución en la calle se habían iniciado en ella por culpa de las drogas. Finalmente, a partir del análisis de los datos recopilados por APRAMP en la década de los 90 (Meneses-Falcón, 2003) se encontró que un 65\% de las españolas 
padecían alguna adicción (toxicomanía o alcoholismo) y en un $68 \%$ de los casos ejercían en la calle.

Como vemos, la motivación principal de este grupo de mujeres para ejercer la prostitución es costearse el consumo de drogas, la gran mayoría de ellas si no estuviesen enganchadas no ejercerían la prostitución. En el estudio llevado a cabo por Potterat et al. (1998) se sugiere un vínculo complejo entre el uso de drogas ilegales y la subsiguiente entrada en prostitución, ya que encontraron que "un $66 \%$ de las prostitutas entrevistadas habían usado drogas antes de comenzar a ejercer prostitución, un 18\% comenzaron ambas conductas al mismo tiempo y un $17 \%$ usó drogas después de comenzar a ejercer prostitución" (p.339). Aunque es necesaria una demostración empírica para establecer la relación causal entre estos sucesos (uso de drogas y entrada en prostitución), estos datos demuestran la fuerte secuencia temporal de estos eventos críticos ya que el abuso de sustancias suele preceder a la entrada en prostitución. Según Potterat et al. (1998) los "factores sociales pueden ser la base para la prostitución pero el script para llegar a ser prostituta puede estar escrito por factores psicológicos" (p.340), ya que considera que hay otros factores intermedios, tanto internos como externos a la persona, que influyen en la entrada en prostitución.

Este grupo ha sido foco de atención de gran número de estudios fundamentalmente epidemiológicos y sanitarios, debido a la alta vulnerabilidad que tenían, y tienen, a contraer enfermedades y otros problemas de salud debidos a su consumo de drogas y a su estilo de vida (normalmente en la calle, sin unas condiciones higiénico-sanitarias adecuadas, conductas de riesgo en el consumo y en el ejercicio de la prostitución, etc.) (MenesesFalcón, 2003).

Se trata de un grupo de mujeres que presenta una problemática compleja: a) a nivel físico y psicológico suelen padecer enfermedades y problemas de salud importantes (VIH/SIDA, hepatitis B y C, tuberculosis, trastornos psicológicos, etc.), b) a nivel social son mujeres marginadas y excluidas socialmente, tanto por parte de sus familias como por la sociedad en general, debido a su condición de toxicómanas y prostitutas, c) en cuanto al 
ambiente en el que viven también sufren importantes carencias, suelen estar en la calle, su vida gira entorno al consumo de drogas y suelen ser víctimas de numerosas agresiones físicas, psicológicas y sexuales. (ASE-Psiké, 1997; Baker y Case, 2003; Farley y Barkan, 1998; Meneses-Falcón, 2003).

Los datos obtenidos por ACLAD en un estudio realizado en 1997 con mujeres que ejercen prostitución en la calle apoyan lo anteriormente citado. El 95\% de la muestra son mujeres españolas con baja o nula formación académica y con problemas de adicción a drogas. Son mujeres que provienen de familias desestructuradas, en un $43 \%$ con antecedentes de consumo de drogas y en un $23 \%$ con antecedentes de prostitución.

En cuanto a su estado de salud presentan un problema grave de politoxicomanía, el 92\% fuma diariamente, en el $79 \%$ de los casos consumen una mezcla de cocaína y heroína, y el resto únicamente una de las dos. En el $58 \%$ de los casos la vía de consumo es la inyectada, por lo que conlleva más problemas de salud, sobre todo cuando en un $76 \%$ de los casos han compartido en alguna ocasión material de consumo. "El $80 \%$ de las mujeres refieren que para poder realizar su trabajo tienen que ir colocadas. La causa, para la mitad de ellas, es poder aguantar y que no las dé asco. El resto tiene que ir colocadas para no tener mono durante el trabajo" (ACLAD Valladolid, 1997, p.39).

El $25 \%$ de las entrevistadas refieren ser VIH positivas, un $2.1 \%$ tienen SIDA, un $25 \%$ tienen hepatitis C, un $4.2 \%$ hepatitis B y un $2.1 \%$ tuberculosis. Casi el $60 \%$ ha tenido algún aborto, siendo la media de 1.6 abortos. Un $27 \%$ no dejó de consumir drogas durante el último embarazo que tuvo. Es importante destacar que en un $23 \%$ de los casos la primera relación sexual fue obligada y en un $2.6 \%$ fue ejerciendo prostitución.

"Son mujeres que viven en malas condiciones, con una alimentación deficitaria y con ingresos que utilizan para su drogadicción. Los problemas de salud son elevados y tienen un gran descuido hacia el cuidado del cuerpo. Son mujeres con una falta de identidad y baja autoestima, con carencias afectivas y graves problemas familiares" (ACLAD Valladolid, 1997, p.1). 


\subsubsection{Binomio inmigración-prostitución}

A partir de 1985, año de aprobación de la primera ley de extranjería, el número de inmigrantes en España comenzó a aumentar moderadamente, pero con las sucesivas leyes y reformas se ha vivido un incremento espectacular de personas inmigrantes, tanto en nuestro país como en el resto de Europa. Según los datos oficiales (INE, 2006), el colectivo de inmigrantes en España supone ya un $10 \%$ de la población total, pudiendo ser mayor la cantidad al no contabilizarse muchos de los inmigrantes ilegales existentes.

Según la ONU, las mujeres emigran tanto como los hombres, estamos asistiendo a una feminización de la inmigración, suponen 95 de los 191 millones de personas migrantes que viven fuera de sus países de origen. Según los datos de la ONG Córdoba Acoge, durante el año 2000 , el $59 \%$ de las 2.974 personas atendidas fueron mujeres, lo que produjo una inversión de los porcentajes con respecto a años anteriores. Si analizamos este dato en función de la nacionalidad, encontramos que hay varios países donde la emigración es fundamentalmente femenina como en la República Dominicana, Brasil, Colombia, Perú, Filipinas, Guinea Ecuatorial, Cabo Verde, Rusia y Bolivia (Fernández, 2004; MenesesFalcón, 2003).

Según diferentes estudios realizados en la década de los 90 (Agustín, 2001), el porcentaje de mujeres extranjeras que ejercen prostitución no ha hecho más que multiplicarse año tras año. Esta información la confirma el Informe de la Guardia Civil del año 2000 donde se señala que el $90 \%$ de las trabajadoras sexuales son extranjeras. Aparecen con cierta consistencia tres zonas principales de procedencia de mujeres extranjeras ocupadas en la industria del sexo en España, y son en primer lugar América Latina (Brasil, Colombia, Paraguay, etc.), seguido de los países de Europa del Este (Rumanía, Bulgaria, etc.) y en tercer lugar las mujeres procedentes de África (Nigeria, Sierra León, etc.).

Hace unos años las mujeres que emigraban lo hacían por motivos matrimoniales o familiares, no solían hacerlo por sí solas. En la actualidad este proceso ha cambiado, y 
encontramos que las mujeres cuentan con un proyecto migratorio autónomo e independiente. Pero incluso en la inmigración encontramos diferencias entre los géneros ya que las mujeres suelen seguir posibilidades migratorias diferenciadas en comparación con los hombres e inserciones laborales específicas (trabajo doméstico, de cuidados, de limpieza y prostitución) (Agustín, 2001, 2005).

Las leyes que regulan las migraciones se han vuelto muy restrictivas de manera que los resquicios que quedan abiertos son muy pocos y pensados desde el punto de vista masculino, ya que se apoyan en la posesión de un contrato laboral. Disponer de un contrato de trabajo sólo es posible en determinadas actividades desempeñadas principalmente por hombres (Juliano, 2004a), ya que las mujeres siguen realizando trabajos típicamente femeninos que son generalmente desregularizados, mal pagados y sin contrato laboral. Así, la ilegalidad pasa a ser la compañera casi constante de la migración femenina autónoma y el trabajo sexual pasa a ser una opción económica a valorar seriamente, porque "la actividad sexual no es el trabajo de la mayoría de las inmigrantes, pero la mayoría de las trabajadoras sexuales son inmigrantes", (Juliano, 2004a, p.222), como dice Agustín (2001), "hablar ahora de la prostitución en Europa es hablar de migración" (p.92).

En estas circunstancias, como afirma Juliano (2004a), "se les exigen requisitos imposibles para entrar al país, con lo que se les arroja a las manos de las redes que trafican con personas, (...). Es evidente que no está dentro de su voluntad ser estafadas y pagar cantidades enormes por los costos de los pasajes. Pero también es cierto que tenían voluntad de emigrar, que habían apostado muchos esfuerzos a esta esperanza y que en la mayoría de los casos en que se decantan por el trabajo sexual lo hacen como una opción temporal y por las ventajas económicas comparativas que le encuentran respecto a las otras malas y pobres opciones ofrecidas" (p.223).

Podemos encontrar una gran variedad de motivaciones que llevan a una persona a abandonar su país. Obviamente las razones económicas suelen ser las más poderosas, pero no podemos olvidar que puede haber otras opciones personales; los migrantes 
potenciales descubren que los países del primer mundo son lugares sofisticados y cómodos donde sus proyectos vitales cuentan con mayores y mejores oportunidades (Agustín, 2001).

De la misma forma existen gran variedad de motivaciones para que una persona decida ejercer prostitución. En muchas ocasiones la prostitución es la única opción o la más rentable económicamente para las mujeres emigrantes, de manera que se convierte en refugio económico y social, por precario o ilegítimo que sea, para muchas mujeres que buscan asilo escapando de la explotación y el abuso legal e ilegal que sufren en sus países de origen (Pheterson, 2000).

¿Pero cómo se lleva a cabo el proceso migratorio? Laura Oso y Marcela Ulloa (2001) distinguen cinco fases en el proceso migratorio: (1) decisión de emigrar, (2) financiación del proceso migratorio, (3) organización del viaje (compra de billete, pasaporte, carta de invitación), (4) el transporte y (5) recepción y acogida en la sociedad receptora. Cada una de estas fases se ve mediatizada por las condiciones en las que se afrontan los gastos y cómo se lleva a cabo, es decir, si se hace de forma autónoma o recurriendo a personas o redes que prestan el dinero y facilitan los documentos necesarios para ello.

En la siguiente tabla (ver Tabla 8) se resumen las diferentes posibilidades encontradas en el proceso migratorio. 
Tabla 8. Tipo de inmigración de mujeres colombianas y ecuatorianas (Solana, 2003, p.188)

TIPOS DE INMIGRACIÓN DE MUJERES COLOMBIANAS Y ECUATORIANAS

Servicio doméstico y prostitución en Madrid y Galicia

\begin{tabular}{|c|c|c|c|c|}
\hline Fases del éxodo & Migración autónoma & $\begin{array}{l}\text { Entidades prestamistas privadas } \\
\text { en el país de origen implicados, } \\
\text { con ánimo lucrativo en la } \\
\text { migración }\end{array}$ & $\begin{array}{l}\text { Personas en España, con ánimo lucrativo, implicados } \\
\text { en la migración (de manera independiente o con un } \\
\text { contacto en el país de origen) }\end{array}$ & $\begin{array}{l}\text { Redes organizadas implicadas en } \\
\text { la migración de mujeres }\end{array}$ \\
\hline $\begin{array}{l}\text { Decisión de la } \\
\text { migración }\end{array}$ & $\begin{array}{l}\text { Decisión autónoma o familiar } \\
\text { de la migración }\end{array}$ & $\begin{array}{l}\text { Decisión autónoma o familiar de la } \\
\text { migración. Captación de agencias } \\
\text { de viajes (reclamos/anuncios) }\end{array}$ & $\begin{array}{l}\text { Decisión autónoma o familiar de la migración. } \\
\text { Reclutamiento o captación, con o sin engaño, de los } \\
\text { propios individuos o a través de un contacto en Colombia o } \\
\text { Ecuador }\end{array}$ & $\begin{array}{l}\text { Reclutamiento o captación, con o sin } \\
\text { engaño y coacción, de redes } \\
\text { organizadas y mafias }\end{array}$ \\
\hline $\begin{array}{l}\text { Financiación del } \\
\text { billete y bolsa de } \\
\text { viaje }\end{array}$ & $\begin{array}{l}\text { Recursos propios. } \\
\text { Financiación o préstamo sin } \\
\text { intereses de amistades u otros } \\
\text { migrantes }\end{array}$ & $\begin{array}{l}\text { Préstamos de bancos (deuda con } \\
\text { intereses). Prestamistas privados } \\
\text { (deuda con intereses). Agencias de } \\
\text { viaje (deuda con intereses) } \\
\text { Hipotecas }\end{array}$ & $\begin{array}{l}\text { Préstamo con intereses de migrantes asentados (deuda } \\
\text { con intereses). Españoles/as que invierten en el préstamo } \\
\text { de dinero a migrantes (deuda con intereses). } \\
\text { Empleadores/as que invierten, con o sin intereses en el } \\
\text { viaje de migrantes (deuda, reembolso o pago con trabajo) }\end{array}$ & $\begin{array}{l}\text { Financiación del viaje por las redes } \\
\text { organizadas y mafias bajo un } \\
\text { contrato de pago en trabajo o dinero } \\
\text { con intereses. }\end{array}$ \\
\hline $\begin{array}{l}\text { Organización del } \\
\text { viaje }\end{array}$ & $\begin{array}{l}\text { Organización propia o } \\
\text { apoyada por la red migrante }\end{array}$ & $\begin{array}{l}\text { Organización propia o apoyada por } \\
\text { la red migrante. Participación de } \\
\text { agencias de viaje en las gestiones }\end{array}$ & $\begin{array}{l}\text { Organización propia o apoyada por las personas } \\
\text { implicadas en el préstamo. Ventas de cartas de invitación }\end{array}$ & $\begin{array}{l}\text { Organización del viaje por parte de la } \\
\text { red o mafia }\end{array}$ \\
\hline $\begin{array}{l}\text { Transporte, consejos } \\
\text { y ayuda para pasar la } \\
\text { frontera }\end{array}$ & Ayuda de otros/as migrantes & $\begin{array}{l}\text { Ayuda de otros/as migrantes. } \\
\text { Consejos de la agencia de viajes }\end{array}$ & $\begin{array}{l}\text { Consejos y apoyo de las personas implicadas en el } \\
\text { préstamo }\end{array}$ & Transporte apoyado en la red o mafia \\
\hline $\begin{array}{l}\text { Recepción e } \\
\text { inserción inicial en } \\
\text { España }\end{array}$ & $\begin{array}{l}\text { Apoyo en las redes familiares } \\
\text { y comunitarias }\end{array}$ & $\begin{array}{l}\text { Apoyo en las redes familiares y } \\
\text { comunitarias. Contactos de la } \\
\text { agencia de viajes (personas, } \\
\text { direcciones) }\end{array}$ & $\begin{array}{l}\text { Recogida e inserción inicial facilitada por las personas } \\
\text { implicadas en el préstamo }\end{array}$ & $\begin{array}{l}\text { Recogida y traslado al lugar de } \\
\text { trabajo por parte de la red o mafia }\end{array}$ \\
\hline
\end{tabular}


Nadie niega la existencia de redes mafiosas de tráfico y trata de personas. Lo que queremos mostrar es la existencia de una migración autónoma o relativamente autónoma para el ejercicio de la prostitución u otros trabajos, la cual en muchas ocasiones es negada o infravalorada (Solana, 2003). Según el estudio de VOMADE (Asociación Voluntariado de Madres Dominicanas) realizado en 1994 con 528 mujeres, el 21\% de éstas vinieron a través de redes familiares y de amistades, un $37 \%$ había hipotecado sus bienes familiares y un $17 \%$ había recibido un préstamo de amigos. (Solana, 2003), en resumen, un $75 \%$ de las mujeres entrevistadas no fueron víctimas de una red mafiosa o criminal. Estos datos apoyan la idea sobre la existencia de un amplio apoyo social al proyecto migratorio de las mujeres, sin que sea en todos los casos un hecho delictivo. Esta diversidad de redes y la voluntariedad con la que las personas inmigrantes aceptan las condiciones del proceso explican la escasa cantidad de denuncias realizadas (Informe de la Guardia Civil, 2002).

En relación con la existencia de mafias dedicadas al tráfico de personas, se ha demostrado que en la medida en que se multiplican los obstáculos legales para la llegada de extranjeros/as, estas personas no tienen más remedio que recurrir a estas redes de tráfico para migrar, las cuales aprovechan esta situación para cobrarles precios abusivos. En la actualidad se ha encontrado que las mujeres procedentes de Europa del Este y del África Subsahariana son las que en mayor medida son víctimas de estas redes de tráfico de personas, mientras que las latinoamericanas disfrutan de mayor autonomía (Juliano, 2004a).

Dentro de las redes de tipo coercitivo, es decir, aquellas "que usan presiones extraeconómicas y/o amenazas de violencia para reforzar su objetivo económico" (Juliano, 2004a, p.198), encontramos diferentes tipos: (1) Grupos de base étnica, los cuales captan mujeres en zonas rurales y con escaso nivel de formación mediante ofertas explícitas en trabajo sexual u ofertas disimuladas en otros trabajos, que mediante amenazas de violencia (física o simbólica) las controlan, encontramos ejemplos entre las mujeres subsaharianas; (2) Pandilla delictiva, grupo de cómplices que se coordinan para hacer presiones tanto en el lugar de origen como de llegada, para captar y controlar a las personas que quieren emigrar. Actúan a través de ligámenes personales y relaciones de pareja, pudiendo presionar por la 
opción del trabajo sexual, pero también actúa con otros trabajos. Encontramos ejemplos entre las mujeres de Europa del Este; (3) Banda delictiva organizada, grupos organizados internacionalmente que combinan el tráfico de personas con otros delitos como pornografía, venta de armas y drogas. Se han encontrado ejemplos entre las mujeres rusas.

Hay una serie de factores asociados a la condición de ser inmigrante y a la condición de ser ilegal que aumentan la vulnerabilidad a diferentes riesgos (e.g. exclusión social, discriminación, soledad, desprotección, etc.) de este colectivo. Pero si además añadimos otros dos factores, como son el hecho de ser mujer y ejercer prostitución se agrava el problema. Como dice Juliano (2004a, p.39), "el rechazo social se acrecienta cuando los estigmas se suman unos a otros o se combinan con otros estereotipos desvalorizantes. Tal es la situación que padecen las mujeres inmigrantes en general y más en particular las que se dedican al trabajo sexual".

Planteamos en el siguiente cuadro resumen (ver Figura 2) las relaciones existentes entre diferentes factores relacionados con la inmigración y otros factores de exclusión social, como ser mujer, ser ilegal y ejercer prostitución. 


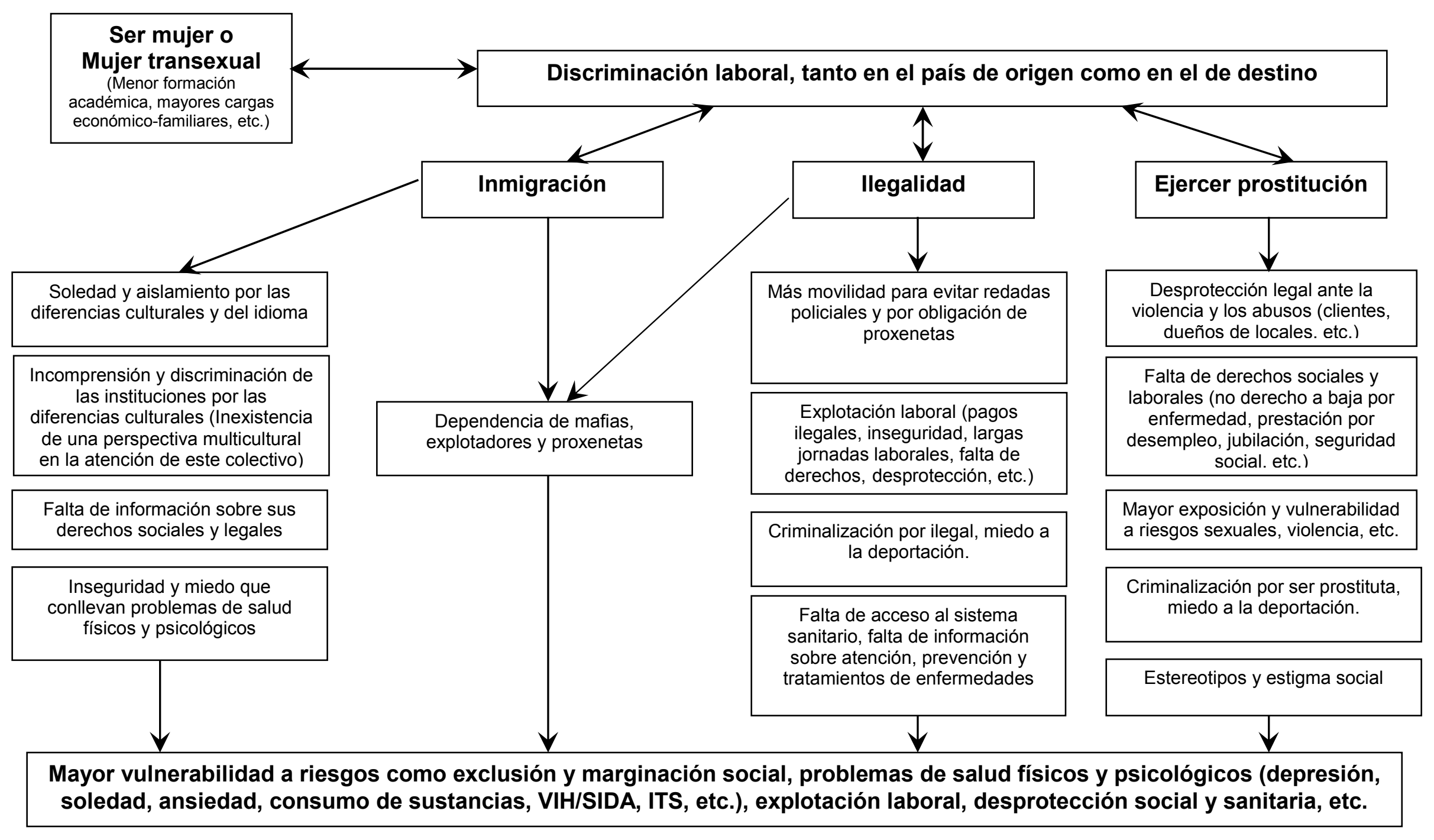

Figura 2. Cuadro resumen de los factores relacionados con la exclusión y marginación social de las personas que ejercen prostitución 
Como vemos, para estudiar temas relacionados con la prostitución en la actualidad es necesario adoptar un marco teórico migratorio, es decir, es necesario tener en cuenta las características de la población migrante y los factores que van asociados al proceso migratorio para analizar y comprender en profundidad el fenómeno a estudiar. Un marco migratorio permite considerar todos los aspectos posibles de las vidas y los viajes de estas personas, las sitúa en períodos de crecimiento personal y aceptación de riesgos.

El colectivo de personas migrantes en general, y de las que trabajan en la industria sexual en concreto, presentan una gran heterogeneidad, y deben tenerse en cuenta todos estos factores a la hora de analizar e intervenir en esta realidad. "Las personas migrantes que vienen a trabajar a la industria sexual europea son de toda clase, color, edad, etnia, nacionalidad, y no son sólo mujeres sino hombres y transgéneros también. Llegan por incontables rutas: solos, con amigos, en pareja o en grupos acompañados. Algunos tienen dinero, otros llegan endeudados. Su documentación puede ser verdadera o falsa, algunos vienen con visado de turista. Muchas de estas personas han planificado sus viajes personalmente durante largo tiempo, mientras que a otras se les ha prestado una oportunidad con poco tiempo para planificarlo. Alguno de estos viajeros y viajeras potenciales ya ejercían la prostitución en su país, mientras que otros no" (Agustín, 2001, p.25).

1.5.3. Binomio transexualidad/travestismo-prostitución

En España las personas transexuales y travestis que ejercen prostitución son cada vez más numerosas, constituyen aproximadamente un tercio del colectivo de personas que ejercen prostitución (Agustín, 2001; Belza et al., 2000; Pelúcio, 2005a; van der Helm, 2004). Tanto el transexualismo como el travestismo son definidos como desórdenes de la identidad sexual según sendas clasificaciones internacionales de enfermedades, CIE-10 y DSM-IVTR. En la transexualidad la identidad y rol de género de un sexo coexiste con las características primarias y secundarias del otro sexo; así un hombre transexual es una 
persona que se siente, piensa y actúa como hombre aunque su sexo biológico es femenino, y una mujer transexual es una persona que se siente, piensa y actúa como mujer aunque su sexo biológico es masculino (Fernández, 2006). Sin embargo, una persona travesti es definida como la persona que tiene una fuerte compulsión a vestirse con ropas del sexo opuesto con el fin de disfrutar de la experiencia de pertenecer al sexo opuesto, pero sin ningún deseo de llevar a cabo un cambio de sexo permanente.

Existe gran confusión conceptual entre transexualismo y travestismo entre la literatura europea y la latinoamericana, ya que ésta última considera que la travesti también se siente identificada con el otro sexo y lleva a cabo procesos de cambio de sexo como la hormonación y la cirugía. Como cita Fernández (2000) "Harry Benjamin, llamado padre del transexualismo (...) establece una diferencia entre travestismo y transexualismo (...): en el travestismo los órganos sexuales son fuente de placer; en el transexualismo son una fuente de disgusto." (p.10). Mientras que la travesti no renuncia a la funcionalidad de su pene, es decir se viste de mujer pero considera indispensable para su excitación la anatomía del pene, el transexual renuncia a ello, y puede llegar a practicarse cirugía de reasignación de sexo.

Un hecho significativo del trabajo de Benjamin fue la relación que plantea entre el sexo y el género, consideradas ambas como herramientas conceptuales en el diagnóstico clínico de los transexuales. Afirmando que el sexo "es más aplicable allí donde está implicada la sexualidad, la libido y la actividad sexual; el género es el lado no sexual del sexo. El género está localizado arriba del cinturón y el sexo abajo del cinturón" (p.10). Como afirma Fernández (2000), "la distinción teórica entre sexo y género significó la opción por la identidad travesti, la posibilidad de imitar las cualidades genéricas" (p.11). En algunos trabajos se considera el travestismo como un tercer género, así lo defiende Gilbert Herdt (1996) en su libro titulado "Third sex, third gender. Beyond sexual dimorphism". Dado que las personas transexuales/travestis procedentes de Latinoamérica se autodenominan a sí mismas travestis utilizaremos en adelante este término. 
En España, la mayoría de las travestis que ejercen prostitución son de origen brasileño (Agustín, 2001; Pelúcio, 2005b) y hemos encontrado numerosos trabajos realizados sobre este colectivo en Brasil donde se intenta definir lo que significa ser travesti diferenciándolo de la transexualidad. "Las travestis son personas que les gusta relacionarse sexual y afectivamente con otros hombres. Por tanto intentan insertar en sus cuerpos símbolos que son socialmente vistos como propios de lo femenino. Pero, no desean cambiar sus genitales, con los cuales, generalmente, conviven sin grandes conflictos" (Pelúcio, 2006a). En la bibliografía consultada encontramos que ser travesti es visto como una forma de vida, de sentirse, de comportarse, algo que nos recuerda a la teoría del tercer género, en tanto que las personas travestis muestran sus propias características psicosociales definitorias (roles, tareas, etc.), una mezcla de atributos prototípicamente femeninos y masculinos (Anhel, Teixeira, Marilac y Costa, 2006; Fernández, 2000; Gómez, Peri, Andrés y de Pablo, 2001; Pelucio, 2005b, 2006a,b). Por tanto, las travestis llegan a tomar hormonas y practicarse cirugía (pechos, caderas, glúteos, nariz, etc.) para parecer cada vez más femeninas, pero no dan el paso final de la vaginoplastia debido a que sus genitales no les crean conflictos y disfrutan de su sexualidad con su pene.

Como hemos dicho, la mayoría de ellas son inmigrantes procedentes de países latinoamericanos (principalmente Brasil) y entre sus motivaciones migratorias no sólo encontramos razones económicas sino también motivos relacionados con el hecho de ser travestis. Como afirma Larissa Pelúcio (2005b) la prostitución travesti emigra "por la opresión material y simbólica que rodea a las travestis en los guetos, dificultando el acceso a la educación, al mercado de trabajo y comprometiendo sus proyectos de transformación e inserción social fuera de la prostitución" (p.243).

El estigma, el rechazo y la exclusión social que sufren las personas transexuales y travestis desde las diferentes esferas sociales (familia, colegio, sociedad) las lleva, en muchas ocasiones, a abandonar tempranamente el ambiente familiar y académico y a la búsqueda de otros ambientes donde poder expresarse y sentirse ellas mismas. Estas circunstancias unidas a las mayores dificultades de inserción social y laboral por su 
condición de transexual o travesti, las lleva en un alto porcentaje a recurrir a la prostitución como fuente de ingresos y ambiente de identificación y aprendizaje (Fernández, 2000; Pelúcio, 2005b).

Encuentran en el ambiente prostitucional un nuevo escenario para vivir su identidad y aprender a transformarse en el cuerpo femenino deseado, de hecho, existe la figura de las pupilas y la madre. Las primeras buscan en la madre protección callejera y buscan también modelos de identificación y pautas culturales para moverse en el escenario de la prostitución. Las pupilas aprenden de sus madres la manera de vestirse, de maquillarse, de transformar su cuerpo (Fernández, 2000) y aquendar a neca (Pelúcio, 2006a) que significa esconder el pene.

En un principio, el ejercicio de la prostitución proporciona los ingresos necesarios para transformar el cuerpo. Hasta un $70 \%$ de las ganancias son invertidas en ropas, maquillajes, hormonas, silicona, etc. Porque ser travesti es un proceso sin fin en el que el objetivo último es passar por mulher, aunque para ello haya que poner en riesgo sus vidas. En la mayoría de los casos, tanto en Brasil como en España, el proceso transformador no es llevado a cabo por profesionales especializados, sino que entre ellas mismas se intercambian hormonas y consejos de cómo aplicar la silicona. Incluso en Brasil encontramos la figura de las bombadeiras, las cuales son en su mayoría travestis mayores que han aprendido cómo inyectar (bombar en brasileño) silicona industrial en el cuerpo de las travestis. Este proceso es muy doloroso, difícil de realizar y peligroso, y a pesar de los riesgos y el conocimiento de los mismos el $80 \%$ de las entrevistadas por Pelúcio (2006a) afirman que se aplicarían silicona.

Como decíamos anteriormente, para las travestis migrar no sólo significa optar a un mejor nivel de vida, migrar significa cambiar de estatus entre las propias travestis. El sueño de las travestis brasileñas que viven de la prostitución es ir a Europa. En Europa existe algo que todas las travestis repiten: respeto a su condición. En la década de lo 80 el sueño era viajar a París, en los 90 la meca cambió a Italia y en la década actual parece ser España el nuevo destino (Pelúcio, 2005b). Las travestis que consiguen viajar a Europa y regresan a 
Brasil con dinero y glamour se las denomina travestis europeas o tops. Como afirma Larissa Pelúcio (2005b), "en Europa (...) aprenden a hablar en otro idioma, conocen culturas diferentes, enorgulleciéndose de su nuevo refinamiento burgués, que como consecuencia lleva un alejamiento del guetto" (p.245).

Pero la prostitución travesti no es todo glamour, dinero, belleza y refinamiento, hay diferentes factores relacionados con el hecho de ser travesti, inmigrante que ejerce prostitución que las coloca en una de las posiciones más vulnerables de todo el colectivo de personas que ejercen prostitución (Anhel et al., 2006). El colectivo de travestis que ejercen prostitución constituye el grupo más estigmatizado y discriminado, tanto por la sociedad como por los clientes e incluso por sus compañeras, mujeres biológicas, que ejercen prostitución. Esta circunstancia va unida, en muchas ocasiones, al ejercicio de la prostitución en la calle donde las condiciones de trabajo son mucho más duras y son más vulnerables a agresiones físicas, psicológicas y sexuales. Todos estos factores las llevan en muchas ocasiones al consumo de drogas y alcohol, que a su vez las hace más vulnerables a otros riesgos (Fernández, 2000; Gómez et al., 2001).

Vemos que el grupo de personas travestis que ejercen prostitución se enfrenta a numerosos riesgos de salud vinculados al hecho de ser travesti, de ser inmigrante y de ejercer prostitución. De hecho, se ha encontrado que presentan numerosos problemas de salud como altas tasas de infección por VIH/SIDA y otras ITS (Anhel et al., 2006; Reback, Lombarda, Simon y Frye, 2005), altas tasas de suicidio (Fernández, 2006), consumo de drogas y alcohol (Gómez et al., 2001) y gran número de agresiones físicas y sexuales (Pelúcio, 2005b), etc. 


\subsection{Dimensiones del fenómeno}

En este apartado haremos una revisión de los datos más interesantes obtenidos en los estudios realizados en diferentes provincias españolas y, en concreto, en Castilla y León en relación con la prostitución.

\subsubsection{Estudios realizados a nivel nacional}

- Estudio realizado en Asturias (Pons, 1992)

El estudio realizado en la provincia de Asturias durante el año 1992 utilizó tanto técnicas cualitativas como cuantitativas, encuestando a 311 prostitutas y realizando 24 entrevistas en profundidad. Un $22 \%$ son extranjeras, de las cuales el $50 \%$ proceden de Latinoamérica. Tienen una media de edad de 30 años y un nivel académico bajo $(1.3 \%$ no lee ni escribe, y un $55 \%$ apenas ha terminado los estudios primarios). En cuanto a su vivienda y unidad de convivencia, un $24.5 \%$ habita en una vivienda precaria (calle, pensión, chabola, etc.), en un $23 \%$ viven solas y en un $20 \%$ con una compañera de trabajo o una amiga. Un $6.5 \%$ trabaja en la calle, un $68 \%$ en whiskerías, clubes o bares y el resto en pisos u otros locales.

El $71 \%$ son madres, con una media de dos hijos/as, pero en un $54 \%$ de los casos estos/as niños/as no viven con la madre y sólo un $9.5 \%$ de los padres o compañeros se encargan de ellos/as. Esta alta tasa de natalidad se debe en gran parte a que un $32 \%$ no usa ningún método anticonceptivo o de barrera con su pareja. Se detectó una alta tasa de embarazos, el 74\% de las menores de 23 años habían estado embarazadas alguna vez, de las mujeres embarazadas un $67.5 \%$ tuvieron algún aborto, de los cuales un $34 \%$ fue provocado y un $26.2 \%$ abortó fuera del sistema sanitario. De las mujeres que habían tenido hijos/as un $19 \%$ afirmó no haber descansado de trabajar durante ninguno de los meses de embarazo. 
En cuanto al uso de métodos anticonceptivos o de barrera con el cliente, hemos encontrado que un $2 \%$ no usa ninguno. Entre los métodos más usados con el cliente están el preservativo (42\%) y la píldora (41\%), aunque todavía un $5.3 \%$ no cree o no conoce que el preservativo prevenga las ITS. Se encontró que a mayor edad, se daba un menor uso del preservativo con el cliente, entre las mujeres más mayores un $27 \%$ no exigía el uso del preservativo. Siguiendo con temas relacionados con la salud, encontramos que un $30 \%$ de las entrevistadas no tienen cobertura sanitaria y un $10.3 \%$ nunca acude al médico. Casi un $49 \%$ piensa que ellas no se pueden o no saben si pueden infectarse por el VIH/SIDA.

Los dos grupos que peores condiciones presentan son las mujeres que trabajan en la calle, ya que son las que mayor edad tienen y son toxicómanas, y las inmigrantes debido principalmente a su ilegalidad (65\%), que conlleva riesgos como la explotación, el engaño, el aislamiento, etc.

En cuanto a los datos facilitados respecto a la industria sexual, en este estudio se detectó un $1.3 \%$ de menores ejerciendo prostitución. Se estimó entorno a 1.400 prostitutas en Asturias, las cuales ganaban una media de 2.000 euros mensuales. Se calculó que la prostitución en esta comunidad movía entorno a los 42.000 .000 de euros anualmente. Se estudió la opinión de expertos y prostitutas en relación a la legalización de la prostitución, y en ambos casos se mostraron mayoritariamente a favor.

- Estudio realizado en la ciudad de Zaragoza (Cáritas de Zaragoza, 1996)

La institución Cáritas Diocesana de Zaragoza realizó un estudio sobre la situación de marginalidad de las personas que ejercen prostitución en la calle en su provincia. Su objetivo fue profundizar en el conocimiento de la realidad y el entorno de las mujeres que ejercen prostitución y utilizaron para ello una metodología mixta, cualitativa y cuantitativa, entrevistando a 41 mujeres españolas.

Entre los datos de mayor interés encontrados en este estudio podemos destacar que las entrevistadas tienen un nivel académico muy bajo (22\% no sabe ni leer ni escribir y un $41 \%$ no terminó sus estudios primarios), un 50\% abandonó los estudios antes de los 12 años. Las entrevistadas presentan entornos familiares muy desestructurados, en un $71 \%$ de 
los casos se independizaron de las familias siendo menores de edad y en un $54 \%$ afirma que la razón fueron los conflictos familiares. El entorno familiar de estas mujeres falló cuando eran menores, de hecho un $35.7 \%$ afirma que comenzó a ejercer prostitución siendo menor de edad.

Entre las causas que las llevaron a ejercer la prostitución destacamos las dos principales, en un $41.5 \%$ fue la falta de ingresos y un $22 \%$ para costearse su consumo de drogas. $Y$ entre los motivos que las mantienen ejerciendo esta actividad podemos destacar que un $50 \%$ de los casos era por costearse las drogas, un $33.3 \%$ por no tener ingresos y un $16.6 \%$ por mantener a su familia. Como vemos cambian las causas de entrada por los motivos por los que se mantienen, entran por no tener otros ingresos pero un $30 \%$ se engancha a las drogas y sigue ejerciendo por costearse el consumo.

La situación sociosanitaria que presenta esta muestra es muy precaria, los malos tratos y los abusos son frecuentes a lo largo de su ciclo vital. Un $30 \%$ vive en la calle, en pensiones o en albergues municipales. Presentan problemas de salud pero no acuden a revisiones médicas periódicas. Destacan entre sus problemas psicológicos el sentimiento de soledad que las acompaña diariamente, están aisladas de sus familias y de sus hijos/as (un $66 \%$ no convive con sus hijos/as).

- Estudio realizado en la ciudad de Barcelona (Medeiros, 2000)

Regina de Paula Medeiros, antropóloga brasileña, realizó este estudio en el barrio chino de Barcelona durante más de dos años de trabajo en el ambiente de prostitución de calle. Su objetivo fue reconstruir de una manera fidedigna el contexto cultural y social en el que se desarrolla la vida de sus informantes. Entender las normas y valores sexuales de este ambiente, y cómo influyen en sus conductas de protección de la salud (e.g. el uso del preservativo), lo cual es de gran importancia para organizar estrategias de intervención específicas.

La metodología seguida es diferente a la llevada a cabo en otros estudios presentados en esta revisión, ya que es de corte cualitativo basada en observación participante y entrevistas en profundidad. Su objetivo como veremos no trata de cuantificar 
el fenómeno de la prostitución sino de analizar en profundidad las dinámicas subyacentes al mismo relacionadas con los hábitos saludables.

La autora distingue cuatro tipos de prostitución, todos ellos considerados de exterior, ya que las personas que ejercen en ellos no están vinculadas a ambientes cerrados: la de calle (trabajan en las calles del Barrio Chino), la del campo del Barça (trabajan en los aledaños del campo del Barça y hay tanto mujeres como transexuales), las prostitutas de las Ramblas (trabajan en la Rambla de Santa Mónica, y hay mujeres y transexuales) y las prostitutas de bar.

Según esta autora, en el mundo de la prostitución la mercancía en circulación es el placer. El valor de la transacción que se da entre la prostituta y el cliente es diferente para cada uno de los actores implicados, para la prostituta el valor se expresa en el orden del dinero, mientras que para el cliente es representado por el orgasmo. La relación que establecen es de interdependencia, y las relaciones de poder que se dan entre ambos actores es expresado en la negociación, "momento en el que la correlación de fuerzas es más evidente" (Medeiros, 2000, p.200). El análisis que hace esta autora de las relaciones de poder es interesante, según ella, las prostitutas creen que dominan parcialmente el ambiente a través de su saber sexual, pasando a ser un dominio total a partir del momento en que reciben el dinero para la ejecución del servicio.

En su análisis concede gran importancia al estigma que soportan las mujeres que ejercen prostitución. A la prostituta se le atribuyen multitud de atributos peyorativos que la estigmatizan, como por ejemplo: transgresora sexual, pecadora, peligrosa, viciosa y escandalosa. Al tratarse de prostitución de calle, este estudio se enfrenta con la realidad más estigmatizada y excluida (sin apoyo institucional, sin seguridad en el trabajo, en ocasiones sin apoyo familiar ni social, etc.), lo cual influye en sus conductas y estado de salud.

A partir de este estudio la autora concluye que los preservativos no representan una única vía de prevención del SIDA, sino más bien la capacidad que ellas mismas poseen 
para manejar su trabajo y el indiscutible conocimiento para manejar estrategias de negociación con sus clientes.

- Estudio realizado en la Comunidad Autónoma Vasca (Emakunde, 2001)

Emakunde, el Instituto Vasco de la Mujer, llevó a cabo una investigación de tipo cualitativo sobre el colectivo de mujeres que ejercen la prostitución en la Comunidad Autónoma Vasca. En él se establecen tres objetivos: (1) Conocer, comprender y profundizar en una realidad tan compleja, y a la vez, tan oculta y marginal como es la prostitución, (2) Analizar los colectivos en función del lugar donde ejercen prostitución, y (3) Establecer medidas de intervención para cada uno de los perfiles analizados.

En la primera parte del estudio, que trata de lograr el primer objetivo planteado, se detectan una serie de cambios surgidos en el mundo de la prostitución en los últimos años, como son: desaparición de la prostitución de calle, mayor número de extranjeras (del 80 al $90 \%$ ), y hay un cambio en los lugares de ejercicio priorizándose los macrocentros del extrarradio y los pisos. En cuanto a la industria sexual en la Comunidad Autónoma Vasca se calcula la existencia de aproximadamente 102 clubes (43 en capital y 59 en provincia) y 132 pisos. En cuanto al número de mujeres implicadas en esta actividad se estiman unas 1.780 (160 en calle, 434 en clubes y 782 en pisos). Se mueven, solamente en los clubes ya que los pisos es un fenómeno muy oculto, más de 38.000 .000 de euros anualmente y los periódicos tienen unas ganancias de aproximadamente 6.000 euros diarios con los anuncios de contactos mediante los que se dan a conocer las personas que ejercen prostitución.

En la segunda parte del estudio, correspondiente al segundo objetivo, se han realizado 39 entrevistas en profundidad ( $20.5 \%$ en calle, $51.3 \%$ en club y $28.2 \%$ en pisos). El perfil que se ha dibujado sobre la persona que ejerce prostitución en esta comunidad es el de mujer latinoamericana (72\%) que ejerce fundamentalmente en pisos, joven (entorno a los 26 y 35 años), soltera (67\%), con hijos/as (60\%) con estudios primarios o secundarios. Se han encontrado diferencias entre españolas y extranjeras; las extranjeras comienzan a ejercer prostitución por problemas económicos asociados a las crisis de sus países, separaciones o abandono de sus parejas e imposibilidad de mantener a la familia (hijos/as, 
padre/madre y hermanos/as). Llegan a España para buscar trabajo, algunas veces vienen directamente a ejercer prostitución, otras a otros trabajos. Cuando llegan a España muchas acaban quedándose sin papeles por lo que se encuentran con que sólo pueden aspirar a trabajos con baja cualificación, sin regular y mal pagados. Esta situación choca contra sus expectativas económicas y a través de diferentes contactos (normalmente amigas o conocidas) terminan ejerciendo prostitución. Las mujeres españolas son una minoría en la actualidad, o son mujeres con problemas de drogas que se prostituyen para costearse su adicción o son mujeres que por problemas de baja cualificación y desempleo terminan ejerciendo prostitución como forma de ingresos.

En la tercera y última parte del estudio, se han diseñado diferentes líneas de intervención con el objetivo de mejorar las condiciones de vida del colectivo, y son: información sobre recursos y servicios, salud, seguridad, vivienda, regularización de su residencia y alternativas de inserción laboral.

- Estudio realizado en la Comunidad Autónoma Andaluza (Defensor del pueblo Andaluz, 2002)

El Defensor del Pueblo Andaluz elaboró en 2002 un informe titulado La prostitución: realidad y políticas de intervención pública en Andalucía. El objetivo de este trabajo fue plantear la discusión y el debate sobre la posición que los poderes públicos deben ofrecer ante este fenómeno que es, por encima de otras valoraciones, un grave problema para los sectores sociales que lo padecen.

Las dos características destacadas en este estudio al elaborar el perfil de la persona que ejerce prostitución en Andalucía son, por una lado la dependencia a sustancias tóxicas, y por otro la existencia de mujeres extranjeras, las cuales superan el $75 \%$ del colectivo.

En la elaboración de este informe se ha detectado prostitución en calle, en club de alterne, en domicilios privados y otras formas nuevas de prostitución (salones de masaje, vía internet, servicios de acompañamiento, etc.), siendo la de calle la que mayor rechazo social ha provocado entre los vecinos de diferentes barrios, los cuales han forzado el desplazamiento de la prostitución de unas calles a otras. 
Se distinguen tres perfiles diferentes de personas que ejercen prostitución en Andalucía, por un lado la mujer que se prostituye en la calle, con una edad media de 35 años, procedente de un nivel socioeconómico bajo, con cargas familiares no compartidas y un alto índice de analfabetismo. Se inicia en la prostitución cuando aún es menor como una forma de obtener ingresos económicos para satisfacer su dependencia a las drogas. Alcanzan un alto deterioro físico y psíquico. Por otro lado, encontramos las mujeres que se prostituyen en locales y clubes de alterne, con una media de 35 años pero con mayor nivel educativo. Vive con sus hijos, cuya custodia no comparte, y trabaja para garantizar sus necesidades básicas. Se inicia en la prostitución para resolver sus problemas económicos, no consume ninguna droga, ejerce en locales cerrados y suelen contar con rigurosos controles sanitarios. Finalmente, ha aparecido un tercer perfil diferente a los otros dos, se trata de las mujeres inmigrantes. Provienen de países pobres, buscan mejores condiciones de vida para ellas y sus familias y a veces vienen a través de redes que se aprovechan de su difícil situación económica.

Se ha intentado estimar la cantidad de mujeres y locales dedicados a esta actividad en Andalucía. Contando con la dificultad que entraña éste cálculo, se ha estimado la existencia de 1.404 locales de alterne, donde cada uno cuenta con una media de 10 a 15 mujeres, lo que significa que en torno a 21.060 mujeres ejercen prostitución. Respecto a la prostitución de calle y de pisos privados, no hay datos fiables, pero se estima que alrededor de 680 mujeres ejercen en la calle donde el $85 \%$ son españolas.

Finalmente, se concluye que el fenómeno de la prostitución de mujeres inmigrantes presenta seis focos de necesaria intervención social: los relacionados con la aplicación de la ley de extranjería, con las condiciones sanitarias, condiciones de trabajo, la dificultad de acceso a otros mercados de trabajo, problemas con los hijos, compañeros y clientes y los derivados del estigma social.

- Estudio realizado en el Principado de Asturias (Fernández, 2004)

La Consejería de Vivienda y Bienestar social del Principado de Asturias publicó este estudio realizado por $M^{a}$ Jesús Fernández Ollero durante el año 2002 y 2003 en diferentes 
localidades de Asturias. Este trabajo de naturaleza descriptiva estudió las condiciones laborales y el perfil sociosanitario de 115 personas que ejercen prostitución.

El objetivo general de esta investigación fue ampliar el conocimiento sobre la realidad del fenómeno de la prostitución, desde un enfoque integral, con el fin de ofrecer pautas de intervención y prevención en los aspectos psicosociosanitarios ajustadas a las necesidades del sector. Pasamos a continuación a resumir los resultados obtenidos en cada uno de estos estudios.

En cuanto al primer estudio, Descripción de las condiciones laborales y perfil sociosanitario de 115 trabajadoras sexuales, se encontró que el $94.8 \%$ eran inmigrantes, de las cuales el $79.1 \%$ eran latinoamericanas. Todas las participantes del estudio ejercían prostitución en club (hotel-club, club, barra americana, whiskería, o bar de alterne) ya que es el tipo de prostitución más habitual en Asturias. La prostitución de calle prácticamente ha desaparecido en esta comunidad, se reduce a zonas específicas donde la totalidad de personas son españolas con problemas de drogadicción.

En relación a las condiciones laborales en las que ejercen esta actividad, normalmente impuestas por los/as dueños/as de cada local, se encontró que: (1) deben trabajar todos los días, excepto el día de descanso (normalmente lunes o martes) y si se falta habrá una sanción de $30 €$; (2) no pueden llegar tarde, si esto sucede habrá sanción; (3) no se puede contactar con los clientes fuera del trabajo; (4) está prohibido consumir drogas o alcohol; (5) es obligatorio usar preservativo que se pueden comprar en el mismo establecimiento por $1 € ;(6)$ tienen que realizar revisiones médicas periódicas para el control de ITS; (7) si viven en club-hotel deben cenar por turnos para no dejar el local vacío en el horario previsto; (8) no pueden estar parada o sentada cuando hay clientes; (9) la negociación del servicio y del precio se realiza antes de la prestación del mismo; (10) no deben demorarse en la habitación tras la realización de un servicio, y (11) el horario de trabajo es de 8 horas diarias excepto los fines de semana que son más.

En cuanto a las condiciones económicas, el precio de los servicios, con una duración mínima de 20 minutos, oscilan entre 40 y $60 €$, y el porcentaje de ganancia para la 
trabajadora sexual y para el propietario es de $75 \%-25 \%$ respectivamente. Tienen una media de 3 clientes por día y unas ganancias mensuales netas que oscilan entre 1500 a $2000 €$.

En relación a las prácticas sexuales demandadas, la más habitual es el sexo oral al hombre (felación). Respecto al uso del preservativo, todas dicen usarlo siempre, pero la realidad parece ser diferente, ya que está condicionada por factores como la presión económica y la confianza con el cliente. Las trabajadoras sexuales señalan que la atracción y el placer también están presentes en su trabajo, disfrutando más si el cliente es atractivo y presenta buenas condiciones higiénicas.

Se analizaron los inconvenientes que las entrevistadas encontraban en este trabajo, y sus quejas más habituales fueron: (1) lugar de trabajo cerrado, poco ventilado, con mucho humo, sin luz natural y excesivo ruido por la música, (2) debido a su horario nocturno presentan trastornos en el sueño y desajustes alimentarios, siendo las mujeres que viven en club las que peores condiciones laborales presentan, (3) debido a sus horarios se quejan de problemas para relacionarse socialmente con sus amistades, para realizar actividades de ocio o simplemente falta de tiempo para realizar gestiones administrativas que únicamente se pueden realizar por las mañanas, (4) el no hacer nada las lleva a un estado de apatía y de falta de interés por todo, y (5) existen rivalidades entre las diferentes trabajadoras del mismo local, estando divididas por nacionalidades. En general, las personas que ejercen en club presentan mejores condiciones laborales que las de piso.

Finalmente, en relación con los problemas de salud, un $50.4 \%$ han tenido algún aborto, siendo en un $10.8 \%$ de los casos tres o más de tres abortos. Un $33 \%$ dice tomar anticonceptivos y casi el $100 \%$ usa preservativo con el cliente, mientras que sólo lo hace un $31.8 \%$ con la pareja. Un $9.6 \%$ dice haber padecido alguna ITS siendo las más frecuentes vaginosis, candidiasis y tricomonas. En cuanto al consumo de drogas, un $54 \%$ fuma, un $38 \%$ bebe más de 3 copas de alcohol al día y un 93\% afirma consumir otras drogas siendo el hachís y la cocaína las más habituales. 
- Estudio realizado en la Comunidad autónoma de Navarra (Defensora del Pueblo de la Comunidad Foral de Navarra, 2005)

La Defensora del Pueblo de Navarra realizó un Informe especial al Parlamento titulado Derechos Humanos y Prostitución en Navarra, sobre la situación de la prostitución en esta comunidad.

Según este informe el fenómeno de la prostitución en Navarra ha cambiado en los últimos años, y dentro de estos cambios destacan: la extranjerización, el aumento del número de clubes de plaza y su desarrollo como actividad organizada para la obtención de altos beneficios económicos, la alta movilidad de las personas que ejercen prostitución, la reducción de la prostitución callejera ejercida por drogodependientes, el desarrollo de la prostitución masculina y de transexuales y la diversificación de recursos y ofertas de servicios sexuales.

La prostitución en Navarra es mayoritariamente femenina y estiman que el número de prostitutas se sitúa entre 500 y 775 mujeres. El $85 \%$ de ellas trabaja en clubes, el $10 \%$ trabaja en pisos y el $5 \%$ en la calle, en general más del $90 \%$ son inmigrantes. Se calcula que aproximadamente el $53 \%$ de las mujeres trabajan en clubes haciendo plaza donde el dueño cobra una cantidad diaria, generalmente 48 euros, en concepto de alojamiento y manutención.

Para la gran mayoría esta actividad es la única fuente de ingresos y para una minoría constituye un recurso complementario al que acuden en momentos puntuales de mayor necesidad.

Respecto a los riesgos de salud que tiene este colectivo, se ha detectado que son las mujeres de la calle las que peor situación presentan, ya que la prostitución en la calle unida a las drogodependencias lleva aparejada una serie de enfermedades, como la hepatitis, el VIH/SIDA, etc.

La prostitución de hombres y transexuales supone un grupo minoritario en comparación con las mujeres y trabajan en calle o en pisos. En cuanto a su estado de salud, especialmente el de los transexuales, se han detectado algunos problemas específicos, 
como la hormonación con estrógenos sin control sanitario, los tratamientos de cirugía estética por personas sin titulación y los problemas de salud mental (ansiedad, irritabilidad, consumo de drogas, etc.) derivados de la angustia por identidad conflictiva.

\subsubsection{Estudios realizados en Castilla y León}

Se han realizado diferentes estudios sobre la prostitución y las personas implicadas en ella en Castilla y León. Algunos han estudiado la situación relativa a alguna provincia o ciudad, como por ejemplo el estudio realizado en la provincia de Salamanca (Alonso, 2001), en la ciudad de Valladolid (APRAM, 1997; Gutiérrez, Pinedo y Martín, 2006; Pinedo y Martín, 2006) y en Palencia (2008); mientras que otros hacen referencia a la comunidad autónoma en general (ASE-PSIKÉ, 1998; López y Pinedo, 2007). A continuación presentamos los datos más relevantes encontrados en estos estudios, presentaremos la revisión por orden cronológico para reflejar los cambios que se han producido con el paso del tiempo.

- Estudio realizado en la ciudad de Valladolid (APRAM, 1997)

En primer lugar hemos revisado un estudio realizado en la ciudad de Valladolid en 1997 por APRAMP y encargado por el Excmo. Ayuntamiento de Valladolid. Su objetivo general fue profundizar en el conocimiento de la realidad y el entorno de las prostitutas marginales que ejercen su actividad en Valladolid, con el fin de descubrir en que grado están satisfechas sus necesidades básicas. En este estudio se utilizó metodología cualitativa y cuantitativa entrevistando tanto a expertos como a prostitutas. Distinguen diferentes tipos de prostitución en función del lugar donde se ejerce, en calle (32\%), en club o whiskerías (50\%) o en casas de citas (18\%).

En cuanto al análisis cualitativo, se llevaron a cabo entrevistas en profundidad y grupos de discusión. Se encontró que hay grandes diferencias entre las mujeres que ejercen en la calle y en clubes, fundamentalmente porque las primeras ejercen la actividad para costearse el consumo de drogas. Todas ellas se quejan de ejercer la actividad en malas condiciones (muchas horas y poca higiene en el lugar de trabajo, etc.). La mayoría son 
españolas aunque comienzan a aparecer los primeros grupos de extranjeras, las cuales son rechazadas por las autóctonas puesto que son vistas como competencia y causantes del descenso de los precios de los servicios. En general presentan niveles culturales muy bajos. Comienzan a ejercer muy jóvenes, algunas menores de edad, y en ocasiones presionadas por sus familias, las cuales suelen ser muy numerosas y con escasos recursos económicos. Muchas son madres solteras y han sido rechazadas por sus familias y abandonadas por sus parejas por lo que se ven abocadas a ejercer esta actividad. En general presentan malas relaciones con sus familias. Aunque todas afirman tener cobertura sanitaria no suelen realizarse reconocimientos médicos. Los malos tratos son frecuentes en sus vidas, por parte de sus padres, su pareja, los clientes e incluso los jefes de los locales donde trabajan.

La parte cuantitativa del estudio se basa en los datos recogidos en 50 entrevistas realizadas a prostitutas de Valladolid. Sólo un $20 \%$ son extranjeras el resto son españolas. Los motivos económicos relacionados con la entrada en la prostitución (subsistencia y mantener a la familia) y los relacionados con el consumo de drogas son los más numerosos. Un $60 \%$ afirma ocultar siempre que ejercen prostitución, por lo que se ven obligadas a llevar una doble vida. En cuanto a su estado de salud, un $46 \%$ afirma haber padecido alguna ITS y un $11.5 \%$ son seropositivas al VIH. Un $70 \%$ han tenido algún aborto y casi un $40 \%$ consume drogas frecuentemente, siendo la sustancia más consumida la heroína.

En cuanto a los datos relacionados con la industria sexual en general, un $47 \%$ afirma conocer la existencia de prostitución de menores y un $45 \%$ conoce la existencia de mujeres ejerciendo prostitución retenidas a la fuerza. Finalmente un $49 \%$ dice conocer la existencia de redes de prostitución organizada.

- Estudio realizado en la provincia de Salamanca (Alonso, 2001)

El estudio realizado en la provincia de Salamanca siguió una metodología mixta cualitativa y cuantitativa en la que integraron no sólo la visión de las personas implicadas directamente en la prostitución sino que también analizaron la percepción y las opiniones de otros informantes de interés como la policía local, la guardia civil, las asociaciones de vecinos y profesionales que atienden este colectivo. Su objetivo general fue confeccionar un 
mapa de la prostitución en Salamanca y provincia, conocer las condiciones sociales e higiénico-sanitarias en las que trabajan las personas que ejercen prostitución y analizar su situación personal, familiar y humana.

En este estudio se realizaron 50 entrevistas en clubes, pisos y calle. El $80 \%$ de las entrevistadas eran extranjeras mayoritariamente latinoamericanas. En cuanto a las condiciones en las que ejercen la actividad, afirman trabajar más de 8 horas diarias de media, y el $70.7 \%$ lo hace por causas económicas, mientras que un 3.1\% comenzó siendo engañadas. Casi el 70\% cambian de lugar para trabajar haciendo plaza, en un $60 \%$ porque ellas lo deciden y en un $40 \%$ porque así lo establecen los dueños de los locales. Estiman que cada mujer tiene unas ganancias brutas mensuales de $5.500 €$ aunque para ellas suele quedar unos $2.000 €$, después de descontar sus gastos y porcentajes para los/as dueños/as. Un $4.2 \%$ afirma estar muy satisfecha con la prostitución, un $56.3 \%$ satisfecha y un $39.5 \%$ poco o nada satisfecha. En cuanto a sus condiciones sanitarias un $25 \%$ no tiene ningún tipo de cobertura médica, un $34.3 \%$ afirma haber tenido algún aborto y un $22.2 \%$ ha tenido en alguna ocasión alguna infección de transmisión sexual. Se ha detectado la existencia de malos tratos durante el ejercicio de la prostitución y en la mayoría de los casos los agresores han sido el cliente o la pareja.

En cuanto a los datos relacionados con la industria del sexo en la ciudad de Salamanca y su provincia se estima que hay aproximadamente 800 mujeres ejerciendo prostitución; se realizan aproximadamente unos 2.500 servicios sexuales por día en toda la provincia y se mueven al año más de 43.000 .000 de euros, lo que supone aproximadamente el $1.32 \%$ de PIB provincial.

- Estudios realizados en la ciudad de Valladolid (Gutiérrez-Cortines, Pinedo y Martín, 2006; Pinedo y Martín, 2006)

La Universidad de Salamanca en colaboración con ACLAD, ha realizado durante los últimos tres años dos estudios, tanto de naturaleza cualitativa como cuantitativa, relacionados con la prostitución y las personas implicadas en ella. 
En primer lugar se realizó un estudio de naturaleza cualitativa cuyo objetivo era explorar, describir y analizar los discursos de mujeres que ejercen prostitución, en la calle, clubes y pisos, sobre su calidad de vida, su salud y el estado de sus necesidades interpersonales (Pinedo y Martín, 2006). Para ello se llevaron a cabo dos entrevistas grupales, una de ellas con mujeres que ejercen la actividad en la calle y el otro con mujeres que la ejercen en pisos o clubes. En general se encontró que las mujeres que ejercen en la calle tienen mayor número de problemas y necesidades (malos tratos, inseguridad, problemas de salud, etc.) que las que ejercen en pisos o clubes, y esto puede deberse a que en su mayoría son drogodependientes. Pero, para ambos grupos, el principal problema era la discriminación, el estigma y la soledad que sentían, seguido de la dificultad para usar condones con los clientes y falta de higiene en el lugar de trabajo.

El segundo estudio, de naturaleza cuantitativa, tuvo como objetivo general conocer y estudiar el fenómeno de la prostitución en la ciudad de Valladolid. Se llevó a cabo una entrevista semiestructurada a 76 personas ( $91 \%$ mujeres y $9 \%$ transexuales) siendo en un $75 \%$ de los casos extranjeras, de las cuales un $64 \%$ eran latinoamericanas. En este estudio se diferencian tres tipos de perfiles, prostitución de calle $(14 \%)$, de club $(22 \%)$ y de piso $(63 \%)$.

Según los datos de este estudio la situación más precaria la presentan las personas que trabajan en la calle, debido a que el $100 \%$ son toxicómanas y son las que presentan mayor número de casos de infecciones de transmisión sexual (47\%) y de VIH/SIDA (37\%). Este grupo esta formado por mujeres españolas, que comenzaron a ejercer con una media de 26 años, llevando casi 8 años ejerciendo y trabajando unas 10 horas al día; son las que menos satisfacción muestran con el ejercicio de la prostitución, la cual la ejercen fundamentalmente para costear su adicción a las drogas. Además, este grupo es el que mayor número de agresiones sufre, tanto a nivel físico como a nivel psicológico y sexual.

En los pisos y clubes trabajan fundamentalmente mujeres extranjeras, de las cuales un $60 \%$ son ilegales. Un $54 \%$ viajó a España conociendo la actividad a la que se iban a dedicar y la mayoría afirman comenzar a ejercer esta actividad por motivos económicos. Las 
mujeres extranjeras comienzan a ejercer con una media de edad de 24 años, llevan aproximadamente uno 4 años ejerciendo y trabajan más de 15 horas al día. Son las mujeres extranjeras las que mejor estado de salud presentan: se hacen más reconocimientos médicos, tienen menos ITS, menos embarazos no deseados a lo largo de su vida, menos abortos y consumen menos drogas.

En general, la muestra entrevistada afirma necesitar más información sobre ITS, más higiene y protección en el trabajo, atención sociosanitaria especializada, legalizar la prostitución y otras alternativas laborales. Este estudio concluye que la exclusión social, el aislamiento y el estigma que sufre este colectivo es uno de los factores que las hace más vulnerables a diferentes riesgos (violencia, conductas sexuales de riesgo, explotación, etc.).

En cuanto a los datos relacionados con la industria del sexo, se calcula que únicamente en la ciudad de Valladolid realizan esta actividad de 360 a 440 personas y que diariamente se compran entre 1.951 y 2.384 servicios sexuales. En total estiman que al año se mueven más de 28.000 .000 de euros en la industria sexual.

- Estudio realizado en la provincia de Palencia (Diputación de Palencia, 2008)

Durante el año 2007 se llevó a cabo un trabajo titulado Variables sociodemográficas en mujeres en riesgo de exclusión social encargado por la Diputación de esta provincia, y cuyo objetivo general fue conocer y estudiar el fenómeno de la prostitución, en todas sus formas, en la provincia de Palencia. Este trabajo, de naturaleza cuantitativa, se basó en los datos recogidos mediante 54 entrevistas semiestructuradas a personas que ejercen prostitución en clubes de la provincia de Palencia.

El perfil sociodemográfico que nos ofrecen los datos de este estudio es el de una mujer inmigrante, con un nivel académico medio, que vive en el club donde ejerce prostitución, la cual es su única fuente de ingresos, y tienen familiares a su cargo (una media 3.17 personas dependen de ellas económicamente).

En cuanto a sus relaciones sociofamiliares, el $80 \%$ no tiene pareja, sus familias se encuentran en sus países de procedencia $(88.7 \%)$ y sus hijos/as viven con sus familiares en 
sus países de origen. Sienten una baja satisfacción con el contacto familiar, es decir, se sienten solas a este nivel.

Viajan a España con una edad media de 24.5 años y un $48 \%$ ha costeado su viaje migratorio mediante una deuda, el resto con sus propios medios o ayudas familiares. Un 74\% sabía que venían a España a ejercer prostitución y aproximadamente la mitad de las entrevistadas se encuentran legalmente en el país.

Están una media de casi 2 años ejerciendo prostitución, pasando después a otras actividades económicas o regresando a sus países. Casi la totalidad de las encuestadas (89\%) afirma ejercer prostitución por motivos económicos (necesitar dinero rápidamente, no tener otro trabajo, etc.). Es habitual la movilidad dentro de este colectivo ya que casi el $60 \%$ afirma cambiar de local o de ciudad para ejercer prostitución una vez al mes. Soportan largas jornadas laborales, en torno a 10 horas diarias, en ocasiones sin descansar ningún día de la semana. En cuanto a la libertad para elegir sus condiciones laborales la mayoría puede elegir sus vacaciones, los precios de los servicios y los clientes a los que atiende, pero no es así en el horario que realizan, el cual es impuesto por el club. En general afirman sentir poca seguridad durante el ejercicio de esta actividad y un $80 \%$ cree necesaria su legalización para tener acceso a derechos laborales y sociales.

En cuanto a sus condiciones sanitarias, se sienten satisfechas con su salud y su calidad de vida y un $89 \%$ afirma realizarse reconocimientos médicos periódicamente. Un $87 \%$ dice cuidar su alimentación y un $46 \%$ tiene problemas para dormir (tarda en conciliar el sueño, despertar precoz, etc.). Un 9.3\% consume habitualmente drogas como la cocaína y/o hachís/cannabis y un $22.2 \%$ consume tabaco y alcohol diariamente. Se encontró que las mujeres que bebían alcohol diariamente eran las que llevaban más tiempo ejerciendo prostitución y sentían menor satisfacción con el ejercicio de la prostitución y con su calidad de vida.

Se analizó también su salud sexual, y en relación con el uso de métodos anticonceptivos se encontró que un 52\% afirmaba usarle tanto en sus relaciones de pareja como con los clientes, mientras que el resto se desprotegía en sus relaciones de pareja. Un 
$70.4 \%$ afirmó haber tenido prácticas de riesgo en alguna ocasión, siendo la más habitual la rotura de preservativo seguida del sexo oral sin protección (francés natural). Un 39\% tuvo embarazos no deseados antes de ejercer prostitución y un $5.6 \%$ durante el ejercicio de la misma. Un 22.2\% afirmó tener algún problema de tipo sexual (trastornos en el deseo, en la excitación o en el orgasmo). Finalmente, se encontró que la violencia física, psicológica y sexual durante el ejercicio de la prostitución era prácticamente inexistente.

En cuanto a los datos referentes a la industria del sexo, se calculó que había 160 personas ejerciendo prostitución en los 11 clubes existentes en la provincia. Se estimó que 600 hombres acudían diariamente a la compra de este tipo de servicios generando unas ganancias de $24.000 €$ diarios a este sector, es decir, unos 8.760.000€ anuales.

- Estudio realizado en Castilla y León (ASE-PSIKÉ,1998)

Hemos revisado dos estudios realizados en Castilla y León, uno realizado hace diez años (ASE-PSIKÉ, 1998) y otro más reciente (López y Pinedo, 2007) que nos mostrará la situación actual de la prostitución y ayudará a ver los cambios ocurridos entre un momento temporal y otro.

El estudio realizado por ASE-PSIKÉ en 1998 fue de naturaleza cuantitativa en el que se entrevistaron a 302 mujeres que ejercían prostitución en alguna de las provincias de Castilla y León. El objetivo general del estudio fue conocer las características psicológicas, laborales, económicas y sociales de las mujeres que se dedican a la prostitución, de las personas relacionadas con ellas (hijos, clientes, pareja,...), prestando especial atención a la inserción social actual de estas mujeres, su estado de salud y sus expectativas futuras de vida. Se entrevistó a mujeres que trabajaban en diferentes tipos de prostitución, un $9 \%$ de calle, un $44 \%$ de club, un $38 \%$ de club de carretera y un $5 \%$ de piso. El $41.5 \%$ de las entrevistadas eran extranjeras siendo la mayoría latinoamericanas.

Son mujeres con un nivel educativo muy bajo y cuya experiencia laboral anterior a la prostitución es inexistente o en trabajos sin cualificación. Vienen de familias con un nivel socioeconómico bajo, donde en un $15 \%$ han tenido otro familiar ejerciendo prostitución. El 
$79 \%$ no tiene pareja pero un $63 \%$ tiene hijos/as de los cuales en un $47 \%$ de los casos los padres no les han reconocido, sólo un $15 \%$ afirma convivir con sus hijos/as.

Comienzan a ejercer prostitución con una edad media de 24 años y las causas de entrada en la prostitución son económicas (48\%), por destrucción matrimonial (14\%) o por costearse las drogas (17\%). Un 12\% compagina la prostitución con otros trabajos y suelen trabajar un mínimo de 8 horas diarias.

En cuanto a su estado de salud un $30 \%$ no tiene cobertura sanitaria. Un $93.4 \%$ usa preservativo con los clientes, un $6.6 \%$ no lo usa, un $29.5 \%$ afirma haber tenido alguna ITS. El $36.4 \%$ afirma no usar preservativo con su pareja y un $48 \%$ de los casos han tenido algún aborto. En cuanto al consumo de drogas, un $36 \%$ consume drogas, siendo un $10 \%$ heroína o cocaína, un $11 \%$ cannabis o anfetaminas, un $15 \%$ alcohol de forma habitual y un $64 \%$ afirma consumir tabaco diariamente.

En este estudio se estima que hay 2.562 mujeres ejerciendo prostitución en Castilla y León, es decir, existe una ratio de población femenina en Castilla y León versus población de mujeres prostitutas de 1.96 por cada 1.000 mujeres. $Y$ se estima que se mueven aproximadamente 2.5 millones de euros al mes en la industria sexual en esta comunidad.

- Estudio realizado en Castilla y León (López y Pinedo, 2007)

Finalmente vamos a comentar el último estudio realizado en Castilla y León en materia de prostitución (López y Pinedo, 2007). Se trata de un estudio de naturaleza cuantitativa, en el que se realizaron 237 entrevistas entre los diferentes tipos de prostitución existentes en Castilla y León: un $4.6 \%$ en calle, un $29.5 \%$ en club de ciudad, un $15.6 \%$ en club de carretera y un $50.2 \%$ en pisos. La muestra estaba compuesta por un $88.2 \%$ de mujeres y el resto por mujeres transexuales. Cerca del $87 \%$ de las entrevistadas eran extranjeras donde un $82 \%$ eran latinoamericanas. El $70 \%$ tienen hijos/as y un $38.6 \%$ convive con otras compañeras de actividad.

Dado que la mayoría son extranjeras se analizó el proceso migratorio en profundidad, encontrando que los motivos migratorios son principalmente económicos. Un $35.5 \%$ viaja a Europa mediante una deuda contraída, el resto migran con sus propios 
recursos o con la ayuda de familiares o amigos. La deuda media es de aproximadamente 3.000 euros, además las entrevistadas afirman tener la responsabilidad económica de al menos 2.4 personas (hijos, padres, etc.) y casi un $50 \%$ se encuentra en situación ilegal por lo que muchas no aceptan trabajos con bajos recursos puesto que tienen grandes cargas económicas. Un $52 \%$ afirmó saber que iba a ejercer prostitución antes de salir de su país.

Un 8\% compagina la prostitución con otro trabajo normalizado, el cual suele ser no cualificado y mal pagado (limpieza, cuidadora, etc.). Comienzan a ejercer prostitución con una media de 26 años impulsadas por motivos económicos, un $7.3 \%$ afirma haber sido obligada por una tercer persona para comenzar a ejercer prostitución. Respecto a cómo comenzaron a ejercer prostitución, un $22 \%$ afirma haber sido ellas mismas las que se pusieron en contacto con un local para comenzar a ejercer mientras que casi un $70 \%$ fueron informadas por otra persona, en su mayoría amigas o conocidas.

Presentan un nivel bajo de satisfacción con las condiciones en las que ejercen prostitución, ya que presentan gran movilidad para trabajar (un $50 \%$ realiza plaza) y un $60 \%$ afirma compartir sus ingresos con los dueños/as de los locales. Trabajan muchas horas al día, una media de 13 horas, y atienden a una media de cuatro clientes por día. Cuando se las preguntó por las condiciones en las que las gustaría trabajar un 30\% afirmó que legalmente, aunque la mayoría $(74 \%)$ rechaza la idea de trabajar en un barrio rojo como en otras ciudades europeas. Un $85 \%$ está de acuerdo con la legalización de la actividad ya que consideran que obtendrían más derechos (62\%) y podrían legalizar su situación (23\%). Un $77.8 \%$ afirma que se daría de alta en la seguridad social si se legalizase la actividad.

En cuanto a su salud tienen un nivel de satisfacción bueno, un 92\% afirma hacerse reconocimientos médicos frecuentemente. El consumo de drogas no está generalizado, normalmente es un consumo esporádico. En cuanto a las conductas sexuales de riesgo, el $100 \%$ afirma usar preservativo con el cliente, aunque un $38 \%$ no lo usa con la pareja, por lo que en ocasiones es una vía de infección o embarazo no deseado. Al $63 \%$ de la muestra se le ha roto en alguna ocasión el preservativo y un 33\% afirma hacer en ocasiones felaciones sin protección. Un $11 \%$ afirma haber tenido alguna ITS y un $2 \%$ sabe que es seropositiva al 
VIH/SIDA. En cuanto a su vida sexual el $82 \%$ afirma no tener ningún tipo de problema sexual en su vida, un $60 \%$ ha sentido en alguna ocasión placer sexual con el cliente y un $19 \%$ bastantes veces. Las agresiones y abusos durante el ejercicio de la prostitución existen, pero no se dan de forma generalizada.

Finalmente vamos a tratar uno de los temas más asociados a la prostitución, nos referimos al estigma y al rechazo que sienten las personas que realizan esta actividad. Un $76 \%$ considera que sufren un gran rechazo y estigma, lo cual las lleva a ejercer su actividad de la manera más clandestina posible, viviendo una doble vida que las dificulta en gran medida la satisfacción adecuada de sus necesidades emocionales y sociales. Cuando se las preguntó qué personas conocían la actividad que realizaban, un $6.9 \%$ lo sabían los hijos/as, un $19 \%$ su padre o madre, un $28 \%$ hermanos/as y en un $21 \%$ la pareja.

\subsubsection{Evolución del fenómeno de la prostitución}

La segunda mitad de los años ochenta supone un periodo crítico dentro del mundo de la prostitución. Hasta esta fecha había predominado la prostitución clásica, el carácter de esta prostitución estaba fuertemente marcado por experiencias migratorias (de zonas rurales a urbanas principalmente) dirigidas hacia el servicio doméstico por razones principalmente económicas. Era el sueño de llegar a la capital y prosperar, pero en ocasiones el sueño no se lograba, las condiciones de trabajo eran de semiexplotación, y aparecía la figura de iniciación: bien una compañera, una tocaya o bien una figura masculina, el novio. Ejercer la prostitución era una forma de alcanzar la meta económica que no se había logrado en otros trabajos (Barahona, 2001). Otra causa fundamental eran los embarazos no deseados. A estas mujeres rechazas por sus familias y/o abandonadas por sus parejas pocas opciones les quedaban además de la prostitución. La figura del chulo era frecuente, entendiendo al chulo como personaje afectivo que, a través del engaño, conducía o mantenía a mujeres en el ejercicio de la prostitución (Barahona, 2001). 
Es a finales de los años ochenta cuando aparece la figura de la drogodependiente, que cambia radicalmente el mundo de la prostitución, la cual es rechazada por la denominada prostituta clásica. La principal razón de estas mujeres era conseguir el dinero necesario para costear su consumo de drogas, por lo que más que prostituta que consume drogas, se la considera drogodependiente que ejerce la prostitución. Las mujeres que ejercen para costearse su consumo de drogas se ven rodeadas de otros problemas como la violencia física, psicológica y/o sexual, las enfermedades derivadas del consumo de drogas (especialmente heroína y cocaína inyectadas), vivir en la calle, etc. (CIMTM, 2001; Pinedo y Martín, 2006; Vanwesenbeeck, 2001).

Es hacia los años noventa cuando comienza a aparecer un tercer tipo de prostitución, el de personas inmigrantes, fundamentalmente latinoamericanas (Brasil, Colombia, Ecuador, etc.) y africanas (subsaharianas principalmente). Es con la llegada de estas últimas cuando comienzan a descubrirse mafias dedicadas a la explotación sexual. A finales de los noventa y principios del dos mil comienzan a aparecer grupos de mujeres de los países de Europa del Este (Rumanía, Bulgaria, etc.) y de otros países latinoamericanos (Paraguay, Argentina, Venezuela, etc.). El colectivo de inmigrantes dedicado a la prostitución trabaja fundamentalmente en lugares cerrados como clubes, pisos de relax, etc. creándose nuevos espacios como los hoteles-plaza, donde las mujeres viven y ejercen la prostitución en el mismo local en régimen de hotel. Con este nuevo perfil en el mundo de la prostitución aparecen nuevos problemas asociados a la inmigración como el aislamiento social, la soledad, la explotación laboral, etc. (Agustín, 2001; CIMTM, 2001).

Dentro del colectivo de inmigrantes debemos destacar la existencia no sólo de mujeres sino también de un importante colectivo de hombres y mujeres transexuales, los cuales dirigen sus servicios sexuales a clientela fundamentalmente masculina, independientemente de su orientación del deseo.

En los últimos años no sólo ha cambiado el perfil de la persona que ejerce prostitución, sino también los lugares donde se ejerce. Podemos ver que ha habido algunos cambios en el panorama de la prostitución con el paso del tiempo, tanto en Castilla y León 
como en el resto de comunidades autónomas. Los principales cambios que podemos destacar son:

- Aumento de locales para esta actividad y personas dedicadas a ella

- Cambio de lugares donde se ejercía la prostitución, hace 10 años estaba focalizada en la calle, whiskerías y pequeños clubes de ciudad y ahora se centra en pisos privados y macro clubes de carretera. Esto conlleva un cambio en la organización de los locales; ha desaparecido la figura tradicional del chulo o el macarra y surge la organización empresarial del negocio de la prostitución.

- La disminución de prostitutas españolas y toxicómanas y el gran aumento de prostitutas inmigrantes.

- Caída de los precios (un servicio sexual prácticamente cuesta lo mismo que hace diez años) debido, en parte, a la amplia y variada oferta.

- La aparición, cada vez más numerosa, de mujeres transexuales y varones en el mundo de la prostitución.

- El perfil de las personas que ejercen prostitución ha cambiado. Hace unos años la mujer española que ejercía prostitución estaba rodeada de múltiples factores de exclusión social (baja o nula formación académica, escasas oportunidades laborales, familias desestructuradas, nivel socioeconómico bajo, malos tratos y abusos, consumo de drogas, prisión, ejerciendo en la calle, etc.), mientras que en la actualidad las personas inmigrantes no presentan estas características (emigran por la pobreza de sus países, eligen la prostitución por su condición de ilegales o por ganar dinero más rápidamente, no presentan problemas de drogas y ejercen fundamentalmente en pisos o clubes).

- La introducción de nuevas tecnologías (internet, chats, páginas web, etc.) tanto para la difusión de las personas y los servicios que se realizan como para llevar a cabo estos servicios vía chat o cámara web, ha revolucionado el mundo de la prostitución. 
Pero también podemos destacar algunos aspectos que no han cambiado con el paso del tiempo, como por ejemplo:

- Las malas condiciones en las que ejercen esta actividad, en todos los estudios se reclaman mejores condiciones sociolaborales y, en algunos, la legalización de la prostitución.

- La desigualdad entre hombres y mujeres como causa de entrada en la prostitución. Las mujeres soportan más cargas económicas y familiares cuando son las que menos acceso tienen a la formación y los trabajos bien remunerados.

- En la práctica totalidad de los estudios señalan el estigma, el aislamiento, la marginalidad y la exclusión social como los principales problemas de las personas que ejercen prostitución, los cuales conllevan otros como mayor vulnerabilidad a los riesgos, sentimientos de soledad, etc. 
1.7. Prostitución en internet: una nueva visión

Con la llegada de las nuevas tecnologías Internet se ha convertido en el paraíso del sexo. Los datos hablan por sí solos: el $12 \%$ de las páginas web albergan contenidos para adultos, la palabra más buscada en la red es sexo y el $35 \%$ de las descargas por Internet tienen contenido sexual. Como afirma Agustín (2001), "el lugar más recientemente habitado por las trabajadoras sexuales migrantes es el ciberespacio que, como el espacio cosmopolita, no tiene fronteras" (p.124). Debido a la accesibilidad y el anonimato que proporciona internet se ha convertido en el lugar ideal para comprar y vender todo tipo de servicios sexuales, ya se trate de sexo virtual, de servicios de acompañantes, de alquiler o compra de vídeos pornográficos, etc.

El negocio del sexo en la red (ciberporno) constituye uno de los motores básicos de crecimiento de la propia red. En ella la mayor novedad ha sido el traslado a la pantalla del ordenador de los tradicionales peep shows en forma de web-cam y salas de chat, donde la forma de pago puede ser un fijo mensual, por tiempo de conexión o mediante llamada a un número 900 (Agustín, 2001; Sanders, 2005). Este tipo de servicios se adquieren con total anonimato y consisten en observar a través de la web-cam a la persona que has elegido. Normalmente el cliente puede pedir a la persona que está pagando que haga aquellas posturas o actividades que desea. Está claro que este tipo de actividad sexual está fuera de todo riesgo en cuanto a que no hay ningún tipo de contacto real entre las personas.

Internet no sólo es un medio donde se puede comprar y vender sexo, sino que también está reemplazando gradualmente las calles, bares y periódicos como lugares donde captar clientes. Encontramos páginas web de contactos tanto individuales como colectivas, donde cada mujer, hombre y/o transexual/travesti pueden publicar sus fotos, servicios que realiza, precios y datos de contacto. Cada una de las páginas web o blogs se pueden encontrar todo tipo de materiales que intentan enganchar la atención del cliente como vídeos, fotos, relatos eróticos, etc. 
Pero, sin lugar a dudas, el uso menos sospechado de internet en el mercado del sexo ha sido como canal de comunicación entre personas que ejercen prostitución y clientes, tanto juntos como por separado. Hemos encontrado canales y foros de discusión de personas que ejercen prostitución en los que comentan y discuten todo tipo de temas relacionados con su actividad (prevención de enfermedades, lugares donde recoger preservativos gratuitos, mejores locales para trabajar, etc.). De hecho existen ya listas negras virtuales de clientes donde se exponen datos y características de aquellos clientes desagradables o violentos, como un intento de prevenir episodios agresivos durante el ejercicio de la prostitución.

Hemos encontrado también multitud de páginas web donde asociaciones de personas que ejercen prostitución publicitan y amplían la lucha por los derechos sociales y laborales de las personas que ejercen esta actividad. Se han organizado congresos, festivales, exposiciones de arte, etc. desde la red virtual donde participan personas que ejercen prostitución en todo el mundo.

Entre los clientes se han creado foros de discusión en los que cada forero comenta sus experiencias en el mercado del sexo, ofreciendo al resto de usuarios información sobre los locales donde hay mejor ambiente, donde han encontrado los mejores servicios, etc.

Como vemos "existe toda una comunidad virtual de compradores, vendedores y organizadores del comercio sexual" (Sanders, 2005, p.27). De hecho, se está convirtiendo en la puerta de entrada de la mujer como cliente al mercado del sexo facilitado por la privacidad y anonimato con la que se puede acceder a los servicios y contenidos sexuales. Según un estudio realizado en Europa por Nielsen NetRatings en 2001 se encontró que "el $26 \%$ de las personas que visitan sitios web pornográficos con mujeres" (Agustín, 2001, p.124). 


\section{CAPITULO II: LAS NECESIDADES INTERPERSONALES}

Como hemos visto en el capítulo anterior la mayoría de los estudios que se han llevado a cabo sobre la prostitución se han centrado en la recogida de datos sociodemográficos, sobre las causas de entrada en la actividad, prácticas de riesgo, etc. pero en ningún estudio investigan en profundidad cómo afecta el ejercicio de esta actividad en la vida interpersonal y social de estas personas a pesar de la discriminación y exclusión social que soporta este colectivo. Por ello consideramos muy importante centrarnos en el estudio de las necesidades interpersonales de las personas que ejercen prostitución ya que éstas influyen en la salud y calidad de vida de las personas. En primer lugar vamos a hacer referencia a las principales teorías sobre las necesidades humanas, para posteriormente comentar las necesidades interpersonales básicas.

\subsection{Teorías de las necesidades humanas}

Se ha dado importante apoyo teórico y empírico a las relaciones existentes entre la satisfacción de las necesidades humanas, la salud y el desarrollo óptimo de los seres humanos y las sociedades (Bartholomew y Horowitz, 1991; Bowlby, 1958; Brehm, 1985; DiTomaso y Spinner, 1997; Doyal y Gough, 1992; Feeney y Noller, 1996; Hazan y Shaver, 1987; López, 1995; Maslow, 1954; Max-Neef, 1986; Ochaíta y Espinosa, 2004; Peplau y Perlman, 1982; Rubenstein y Shaver, 1982; Ryan y Deci, 2000; Weiss, 1973), por ello, en este capítulo queremos hacer un breve recorrido sobre las diferentes teorías de las necesidades humanas para aplicarlo posteriormente al estudio de las personas que ejercen prostitución.

El estudio de las necesidades humanas puede abarcarse desde distintas perspectivas, aunque nuestro interés se centra en el enfoque psicológico y sociológico. Mientras que el enfoque psicológico se ha centrado en el estudio de las necesidades humanas buscando la autonomía y el desarrollo del individuo, las corrientes sociológicas 
entienden las necesidades humanas como promotoras del desarrollo de los pueblos y las sociedades. Dentro de las teorías del primer grupo encontramos una de las teorías más importantes de la historia de la psicología, la teoría de las necesidades humanas de Abraham Maslow (1954). Mientras que, dentro del enfoque sociológico, encontramos también importantes teorías como la formulada por el chileno Mandfred Max-Neef (1974) o la propuesta por Doyal-Gough (1992). Este último grupo de teorías plantean una visión distinta de la sociedad, plantean un cambio en los ámbitos políticos y económicos que posibiliten una concepción más amplia de las necesidades humanas favoreciendo el florecimiento de sociedades más justas (donde no haya tantas diferencias entre pobres y ricos) y más desarrolladas (sociedades que faciliten la satisfacción de las necesidades de los miembros que las forman).

Dado que nuestro propósito aquí no es hacer una revisión exhaustiva sobre las teorías de las necesidades humanas generales, sino que nos queremos centrar en las necesidades interpersonales, haremos una breve referencia a las teorías generales como punto de partida para una posterior exposición sobre las necesidades interpersonales y finalmente, expondremos la última formulación de la teoría de las necesidades de López (2008), la cual será el marco teórico de este estudio.

\subsubsection{Teoría de las necesidades de Maslow (1954)}

Maslow (1954) formuló su teoría de las necesidades humanas desde el enfoque de la psicología humanista, denominó a su enfoque psicología del ser, ya que para él la gente autorrealizada estaba motivada por los valores del ser, son valores que se desarrollan de forma natural en los seres humanos, sin mediar la religión o la cultura. Sus principales preocupaciones giraban entorno al desarrollo pleno del ser humano y al conocimiento completo de la naturaleza humana y su potencial. En contra del determinismo y el reduccionismo planteado por la teoría del instinto, ofrece una explicación holística del ser humano considerándolo un todo integrado y organizado, por lo que todo el individuo está 
implicado en la satisfacción de sus necesidades. Para él, los seres humanos somos animales necesitados, continuamente tenemos necesidades insatisfechas que motivan nuestra conducta. Además, las necesidades o deseos últimos son universales, son los medios para alcanzarlas los que se encuentran culturalmente determinados.

Otro aspecto a destacar de su teoría es que las necesidades se encuentran ordenadas dentro de una jerarquía de relativo dominio o prepotencia, de manera que primero surgen las necesidades más básicas y, cuando éstas son satisfechas, surgen necesidades de orden superior, donde el motivo final es la autorrealización.

Las jerarquizó en el siguiente orden: 1) Necesidades fisiológicas: son necesidades básicas para el ser humano y su supervivencia (dormir, beber, comer, etc.); 2) Necesidades de seguridad: necesidad de sentirse seguro y protegido (seguridad física, laboral, familiar, etc.); 3) Sentido de pertenencia y necesidad de amor: son las necesidades de asociación, participación y aceptación; 4) Necesidad de estima: necesidad de reconocimiento, se refieren a la manera en que se reconoce el trabajo del personal y se relaciona con la autoestima; y 5) Necesidad de autorrealización: es la más elevada, se halla en la cima de la jerarquía, a través de su satisfacción personal, se encuentra un sentido a la vida mediante el desarrollo de su potencial (ver Figura 3).

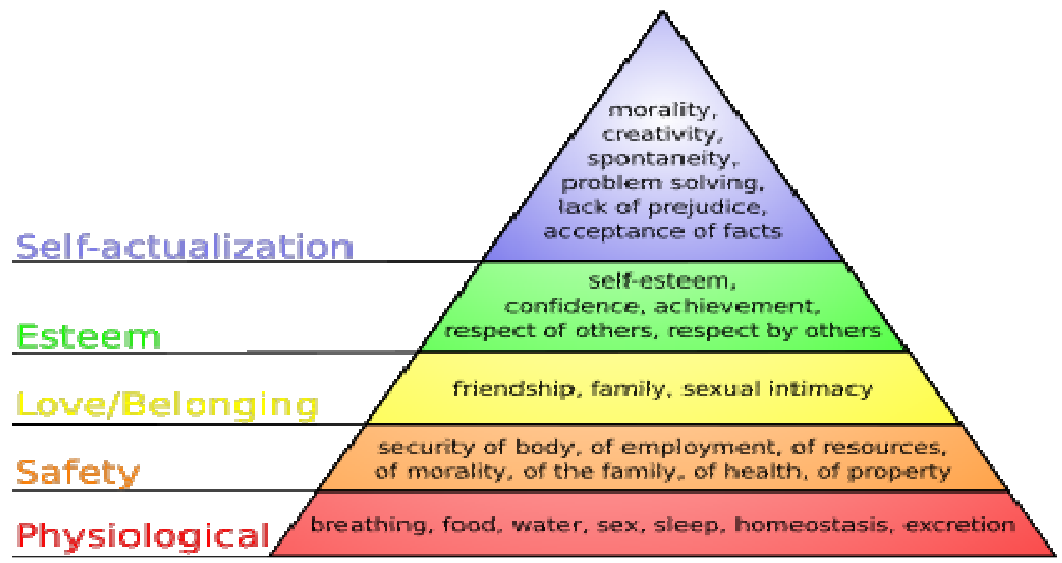

Figura 3. Pirámide jerárquica de las necesidades humanas de Maslow (1954)

Queremos hacer hincapié en la necesidad denominada sentido de pertenencia $y$ necesidad de amor, también denominada necesidad de afiliación, ya que estaría relacionada con el desarrollo afectivo del individuo, con sus necesidades de asociación, participación y 
aceptación, haría referencia a las necesidades interpersonales básicas, de las cuales hablaremos más adelante. Cuando la persona tiene insatisfecha esta necesidad sentirá "las punzadas de la soledad, el destierro, el rechazo, la ausencia de amistad y el desarraigo" (Maslow, 1954, p.96). Mientras que las personas autorrealizadas tendrían relaciones interpersonales en las que muestran una mayor simpatía, cariño, e identificación por los seres humanos, estableciendo relaciones más profundas. En su exposición afirma que amor no es sinónimo de sexo, ya que para él, el sexo, sería una necesidad puramente fisiológica, aunque reconoce que el comportamiento sexual humano está determinado por muchos factores, es decir, no sólo por las necesidades sexuales sino también por otras necesidades como el amor, el cariño, etc. por ello, las personas autorrealizadas mostrarían una vida sexual más satisfactoria.

En cuanto a la relación entre satisfacción de necesidades y el estado de salud, Maslow afirma que el grado de gratificación de las necesidades básicas está rotundamente relacionado con el grado de salud mental, y se pregunta si se podría decir que la gratificación más completa de las necesidades y la salud ideal son lo mismo. Define la salud como algo más que la ausencia de enfermedad, al igual que planteó la OMS en 1946, unos años antes de la publicación de su obra. Para Maslow (1954), "vivir al nivel de las necesidades superiores significa mayor eficiencia biológica, mayor longevidad, menos enfermedad, mejor sueño, apetito, etc. Las gratificaciones de las necesidades superiores tienen también un valor de supervivencia y un valor de crecimiento" (p.130). Así pues, la búsqueda y la gratificación de las necesidades superiores representan una tendencia general hacia la salud.

A pesar de que la teoría de Maslow ha sido vista como una mejora en las teorías previas sobre la personalidad y la motivación, los conceptos como la autorrealización resultan algo vagos. Como consecuencia, la operatividad de la teoría de Maslow es complicada. No hay ninguna prueba de que cada persona tenga la capacidad de convertirse en un ser autorrealizado. Más aún, Wabha y Bridwell (1976), en una revisión extensa de la 
teoría de Maslow, encontraron escasas evidencias de que este orden de necesidades de Maslow fuese así o de que existiera jerarquía alguna.

Si aplicásemos la teoría de Maslow al estudio de las necesidades de las personas que ejercen prostitución tomando en cuenta las características en las que viven y realizan esta actividad, podríamos pensar que se trataría de un colectivo que no goza de un estado de salud adecuado debido a que tendría dificultades para cubrir sus necesidades humanas, de hecho, únicamente parecen cubrir satisfactoriamente las necesidades fisiológicas más básicas (dormir, comer, etc.)

Encontrarían las primeras dificultades para satisfacer las necesidades de protección y seguridad, ya que por la naturaleza de la actividad y dado que no está reconocida como un trabajo no goza de los derechos, la seguridad y la protección con la que deberían vivir y trabajar. También se enfrentan a dificultades para satisfacer la necesidad de pertenencia y aceptación, factores como ser inmigrante, transexual, drogodependiente, etc. y además ejercer prostitución excluye a este colectivo de la sociedad y en ocasiones de sus propios círculos sociales y familiares. Finalmente, debido al estigma que rodea al ejercicio de la prostitución, difícilmente pueden satisfacer su necesidad de reconocimiento si no es ocultando la verdadera fuente de sus recursos económicos.

Para Maslow, satisfacer las necesidades más básicas posibilita acceder a las necesidades de orden superior, vistas las dificultades con las que se enfrenta este colectivo podríamos suponer que tienen importantes dificultades para llegar a la autorrealización.

\subsubsection{Teoría de las necesidades de Manfred Max-Neef (1986)}

Max-Neef, Elizalde y Hopenhayn (1986) elaboraron una teoría del desarrollo humano con el objetivo de superar los planteamientos económicos de las políticas neoliberales actuales. Su teoría también es denominada economía ecológica, la cual, no es una rama de la teoría económica, sino un campo de estudio transdisciplinario que estudia las relaciones entre el sistema natural y el subsistema social y económico, incluyendo los conflictos entre 
el crecimiento económico y los ecosistemas. Esta teoría está relacionada con la teoría del desarrollo humano que asume una relación inherente entre la salud de los ecosistemas y la de los seres humanos.

La satisfacción de las necesidades humanas fundamentales es el principio más importante que proponen estos autores, para ellos el desarrollo va unido a la calidad de vida de las personas, y se consigue a través de la satisfacción de sus necesidades humanas fundamentales. Estas necesidades son universales, es decir, no cambian con la cultura ni la época, aunque sí que pueden variar los medios empleados para su satisfacción (Max-Neef et al, 1986).

A nivel conceptual distinguen entre necesidades y satisfactores, las necesidades serían universales y los satisfactores serían los modos o formas en las que cada cultura hace frente a sus necesidades. Las necesidades serían categorías existenciales (ser, tener, hacer y estar) y axiológicas (subsistencia, protección, afecto, entendimiento, participación, ocio, creación, identidad y libertad) interrelacionadas (ver Tabla 9). Cuando una necesidad no es satisfecha se considera una carencia, mientras que cuando es satisfecha se considera crecimiento. La satisfacción de estas necesidades es lo que determina un óptimo estado de salud psicológica (Max-Neef et al, 1986). 
Tabla 9. Necesidades y satisfactores (Max-Neef et al., 1986, p.42)

\begin{tabular}{|c|c|c|c|c|}
\hline \multirow{2}{*}{$\begin{array}{c}\text { Necesidades } \\
\text { según categorías } \\
\text { axiológicas }\end{array}$} & \multicolumn{4}{|c|}{ Necesidades según categorías existenciales } \\
\hline & Ser & Tener & Hacer & Estar \\
\hline Subsistencia & $\begin{array}{l}\text { 1. Salud física, mental, } \\
\text { equilibrio, solidaridad, } \\
\text { humor, adaptabilidad. }\end{array}$ & $\begin{array}{l}\text { 2. Alimentación, } \\
\text { abrigo, trabajo. }\end{array}$ & $\begin{array}{l}\text { 3.Alimentar, procrear, } \\
\text { descansar, trabajar. }\end{array}$ & $\begin{array}{l}\text { 4. Entorno vital, entorno } \\
\text { social }\end{array}$ \\
\hline Protección & $\begin{array}{l}\text { 5. Cuidado, adaptabilidad, } \\
\text { autonomía, equilibrio, } \\
\text { solidaridad }\end{array}$ & $\begin{array}{l}\text { 6. Sistemas de } \\
\text { seguros, ahorro, } \\
\text { seguridad social, } \\
\text { sistemas de salud, } \\
\text { legislaciones, } \\
\text { derechos, familia, } \\
\text { trabajo. }\end{array}$ & $\begin{array}{l}\text { 7. Cooperar, prevenir, } \\
\text { planificar, cuidar, } \\
\text { curar, defender. }\end{array}$ & $\begin{array}{l}\text { 8. Contorno vital, contorno } \\
\text { social, morada. }\end{array}$ \\
\hline Afecto & $\begin{array}{l}\text { 9. Autoestima, } \\
\text { solidaridad, respeto, } \\
\text { tolerancia,generosidad, } \\
\text { receptividad, pasión, } \\
\text { voluntad, sensualidad, } \\
\text { humor. }\end{array}$ & $\begin{array}{l}\text { 10. Amistades, } \\
\text { parejas, familia, } \\
\text { animales domésticos, } \\
\text { plantas, jardines. }\end{array}$ & $\begin{array}{l}\text { 11. Hacer el amor, } \\
\text { acariciar, expresar } \\
\text { emociones, compartir, } \\
\text { cuidar, cultivar, } \\
\text { apreciar. }\end{array}$ & $\begin{array}{l}\text { 12. Privacidad, intimidad, } \\
\text { hogar, espacios de } \\
\text { encuentro. }\end{array}$ \\
\hline Entendimiento & $\begin{array}{l}\text { 13. Conciencia crítica, } \\
\text { receptividad, curiosidad, } \\
\text { asombro, disciplina, } \\
\text { intuición, racionalidad }\end{array}$ & $\begin{array}{l}\text { 14. Literatura, } \\
\text { maestros, método, } \\
\text { políticas } \\
\text { educacionales y } \\
\text { comunicacionales. }\end{array}$ & $\begin{array}{l}\text { 15. Investigar, } \\
\text { estudiar, } \\
\text { experimentar, educar, } \\
\text { analizar, meditar, } \\
\text { interpretar. }\end{array}$ & $\begin{array}{l}\text { 16. Ámbitos de interacción } \\
\text { formativa: } \\
\text { escuelas,universidades, } \\
\text { academias, agrupaciones, } \\
\text { comunidades, familia. }\end{array}$ \\
\hline Participación & $\begin{array}{l}\text { 17. Adaptabilidad, } \\
\text { receptividad, solidaridad, } \\
\text { disposición, convicción, } \\
\text { entrega, respeto, pasión, } \\
\text { humor }\end{array}$ & $\begin{array}{l}\text { 18. Derechos, } \\
\text { responsabilidades, } \\
\text { obligaciones, } \\
\text { atribuciones, trabajo }\end{array}$ & $\begin{array}{l}\text { 19. Afiliarse, cooperar, } \\
\text { proponer, compartir, } \\
\text { discrepar, acatar, } \\
\text { dialogar, acordar, } \\
\text { opinar. }\end{array}$ & $\begin{array}{l}\text { 20. Ámbitos de interacción } \\
\text { participativa: partidos, } \\
\text { asociaciones, } \\
\text { iglesias,comunidades, } \\
\text { vecindarios, familias. }\end{array}$ \\
\hline Ocio & $\begin{array}{l}\text { 21. Curiosidad, } \\
\text { receptividad, } \\
\text { imaginaciones, } \\
\text { despreocupación, humor, } \\
\text { tranquilidad. }\end{array}$ & $\begin{array}{l}\text { 22. Juegos, } \\
\text { espectáculos, fiestas, } \\
\text { calma. }\end{array}$ & $\begin{array}{l}\text { 23. Divagar, } \\
\text { abstraerse, soñar, } \\
\text { añorar, fantasear, } \\
\text { evocar, relajarse, } \\
\text { divertirse, jugar. }\end{array}$ & $\begin{array}{l}\text { 24. Privacidad, intimidad, } \\
\text { espacios de encuentro, } \\
\text { tiempo libre, ambientes, } \\
\text { paisajes. }\end{array}$ \\
\hline Creación & $\begin{array}{l}\text { 25. Pasión, voluntad, } \\
\text { intuición, imaginación, } \\
\text { audacia, racionalidad, } \\
\text { autonomía, inventiva, } \\
\text { curiosidad }\end{array}$ & $\begin{array}{l}\text { 26. Habilidades, } \\
\text { destrezas, método, } \\
\text { trabajo }\end{array}$ & $\begin{array}{l}\text { 27. Trabajar, inventar, } \\
\text { construir, idear, } \\
\text { componer, diseñar, } \\
\text { interpretar. }\end{array}$ & $\begin{array}{l}\text { 28. Ámbitos de } \\
\text { producción y } \\
\text { retroalimentación: talleres, } \\
\text { ateneos, } \\
\text { audiencias,estaciones de } \\
\text { expresión, libertad } \\
\text { temporal }\end{array}$ \\
\hline Identidad & $\begin{array}{l}\text { 29. Pertenencia, } \\
\text { coherencia, } \\
\text { diferenciación, } \\
\text { autoestima, asertividad }\end{array}$ & $\begin{array}{l}\text { 30. Símbolos, } \\
\text { lenguajes, hábitos, } \\
\text { costumbres, grupos } \\
\text { de referencia, } \\
\text { sexualidad, valores, } \\
\text { normas, roles, } \\
\text { memoria histórica, } \\
\text { trabajo }\end{array}$ & $\begin{array}{l}\text { 31. Comprometerse, } \\
\text { integrarse, } \\
\text { confrontarse, definirse, } \\
\text { reconocerse, } \\
\text { actualizarse, crecer }\end{array}$ & $\begin{array}{l}\text { 32. Socio-ritmos, entornos } \\
\text { de la cotidianeidad, } \\
\text { ámbitos de pertenencia, } \\
\text { etapas madurativas }\end{array}$ \\
\hline Libertad & $\begin{array}{l}\text { 33. Autonomía, } \\
\text { autoestima, voluntad, } \\
\text { pasión, asertividad, } \\
\text { apertura, } \\
\text { determinación,audición, } \\
\text { rebeldía ,tolerancia }\end{array}$ & $\begin{array}{l}\text { 34. Igualdad de } \\
\text { derechos }\end{array}$ & $\begin{array}{l}\text { 35. Discrepar, } \\
\text { optar,diferenciarse, } \\
\text { arriesgar,conocerse, } \\
\text { asumirse, } \\
\text { desobedecer, meditar }\end{array}$ & $\begin{array}{l}\text { 36. Plasticidad espacio- } \\
\text { temporal }\end{array}$ \\
\hline
\end{tabular}

Una de las críticas principales a esta teoría ha sido el excesivo número de necesidades y lo poco clara que resulta su clasificación (Ochaíta y Espinosa, 2004).

Desde la teoría de Max-Neef, como en la teoría de Maslow, encontramos que las personas que ejercen prostitución se enfrentarían a importantes dificultades para cubrir 
satisfactoriamente sus necesidades, por lo que su salud psicológica podría verse perjudicada.

En primer lugar las necesidades de subsistencia estarían cubiertas, pero necesidades como la protección (ser inmigrante ilegal ejerciendo prostitución no facilita el acceso a seguridad social, sistema sanitario, etc.); el afecto (estar lejos de tu país, de tu familia, pareja, amistades, etc. además del aislamiento social con el que viven no facilita la satisfacción de esta necesidad); el entendimiento y la participación (precisamente las asociaciones pro-derechos de las personas que ejercen prostitución luchan por satisfacer estas necesidades, ya que reivindican el derecho a la participación social como colectivo); el ocio (las personas que ejercen prostitución no suelen tener ni tiempo ni dinero para realizar actividades de ocio debido a las presiones económicas con las que viven); la identidad (las personas inmigrantes luchan por conservar su identidad en el país de destino, conservando sus normas, costumbres, etc. lo cual es difícil en muchas ocasiones) y la libertad (si no hay igualdad de derechos no hay libertad, y este colectivo se enfrenta a grandes dificultades para hacer valer sus derechos).

\subsubsection{Teoría de las necesidades de Doyal y Gough (1992)}

Considerada como otra de las teorías contemporáneas más importantes en el estudio de las necesidades humanas, Doyal y Gough (1992) definen las necesidades humanas como objetivos y estrategias cuya consecución posibilita participar exitosamente en la sociedad. Como los autores anteriores, defienden la universalidad de las necesidades humanas aunque los satisfactores dependen del contexto sociocultural, y critican la equiparación entre necesidades e impulsos.

Podemos considerar la teoría propuesta por Doyal y Gough como una mejora a la teoría de Max-Neef en cuanto a que concretiza y define mejor las necesidades humanas básicas y los satisfactores. Establecen dos necesidades básicas (la salud física y la autonomía), que son interdependientes de cara a la integración del individuo en la sociedad, 
es decir, se influyen mutuamente y de este proceso dependerá la integración social de la persona (ver Tabla 10). Por otra parte, definen los satisfactores como "aquellas cualidades de los bienes, servicios, actividades y relaciones que favorecen la salud física y la autonomía humana en todas las culturas" (Doyal y Gough, 1994, p.201). Los satisfactores han de contribuir positivamente a una mejora en la salud física y la autonomía en todas las culturas.

Tabla 10. Necesidades y satisfactores de la teoría de las necesidades humanas de Doyal y Gough (19994, p.202)

\begin{tabular}{cll}
\hline Necesidades & & \multicolumn{1}{c}{ Satisfactores } \\
\hline Salud física & - & Alimentos nutritivos y agua limpia \\
& - & Alojamientos adecuados a la protección contra los elementos \\
& - & Ambiente laboral desprovisto de riesgos \\
& - & Atención sanitaria apropiada \\
\hline Autonomía & - & Seguridad en la infancia \\
& - & Relaciones primarias significativas \\
& - & Seguridad física \\
& - & Seguridad económica \\
& - & Enseñanza adecuada \\
& - & Seguridad en el control de nacimientos, en el embarazo y en el parto
\end{tabular}

Definen la salud física desde una concepción negativa, salud como ausencia de enfermedad, ya que de esta forma puede considerarse transcultural, "Si una persona desea llevar una vida activa y satisfactoria a su modo, irá en su interés objetivo satisfacer sus necesidades básicas a fin de optimizar su esperanza de vida y de evitar enfermedades y dolencias físicas graves conceptualizadas en términos médicos. Esto vale para todos, en todas partes" (Doyal y Gough, 1994, p.89). La ausencia de enfermedad permite al individuo participar activamente en la sociedad.

Para complementar las carencias presentes en la definición negativa de salud física, estos autores definen la segunda necesidad humana, la autonomía, como "la capacidad de formular objetivos y estrategias consistentes que tienen por adecuados a sus intereses y a sus intentos de ponerlos en práctica en las actividades que emprenden“(Doyal y Gough, 1994, p.90). La autonomía se ve influida por el grado de comprensión de la cultura o 
sociedad, la salud mental o psicológica y por las oportunidades objetivas que tiene el individuo para ser autónomo.

En esta teoría, el fin de la satisfacción de las necesidades interpersonales es la integración social, precisamente uno de los problemas más importantes con los que se enfrenta el colectivo de personas que ejercen prostitución, la exclusión social. Ejercer prostitución y ser, en su mayoría, inmigrantes va a dificultar tanto la necesidad de tener salud física (no tienen un ambiente laboral seguro y en ocasiones carecen de atención sanitaria adecuada) como la necesidad de autonomía (no tienen relaciones significativas ni seguridad económica).

2.1.4. Teoría de la autodeterminación de Deci y Ryan (2000)

Esta teoría, también denominada teoría de la autodeterminación, considera la motivación como un continuo con tres variables y diferentes grados de autodeterminación. En un primer nivel sitúa la motivación intrínseca (cuando no existen recompensan externas) que sería el nivel máximo de autodeterminación; en un segundo nivel la motivación extrínseca (cuando en la actividad no existe un fin en sí mismo) y el tercero la amotivación (la falta completa de motivación) sería el nivel más bajo de autodeterminación.

Definen la necesidad como un estado estimulante que si es satisfecho conduce al bienestar de la persona, pero de no ser satisfecho provoca malestar. Desde esta teoría, los seres humanos nos guiamos por tres necesidades básicas (ver Figura 3) las cuales se consideran esenciales, universales e innatas, y su adecuada resolución conlleva un estado óptimo de salud psicológica (Simpson y Tran, 2006). 


\section{TEORIA DE LA AUTODETERMINACIÓN}

(Deci y Ryan, 2000)

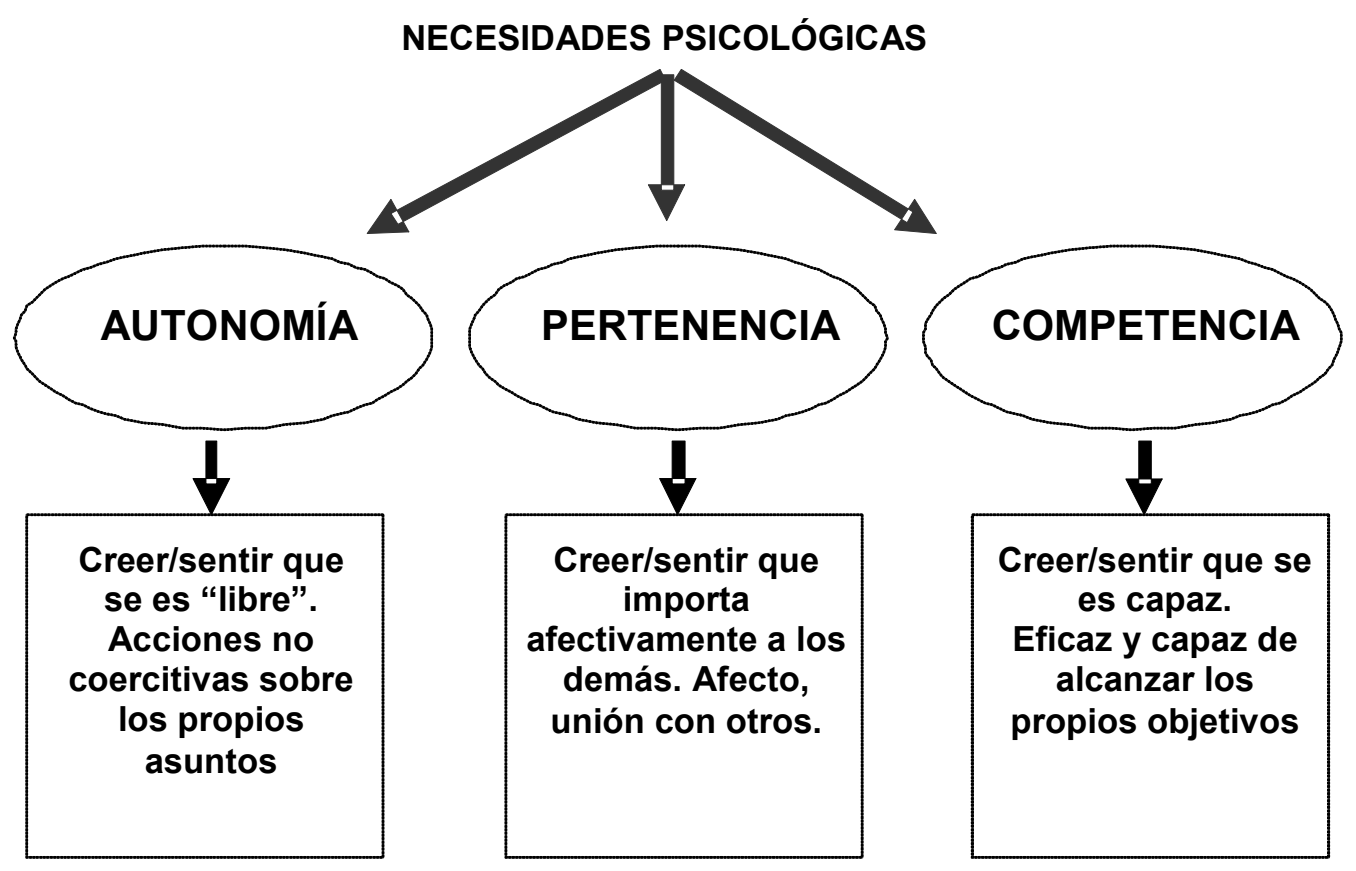

Figura 3. Teoría de la autodeterminación de Ryan y Deci (López, 2008)

Es de especial interés la atención que prestan desde esta teoría a las relaciones entre las necesidades humanas y el bienestar psicológico de la persona. Para la teoría de la autodeterminación el bienestar psicológico se considera como un funcionamiento psicológico vital basado en experiencias positivas y saludables, y en un sentido del yo congruente e integrado (Deci y Ryan, 1985, 2000; Ryan y Deci, 2000, 2001; Simpson y Tran). Esta teoría maneja como indicadores de bienestar psicológico medidas de autoestima, satisfacción con la vida y vitalidad subjetiva, las cuales se relacionan con la medida de calidad de vida que hemos usado en este estudio.

Sentir un nivel adecuado de bienestar psicológico y de calidad de vida a través de la satisfacción de necesidades interpersonales puede ser difícil en el colectivo de personas que ejercen prostitución ya que, como hemos visto, encuentran dificultades para satisfacer necesidades como la autonomía y la relación interpersonal.

En resumen, si consideramos las teorías comentadas hasta ahora en conjunto, vemos bastantes similitudes entre unas y otras. En primer lugar todas ellas consideran las necesidades humanas universales pero sus satisfactores están determinados culturalmente. 
En segundo lugar, la satisfacción de estas necesidades se relaciona con el desarrollo del individuo y por tanto de la sociedad donde vive el individuo. $Y$ finalmente, describen fuertes relaciones entre la satisfacción de las necesidades humanas, la salud biopsicosocial y la calidad de vida de las personas. Se han descrito los importantes beneficios que tiene la satisfacción de las necesidades humanas sobre la integración social del individuo.

Todas las teorías descritas coinciden en que los satisfactores de las necesidades humanas están determinados culturalmente, de manera que lo que para nosotros puede suponer un satisfactor de una necesidad concreta para otras personas pertenecientes a otro contexto social y cultural puede no serlo, y viceversa. Es interesante tener en cuenta esta perspectiva cultural al interpretar los datos que obtengamos en nuestro estudio ya que la mayoría de la muestra está compuesta por personas de diferentes culturas.

Y finalmente, apoyándonos en todo lo dicho anteriormente sobre el fenómeno de la prostitución podemos afirmar que necesidades como el sentido de pertenencia, el afecto, el establecimiento de relaciones significativas, son difíciles de cubrir y satisfacer por este colectivo porque las condiciones en las que viven y ejercen prostitución no lo posibilitan (vivir lejos de la familia, de las amistades, aislada de la sociedad sin tiempo libre, miedo a relacionarse por ser ilegal, gran movilidad, estigma asociado a la prostitución, etc.). A continuación nos vamos a centrar en este tipo de necesidades, las necesidades interpersonales básicas, y analizar cómo pueden ser satisfechas y qué dificultades se enfrentan para su satisfacción las personas que ejercen prostitución. 


\subsection{Teorías de las necesidades interpersonales}

Cada persona a lo largo de su vida necesita establecer diferentes vínculos afectivos y sociales con diferentes personas. Cada uno de estos lazos tiene una serie de funciones y beneficios para el desarrollo correcto y el estado de salud óptimo de las personas (Cacciopo, Hawkley, Crawford, Ernst, Burleson, Kowaleski, Malarkey, Cauter y Bernston, 2000; Carnelley, Pietromonaco y Jaffe, 1994; Feeney y Noller, 1996; Fitness, 2006; Hazan, Campa y Gur-Yaish, 2006; López, 1995; Mahon, Yarcheski y Yarcheski, 2004; Noller y Feeney, 2006). Como afirman Simpson y Tran (2006), "estar involucrado en relaciones estables y satisfactorias, es de hecho, percibido por la mayoría de la gente como un ingrediente crítico para la felicidad y el bienestar en la vida" (p.3). De hecho, muchos son los estudios que han documentado el efecto amortiguador de las relaciones interpersonales satisfactorias sobre la mortalidad, la morbilidad física y psicológica, y la recuperación de enfermedades crónicas (Simpson y Tran, 2006).

Cuando estos vínculos no se establecen de la manera adecuada la persona experimentará una insatisfacción en sus necesidades de vinculación, denominada sentimiento de soledad. El sentimiento de soledad (Weiss, 1973) aparece cuando la persona no satisface de una manera adecuada, lo que López (1995) denomina necesidades interpersonales básicas. Dentro del mundo de lo afectivo-emocional, encontramos vínculos como el amor y la amistad, y en la otra cara de la misma moneda, la soledad y la desvinculación. Por lo tanto, estudiar o conocer una de las caras implica entender la inversa, ya que son procesos opuestos. Entender la soledad nos lleva a comprender la importancia de la vinculación humana.

Hay diferentes teorías que estudian e intentan explicar la aparición del sentimiento de soledad desde diferentes perspectivas, por un lado, las teorías que defienden la vinculación y la intimidad como una necesidad de los seres humanos (Bowlby, 1976; Fromm-Reichman, 1959; López, 1995; Weiss, 1973), y por otro, las teorías cognitivas que enfatizan los procesos de percepción y evaluación de las relaciones sociales como punto de origen de 
este estado (De Jong y Van Tilburg, 1999; Lopata, 1982). Mientras que el enfoque de las necesidades enfatiza los aspectos afectivos de la soledad y defiende que las personas pueden experimentarla sin reconocerse a sí mismas explícita o conscientemente la naturaleza de su malestar, el enfoque cognitivo destaca la percepción y la evaluación de las relaciones y carencias sociales y afirma que las personas se etiquetan a sí mismas como personas que se sienten solas debido a la puesta en marcha de estos procesos cognitivos. Este enfoque pone el énfasis en la discrepancia entre lo que una persona quiere, en términos de afectividad interpersonal e intimidad, y lo que tiene. A mayor discrepancia entre ambos aspectos mayor soledad sentirá la persona (De Jong y Van Tilburg, 1999).

Como es de esperar cada uno de los enfoques dan sus propias definiciones sobre la soledad, pero Peplau y Perlman (1982) han identificado una serie de factores comunes a todas ellas, que son: 1) la soledad es resultado de las deficiencias en las relaciones sociales de una persona, 2) la soledad es una experiencia subjetiva, no es sinónimo de aislamiento social que es un hecho objetivo y 3) la experiencia de la soledad es desagradable y molesta.

Se han identificado diferentes antecedentes o causas de la soledad (Peplau y Perlman, 1982): por un lado se ha hablado de los sucesos o cambios que pueden precipitar la aparición del sentimiento de soledad, estaríamos hablando de un enfoque situacional que defiende que son las características estructurales de la red o el contexto social (e.g. el tamaño, la densidad, la intimidad, la composición etc. de la red social) y las características funcionales (e.g. el apoyo ofrecido por los miembros de la red) las que están asociadas con sentimientos de soledad. Y por otro lado, se ha mencionado una serie de factores 0 características personales (e.g. autoestima, timidez, ansiedad social, apego, etc.) las que hacen que una persona sea más vulnerable que otras a sentirse sola ante la misma situación o que su estado persista durante más tiempo, se trataría de un enfoque centrado en las características de personalidad de las personas. Ambas teorías no serían incompatibles ya que las características de personalidad y el contexto social interactúan (Larose, Guay y Boivin, 2002; Weiss, 1973). 
Son muchos los autores (psicólogos, antropólogos, etc.) que a lo largo de la historia han estudiado el origen, las funciones, etc. de los vínculos afectivos y sociales y del sentimiento de soledad. Pero uno de los temas que más ampliamente se ha documentado es el efecto beneficioso que tiene el establecimiento de vínculos satisfactorios (con familia, pareja, amistades, etc.) sobre el estado de salud (Cacciopo, Hawkley, Crawford, Ernst, Burleson, Kowaleski, Malarkey, Cauter y Bernston, 2000; Carnelley, Pietromonaco y Jaffe, 1994; Feeney y Noller, 1996; Fitness, 2006; Hazan, Campa y Gur-Yaish, 2006; López, 1995; Mahon, Yarcheski y Yarcheski, 2004; Noller y Feeney, 2006). A continuación haremos un breve repaso por las teorías sobre las necesidades interpersonales más importantes hasta el momento, para finalmente concluir con la presentación del marco teórico en el cual hemos basado este estudio: la teoría de las necesidades interpersonales básicas de López (1995, 2008).

2.2.1. Teoría del apego de Bowlby (1958)

Según Weiss (1975) para conocer la importancia de las consecuencias de un déficit relacional, como es la soledad, debemos remontarnos a las teorías de Freud y Bowby que establecían las relaciones entre los vínculos familiares tempranos y el posterior desarrollo normal o psicopatológico de la persona adulta.

Bowlby desarrolló la teoría del apego, una teoría novedosa sobre el desarrollo afectivo humano, basándose en dos fuentes teóricas, la etología y el psicoanálisis. Partiendo de las observaciones de Darwin, Lorenz, Harlow, y Freud, entre otros, estableció que los seres humanos, desde que nacen, tienen la necesidad innata o primaria, que no aprendida o secundaria, de establecer vínculos estables e incondicionales con diferentes personas a lo largo del ciclo vital. En la infancia con el cuidador principal, normalmente la madre, y en la etapa adulta con la pareja (Bowlby, 1986).

Estudió los procesos mediante los cuales se forman y se rompen los lazos o vínculos de afecto. Su formulación teórica nos ha proporcionado una explicación detallada sobre el 
desarrollo, las funciones y el mantenimiento de la conducta de apego (Feeney y Noller, 1996), la cual es definida como cualquier conducta cuyo resultado es lograr o mantener la proximidad con otra persona que es diferenciada y preferida a otras (Bowlby, 1976). Además establece que el vínculo afectivo del apego, desarrollado a partir de los seis primeros meses de vida a través de las relaciones entre el bebé y la persona que lo cuida (normalmente la madre), modelará durante su vida adulta el establecimiento y mantenimiento de otros lazos afectivos con amigos/as, con la pareja, etc. (Bowlby, 1986).

Destacó la función básica y primordial de los vínculos para la supervivencia del ser humano y de su especie. Una de las funciones del apego es mantener a los dos seres vinculados en contacto, de manera que este contacto permita las conductas de protección y cuidado, entre otras, elevando la probabilidad de supervivencia de los miembros.

Bowlby (1976) definió una serie de puntos claves relacionados con el apego y las diferencias individuales. Cada persona desarrolla un estilo de apego a partir de las experiencias tempranas (en la infancia y adolescencia) que tiene con sus cuidadores principales. Estas experiencias son incorporadas en los working models propios (modelos mentales), que son definidos como teorías implícitas, creencias, recuerdos y expectativas que tienen las personas sobre si sus figuras de apego estarán disponibles y serán receptivas cuando las necesiten (Simpson y Tran, 2006). Estos modelos mentales juegan un papel muy importante en las nuevas relaciones sociales que la persona establecerá a lo largo de su vida. Estas expectativas sobre la disponibilidad y receptividad del/a cuidador/a, que se han incorporado en los modelos mentales de la persona están influidas por dos variables: 1) si la figura de apego es evaluada como el tipo de persona que generalmente es receptiva y responde a las llamadas de apoyo y protección, componiendo el modelo de los otros y 2) si el propio yo es evaluado como el tipo de persona hacia el que los demás responden de manera protectora, conformando el modelo del yo. Estos modelos mentales sobre el yo y los otros desarrollados en la infancia y adolescencia persisten a lo largo de la vida. 
Los primeros estudios detallados sobre las diferencias individuales en el estilo de apego fueron llevados a cabo por Ainsworth (Feeney y Noller, 1996). Ella diferenció tres estilos de apego a partir de sus observaciones sobre la relación entre bebés y sus madres: 1) estilo evitativo, los bebés respondían con defensividad y evitación al contacto íntimo con la figura de apego; la madre tenía un estilo relacional rígido, hostil, que rechazaba el contacto, 2) estilo seguro, los bebés que eran seguros eran sociables, realizaban gran cantidad de exploración activa sobre el ambiente y respondían positivamente a la madre; las madres por su parte, eran receptivas, cálidas y estaban disponibles y 3) estilo ansiosoambivalente, mostraban conductas de protesta, malestar ante la separación y ambivalencia hacia la madre en el reencuentro; por su parte las madres se mostraban más insensibles, intrusivas e inconsistentes en su conducta.

Se ha validado el modelo tripartito de Ainsworth por múltiples autores encontrándose la necesidad de añadir un cuarto estilo de apego infantil, el estilo desorganizadodesorientado, donde los bebes mostrarían conductas contradictorias ante la madre, confusión o aprensión ante la llegada de la madre y estado afectivo cambiante o deprimido (Feeney y Noller, 1996).

Todos los puntos clave de la teoría del apego de Bowlby han sido explorados en personas adultas y se ha encontrado que este vínculo desarrolla las mismas funciones que en la infancia, de hecho, Ainsworth y Weiss (Feeney y Noller, 1996) concluyeron que los criterios del apego se han encontrado en la mayoría de los matrimonios y relaciones de pareja.

Según Bowlby (1986), debido al funcionamiento mental (working models) del yo y de los otros, hay personas que en la etapa adulta son incapaces de reconocer figuras de apego adecuadas y dispuestas a ayudarle, y/o no saben colaborar con esas personas para conseguir unas relaciones gratificantes. En tales casos, estas personas tendrían una forma de funcionamiento alterado o insano.

Posteriormente ha habido un gran desarrollo teórico sobre el apego en adultos llevado a cabo por autores como Hazan y Shaver (1987), Bartholomew y Horowitz (1991), 
Feeney y Noller (1996) y un largo etcétera. El argumento básico de Hazan y Shaver (Feeney y Noller, 1996) era que el amor romántico se puede conceptualizar como un proceso de apego, los amantes y/o esposos estarían vinculados de la misma manera que lo describía Bowlby. Definen tres estilos de amor que se corresponderían con los estilos de apego y evaluaron las diferencias existentes entre ellos (ver Tabla 11).

Tabla 11. Diferencias según el estilo de apego en la historia de apego, los modelos mentales y las experiencias de amor (Feeney y Noller, 1996, p.31)

\begin{tabular}{lccc}
\hline & APEGO SEGURO & APEGO EVITATIVO & APEGO AMBIVALENTE \\
\hline HISTORIA DE & $\begin{array}{c}\text { Relaciones cálidas con } \\
\text { ambos progenitores y entre }\end{array}$ & $\begin{array}{c}\text { Madres percibidas } \\
\text { como frías y distantes }\end{array}$ & Madres percibidas como injustos \\
& ambos progenitores. & & \\
\hline MODELOS & Fáciles de conocer; seguros & Relaciones amorosas & Dudan de sí mismos; no son \\
MENTALES & en sí mismos; perciben a los & raramente duraderas & entendidos por las otras personas; \\
& demás como bien & y con poca intensidad. & fáciles de enamorarse, pero \\
& intencionados; relaciones & & raramente un amor real; las otras \\
& amorosas duraderas. & & personas no desean compromisos. \\
\hline EXPERIENCIAS & Felicidad; amistad; confianza. & Miedo a la intimidad; & Obsesivos y envidiosos; deseos de \\
DE AMOR & & dificultades para & unión y reciprocidad; fuerte atracción \\
& & aceptar a la pareja. & sexual; extremos emocionales. \\
\hline
\end{tabular}

Encontraron que en las muestras estudiadas, la frecuencia hallada de cada uno de los tres estilos de apego es similar aproximadamente a la encontrada en los niños/as. Además, las personas clasificadas en cada uno de los estilos de apego diferían entre sí en los modelos mentales sobre sí mismos y los otros, y en sus experiencias amorosas (Feeney y Noller, 1996).

Otra aproximación teórica y empírica interesante es la de Bartholomew y Horowitz (1991). Su modelo se basó en la relación que establecía Bowlby entre los diferentes estilos de apego y los diferentes modelos mentales del yo y de los otros. Según Bartholomew tanto el modelo del yo como el de los otros pueden ser dicotomizados en positivos o negativos, combinando ambos modelos podemos definir cuatro estilos de apego. En la Figura 4 podemos ver los cuatro estilos de apego definidos. 


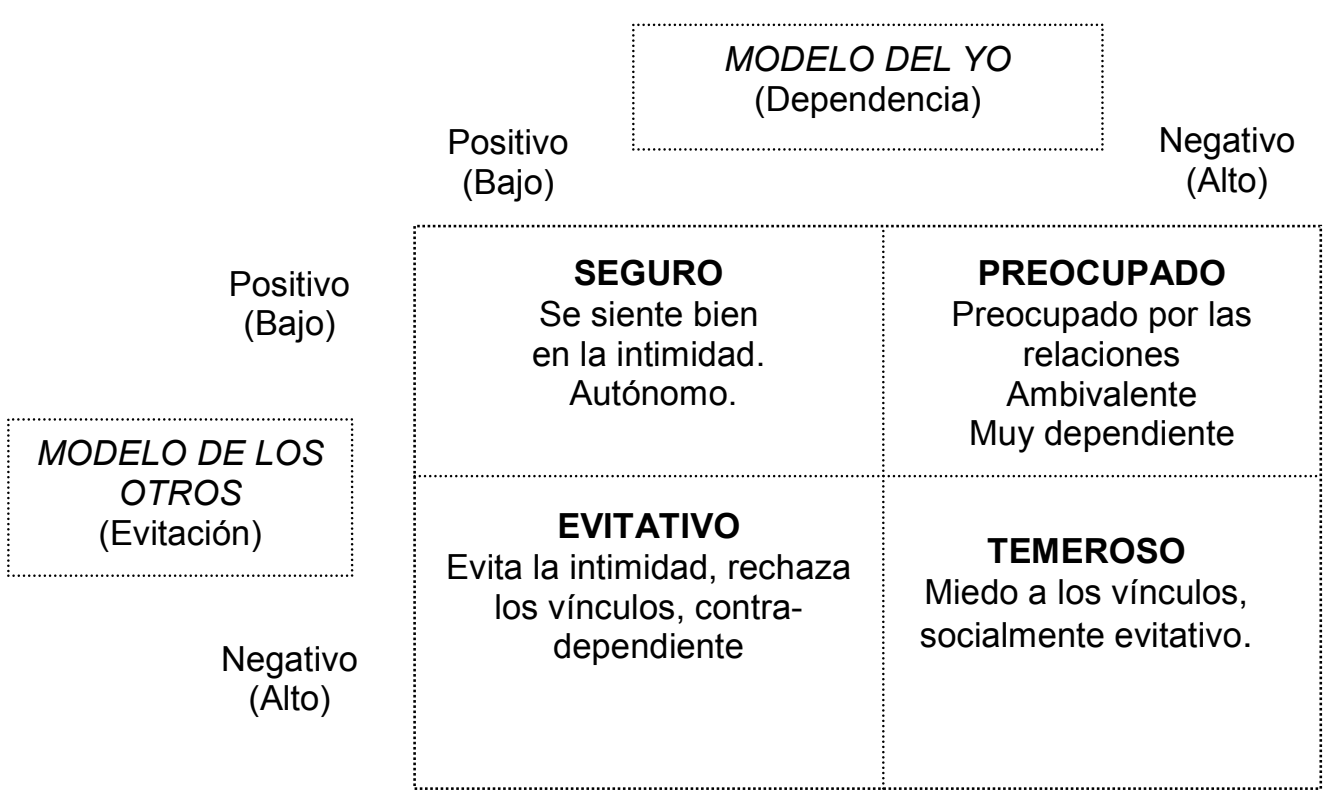

Figura 4. Modelo de los cuatro estilos de apego adulto de Bartholomew (Bartholomew y Horowitz, 1991).

Los datos empíricos hallados en diferentes estudios (Feeney y Noller, 1996) apoyan la utilidad del modelo de cuatro estilos para el apego adulto. Es interesante además destacar que la tipología de los cuatro estilos de apego es también consistente con la investigación que sugiere la adopción de un cuarto estilo de apego en niños/as, anteriormente comentado, el estilo desorganizado-desorientado.

\subsubsection{Teoría de la soledad de Weiss (1973)}

Aunque la historia de la soledad es larga, el estudio científico de la misma y más en concreto su estudio desde el punto de vista psicológico es bastante reciente. La publicación de la obra de Robert Weiss (1973) titulada Soledad: la Experiencia del Aislamiento Emocional y Social fue considerada una de las piedras angulares del estudio de la soledad (Peplau y Perlman, 1982).

Podemos situar a Weiss (1973) dentro del enfoque de las necesidades, ya que para él, el ser humano tiene una serie de necesidades de vinculación que debe satisfacer adecuadamente para poder desarrollarse adecuadamente. Se basó en la teoría del apego 
de Bowlby (1976) para explicar qué es lo que ocurre en los seres humanos cuando hay un déficit relacional.

Como Bowlby, Weiss (1973) defendía que los seres humanos tienden a establecer fuertes lazos emocionales con diferentes personas a lo largo de su vida, y que cuanto más fuertes y duraderos sean más segura se sentirá la persona en el mundo que la rodea y más probabilidad de supervivencia tendrá.

La soledad es un estado emocional desagradable, que motiva la búsqueda de relaciones con otras personas ya que hay una necesidad insatisfecha de intimidad con otros seres humanos. Según Weiss (1973) "La soledad aparece siempre como respuesta a la ausencia de algún tipo particular de relación o más exactamente como respuesta a la ausencia de algunas necesidades relacionales en particular (...) la soledad es una respuesta a un déficit relacional” (p.17)

Como ya hemos mencionado anteriormente, se han distinguido dos enfoques en cuanto a las causas o antecedentes de la soledad, por un lado el enfoque situacional y por otro el enfoque centrado en las características de la persona. Para Weiss (1973) ambos enfoques pueden ser compatibles y que en la mayoría de las situaciones interactúa la persona con el ambiente. Aún así destaca la aproximación situacional como más atractiva, y expone una serie de situaciones de especial riesgo de soledad, como son: 1) la situación de las personas que se encuentran sin pareja, y 2) la situación de las personas que están desarraigadas en la sociedad.

Weiss (1973) distingue diferentes tipos de relaciones que pueden conllevar déficits relacionales con síndromes de respuestas concretos. Exactamente defiende una teoría multidimensional de la soledad, donde distingue dos dimensiones: Soledad por aislamiento emocional y soledad por aislamiento social.

1) Soledad por aislamiento emocional, se trataría de una forma de soledad que aparece en la ausencia de un vínculo de apego emocional cercano y podría ser remediado, únicamente, por la integración de otra figura de apego emocional o por la reintegración de la figura perdida. Los sistemas que proporcionan apego y la naturaleza de los sentimientos de 
apego cambian con la madurez. Comienzan en el niño hacia los seis meses de edad y conforme se crece se va confiando más en la accesibilidad de las figuras de apego hasta que en la adolescencia se logra una reorganización del sistema afectivo y los padres son suplantados por nuevas figuras como son los iguales y la pareja. En la mayoría de los casos los vínculos de apego que la persona forma a lo largo de su vida son relativamente duraderos, pero cuando se rompe alguno de ellos (por muerte, por separación, etc.) aparece el sentimiento de soledad emocional. Cuando las personas sienten soledad emocional tienen la sensación de estar en un mundo desolador y pueden expresarlo en términos de sentirse vacíos o muertos.

2) Soledad por aislamiento social, se daría en la ausencia de pertenencia a una red social y sólo sería aliviada accediendo a una nueva red social o volviendo a una red social anterior. Según Weiss (1973), puede ser producida por cualquier alteración importante del rol social, como por ejemplo, perder el trabajo, cambiar de lugar de residencia, vivir en una comunidad que te margina y rechaza, etc. Relacionarse con iguales es tan importante para el bienestar como el vínculo del apego. Las interacciones con los iguales van evolucionando a lo largo del ciclo vital, surge en los/as niños/as entre uno y dos años y se desarrolla con los juegos compartidos; en la adolescencia cobra gran importancia debido a que el adolescente necesita el grupo de amistades para autodefinirse y expresarse; finalmente en la etapa adulta la integración social se puede lograr en diferentes círculos, el laboral, el vecindario, etc. Las aportaciones de la red social son diferentes a las proporcionadas por el apego, pero igualmente necesarias. Proporciona información, consejo, ayuda, etc. y no podemos olvidar los placeres que proporciona, como las salidas, fiestas, etc. la soledad social no permitiría tener estas gratificaciones sociales, sin las cuales sería más difícil vivir. Los sentimientos asociados a la soledad social se expresan en términos de aburrimiento o falta de rumbo, junto con sentimientos de marginación (Weiss, 1973).

La tipología definida por Weiss (1973) ha recibido apoyo empírico en los resultados de diferentes estudios (DiTomaso y Spinner, 1997; Rubenstein y Shaver, 1982). En el estudio llevado a cabo por Rubenstein y Shaver (1982), los autores preguntaron a su 
muestra, en primer lugar, sobre los sentimientos que consideraban asociados a la soledad, en segundo lugar, sobre las causas de la soledad, y por último, sobre las reacciones que tenían ante una situación se soledad. Sometieron a análisis factorial las respuestas registradas obteniendo así un gran apoyo a los distintos tipos de soledad defendidos por Weiss.

Como estos autores afirman (1982) "Los autoinformes de éstas personas sobre sus sentimientos y razones están muy estructuradas, y esa estructura encaja bien con la distinción de Weiss (1973) entre soledad social y emocional" (p.217). En la Tabla 12 resumimos la similitud entre la teoría de Weiss (1973) y los hallazgos empíricos de Rubenstein y Shaver (1982).

Tabla 12. Similitudes entre la teoría de la soledad de Weiss y los hallazgos de Rubenstein y Shaver (1982)

\section{Resultados de Rubenstein y Shaver (1982)}

Tipología de Weiss (1973)

Sentimientos

Razones

\begin{tabular}{cll}
\hline Soledad Emocional & Desesperación & No tener una figura de apego \\
\hline Soledad Social & Aburrimiento impaciente & Marginación \\
\hline
\end{tabular}

En resumen, como Rubenstein y Shaver (1982) afirman "la prominencia de estas dimensiones en nuestros datos es una fuerte evidencia de su validez, y es signo de que podrían construirse escalas separadas para medir la soledad social y emocional” (p. 218).

Weiss (1973) identificó seis aportaciones sociales que necesitamos los seres humanos y obtenemos únicamente de nuestras relaciones interpersonales, y eran: apego, integración social, vínculos de confianza, consejo u orientación, refuerzo de valores y oportunidades de educación y/o transmisión de normas. Posteriormente DiTomaso y Spinner (1997) realizaron un estudio para, en primer lugar, examinar la relación propuesta por Weiss entre las aportaciones sociales que dan las relaciones interpersonales y la soledad, y en segundo lugar, ver las relaciones entre soledad y salud mental.

DiTomaso y Spinner (1997) encontraron que efectivamente, de forma consistente con lo teorizado por Weiss (1973) y lo demostrado por Rubenstein y Shaver (1982) el apego es el primer predictor de la soledad emocional y el consejo u orientación el segundo. 
Podemos ver que este resultado es consistente también con la teoría del apego de Bowlby (1976) e interpretarlo como que la asociación de estos dos predictores con la soledad emocional durante la adultez es una reorientación hacia la pareja de los lazos de apego de la infancia definidos por Bowlby. También se confirmó la integración social como el predictor principal de la soledad social y el consejo u orientación y el apego como predictores secundarios. De esta manera las personas que mantengan relaciones interpersonales satisfactorias tendrán más probabilidad de recibir en mayor medida las aportaciones sociales citadas, necesarias para el bienestar personal (DiTomaso y Spinner, 1997).

Aunque muchos autores han apoyado la validez de las dimensiones definidas por Weiss (Ver la revisión de DiTomaso y Spinner, 1997; Rubenstein y Shaver, 1982; Russell, Cutrona, Rose y Yurko, 1984) no se han desarrollado muchos instrumentos basándose en ellas. Vincenzi y Grabosky (1987) construyeron el Inventario de soledad social y emocional (ESLI) basándose en las dimensiones citadas, pero se realizó con fines diagnósticos y no es apropiado su uso en investigación (DiTomaso y Spinner, 1993).

Debido a esta falta de instrumentos adecuados para medir las diferentes dimensiones de la soledad, DiTomaso y Spinner, en 1993, publicaron la validación de la primera Escala de Soledad Emocional y Social para Adultos (SELSA) derivada también de la tipología de Weiss. El análisis de componentes principales (PCA) sugirió extraer 3 componentes: Relaciones Familiares, Relaciones Románticas y Relaciones Sociales. Estos tres componentes reflejaban la tipología de Weiss (1973) ya que la Soledad Emocional simplemente era desglosada en dos tipos de soledad emocional, la romántica y la familiar (Bowlby, 1976; López, 1995; Weiss, 1973).

Como vemos, la teoría propuesta por Weiss y ampliada posteriormente por otros autores, adquiere una interesante aplicación en el estudio de las personas que ejercen prostitución. Además supone un análisis científico muy innovador ya que no hemos encontrado estudios que de forma directa hayan estudiado el estado de las relaciones interpersonales de este colectivo. 
Según todo lo comentado respecto a las dos dimensiones de soledad estudiadas por Weiss, encontramos diferentes factores en la vida de las personas que ejercen prostitución que dificultan en gran medida la satisfacción con sus relaciones interpersonales, y por lo tanto favorecen el sentimiento de soledad. En cuanto a la soledad emocional nos referimos a factores tales como tener a su familia e hijos/as en sus países de origen, ser solteras, ser rechazadas por sus familias, etc. ya que como hemos visto en los estudios consultados es un colectivo que en su mayoría no tiene pareja y son inmigrantes. En cuanto a la soledad social, hay factores como la actividad que realizan, ser inmigrantes, consumir drogas, ser transexuales, etc. que favorecen su exclusión social (Agustín, 2001; Elias, Bullough, Elias \& Brewer, 1989; Juliano, 2004a; López y Mestre, 2006; Medeiros, 2000; Perkins, 1991; Pheterson, 1990, 2000; Sanders, 2005; Solana, 2003; Weitzer, 2005).

Como vimos anteriormente según Weiss hay seis aportaciones sociales que necesitamos los seres humanos y obtenemos únicamente de nuestras relaciones interpersonales, al referirnos al colectivo de personas que ejercen prostitución, encontramos que aportaciones como el apego, la integración social y los vínculos de confianza son difíciles de cubrir satisfactoriamente debido principalmente al estigma asociado a la prostitución y al hecho de ser inmigrante, transexual y/o drogodependiente.

\subsubsection{Teoría SPF (Social Production Functions) de Steverink y Lindenberg (2006)}

Una de las propuestas más actuales relacionada con las necesidades sociales es la de Steverink y Lindenberg (2006). Para estos autores las necesidades son todo aquello que física o socialmente es necesario para el desarrollo y el bienestar de una persona. Como las teorías que hemos comentado anteriormente Staverink y Lindenberg (2006) entienden que las necesidades son universales, inherentes a la especie humana y están presentes a lo largo de la vida.

La teoría SPF integra dos teorías, la teoría de las necesidades, metas y recursos y la teoría de la conducta. La primera consiste en una jerarquía de necesidades universales, de 
metas instrumentales y de recursos. Las necesidades hacen referencia a un conjunto de necesidades físicas y sociales básicas que al ser mínimamente cubiertas por la persona experimentará bienestar. Las necesidades se encontrarían en lo alto de la jerarquía mientras que las metas y los recursos se encontraría en lo más bajo y serían los instrumentos con los que cubrir las necesidades. La teoría conductual afirmaría que, en general, las personas intentan mantener y mejorar los niveles de satisfacción de las necesidades. Debido a esta tendencia natural las personas intentarán sustituir o compensar cuando baja el nivel de satisfacción de una necesidad por un aumento en el esfuerzo por satisfacer otra necesidad (Steverink y Lindenberg, 2006).

Según esta teoría hay tres necesidades sociales: afecto, confirmación de la conducta y estatus (ver Figura 5). La necesidad de afecto requiere que la persona se sienta aceptada, amada, querida, comprendida y empatizada, saber que sus sentimientos son recíprocos, con el sentimiento de que otras personas están dispuestas a ayudarla sin esperar algo a cambio, saber que su bienestar está entrelazado con el de otras personas y sentir que otras personas quieren estar cerca física y emocionalmente. En definitiva la persona se siente amada como es ("to be"). La necesidad de confirmación conductual es satisfecha cuando la persona siente que está obrando bien ("to do") según su propio criterio y a los ojos de otras personas que le son relevantes. Incluye hacer buenas cosas y hacerlas bien, sentirse una buena persona, ser útil, contribuir al bien común y formar parte de un grupo. La necesidad de estatus se satisface con el sentimiento de que uno está siendo tratado con respeto, tomado en serio, es independiente y autónomo, rinde más que otros, tiene influencia, se hace a sí mismo y es conocido por sus logros, habilidades y recursos ("to have") (López 2008).

Estas necesidades pueden satisfacerse en diferente grado aunque cierto nivel de satisfacción es necesario para alcanzar el bienestar subjetivo. Según estos autores los recursos y oportunidades de las personas pueden ir variando a lo largo de la vida por lo que es necesaria una adaptación para satisfacer estas necesidades. 


\section{TEORÍA SPF: SOCIAL PRODUCTION FUNCIONS}

\section{(Steverink y Lindberg, 2006)}

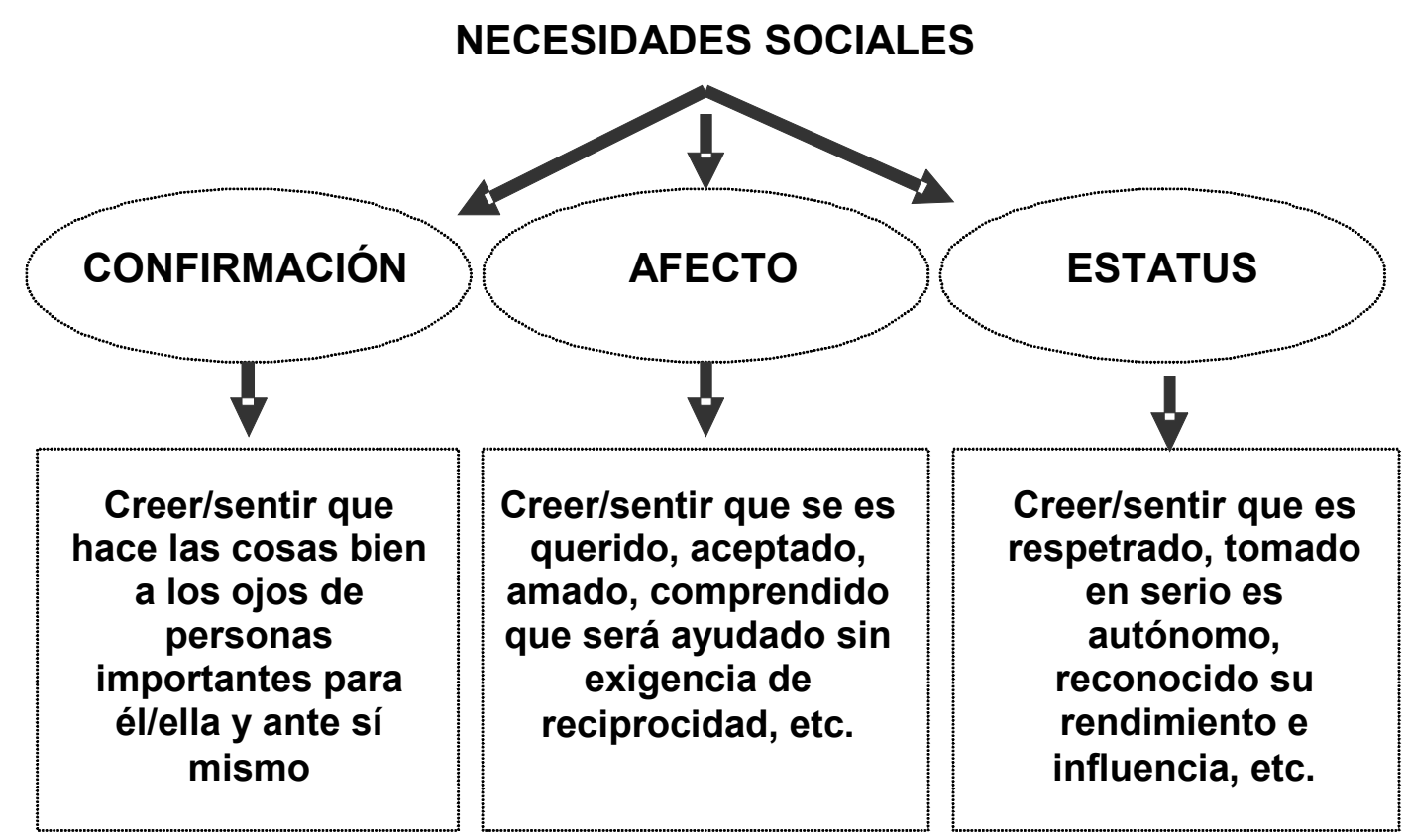

Figura 5. Teoría de las necesidades sociales de Steverink y Lindenberg (López, 2008)

Una vez más encontramos que las personas que ejercen prostitución pueden encontrar serias dificultades para satisfacer las necesidades sociales propuestas en esta teoría, y de nuevo puede deberse a factores relacionados con el ejercicio de la prostitución y la inmigración. En concreto pueden presentar dificultades para cubrir su necesidad de afecto ya que en la gran mayoría de los casos no disponen de una cercanía física con sus familiares y amistades más íntimas. Pero es especialmente interesante para nuestro estudio la necesidad de confirmación conductual, ya que debido a que la prostitución es una de las actividades más estigmatizadas y repudiadas por la sociedad, será difícil conseguir la confirmación por parte de otras personas de que se está obrando bien. Debido, precisamente, a este aspecto la mayoría de las mujeres que ejercen prostitución optan por ocultar la actividad que realizan y llevar una doble vida. De esta manera podrían conseguir la aprobación de aquellas personas importantes para ellas ya que consiguen el dinero necesario para mantener a sus familias, aunque no se sepa de donde proviene. Finalmente también nos parece difícil que las personas que ejercen prostitución puedan satisfacer su 
necesidad de estatus ya que la sociedad en general no trata con respeto a este colectivo, al contrario lo rechaza, insulta, etc. De nuevo volvemos a la doble vida como herramienta para evitar todas las consecuencias sociales negativas asociadas al ejercicio de la prostitución. Aunque el llevar una doble vida también conlleve otras consecuencias negativas para la propia persona como es la culpa, la preocupación constante, el estrés, etc.

2.2.4. Teoría de las necesidades interpersonales básicas de López $(1995,2008)$

El modelo interactivo de las necesidades interpersonales básicas de López (1995, 2008) que a continuación comentaremos, aglutina y da mayor sentido, dentro de una teoría general del desarrollo social, a importantes teorías comentadas anteriormente, y constituye el marco teórico referencial de nuestro estudio.

Para este autor (1995), el desarrollo del ser humano es el resultado de una interacción entre el individuo y la sociedad en la que se encuentra, de manera que el desarrollo de las personas es multidimensional, multidireccional y multicausal. En la interacción recíproca, entre el individuo y la sociedad, cada una de las partes intenta realizar sus propios propósitos, el del individuo será satisfacer sus necesidades y los de la sociedad lograr la conformación social de los miembros que la componen. Gracias a esta interacción, surgen y se resuelven las necesidades interpersonales, de naturaleza biológica y psicosocial.

La teoría que plantea López (2008), a diferencia de otras teorías humanas, sitúa las necesidades mentales, emocionales, afectivas y sociales en el mismo nivel que aquellas de salud y autonomía (ver Figura 6). Concibe el ser humano como un ente cultural y filosófico que necesita aprender e interpretar la realidad, y un ser para el contacto y la vinculación, que necesita relacionarse afectivamente con los demás. Por tanto las necesidades de vinculación son necesarias para el bienestar del individuo y son tan importantes como la satisfacción de sus necesidades fisiológicas. 


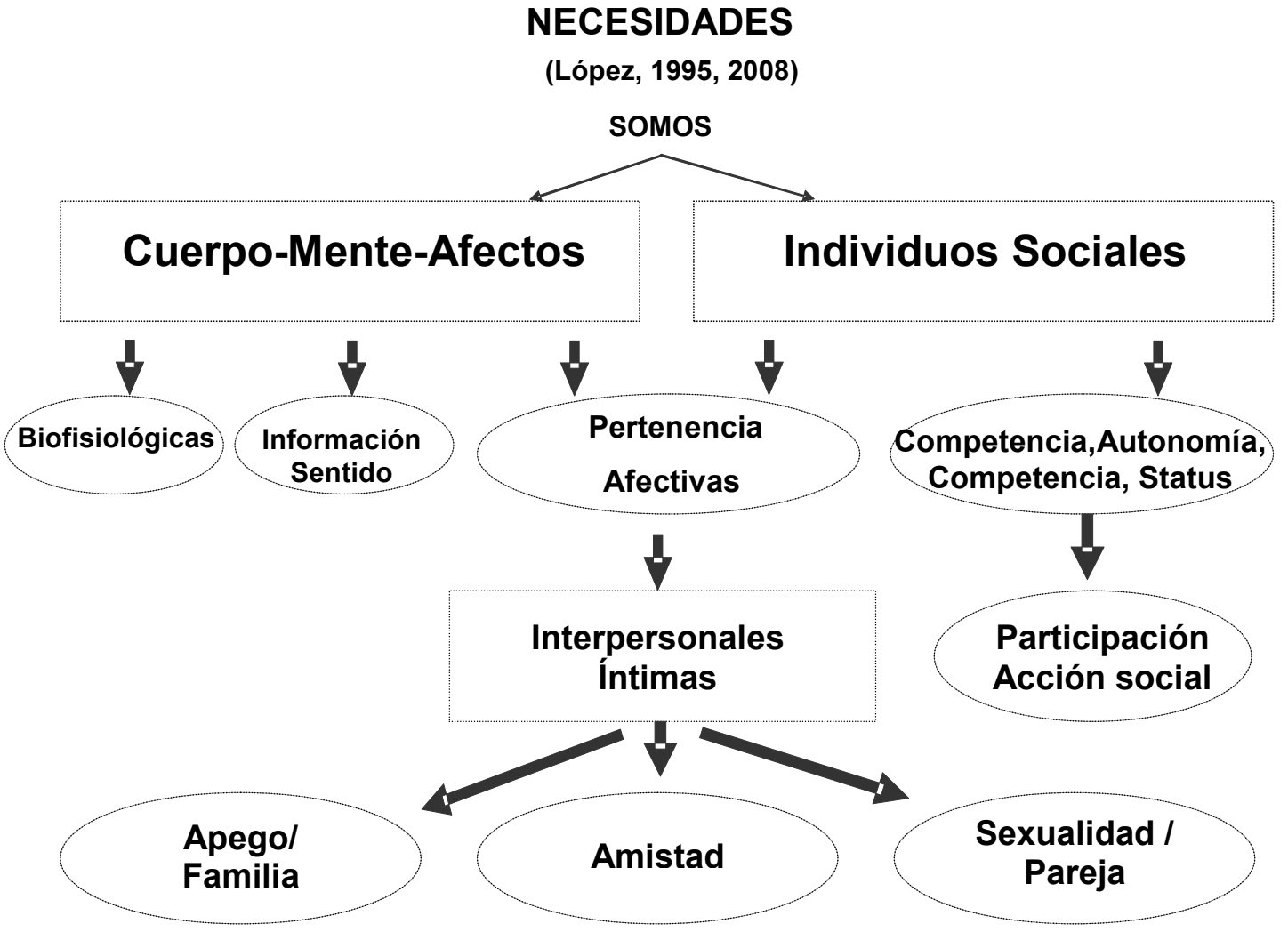

Figura 6. Las necesidades humanas en el desarrollo de los seres humanos (López, 2008, p.14)

Como los autores anteriormente citados, López (1995) considera las necesidades interpersonales universales y características de la especie humana. Toda persona debe resolverlas adecuadamente, pero la forma en que cada una las satisface es diferente, entran en juego factores educativos, culturales, personales, etc. que reflejan la gran diversidad del ser humano.

Estas necesidades de los individuos son de naturaleza variada, como afirma López (1995) "La especie humana está necesitada de resolver su soledad y su desamparo con fuertes vínculos con los demás. El vínculo del apego a personas que son entendidas y sentidas como incondicionales, el vínculo de la amistad y el vínculo del enamoramiento (...) la naturaleza de cada uno de éstos vínculos es bien distinta, pero todos ellos hacen del ser humano una especie para la vinculación" (p.39). Pero lo más importante es que "La satisfacción de estas tres necesidades, sentidas subjetivamente, favorecen la supervivencia de la especie. El apego contribuye a asegurar los 'cuidados' y la protección que requiere la cría, la red de relaciones asegura la pertenencia a un grupo y, por consiguiente la defensa y 
la alimentación, y por último, la actividad sexual conlleva la reproducción” (López, 1997, p.44).

Resumiendo, las necesidades interpersonales que define López $(1997,2008)$ son tres: la necesidad de establecer vínculos afectivos, la necesidad de una red de relaciones sociales y añade como novedad la necesidad de contacto corporal e intimidad o necesidad sexual. En los últimos años, las necesidades sexuales han adquirido un importante apoyo dentro del estudio de las necesidades interpersonales básicas, de manera que Noller y Feeney (2006) las han incluido en su último trabajo sobre las relaciones interpersonales de los seres humanos.

Según López (1997), a cada necesidad le corresponde un vínculo mediante el cual satisfacer tal necesidad, y si el individuo no satisface adecuadamente estas necesidades, aparte de otras consecuencias objetivas, sentirá soledad emocional, soledad social y soledad sexual-amorosa. Pero lo que nos parece más interesante de esta teoría para el estudio que nos ocupa es que relaciona cada tipo de soledad con una serie de riesgos asociados (ver Figura 7).

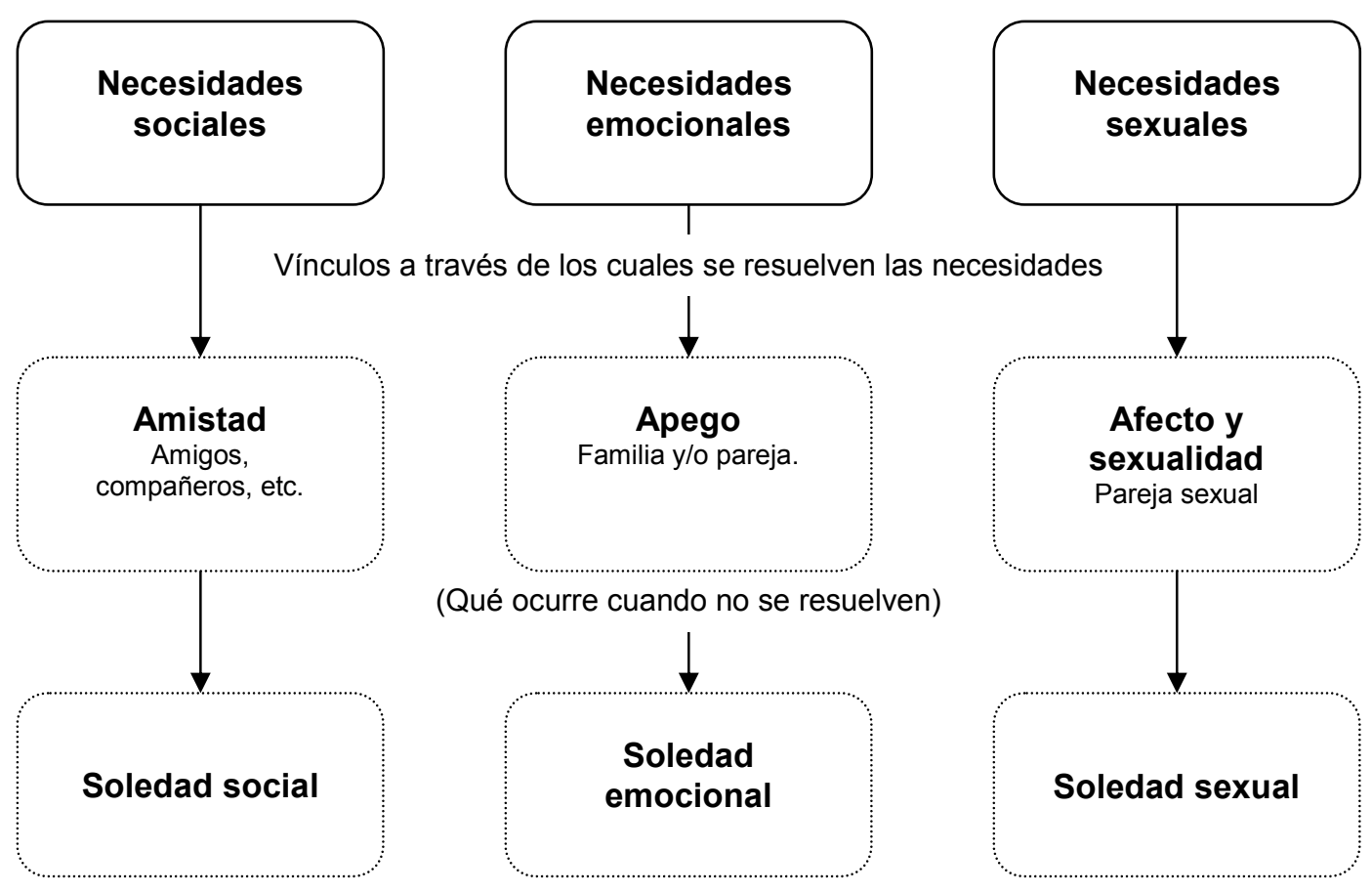

Figura 7. Necesidades interpersonales básicas de López (Carcedo, 2005, p.29) 
Las necesidades afectivas o emocionales, hacen referencia a la necesidad de establecer vínculos afectivos percibidos como incondicionales y duraderos, como es el vínculo del apego. Las figuras de apego importantes en la edad adulta pueden ser más de una, pero ¿qué ocurre cuando no se resuelve de manera satisfactoria esta necesidad? Aparecerán sentimientos de soledad emocional, donde el riesgo principal asociado es que la principal figura de apego sea una persona de riesgo (ver Tabla 13). Diferentes estudios han constatado los efectos positivos que tiene el matrimonio sobre la salud, como por ejemplo, tener mejor salud física y psicológica, tener una mejor situación financiera, tener más y mejores relaciones sexuales, etc. (Noller, 2006)

Tabla 13. Riesgos asociados a la resolución inadecuada de la necesidad afectiva

\section{RIESGOS ASOCIADOS A LA NECESIDAD AFECTIVA}

1 Principales figuras de apego de riesgo:

a) Pareja sexual delincuente, consumidora de drogas y/o violenta con la propia pareja.

b) Padre, madre y/o hermano, mejor amigo/a delincuentes y/o consumidores de drogas y/o personas violentas.

2 Compartir actividades de riesgo con las figuras de apego (delitos y consumo de drogas)

Las necesidades sociales, hacen referencia a la necesidad de disponer de una red de relaciones sociales. Según López, $(1995,2008)$ se resuelve normalmente a través de relaciones satisfactorias de amistad, la relación con conocidos y compañeros, la pertenencia a la comunidad, etc. que proporcionan un sentimiento de pertenencia a un grupo social. Cuando esta necesidad no se resuelve adecuadamente aparecerá el sentimiento de soledad social. Algunos de los riesgos asociados a la insatisfacción de esta necesidad serían tener amistades drogodependientes, delincuentes, agresivas, etc. (ver Tabla 14). El apoyo social es considerado como una de las variables principales que podrían mediar entre la integración social y un mejor estado de salud. De hecho se asocia con efectos beneficiosos para la salud a través de su influencia en las emociones, pensamientos y conductas de salud (Simpson y Tran, 2006). 
Tabla 14. Riesgos asociados a la resolución inadecuada de la necesidad social

RIESGOS ASOCIADOS A LA NECESIDAD SOCIAL

1 Amigos o compañeros de riesgo (delincuentes y/o consumidores de drogas)

2 Compartir actividades de riesgo (delitos y consumo de drogas)

Las necesidades sexuales, hacen referencia a la necesidad de contacto corporal placentero e intimidad sexual. Según López $(1995,2008)$ se resuelven, generalmente, a través de relaciones personales íntimas satisfactorias asociadas al deseo sexual, la atracción, el enamoramiento y los afectos interpersonales con la pareja sexual que aportan una sensación de bienestar sexual y sexuado. Cuando las necesidades sexuales no son satisfechas aparecerán sentimientos de soledad o de frustración sexual. Uno de los riesgos asociados a la inadecuada resolución de esta necesidad sería el involucrarse en conductas sexuales de riesgo (ver Tabla 15).

Tabla 15. Riesgos asociados a la resolución inadecuada de la necesidad sexual

RIESGOS ASOCIADOS A LA NECESIDAD SEXUAL

\begin{tabular}{ll}
\hline 1 & Relaciones sexuales no saludables \\
\hline 2 & Embarazos no deseados \\
\hline 3 & ETS y VIH/SIDA \\
\hline 4 & Víctimas o victimarios (ciertas parafilias, sadismo, pedofilia,...) de cualquier tipo de agresión sexual \\
& (coerción sexual, violación y abuso sexual) \\
\hline
\end{tabular}

Tenemos que entender también que, como afirma López $(1995,2008)$, estas tres necesidades se interrelacionan a lo largo del ciclo vital. Por ejemplo, la historia afectiva condiciona la historia sexual; la historia familiar, la historia y el estilo de apego actual se sitúan como predictores de la satisfacción sexual, afectiva y general en las relaciones de pareja (López et al., 1994).

Como vemos, la teoría de López añade las necesidades sexuales al estudio de las necesidades interpersonales básicas. Dada la naturaleza de la prostitución es interesante comprobar si las personas que la realizan cubren satisfactoriamente esta necesidad, si la 
cubren sin riesgos y qué diferencias o semejanzas se han encontrado en la satisfacción sexual con sus parejas y sus clientes. 
2.3. Las necesidades interpersonales en las personas que ejercen prostitución

Temas relacionados con las relaciones y las emociones en la vida social, los sentimientos de soledad, los deseos, etc. no han sido estudiados en las personas que ejercen prostitución, aunque como hemos visto son de gran importancia en el estudio de la salud, de las conductas de riesgo, etc. (Agustín, 2001; Sanders, 2004, 2005).

Las personas que ejercen prostitución pueden encontrar dificultades a la hora de satisfacer sus necesidades humanas, y más concretamente sus necesidades interpersonales. Dos aspectos que dificultan enormemente la satisfacción de las necesidades relacionales, y que han sido ampliamente documentados en diferentes trabajos, son los prejuicios y el estigma asociados a la venta de servicios sexuales, los cuales propician la soledad (Agustín, 2001; Baker, Wilson y Winebarger, 2004; Bindman y Doezema, 1997; Elias et al., 1989; Juliano, 2004a; López y Mestre, 2006; Medeiros, 2000; Pheterson, 1990, 2000; Perkins, 1991; Sanders, 2006; Shaver, 2005; Vandepitte, 2006; Weitzer, 2005a; Wolfers, 1999).

Según Pinillos el prejuicio "es un universal del comportamiento humano, pertenece a la naturaleza del hombre" (1982, p.15) debido a que desempeña diversas funciones, como por ejemplo la justificación sobre el control y la explotación del grupo prejuzgado. Por tanto, el prejuicio constituye un mecanismo de cobertura de los intereses de quien prejuzga, que consiste en proyectar sobre las personas prejuzgadas rasgos inmodificables e inhumanos. Si la otra persona es deshumanizada, la injusticia o crueldad se convierte en justicia (Pinillos, 1982).

Las personas que ejercen prostitución han sido y son uno de los grupos sociales más prejuzgados de la historia por la actividad que realizan, y la situación se agrava al sumarse el factor género, el ser inmigrante o pertenecer a una minoría sexual, de esta manera se justifica su control, represión y explotación (Juliano, 2004a; Pheterson, 2000). Entre los prejuicios que se han citado sobre este colectivo encontramos que son: víctimas indefensas, incultas, sin capacidad intelectual, sin intereses, irresponsables, perezosas, inestables, 
invadidas por sus instintos, pesimistas, sin sentido del ahorro, supersticiosas, fatalistas, traumatizadas, delincuentes, viciosas, sumisas, frígidas, promiscuas, impasibles, insensibles, fuente de infección, etc. (Agustín, 2001; Juliano, 2002; Perkins, 1991; Pheterson, 1990). De hecho, como ya hemos visto, multitud de estudios de investigación, supuestamente científicos, se han basado en los prejuicios que rodean a este colectivo, centrándose en evaluar únicamente aspectos como la victimización, las enfermedades de transmisión sexual y el consumo de drogas (Pheterson, 1990; Savitz y Rosen, 1988; Vanwesenbeeck, 2001). Otro ámbito que exacerba y mantiene los prejuicios sobre este colectivo son los medios de comunicación (prensa, televisión, etc.), los cuales únicamente prestan atención a las características morbosas de este fenómeno (VIH/SIDA, drogas, violencia, etc.), facilitando su descrédito y discriminación.

Los prejuicios son actitudes que preceden o facilitan la aparición del estigma, el cual es una marca impuesta debido a un comportamiento social inadecuado, en este caso la prostitución. Pero el estigma de puta planea sobre todas las mujeres, es un mecanismo de control social sobre todas, ya que las mujeres con conductas no acordes con el modelo dominante patriarcal son calificadas de putas aunque no hayan ejercido prostitución. El hecho de que puta sea el peor insulto que se aplica a una mujer y que hijo de puta sea la injuria más grave aplicable a un hombre, nos acerca a la agresividad con la que la sociedad controla a la mujer, y en concreto su sexualidad (Juliano, 2004a; López y Mestre, 2006; Sanders, 2005)

Con el estigma llega el aislamiento, la discriminación y la exclusión social, ya que su función es etiquetar a los grupos o personas que tienen comportamientos socialmente inadecuados para posteriormente colocarlos fuera de los límites de interés del grupo hegemónico. Como vemos los prejuicios y el estigma desvalorizan a este colectivo por ser mujeres, o peor aún por ser travestis, por ser inmigrantes y por ejercer prostitución. Esta desvalorización facilita la ocurrencia de episodios violentos hacia este colectivo ya que legitima a los ojos de los agresores un tratamiento que no tenga en consideración sus 
derechos, sus opiniones o incluso su seguridad física (Bindman y Doezema, 1997; Juliano, 2004a; Medeiros, 2000).

En el caso de las personas que ejercen prostitución la única vía de escape de este estigma, es llevar una doble vida en la que se oculte todo rastro sobre el ejercicio de la prostitución o migrar a otro país (Sanders, 2005). Pero tampoco son soluciones fáciles de llevar a cabo e inocuas, ya que suelen conllevar altos niveles de estrés, malestar psicológico, desarraigo, soledad, vulnerabilidad, etc. que afectan la salud de la persona. Como afirman López y Pinedo (2007) "el verse obligadas a llevar una doble vida (...) dificulta gravemente la satisfacción de las necesidades emocionales, afectivas y sociales" (p.138). Ambas opciones, el ocultamiento o no de la prostitución conllevan daños o perjuicios a la persona, por una parte el aislamiento de la doble vida y por otra el aislamiento provocado por el estigma. En un estudio realizado por Perkins (1999) se establecieron los aspectos de la prostitución menos deseados por las entrevistadas y se encontró en primer lugar tener sexo con hombres que no te gustan y en segundo lugar el estigma social de ser una prostituta.

El estigma tiñe al completo las relaciones interpersonales de la persona, con su familia, pareja, hijos/as, amistades, vecinos, etc. pero en este caso, el estigma de puta (mala mujer, pecadora, etc.), se convierte en un estatus social adquirido de por vida, que no desaparecerá cuando se produzca un cambio de actividad, "quien ha sido puta siempre lo será" (López y Mestre, 2006, p. 47). El estigma se pega como una señal identitaria de la que nadie se puede desprender impregnando otros roles como ser esposas, ser madres, ser hijas, etc., las acompaña a lo largo de toda su vida y en todas sus facetas. Este estigma las desacredita ante la sociedad de manera que se convierten en personas de segunda, sin derechos de ningún tipo (Petherson, 2000). Son mujeres rechazas por la sociedad, por sus familias, por las instituciones, etc. (Juliano, 2002, 2004a; Junco, 2003).

A modo de resumen vamos a reproducir un fragmento del trabajo de Warr y Pyett (1999) "El trabajo sexual puede dar a las mujeres mayores beneficios económicos (...) pero para muchas trabajadoras del sexo hay costos importantes en términos de soledad 
emocional y ausencia de relaciones íntimas. (...) No puede haber duda de que el estigma social vinculado al trabajo sexual contribuye a las dificultades afrontadas por las trabajadoras sexuales en sus vidas privadas (...) A la vez, las nociones de amor y relaciones románticas pueden desempoderar a las trabajadoras sexuales, (...) con consecuencias severas para su salud y bienestar"(p.305).

2.3.1. Necesidad de establecer vínculos afectivos incondicionales y duraderos: vínculos de apego

Como hemos visto diversos autores han señalado que los vínculos afectivos desarrollados en la etapa adulta, con familiares y con la pareja, son similares y se ven influidos por los vínculos de apego desarrollados en la infancia (Bartholomew y Horowitz, 1991; Bowlby, 1986; Farley y Shaver, 2000; Hazan y Shaver, 1987; López, Etxebarría, Fuentes, y Ortiz, 1999).

En ocasiones las personas que ejercen prostitución tienen dificultades para mantener relaciones satisfactorias con su familia debido a que, como ocurre con otras relaciones sociales, deben llevar una doble vida ocultando el ejercicio de la prostitución o deben soportar el rechazo familiar cuando conocen la actividad que realizan.

Cuando la persona decide ocultar el ejercicio de la prostitución debe mantener una doble vida para evitar que salga a la luz su verdadera ocupación y ser rechazada por su familia. Este ocultamiento de la realidad se hace no sólo para evitar el rechazo familiar, sino también para evitar que el estigma cubra también a su familia y sean rechazados socialmente por la actividad que ella realiza. Esta doble vida es más fácil de llevar cuando la persona migra a otro país pero aún así conlleva un gran malestar y sentimiento de culpa para la persona (Medeiros, 2000).

Cuando la persona decide contar a su familia la realidad, puede haber dos consecuencias: que lo acepten o no. Existen varios motivos para que la familia apruebe el comportamiento de la prostituta, por ejemplo, las condiciones económicas suelen ser un 
factor de gran influencia, ya que cuando hay grandes niveles de pobreza, la prostitución como fuente de recursos económicos deja de ser mal vista. El comentario de una prostituta que transcribe Medeiros (2000) en su libro refleja perfectamente esta situación: "Mi familia no se interesa por nada porque, además de ser muy pobre, puedo ayudarla (...) Meter moral en la pobreza es tontería" (p.100). Sin embargo, si la familia no acepta o no comprende esta situación las relaciones familiares se deterioran e incluso se rompen definitivamente, lo que supone una "falta de apoyos afectivos y efectivos, no sólo en el vivir de cada día, sino además ante cualquier situación problemática" (Pons, 1992, p. 105).

En cuanto al establecimiento de vínculos afectivos con una pareja encontramos que en la mayoría de los estudios consultados, entorno al $80 \%$ de las personas que ejercen prostitución, son solteras, viudas, separadas o divorciadas, es decir, se encuentran sin pareja, pero ¿qué factores están relacionados con este dato? Por un lado, como hemos visto anteriormente, las mujeres solteras con hijos/as soportan importantes dificultades económicas y familiares que facilitan la entrada en el ejercicio de esta actividad. Además, también puede considerarse un factor relacionado con la entrada en la prostitución en cuanto a que muchas mujeres afirman que si tuvieran pareja no podrían ejercer esta actividad, por los sentimientos de culpa que les conllevaría.

Otro factor que puede dificultar el establecimiento de relaciones de pareja por parte de las personas que ejercen prostitución es el estigma. El estigma que rodea la prostitución se extiende especialmente sobre las parejas de estas personas, las cuales son vistas como proxenetas o chulos que se aprovechan y se lucran de la prostitución ajena mediante el engaño y la explotación. Debido a esta circunstancia a una persona que ejerce prostitución no se la considera como una potencial pareja, sino como una persona con la que pasar el rato, satisfacer sus necesidades sexuales, etc. y siempre de forma oculta.

Finalmente, las personas que ejercen prostitución suelen disponer de poco tiempo de ocio por lo que ven restringido el contacto con personas que podrían ser parejas potenciales. En muchas ocasiones las únicas personas con las que mantienen algún tipo de 
contacto son los propios clientes, por lo que no es infrecuente el establecimiento de relaciones de pareja con ellos.

Como vemos, el hecho de ser en su mayoría personas sin pareja, conlleva por un lado dificultades en la satisfacción de la necesidad de una vinculación afectivo-emocional incondicional (Sanders, 2004, 2005) y por otra puede ser entendida como un factor de riesgo para la entrada en la prostitución.

\subsubsection{Necesidad de disponer de una red de relaciones sociales}

Como ya hemos dicho la necesidad de una red social, de mantener vínculos y/o relaciones sociales, de sentirse perteneciente a un grupo, está obstaculizada por el estigma y los prejuicios que soporta este colectivo. Pero también se ve entorpecida por factores relacionados con la inmigración y las condiciones en las que se ejerce prostitución: como por ejemplo el hecho de haber dejado en sus países de origen a su red social más íntima y cercana; estar ilegalmente en el país de destino; trabajar en régimen de plaza durante muchas horas al día; trabajar en clubes de carretera aislados viviendo en el mismo lugar donde ejercen; tener turnos de trabajo de tarde-noche y fines de semana, etc., dificultando así el disfrute del tiempo de ocio y la relación social (Pons, 1992).

De nuevo el estigma aparece como otro factor relacionado con la insatisfacción de las necesidades interpersonales. Se unen dos factores que dificultan las relaciones sociales, uno por parte de la sociedad y otro por parte de la propia persona que ejerce prostitución. La sociedad evita establecer vínculos afectivos o sociales con estas personas excluidas para evitar que les salpique el estigma, y por otra, la prostituta quiere mantener en secreto absoluto la actividad que realiza por lo que decide aislarse, reduciendo su red social al máximo y centrándose únicamente en personas de mayor confianza, o relacionándose únicamente con personas que también ejercen prostitución, donde su secreto está a salvo (Brewis y Linstead, 2000) 
Otro aspecto desde el cual se discrimina y aísla a las mujeres que ejercen prostitución, es el laboral, al tener negado el estatus de mujeres trabajadoras, carecen también de una red social en el trabajo, no pueden asociarse ni sindicarse, ya que no se considera un trabajo la actividad que realizan (Bindman, 2004; Juliano, 2002; Petherson, 1996). Las personas que trabajan en otro tipo de actividades suelen encontrar en el ambiente laboral una oportunidad más de relación social, mediante las relaciones en el horario de trabajo, mediante la organización de grupos relacionados con el trabajo, como son los sindicatos, las asociaciones, etc. Con esto no queremos decir que entre las mismas prostitutas no haya relaciones de apoyo, amistad o compañerismo, pero si es cierto que no suelen ser redes sólidas y formales. Aunque la asociación más conocida y publicitada es la de la prostituta con el chulo, existen también casos de asociación formal o informal para la lucha por sus derechos, cada vez más numerosos en Europa. Pero la mayoría de los Estados miembros funcionan con políticas abolicionistas, las cuales únicamente luchan por proteger a las personas que ejercen prostitución de explotadores y no facilitan otro tipo de redes asociativas (Juliano, 2002).

\subsubsection{Necesidad de contacto corporal placentero e intimidad sexual}

Poco se sabe sobre el estado de la necesidad sexual o erótica de las personas que ejercen prostitución. El tema de las relaciones de sexuales no comerciales sigue formando parte de los estereotipos, en la medida que se considera imposible que estas mujeres mantengan unas relaciones de pareja satisfactorias ejerciendo esta actividad (Junco, 2003). De esta manera hay pocos estudios que consideren seriamente la evaluación de la satisfacción sexual de las mujeres que ejercen prostitución, tanto en las relaciones sexuales comerciales como las no comerciales.

Hemos consultado varios estudios en los que se toma en consideración esta temática, y hemos encontrado datos contradictorios, aunque parece haberse encontrado 
mayor apoyo a la hipótesis consistente en que este colectivo presenta niveles de satisfacción sexual equiparables al resto de la población.

El estudio realizado por ASE-Psiké (1997) informa que en general, la mujer que ejerce prostitución no siente ninguna satisfacción sexual en sus relaciones con los clientes, "únicamente un $6 \%$ de ellas manifiesta tener satisfacción sexual en el ejercicio de la actividad sexual profesionalizada" (p.108). Estas cifras contrastan con las obtenidas a cerca de su vida privada, la cual es satisfactoria, aunque hay que destacar que un $13,33 \%$ dice no sentir ninguna satisfacción sexual en sus relaciones con sus parejas fuera del ámbito de la prostitución. "Estamos, ante una correlación inversa que nos permite afirmar sin lugar a dudas que la satisfacción sexual disminuye cuando el sexo se profesionaliza" (p.109).

En el estudio realizado en la provincia de Palencia (Diputación de Palencia, 2008), un $24.1 \%$ afirmó haber sentido placer sexual alguna vez y un $25.9 \%$ afirmó haberlo sentido en bastantes ocasiones con los clientes, luego la mitad de las personas entrevistadas afirman no haber sentido en ninguna ocasión satisfacción sexual con el cliente.

Junco (2003) nos ofrece otra visión sobre este aspecto, y afirma que "cuando se aborda el tema de la prostitución se omiten usualmente varios asuntos centrales y subyacentes: los deseos, las emociones y los sentimientos de las personas de ambos lados de la transacción sexual” (p.181). En su artículo intenta llamar la atención hacia temas como el deseo sexual y la diversión que experimentan muchas de las personas involucradas en la industria del sexo. "En las relaciones sexuales, tanto cuando incluyen un aspecto financiero como cuando no, los sentimientos y los deseos son primordiales. Incluso en lo que es directamente una relación de prostitución, imaginarse que son sólo 'actos sexuales' impide la comprensión global de la experiencia" (p.190).

Gail Pheterson (2000) afirma, que en contra de los estereotipos sobre la vida sexual de las personas que ejercen prostitución (mujeres frígidas, insensibles, etc.), las investigaciones realizadas por Savitz y Rosen (1988) demuestran que son sexualmente más comunicativas en su vida privada y que poseen la capacidad de separar el sexo comercial y el sexo en sus relaciones privadas. Pero parece ser que estos resultados no son 
concluyentes, ya que hay gran variedad de situaciones: personas que reprimen sus sentimientos con sus clientes mientras que otras no lo hacen, personas que reprimen sus orgasmos con clientes mientras que otras no, etc.

En su estudio, Medeiros (2000) afirma que "las relaciones sexuales también son diferentes, pues con el compañero pueden entregarse y 'correrse', mientras que con el cliente, de acuerdo con sus reglas, no deben enamorarse, tampoco alcanzar el orgasmo y, en consecuencia, no hay entrega total, es una relación vigilada" (p.104) Pero a pesar de sus reglas implícitas muchas personas sienten placer sexual en sus relaciones con los clientes, al menos en algunas ocasiones (Agustín, 2001; Diputación de Palencia, 2008; Medeiros, 2000; Perkins, 1991; Pheterson, 2000; Pinedo, 2008)

También se han encontrado diferencias en la satisfacción sexual entre mujeres y mujeres transexuales que ejercen prostitución, encontrándose que "respecto a la satisfacción sexual, las transexuales tienen más probabilidad que las mujeres, pero menos que los hombres, para decir que disfrutan las experiencias sexuales con los clientes" (Weitzer, 2005a, p.222). "Otro estudio brasileño también informó que las trabajadoras transexuales tenían una considerable satisfacción con sus relaciones sexuales con clientes (...) (Kulick, 1998)" (Weitzer, 2005a, p.222). Finalmente, en un estudio realizado en España, se encontraron diferencias significativas entre el nivel de satisfacción sexual de las mujeres biológicas y las transexuales respecto a sus relaciones con clientes, siendo éstas últimas las que mejor situación presentaban (Pinedo, 2008b).

Como hemos visto en la teoría de López sobre los riesgos asociados a la insatisfacción de las necesidades interpersonales básicas, encontramos que el sentir soledad puede influir negativamente en la adopción de conductas de sexo seguro con sus parejas. En su estudio realizado con mujeres pobres Sobo (1995) encontró que para ellas el sexo desprotegido indicaba cercanía emocional o una perfecta unión. Sobo sugiere que las mujeres con menos apoyo social dependen más de sus parejas para cubrir sus necesidades emocionales y sociales (Warr y Piett, 1999). Esta hipótesis apoyaría la teoría de López y las personas que ejercen prostitución podrían tener conductas sexuales de riesgo con sus 
parejas como una vía de acceso a una mayor intimidad y satisfacción de sus necesidades emocionales y sociales.

Esta hipótesis fue apoyada por el estudio realizado por Warr y Piett (1999) donde concluyen que "los riesgos fueron pasados por alto en las relaciones privadas donde no usar el condón es la base de una frágil intimidad. La mayoría de las mujeres que siente soledad en este estudio eran aquellas que también necesitaban un romance o una intimidad más intensa $(. .$.$) en el caso de las trabajadoras de calle, que enfrentan la mayoría de los$ problemas y los más serios de violencia en sus vidas, eran aquellas que se involucraban en mayores riesgos en sus vidas privadas" (p.305). 


\section{CAPITULO III: LA SALUD Y LA CALIDAD DE VIDA}

\subsection{La calidad de vida relacionada con la salud}

En 1946, la OMS define la salud como un estado completo de bienestar físico, mental y social. Esta definición concibe la salud de forma positiva, no sólo como la ausencia de enfermedad y se admite que puede no haber salud aún en ausencia de enfermedad. Aún siendo una definición mucho más amplia y aceptable que las anteriores, se vio la necesidad de valorar de nuevo este concepto debido a que se consideró demasiado idealista y estático, encontrándose discutible la equiparación que realiza entre bienestar y salud.

Por todo ello, en 1958 se añaden una serie de matices a la definición anterior y se considera que la salud es la capacidad de realizar el potencial individual y la respuesta que el individuo da al ambiente en el que se desarrolla. De esta manera la OMS intenta completar el concepto anterior concediendo un papel más activo al individuo, definiendo más claramente lo que es el bienestar, y aportando un concepto más dinámico y teleológico, ya que considera el ambiente cambiante y propone un fin, el desarrollo personal, es decir, conseguir el mayor bienestar posible (OMS, 1958).

Como vemos, la salud va más allá de la ausencia de enfermedad. Una persona puede sentirse enferma sin que la medicina detecte la existencia de enfermedad, y a la vez, una persona con una enfermedad crónica puede no sentirse enferma. Toda persona tiene una percepción propia de su estado de salud, pero ésta se ve influida por múltiples factores que no son sólo biológicos. Debido a esta multiplicidad de factores se ve la necesidad de partir de un modelo de salud amplio y positivo que les tenga en cuenta. Bowling (1997) enumera algunos de estos factores no biológicos que influyen en la percepción de salud de la persona, como el estado psicológico de la persona, la motivación y adherencia al tratamiento, las estrategias de afrontamiento, el estado socioeconómico, la disponibilidad de cuidados de salud, las redes de apoyo social, las creencias y conductas culturales e individuales, etc. 
Según Bowling (1997), cuando la OMS dio el nuevo concepto de salud positiva, no aportó ni una definición conceptual ni operacional, lo que supuso una gran controversia. A pesar de ello, actualmente hay un amplio acuerdo que defiende la salud positiva como la capacidad para afrontar situaciones estresantes y mantener un sistema de apoyo social fuerte, la integración en la comunidad, una alta satisfacción moral y vital, bienestar psicológico e incluso buenos niveles de forma y salud física (Lamb, 1988). En esta nueva concepción de salud se toman en cuenta no sólo aspectos individuales relacionados con el área física y psicológica, sino que también aparecen elementos nuevos relacionados con el área social (i.e. el apoyo social, la integración comunitaria, etc.).

La introducción del área social dentro del concepto de salud ha sido apoyada por diversos autores (Donald et al. 1978; Kaplan, 1975; Lerner, 1973). La salud social es una dimensión del bienestar individual distinta de la salud física y mental. El estado de salud puede verse influido por factores externos al individuo que no son de salud y que pueden tanto beneficiarla (e. g. red social amplia) como perjudicarla (e. g. el aislamiento social). Dentro del concepto de salud social, Kaplan (1975) subrayó como término clave de la salud social el apoyo social y distinguió algunas áreas, como los logros y la posición jerárquica en el trabajo; el apoyo familiar; la actividad social y las amistades; una economía adecuada; los logros personales y la satisfacción filosófica y sexual.

En resumen, la salud en general, y aspectos integrados en ella como la salud positiva y social derivados de la definición de salud de la OMS (1958), nos llevan a un concepto muy relacionado que, en los últimos años, ha pasado a ser un asunto prioritario en el discurso de muchos sectores de la sociedad, político, comercial, social, económico, sanitario, etc., se trata de la calidad de vida.

Han surgido así numerosos estudios e investigaciones sobre la calidad de vida, tanto referidos a la población general como a colectivos específicos como las personas mayores, las personas con discapacidad, etc. Según la OMS (1994), la calidad de vida es la percepción personal de un individuo de su situación en la vida, dentro del contexto cultural y de valores en que vive, y en relación con sus objetivos, expectativas, valores e intereses. 
Siguiendo esta definición, se establecen seis áreas que describen los aspectos fundamentales de la calidad de vida en todas las culturas, y son: área física, psicológica, nivel de independencia, relaciones sociales, entorno y creencias personales.

Durante los últimos treinta años no se encontró consenso sobre la definición de este concepto, es durante ésta última década cuando se comienzan a realizar múltiples esfuerzos por mejorar la base conceptual y empírica de este constructo de calidad de vida, los cuales se han visto reflejados en la publicación de una serie de principios básicos (ver Tabla 16) en relación a la conceptualización, la medida y la aplicación del concepto (Verdugo, 2006).

Tabla 16. Principios básicos en la conceptualización, medida y aplicación del concepto de calidad de vida (Verdugo, 2006, p.31)

\section{CONCEPTUALIZACIÓN:}

1. La calidad de vida es multidimensional y está influida por factores personales, ambientales y su interacción

2. La calidad de vida tiene los mismos componentes para todas las personas

3. La calidad de vida tiene componentes para todas las personas

4. La calidad de vida se mejora con la autodeterminación, los recursos, el propósito de vida y un sentido de pertenencia

\section{MEDIDA:}

1. La medida en calidad de vida implica el grado en el que las personas tienen experiencias de vida que valoran

2. La medida de calidad de vida refleja las dimensiones que contribuyen a una vida completa e interconectada

3. La medida en calidad de vida considera los contextos de los ambientes físico, social y cultural que son importantes para las personas

4. La medida de calidad de vida incluye medidas de experiencias tanto comunes a todos los seres humanos como aquellas únicas a las personas

\section{APLICACIÓN:}

1. La aplicación del concepto de calidad de vida mejora el bienestar dentro de cada contexto cultural

2. Los principios de calidad de vida deben ser la base de las intervenciones y los apoyos

3. Las aplicaciones de calidad de vida han de estar basadas en evidencias

4. Los principios de calidad de vida deben tener un sitio destacado en la educación u formación profesional 
Basándose en este trabajo se ha producido un consenso en relación a cuatro directrices que pueden servir como base a la hora de utilizar los resultados relativos a la calidad de vida, y son: (1) Reconocer la multidimensionalidad de la calidad de vida; (2) Desarrollar indicadores para las respectivas dimensiones/áreas de calidad de vida; (3) Evaluar los aspectos subjetivos y objetivos de la calidad de vida; y (4) Centrarse en los predictores de resultados de calidad.

Dado que nuestro objetivo aquí no es profundizar en todos los aspectos relacionados con la calidad de vida vamos a realizar una breve revisión de las dimensiones, los indicadores y los tipos de evaluación de este concepto.

Se ha definido como dimensiones de calidad de vida al "conjunto de factores que componen el bienestar personal. El conjunto representa el rango sobre el cual el concepto de calidad de vida se extiende y de este modo define la calidad de vida" (Verdugo, 2006, p.32). En cuanto a la definición de los indicadores de la calidad de vida, se entiende que son "percepciones, conductas y condiciones relativas a la calidad de vida que dan indicio del bienestar personal" (Verdugo, 2006, p.33). A continuación presentamos el resumen de las dimensiones y sus correspondientes indicadores que Schalock y Verdugo presentan en su libro (ver Tabla 17).

Tabla 17. Dimensiones de calidad de vida e indicadores de calidad (Verdugo, 2006, p.34)

\begin{tabular}{ll}
\hline DIMENSIONES & INDICADORES MÁS COMUNES \\
Bienestar emocional & Alegría, autoconcepto, ausencia de estrés \\
Relac. interpersonales & Interacciones, relaciones de amistad, apoyos \\
Desarrollo personal & Estado financiero, empleo, vivienda \\
Bienestar físico & Educación, competencia personal, realización \\
Autodeterminación & Atención sanitaria, estado de salud, actividades de la vida diaria \\
Derechos & Autonomía/control personal, metas y valores personales, elecciones \\
Inclusión social & Legales y humanos (dignidad y respeto) \\
& Integración y participación en la comunidad, roles comunitarios, apoyos \\
& sociales
\end{tabular}

Según los autores consultados es importante evaluar tanto los aspectos subjetivos como los objetivos de la calidad de vida (Verdugo, 2006). Parece ser que decantarse por un 
tipo de medida u otro está influenciado por los objetivos de la medición. Si el objetivo es determinar si una persona está tan satisfecha con su vida como otros subgrupos de población, deberíamos medir su nivel de satisfacción (medida subjetiva). Mientras que si el objetivo es evaluar el funcionamiento de un determinado programa o intervención es más acertado utilizar indicadores objetivos (medida objetiva).

En el polo más subjetivo, se encuentran aquellos autores que se basan en las líneas teóricas definidas por la Organización Mundial de la Salud, entre otras. En esta línea, el Grupo WHOQOL (1993), ha incluido en su definición la percepción del individuo sobre su situación en la vida, y lo define como un concepto abstracto y complejo que comprende diferentes áreas, que unidas contribuyen a un todo, a la satisfacción personal y a la autoestima (Bowling, 1997). Este grupo de investigación de la OMS creó un instrumento de medida de la calidad de vida compuesto por cuatro dimensiones que abarcan aspectos equivalentes a las comentadas en la Tabla 17, y son: salud física, salud psicológica, salud social y salud ambiental (WHOQOL group, 1994, 1995).

Mientras, en el polo más objetivo, suelen situarse posturas teóricas menos relacionadas con la psicología o las ciencias sociales (e. g. la ecología, la economía, etc.).

Otros, como Fernández-Ballesteros y Maciá (1993) defienden posturas intermedias donde ambos puntos deben tenerse en cuenta. Como bien reflejan en una de sus obras (1998) "nosotros mantenemos que la operacionalización reduccionista de la calidad de vida -si es exclusivamente subjetiva o exclusivamente objetiva- puede empobrecer e invalidar un concepto que, por su naturaleza, es extraordinariamente diverso" (p.79).

Aunque también hubo controversia, existe en la actualidad un consenso generalizado en definir la calidad de vida como un concepto general para todas las personas independientemente de su cultura (WHOQOL Group, 1995; Fernández-Ballesteros, 1998), dado que las necesidades humanas básicas son bastante generales, parece probable que los componentes de la calidad de vida también lo sean.

La confusión conceptual que ha existido desde el comienzo del estudio de la calidad de vida en los años 70 y 80 se refleja en la gran cantidad de instrumentos de medida 
construidos desde diferentes perspectivas, los cuales han proliferado en estos últimos años (WOQOL, MOS, IQOLA, NHP, SIP, FQLS, LSR, SWLS, CLS, etc.) (Véase una revisión mas exhaustiva en Bowling, 1997; Brown \& Laird, s. f.; Felce \& Perry, 1995; FernándezBallesteros, 1993; Sirgy, 2002).

En resumen, encontramos un amplio consenso en que la calidad de vida, es un concepto multidimensional, que incluye diferentes áreas vitales, y general, para todas las personas independientemente de su cultura. Además, hay un gran apoyo a las perspectivas subjetivas, que miden la calidad de vida desde la percepción o evaluación subjetiva que hace la persona. Desde este enfoque se relaciona este constructo con otros como la felicidad, la satisfacción vital y el bienestar subjetivo (Fernández-Ballesteros, 1998; Sirgy, 2002).

Es importante destacar la relación que algunos autores establecen entre la calidad de vida y la satisfacción de las necesidades humanas. Una mayor satisfacción de las necesidades humanas se corresponderá con una mayor calidad de vida percibida o bienestar subjetivo. El bienestar y la felicidad se encuentran relacionados con la salud, ya que la felicidad aumenta la salud y promueve la longevidad. La felicidad tiene un valor de supervivencia para la especie humana, ya que una vida feliz promueve el ser más activos, formar lazos sociales más fuertes y preservar la salud (Sirgy, 2002). 
3.2. La calidad de vida y la salud de las personas que ejercen prostitución

Como ya hemos visto el concepto de calidad de vida está basado, entre otras cosas, en la integración social y las relaciones interpersonales, lo cual nos hace pensar de un modo diferente sobre las personas que se encuentran al margen de la sociedad y de qué manera podríamos generar un cambio organizacional y de la comunidad para incrementar su bienestar personal y reducir la exclusión. Vemos la necesidad de evaluar el estado de la calidad de vida, en todas sus dimensiones, en el colectivo de personas que ejercen prostitución, porque es necesario conocer el nivel de bienestar que presenta este grupo de población. Y además es necesario ver las relaciones existentes entre la satisfacción de sus necesidades interpersonales y su calidad de vida.

Son inexistentes los estudios que han tomado en cuenta el marco conceptual de la calidad de vida para estudiar al colectivo de personas que ejercen prostitución. Ya hemos visto que se han centrado fundamentalmente en estudiar cómo es su salud física (VIH/SIDA, drogas, agresiones, etc.) y en ocasiones su salud psicológica (estrés, trastorno de estrés postraumático, etc.), pero en contadas ocasiones han hecho referencia al ámbito social en sus vidas, cuando hemos visto las graves carencias que presentan debido al estigma y la exclusión social que sufren.

\subsubsection{Salud física}

Son muchos los estudios realizados sobre el estado de salud física de las personas que ejercen prostitución y todos ellos concluyen que las personas que ejercen en la calle son las que presentan los problemas de salud más graves (VIH/SIDA, violencia, drogodependencias, etc.) (Brents y Hausbeck, 2005; Church, Henderson, Barnard y Hart, 2001; Farley y Barkan, 1998; Raphael y Shapiro, 2004; Surrat et al., 2004; Wiliamson y Folaron, 2001). De hecho en algunos estudios se ha comprobado que las personas que ejercen prostitutición en la calle y consumen drogas tienen tasas de mortalidad 
significativamente superiores a la población general, donde las principales causas de muerte son los homicidios, el consumo de drogas, accidentes, VIH/SIDA y cáncer (Potterat et al., 2004).

Pero en la actualidad se están encontrando también altas tasas de seropositividad al $\mathrm{VIH} / \mathrm{SIDA}$ y altos porcentajes de consumo de drogas en el colectivo de transexuales y travestis que ejercen esta actividad, constituyendo un nuevo grupo en el que debemos focalizar nuestros estudios e intervenciones (Anhel et al., 2006; Belza et al., 2000; Gómez et al., 2001; Jordan, 2005; Pelucio, 2006; Reback et al., 2005; Woods et al., 2001).

\subsubsection{Salud psicológica}

Algunos estudios también han tenido en cuenta la salud psicológica evaluando variables como el estrés laboral, la depresión, el trastorno de estrés postraumático, etc. y parece que la prostitución no tiene un efecto uniforme sobre la salud mental y la autoimagen de las personas que la ejercen prostitución, probablemente el tipo de prostitución influya en ello, siendo las de calle las que peores condiciones presentan.

En un estudio realizado en el Harlem por El-Bassel en 1997, se comparó 176 consumidoras de drogas que ejercían prostitución en la calle con 170 consumidoras de drogas no prostitutas, y se encontró que las prostitutas que ejercían en la calle y consumían drogas tenían peor salud mental (El-Bassel, Schilling, Irwin, Faruque, Gilbert, Von Bargen, Serrano, y Edwin, 1997).

En el estudio realizado por De Schampheleire (1990) se evaluó la personalidad de una muestra de 41 prostitutas que ejercían tanto en pisos como en la calle en Bruselas mediante el MMPI y se comparó con 96 mujeres que no ejercían prostitución. Se encontró que "las prostitutas de Bruselas mostraron patrones similares en el MMPI a las prostitutas callejeras de Nueva York en los niveles y tipos de problemas emocionales. Informaron de un número de miedos y ansiedad neuróticas, baja moral y sentimientos de resentimiento y 
depresión, pobres relaciones familiares y con las autoridades y también numerosas preocupaciones sobre su salud" (p.348).

Otro estudio realizado sobre la personalidad de las prostitutas por O'Sullivan, Zuckerman y Kraft (1996) se compararon las puntuaciones en 5 escalas del Cuestionario de Personalidad Zuckerman-Kulhman entre una muestra de prostitutas callejeras que consumían drogas y otra muestra control, y se encontró que únicamente había diferencias en la escala de Búsqueda impulsiva de sensaciones, donde puntuaban más alto las prostitutas.

En 1998 Ford realizó un estudio sobre estrés laboral en este colectivo, de manera que informa "sobre dos proyectos en los que comparó mujeres y hombres que ejercen prostitución en la calle con un grupo de auxiliares y celadores de un hospital. La evidencia indica que las/os trabajadores sexuales y el personal del hospital experimentan niveles similares de estrés laboral. Se encontró que la violencia fue un aspecto estresante en ambos tipos de trabajo, ya que el personal sanitario mostró mayor probabilidad de ser acosados por sus pacientes que las personas que ejercían trabajo sexual por sus clientes" (Shaver, 2005, p. 313)

El estudio comparativo realizado en Asturias sobre el nivel de estrés psicosocial entre una submuestra de 35 trabajadoras sexuales y otra muestra de 35 mujeres que trabajaban en hostelería, encontró que las trabajadoras sexuales y las hosteleras no presentaban diferencias significativas. Pero si que se obtuvieron en algunas subescalas, como la Musculoesquelético (quejas somáticas respecto a dolores de espalda, piernas) y la de Piel y Alergia (quejas respecto a alergias en la piel), donde las hosteleras puntúan más alto en esta subescala, mientras que en la escala Genitourinario puntúan más alto las trabajadoras sexuales (molestias relacionadas con dolores menstruales, molestias genitales, etc.). Como vemos, ambas muestras difieren en el tipo de quejas psicosomáticas, y parece haber relación entre el tipo de quejas y el tipo de actividad que desempeñan.

Mientras, en un estudio realizado en Nueva Zelanda por Romans (2001) donde se comparó la salud de un grupo de 29 personas que ejercía prostitución de interior (salones, 
chicas de compañía, etc.) con otra muestra igualada en edad pero sin ejercer prostitución, se encontró que no había diferencias significativas ni en salud física, ni en autoestima, ni en salud mental, ni en la calidad de sus relaciones sociales (Weitzer, 2005a).

En otro estudio se encontró que las chicas de contactos, las trabajadoras de burdeles y las de salones de masaje generalmente "se consideraban así mismas bien, manifestando un control emocional bueno (...) mientras que las chicas de la calle manifestaban problemas psicológicos significativos (Exner et al., 1977). El estrés y el peligro asociado con el trabajo de calle contribuye a una evaluación negativa del trabajo y también con problemas psicológicos" (Weitzer, 2005a, p.218).

Otro estudio que comparó prostitución de interior (chicas de contactos y chicas de burdeles) y de exterior (calle) en California y Nevada encontró "que el 97\% de las chicas de contactos informaron de un incremento en su autoestima tras comenzar a trabajar en prostitución, comparado con el $50 \%$ de las trabajadoras de burdeles y sólo un $8 \%$ de las de la calle (Prince, 1986: 454). Las chicas de contactos expresaron una visión más positiva de su trabajo; las trabajadoras de burdeles estaban en general satisfechas con su trabajo; pero las de la calle evaluaron su trabajo más negativamente" (Weitzer, 2005a, p.218). Resultados similares se encontraron en un estudio realizado con una muestra de personas que ejercían prostitución en bares en EEUU, donde "tres cuartas partes de ellas sentían que su vida había mejorado tras entrar en la prostitución" (Weitzer, 2005a, p.218). Otros estudios realizados en diferentes países (Países Bajos, Australia, etc.) también apoyan estos resultados (Weitzer, 2005a).

El bienestar psicológico de este colectivo está asociado con un conjunto de factores estructurales, incluyendo su educación, el control sobre sus condiciones de trabajo, los recursos de protección, etc., y parece ser que el hecho de ejercer prostitución de interior está asociado con un mejor estado de salud y calidad de vida. Como Lucas (1998) concluyó desde sus entrevistas con chicas de compañía y chicas de contactos, estas mujeres "tenían todos los medios económicos, sociales y emocionales para estructurar su trabajo de forma que las convenía y las proporcionaba (...) la habilidad para mantener una autoimagen 
saludable". En resumen, aunque ciertos aspectos del trabajo no son agradables, las prostitutas de locales tienen mayor probabilidad que las de la calle para informar de aspectos positivos de su trabajo" (Weitzer, 2005a, p.219)

\subsubsection{Salud social}

Como venimos viendo los aspectos relacionados con la salud social, muy relacionados con las necesidades sociales anteriormente comentadas, que pueden estar afectados en el grupo de personas que ejercen prostitución son la integración social, el establecimiento de redes sociales de apoyo, etc. Estudios como el de Solana (2003) nos muestran que para las mujeres inmigrantes que ejercen en clubes "sus principales problemas y temores tienen que ver con su condición de extranjeras en situación de irregularidad administrativa (...) con la falta de regulación de la actividad que ejercen y con la estigmatización que marca socialmente a las prostitutas, con todo lo que estos tres factores conllevan, los cuales, sumados a las condiciones espaciales y temporales de trabajo en los locales, coartan sus vínculos y relaciones sociales alimentando procesos de exclusión y segregación social” (p.163)

Otro aspecto muy relacionado con la salud social es el tener acceso a redes de apoyo sanitario y servicios de salud, las cuales suelen ser inaccesibles para aquellos estratos de la prostitución más aislados. El acceso a los servicios de salud también se ve influido por el poder adquisitivo de la persona, ya que aunque en España la red sanitaria es gratuita, muchas de las personas que ejercen prostitución prefieren ser atendidas en clínicas privadas donde no es necesario tener tarjeta sanitaria, ni estar empadronada, etc. Como afirman Harcourt y Donovan (2005) "De forma proporcional con lo económico de la prostitución, la salud es generalmente mejor donde las trabajadoras sexuales tienen un mayor estatus medido por su habilidad para ganar buenos ingresos, ser selectivas con sus clientes, y sus servicios, y son apoyadas por servicios de salud y organizaciones comunitarias" (p.205). 
3.3. Relaciones entre calidad de vida, salud y necesidades interpersonales

Como hemos dicho anteriormente son múltiples las referencias que relacionan la salud y la calidad de vida con la satisfacción adecuada de las necesidades interpersonales (Brehm, 1985; DiTomaso y Spinner, 1997; López, 1995; Maslow, 1954; Ochaíta y Espinosa, 2004; Peplau y Perlman, 1982; Steverink y Lindenberg, 2006), y como DiTomaso y Spinner (1997) afirman "Considerando las diferentes definiciones de soledad, que la describen como un estado aversivo y estresante, no sorprendería que estuviese unida a problemas de salud" (p.418).

Ya en 1973 Weiss postuló la existencia de diferentes patrones sintomatológicos que acompañan a cada tipo de soledad y que perjudican la salud, física y psicológica, de la persona. Por ejemplo, para la soledad emocional se esperaba que se viera acompañada de los siguientes síntomas: ansiedad, hipervigilancia, susceptibilidad, sentimientos de abandono, miedo, etc. La soledad social se asociaba con aburrimiento, depresión, falta de rumbo, marginación, problemas de conducta, adicciones como el alcoholismo, etc. $\mathrm{Y}$ finalmente, ambos tipos de soledad compartían los siguientes síntomas: falta de concentración, estrés, tensión, problemas de sueño, marginación, depresión, inquietud e insatisfacción generalizada.

Peplau y Perlman (1982) exponen una serie signos o síntomas asociados a la experiencia de la soledad, entre ellos destinan un apartado a los problemas sociales y médicos asociados. Según estos autores la soledad está asociada a varios problemas que afectan no sólo a la salud de las personas sino también a la salud de la sociedad donde estas personas viven y se desarrollan. Según Fischer y Phillips (1982, p.21) "Cuando hay personas aisladas, no se benefician de la vida social. Cuando una sociedad está compuesta por miembros aislados y solos es más propensa a desmoronarse". En cuanto a problemas de tipo social como son la delincuencia juvenil, los problemas de conducta, etc. se ha encontrado que correlacionan con la soledad (Peplau y Perlman, 1982). 
En cuanto a la salud de las personas, estos autores han encontrado relaciones entre la soledad y el suicidio, la depresión, la ansiedad, problemas de salud físicos, algunos derivados de los psicológicos, etc. Para estos autores está claro que la soledad hace más vulnerables a las personas a padecer enfermedades y problemas de salud, tanto físicos como psicológicos. Añaden además que esta relación entre variables puede darse en ambas direcciones, la soledad puede perjudicar la salud y a la vez la mala salud puede precipitar el sentimiento de soledad.

DiTomaso y Spinner (1997), en su revisión sobre el tema, informan de resultados similares a los anteriores. La soledad se asociaba con depresión y otros estados de humor disruptivos. También se la ha asociado con problemas de conducta y de salud mental como ansiedad, neuroticismo, baja autoestima y un alto potencial suicida. En su estudio con población universitaria, encontraron que la soledad social fue el mejor predictor de la depresión, tal como Weiss (1973) había teorizado, pero contrariamente a lo dicho por este mismo autor, la ansiedad no estuvo asociada con la soledad emocional sino también con la soledad social. Aunque hayan encontrado resultados parcialmente contrarios a los de Weiss (1973), hay que tener en cuenta, como los mismos autores afirman, que éstos se refieren únicamente a población universitaria, por lo que es más que seguro que en otras muestras de diferentes edades la soledad social no sea tan crítica en la experiencia de problemas de salud mental como lo es en esta muestra de jóvenes.

Otros autores como Booth (1995) alertan sobre las implicaciones clínicas que tienen las relaciones existentes entre salud mental y soledad. Concretamente llama la atención sobre la importancia del diagnóstico diferencial en el ámbito clínico entre soledad y depresión, debido a que son dos síndromes que comparten algunos síntomas y pueden ser confundidos, perjudicando así el tratamiento del paciente. Tras una revisión sobre el tema, establece tres factores para realizar el diagnóstico diferencial, los cuales son: 1) ¿Cuál es el foco de insatisfacción del cliente?, si la insatisfacción que tiene el cliente está principalmente dentro de la esfera interpersonal estaríamos hablando de soledad, si fuera sobre su vida más en general podría ser más probable la depresión, 2) ¿Qué duración tienen los síntomas 
o las quejas? si los síntomas son temporales, sin desechar la posibilidad de depresión se deberá inclinar por la soledad y 3) ¿Se encuentra la culpa dentro de los síntomas? Si hay sentimientos de culpa en el paciente será más probable que estemos hablando de depresión que de soledad.

Un estudio más relacionado con las consecuencias de la soledad sobre la salud física fue desarrollado por Cacioppo et al. (2002). Llevaron a cabo dos estudios con el fin de evaluar cuatro posibles mecanismos mediante los cuales la soledad podría ejercer efectos negativos sobre la salud, los mecanismos evaluados fueron: 1) las conductas de salud, 2) la activación cardiovascular, 3) los niveles de cortisol y 4) el sueño. En ambos estudios, dividieron a la muestra en dos grupos según su puntuación en la UCLA-R, un grupo con puntuaciones altas en soledad y un grupo con puntuaciones bajas. En el primer estudio se encontró que el grupo que sentían mayor soledad tenía un consumo mayor de drogas, tenían un sueño de peor calidad y mostraban un patrón cardiovascular diferente que les mostraba más ansiosos y temerosos que el grupo de participantes que no se sentían solos. En el segundo estudio, con el mismo diseño experimental, evaluaron las mismas variables pero en una muestra de adultos mayores y encontraron que el patrón de actividad cardiovascular en el grupo con puntuaciones altas en soledad era diferente y se parecía a un estilo de afrontamiento pasivo que refleja sentimientos generalizados de miedo. Estos datos son interesantes ya que el grupo que siente soledad parece que percibe su mundo social como menos reforzador y más amenazante, en general, que el grupo de personas con bajas puntuaciones en soledad. Finalmente, en cuanto a las medidas de calidad del sueño, el grupo de sujetos que sentían soledad mostró peor calidad del sueño, como se encontró en el estudio primero. Pero, como los autores afirman, hasta ahora no se sabe cuales son los mecanismos mediante los cuales la soledad puede, con el tiempo, disminuir la salud y bienestar de las personas. 


\section{DESARROLLO DEL ESTUDIO}

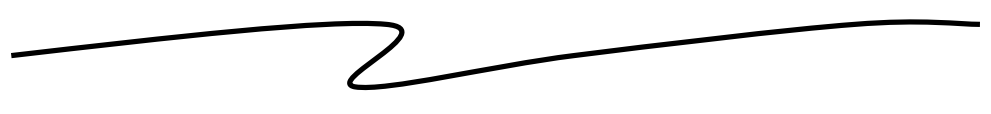

\section{CAPITULO IV: PLANTEAMIENTO DEL PROBLEMA}

Como hemos visto a lo largo de la exposición teórica hay numerosos motivos que hacen necesario el estudio científico del colectivo de personas que ejercen prostitución, en concreto las condiciones en las que ejercen esta actividad, su estado de salud biopsicosocial y su calidad de vida.

En primer lugar es necesario su estudio debido al importante número de personas que constituyen este colectivo. En España, como en el resto del mundo, las cifras son confusas, pero se sitúan entre 300.000 y 500.000 el número de personas que realizan esta actividad. Concretamente en Castilla y León las cifras se encuentran entre 3.000 y 3.500 personas. Como vemos se trata de un colectivo importante en el que es necesario estudiar su realidad para intervenir de forma eficaz (Alonso, 2001; Ase-Psiké, 1997; Gutiérrez, Pinedo y Martín, 2000; López y Pinedo, 2007; Solana, 2003).

En segundo lugar, hemos asistido en las últimas décadas a un cambio del perfil de las personas que se dedican a esta actividad de forma que nos encontramos ante un desconocimiento de la realidad actual. Hace más de tres décadas predominaba la denominada prostitución clásica, compuesta por mujeres españolas con bajo nivel académico y grandes dificultades económicas (Barahona, 2001). En la década de los 80 aparece un nuevo perfil, las mujeres drogodependientes que ejercen prostitución para costearse su adicción (ASE-Psiké, 1997; Baker y Case, 2003; CIMTM, 2003; Farley y Barkan, 1998; Meneses-Falcón, 2003; Potterat et al., 1998). Sin embargo en los últimos años ha surgido con fuerza un nuevo perfil, las personas inmigrantes, donde no sólo hay 
mujeres sino también transexuales, travestis y hombres, los cuales presentan características y problemática diferenciadas que han sido poco estudiadas (Agustín, 2001; Fernández, 2004; Juliano, 2004a; Meneses-Falcón, 2003; Pheterson, 2000).

También hemos encontrado cambios en los lugares donde se ejerce esta actividad, de manera que la prostitución de calle casi ha desaparecido, la prostitución de club se ha trasladado (de pequeños clubes de ciudad a macroclubes de carretera) y ha surgido la prostitución de pisos de relax (Fernández, 2004; Harcourt y Donovan, 2006; López y Pinedo; Salas, 2004; McKeganey, 2006; Medeiros, 2000; Perkins, 1991; Shaver, 2005; Weitzer, 2005a). Así, debido a la evolución del fenómeno, se pueden distinguir diferentes tipos de prostitución con características definitorias que no pueden ser tratados de forma homogénea. Por ello, se ve necesario realizar estudios con el fin de analizar las diferencias existentes entre cada uno de los perfiles. Muchos autores recomiendan hacer estudios comparativos a partir de esta variable en un intento de poner fin a la asunción de homogeneidad y rebatir los estereotipos que rodean a este colectivo (Shaver, 2005; Vandepitte, 2006; Vanwesenbeeck, 2001; Weitzer, 2005a).

En tercer lugar, es un colectivo discriminado y excluido de la sociedad debido a los estereotipos, el estigma y la discriminación que sufren, no sólo por la actividad que realizan sino también por el hecho de ser inmigrantes. Como hemos visto, este colectivo se ve rodeado de multitud de estereotipos que no sólo están originados y mantenidos por la población general, sino que también se han visto fomentados por estudios supuestamente científicos (Agustín, 2001; Elias, Bullough, Elias \& Brewer, 1998; Perkins, 1991; Vanwesenbeeck, 2001; Weitzer, 2005a). La consecuencia directa de los estereotipos es el estigma, y con ella la discriminación y la exclusión social que conllevan sentimientos de soledad, y ésta una serie de riesgos para la salud y una peor calidad de vida, aspecto que no ha sido evaluado en este colectivo en ningún estudio.

En resumen, encontramos que las personas que ejercen prostitución en la actualidad presentan peores condiciones de vida, por una parte por el hecho de ejercer prostitución (e.g. trabajan muchas horas, con gran movilidad, aislamiento, estigma, discriminación, etc.) 
y por otra, por el hecho de ser inmigrantes (ilegalidad, endeudamiento, desarraigo, soledad, etc.) que pueden influir negativamente en su salud física, psicológica y social, lo que derivaría en una peor calidad de vida.

Por ello, para el análisis de la situación de este colectivo utilizaremos un novedoso marco teórico basado en las relaciones entre las necesidades humanas y la calidad de vida. En concreto nos basaremos en la teoría de las necesidades interpersonales básicas de López $(1995,2008)$, según la cual todo ser humano tiene una serie de necesidades emocionales, sociales y sexuales que debe cubrir satisfactoriamente para un correcto desarrollo, estado de salud y calidad de vida.

Hemos incluido la calidad de vida en el marco teórico de nuestro estudio ya que existe gran apoyo empírico que avala que las necesidades interpersonales básicas influyen en el estado de salud y la calidad de vida de las personas (Booth, 1995; Brehm, 1985; Cacioppo et al., 2002; DiTomaso y Spinner, 1997; Fischer y Phillips, 1982; López, 1995; Maslow, 1954; Ochaíta y Espinosa, 2004; Peplau y Perlman, 1982). En nuestro estudio hemos analizado aquellos factores relacionados con el mundo de la prostitución y con las necesidades interpersonales que podrían influir en la calidad de vida de este colectivo, de manera que podamos especificar aquellos factores en los que podemos intervenir para mejorar la calidad de vida de este colectivo.

Nuestro estudio se dividirá en tres partes fundamentales, en primer lugar, haremos una descripción del perfil actual de las personas que ejercen prostitución; en segundo lugar, analizaremos el estado de sus necesidades interpersonales básicas, y, finalmente, analizaremos el estado de su calidad de vida y los factores explicativos de la misma (ver Figura 8). 


\section{TIPOS DE PROSTITUCIÓN}

Exterior (Calle)

Interior (Club y Piso)

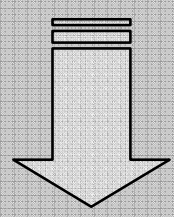

\section{DESCRIPCIÓN DEL PERFIL ACTUAL DE LAS PERSONAS QUE} EJERCEN PROSTITUCIÓN

Formación e historia laboral

Caracteristicas y condiciones del ejercicio de la prostitución

Historia familiar y social

ANÁLISIS COMPARATIVO DEL ESTADO DE LAS NECESIDADES INTERPERSONALES BÁSICAS

Soledad emocional familiar

Soledad emocional de pareja

Soledad social

\section{ANÁLISIS COMPARATIVO DE LA CALIDAD DE VIDA}

Salud física

Salud Psicológica

Salud Social

Salud ambiental

\section{FACTORES EXPLICATIVOS DE LA CALIDAD DE VIDA}

Factores de salud relacionados con el ejercicio de la prostitución Factores relacionados con las necesidades interpersonales básicas

Figura 8. Cuadro resumen de las tres partes principales del estudio 


\section{CAPITULO V: OBJETIVOS E HIPÓTESIS}

A continuación, presentamos los objetivos generales que guían la realización de esta Tesis Doctoral, junto con las hipótesis de trabajo derivadas de cada uno de ellos. En el establecimiento de los objetivos, tuvimos en cuenta las consideraciones previamente planteadas sobre las necesidades detectadas en el estudio del fenómeno de la prostitución. La finalidad del presente trabajo puede sintetizarse en cuatro objetivos principales:

OBJETIVO 1. Describir un perfil de la prostitución en Castilla y León planteando las características específicas para cada tipo de prostitución (exterior e interior).

Este perfil lo dibujaremos a partir de las siguientes áreas temáticas:

- Características de las personas que la ejercen

- Formación e historia laboral

- Características y condiciones del ejercicio de la prostitución

- Historia familiar y social

- Estado de salud física, psicológica y sexual

OBJETIVO 2. Analizar el grado en el que este colectivo satisface sus necesidades interpersonales básicas (necesidades emocionales, sociales y sexuales), en primer lugar para la muestra general y después para cada uno de los tipos de prostitución.

Hipótesis ${ }_{2.1}$. Las personas que ejercen prostitución mostrarán un peor estado de sus necesidades interpersonales básicas en comparación a la población general

Hipótesis 2.2. Esto es así tanto para las personas que ejercen prostitución de exterior como para las de interior. Ambos grupos tendrán serias dificultades para satisfacer adecuadamente sus necesidades interpersonales básicas. Es decir, tanto las personas que ejercen prostitución de exterior como las que ejercen prostitución de interior sentirán altos 
niveles de soledad emocional, social y sexual ((Agustín, 2001; Baker et al., 2004; Elias et al., 1989; Juliano, 2004a; López y Mestre, 2006; López y Pinedo, 2008; Medeiros, 2000; Pheterson, 1990, 2000; Perkins, 1991; Pinedo y Martín, 2007; Pons, 1992; Sanders, 2006; Shaver, 2005; Vandepitte, 2006; Weitzer, 2005a; Wolfers, 1999)

OBJETIVO 3. Analizar la calidad de vida de este colectivo en cada una de sus dimensiones (salud física, psicológica, social y ambiental), en primer lugar para la muestra general y después para cada uno de los tipos de prostitución.

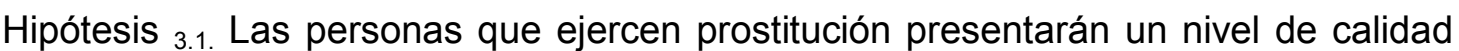
de vida más bajo que la población general, y esto será así en todas las dimensiones que componen la calidad de vida.

Hipótesis 3.2. El nivel de calidad de vida de las personas que ejercen prostitución de exterior será peor que el de las que ejercen en interior, debido a que en su mayoría presentan problemas de drogodependencias y a las malas condiciones en las que ejercen esta actividad.

OBJETIVO 4. Plantear una posible explicación a las diferencias en calidad de vida de las personas que ejercen prostitución a partir de variables de salud relacionadas con la prostitución y variables relacionadas con las necesidades interpersonales, para establecer pautas de intervención que mejoren la calidad de vida de este colectivo. En primer lugar para la muestra general y después para cada uno de los tipos de prostitución, teniendo en cuenta las diferentes dimensiones de la calidad de vida.

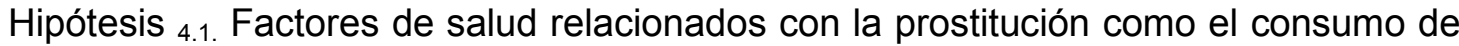
drogas, el VIH/SIDA y la violencia sufrida durante el ejercicio de la prostitución serán 
factores explicativos específicos de la calidad de vida para el grupo de prostitución de exterior, y en concreto la dimensión de salud física.

Hipótesis 4.2. Factores de salud como la depresión, la ansiedad y la autoestima serán factores explicativos de la calidad de vida tanto para las personas que ejercen prostitución de interior como de exterior, y en concreto para la dimensión de salud psicológica.

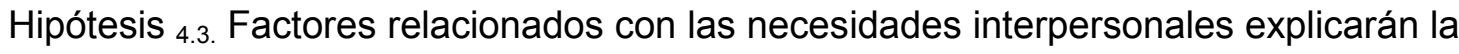
calidad de vida tanto para las personas que ejercen prostitución de interior como de exterior, y en concreto la dimensión de salud social.

Hipótesis 4.4. Factores relacionados con las necesidades interpersonales básicas como la soledad social y familiar serán factores explicativos específicos de la calidad de vida de las personas que ejercen prostitución de exterior ya que son las que presentan mayor discriminación social y peores relaciones familiares. $Y$ en concreto serán factores explicativos de las dimensiones de salud física y psicológica.

Hipótesis ${ }_{4.5}$. Los factores relacionados con las necesidades interpersonales básicas explicarán mejor la calidad de vida y sus dimensiones que los factores de salud relacionados con la prostitución del colectivo que ejerce esta actividad, tanto en el subgrupo de prostitución de exterior como de interior ya que consideramos las necesidades interpersonales básicas aspectos claves en la calidad de vida de las personas. 


\section{CAPÍTULO 6. MÉTODO}

\subsection{Diseño}

Basándonos en el sistema de clasificación de las metodologías de investigación en Psicología de Montero y León (2005), el plan de investigación que hemos seguido es de naturaleza cuantitativa. En concreto, teniendo en cuenta los objetivos y condiciones de la investigación, hemos utilizado una metodología selectiva, y siguiendo un diseño transversal, hemos recogido los datos en un único momento temporal mediante una entrevista semiestructurada y diferentes escalas.

\subsection{Participantes}

No se conoce con exactitud la población de personas que ejercen prostitución en Castilla y León, debido principalmente a que las personas implicadas niegan y ocultan la realización de esta actividad y la clandestinidad en la que la realizan. Pero a partir de algunos estudios realizados en esta comunidad podemos afirmar que el número se sitúa entre 3.000 y 3.500 personas (Alonso, 2001; Asé-Psiké, 1998; Gutiérrez, Pinedo y Martín, 2006; López y Pinedo, 2007; Solana, 2003).

La selección de la muestra se realizó mediante un muestreo incidental pero siguiendo unos determinados criterios. Entrevistamos a todas aquellas personas a las que accedimos y decidieron voluntariamente participar en el estudio tras la explicación de nuestros objetivos. Para ello, acudimos directamente a los lugares donde se ejerce prostitución para acceder a un mayor número de personas y evitar los sesgos de una muestra compuesta únicamente por personas contactadas a través de ONGs, servicios sociales, prisiones, etc.

No obstante, y con el fin de obtener una muestra lo más representativa posible, hemos tenido en cuenta los siguientes criterios: 
- $\quad$ Se recogieron datos de personas que ejercen prostitución tanto en capitales como en provincias, de la forma más equilibrada posible.

- $\quad$ Se recogieron datos de personas que ejercían prostitución tanto en clubes como en pisos, y en las ciudades donde existía prostitución de calle se intentó acceder a este subgrupo.

- Se realizaron entrevistas por cada uno de los siguientes grupos de nacionalidades: españolas y extranjeras; y dentro de este último grupo africanas, latinoamericanas, asiáticas y de Europa del este.

- No se realizaron más de 10 entrevistas por local (piso o club) para garantizar la representatividad de la muestra.

- $\quad$ Las personas entrevistadas debían hablar español sin gran dificultad.

Realizamos entrevistas en seis provincias de Castilla y León (León, Zamora, Salamanca, Valladolid, Palencia y Burgos). Planteamos la participación en la entrevista a un total de 238 personas, de las cuales 146 accedieron a responder, lo cual supone un 61.34\%. Los principales motivos por los que 92 personas no participaron fueron: falta de tiempo, falta de interés y movilidad a otro local de trabajo.

La edad media de nuestra muestra es de 30.88 años $($ d.t. $=7.63)$, con un mínimo de 19 años y un máximo de 53 años, siendo más jóvenes las mujeres extranjeras con una media de edad de 29.50 (d.t.=7.05) que las españolas con una media de 35.58 años (d.t.=7.77).

En relación a la composición de la muestra en cuanto a la variable sexo, (ver Figura 9), el porcentaje más importante es el de mujeres (81.5\%), seguido de mujeres transexuales $(15.1 \%)$ y varones $(3.4 \%)$ 


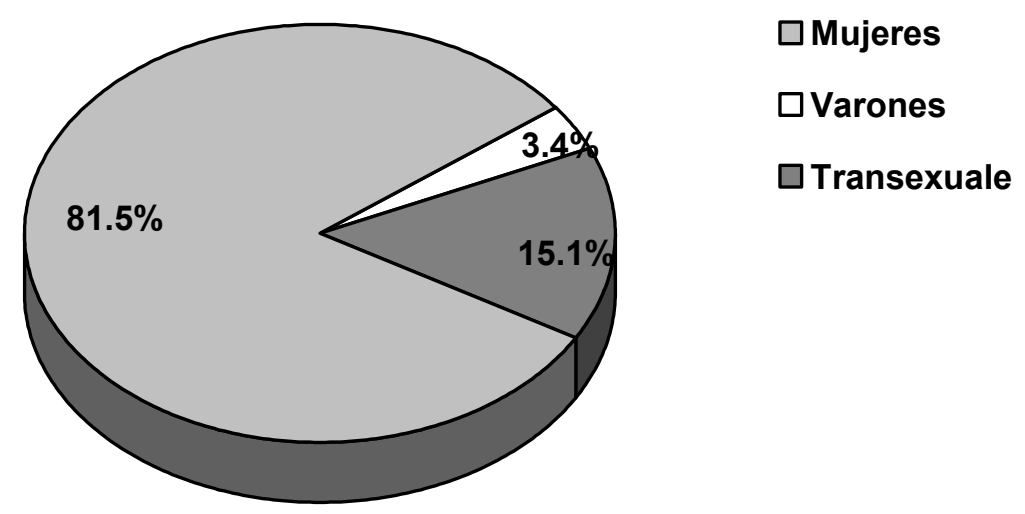

Figura 9. Distribución de la muestra en relación con la variable género

Por otra parte, y como se recoge en diferentes estudios, hay diferentes tipos de prostitución: prostitución de exterior (prostitución de calle) y prostitución de interior (prostitución de club o piso) (Agustín, 2001; Harcourt y Donovan, 2006; Medeiros, 2000; Ribeiro, Silva, Bessa y Sacramento, 2005; Shaver, 2005; Vandepitte, 2006; Vanwesenbeeck, 2001; Weitzer, 2005a). En nuestro estudio hemos tratado de reflejar con bastante rigurosidad la realidad teniendo en cuenta otros estudios realizados en Castilla y León, donde la prostitución de calle supone aproximadamente el 5\%, la prostitución de club un $35 \%$ (tanto en carreteras como en ciudades) y la de piso un 60\% (Alonso, 2001; Gutiérrez, Pinedo y Martín, 2006; Jiménez y Vallejo, 1999; López y Pinedo, 2007).

Muchos autores recomiendan hacer estudios comparativos a partir de esta variable en un intento de poner fin a la asunción de homogeneidad y falsear algunos de los estereotipos que rodean a este colectivo (Shaver, 2005; Vandepitte, 2006; Vanwesenbeeck, 2001; Weitzer, 2005a). Así, en la Figura 10, vemos que en nuestra muestra el grupo mayoritario es el de personas que ejercen en pisos de relax (63.01\%), una de las formas de prostitución emergente en los últimos años, mayoritaria dentro de las ciudades y menos conocida por su clandestinidad e invisibilidad. Mientras, la prostitución de calle $(14.38 \%)$ en nuestra comunidad autónoma, es cada día menos frecuente. Sólo hemos encontrado prostitución de calle en Valladolid, Salamanca y León, existiendo aproximadamente de 4 a 
15 mujeres en cada provincia. La prostitución en club es más numerosa (22.6\%) y evidente, sobretodo en los clubes de carretera que funcionan en régimen de hotel, donde puede haber de 20 a 100 personas trabajando por local, aunque nuestra muestra está compuesta fundamentalmente por personas que ejercen prostitución en club de ciudad ya que entrevistar a personas de club de carretera es mucho más complicado, debido a sus horarios de trabajo y descanso.

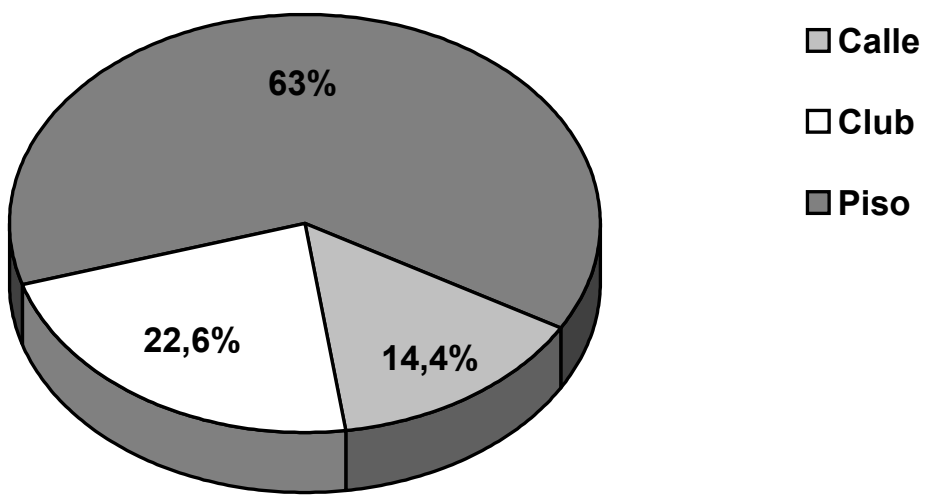

Figura 10. Distribución de la muestra en función del tipo de prostitución

Por tanto, a partir de nuestros datos y el conocimiento de la realidad en Castilla y León por los estudios consultados, podemos afirmar que nuestra muestra refleja de forma adecuada la realidad existente, aunque sería más apropiada si contásemos con algunas entrevistadas más en el grupo de club.

En cuanto a la nacionalidad, según los datos de diferentes estudios, entre un 80 y un 90\% de las personas que ejercen prostitución son inmigrantes (Agustín, 2001; Informe de la Guardia Civil, 2002; Juliano, 2004) por lo que hemos prestado especial atención al proceso migratorio y hemos tratado de que la muestra refleje las nacionalidades más habituales. En la Figura 11 mostramos la distribución de la muestra en función de la nacionalidad. Entre las personas extranjeras $(77 \%)$ la nacionalidad dominante es la latinoamericana (Brasil, Colombia, República Dominicana, Cuba, etc.) siendo el $88,5 \%$ de las entrevistadas 
extranjeras, seguidas por las personas provenientes de Europa del Este (6\%), de África (4.5\%) y Asiáticas (1\%).

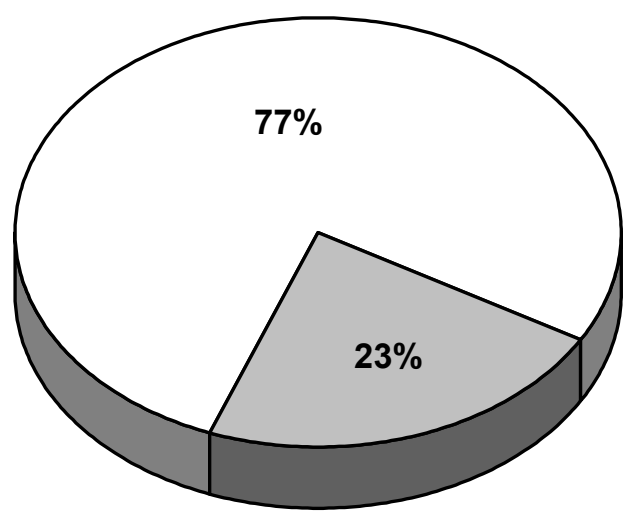

口Españolas

口Extranjeras

Figura 11. Distribución de la muestra en función de la nacionalidad

Dado que la mayoría de las personas entrevistadas son extranjeras, hemos analizado su situación legal actual. La mayoría de las personas que ejercen prostitución (48.7\%) están legalmente en nuestro país, un $13.3 \%$ se encuentran tramitando sus papeles para legalizar su situación y un $38 \%$ se encuentra ilegalmente.

Mostramos a continuación (ver Figura 12) la distribución de las personas entrevistadas en función de su nacionalidad y el tipo de prostitución. Como vemos en club y piso encontramos fundamentalmente personas extranjeras, siendo el $81.8 \%$ y el $83.7 \%$ respectivamente. Mientras, en la calle es el único tipo de prostitución donde las personas españolas superan ligeramente el número de extranjeras (57.1\%). 


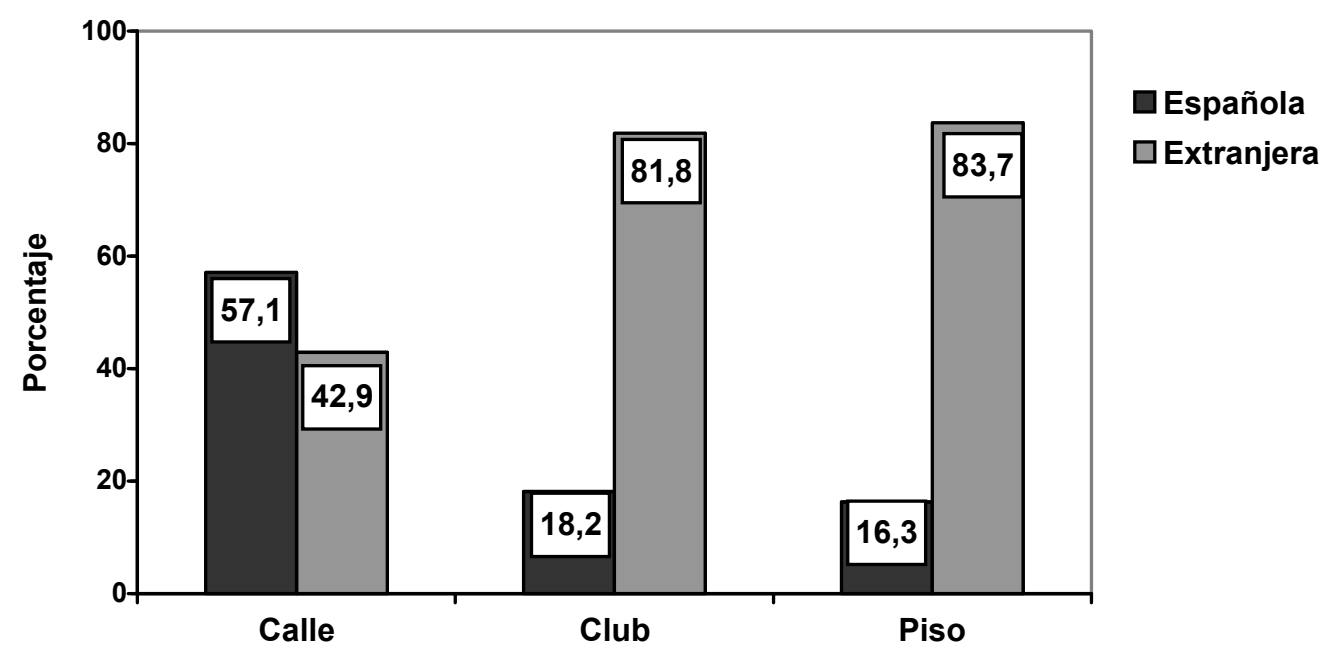

Figura 12. Distribución de la muestra en función de la nacionalidad y el tipo de prostitución

Finalmente mostramos la distribución de la muestra en función de su género y el tipo de prostitución (Figura 13). Podemos ver que en calle encontramos un importante porcentaje de personas transexuales ejerciendo prostitución, esto se debe en parte a que la calle ofrece mayor libertad, ya que muchos dueños/as de clubes no admiten transexuales en sus locales. Lo mismo ocurre con las mujeres toxicómanas, las cuales ejercen en la calle porque tampoco se las admite en otros locales, donde el consumo de drogas está prohibido. Si atendemos a la distribución en clubes, es la más homogénea, ya que está compuesta casi en exclusiva por mujeres, mientras que en los pisos encontramos mujeres, transexuales y los únicos hombres entrevistados. 


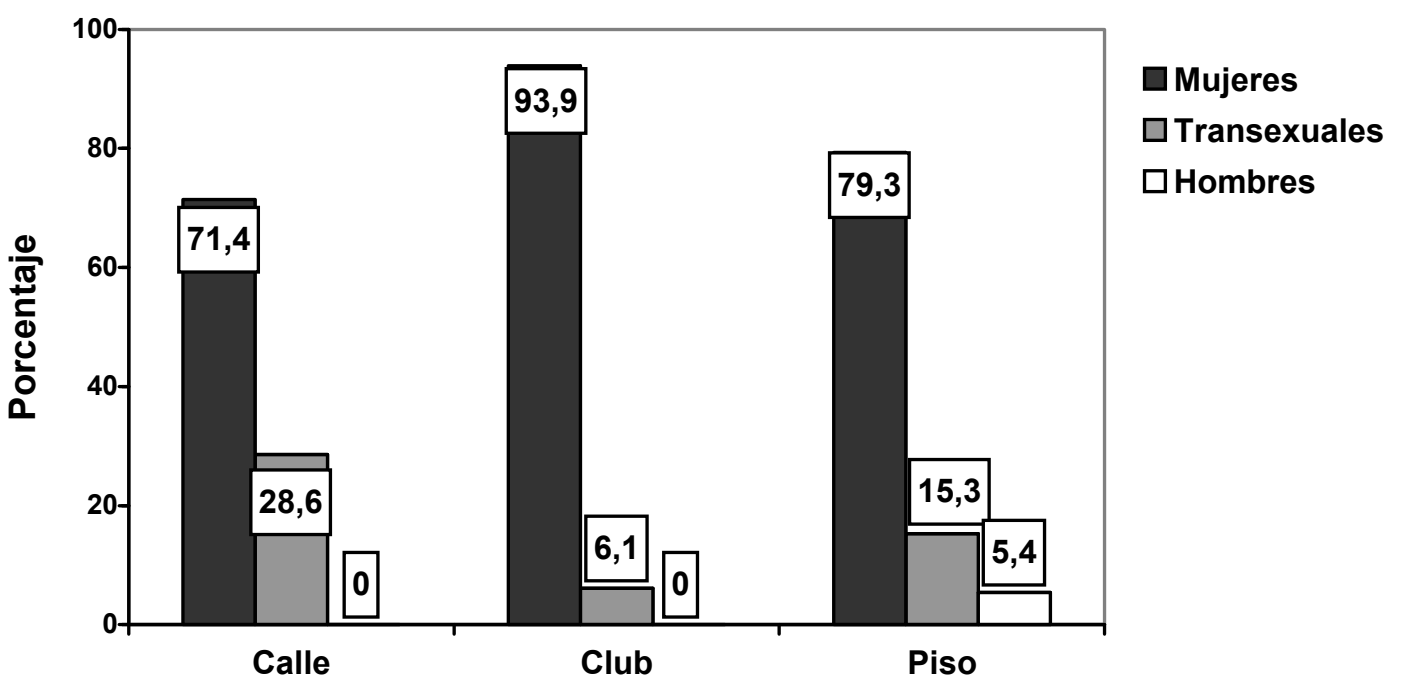

Figura 13. Distribución de la muestra en función del género y el tipo de prostitución 


\subsection{Variables e instrumentos}

A continuación pasamos a definir las variables y los instrumentos de medida utilizados para evaluarlas en este estudio, en ambos casos los hemos estructurado en diferentes bloques o grupos temáticos (Ver Tabla 18).

Tabla 18. Variables e instrumentos de medida utilizados en el estudio

\section{SOCIODEMOGRÁFICAS Y RELACIONADAS CON LA PROSTITUCIÓN:}

\section{Edad, género, nacionalidad y situación legal (extranjeras)}

\section{Formación e historia laboral anterior:}

- Nivel de formación y años de escolarización

- Historia laboral anterior a la prostitución

\section{Situación laboral actual:}

- Ingresos: Otros trabajos, ayudas y prostitución.

- Tipo de prostitución

- Edad de entrada en la prostitución

- Tiempo ejerciendo prostitución

- Causas de entrada en la prostitución

- Motivos por los que dejaría la prostitución

\section{Condiciones laborales en el ejercicio de la prostitución:}

- Modalidad de cobro y precios de los servicios

- Número de horas ejerciendo prostitución por día

Entrevista semiestructurada

- Número de clientes atendidos por día

- Movilidad para ejercer prostitución

- Satisfacción general con la prostitución

- Necesidades percibidas

- Aspectos positivos de la legalización de la prostitución

\section{Vida familiar y social:}

- Estado civil y unidad de convivencia

- $\quad$ Número de hijos/as

- Con quién viven los hijos/as

- Tener el apoyo del padre de los/as hijos/as

- Motivos de separación con el padre de sus hijos/as

- Lugar donde vive la familia de origen

- Lugar donde viven las amistades más íntimas

- Tienen amistades en el mundo de la prostitución

- Satisfacción con el contacto social y familiar 


\section{ESTADO DE SALUD:}

\section{Salud física:}

- Asistencia a los servicios sociosanitarios

- Razones por las que no acuden a los mismos

- Frecuencia de los reconocimientos médicos

Entrevista

- Consumo drogas: tiempo, tipo y frecuencia de consumo

semiestructurada

- $\quad$ Agresiones físicas durante el ejercicio de la prostitución: tipo de agresor $y$ frecuencia de las agresiones

\section{Salud Sexual}

- Edad primera relación sexual no coital y coital

- $\quad$ Número de parejas sexuales

- Uso de métodos anticonceptivos y de barrera

- Embarazos no deseados e interrupciones voluntarias del embarazo

- Infecciones de transmisión sexual y VIH/SIDA

- Agresiones sexuales durante el ejercicio de la prostitución: tipo de Entrevista
semiestructurada agresor y frecuencia de las agresiones

- Placer sexual con el cliente

\section{Salud psicológica:}

- Salud mental anterior (ansiedad o depresión)

- Salud mental actual:

- Ansiedad

- Depresión

- Autoestima

$S C L-90-R$

(Derogatis, 1994)

RSE(Rosenberg, 1965)

- Agresiones psicológicas durante el ejercicio de la prostitución: tipo de agresor y frecuencia de las agresiones

\section{NECESIDADES INTERPERSONALES BÁSICAS:}

Necesidades emocionales: Soledad emocional

- Necesidades emocionales familiares

SELSA-SHORT
DiTomaso, Brannen y

Best, 2004)

- Necesidades emocionales de pareja

Necesidades sociales: Soledad social

Necesidades sexuales: Soledad o frustración sexual

- Satisfacción sexual

- Depresión sexual

\section{CALIDAD DE VIDA:}

- Salud física

- Salud psicológica

- Salud social

WHOQOL BREF

(OMS, 1996)
MSSCQ

(Snell, 1995)

- Salud ambiental 
Además, a partir de la información que obtuvimos en un estudio previo de naturaleza cualitativa en el que tratamos de analizar la situación de la prostitución en Castilla y León, orientamos el diseño del presente trabajo. En este estudio piloto realizamos dos entrevistas grupales, una de ellas con un grupo de mujeres que ejercen prostitución en la calle y son toxicómanas, y la otra con un grupo de mujeres que ejercen en piso o club. Estas entrevistas fueron grabadas, transcritas y analizadas mediante un sistema de categorías (Pinedo y Martín, 2006) lo que nos permitió obtener un material de gran interés complementario al estudio actual de naturaleza cuantitativa. Hemos utilizado algunos comentarios que recogimos en este estudio previo para apoyar los resultados obtenidos en este estudio cuantitativo, por lo que a lo largo de la exposición de los resultados intercalaremos los comentarios que hicieron las mismas mujeres que ejercen prostitución.

6.3.1. Perfil sociodemográfico de las personas que ejercen prostitución

Con el fin de dibujar un perfil sociodemográfico de las personas que ejercen prostitución en Castilla y León, se incluyeron las siguientes variables en la entrevista semiestructurada:

(1) Variables sociodemográficas: Hemos incluido el estudio de las variables edad, género, nacionalidad y estado legal, en el caso de las extranjeras.

Para medir la variable género consideramos tres categorías: mujer, mujer transexual y varón; La nacionalidad la hemos considerado en dos categorías: españolas y extranjeras; y entre éstas últimas se consideró tanto su procedencia (latinoamericanas, africanas, europa del este, otras) como su situación administrativa en España (legal, ilegal y en trámites de legalización).

La variable nacionalidad ha sido utilizada como variable independiente para obtener los diferentes perfiles dentro del mundo de la prostitución en algunas partes del estudio. 
6.3.2. Formación e historia laboral: nivel académico, historia laboral anterior al ejercicio de la prostitución, tipo de prostitución que ejercen y condiciones laborales actuales.

Para medir su nivel académico, hemos evaluado su formación mediante las siguientes categorías: No sabe ni leer ni escribir, primaria, secundaria, FP/módulos y estudios universitarios; además de considerar el número de años que han estado escolarizadas.

Para evaluar su historia laboral pasada, hemos pedido que nos informen sobre qué trabajo desempeñaban antes de ejercer la prostitución para así conocer su nivel socioeconómico y su relación con el nivel académico.

Para evaluar su situación laboral actual, consideramos en primer lugar sus fuentes de ingresos (si únicamente ejercían prostitución, si la compaginaban con otros trabajos o si percibían algún tipo de ayuda social). A continuación les preguntamos el tipo de prostitución que ejercían mediante las siguientes categorías: calle, club y piso. Esta variable ha sido utilizada como variable independiente para obtener los diferentes perfiles dentro del mundo de la prostitución. También consideramos la edad a la que comenzaron a ejercer prostitución y el tiempo que llevaban ejerciéndola.

Hemos tenido en cuenta también las posibles causas de entrada y los motivos que les llevarían a salir de la prostitución. Para evaluar este aspecto hemos planteado cuatro posibles causas de entrada y cuatro posibles motivos de salida equivalentes, que son: (1) No encontrar otro trabajo / Cuando encuentre otro trabajo, (2) Ganar más dinero que en otros trabajos / Cuando encuentre un trabajo donde gane el mismo dinero, (3) Costearte el consumo de drogas / Cuando deje de consumir drogas y (4) Por obligación de una tercera persona / Cuando dejen de obligarme. De esta manera podemos examinar las razones más importantes para entrar y salir de la prostitución, y si hay relación entre lo que las han llevado a entrar y lo que las llevaría a salir. Cada una de estas causas y motivos las hemos evaluado en una escala de 5 puntos (1-Muy en desacuerdo a 5-Muy de acuerdo). 
En las condiciones laborales, hemos considerado por una parte los aspectos económicos (ingresos) y, por otra, los aspectos organizativos de la actividad (tipo de servicios sexuales que realizan, las diferentes formas de cobro, los precios, las horas de trabajo, el número de clientes, la movilidad que presentan y la frecuencia con la que cambian de local o ciudad).

Finalmente hemos evaluado la satisfacción que sienten con el ejercicio de la prostitución en general, teniendo en cuenta tres aspectos: los ingresos que obtienen, las condiciones en las que trabajan y el trabajo en sí mismo. Para ello hemos utilizado de nuevo una escala de 5 puntos (1-Muy insatisfecha a 5-Muy satisfecha). Además, hemos pedido que indicaran si consideraban importantes para su colectivo una serie de necesidades que planteamos a partir de la bibliografía consultada, y son las siguientes: mas información sobre ITS, más higiene y seguridad en el lugar de trabajo, más ayudas sanitarias para el colectivo, más oportunidades laborales alternativas y la legalización de la prostitución como actividad laboral, además realizamos una pregunta abierta sobre los posibles aspectos positivos asociados con la legalización.

6.3.3. Vida familiar y social: relaciones interpersonales a nivel de pareja, familia y amistades.

En primer lugar, con el fin de presentar su situación familiar, sus responsabilidades y cargas familiares hemos recogido información sobre su estado civil, si tienen hijos/as, la composición de su unidad familiar o de convivencia y el lugar de residencia de su familia de origen.

En segundo lugar, y con el fin de conocer su red social se preguntó si tienen amistades, tanto fuera del mundo de la prostitución (personas ajenas a esta actividad), como compañeras con las que ejercen prostitución; y se consideró dónde residen esas amistades para evaluar el grado de cercanía con las mismas. 
Finalmente, hemos evaluado el grado de satisfacción con sus relaciones familiares y sociales, considerando la frecuencia de contacto y el vínculo mantenido con la familia de origen, con sus hijos/as, con sus amistades más íntimas y sus compañeras dentro de la prostitución. Lo hemos evaluado mediante una escala de 5 puntos (1- Nada y 5- Mucho). Para nosotros es interesante conocer estas variables ya que consideramos que pueden influir en la adecuada o inadecuada satisfacción de sus necesidades interpersonales básicas.

\subsubsection{Estado de salud física, sexual y psicológica.}

Dentro del apartado de salud física nos hemos centrado en tres importantes apartados dentro del estudio de este colectivo, los reconocimientos médicos a que se someten, el consumo de drogas y las agresiones físicas que han sufrido durante el ejercicio de la prostitución.

En primer lugar registramos la frecuencia con la que realizan reconocimientos médicos generales mediante las categorías: cada 3 meses, cada 6 meses, una vez al año y menos de una vez al año.

Para evaluar su consumo de drogas preguntamos por el tiempo y la frecuencia de consumo de cinco sustancias diferentes (heroína, cocaína, hachís o marihuana, tabaco y alcohol) y la hemos medido en una escala de 5 puntos (0-Nunca a 4-Diariamente).

En el caso de las agresiones físicas, las entrevistadas debían responder si las habían sufrido, con qué frecuencia las habían sufrido mediante una escala de 5 puntos (0-Nunca a 4-Frecuentemente) y qué personas habían sido los agresores (cliente, pareja, compañeras/os y jefes/as).

El apartado de salud sexual adquiere especial relevancia debido a la actividad que realizan, ya que son muchos los estereotipos relacionados con la historia sexual de las personas que ejercen prostitución, por ello queremos analizar objetivamente la realidad de este colectivo. Hemos analizado su historia sexual evaluando la edad de sus primeros 
contactos sexuales no coitales y coitales, consideramos contacto sexual no coital aquel contacto sexual que no conlleva penetración vaginal o anal (caricias, besos, etc.); y contacto sexual coital aquel que conlleva penetración oral, vaginal o anal. Registramos también el número de parejas sexuales que habían tenido antes de entrar en la prostitución, es decir, parejas con las que habían mantenido alguna relación sexual coital. Para terminar preguntamos si habían tenido algún embarazo a término antes de ejercer prostitución, a qué edad fue el primer embarazo y si fue deseado o no.

Evaluamos algunas conductas sexuales de riesgo como por ejemplo si se habían practicado alguna interrupción voluntaria del embarazo, tanto antes de ejercer prostitución como durante el ejercicio de la prostitución. Si habían tenido alguna infección de transmisión sexual en alguna ocasión y si eran seropositivas al VIH. Analizamos también el uso de métodos anticonceptivos y de barrera, tanto con el cliente como con la pareja.

También analizamos en este apartado las agresiones sexuales sufridas durante el ejercicio de la prostitución. Las personas entrevistadas debían responder si habían sufrido agresiones sexuales, con qué frecuencia (0-Nunca a 4-Frecuentemente) y qué personas habían sido los agresores: el cliente, la pareja, compañeras/os y jefes/as. Por último, preguntamos si sienten placer sexual en sus relaciones sexuales con el cliente utilizando tres categorías de respuesta: ninguna vez, alguna vez y bastantes veces.

Finalmente, en el apartado de salud psicológica hemos evaluado su estado de salud mental anterior a la prostitución y su estado de salud mental actual (síntomas de depresión, ansiedad y autoestima).

Para medir la salud mental anterior hemos preguntado si habían sido diagnosticadas de depresión o ansiedad en alguna ocasión anterior al ejercicio de la prostitución. Para evaluar su estado de salud psicológica actual hemos utilizado tres escalas. En primer lugar hemos usado la versión española del "Sympton Checklist 90 Revised" "(SCL-90-R, 1994) para medir los síntomas de depresión y ansiedad en nuestra muestra. Es un cuestionario autoaplicado que mide el malestar subjetivo en 9 dimensiones sintomáticas (Somatización, Obsesión-compulsión, Sensibilidad interpersonal, Depresión, Ansiedad, Hostilidad, Ansiedad 
fóbica, Ideación paranoide y Psicoticismo), las cuales se pueden usar de forma independiente.

En concreto hemos usado la subescala de depresión y de ansiedad. El autor define la Depresión como una "dimensión (...) que incluye vivencias disfóricas, de desánimo, anhedonia, desesperanza, impotencia y falta de energía, así como ideas autodestructivas y otras manifestaciones cognitivas y somáticas características de los estado depresivos" y es medida a partir de 13 ítems. Por su parte, la Ansiedad es definida como una "dimensión (...) que incluye también signos generales de tensión emocional (nerviosismo, sentirse temeroso, etc.) y sus manifestaciones psicosomáticas (taquicardia, temblores, etc.)" y se mide mediante una escala de 10 ítems. Cada uno de los ítems corresponde a un síntoma o malestar específico frente al cual el sujeto debe indicar con qué frecuencia lo ha experimentado durante la última semana, empleando la escala de 0-Nada a 4Frecuentemente.

Estas dos escalas han mostrado constancia transcultural y buena consistencia interna medida a través del $\alpha$ de Cronbach tanto en la muestra original (Escala de depresión: .86 y Escala de ansiedad: .90) como en nuestra muestra de personas que ejercen prostitución (Escala de depresión: .89 y Escala de Ansiedad: .85). Se ha demostrado su validez discriminante entre grupos de pacientes psiquiátricos y normales, en diferentes estudios realizados en España (González de Rivera, 2002).

Por otra parte, hemos medido la autoestima mediante la escala Rosenberg SelfEsteem (RSE) (Rosenberg, 1965) que es una de las más utilizadas para la medición global de la autoestima. Rosenberg (1989) define la autoestima como una actitud positiva o negativa sobre un objeto particular: el sí mismo. Está compuesta por 10 ítems que se responden en una escala tipo Likert de 4 puntos, que va desde 1 Muy de acuerdo a 4 Totalmente en desacuerdo. La mitad de los ítems están enunciados positivamente y la otra mitad negativamente. La consistencia interna calculada mediante el coeficiente $\alpha$ de Cronbach fue de .87 para una muestra española (Vázquez, Jiménez y Vázquez, 2004) y de .75 para nuestra muestra. 
Para terminar con este punto, hemos analizado si han recibido malos tratos psicológicos durante el ejercicio de la prostitución. En este apartado debían responder si habían sufrido malos tratos psicológicos, con que frecuencia (0-Nunca a 4-Frecuentemente) y por parte de quien: el cliente, la pareja, compañeras/os y jefes/as.

\subsubsection{Necesidades interpersonales básicas: el sentimiento de soledad}

El ser humano es un ser social y como tal tiene unas necesidades interpersonales básicas (emocionales, sociales y sexuales) que debe cubrir satisfactoriamente para su correcto desarrollo y buen estado de salud. Cuando estas necesidades interpersonales no son satisfechas de forma adecuada aparece el sentimiento de soledad en sus diferentes dimensiones, por ello en adelante hablaremos de soledad emocional y social y frustración o soledad sexual.

En el estudio de la soledad, Weiss (1973) propuso dos dimensiones diferenciadas: soledad social y emocional. Esta diferenciación cuenta con gran apoyo empírico (De Jong y Van Tilburg, 1999; DiTomaso y Spinner, 1997; Peplau y Perlman, 1982; Rubenstein y Shaver, 1982) pero nosotros vamos a basarnos en el modelo interactivo de las necesidades interpersonales básicas de López $(1995,2008)$. Este modelo aglutina y da mayor sentido, dentro de una teoría general del desarrollo social, a diferentes teorías muy importantes comentadas anteriormente (Weiss, 1973, Bowlby, 1958; Steverink y Lindenberg, 2006), y añade a estos dos tipos de soledad un tercer tipo: la soledad o frustración sexual-amorosa.

Weiss (1973) define la soledad emocional como el resultado de la ausencia de una relación de apego muy cercana que produce sentimiento de soledad, ansiedad, estado de alerta, hipersensibilidad a pequeñas señales, constante atención a señales para resolver la soledad, abandono, focalización en las amenazas de abandono, miedo y constante evaluación. Cuando esta pérdida de la relación de apego ocurre dentro de la familia se denomina soledad emocional familiar, y cuando se produce en la relación de pareja, se conoce como soledad emocional romántica o de pareja (DiTomaso y Spinner, 1993). 
Mientras, la soledad social se define como el resultado de la ausencia de pertenencia a una red social satisfactoria que además conlleva sentimientos de aburrimiento, depresión, falta de metas, marginación, sentimiento de falta de sentido de la vida, deseo de búsqueda de compañía de personas, y que puede implicar, en algunos caso, comportamientos desviados.

Hemos medido los sentimientos de soledad Social y Emocional mediante la escala breve "Social and Emocional Loneliness Scale for Adults- Short" (SELSA-S) (DiTomaso, Brannen y Best, 2004). Esta escala de 15 ítems consta de 3 subescalas que evalúan soledad social, soledad emocional familiar y soledad emocional romántica o de pareja. Cada subescala consta de cinco ítems que se responden en una escala de siete puntos (1- Muy en desacuerdo a 7- Muy de acuerdo).

La consistencia interna de las 3 subescalas calculada mediante el coeficiente $\alpha$ de Cronbach fue alta, de .89 para la subescala de soledad emocional familiar, .87 para la subescala de soledad emocional de pareja y de .90 para la soledad social. La consistencia interna obtenida en nuestra muestra también fue buena .81 para la subescala de soledad familiar, .84 para la de soledad romántica y .84 para la de soledad social.

Por último, y en relación con la última dimensión denominada soledad o frustración sexual, hablaremos de satisfacción y depresión sexual. La satisfacción sexual se define como la tendencia a sentir respuestas afectivas positivas que surgen de la evaluación que uno mismo hace de los aspectos relacionados con su sexualidad, y la depresión sexual como la experiencia de sentimientos de tristeza, infelicidad, y depresión respecto a la vida sexual de uno mismo.

Para evaluar las necesidades sexuales-amorosas usamos dos subescalas, una de satisfacción y otra de depresión sexual, del cuestionario "The Multidimensional Sexual SelfConcept Questionaire" (MSSCQ) de Snell (1995). El cuestionario consta de 20 subescalas que pueden ser utilizadas independientemente, en este caso únicamente usamos dos de ellas, una evalúa satisfacción sexual, definida por el autor como la tendencia a estar altamente satisfecho/a con los aspectos de la propia vida sexual; y la otra depresión sexual, 
definida por el autor como la experiencia de sentimientos de tristeza, infelicidad, y depresión respecto a la propia vida sexual.

La subescala de satisfacción sexual está formada por 5 ítems que se responden en una escala tipo Likert de 5 puntos (1- Muy en desacuerdo a 5- Muy de acuerdo). La consistencia interna calculada mediante el coeficiente $\alpha$ de Cronbach fue alta, de .91 para esta subescala. La subescala de depresión sexual está formada también por 5 ítems que se responden en una escala de tipo Likert de 5 puntos igual que la escala anterior. La consistencia interna fue calculada mediante el coeficiente $\alpha$ de Cronbach y también fue alta de .86 .

\subsubsection{Calidad de vida}

Cuando la OMS define la calidad de vida asume tres hechos relacionados con este constructo: (1) el término se compone de una gama amplia de facetas, (2) se puede construir una medida cuantitativa, fiable y válida de calidad de vida para aplicarla a diferentes poblaciones, y (3) cualquier factor que afecte a la calidad de vida repercutirá en algunas de sus facetas. Basándose en estas premisas, la OMS define calidad de vida y diseña una medida para evaluarla. Entiende que la calidad de vida "es la percepción del individuo de su posición en la vida en el contexto de la cultura y sistema de valores en los que vive y en relación con sus objetivos, expectativas, estándares y preocupaciones. Es un concepto amplio que incorpora, de forma compleja, la salud física de la persona, el estado psicológico, el nivel de independencia, las relaciones sociales, el ambiente y las creencias personales" (Lucas, 1996, p.8)

La calidad de vida la evaluamos mediante el cuestionario WHOQOL-BREF, una versión resumida del WHOQOL-100, creado por la OMS en 1996 y adaptado por Lucas en su versión española (Lucas, 1996). Es una medida multidimensional y subjetiva de la calidad de vida basada en la definición de la OMS sobre este constructo (WHOQOL Group, 1994). Contiene 24 ítems y muestra altas correlaciones con la versión larga de 100 ítems, que van 
de .89 (área 3. relaciones sociales), a .95 (área 1. salud física). Es un instrumento construido a nivel internacional de manera que puede ser usado transculturalmente. Consta de 4 áreas: 1. Salud física (7 ítems), 2. Salud psicológica (6 ítems), 3. Salud Social (3 ítems) y 4. Salud Ambiental (8 ítems), y las respuestas se dan en una escala tipo Likert de 5 puntos (1Nada/Muy mal a 5- Extremadamente/Muy bien).

La OMS no define explícitamente cada una de las áreas que componen la calidad de vida pero si que enumera cada una de las facetas que las componen. Así, la salud física consta de las facetas dolor, energía, sueño, movilidad, actividad, medicación y trabajo. La salud psicológica consta de sentimientos positivos y negativos, pensamiento, autoestima, imagen corporal y espiritualidad. La salud social se compone de relaciones, apoyo y actividad sexual. Finalmente la salud ambiental incluye seguridad, hogar, economía, servicios, información, ocio, ambiente y transporte (Lucas, 1996).

En España fue validado en una muestra de Barcelona, y su consistencia interna, medida con $\alpha$ de Cronbach, varía entre .74 (área 2. psicológica) y .80 (área 1. salud física). En nuestra muestra la consistencia interna fue también buena oscilando de .75 (área 3 . social) a .84 (área 2. psicológica).

\subsection{Procedimiento}

Expondremos primero el procedimiento seguido en la recogida de la información para contactar con las personas que han compuesto la muestra. En primer lugar contactamos con ONGs y Asociaciones de cada provincia que trabajan con este colectivo para documentarnos, desde su experiencia, sobre las características de la prostitución en las ciudades de nuestra comunidad, y qué estrategias consideraban más adecuadas para acceder a este grupo de población.

En Zamora contactamos con el Comité Ciudadano Antisida de Zamora, el cual cuenta también con un programa específico dirigido a este colectivo. Les imparten cursos de 
diferentes temáticas (sexo seguro, prevención de violencia, etc.), las atienden a nivel sociosanitario y las entregan material preventivo a muy bajo coste.

En Salamanca contactamos con la Asociación para la Reinserción de Mujeres Prostitutas (APRAMP), la cual también dirige sus esfuerzos a la atención y ayuda de mujeres que ejercen prostitución ofreciendo trabajos alternativos, cursos formativos y alimentos gratuitos.

En Burgos contactamos con el Servicio de Apoyo a la Mujer "Betania", con sede en Burgos y en Miranda de Ebro. La intervención social, formativa y laboral de este servicio parte del acercamiento y conocimiento directo de la realidad y necesidades de las mujeres que ejercen prostitución.

En Valladolid, Palencia, Salamanca y León contamos con la ayuda del Proyecto LUA que trabaja desde el año 2005 específicamente con personas que ejercen prostitución dentro de la Asociación de Ayuda ACLAD. LUA ofrece a toda persona que ejerce trabajos sexuales atención médica, social, psicológica y jurídica, además de entregarles material preventivo. Todos los servicios son gratuitos, confidenciales y no necesitan documentación en regla. También cuentan en el proyecto con la realización de Talleres de sexo más seguro impartidos en la calle, clubs y pisos donde hay personas ejerciendo prostitución.

En un primer momento, comenzamos a realizar las entrevistas a través de las asociaciones con las que habíamos contactado y se llevaban a cabo en las mismas sedes de estas asociaciones. Pero el número de participantes fue ínfimo por lo que cambiamos de estrategia para captar participantes para el estudio. Es en este momento, cuando tomamos contacto con una nueva asociación, ACLAD, con sede en Valladolid, León, Salamanca y Palencia. Mediante esta asociación tuvimos acceso a todas las personas que ejercen prostitución en la calle de Palencia, León y Valladolid.

Tras la buena acogida de las personas de la calle, comenzamos a colaborar directamente con esta asociación y a contactar con mujeres que ejercían prostitución en clubes y pisos. De esta forma teníamos contacto directo con las personas que ejercen prostitución sin mediación de ninguna persona. El 90\% de las entrevistas las realizamos 
mediante esta vía, acudiendo directamente a los lugares donde se ejerce prostitución en Valladolid, Salamanca, León y Palencia y contactando directamente con las personas que allí trabajan. La mayoría de las entrevistas se han realizado en los mismos pisos y clubes donde ejercen la prostitución, aunque alguna también la realizamos en la sede de ACLAD, cuando las entrevistadas acudían a recoger material preventivo o a la consulta del medido.

Para acudir a los pisos de relax donde se ejerce prostitución establecíamos un primer contacto telefónico accediendo a sus números a través de la sección de contactos del periódico. Llamábamos telefónicamente, preguntábamos por la persona encargada del local y explicábamos en que consistía nuestro estudio informando a su vez de los servicios de la Asociación, para así ofrecer más fiabilidad y que ellas obtuvieran información útil a cambio.

Para contactar con las mujeres que trabajaban en clubes acudíamos directamente a los mismos. Sobre las $15 \mathrm{~h}$ a los clubes de carretera, que están aún cerrados, las chicas están comiendo y no hay clientes, por lo que podemos hablar con ellas tranquilamente y explicar nuestros objetivos. Y sobre las $21 \mathrm{~h}$ o $22 \mathrm{~h}$ a los clubes de ciudad, que es la hora a la que abren, y podemos encontrar a las mujeres que trabajan allí, ya que en ellos no viven a diferencia de los clubes de carretera donde están en régimen de hotel.

En cuanto a la aplicación de los instrumentos de recogida de datos, las entrevistas fueron individuales y heteroadministradas, su duración osciló de 40 minutos a 1 hora y media, dependiendo de la forma de respuesta, más extensa o más escueta, de la persona. Primero informábamos a la persona de los objetivos del estudio, de la confidencialidad y anonimato de los datos ofrecidos y de la posibilidad de no contestar aquellas preguntas que le pareciesen difíciles o personales. Se obtuvo un consentimiento verbal de la voluntariedad de su participación, ya que no consideramos conveniente establecer un consentimiento escrito donde apareciesen sus datos personales.

Posteriormente se aplicó la entrevista semiestructurada que constaba de diferentes partes o bloques temáticos que fueron administrados en el siguiente orden: (1) Datos sociodemográficos, (2) El proceso migratorio, (3) Condiciones sociales y laborales y (4) Salud física, sexual y mental. En este último apartado iban incluidas las escalas utilizadas en 
el siguiente orden: Subescala de depresión y ansiedad: SCL-90-R; Escala de soledad social y emocional (SELSA-S); Subescala de satisfacción y depresión sexual (MSSCQ); Escala de calidad de vida (WHOQOL BREF) y Escala de autoestima (RSE) (ANEXO).

Tras la realización de la entrevista se agradeció a la persona su participación en el estudio, se les entregó material preventivo (60 preservativos masculinos, 12 preservativos femeninos y 10 sobres monodosis de lubricante) gratuito y se les recordó la posibilidad se seguir asistiendo a los servicios de las diferentes ONGs o Asociaciones existentes.

\subsection{Análisis estadísticos}

El análisis de los datos recogidos se llevó a cabo a través del paquete estadístico SPSS 15.0. Con el fin de alcanzar los objetivos propuestos, hemos realizado una serie de análisis descriptivos e inferenciales con el propósito de estudiar la relación entre variables y las diferencias significativas entre los grupos (grupo de calle, de club y de piso). Para la comparación de grupos en las diferentes variables hemos utilizado técnicas como el contraste t y el ANOVA, en este último caso con las pruebas a posteriori correspondientes. Para analizar la relación entre las variables hemos utilizado la correlación de Pearson y la Regresión Múltiple paso a paso para conocer la influencia de un grupo de variables sobre la explicación de las diferencias en la variable dependiente dada. Para todos los análisis estadísticos hemos utilizado un $\alpha=.01$ y en todos los casos indicamos el tamaño del efecto obtenido. 


\section{CAPITULO 7. RESULTADOS}

Este capítulo está organizado en cuatro apartados correspondientes con los objetivos de la Tesis Doctoral.

En el primero de ellos, se exponen los resultados relativos al perfil de las personas que ejercen prostitución en Castilla y León. En el segundo los datos relacionados con las necesidades interpersonales básicas (emocionales, sociales y sexuales) de la muestra. En el tercer apartado analizaremos la calidad de vida y las subescalas que la componen en el colectivo estudiado. Para finalmente terminar con el cuarto apartado en el que analizaremos los predictores de la calidad de vida de las personas que ejercen prostitución.

\subsection{Perfil de las personas que ejercen prostitución en Castilla y León}

A lo largo de este punto vamos a completar un perfil de las características sociodemográficas y las condiciones en las que vive y trabaja este colectivo, describiendo su formación, su vida laboral, su vida familiar y social y su estado de salud física, sexual y psicológica.

\subsubsection{Formación e historia laboral}

En este apartado vamos a describir en primer lugar como es su nivel de formación, y en segundo lugar su historia laboral, tanto antes de ejercer prostitución, como en la actualidad, en el ejercicio de la prostitución y/u otros trabajos. También analizaremos las causas de entrada y los motivos por los que saldrían de la prostitución, las condiciones en las que ejercen esta actividad, su satisfacción en ella y las necesidades que perciben.

7.1.1.1. Nivel de estudios

En cuanto al nivel de estudios alcanzado, la mayoría de las entrevistadas han terminado secundaria o FP/ módulos (60\%), un $28 \%$ ha terminado los estudios primarios, 
un $11 \%$ posee educación universitaria, mientras que un $1 \%$ de la muestra no sabe ni leer ni escribir.

Hemos analizado el nivel académico y hemos encontrado relación con la variable tipo de prostitución $\left(\chi_{(8)}^{2}=25.43, p=.001, C=.39\right)$, de manera que el grupo de la calle tiene en mayor medida un nivel académico de primaria (residuos tipificados corregidos=2.2); en el grupo de club aunque también el porcentaje más importante es el de estudios de primaria, presenta un porcentaje significativamente más alto con un nivel académico universitario que los otros grupos (residuos tipificados corregidos=2.1); y finalmente, el grupo de piso presenta un nivel académico de secundaria (residuos tipificados corregidos=2) y de FP/Módulos (residuos tipificados corregidos=2.3) (ver Figura 14).

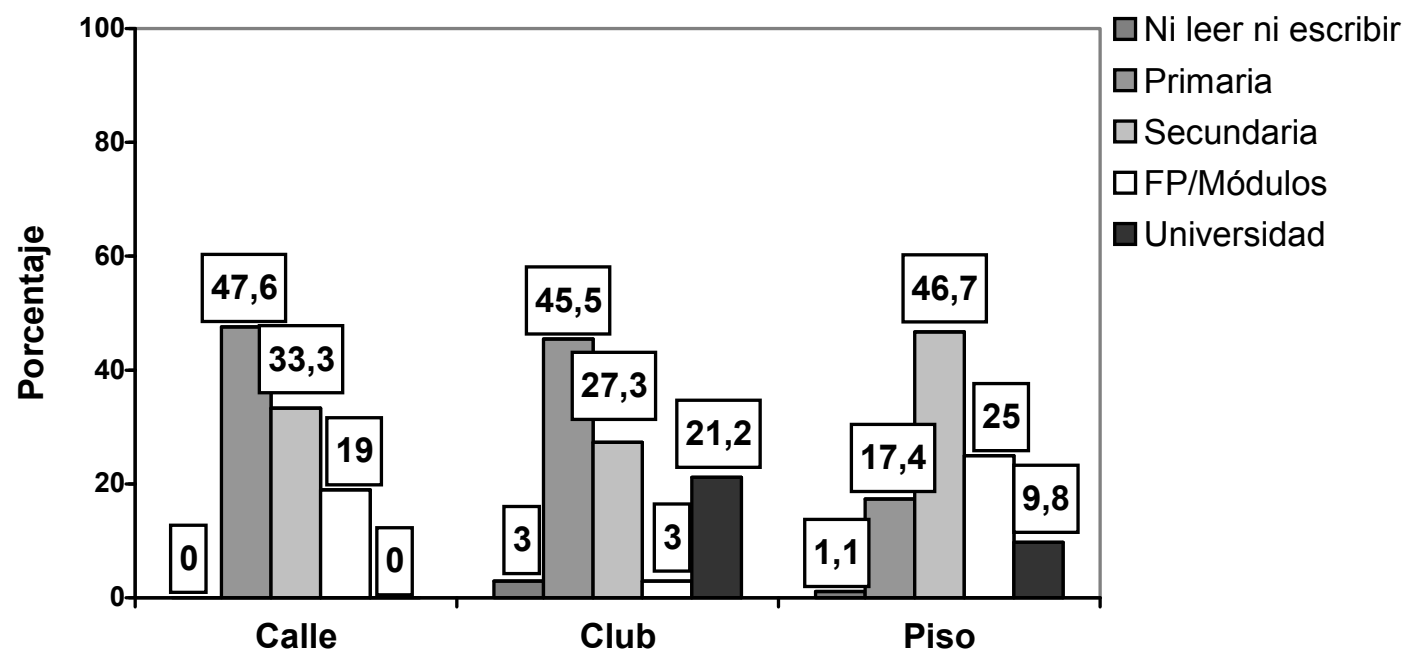

Figura 14. Nivel de estudios de las personas entrevistadas en función del tipo de prostitución

También hemos analizado los años que han estado escolarizadas las personas entrevistadas y hemos obtenido una media de 18.14 años $($ d.t.= 4.70) siendo el valor mínimo de 0 años, es decir, que nunca han asistido al colegio, y el máximo de 36 años, que continúan estudiando.

Vemos que, exceptuando el grupo de calle, no es un colectivo sin formación, el $88 \%$ tiene como mínimo educación secundaria o FP/módulos, algunas personas continúan estudiando en la actualidad y un $11 \%$ tiene estudios universitarios. Por tanto, nuestros datos no apoyan el estereotipo de colectivo que ejerce la prostitución sin ningún tipo de formación 
académica. En este punto, podemos destacar el caso de una de las entrevistadas de origen boliviano que se encontraba ejerciendo prostitución para poder pagarse los estudios de doctorado en su país.

\subsubsection{Historia laboral}

Su historia laboral anterior a la prostitución la hemos evaluado a partir de una pregunta abierta que posteriormente hemos categorizado en cuatro categorías según el nivel de cualificación requerido para desempeñar el trabajo. Un $54.8 \%$ de las personas entrevistadas han realizado trabajos sin cualificación (e.g. camarera, limpieza, cuidadora, etc.), seguido por un $21.9 \%$ que no tenían ningún tipo de trabajo asalariado antes de ejercer prostitución (e.g. amas de casa, estudiantes, paro, etc.), un $19.2 \%$ ha realizado trabajos que requieren una cualificación media (e.g. corte y confección, peluquería, administración, etc.) y finalmente un $4.1 \%$ ha desempeñado trabajos con cualificación superior (e.g. ingeniería, pedagogía, enfermería, etc.). Es interesante comprobar que, aunque son personas con formación media, el $76.7 \%$ no desempeña trabajos cualificados o incluso no trabaja, lo que nos orienta hacia una de las causas fundamentales de la prostitución: la disposición de bajos recursos económicos, debido a una falta de integración en el mercado de trabajo, la precariedad o la discriminación laboral. Probablemente estamos ante uno de los cambios fundamentales que se han dado en el perfil de las personas que ejercen prostitución, ya que hace dos décadas encontrábamos realizando esta actividad a personas con poca o escasa cultura.

Hemos encontrado relación entre su historia laboral anterior al ejercicio de la prostitución y la variable tipo de prostitución $\left(\chi_{(6)}^{2}=25.89, p=.000, C=.39\right)$, de manera que el grupo de la calle ha realizado en mayor medida trabajos no asalariados (residuos tipificados corregidos=23.6); el grupo de club había realizado en mayor proporción trabajos no cualificados, pero se obtiene que un porcentaje significativamente superior a los otros grupos había realizado trabajos con cualificación superior (residuos tipificados 
corregidos=2.6); del mismo modo, en el grupo de piso el mayor porcentaje había ejercido trabajos no cualificados, pero un porcentaje significativamente superior a los otros grupos había desempeñado trabajos con cualificación media (residuos tipificados corregidos=2.8) (Ver Figura 15).

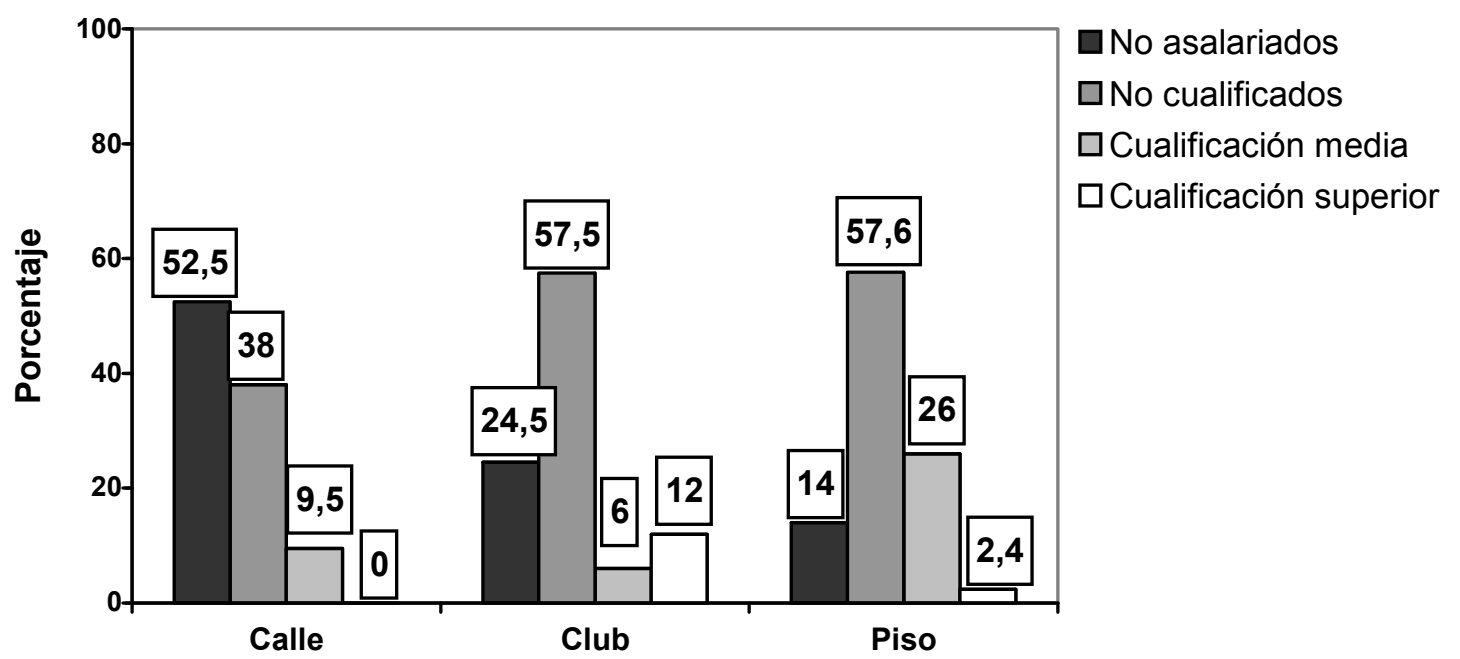

Figura 15. Historia laboral anterior a la prostitución en función de la prostitución

A continuación vamos a describir como es la situación laboral actual de las personas entrevistadas y sus ingresos económicos, tanto dentro como fuera de la prostitución. Con relación a este aspecto hemos encontrado diferentes situaciones: algunas personas ejercen prostitución a tiempo completo por lo que es su única fuente de ingresos; mientras que otras compaginan la prostitución con otros trabajos o reciben ayudas sociales que complementan sus ingresos.

En la Tabla 19, hemos resumido las diferentes situaciones laborales que presentan las personas entrevistadas junto con los ingresos que obtienen y no hemos encontrado diferencias significativas entre el tipo de prostitución (calle, club o piso) y los ingresos obtenidos en prostitución $\left(\mathrm{F}_{(2,143)}=1.34, \mathrm{p}=.27\right)$, los ingresos obtenidos en prostitución $y$ otros trabajos $\left(\mathrm{F}_{(2,143)}=1.33, \mathrm{p}=.27\right)$, los ingresos obtenidos en prostitución y las ayudas sociales $\left(F_{(2,143)}=.05, p=.95\right)$ y los ingresos totales $\left(F_{(2,143)}=.62, p=.54\right)$. Como vemos, la mayoría (87\%) ejercen prostitución como única fuente de ingresos, siendo las que mayores ganancias mensuales obtienen $(2408 €)$. Mientras, la media de ingresos por otros trabajos 
diferentes a la prostitución es de $417.50 €$ mensuales y la de las ayudas económicas que reciben de $293.40 €$ mensuales.

Tabla 19. Situación laboral actual e ingresos económicos mensuales en euros de las personas entrevistadas

\begin{tabular}{|c|c|c|c|c|c|c|c|c|c|c|c|}
\hline \multirow{2}{*}{$\begin{array}{l}\text { Situación } \\
\text { laboral }\end{array}$} & \multirow{2}{*}{$\begin{array}{c}N \\
(\%)\end{array}$} & \multicolumn{3}{|c|}{$\begin{array}{c}\text { Ingresos por } \\
\text { prostitución }(€)\end{array}$} & \multicolumn{3}{|c|}{$\begin{array}{c}\text { Ingresos por } \\
\text { Otros trabajos }(€)\end{array}$} & \multicolumn{3}{|c|}{$\begin{array}{c}\text { Ingresos por } \\
\text { Ayudas (€) }\end{array}$} & \multirow{2}{*}{$\begin{array}{c}\text { Ingresos } \\
\text { Totales }(€) \text { ) } \\
\text { Media } \\
\text { (d.t.) }\end{array}$} \\
\hline & & $\begin{array}{l}\text { Media } \\
\text { (d.t.) }\end{array}$ & Mín. & Máx. & $\begin{array}{c}\text { Media } \\
\text { (d.t.) }\end{array}$ & Mín. & Máx. & $\begin{array}{l}\text { Media } \\
\text { (d.t.) }\end{array}$ & Mín. & Máx. & \\
\hline Prostitución & $\begin{array}{l}127 \\
(87)\end{array}$ & $\begin{array}{c}2408.6 \\
(1365.10)\end{array}$ & 300 & 8000 & & & & & & & $\begin{array}{c}2408,66 \\
(1365.10)\end{array}$ \\
\hline $\begin{array}{c}\text { Prostitución y } \\
\text { otro trabajo }\end{array}$ & $\begin{array}{c}8 \\
(5.5)\end{array}$ & $\begin{array}{c}987.50 \\
(551.46)\end{array}$ & 200 & 2000 & $\begin{array}{c}417.50 \\
(275.82)\end{array}$ & 30 & 700 & & & & $\begin{array}{l}1417.50 \\
(689.16)\end{array}$ \\
\hline $\begin{array}{c}\text { Prostitución } \\
\text { y ayudas }\end{array}$ & $\begin{array}{l}10 \\
(7)\end{array}$ & $\begin{array}{c}1350 \\
(1027.70)\end{array}$ & 200 & 3000 & & & & $\begin{array}{l}293.40 \\
(64.39)\end{array}$ & 200 & 400 & $\begin{array}{c}1643.40 \\
(1029.37)\end{array}$ \\
\hline $\begin{array}{l}\text { Prostitución, } \\
\text { trabajo, ayudas }\end{array}$ & $\begin{array}{c}1 \\
(0.5)\end{array}$ & $\begin{array}{c}1100 \\
(0)\end{array}$ & 1100 & 1100 & $\begin{array}{l}572 \\
(0)\end{array}$ & 572 & 572 & $\begin{array}{l}80 \\
(0)\end{array}$ & 80 & 80 & $\begin{array}{c}1752 \\
(0)\end{array}$ \\
\hline Totales & $\begin{array}{c}146 \\
(100)\end{array}$ & $\begin{array}{c}2249.32 \\
(1369.13)\end{array}$ & 200 & 8000 & $\begin{array}{c}434.70 \\
(263.10)\end{array}$ & 30 & 700 & $\begin{array}{c}274 \\
(88.72)\end{array}$ & 80 & 400 & $\begin{array}{c}2297.44 \\
(1339.10)\end{array}$ \\
\hline
\end{tabular}

En relación con la edad de entrada en la prostitución, no hemos encontrado diferencias significativas en función del tipo de prostitución $\left(F_{(2,143)}=2.33, p=.10\right)$. La media general se encuentra en torno a los 25 años, como se puede observar la variabilidad es importante, encontrando mujeres que han comenzado a los 14 años y otras a los 50 años. En general, no parece que haya un inicio temprano condicionado por familias desestructuradas, como podía estar asociado a la prostitución de hace veinte años, sino una asociación entre inmigración, necesidades económicas y prostitución.

En cuanto al tiempo que llevan ejerciendo esta actividad, tampoco hemos encontrado diferencias significativas en función del tipo de prostitución $\left(F_{(2,143)}=3.55, p=.03\right)$, por lo que hemos hallado una media general de 4 años, pero también hay una gran variabilidad, de manera que encontramos mujeres que llevan menos de un año ejerciendo hasta las que llevan casi toda su vida (30 años). En nuestros datos encontramos personas que están prácticamente toda su vida ejerciendo prostitución, como lo hacía la prostituta clásica, y personas que sólo están un breve periodo de tiempo en el que ganan el dinero que necesitan para cubrir sus necesidades (comprar una casa en su país, poner un negocio, pagar los estudios de sus hijos/as, etc.) 
Como vemos, el hecho de tener un trabajo mal pagado, carecer del mismo o tener escasas ayudas sociales es un poderoso motivo para recurrir a la prostitución como fuente alternativa de ingresos económicos, especialmente cuando hablamos de personas extranjeras que tienen cargas económicas y familiares. Al fijarnos en la edad con la que comienzan a ejercer prostitución y el tiempo que llevan en ella, un pequeño número de personas comenzaron muy jóvenes y que únicamente conocen esta forma de generar ingresos económicos.

\subsubsection{Causas de entrada y motivos de salida}

A continuación, vamos a analizar las causas que han alegado como razones para su entrada en la prostitución y los motivos por los que dejarían de ejercerla. Entre las cuatro posibles causas de entrada y los cuatro posibles motivos de salida equivalentes, únicamente hemos considerado en el análisis los relacionados con el trabajo y el dinero, debido a que el resto de causas y motivos prácticamente no han sido seleccionadas como opción de respuesta por las personas entrevistadas (ver Tabla 20).

Hemos realizado un ANOVA mixto con un factor inter, el tipo de prostitución, y dos factores intra, las causas de entrada y los motivos de salida de la prostitución. Hemos incluido dos causas de entrada y dos motivos de salida, que son, no encontrar otro trabajo y ganar más dinero que en otros trabajos, como causas de entrada, y cuando encuentre otro trabajo y cuando encuentre un trabajo donde gane el mismo dinero, como motivos de salida. 
Tabla 20. Causas de entrada y motivos de salida de la prostitución en función del tipo de prostitución

\begin{tabular}{|c|c|c|c|c|c|c|c|c|c|}
\hline Causas de entra & & $\mathbf{n}$ & Media & d.t. & Motivos de salida & & $\mathbf{N}$ & Media & d.t. \\
\hline \multirow{4}{*}{ No encontrar trabajo } & Calle & 21 & 1.71 & 1.52 & \multirow{4}{*}{$\begin{array}{c}\text { Cuando encuentre otro } \\
\text { trabajo }\end{array}$} & Calle & 21 & 1.86 & 1.46 \\
\hline & Club & 33 & 3.03 & 1.72 & & Club & 33 & 3.61 & 1.44 \\
\hline & Piso & 92 & 2.85 & 1.89 & & Piso & 92 & 2.98 & 1.90 \\
\hline & Total & 146 & 2.73 & $\overline{1.84}$ & & Total & 146 & 2.96 & 1.82 \\
\hline \multirow{4}{*}{$\begin{array}{c}\text { Ganar más dinero } \\
\text { que en otros trabajos }\end{array}$} & Calle & 21 & 2.57 & 1.91 & \multirow{4}{*}{$\begin{array}{l}\text { Cuando encuentre } \\
\text { trabajo con ingresos } \\
\text { similares }\end{array}$} & Calle & 21 & 1.90 & 1.70 \\
\hline & Club & 33 & 3.94 & 1.39 & & Club & 33 & 4.30 & 1.24 \\
\hline & Piso & 92 & 3.83 & 1.64 & & Piso & 92 & 3.73 & 1.77 \\
\hline & Total & 146 & 3.67 & 1.68 & & Total & 146 & 3.60 & 1.80 \\
\hline \multirow{4}{*}{$\begin{array}{l}\text { Costearte el } \\
\text { consumo de drogas }\end{array}$} & Calle & 21 & 2.81 & 1.99 & \multirow{4}{*}{ Cuando deje las drogas } & Calle & 21 & 2.67 & 1.98 \\
\hline & Club & 33 & 1.15 & .62 & & Club & 33 & 1.00 & .00 \\
\hline & Piso & 92 & 1.05 & .43 & & Piso & 92 & 1.03 & .31 \\
\hline & Total & 146 & 1.33 & 1.06 & & Total & 146 & 1.26 & .97 \\
\hline \multirow{4}{*}{$\begin{array}{l}\text { Por obligación de } \\
\text { alguien }\end{array}$} & Calle & 21 & 1.90 & 1.67 & \multirow{4}{*}{$\begin{array}{l}\text { Cuando dejen de } \\
\text { obligarme }\end{array}$} & Calle & 21 & 1.00 & .00 \\
\hline & Club & 33 & 1.42 & 1.20 & & Club & 33 & 1.00 & .00 \\
\hline & Piso & 92 & 1.18 & .80 & & Piso & 92 & 1.00 & .00 \\
\hline & Total & 146 & 1.34 & 1.08 & & Total & 146 & 1.00 & .00 \\
\hline
\end{tabular}

En primer lugar, encontramos que ninguna de las interacciones era significativa por lo que pasamos a analizar los efectos principales. En cuanto a los factores intra, no encontramos diferencias significativas entre las causas de entrada $\left(F_{(1,143)}=.23, p=.63\right)$, pero sí entre los motivos de salida $\left(F_{(1,143)}=14.98, p=.000, \eta^{2}=.10\right)$ por ello, podemos concluir que priman los aspectos económicos (ver Tabla 20), es decir, las personas entrevistadas saldrían de la prostitución si encontrasen un trabajo donde ganasen ingresos similares a la prostitución.

Hemos encontrado efectos significativos del tipo de prostitución $\left(F_{(2,143)}=17.51, p=.000, \eta^{2}=.20\right)$, realizadas las pruebas a posteriori hemos obtenido que las diferencias se dan entre el grupo de la calle con el de club $(p=.000)$ y el de piso $(p=.000)$. No encontrándose diferencias entre el club y el piso. Parece (ver Tabla 20) que los motivos económicos y laborales no son los que llevan a entrar o salir de la prostitución al grupo de calle, pero si a los otros dos grupos. 
A continuación, presentamos algunos de los comentarios recogidos mediante la pregunta abierta sobre otras posibles causas por las que comenzaron a ejercer prostitución. De nuevo, los aspectos económicos relacionados con ganar más dinero y más rápido son los más referidos.

"Vine a trabajar en esto para ganar un dinero rápidamente" (Colombiana, 25 años)

“Comencé a ejercer prostitución para pagar la deuda de mi viaje lo más rápidamente y porque estoy ilegal y no puedo trabajar en otra cosa" (Colombiana, 35 años)

"Para pagar mi casa, en nuestro país es muy difícil comprar una casa con el sueldo que ganamos" (Transexual Brasileña, 26 años)

"Para operarme de pechos, nariz y pómulos, las operaciones son muy caras y los travestis no tenemos muchas opciones en otros trabajos" (Transexual Brasileña, 33 años)

"Necesitaba dinero para mis estudios y los de mi hijo" (Brasileña, 23 años) "Por necesidad, murió mi padre y teníamos muchas dificultades económicas" (Española, 28 años)"

También hemos registrado mediante otra pregunta abierta otros posibles motivos de salida de la prostitución. A continuación transcribimos algunos de los comentarios recogidos donde volvemos a ver de nuevo los temas económicos como principales motivos. 
"Cuando ahorre lo planteado y logre mi meta económica" (Brasileña, 47 años)

"Me proporciona dinero extra, de momento no quiero dejarlo" (Española, 35 años)

"Cuando pague las deudas que tengo" (Brasileña, 30 años)

"Cuando consiga papeles y pueda trabajar en otras cosas" (Paraguaya, 45 años)

"Cuando tenga un trabajo que me permita vivir y mantener a mis hijos"

(Colombiana, 35 años)

“Cuando me canse” (Brasileña, 22 años)

"Cuando encuentre una pareja y me case, ahí me retiraré de esto"

(Colombiana, 30 años)

Aunque, como hemos indicado, no hemos analizado las otras dos causas y motivos conjuntamente, vamos a analizarlos ahora de forma más detallada. Por un lado los motivos relacionados con el consumo de drogas y, por otro, los relacionados con haber sido obligada a ejercer prostitución.

Hemos dicotomizado las respuestas a las variables causa de entrada/motivo de salida relacionadas con el consumo de drogas, en dos respuestas (sí o no), de manera que las respuestas: 1 Muy en desacuerdo y 2 Bastante en desacuerdo, pasaron a ser No; y al resto de opciones: 3 Algo de acuerdo, 4 Bastante de acuerdo y 5 Muy de acuerdo, pasaron a ser Sí.

En cuanto a la relación entre la causa de entrada en la prostitución relacionada con el consumo de drogas y el tipo de prostitución (ver Tabla 21), encontramos relación entre ambas variables $\left(\chi_{(2)}^{2}=46.06, p=.000, C=.49\right)$, de manera que las personas que trabajan en la calle han comenzado a ejercer prostitución para costearse las drogas en mayor medida (residuo tipificado corregido $=6.7$ ), mientras que las mujeres que trabajan en piso lo afirman en menor medida (residuos tipificados corregidos=-4.3). También hay relación entre el tipo de prostitución y el motivo de salida de la prostitución relacionado con las drogas $\left(\chi_{(2)}^{2}=\right.$ 49.90, $p=.000, C=.51$ ), de forma que las personas que ejercen en la calle alegan en mayor medida que dejarían la prostitución si dejasen de consumir drogas (residuo tipificado 
corregido=7.1), mientras que las de piso lo afirman en menor medida (residuo tipificado corregido=-.6).

Este resultado explicaría el obtenido anteriormente, como vimos en el caso de las prostitutas de calle los motivos laborales y económicos no eran la causa principal de entrada ni el motivo de salida, ahora comprobamos que en este grupo el consumo de drogas tiene mayor relevancia.

Tabla 21. Costearse las drogas como causa de entrada y motivo de salida en función del tipo de prostitución

\begin{tabular}{|c|c|c|c|c|c|c|c|c|c|c|c|}
\hline \multirow{2}{*}{\multicolumn{2}{|c|}{$\begin{array}{c}\text { Causa de } \\
\text { entrada }\end{array}$}} & \multicolumn{4}{|c|}{ Tipo de prostitución } & \multirow{2}{*}{\multicolumn{2}{|c|}{$\begin{array}{l}\text { Motivo de } \\
\text { Salida }\end{array}$}} & \multicolumn{4}{|c|}{ Tipo de prostitución } \\
\hline & & Calle & Club & Piso & Total & & & Calle & Club & Piso & Total \\
\hline \multirow{3}{*}{$\begin{array}{l}\text { Costearse } \\
\text { las drogas }\end{array}$} & Si & $\begin{array}{c}10 \\
(47.62 \%)\end{array}$ & $\begin{array}{c}2 \\
(6.06 \%)\end{array}$ & $\begin{array}{c}1 \\
(1.09 \%)\end{array}$ & $\begin{array}{c}13 \\
(8.90 \%)\end{array}$ & \multirow{3}{*}{$\begin{array}{l}\text { Cuando } \\
\text { deje las } \\
\text { drogas }\end{array}$} & Si & $\begin{array}{c}9 \\
(42.86 \%)\end{array}$ & $\begin{array}{c}0 \\
(0 \%)\end{array}$ & $\begin{array}{c}1 \\
(1.08 \%)\end{array}$ & $\begin{array}{c}10 \\
(6.8 \%)\end{array}$ \\
\hline & No & $\begin{array}{c}11 \\
(52.38 \%)\end{array}$ & $\begin{array}{c}31 \\
(93.94 \%)\end{array}$ & $\begin{array}{c}91 \\
(98.90 \%)\end{array}$ & $\begin{array}{c}133 \\
(91.10 \%)\end{array}$ & & No & $\begin{array}{c}12 \\
(57.14 \%)\end{array}$ & $\begin{array}{c}33 \\
(100 \%)\end{array}$ & $\begin{array}{c}91 \\
(98.91 \%)\end{array}$ & $\begin{array}{c}136 \\
(93.2 \%)\end{array}$ \\
\hline & Total & 21 & 33 & 92 & 146 & & Total & 21 & 33 & 92 & 146 \\
\hline
\end{tabular}

A continuación transcribimos dos comentarios realizados por dos mujeres que ejercen en la calle sobre la relación entre la prostitución y el consumo de drogas.

"Es un círculo vicioso, para estar ahí tienes que ponerte hasta las patas porque sino no lo aguantas y entonces entras en un círculo" (Española, 39 años)

"Yo es hacerme un coche y subir a pillar, y me dice muchas veces la gitana ¡Pero si hace un rato chacha que has pillao!" y ya, pero es que yo no se montarme en un coche si no me he puesto antes, osea yo me bajo de un coche, gano dinero y me voy, si me hiciera cuatro coches seguidos se que ganaría mucho dinero y no tendría que ir a pillar veinte veces pero yo no se lo que es bajarme de un coche y hacerme otro seguido sin ponerme antes. Y no estoy de mono ¿eh? Pero no puedo, además si no voy puesta, me veo sucia, y no tengo la misma capacidad para pedir dinero al cliente" (Española, 33 años)

En cuanto a la causa de entrada/ motivo de salida haber sido obligada por alguien y cuando dejen de obligarme, hemos dicotomizado ambas variables de la misma forma que en 
el caso anterior, pero en este caso también hemos considerado relevante el análisis no sólo en función del tipo de prostitución, como venimos haciendo hasta ahora, sino que también consideraremos la variable nacionalidad. En ambos análisis reflejamos únicamente la causa de entrada haber sido obligada por alguien ya que ninguna de las personas entrevistadas alegó este motivo para dejar de ejercer prostitución, es decir, en la actualidad ninguna de las personas que hemos entrevistado se mantiene en la prostitución porque se sienta obligada por terceras personas, sino por otros motivos, los económicos, como hemos visto anteriormente.

En primer lugar, un $9.6 \%$ de la muestra ha afirmado que comenzaron a ejercer prostitución obligadas por una tercera persona, pero no hemos encontrado relación entre esta variable y el tipo de prostitución $\left(\chi_{(2)}^{2}=6.97, p=.03\right)$, de manera que esta causa de entrada se distribuye por igual entre el grupo de calle, de club y de piso.

Como hemos visto en la parte teórica, debemos distinguir entre delito de prostitución, tráfico ilícito de personas y la trata de personas con fines de explotación sexual. Por ello, nos hemos preguntado si existe relación entre la nacionalidad y el haber comenzado a ejercer prostitución obligadas por otras personas. Al realizar este análisis, tampoco hemos encontrado relación entre ambas variables $\left(\chi_{(1)}^{2}=1.52, p=.22\right)$, por lo que no se puede decir que sea una causa de entrada más importante en las personas extranjeras.

En las mujeres extranjeras encontramos que un $92 \%$ no había comenzado a ejercer prostitución obligadas por una tercera persona. Por ello, tratando de profundizar en este aspecto hemos analizado también si sabían que venían a ejercer esta actividad y si en sus países habían ejercido prostitución en alguna ocasión. Y hemos encontrado que el $54 \%$ sí que sabían que venían a ejercer prostitución mientras que un $46 \%$ vinieron a otros trabajos y por diferentes circunstancias (sueldos bajos, malas condiciones laborales, estar ilegales y no poder trabajar en otra cosa, etc.) acabaron ejerciendo prostitución como fuente alternativa de recursos económicos. En cuanto a si han ejercido prostitución en su país de origen, hemos encontrado que un $21.2 \%$ afirma haberla realizado. 
Sabemos que un factor relacionado con la prostitución de personas inmigrantes es el encontrarse ilegalmente en el país, por ello hemos querido comprobar cual es la situación administrativa de las personas extranjeras que hemos entrevistado. Hemos obtenido que un $48.7 \%$ de la muestra se encuentra legalmente en nuestro país, un $38.1 \%$ ilegalmente y un 13.3\% en trámites de legalización pero no hemos encontrado relación entre la situación administrativa y el tipo de prostitución en nuestra muestra $\left(\chi_{(4)}^{2}=8.58, p=.07\right)$.

Como podemos ver, sobre todo en los grupos de club y piso, existe una correspondencia entre las causas de entrada y los motivos de salida de la prostitución, entran por causas fundamentalmente económicas y salen por lo mismo, cuando encuentren un trabajo que les compense económicamente. Pero no parece ser así en las mujeres que ejercen en la calle, donde costearse el consumo de drogas parece ser la causa más poderosa, tanto para la entrada como para la salida de la prostitución. Además, la mayoría de nuestra muestra afirma haber comenzado a ejercer prostitución voluntariamente, sin que una tercera persona la obligara a ello, independientemente del tipo de prostitución y la nacionalidad de las entrevistadas.

Dado que la causa principal por la que la mayoría de la muestra ha comenzado a ejercer prostitución es la económica, podemos preguntarnos ¿Por qué otras personas con circunstancias económicas similares e incluso más precarias no han comenzado a ejercer prostitución? ¿Qué factores se unen a los económicos para que estas personas opten por ejercer prostitución? Obviamente, para contestar a estas preguntas deberíamos realizar un análisis comparativo entre personas que no ejercen prostitución y las que sí la ejercen, pero podemos afirmar, a partir de nuestra experiencia en el campo, que para que una persona tome la difícil decisión de ejercer prostitución deben unirse diversos factores (necesidad económica urgente, cargas familiares, dificultad para realizar otros trabajos, etc.), las cuales las constatamos a lo largo de nuestros datos. 


\subsubsection{Condiciones laborales}

A continuación vamos a pasar a describir las condiciones laborales en las que nuestra muestra ejerce prostitución. En primer lugar, vamos a ver los aspectos económicos y de organización de esta actividad (tipo de servicios, formas de cobro, precios, ingresos, horas de trabajo y número de clientes) y después analizaremos otras características (movilidad y frecuencia de movilidad).

Los servicios sexuales suelen cobrarse en dos modalidades diferentes, en función del tiempo que dura el servicio o por tipo de servicio realizado. Cuando la persona cobra por servicio lo más habitual es cobrar un servicio completo, el cual consiste en felación y penetración, y la duración puede ser variable, aunque nunca suele ser superior a 40 minutos.

Cuando los servicios se cobran por tiempo, suelen ofertarse diferentes opciones y los más habituales son de 20 minutos, de 40 minutos y de 1 hora. Dependiendo del tiempo están incluidos unos servicios u otros, por ejemplo, en un servicio de 20 minutos puede haber sólo penetración o sólo felación; en un servicio de 40 minutos puede haber masaje, felación y penetración; y un servicio de una hora puede incluir masaje, felación, penetración y griego. Estos matices son los más genéricos, ya que cada cliente puede pedir cualquier tipo de servicio y negociarlo con la persona que ejerce prostitución para llegar a un acuerdo mutuo en cuanto al servicio a realizar y el precio a pagar, el pago de servicios siempre se hace por adelantado.

Encontramos relación entre el tipo de prostitución y la forma de cobro de los servicios $\left(\chi_{(2)}^{2}=54.89, p=.000, C=.52\right)$, de manera que en la calle es más frecuente cobrar por servicio (residuo tipificado corregido=6.8). Mientras que en club y piso es más habitual cobrar por tiempo, aunque las diferencias son significativas únicamente en el último caso ( residuos tipificado corregidos $=6.2$ ).

A continuación describiremos los aspectos puramente económicos en relación con el ejercicio de la prostitución, es decir, los precios de los servicios o el tiempo contratado. 
Como vemos en las medias de la Tabla 22, los precios de la calle son los más bajos, seguidos de los de club y los de piso.

Tabla 22. Precios $(€)$ de los servicios y tiempo contratado en función del tipo de prostitución

\begin{tabular}{|c|c|c|c|c|c|}
\hline & & \multicolumn{3}{|c|}{ Tipo de prostitución } & \multirow{2}{*}{ Total } \\
\hline & & Calle & Club & Piso & \\
\hline \multirow{3}{*}{$\begin{array}{c}\text { Servicio } \\
\text { completo } \\
(€)\end{array}$} & Media & 27.67 & 31.11 & 50 & 31.30 \\
\hline & (d.t.) & (8.63) & (7.41) & $(17.32)$ & (11.32) \\
\hline & Min-Max & $20-40$ & $25-50$ & $30-60$ & $20-60$ \\
\hline \multirow{3}{*}{$\begin{array}{l}\text { Servicio de } 20 \\
\text { min. } \\
(€)\end{array}$} & Media & 30 & 41.76 & 40.94 & 40.46 \\
\hline & (d.t.) & (0) & (19.68) & $(5.37)$ & (9.33) \\
\hline & Min-Max & $30-30$ & $20-80$ & $30-60$ & $20-80$ \\
\hline \multirow{3}{*}{$\begin{array}{l}\text { Servicio de } 40 \\
\text { min. }\end{array}$} & Media & 46.67 & 51.47 & 58.10 & 56.10 \\
\hline & (d.t.) & $(5.16)$ & $(10.46)$ & $(11.09)$ & $(11.19)$ \\
\hline & Min-Max & $40-50$ & $40-70$ & $40-90$ & $40-90$ \\
\hline \multirow{3}{*}{$\begin{array}{l}\text { Servicio de } 1 \\
\text { hora }\end{array}$} & Media & 60 & 90.50 & 84.90 & 85.41 \\
\hline & (d.t.) & (0) & (18.48) & $(11.31)$ & (13.73) \\
\hline & Min-Max & $6-60$ & $60-120$ & $70-120$ & $60-120$ \\
\hline
\end{tabular}

Pasamos, a continuación a analizar otro aspecto muy relacionado con el tema económico, el número de horas de trabajo y el de clientes por día en función del tipo de prostitución.

Hemos encontrado diferencias significativas en función del tipo de prostitución en el número de horas de trabajo al día $\left(\mathrm{F}_{(2,143)}=21.64, \mathrm{p}=.000, \eta^{2}=.23\right)$ de manera que las personas que ejercen en piso trabajan significativamente más horas que las de calle $(p=.000)$ y club $(p=.000)$, no encontrando diferencias significativas entre calle y club (ver Figura 16).

En cuanto al número de clientes por día hemos encontrado diferencias significativas $\left(F_{(2,143)}=4.84, p=.01, \eta^{2}=.06\right)$ de manera que son las personas que ejercen prostitución en la calle las que mayor número de clientes atienden por día respecto a las de piso $(p=.01)$, no encontrando diferencias significativas entre las de club y piso (ver Figura 16). 

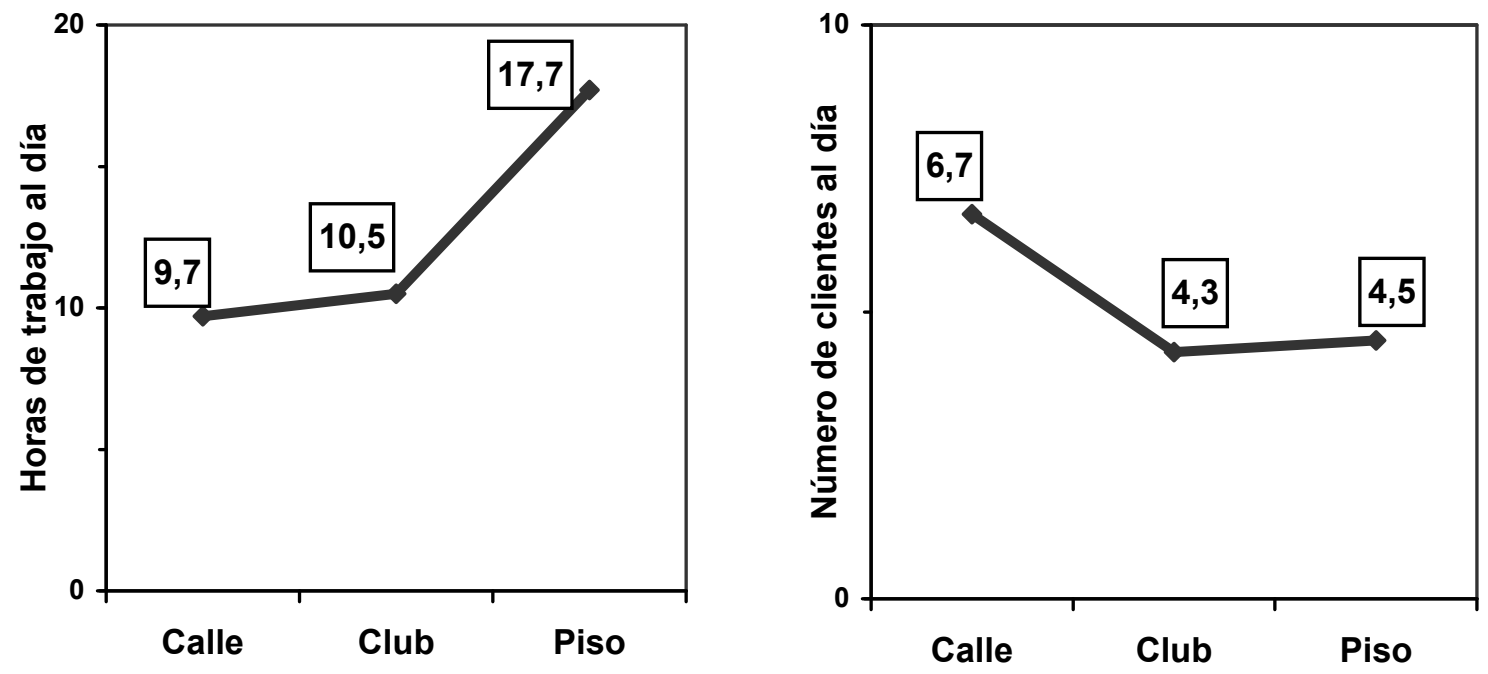

Figura 16. Horas de trabajo al día y número de clientes al día en función del tipo de prostitución

Pasamos a continuación a analizar los ingresos económicos obtenidos por cada uno de los grupos (calle, club o piso) en el ejercicio de la prostitución. No hemos encontrado diferencias significativas entre los grupos en cuanto a sus ingresos económicos $\left(F_{(2,143)}=\right.$ $1.34, p=.27$ ). Las personas de la calle (media $=2390.5$, d.t. $=960.7)$ ganan prácticamente lo mismo que las de club (media= 1909.1, d.t.=1101.5) y piso (media= 2339.13, d.t.=1517.4), aún teniendo los precios más bajos debido, probablemente, a que tienen un mayor número de clientes al día.

Puede parecer que unos ingresos de aproximadamente $2.250 €$ son elevados. Pero debemos tener en cuenta que en la mayoría de las ocasiones son brutos, es decir, normalmente las personas que ejercen prostitución deben pagar un porcentaje de los servicios que realizan a los/as dueños/as de los pisos o un dinero por la habitación donde trabajan en el club. La calle es el único lugar donde normalmente las ganancias son íntegras para la persona que ejerce prostitución, por ello algunas personas elijen este tipo de prostitución aunque las condiciones sean más duras.

Otro aspecto característico de esta población, es la movilidad. Son un colectivo que continuamente cambian de local, de ciudad e incluso de país para trabajar. Hemos encontrado relación entre la movilidad para trabajar (ver Figura 17) y el tipo de prostitución $\left(\chi_{(2)}^{2}=21.70, p=.000, C=.36\right)$ y podemos afirmar que en la prostitución de calle y club hay una 
menor movilidad aunque sólo en el último caso es significativo (residuos tipificados corregidos $=-4$ ) mientras que en el Piso (residuos corregidos=4.5) existe mayor movilidad para trabajar.

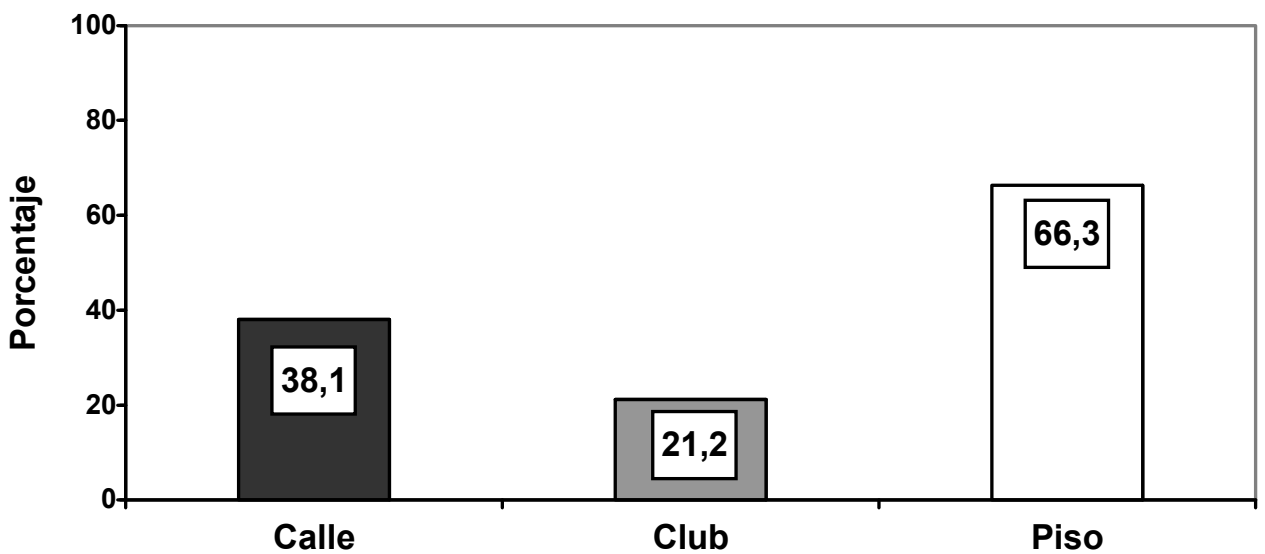

Figura 17. Porcentaje de personas con movilidad para trabajar en función del tipo de prostitución

A continuación, y con el fin de profundizar en el tema de la movilidad, hemos analizado la frecuencia con la que cambian de local para trabajar, y hemos encontrado que la mayoría (67.1\%) ejerce prostitución en régimen de plaza, es decir, cambiando aproximadamente cada 21 días de lugar de trabajo (ver Tabla 23). Esta situación puede perjudicar gravemente las relaciones interpersonales de estas personas ya que les dificulta el establecimiento de una red social de apoyo sólida.

Tabla 23. Frecuencia de movilidad en función del tipo de prostitución

\begin{tabular}{|c|c|c|c|c|c|}
\hline & & \multicolumn{3}{|c|}{ Tipo de prostitución } & \multirow{2}{*}{ Total } \\
\hline & & Calle & Club & Piso & \\
\hline \multirow{4}{*}{ Frecuencia de movilidad } & Una vez al mes (Plaza) & $\begin{array}{c}4 \\
(50 \%)\end{array}$ & $\begin{array}{c}5 \\
(71.43 \%)\end{array}$ & $\begin{array}{c}42 \\
(68.85 \%)\end{array}$ & $\begin{array}{c}51 \\
(67.11 \%)\end{array}$ \\
\hline & Dos o tres al año & $\begin{array}{c}3 \\
(37.5 \%)\end{array}$ & $\begin{array}{c}2 \\
(28.57 \%)\end{array}$ & $\begin{array}{c}11 \\
(18.03 \%)\end{array}$ & $\begin{array}{c}16 \\
(21.05 \%)\end{array}$ \\
\hline & Una al año & $\begin{array}{c}1 \\
(12.5 \%)\end{array}$ & $\begin{array}{c}0 \\
(0 \%)\end{array}$ & $\begin{array}{c}8 \\
(13.11 \%)\end{array}$ & $\begin{array}{c}9 \\
(11.84 \%)\end{array}$ \\
\hline & Total & 8 & 7 & 61 & 76 \\
\hline
\end{tabular}

Como vemos las condiciones en las que nuestra muestra ejerce prostitución no son las más adecuadas. En primer lugar, los precios de los servicios son bajos, por menos de 
$30 €$ se puede conseguir un servicios completo en la calle. Por ello y por la gran oferta existente tienen que trabajar muchas horas al día (media=15 horas, d.t=7.58) para atender al mayor número de clientes posible, ya que como vimos anteriormente realizan esta actividad por motivos fundamentalmente económicos. Además suelen cambiar de local y ciudad para trabajar con mucha frecuencia. Todos estos factores colocan a este colectivo en una posición de mayor vulnerabilidad a riesgos de salud.

\subsubsection{Grado de satisfacción laboral y necesidades percibidas}

A continuación analizamos el grado de satisfacción laboral que siente cada una de las personas entrevistadas con el ejercicio de la prostitución en general, es decir, la satisfacción que sienten con el trabajo en sí, con las condiciones en las que lo realizan, con los ingresos que obtienen, etc.

Como podemos ver en la Tabla 24, el nivel de satisfacción con la prostitución es bajo (media=1.48, d.t.=1.15), es decir, afirman sentirse Nada o Poco satisfechas con el ejercicio de la prostitución. Al comparar las medias en satisfacción entre personas que trabajan en calle, club o piso, hemos encontrado diferencias significativas entre los grupos $\left(F_{(2,143)}=\right.$ 10.83, $\mathrm{p}=.001, \eta^{2}=.13$ ) de forma que las personas que trabajan en piso sienten significativamente más satisfacción con la prostitución que las de club $(p=.000)$. Mientras que no hay diferencias significativas entre las club y calle.

Tabla 24. Satisfacción con la prostitución en función del tipo de prostitución

\begin{tabular}{|c|c|c|c|c|c|c|c|c|c|}
\hline \multicolumn{2}{|c|}{$\begin{array}{c}\text { Satisfacción con la } \\
\text { prostitución }\end{array}$} & $\begin{array}{c}\text { Nada } \\
(0)\end{array}$ & $\begin{array}{l}\text { Poco } \\
\text { (1) }\end{array}$ & $\begin{array}{c}\text { Normal } \\
\text { (2) }\end{array}$ & $\begin{array}{c}\text { Bastante } \\
\text { (3) }\end{array}$ & $\begin{array}{c}\text { Mucho } \\
\text { (4) }\end{array}$ & $\mathbf{N}$ & Media & d.t. \\
\hline \multirow{4}{*}{$\begin{array}{c}\text { Tipo de } \\
\text { prostitución }\end{array}$} & Calle & $\begin{array}{c}11 \\
(7.5 \%)\end{array}$ & $\begin{array}{c}2 \\
(1.4 \%)\end{array}$ & $\begin{array}{c}3 \\
(2.1 \%)\end{array}$ & $\begin{array}{c}5 \\
(3.4 \%)\end{array}$ & $\begin{array}{c}0 \\
(0 \%)\end{array}$ & 21 & 1.10 & 1.30 \\
\hline & Club & $\begin{array}{c}14 \\
(9.6 \%)\end{array}$ & $\begin{array}{c}11 \\
(7.5 \%)\end{array}$ & $\begin{array}{c}7 \\
(4.8 \%)\end{array}$ & $\begin{array}{c}1 \\
(0.7 \%)\end{array}$ & $\begin{array}{c}0 \\
(0 \%)\end{array}$ & 33 & .85 & .87 \\
\hline & Piso & $\begin{array}{c}13 \\
(8.9 \%)\end{array}$ & $\begin{array}{c}19 \\
(13 \%)\end{array}$ & $\begin{array}{c}42 \\
(28.8 \%)\end{array}$ & $\begin{array}{c}10 \\
(6.8 \%)\end{array}$ & $\begin{array}{c}8 \\
(5.5 \%)\end{array}$ & 92 & 1.79 & 1.10 \\
\hline & Total & $\begin{array}{c}38 \\
(26 \%)\end{array}$ & $\begin{array}{c}32 \\
(21.9 \%)\end{array}$ & $\begin{array}{c}52 \\
(35.6 \%)\end{array}$ & $\begin{array}{c}16 \\
(11 \%)\end{array}$ & $\begin{array}{c}8 \\
(5.5 \%)\end{array}$ & 146 & 1.48 & 1.15 \\
\hline
\end{tabular}


Tras comprobar que las personas entrevistadas, en general, no están muy satisfechas con el ejercicio de la prostitución, pasamos a analizar las necesidades que plantean para mejorar sus condiciones de vida y de trabajo. Vemos que hay una serie de necesidades que son elegidas por la mayoría de las entrevistadas independientemente del tipo de prostitución que ejerzan, y son, más información sobre ITS (94.5\%), legalización de la prostitución (91.1\%), alternativas laborales y ayudas sanitarias (87\%) y más higiene en el lugar de trabajo (68.5\%).

Por tanto, únicamente hemos encontrado relación significativa entre la necesidad más protección en el lugar de trabajo y el tipo de prostitución $\left(\chi_{(2)}^{2}=27.10, p=.000, C=.40\right)$ siendo las personas de la calle las que eligen mayoritariamente esta necesidad (residuos tipificados corregidos $=4.5$ ) y las de piso las que en menor medida lo hacen (residuos tipificados corregidos=-4.6) (ver Figura 18).

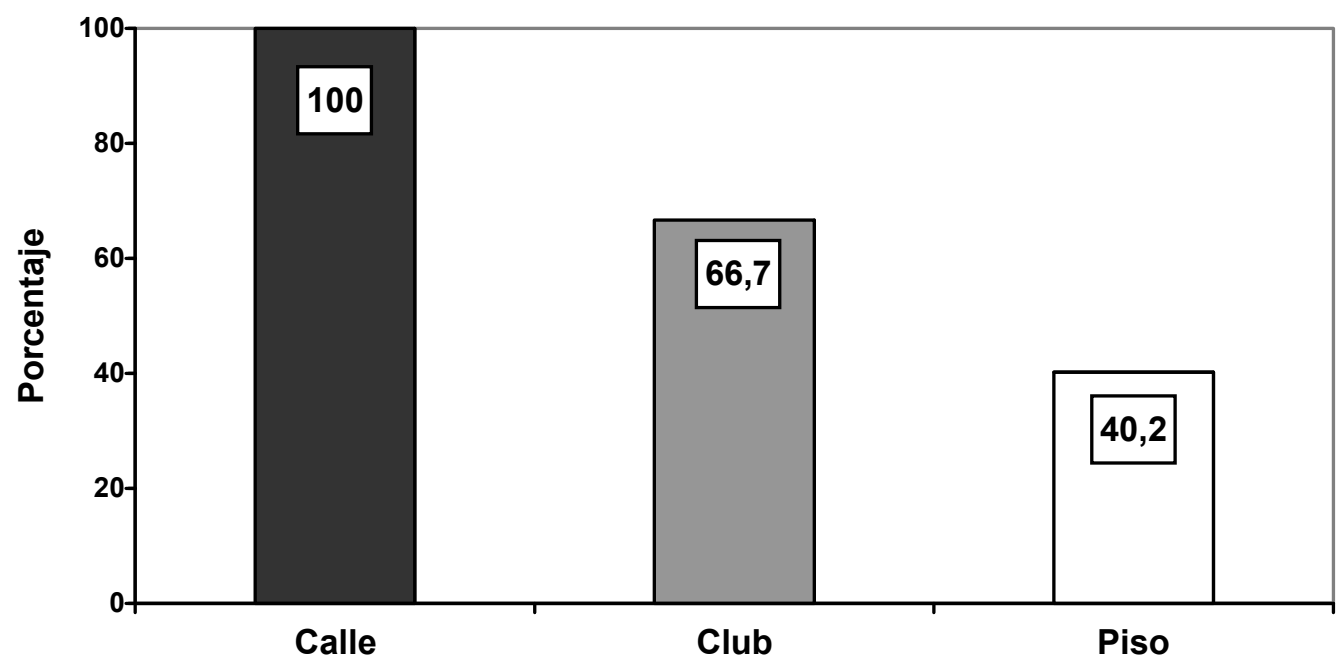

Figura 18. Necesidad de más protección en el trabajo en función del tipo de prostitución

Es lógico que sean las personas que trabajan en la calle las que señalen en mayor medida esta última necesidad ya que ejercen prostitución en el lugar más inseguro, la calle, donde son más vulnerables a todo tipo de riesgos, especialmente a las agresiones (físicas, psicológicas y sexuales) durante el ejercicio de la prostitución.

Debido al interés social que suscita este tema, hemos tratado de profundizar con más detalle en una de las necesidades señaladas por la mayoría de las personas 
entrevistadas, la legalización de la prostitución. Hemos evaluado mediante una pregunta abierta los aspectos positivos que veían a la legalización de la prostitución y hemos resumido todas las respuestas en cuatro opciones diferentes: (1) Para legalizar su situación o conseguir papeles, (2) Para tener más protección y menos explotación, (3) Para tener más derechos sociales y laborales y (4) Para tener más respeto y menos discriminación.

Como se puede observar en la Tabla 25 el motivo más señalado es para tener más derechos sociales y laborales (58\%), que está en consonancia con las necesidades que han señalado con anterioridad (ayudas sociales y sanitarias). En segundo lugar encontramos que el $21 \%$ de las personas entrevistadas afirman que la legalización conllevaría mayor protección.

Tabla 25. Motivos para legalizar la prostitución en función del tipo de prostitución

\begin{tabular}{ccccc}
\hline & \multicolumn{2}{c}{ Tipo de prostitución } & \multirow{2}{*}{ Total } \\
\cline { 2 - 4 } Para legalizar su situación (papeles) & Calle & Club & Piso & 17 \\
\hline Para tener más protección & 3 & 1 & 13 & $(12.8 \%)$ \\
\hline Para tener más derechos sociales y laborales & $(15 \%)$ & $(3.45 \%)$ & $(15.48 \%)$ & 28 \\
& 4 & 11 & 13 & $(21 \%)$ \\
\hline Para un mayor respeto y menos discriminación & $(20 \%)$ & $(37.93 \%)$ & $(15.48 \%)$ & 77 \\
& $(55 \%)$ & $(51.72 \%)$ & $(60.71 \%)$ & $(58 \%)$ \\
\hline Total & 2 & 2 & 7 & 11 \\
\hline
\end{tabular}

A continuación reflejamos algunos de los comentarios registrados en las entrevistas. Hemos trascrito un comentario que ejemplifique cada una de las categorías representadas en la Tabla 25. 
"Podríamos venir legal porque tendríamos permiso de trabajo, y trabajar legalmente y no tener miedo a las redadas y la deportación" (Brasileña, 21 años)

"Ahora vas a denunciar un abuso de un cliente y la delincuente acabas siendo tu, así podríamos denunciar sin miedo a los abusos, además creo que se evitaría mucha delincuencia, muchas mafias" (Española, 28 años)

"Para las chicas que quieren este trabajo les daría mejores condiciones, trabajar con seguridad social, obtener los beneficios de ser mujeres trabajadoras y trabajar autónomamente porque tendríamos acceso a alquileres y préstamos" (Brasileña, 28 años)

"Ayudaría a verlo más normal, habría más respeto y sería un trabajo más.

Muchas personas viven de esto y son discriminadas" (Brasileña, 29 años)

En general podemos ver que las personas entrevistadas están poco satisfechas con la prostitución y plantean una serie de necesidades que deben ser cubiertas. La legalización de la prostitución para obtener derechos sociales y laborales parece ser una de las necesidades más importantes de este colectivo, junto con una mayor información sobre infecciones de transmisión sexual, lo cual nos muestra la preocupación que sienten por su salud.

\subsubsection{Vida familiar y social}

En este punto vamos a describir cómo es la situación sociofamiliar de la muestra de personas entrevistadas. Describiremos, en primer lugar, cómo son sus relaciones familiares, tanto con la familia de origen como con la familia creada. En segundo lugar, describiremos como son sus relaciones sociales, es decir, si consideran que tienen amistades, tanto dentro del ambiente de la prostitución como fuera. Finalmente describiremos la satisfacción que sienten con sus relaciones familiares y sociales. El objetivo último de este punto es evaluar si las personas que ejercen prostitución pueden tener relaciones familiares, sociales y de pareja de forma normalizada y satisfactoria. 
En este caso, hemos realizado los análisis tanto en función del tipo de prostitución (calle, club y piso) como de la nacionalidad (española y extranjera), ya que consideramos que las relaciones familiares y sociales pueden verse muy influenciadas por esta última variable.

\subsubsection{Relaciones familiares}

En primer lugar, no hemos encontrado relación entre el estado civil y el tipo de prostitución $\left(\chi_{(6)}^{2}=3.46, p=.75\right)$, ni entre el estado civil y la nacionalidad $\left(\chi_{(3)}^{2}=3.48, p=.32\right)$, ya que se da un patrón similar en todos los grupos, estando la mayoría de las personas entrevistadas $(80.1 \%)$ sin pareja (solteras, separadas o viudas). No tener pareja puede ser un factor que facilite la entrada en prostitución, no sólo por la falta de apoyo económico de una pareja, sino también porque al ser solteras tienen más libertad para realizar una actividad económica de este tipo. De hecho algunas mujeres mencionaron durante la entrevista que dejarían la prostitución si encontrasen una pareja o se casasen, o incluso que si tuvieran pareja no podrían trabajar en esto.

En cuanto a su unidad de convivencia no encontramos relación con el tipo de prostitución $\left(\chi_{(6)}^{2}=4.70, p=.58\right)$. De manera que encontramos un patrón similar tanto en las mujeres que ejercen en calle como en club o en piso, la mayoría de ellas (58.2\%) viven con amistades o iguales (otras personas que ejercen prostitución).

Pero si que hemos encontrado relación entre la unidad de convivencia y la nacionalidad $\left(\chi_{(3)}^{2}=28.29, p=.000, C=.40\right)$, de manera que las españolas conviven en mayor medida que las extranjeras con la pareja (residuos tipificados corregidos=2.6) y la familia (residuos tipificados corregidos=3.5), mientras que las extranjeras conviven en mayor medida que las españolas con amigos o iguales (residuos tipificados corregidos=4.9) (Ver Figura 19). 


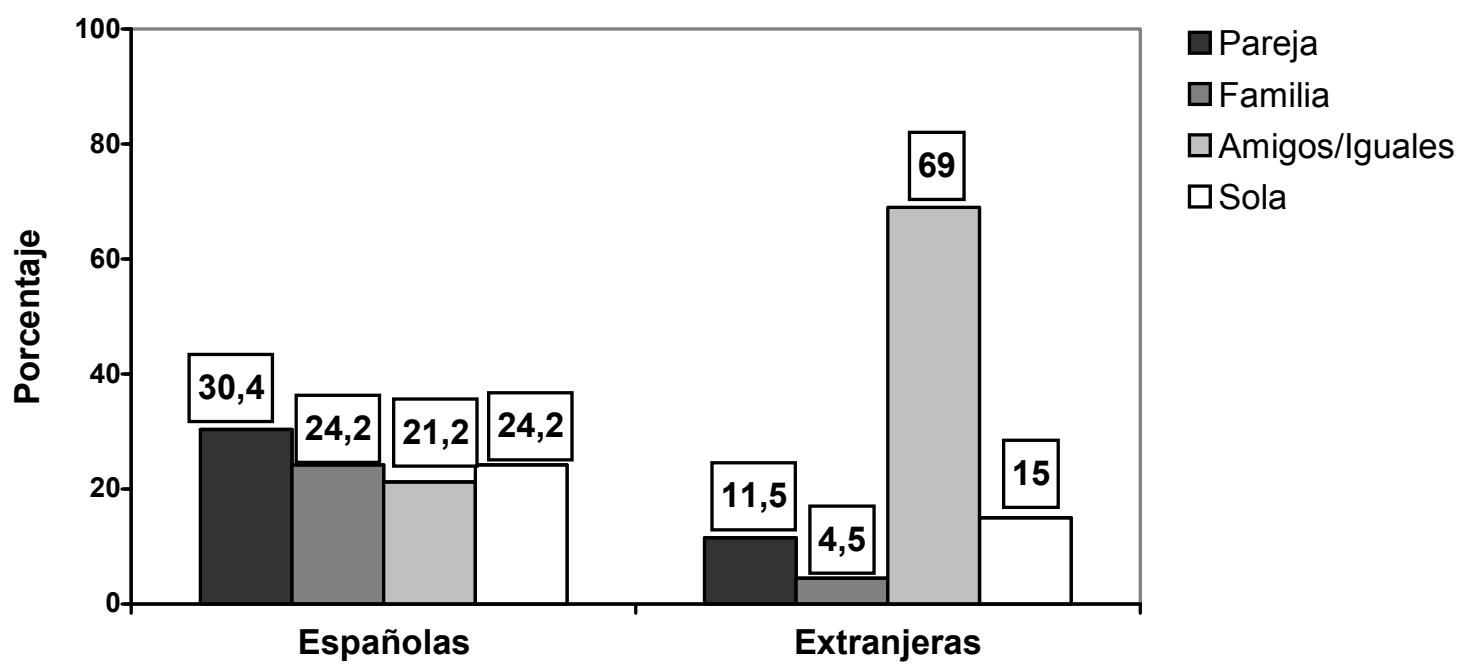

Figura 19. Unidad de convivencia en función de la nacionalidad

A continuación vamos a analizar si tienen hijos/as, si conviven con ellos/as, si el padre se ha responsabilizado de los/as mismos/as, y si en la actualidad conviven en pareja con sus hijos/as, o, en caso contrario, por qué no conviven con el padre.

Hemos encontrado que el $100 \%$ de las personas entrevistadas que tienen hijos/as son mujeres y representan el $58.2 \%$ de la muestra. No hemos encontrado relación entre tener hijos/as y el tipo de prostitución $\left(\chi_{(2)}^{2}=3.72, p=.16\right)$ ni con la nacionalidad $\left(\chi_{(1)}^{2}=3.69, p=.06\right)$. De la misma manera, tampoco hemos encontrado diferencias significativas en el número de hijos/as ni en función del tipo de prostitución $\left(F_{(2,143)}=1.01, p=.37\right)$, ni en función de la nacionalidad $\left(t_{(41.43)}=2.12, p=.04\right)$, la muestra presenta una media de 1.02 hijos/as (d.t.=1.20).

Hemos analizado con quién viven sus hijos/as y hemos encontrado relación con la variable tipo de prostitución $\left(\chi_{(6)}^{2}=18.43, p=.005, C=.50\right)$. De manera que los/as hijos/as de las mujeres que ejercen en la calle viven fundamentalmente con sus abuelos, aunque existe una proporción significativamente más alta que en los otros grupos que viven en los servicios sociales (residuos tipificados corregidos=3.5), y una proporción significativamente menor que en los otros tipos de prostitución que viven con el padre y la madre (residuos tipificados corregidos=-1.9). Mientras que los/as hijos/as de las mujeres que ejercen en piso viven en mayor medida con la madre y el padre (residuos tipificados corregidos=2.1) y en 
menor medida con los/as abuelos/as (residuos tipificados corregidos=-2) en comparación con los otros tipos de prostitución. Los hijos/as de las prostitutas de club viven principalmente con los abuelos. No hemos encontrado relación entre la nacionalidad y con quien viven sus hijos/as $\left(\chi_{(3)}^{2}=9.90, p=.02\right)$.

En resumen, como se observa en la Figura 20, los/as hijos/as de las mujeres que ejercen en la calle y en el club viven fundamentalmente con los abuelos, mientras que en el caso de los/as hijos/as de las mujeres que ejercen en piso viven en mayor medida con la madre y el padre.

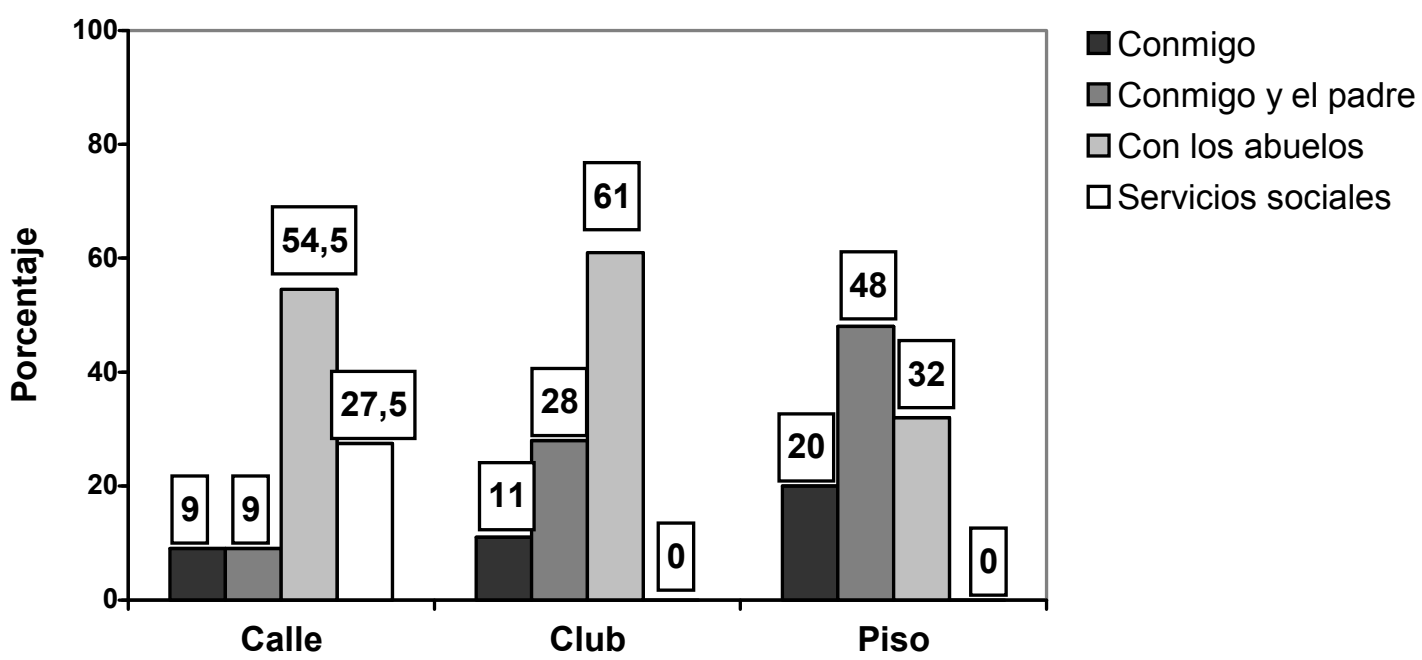

Figura 20. Con quien viven los/as hijos/as en función del tipo de prostitución

Un $35.3 \%$ de la muestra afirma que el padre de sus hijos/as no se hizo responsable de los/as mismos/as, pero no hemos encontrado relación entre tener el apoyo del padre de sus hijos/as y el tipo de prostitución $\left(\chi_{(2)}^{2}=4.84, p=.09\right)$, ni tampoco con la nacionalidad $\left(\chi_{(1)}^{2}=.55, p=.46\right)$. Entendemos que esta falta de responsabilidad por parte de los padres respecto a sus hijos/as es otro factor que carga, entre otras cosas, de mayores responsabilidades económicas a estas mujeres, ya que la supervivencia de sus hijos/as únicamente depende de ellas.

A las entrevistadas que afirmaron no tener el apoyo del padre de sus hijos/as les preguntamos por qué se había separado o no convivían con el padre de sus hijos/as. Los motivos que señalaron con mayor frecuencia la muestra entrevistada fueron: porque la 
relación se terminó (30\%), porque hubo infidelidades $(27.5 \%)$ y porque hubo malos tratos y/o abusos sexuales $(24 \%)$, no obstante no encontramos relación ni con la variable tipo de prostitución $\left(\chi_{(10)}^{2}=13.82, p=.18\right)$, ni con la nacionalidad $\left(\chi_{(5)}^{2}=11.57, p=.04\right)$.

A continuación evaluamos dónde se encuentran sus familias de origen (ver Figura 21), y hemos encontrado relación con la variable tipo de prostitución $\left(\chi_{(4)}^{2}=20.56, p=.000\right.$, $C=.44$ ), de manera que las personas que ejercen prostitución en la calle tienen en mayor medida a sus familias en su misma ciudad (residuos tipificados corregidos=3.1) o en otra ciudad española (residuos tipificados corregidos=2.5). Mientras que las personas que ejercen en piso y en club tienen a sus familias en mayor medida en otro país (residuos tipificados corregidos=2.4) aunque sólo en el primer caso es significativo.

También encontramos relación con la variable nacionalidad $\left(\chi_{(2)}^{2}=65.64, p=.000, C=.66\right)$, de forma que las mujeres españolas tenían a sus familias de origen en mayor medida en su misma ciudad (residuos tipificados corregidos $=7.4$ ) o en otra ciudad española (residuos tipificados corregidos=2.1) en comparación con las extranjeras. Mientras que las extranjeras tenían a sus familiares en mayor medida en otro país (residuos tipificados corregidos=7.6) en comparación con las españolas. Como es de esperar las mujeres españolas tienen a sus familiares más cerca que las extranjeras, las cuales suelen tener a sus familiares en sus países de origen (ver Figura 21). 

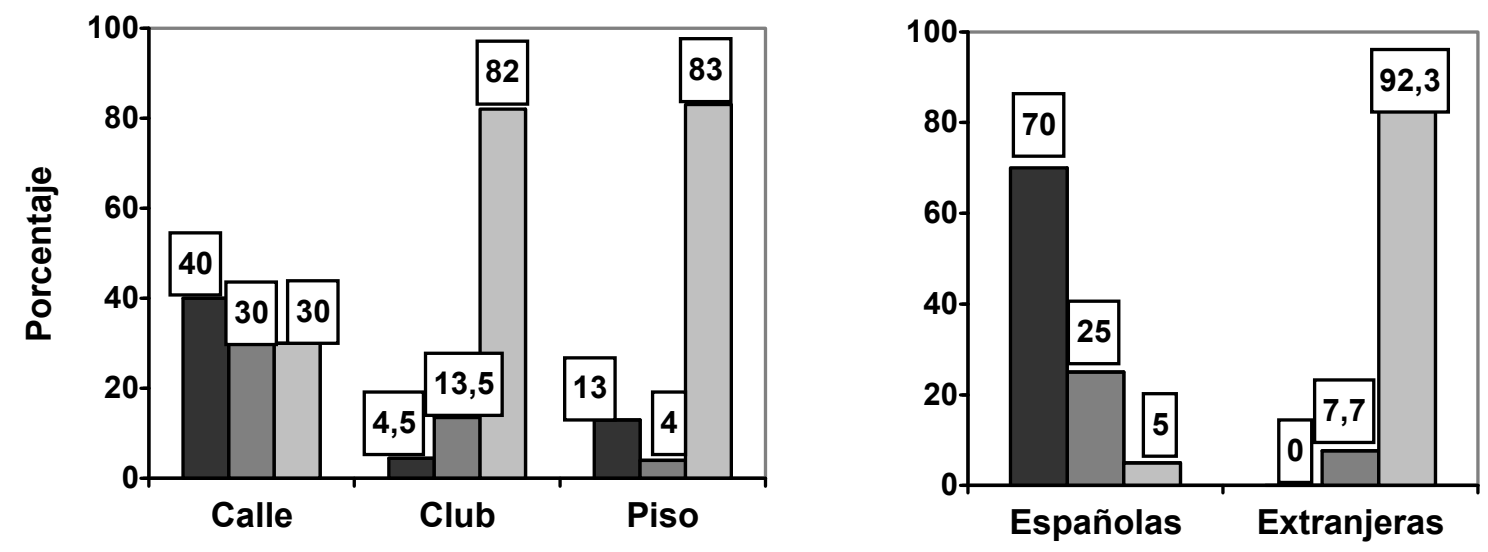

$\square$ En mi misma ciudad $\square$ En otra ciudad $\square$ En otro país

Figura 21. Dónde se encuentra la familia de origen en función del tipo de prostitución y la nacionalidad

Como vemos, aunque podemos encontrar diferencias en función de la nacionalidad y el tipo de prostitución, hay algunos rasgos comunes en nuestra muestra, como que son en su mayoría personas solteras, con hijos/as, aunque se encuentran separadas de sus familias, pareja e hijos/as. Estos aspectos comunes se deben fundamentalmente a que la variable tipo de prostitución y nacionalidad tienen relación puesto que en la calle encontramos a muchas personas españolas ejerciendo prostitución mientras que en clubes y pisos encontramos fundamentalmente extranjeras.

\subsubsection{Relaciones sociales}

A continuación describiremos como son las relaciones sociales de las personas entrevistadas, es decir, dónde se encuentran sus amistades más íntimas y si consideran que tienen amistades dentro del mundo de la prostitución.

Como vemos en la Figura 22, encontramos un patrón diferente en cuanto al lugar donde se encuentran sus amistades más íntimas y tipo de prostitución $\left(\chi_{(6)}^{2}=39.74, p=.000\right.$, $\mathrm{C}=.57$ ). Las mujeres que ejercen prostitución en la calle afirman en mayor medida que sus amistades más íntimas han muerto (residuos tipificados corregidos=5.4) o están en su 
misma ciudad, mientras que las mujeres que ejercen en piso afirman en mayor medida que sus amistades más íntimas se encuentran en otro país (residuos tipificados corregidos=2.3). Por último, las de club tienen a sus amistades intimas en su misma ciudad o en su país de origen.

De la misma forma (ver Figura 22), también encontramos relación con la variable nacionalidad $\left(\chi_{(3)}^{2}=38.80, p=.000, C=.56\right)$, por lo que las españolas afirman en mayor medida que sus amistades más íntimas han muerto (residuos tipificados corregidos=5.6) en comparación con las extranjeras o están en su misma ciudad. Mientras que las extranjeras tienen en mayor medida a sus amistades en otros países (residuos tipificados corregidos $=4.3$ ) en comparación con las españolas o están en su misma ciudad. Como ya hemos señalado con anterioridad, estos aspectos comunes entre el tipo de prostitución y la nacionalidad se deben a que en la calle encontramos fundamentalmente personas españolas ejerciendo prostitución y en los clubes y pisos personas extranjeras.
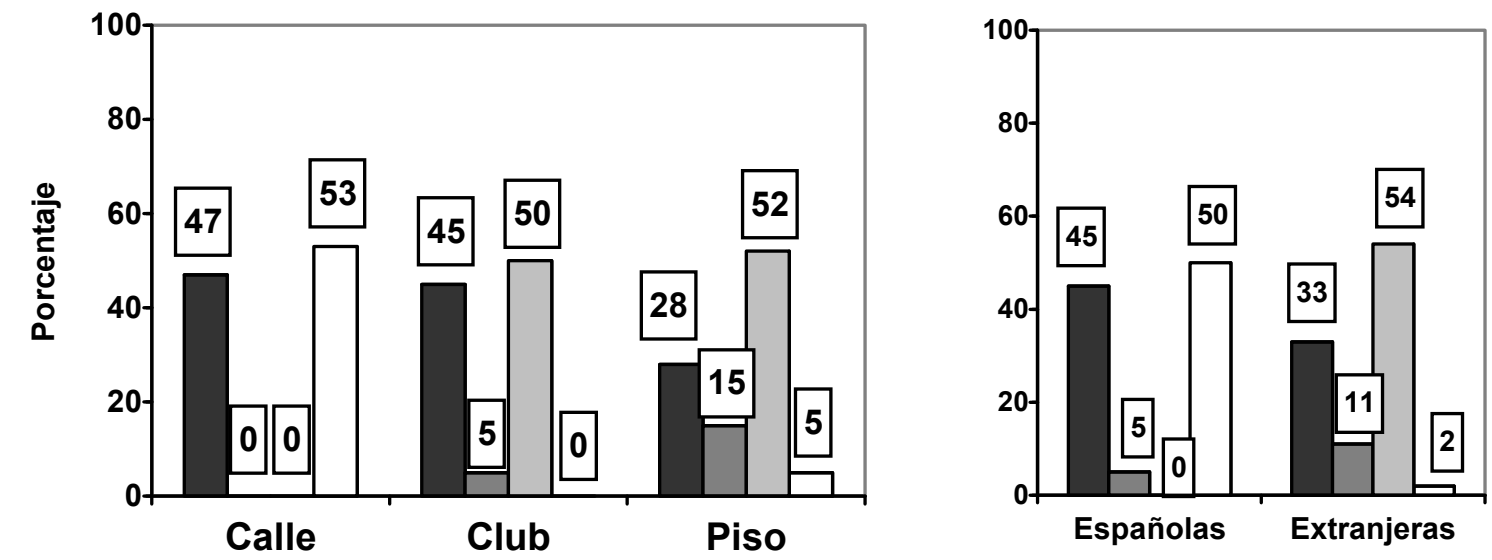

$\square$ En mi misma ciudad $\square$ En otra ciudad $\square$ En otro país $\square$ Han muerto

Figura 22. Dónde se encuentran tus amistades más íntimas en función del tipo de prostitución y la nacionalidad

En lo que se refiere a las amistades con compañeras de trabajo, un $48.3 \%$ de la muestra afirma tenerlas pero no hemos encontrado relación con el tipo de prostitución $\left(\chi^{2}\right.$ $(2)=1.50, p=.47)$ ni con la variable nacionalidad $\left(\chi_{(1)}^{2}=.71, p=.40\right)$. 
Como vemos se vuelve a repetir el mismo patrón que en el punto anterior, hay relación entre la variable tipo de prostitución y nacionalidad, de manera que las personas extranjeras o las que ejercen prostitución de interior tienen a sus amistades más íntimas en sus países de origen, mientras que las españolas o las que ejercen prostitución en la calle afirman en mayor medida que sus amistades más íntimas han muerto, este hecho puede deberse probablemente a que sus amistades también eran drogodependientes.

\subsubsection{Satisfacción sociofamiliar}

Finalmente vamos a analizar la satisfacción sociofamiliar, es decir, el grado de satisfacción que sienten las personas entrevistadas con el contacto y la relación que cada una ellas tiene con su familia de origen, sus hijos/as y sus amistades, tanto fuera del mundo de la prostitución como dentro.

No hemos encontrado diferencias en la satisfacción sociofamiliar entre los diferentes tipos de prostitución. Ni en la satisfacción familiar $\left(\mathrm{F}_{(2,82)}=2.72, \mathrm{p}=.07\right)$, ni en la satisfacción con los/as hijos/as $\left(F_{(2,51)}=2.23, p=.12\right)$, ni en la satisfacción con sus amistades $\left(F_{(2,80)}=\right.$ 2.34, $\mathrm{p}=.10)$, ni en la satisfacción con sus compañeros/as $\left(\mathrm{F}_{(2,57)}=.05, \mathrm{p}=.95\right)$. Tampoco hemos encontrado diferencias significativas en función de la nacionalidad, ni en satisfacción familiar $\left(F_{(1,83)}=1.67, p=.20\right)$, ni en satisfacción con los/as hijos/as $\left(F_{(1,52)}=.28, p=.60\right)$, ni en satisfacción con sus amistades $\left(\mathrm{F}_{(1,81)}=6.14, p=.02\right)$, ni con la satisfacción con sus compañeros/as $\left(F_{(1,58)}=.38, p=.54\right)$.

Las medias obtenidas en todos los casos se sitúan entre 1 y 2 . Esto quiere decir que la respuesta media oscila entre nada y poco satisfecha con el contacto sociofamiliar. Podemos concluir que la muestra entrevistada, en general, está poco satisfecha con sus relaciones familiares y sociales.

A continuación presentamos algunos de los comentarios de las personas que ejercen prostitución sobre sus relaciones familiares y sociales. 
"Mi familia no lo sabe, me toca esconderme para que mi familia no se entere, mi hijo sobre todo" (Española, trabajando en la calle, 36 años)

"Un yonqui, un marido yonqui, no vale ni para tacos de escopeta, seamos realistas, ijoder!

Porque el que te tiene ahí no te quiere, porque el que te pone, se come lo tuyo,

te pega una ostia y a trabajar" (Española, trabajando en la calle, 30 años)

"No, no, no, en la calle no hay amigas. No somos compañeras. No hay solidaridad"

(Española, trabajando en la calle, 36 años)

\subsubsection{Estado de salud}

Como hemos indicado anteriormente, en la actualidad, ya no entendemos la salud como la ausencia de enfermedad, sino como "un estado completo de bienestar físico, mental y social" (OMS, 1946, 1958), por ello hemos analizado diferentes variables de salud que pueden verse afectadas por el ejercicio de la prostitución y se relacionan con los diferentes niveles que componen la salud (física, sexual y psicológica).

\subsubsection{Salud física}

A lo largo de este punto vamos a describir algunos aspectos relacionados con la salud física de las personas entrevistadas que son relevantes para este colectivo. Comentaremos si acuden a los servicios sociosanitarios públicos y si se realizan reconocimientos médicos. Posteriormente, analizaremos en detalle dos aspectos que pueden tener gran incidencia sobre la salud física, como son el consumo de drogas y los malos tratos físicos recibidos durante el ejercicio de la prostitución.

En cuanto a si acuden a los servicios sociosanitarios públicos disponibles en nuestro país, un $65 \%$ afirma que sí pero no hemos encontrado relación entre esta variable y el tipo 
de prostitución $\left(\chi_{(2)}^{2}=8.02, p=.02\right)$, de manera que no hay diferencias en la frecuencia de asistencia entre el grupo de calle, de club y de piso.

Al preguntar a aquellas personas que no acuden a este tipo de servicios las razones por las que no lo hacían, hemos encontrado que las razones más frecuentes son: un $66.6 \%$ por no tener tarjeta sanitaria, un $19.6 \%$ por no haber necesitado nunca este tipo de servicios, un $5.9 \%$ por tener médico privado, un $3.9 \%$ por tener miedo a ser descubierta su situación ilegal y el $4 \%$ restante afirma ser atendida por ONGs que trabajan con ellas. Estos resultados confirman los datos presentados anteriormente sobre las razones por las que consideran positiva la legalización de la prostitución, ya que muchas personas ilegales podrían regularizar su situación y cotizar a la seguridad social si la prostitución fuera considerada un trabajo.

A continuación transcribimos un comentario relacionados con el uso de los servicios sanitarios por las mujeres que ejercen prostitución.

"Muchas vamos sólo cuando es urgente, si es algo leve lo vamos dejando porque no tenemos seguridad social, ni nada, lo vamos dejando pasar que igual más adelante se va a ir a más grande ¿No? porque si se deja una infección pequeña, se te va poniendo a más y a más y a más... pues no iré porque en el Hospital me piden documentación, porque luego me mandan la factura a casa, o por muchas razones" (Rumana, 25 años)

Por lo que respecta a si se realizan reconocimientos médicos, hemos encontrado que la mayoría, un $91.1 \%$ los lleva a cabo. Al preguntar por la frecuencia con la que se los realizan hemos encontrado que un $23.3 \%$ los pasa cada tres meses, un $28.8 \%$ cada seis meses, un $30.1 \%$ uno al año y un $17.8 \%$ cada dos o tres años. Podemos ver que a pesar de las dificultades que se encuentran (no tener tarjeta sanitaria, miedo a la deportación, etc.), las personas entrevistadas se preocupan por su salud y se realizan reconocimientos médicos con frecuencia. 
- Consumo de drogas

A continuación vamos a describir el patrón de consumo de drogas de la muestra entrevistada en función del tipo de prostitución, quienes consumen, qué drogas consumen, durante cuanto tiempo y con qué frecuencia lo hacen.

Hemos encontrado relación entre el consumo de drogas y el tipo de prostitución $\left(\chi^{2}\right.$ $\left.{ }_{(2)}=36.70, p=.000, C=.45\right)$, de manera que son las personas que ejercen prostitución en la calle las que en mayor medida consumen drogas (residuo tipificado corregido=6.1) y las de piso las que en menor medida lo hacen (residuo tipificado corregido =-3.2) (ver Figura 23).

En cuanto al tiempo consumiendo drogas ilegales hemos comparado las medias obtenidas entre las personas consumidoras para cada uno de los tres grupos y hemos encontrado que hay diferencias significativas en los años de consumo $\left(F_{(2,33)}=11.64, p=.000\right.$, $\left.\eta^{2}=.43\right)$ de manera que son las que la calle las que mayor tiempo llevan consumiendo respecto a las de club $(p=.003)$ y las de piso $(p=.001)$, no habiendo diferencias entre estos dos últimos grupos (ver Figura 23).
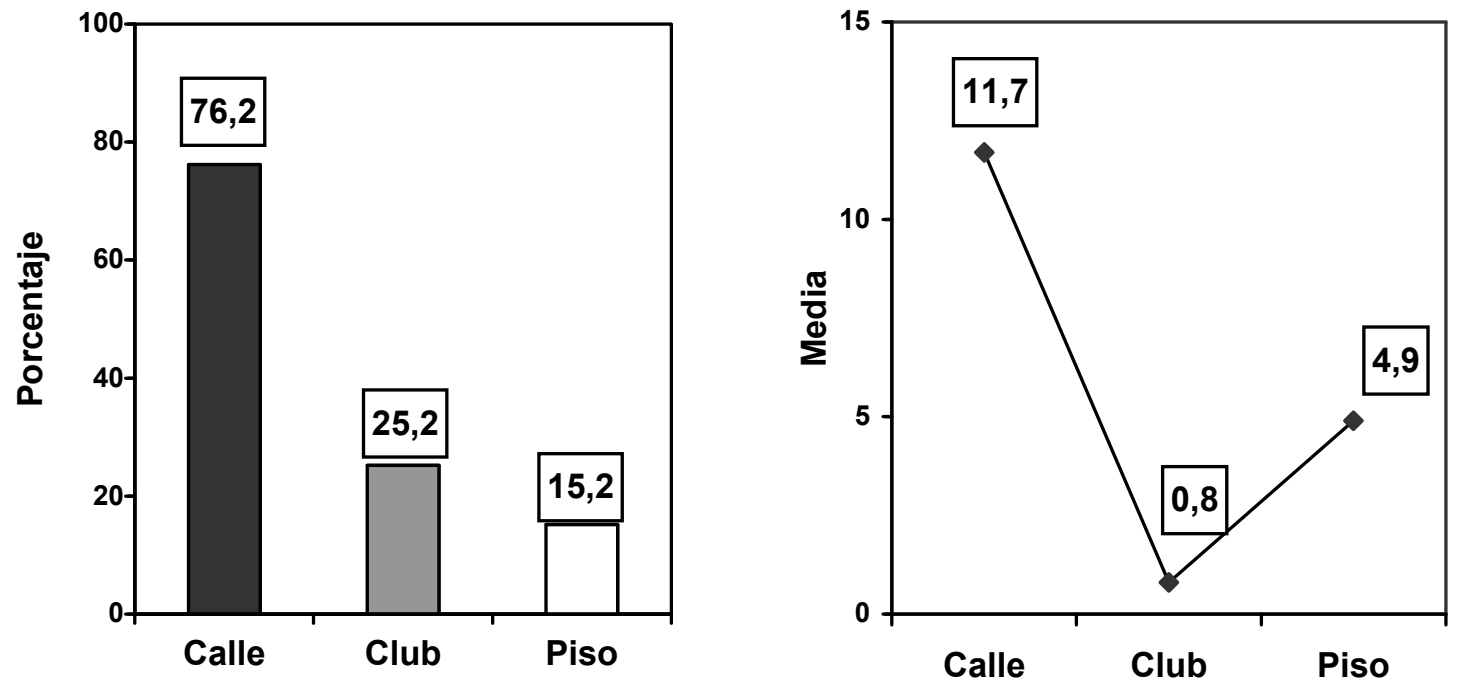

Figura 23. Porcentaje de personas consumidoras de drogas y media de años de consumo en función del tipo de prostitución 
Hemos evaluado la frecuencia de consumo de diferentes tipos de drogas: heroína, cocaína, hachís o marihuana, tabaco y alcohol. Para este análisis hemos realizado un ANOVA mixto (ver Tabla 26) con un factor intra, el tipo de droga consumida, compuesta por cuatro niveles: cocaína, hachís o marihuana, tabaco y alcohol; y un facto inter, el tipo de prostitución (calle, club y piso). Hemos eliminado de este análisis el consumo de heroína debido a que sólo la consumen personas que ejercen prostitución en la calle.

Tabla 26. Frecuencia de consumo de drogas en función del tipo de prostitución

\begin{tabular}{|c|c|c|c|c|c|}
\hline \multicolumn{2}{|c|}{ Frecuencia de consumo* } & \multicolumn{3}{|c|}{ Tipo de prostitución } & \multirow{2}{*}{ Total } \\
\hline riecuen & ve comsuma & Calle & Club & Piso & \\
\hline & $\mathbf{n}$ & 21 & 33 & 92 & 146 \\
\hline \multirow{3}{*}{ Heroína } & Media & 1.86 & 0 & 0 & .26 \\
\hline & (d.t.) & $(2.01)$ & $(0.00)$ & $(0.00)$ & $(.29)$ \\
\hline & $\%$ consumen diariamente & $6.2 \%$ & $0 \%$ & $0 \%)$ & $6.2 \%$ \\
\hline \multirow{3}{*}{ Cocaína } & Media & 2.19 & .36 & .22 & .53 \\
\hline & (d.t.) & $(1.75)$ & $(1.03)$ & $(.72)$ & $(1.20)$ \\
\hline & $\%$ consumen diariamente & $5.5 \%$ & $0.7 \%$ & $0 \%$ & $6.2 \%$ \\
\hline \multirow{3}{*}{ Hachís o marihuana } & Media & 1.05 & .18 & .32 & .39 \\
\hline & (d.t.) & $(1.40)$ & $(.77)$ & $(.97)$ & $(1.02)$ \\
\hline & $\%$ consumen diariamente & $1.4 \%$ & $0.7 \%$ & $2.7 \%$ & $4.8 \%$ \\
\hline \multirow{3}{*}{ Tabaco } & Media & 2.95 & .94 & 1.41 & 1.53 \\
\hline & (d.t.) & $(1.72)$ & $(1.69)$ & $(1.88)$ & $(1.91)$ \\
\hline & $\%$ consumen diariamente & $10.3 \%$ & $4.8 \%$ & $19.9 \%$ & $34.9 \%$ \\
\hline \multirow{3}{*}{ Alcohol } & Media & 2.52 & .79 & 1.76 & 1.65 \\
\hline & (d.t.) & $(1.21)$ & $(1.24)$ & $(1.31)$ & $(1.38)$ \\
\hline & $\%$ consumen diariamente & $2.1 \%$ & $0 \%$ & $0.7 \%$ & $2.7 \%$ \\
\hline \multirow{2}{*}{ Total } & Media & 2.18 & .57 & .93 & 1.09 \\
\hline & (d.t.) & $(1.52)$ & $(1.18)$ & $(1.22)$ & $(1.45)$ \\
\hline
\end{tabular}

* 0 . Nunca; 1.1 ó 2 veces al año; 2.1 ó 2 veces al mes; 3.1 ó 2 veces a la semana; 4 . Diariamente

En primer lugar, hemos encontrado diferencias significativas entre los grupos $\left(F_{(2,142)}=23.88, p=.000, \eta^{2}=.25\right)$, de forma que las personas que trabajan en la calle son las que consumen drogas con mas frecuencia, en comparación con las que trabajan en club $(p=.000)$ y piso $(p=.000)$. No hemos encontrado diferencias significativas entre las personas que trabajan en club y las de piso. 
Hemos encontrado diferencias significativas en la frecuencia de consumo de las diferentes drogas analizadas $\left(F_{(3,426)}=28.23, p=.000, \eta^{2}=.17\right)$, de forma que las drogas mas frecuentemente consumidas son el tabaco y el alcohol en comparación con la cocaína $(p=.000)$ y el hachís $(p=.000)$. También hemos encontrado diferencias entre estas dos ultimas drogas, de forma que la cocaína se consume más frecuentemente que el hachís $(p=.005)$. No hemos encontrado diferencias entre el tabaco y el alcohol.

Finalmente, hemos encontrado interacción entre el tipo de prostitución y la frecuencia de consumo de drogas $\left(F_{(6,426)}=4.09, p=.001, \eta^{2}=.05\right)$, de manera que, en la calle consumen menos hachís que cocaína $(p=.000)$, tabaco $(p=.000)$ y alcohol $(p=.000)$, no encontrando diferencias en el consumo de estas tres últimas drogas. En club no hemos encontrado diferencias significativas entre el consumo de las diferentes tipos de drogas. Mientras que en piso hemos encontrado diferencias significativas de forma que las drogas que más consumen son el tabaco y el alcohol en comparación con cocaína $(p=.000)$ y hachís $(p=.000)$. Hemos encontrado diferencias significativas entre estas dos ultimas drogas de forma que consumen mas frecuentemente hachís que cocaína $(p=.000)$. No hemos encontrado diferencias significativas entre el consumo de tabaco y alcohol (ver Figura 24).

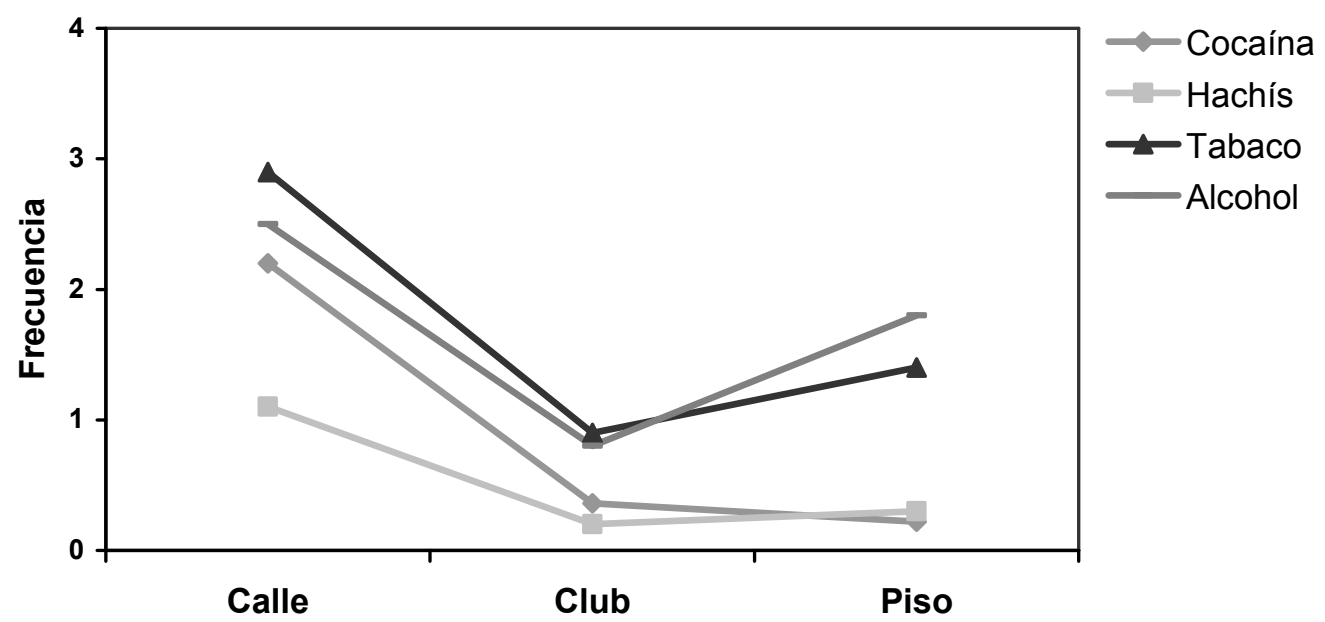

Figura 24. Frecuencia de consumo de drogas en función del tipo de prostitución

Como vemos, exceptuando el grupo de personas que ejercen en la calle, las que ejercen en club o piso presentan medias de frecuencia de consumo cercanas a 0 ó 1 , es 
decir, presentan un consumo de drogas muy esporádico (nunca o 1 ó 2 veces al año). Las personas que ejercen en la calle presentan un consumo más frecuente de todos los tipos de drogas analizadas, destacando, además del consumo de tabaco y alcohol, el consumo de cocaína (5.5\% la consume diariamente) y son las únicas que consumen heroína $(6.2 \%$ la consume diariamente).

- Agresiones físicas durante el ejercicio de la prostitución

Hemos estudiado, por una parte, qué personas han cometido agresiones físicas sobre las personas entrevistadas durante el tiempo que han ejercido prostitución, y por otra, la frecuencia con la que se han dado.

Hemos realizado un ANOVA mixto (ver Tabla 26) con un factor intra, quién ejerce las agresiones físicas, compuesto por cuatro niveles: el cliente, el/la jefe/a, los/a compañeras/os y la pareja; y un factor inter, el tipo de prostitución (calle, club y piso).

Tabla 26. Agresiones físicas en función del tipo de prostitución

\begin{tabular}{|c|c|c|c|c|c|}
\hline \multirow{2}{*}{\multicolumn{2}{|c|}{ Frecuencia agresiones físicas ${ }^{*}$}} & \multicolumn{3}{|c|}{ Tipo de prostitución } & \multirow{2}{*}{ Total } \\
\hline & & Calle & Club & Piso & \\
\hline & $\mathbf{N}$ & 21 & 33 & 92 & 146 \\
\hline \multirow{3}{*}{ Cliente } & Media & 1.33 & .70 & .24 & \multirow{3}{*}{$\begin{array}{c}.50 \\
(.84)\end{array}$} \\
\hline & (d.t.) & $(1.16)$ & $(.98)$ & $(.50)$ & \\
\hline & Min.-Max. & $0-3$ & $0-3$ & $0-2$ & \\
\hline \multirow{3}{*}{ Jefe/a } & Media & .05 & .18 & .03 & \multirow{3}{*}{$\begin{array}{c}.07 \\
(.37)\end{array}$} \\
\hline & (d.t.) & $(.22)$ & $(.63)$ & $(.23)$ & \\
\hline & Min.-Max. & $0-1$ & $0-3$ & $0-2$ & \\
\hline \multirow{3}{*}{ Compañeras/os } & Media & .71 & .15 & .02 & \multirow{3}{*}{$\begin{array}{c}.15 \\
(.50)\end{array}$} \\
\hline & (d.t.) & $(.96)$ & $(.44)$ & $(.21)$ & \\
\hline & Min.-Max. & $0-2$ & $0-2$ & $0-2$ & \\
\hline \multirow{3}{*}{ Pareja } & Media & 1.43 & .15 & .14 & \multirow{3}{*}{$\begin{array}{c}.33 \\
(.94)\end{array}$} \\
\hline & (d.t.) & $(1.70)$ & $(.62)$ & $(.56)$ & \\
\hline & Min.-Max. & $0-4$ & $0-3$ & $0-3$ & \\
\hline \multirow{2}{*}{ Total } & Media & .88 & .30 & .11 & .26 \\
\hline & (d.t.) & $(1.00)$ & $(.67)$ & $(.38)$ & $(.66)$ \\
\hline
\end{tabular}

0.Nunca; 1.Una vez; 2.Algunas veces; 3.Bastantes veces; 4 . Siempre 
Hemos encontrado diferencias significativas en la frecuencia de agresiones físicas en función del tipo de prostitución $\quad\left(F_{(2,143)}=37.47, p=.000, \eta^{2}=.34\right)$, de forma que las personas que trabajan en la calle son las que con mayor frecuencia sufren agresiones físicas en comparación con el grupo de club $(p=.000)$ y piso $(p=.000)$. Mientras que no hemos encontrado diferencia entre estos dos últimos grupos.

Al analizar las diferencias entre quienes ejercen las agresiones físicas $\left(F_{(3,429)}=25.73\right.$, $\left.p=.000, \eta^{2}=.15\right)$, hemos encontrado que el cliente y la pareja son los que con mas frecuencia las ejercen. El cliente ejerce significativamente más agresiones físicas en comparación con los /as compañeros /as $(p=.000)$ y los /as jefes/as $(p=.000)$. Mientras que la pareja ejerce significativamente más agresiones que los/as jefes/as $(p=.000)$. $Y$ hemos encontrado diferencias significativas entre los/as compañeros/as y jefes/as de manera que son los primeros los que en mayor medida ejercen agresiones físicas en comparación con los /as jefes /as $(p=.001)$.

Finalmente, hemos encontrado interacción entre quienes ejercen las agresiones físicas y el tipo de prostitución $\left(\mathrm{F}_{(6,429)}=9.46, \mathrm{p}=.000, \eta^{2}=.12\right)$. De manera que, en la calle, el cliente y la pareja son los que con mayor frecuencia realizan agresiones físicas, en comparación con los compañeros las $(p=.000)$ y jefes /as $(p .=000)$. No hemos encontrado diferencias significativas entre cliente y pareja, aunque si que las hemos encontrado entre compañeros los y jefes/ as siendo los /as compañeros /as quienes más violencia física ejercen en comparación con los jefes las $(p=.000)$. En la prostitución de club hemos encontrado que el cliente es quien ejerce significativamente más violencia física en comparación con jefes las $(p=.001)$, y compañeros /as $(p=.000)$, no encontrando diferencias entre estos dos últimos. Finalmente en los pisos hemos encontrado que el cliente es quien mayor violencia física ejerce en comparación con los las compañeros/ as $(p=.009)$ (ver Figura 25). 


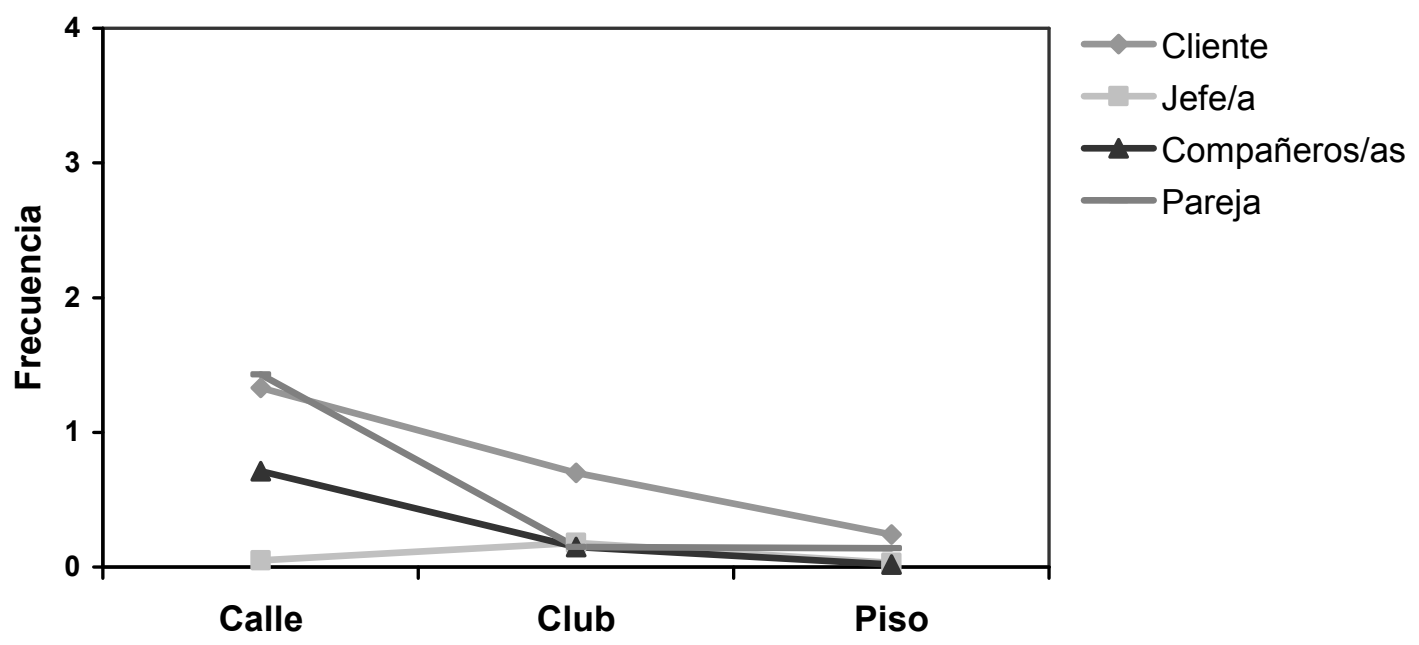

Figura 25. Agresiones físicas durante el ejercicio de la prostitución en función del tipo de prostitución

En resumen, las agresiones físicas dentro del mundo de la prostitución existen, pero debemos reconocer que no son muy numerosas. Si observamos las medias de la frecuencia (ver Figura 25) con la que éstas ocurren podemos ver que, exceptuando el grupo de calle, el resto no llega a una media de uno, es decir, sus respuestas a la pregunta si han sufrido agresiones físicas mientras estaban trabajando oscilan entre nunca y una vez.

Son las personas que trabajan en la calle las que con más frecuencia sufren agresiones físicas, tanto por parte de clientes como por parte de la pareja, e incluso en ocasiones por los/as propios/as compañeros/as. También podemos destacar que de los tres grupos analizados los/as jefes/as no suelen ejercer violencia física, siendo los clientes quienes más violentos son con las personas que ejercen prostitución.

\subsubsection{Salud sexual}

La salud sexual cobra especial importancia en el colectivo de personas que ejercen prostitución debido a la naturaleza de su trabajo. Algunos/as autores/as afirman que los riesgos asociados a la sexualidad deberían considerarse riesgos laborales en las personas que ejercen prostitución (Agustín, 2001). Han existido y existen numerosos mitos relacionados con la sexualidad de este colectivo, se ha dicho que son personas 
caracterizadas por su precocidad sexual y su promiscuidad, además se las ha tachado de ser un foco de infección del VIH/SIDA y de otras ITS (Agustín, 2001; Medeiros, 2000; Vanwesenbeeck, 2001).

En este apartado vamos a hablar sobre diferentes temas relacionados con la salud sexual y la sexualidad de las personas entrevistadas. Describiremos su historia sexual (cuando tuvieron las primeras relaciones sexuales, edad de su primer embarazo, etc.), también las conductas sexuales de riesgo (embarazos no deseados, abortos, VIH/SIDA, etc.), el uso de métodos anticonceptivos y de barrera, las agresiones sexuales que han sufrido durante el ejercicio de la prostitución y finalmente, su estado de satisfacción sexual con el cliente.

- Primeras relaciones sexuales

En primer lugar, vamos a analizar la edad media a la que las personas entrevistadas tuvieron sus primeros contactos sexuales no coitales (ver Figura 26), es decir, los primeros besos, caricias, etc. sin llegar a tener una relación sexual completa. Hemos realizado un ANOVA para comparar las medias de edad de cada uno de los grupos y hemos encontrado diferencias significativas entre los mismos $\left(F_{(2,136)}=4.82, p=.010, \eta^{2}=.01\right)$ de forma que son las personas que ejercen en la calle las que más jóvenes han realizado sus primeras actividades sexuales no coitales, respecto a las personas de club $(p=.01)$, no encontrándose diferencias con las personas que ejercen en piso. 


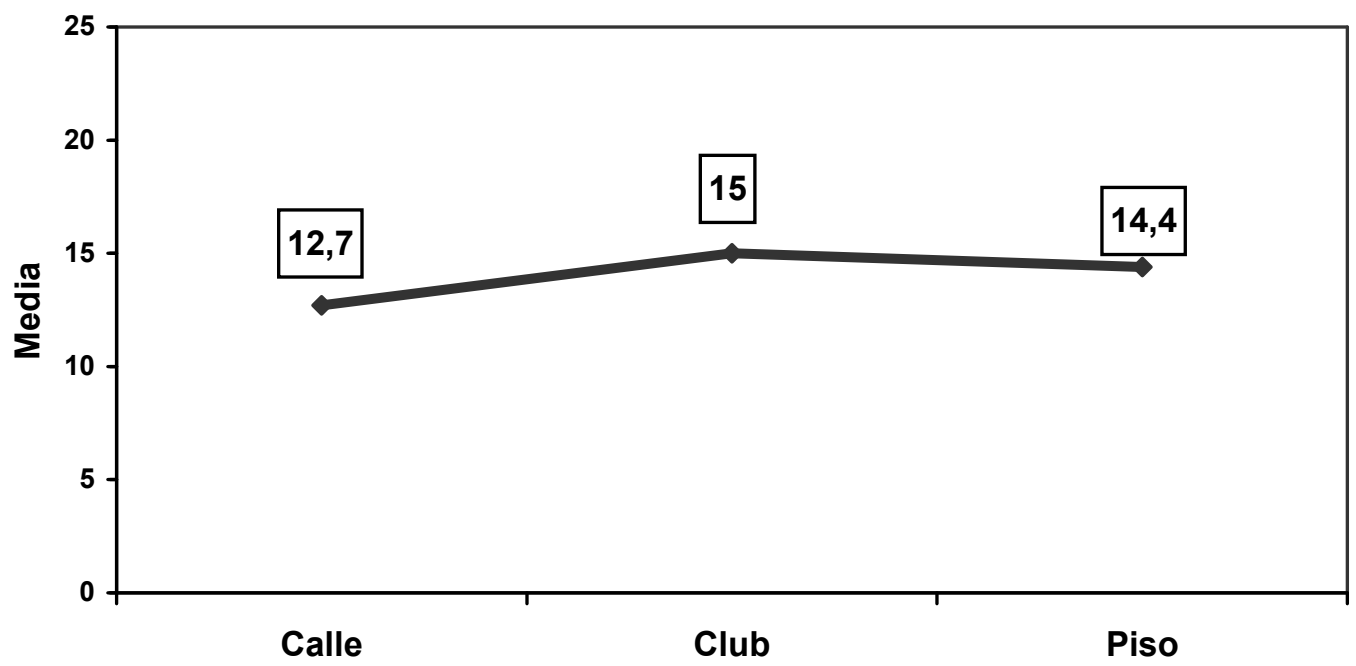

Figura 26. Edad media de los primeros contactos sexuales no coitales en función del tipo de prostitución

Al comparar la edad de las primeras relaciones sexuales coitales (relaciones sexuales con penetración oral, vaginal o anal) entre los tres grupos que componen nuestra muestra no hemos encontrado diferencias significativas $\left(F_{(2,136)}=4.82, p=.02\right)$, de manera que la muestra de personas que ejercen prostitución tienen sus primeras relaciones sexuales coitales a la edad media de 16.40 años (d.t.=2.57).

Con el objetivo de comprobar si realmente las personas que ejercen trabajos sexuales tienen sus primeras relaciones sexuales coitales más jóvenes que el resto de la población y si tienen un mayor número de parejas sexuales, hemos comparado nuestra muestra y los diferentes grupos que la componen con los datos obtenidos de la última "Global sex survey" realizada por Durex durante el año 2005. Hemos elegido este informe como baremo porque nos proporciona datos a nivel mundial, y debido a la heterogeneidad de nacionalidades que componen nuestra muestra hemos pensado que sería más adecuado. Además este informe está realizado a partir de una muestra de 317.000 personas de 41 países diferentes por lo que sus datos son más fiables que otros estudios.

La edad media a la que se tienen las primeras relaciones sexuales coitales según el informe citado es de 17.3 años, esta media es global para todos los países y ambos sexos. En nuestra muestra la media es de 16.40 años $(\mathrm{d} . \mathrm{t} .=2.57)$, realizado una prueba $\mathrm{t}$ hemos encontrado que nuestra muestra tiene su primera relación sexual coital a una edad 
significativamente más joven $\left(\mathrm{t}_{(138)}=-4.15, \mathrm{p}=.000\right.$ ). Al analizarlo en función del tipo de prostitución, encontramos diferencias significativas entre el baremo y las mujeres que ejercen en la calle $\left(t_{(20)}=-5.57, p=.000\right)$, de manera que tienen su primera relación sexual más jóvenes que el baremo, no siendo así en las mujeres que ejercen en piso y club (ver Figura 27).

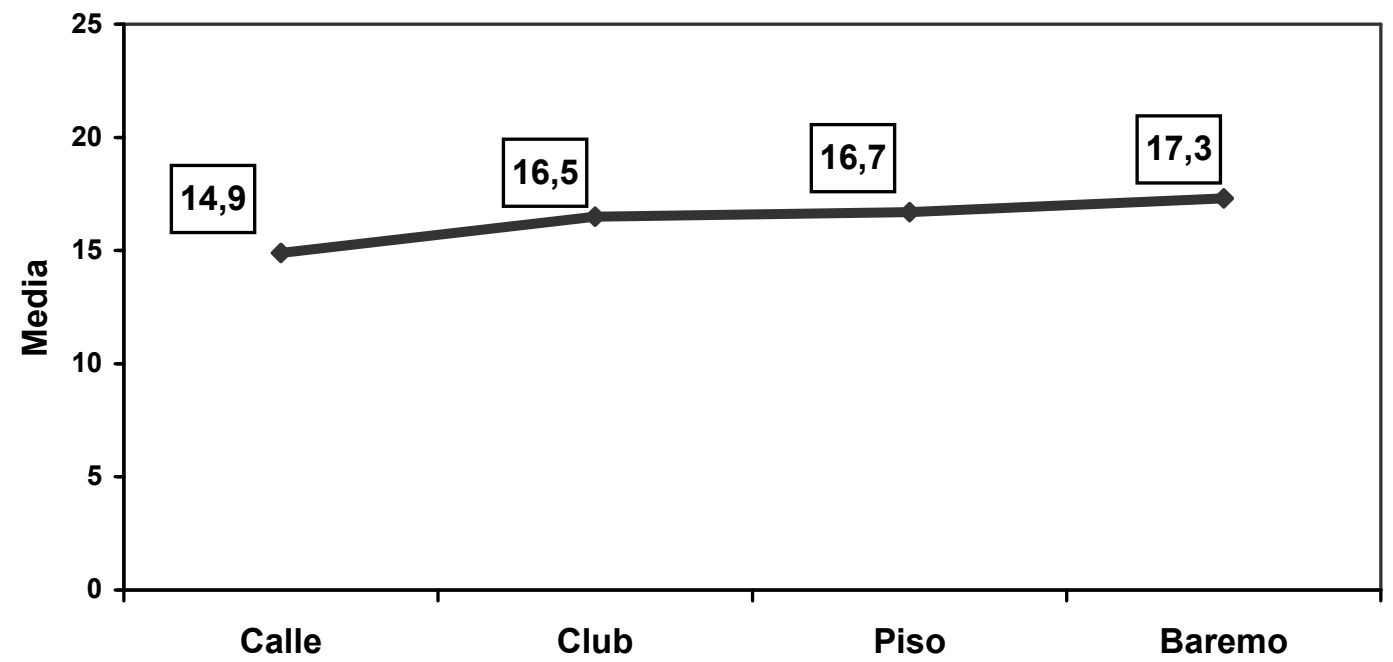

Figura 27. Edad media de los primeros contactos sexuales coitales en función del tipo de prostitución

También hemos comparado el número de parejas antes de ejercer la prostitución de cada uno de los grupos de nuestra muestra (ver Figura 28) y hemos encontrado diferencias entre los grupos $\left(F_{(2,136)}=5.52, p=.005, \eta^{2}=.11\right)$ de forma que, de nuevo, las personas que trabajan en la calle son las que mayor número de parejas tienen antes de ejercer prostitución respecto a las personas que ejercen en piso $(p=.01)$.

En cuanto al número de parejas sexuales que han tenido (ver Figura 28), según el informe la media mundial se sitúa en 9 , mientras que la media de nuestra muestra es de $3.30(\mathrm{~d} . t .=1.58)$, hemos encontrado también diferencias significativas $\left(t{ }_{(138)}=-29.10, p=.000\right)$ de manera que las personas que componen nuestra muestra han tenido un número significativamente menor de parejas sexuales. Hemos obtenido el mismo resultado al analizarlo en función del tipo de prostitución, tanto las personas que ejercen en calle $\left(\mathrm{t}_{(20)}=-\right.$ 5.16, $\mathrm{p}=.000)$, como en club $\left(\mathrm{t}_{(30)}=-13.70, \mathrm{p}=.000\right)$ o piso $\left(\mathrm{t}_{(86)}=-36.46, \mathrm{p}=.000\right)$ han tenido significativamente menos parejas que la población general. 


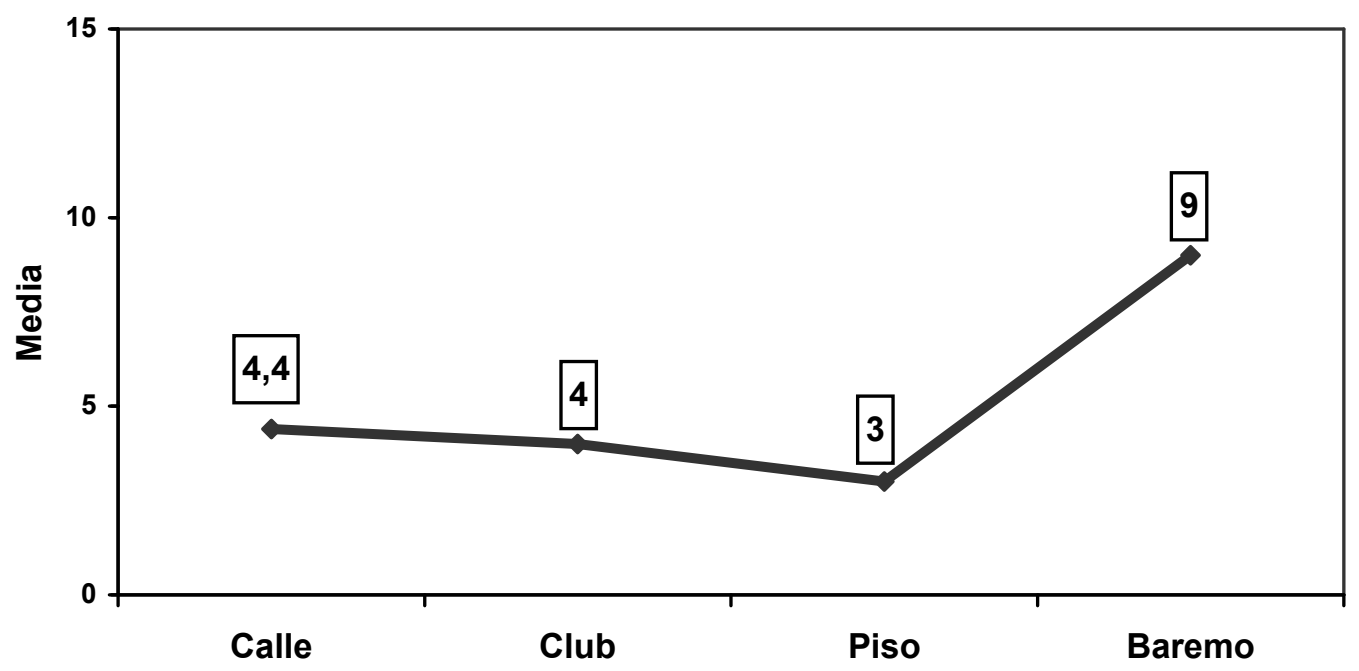

Figura 28. Número medio de parejas sexuales en función del tipo de prostitución

Podemos resumir que nuestra muestra, en general, es más precoz en la edad de sus primeras relaciones sexuales coitales al compararlo con un baremo de población general. Pero dentro de nuestra muestra son las mujeres que trabajan en la calle las que mayor precocidad muestran en comparación con las que trabajan en club o piso. Respecto al mito de la promiscuidad sexual, a partir de los datos de nuestra muestra no podemos decir que sea cierto, ya que tienen significativamente menos parejas sexuales que el baremo de la población general, aunque esta comparación únicamente sea indicativa.

- Uso de métodos anticonceptivos y de barrera

El uso de métodos anticonceptivos y/o de barrera en personas que ejercen trabajos sexuales se ha estudiado a fondo en diferentes estudios (Sánchez et al, 2003; Ward et al., 2004; Warr y Pyett, 1999) a continuación queremos analizar qué tipo de uso hace nuestra muestra de los métodos anticonceptivos y/o de barrera, tanto con el cliente como con su pareja, ya que en ocasiones las infecciones vienen por parte de la pareja, con quienes no toman medidas preventivas.

Hemos analizado el uso de métodos anticonceptivos y de barrera en nuestra muestra, y hemos obtenido que el $100 \%$ afirma usarlos en las relaciones sexuales que 
mantienen con los clientes. No obstante, debemos matizar que este porcentaje es tan elevado debido a que nos referimos a las conductas sexuales con penetración vaginal y/o anal, donde la mayoría de esta población usa métodos de barrera para evitar enfermedades de transmisión sexual. Pero hemos detectado que este uso disminuye cuando nos referimos al sexo oral ("francés natural" o sin protección), ya que muchas prefieren ganar más dinero o conseguir más clientes realizando esta práctica sin protección.

En cuanto a la relación entre el uso del preservativo, femenino y masculino, un $58.2 \%$ de la muestra dice usarlo siempre, mientras que el $41.8 \%$ restante dice sólo usarle con el cliente. Pero no hemos encontrado diferencias en función del tipo de prostitución $\left(\chi^{2}\right.$ (2) $=6.92, p=.03$ ), de forma que los tres tipos de prostitución lo usan en igual medida.

A continuación transcribimos un comentario realizado por una de las entrevistadas en relación al uso de preservativos con los clientes.

“Los tíos tienen mucho miedo de las enfermedades venéreas, pero no se conciencian del uso del preservativo, pero tampoco saben como son, cuando les dices que tú sin preservativo no trabajas se piensan que es porque les vas a pegar alguna enfermedad, ¡No!, no tengo nada, por eso pongo preservativo, porque no quiero contagiarme,

y les dices las enfermedades que pueden coger sin preservativo, la sífilis, la gonorrea,... y les digo cómo... les digo más o menos los síntomas (...) y los tíos ni lo saben ni nada" (Española, trabajando en la calle, 30 años)

En resumen, parece haber un uso adecuado del preservativo en las relaciones sexuales comerciales, aunque no siempre se da de la misma forma en las relaciones sexuales con la pareja, la cual puede ser una vía de infección de enfermedades de transmisión sexual o de embarazos no deseados. 
- Embarazos no deseados e interrupciones voluntarias del embarazo (IVEs)

En los siguientes análisis hemos eliminado a los varones y transexuales ya que hacemos referencia a variables relacionadas con el embarazo. Hemos preguntado si han tenido algún embarazo a término antes de ejercer prostitución y lo hemos analizado en función del tipo de prostitución. Hemos encontrado relación entre ambas variables $\left(\chi_{(2)}^{2}=\right.$ 9.73, $\mathrm{p}=.008, \mathrm{C}=.25$ ) de manera que únicamente las mujeres de club afirman en mayor medida haber tenido un embarazo a término antes de ejercer prostitución (residuos tipificados corregidos=3.1) (ver Figura 29).

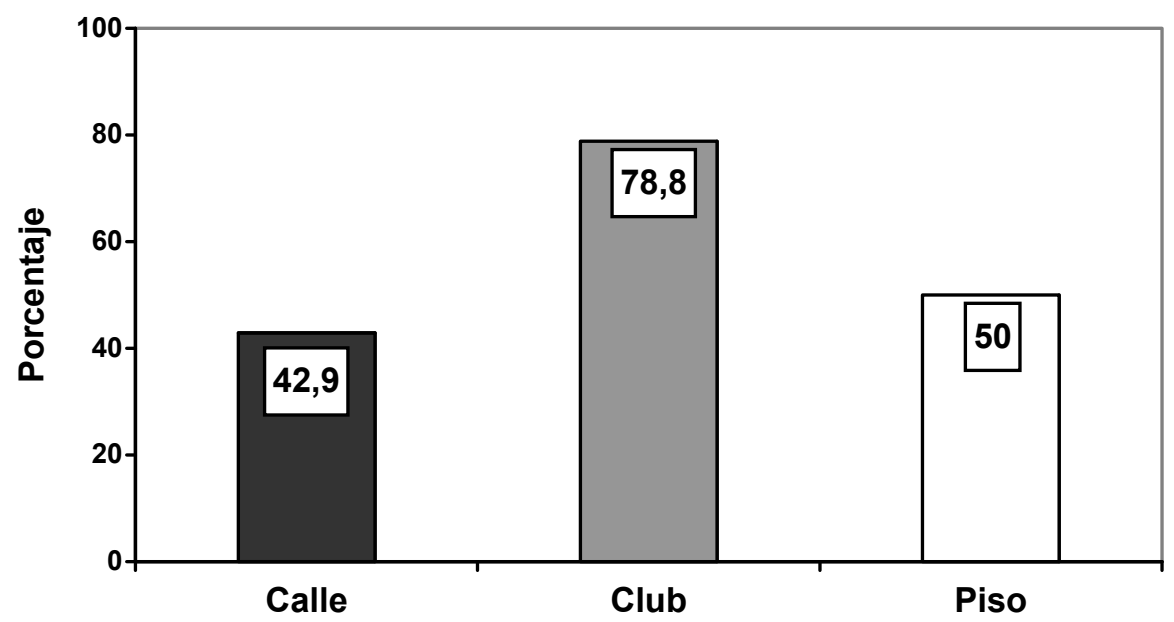

Figura 29. Porcentaje de mujeres con un embarazo a término antes de ejercer prostitución

Al analizar si ese primer embarazo de las mujeres entrevistadas fue deseado o no (ver Figura 30) hemos encontrado relación entre ambas variables $\left(\chi_{(4)}^{2}=13.92, p=.008\right.$, $\mathrm{C}=.30$ ) de forma que las mujeres de la calle afirmaron en mayor medida que no deseaban a ese/a hijo/a (residuos tipificados corregidos=2.2) mientras que las de piso lo dijeron en menor medida (residuos tipificados corregidos=-2.9). 


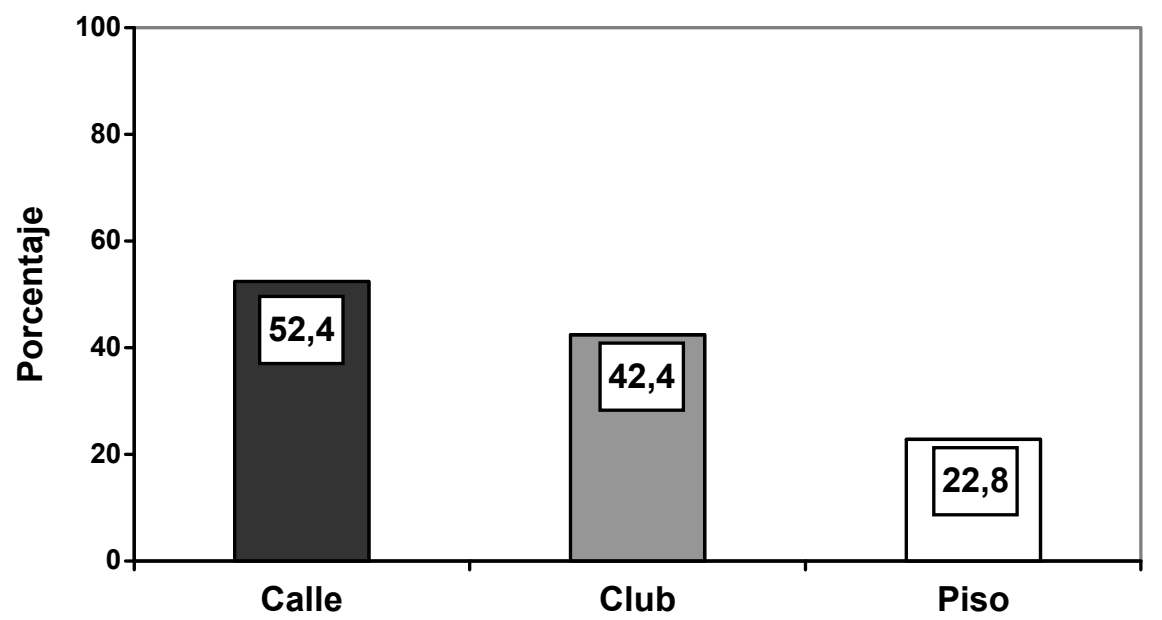

Figura 30. Porcentaje de mujeres cuyo primer embarazo no fue deseado en función del tipo de prostitución

Al analizar la edad media del primer embarazo no hemos encontrado diferencias significativas entre los grupos $\left(F_{(2,86)}=1.26, p=.29\right)$, siendo la media de edad del primer embarazo de 19.25 años (d.t.=3.39) con un mínimo de 13 años y un máximo de 29 años.

A continuación vamos a analizar el número de interrupciones voluntarias del embarazo que nuestra muestra se ha practicado, antes y durante el ejercicio de la prostitución en función del tipo de prostitución. Nos parece interesante analizar este aspecto ya que los embarazos no deseados son un riesgo que corren las mujeres que ejercen prostitución y los abortos, más aún cuando se dan en repetidas ocasiones, es un grave problema de salud.

Hemos analizado el número de abortos o IVEs practicados mediante un ANOVA mixto (ver Tabla 27) con un factor intra con dos niveles: abortos antes de ejercer prostitución y abortos durante el ejercicio; y un facto inter, el tipo de prostitución (calle, club y piso). 
Tabla 27. Interrupciones voluntarias de embarazo en función del tipo de prostitución

\begin{tabular}{|c|c|c|c|c|c|}
\hline & & \multicolumn{3}{|c|}{ Tipo de prostitución } & \multirow{2}{*}{ Total } \\
\hline & & Calle & Club & Piso & \\
\hline & $\mathbf{n}$ & 15 & 31 & 73 & 119 \\
\hline \multirow{3}{*}{ IVEs antes de ejercer prostitución } & Media & 1.27 & .35 & .30 & \multirow{3}{*}{$\begin{array}{c}.44 \\
(.83)\end{array}$} \\
\hline & (d.t.) & $(1.58)$ & $(.61)$ & $(.57)$ & \\
\hline & Min.-Max. & $0-5$ & $0-2$ & $0-2$ & \\
\hline \multirow{3}{*}{$\begin{array}{l}\text { IVEs durante el ejercicio de la } \\
\text { prostitución }\end{array}$} & Media & 1.20 & .26 & .29 & \multirow{3}{*}{$\begin{array}{c}.39 \\
(.68)\end{array}$} \\
\hline & (d.t.) & $(1.21)$ & $(.51)$ & $(.59)$ & \\
\hline & Min.-Max. & $0-4$ & $0-2$ & $0-2$ & \\
\hline \multirow{2}{*}{ Total } & Media & 1.23 & .31 & .30 & .41 \\
\hline & (d.t.) & $(1.40)$ & $(.56)$ & $(.58)$ & $(.79)$ \\
\hline
\end{tabular}

Hemos encontrado diferencias significativas en el número de IVEs en función del tipo de prostitución $\left(\mathrm{F}_{(2,116)}=16.35, \mathrm{p}=.000, \eta^{2}=.22\right)$, de forma que las mujeres que ejercen prostitución en la calle han tenido mayor número de IVEs en comparación con las mujeres que ejercen en club $(p=.000)$ y piso $(p=.000)$, no habiendo diferencias entre estos últimos.

En cuanto al análisis intra, no hemos encontrado diferencias significativas entre el número de IVEs practicados antes de ejercer prostitución y los realizados durante el ejercicio de la misma $\left(F_{(1,116)}=.39, p=.53\right)$. Finalmente, tampoco hemos encontrado interacción entre cuándo se han llevado a cabo los abortos y el tipo de prostitución $\left(F_{(2,116)}=\right.$ $.11, p=.89)$.

Podemos resumir que las mujeres que trabajan en la calle son las que han tenido y tienen mayor número de IVEs, tanto antes como durante el ejercicio de la prostitución, en comparación con el resto de grupos. De nuevo son las que presentan las peores condiciones, esta vez relacionadas con la salud sexual.

- Infecciones de transmisión sexual y VIH/SIDA

Como ya hemos señalado, el colectivo de personas que realizan trabajos sexuales siempre ha sido acusado de ser un foco de infecciones de transmisión sexual y de VIH/SIDA, aunque estudios recientes demuestran que no es así (Medeiros, 2000; Solana, 
2003; Vanwesenbeeck, 2001; Warr y Pyett, 1999) ya que las personas que ejercen prostitución se cuidan y suelen protegerse para evitar el contagio o la infección de este tipo de enfermedades, como hemos visto anteriormente en el apartado de revisiones médicas. Además, los resultados de los estudios sobre la prevalencia de VIH sobre todo en Norte América y Europa indican que aquellas prostitutas que están infectadas por VIH lo están principalmente por el uso de drogas inyectables (Vanwesenbeeck, 2001).

Hemos analizado si las personas entrevistadas han sufrido en alguna ocasión alguna ETS (ver Figura 31) y hemos encontrado relación con el tipo de prostitución $\left(\chi_{(2)}^{2}=13.56\right.$, $\mathrm{p}=.001, \mathrm{C}=.29$ ) de manera que las personas que ejercen en la calle presentan mayor número de ETS (residuos tipificados corregidos=3.5) mientras que las de piso son las que presentan menor porcentaje de ETS (residuos tipificados corregidos=-2.8).

En cuanto a la infección por VIH también hemos encontrado relación entre esta variable (ver Figura 31) y el tipo de prostitución $\left(\chi_{(2)}^{2}=23.96, p=.000, C=.38\right.$ ), de manera que las mujeres que ejercen en la calle son las que en mayor medida son VIH positivas (residuos tipificados corregidos $=4.8$ ) mientras que las mujeres de piso lo son en menor medida (residuos tipificados corregidos=-3.2).

Como vemos las personas que ejercen prostitución en la calle vuelven a ser el grupo con mayores problemas de salud sexual, son las que mayor porcentaje de ITS y VIH/SIDA presentan. Estos datos pueden estar relacionados con que la muestra de personas que ejercen en la calle es, en su mayoría, población drogodependiente, con muchos años de consumo y siendo éste en muchos casos intravenoso, por lo que suele ser la vía de infección. 

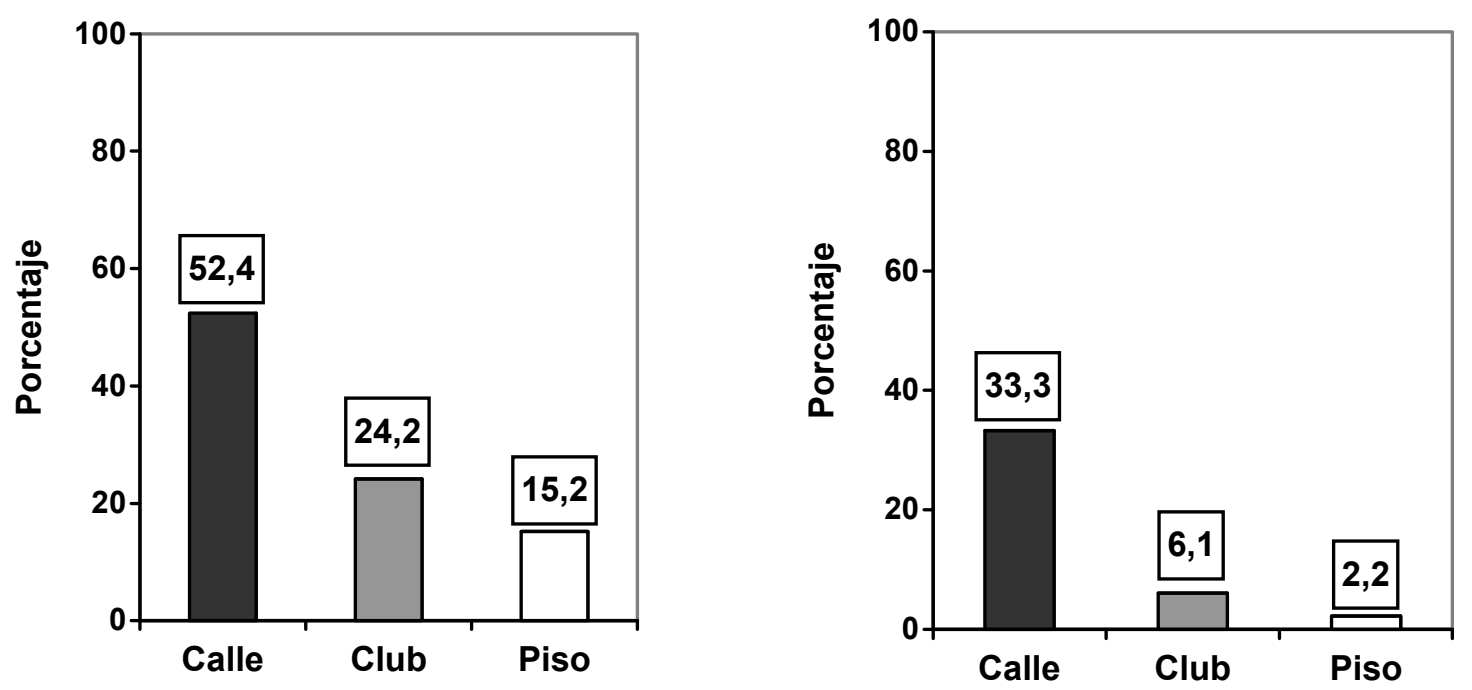

Figura 31 Porcentaje de personas con infecciones de transmisión sexual y personas seropositivas al VIH/SIDA en función del tipo de prostitución

- Agresiones sexuales durante el ejercicio de la prostitución

Las agresiones sexuales dentro del mundo de la prostitución existen, pero si nos fijamos en la Tabla 28, podemos ver que exceptuando las mujeres de la calle, encontramos medias de frecuencia de agresiones sexuales cercanas a 0 , es decir, su respuesta es mayoritariamente nunca.

Hemos analizado la frecuencia de las agresiones sexuales mediante un ANOVA mixto con un factor intra, quien ejerce las agresiones sexuales, compuesto por dos niveles: el cliente y la pareja; y un facto inter, el tipo de prostitución (calle, club y piso). No hemos incluido en el ANOVA las agresiones sexuales cometidas por jefes o encargados/as y compañeras/os porque todas las medias están en torno a cero y no hay variabilidad. 
Tabla 28. Agresiones sexuales durante el ejercicio de la prostitución en función del tipo de prostitución

\begin{tabular}{|c|c|c|c|c|c|}
\hline \multirow{3}{*}{ Agresiones sexuales* } & & \multicolumn{3}{|c|}{ Tipo de prostitución } & \multirow{2}{*}{ Total } \\
\hline & & Calle & Club & Piso & \\
\hline & $\mathbf{n}$ & 21 & 33 & 92 & 146 \\
\hline \multirow{3}{*}{ Por parte del cliente } & Media & .76 & .91 & .30 & .51 \\
\hline & (d.t.) & (1.09) & (1.31) & $(.81)$ & 1.01 \\
\hline & Min.-Max. & $0-3$ & $0-3$ & $0-4$ & \\
\hline \multirow{3}{*}{ Por parte de jefes o encargados } & Media & .10 & .06 & .00 & .03 \\
\hline & (d.t.) & $(.44)$ & $(.35)$ & $(.00)$ & $(.23)$ \\
\hline & Min.-Max. & $0-2$ & $0-2$ & $0-0$ & \\
\hline \multirow{3}{*}{ Por compañeros/as } & Media & .05 & .00 & .00 & .01 \\
\hline & (d.t.) & $(.22)$ & $(.00)$ & $(.00)$ & $(.08)$ \\
\hline & Min.-Max. & $0-1$ & $0-0$ & $0-0$ & \\
\hline \multirow{3}{*}{ Por la pareja } & Media & .62 & .15 & .12 & .20 \\
\hline & (d.t.) & (1.24) & $(.62)$ & (.63) & $(.76)$ \\
\hline & Min.-Max. & $0-4$ & $0-3$ & $0-4$ & \\
\hline \multirow{2}{*}{ Total } & Media & .69 & .53 & .21 & .36 \\
\hline & (d.t.) & (1.17) & $(.97)$ & $(.72$ & $(.89)$ \\
\hline
\end{tabular}

0.Nunca; 1.Una vez; 2.Algunas veces; 3.Bastantes veces; 4. Siempre

En primer lugar, hemos encontrado efectos significativos del tipo de prostitución ( $F$ $\left.(2,143)=5.39, p=.006, \eta^{2}=.07\right)$, de forma que las personas que ejercen prostitución en la calle sufren mayor numero de agresiones sexuales que las que ejercen en piso $(p=.01)$, no encontrándose diferencias significativas entre el resto de grupos (ver Figura 32).

Al analizar las diferentes personas que realizan las agresiones sexuales hemos encontrado diferencias significativas $\left(F_{(1,143)}=12.28, p=.001, \eta^{2}=.08\right)$, de forma que el cliente es quien ejerce mayor violencia sexual en comparación con la pareja $(p=.001)$ (ver Figura 32).

Finalmente, no hemos encontrado interacción entre quien realiza las agresiones sexuales y el tipo de prostitución $\left(F_{(2,143)}=4.00, p=.02\right)$. 


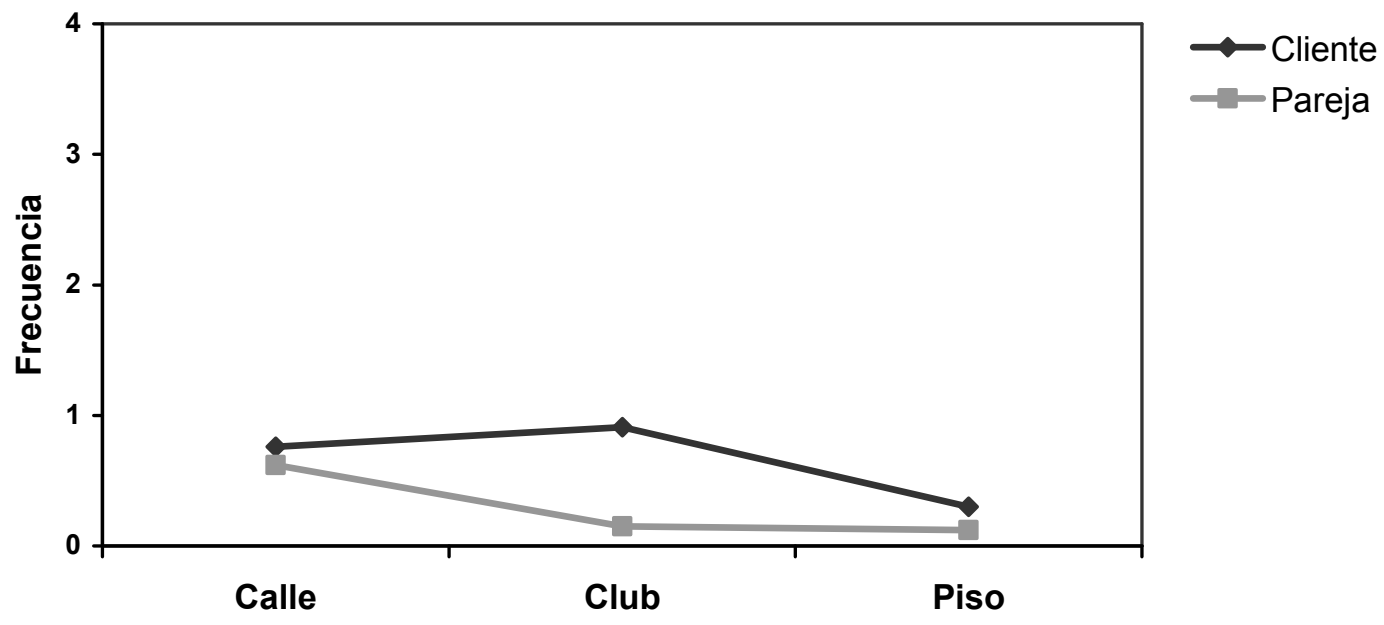

Figura 32. Frecuencia media de agresiones sexuales en función del tipo de prostitución

Podemos ver que tanto en los resultados sobre agresiones físicas como en los resultados sobre agresiones sexuales las personas que ejercen en la calle son las que sufren más violencia en general, y el cliente es quien en mayor medida lleva a cabo esta violencia, seguido en algunos casos por la pareja.

- Placer sexual con el cliente

Para terminar con este punto sobre salud sexual, hemos evaluado si las personas entrevistadas sienten excitación o placer sexual en las relaciones sexuales comerciales realizadas con clientes. Un $30 \%$ de la muestra dice no haber sentido nunca placer o excitación sexual con el cliente, un $46 \%$ dice haberlo sentido alguna vez y un $24 \%$ bastantes veces, pero no hemos encontrado relación con el tipo de prostitución $\left(\chi_{(4)}^{2}=9.40, p=.05\right)$, de manera que tanto el grupo de calle como el de club o piso afirman sentir placer con los clientes de la misma forma.

A continuación transcribimos un comentario realizado por una de las mujeres entrevistadas en relación con el placer sexual sentido con los clientes. 
"A mi algunos clientes me dicen ¿Disfrutas alguna vez? Y yo les digo "yo soy de carne y hueso, si te lo sabes montar bien..." porque hay algunos que te dicen "Pero tu chica ¿te corres alguna vez? Y les dices que si, en cuanto se lo dije, parecía que se me había caído el crucifijo de la pared, ¡madre mía! ¡Contigo no...!”

(Española, trabajando en la calle, 30 años)

Como vemos la mayoría de las personas entrevistadas (70\%) afirman haber disfrutado sexualmente en alguna ocasión con el cliente y algunas de ellas bastantes veces.

\subsubsection{Salud psicológica}

En este apartado analizaremos cómo es el estado de salud mental o psicológica de las personas entrevistadas que ejercen prostitución. Comprobaremos como ha sido su salud mental anterior al ejercicio de la prostitución, cómo es su salud mental actual y si han recibido malos tratos psicológicos durante el ejercicio de la misma.

- Salud mental: niveles de depresión, ansiedad y autoestima

En primer lugar vamos a analizar como ha sido su salud mental anterior, es decir, si han sido diagnosticadas por un profesional en el pasado de depresión o de ansiedad. Hemos encontrado relación entre haber sido diagnosticada de depresión o ansiedad anteriormente a la prostitución y el tipo de prostitución $\left(\chi_{(2)}^{2}=12.46, p=.002, C C=.28\right)$, de forma que las mujeres de la calle dicen en mayor medida que han tenido problemas de ansiedad o depresión (residuos tipificados corregidos=3.3) y las de club lo dicen en menor medida (residuos corregidos tipificados $=-2.0$ ) (ver Figura 33). 


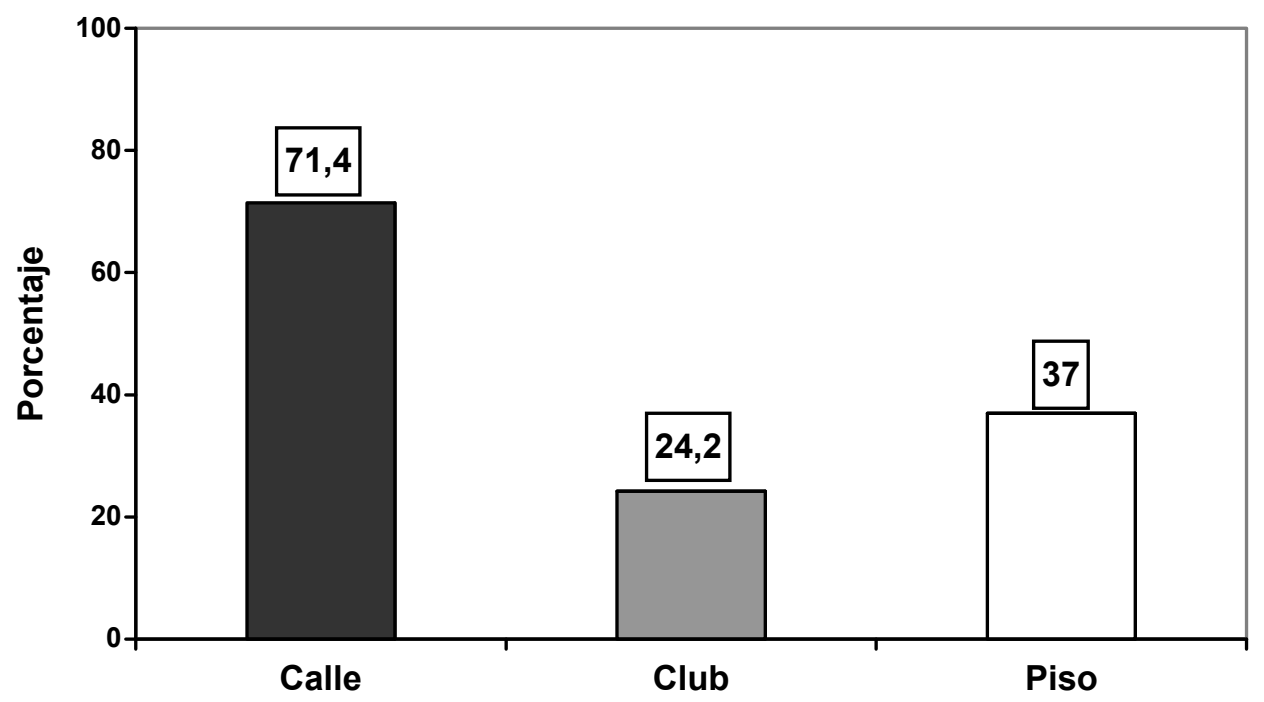

Figura 33. Porcentaje de personas diagnosticadas en el pasado de depresión o ansiedad en función del tipo de prostitución

También hemos evaluado el estado de salud mental actual en nuestra muestra mediante tres escalas que evalúan depresión, ansiedad y autoestima. En primer lugar hemos comparado las puntuaciones obtenidas en depresión y ansiedad de cada uno de los tipos de prostitución (calle, club y piso) con el baremo obtenido de la población general (López y Becoña, 2006).

En cuanto a la depresión hemos obtenido diferencias significativas entre la muestra general y baremo $\left(t_{(145)}=6.46, p=.000\right)$, de manera que nuestra muestra presenta puntuaciones mayores en depresión. De la misma forma hemos obtenido diferencias significativas entre cada uno de los tipos de prostitución: calle $\left(\mathrm{t}_{(20)}=4.51, \mathrm{p}=.000\right)$, club $\left(\mathrm{t}_{(32)}=\right.$ $3.78, p=.001)$ y piso $\left(t_{(91)}=3.70, p=.000\right), y$ el baremo. De forma que los tres tipos de prostitución presentan puntuaciones mayores que el baremo en depresión.

En relación con la ansiedad no hemos obtenido diferencias significativas entre la muestra general y el baremo $\left(\mathrm{t}_{(145)}=1.27, \mathrm{p}=.21\right)$, de forma que nuestra muestra tiene niveles de ansiedad similares a la población general. Sin embargo, sí que hemos encontrado diferencias entre el grupo de calle y el baremo $\left(t{ }_{(20)}=4.15, p=.000\right)$, de forma que las personas que ejercen prostitución en la calle presentan niveles de ansiedad superiores a la población general. 
Después hemos realizado un ANOVA mixto (ver Tabla 29) con un factor intra, la salud mental, compuesto por dos niveles: puntuaciones en depresión y ansiedad y un facto inter, el tipo de prostitución (calle, club y piso).

Tabla 29. Puntuaciones en depresión, ansiedad y autoestima en función del tipo de prostitución

\begin{tabular}{|c|c|c|c|c|c|}
\hline & \multicolumn{5}{|c|}{ Tipo de prostitución } \\
\hline & & Calle & Club & Piso & Total \\
\hline & $\mathbf{n}$ & 21 & 33 & 92 & 146 \\
\hline \multirow{2}{*}{ Depresión } & Media & 1.74 & 1.24 & .97 & 1.14 \\
\hline & (d.t.) & $(1.03)$ & $(.79)$ & $(.66)$ & $(.79)$ \\
\hline \multirow{2}{*}{ Ansiedad } & Media & 1.15 & .59 & .46 & .59 \\
\hline & (d.t.) & $(.69)$ & $(.68)$ & $(.62)$ & (.68) \\
\hline \multirow{2}{*}{ Total } & Media & 1.44 & .92 & .72 & .87 \\
\hline & (d.t.) & $(.86)$ & $(.74)$ & $(. .64)$ & $(.74)$ \\
\hline
\end{tabular}

En primer lugar, hemos encontrado efectos significativos del tipo de prostitución ( $F$ $\left.(2,143)=10.61, p=.000, \eta^{2}=.13\right)$, de forma que las personas que ejercen prostitución en calle presentan peor salud mental que las de club $(p=.01)$ y las de piso $(p=.000)$. No encontrando diferencias significativas entre los dos últimos grupos.

Al analizar los diferentes niveles de salud mental hemos encontrado diferencias significativas $\left(F_{(1,143)}=134.76, p=.000, \eta^{2}=.49\right)$, de manera que la muestra presenta mayor número de síntomas relacionados con la depresión que síntomas relacionados con la ansiedad (ver Figura 34).

Finalmente, no hemos encontrado interacción entre los diferentes niveles de salud mental y el tipo de prostitución $\left(F_{(2,143)}=1.00, p=.37\right)$. Como vemos en la Figura 34 los síntomas de depresión son más frecuentes para los tres grupos. Así mismo, las de calle son las que sufren más síntomas de depresión y de ansiedad en comparación con los otros dos grupos. 


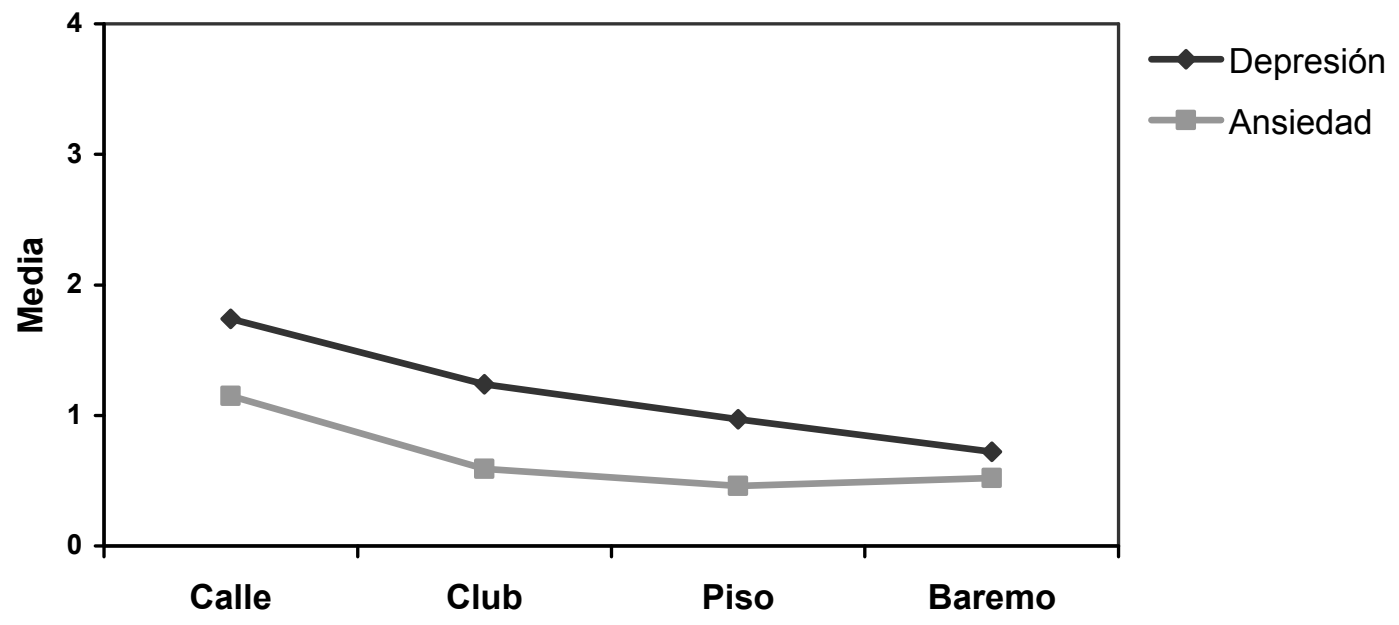

Figura 34. Medias en salud mental en función del tipo de prostitución

Como podemos ver la salud mental de las personas que ejercen en la calle vuelve a ser peor que la del resto de grupos, tanto antes de ejercer prostitución como durante el ejercicio de la misma. Pero debemos destacar que la muestra en general (calle, club y piso) no presenta un nivel óptimo de salud mental ya que tiene niveles de depresión superiores a la población general.

A continuación vamos a analizar el nivel de autoestima de la muestra, para ello hemos comparado el nivel de autoestima de nuestra muestra con los rangos descritos por Burns (2001) a partir de datos obtenidos en España. Según este autor las puntuaciones obtenidas en la escala de autoestima de Rosenberg se pueden interpretar a partir de estos rangos: de 30 a 40 puntos autoestima elevada, de 26 a 29 puntos autoestima media y menos de 25 puntos autoestima baja. Dado que la muestra general tiene una media de 29.9 puntos podría considerarse un nivel de autoestima elevada. Mientras que, como vemos en la Figura 35, las personas de la calle presentan un nivel de autoestima medio lo que significa que aunque no presenta problemas graves es conveniente mejorarla. Mientras, las persona de piso y club presentan un nivel elevado de autoestima considerado un nivel normal.

A continuación hemos comparado las puntuaciones obtenidas en la escala de autoestima por cada uno de los tipos de prostitución (calle, club y piso), y hemos encontrado diferencias significativas entre los grupos $\left(F_{(2,141)}=8.38, p=.000, \eta^{2}=.11\right)$, de forma que las 
personas que ejercen prostitución en piso presentan un mayor nivel de autoestima en comparación con las que trabajan en la calle $(p=.000)$, no hemos encontrado diferencias entre el resto de grupos.

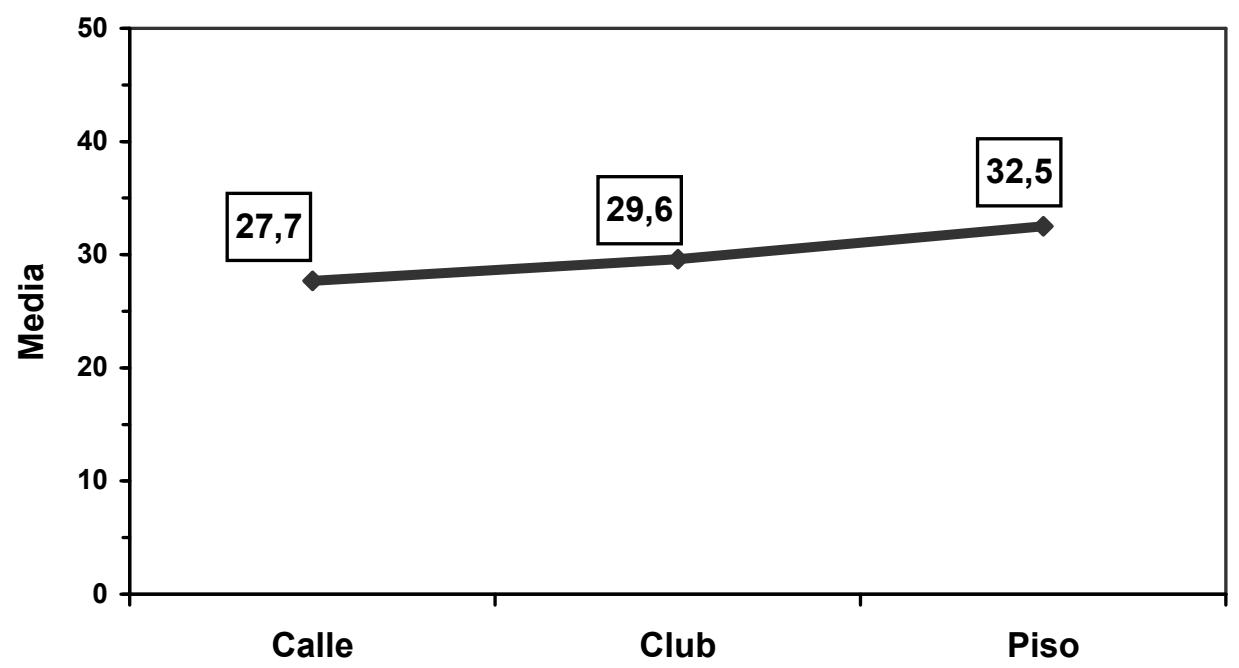

Figura 35. Puntuación media en autoestima en función del tipo de prostitución

En resumen, las personas que ejercen en la calle vuelven a presentar el peor nivel de autoestima en comparación con el resto de tipos de prostitución y debería ser mejorado. Mientras el resto de grupos presentan un nivel de autoestima normal.

- Agresiones psicológicas durante el ejercicio de la prostitución

El estigma y rechazo que siente el colectivo de personas que prostitución por parte de toda la sociedad se plasma en los malos tratos psicológicos que sufren por parte de las personas que las rodean (clientes, jefes/as, pareja e incluso compañeras). Las agresiones psicológicas y las humillaciones dentro del mundo de la prostitución son un problema real que debemos analizar y abordar.

A continuación pasamos a describir las agresiones o malos tratos psicológicos que las personas entrevistadas han sufrido durante el ejercicio de la prostitución. Hemos evaluado, por una parte, qué personas han cometido estas agresiones psicológicas (cliente, jefe/a, compañeras/os y pareja) y por otra, la frecuencia media con la que se han dado. 
Hemos analizado la frecuencia de los malos tratos psicológicos mediante un ANOVA mixto (ver Tabla 30) con un factor intra, quién ejerce las agresiones psicológicas, compuesto por cuatro niveles: el cliente, el/la jefe/a, los/as compañeras/os y la pareja; y un facto inter, el tipo de prostitución (calle, club y piso).

Tabla 30. Agresiones psicológicas en función del tipo de prostitución

\begin{tabular}{|c|c|c|c|c|c|}
\hline \multirow{2}{*}{\multicolumn{2}{|c|}{ Agresiones psicológicas* }} & \multicolumn{3}{|c|}{ Tipo de prostitución } & \multirow{2}{*}{ Total } \\
\hline & & Calle & Club & Piso & \\
\hline & $\mathbf{n}$ & 21 & 33 & 92 & 146 \\
\hline \multirow{3}{*}{ Por parte del cliente } & Media & 1.19 & .88 & .43 & .64 \\
\hline & (d.t.) & $(1.03)$ & $(.43)$ & $(.76)$ & $(.92)$ \\
\hline & Min.-Max. & $0-3$ & $0-3$ & $0-3$ & \\
\hline \multirow{3}{*}{$\begin{array}{c}\text { Por parte de jefes o } \\
\text { encargados }\end{array}$} & Media & .10 & .61 & .17 & .26 \\
\hline & (d.t.) & $(.61)$ & $(.17)$ & $(.67)$ & $(.80)$ \\
\hline & Min.-Max. & $0-1$ & $0-4$ & $0-4$ & \\
\hline \multirow{3}{*}{ Por compañeros/as } & Media & .14 & .52 & .10 & .20 \\
\hline & (d.t.) & $(.36)$ & $(.90)$ & $(.30)$ & $(.53)$ \\
\hline & Min.-Max. & $0-1$ & $0-3$ & $0-1$ & \\
\hline \multirow{3}{*}{ Por la pareja } & Media & 1.57 & .24 & .21 & .41 \\
\hline & (d.t.) & $(1.75)$ & $(.71)$ & $(.78)$ & $(1.07)$ \\
\hline & Min.-Max. & $0-4$ & $0-3$ & $0-4$ & \\
\hline \multirow{2}{*}{ Total } & Media & .75 & .56 & .23 & .38 \\
\hline & (d.t.) & $(.86)$ & $(.97)$ & $(.63)$ & $(.83)$ \\
\hline
\end{tabular}

0.Nunca; 1.Una vez; 2.Algunas veces; 3.Bastantes veces; 4. Siempre

En primer lugar, hemos encontrado diferencias entre los tipos de prostitución en cuanto a las agresiones psicológicas sufridas $\left(F_{(2,143)}=12.92, p=.000, \eta^{2}=.15\right)$, de forma que las personas que ejercen prostitución en piso sufren menos violencia psicológica que las que trabajan en calle $(p=.000)$ o en club $(p=.003)$, entre los cuales no hemos obtenido diferencias significativas.

Hemos encontrado diferencias significativas entre quienes ejercen las agresiones psicológicas $\left(F_{(3,429)}=15.32, \quad p=.000, \eta^{2}=.10\right)$, de manera que el cliente realiza mayor número de agresiones psicológicas en comparación con los/as jefes/as $(p=.000)$ y los/as compañeros/as $(p=.000)$. También hemos encontrado que la pareja ejerce más agresiones psicológicas que los/as jefes/as $(p=.003)$ y los/as compañeros/as $(p=.001)$. Entre el cliente y 
la pareja, y entre los/as jefes/as y compañeros/as no hemos encontrado diferencias significativas.

Finalmente (ver Figura 36), hemos encontrado interacción entre las diferentes personas que ejercen agresiones psicológicas y el tipo de prostitución $\left(F_{(6,429)}=9.33\right.$, $p=.000$, $\left.\eta^{2}=.12\right)$. En las personas que ejercen en la calle, la pareja y el cliente son los que más violencia psicológica ejercen en comparación con los/as jefes/as $(p=.000)$ y compañeros/as $(p=.000)$. No hemos encontrado diferencias significativas ni entre cliente y pareja, ni entre jefes/as y compañeros/as. En club no encontramos diferencias significativas entre las personas que ejercen agresiones psicológicas. $\mathrm{Y}$ en los pisos es el cliente quien ejerce mayor violencia psicológica en comparación con los/as compañeros/as $(p=.002)$, no encontrando de nuevo diferencias entre el resto.

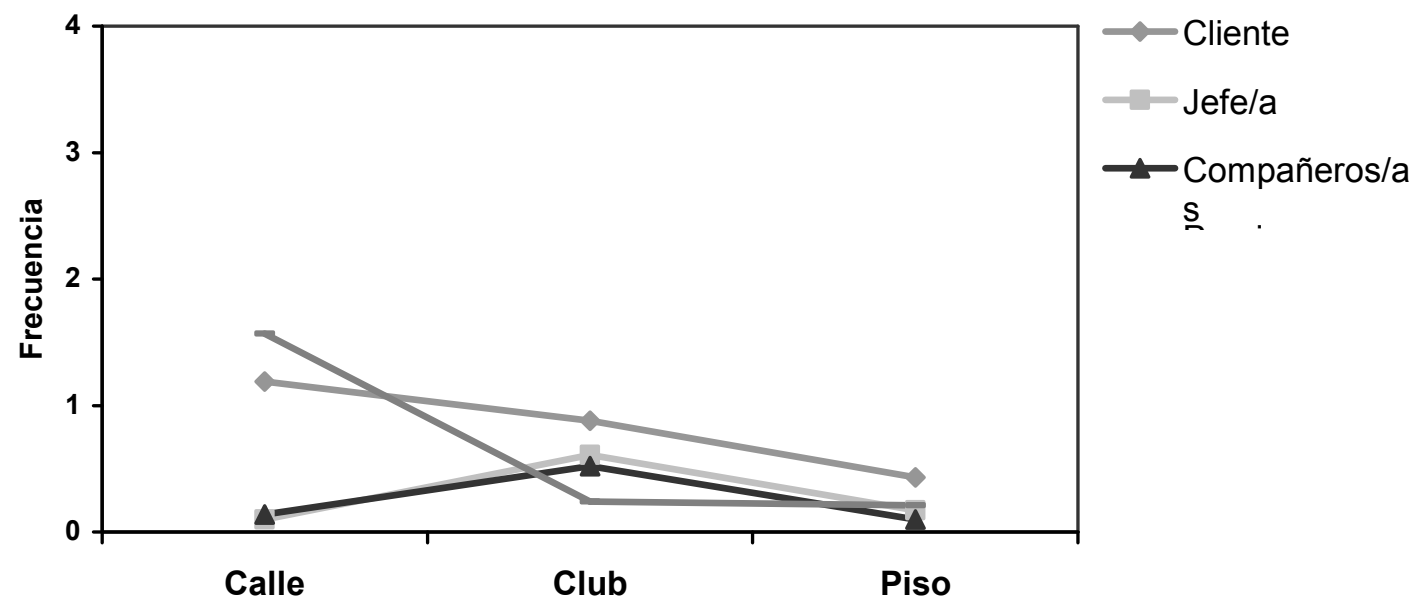

Figura 36. Agresiones psicológicas en función del tipo de prostitución

Como en los casos anteriores, sobre agresiones físicas y sexuales, el cliente es el que más violencia psicológica ejerce sobre las personas entrevistadas. Aunque en el caso de las mujeres de la calle, la pareja también ejerce violencia, incluso más que los clientes. Las que trabajan en club también reciben agresiones psicológicas por parte de sus jefes/as o encargados/as. Transcribimos a continuación algunos comentarios realizados por las personas entrevistadas que apoyan los datos presentados, tanto sobre agresiones físicas, como psicológicas como sexuales. 
"A mí el sábado uno me ha dado de patadas porque estaba borracho y yo no podía terminar el servicio, y decía que le devolviera el dinero, y yo había estado haciendo el trabajo, el servicio, y como no tenemos seguridad y no tenemos una persona que nos defienda aquí... Y me dijo "iQué! ¡Puta yonqui de mierda!... Me hice pis, del miedo me hice pis, y me decía “iMarrana!, mira... ¡Que te estás meando!" y se reía de mí"

(Española, trabajando en la calle, 35 años)

"A mi me veían como un bicho raro ahí, y ya me decian, me insultaban, me decían de todo... y yo bajaba la cabeza porque no tenía papeles, nunca decía nada, nunca, nunca" (Colombiana, trabajando en un piso, 33 años)

"La gente discrimina, y todos te dicen, te voy a denunciar, tu eres extranjera, te voy a deportar, porque eres prostituta, tu eres una puta... así te contesta mucha gente, de mala manera por eso una tiene miedo de todo, y no afronta los problemas. Yo misma a veces tengo miedo a hablar con alguien en la calle" (Brasileña, trabajando en club, 29 años) "Hombre, llega de todo, yo estoy aquí más atenta, les atiendo, les abro la puerta, y cuando algunos te preguntan “¿Dónde están las putitas?” ya les digo, "Mira, esas chicas de las que tu hablas son personas como tu, ¿Y qué haces aquí tu entonces? Coges la puerta y te vas, ellas son personas igual y necesitan el mismo respeto que tu pides para ti" (Colombiana, trabajando en piso, 38 años)

"Que la gente realmente se acerque más a nosotras también porque es un rechazo total, yo puedo ser una estupenda persona pero si saben que hago esto, ¡buf! ¡Es como si tuvieras la lepra! Y yo sigo siendo la misma persona" (Paraguaya, trabajando en piso, 31 años) 
7.2. Necesidades interpersonales básicas: necesidades emocionales, sociales y sexuales

En la actualidad, como vemos en nuestra muestra y otros estudios el colectivo de personas que ejercen prostitución está formado mayoritariamente por personas inmigrantes (Agustín, 2001; Juliano, 2004a; López y Mestre, 2006; López y Pinedo, 2007; Pheterson, 2000; Solana, 2003). Debido a los factores asociados a la inmigración (desarraigo, tener las figuras de apego emocional en sus países de origen, etc.) y a los factores asociados a la prostitución (aislamiento, estigma, marginación, etc.) nos propusimos evaluar los sentimientos de soledad de nuestra muestra, es decir, ver si resuelven adecuadamente sus necesidades interpersonales básicas (necesidades sociales, emocionales y sexuales). Primero hemos analizado si cubren satisfactoriamente sus necesidades emocionales y sociales, y posteriormente evaluamos el estado de sus necesidades sexuales.

En primer lugar, comparamos nuestra muestra con el baremo en las tres subescalas de soledad, y encontramos que sienten mayor soledad emocional familiar $\left(t{ }_{(145)}=4.83\right.$, $\mathrm{p}=.000)$, mayor soledad de pareja $\left(\mathrm{t}_{(145)}=8.91, \mathrm{p}=.000\right)$ y mayor soledad social $\left(\mathrm{t}_{(145)}=7.50\right.$, $\mathrm{p}=.000$ ), que la población del baremo. En todos los casos nuestra muestra siente más soledad.

Al comparar cada uno de los grupos (calle, club y piso) con el baremo de cada una de las subescalas de soledad hemos encontrado diferencias significativas entre los tres grupos y el baremo en soledad romántica y social (ver Tabla 31), no ocurriendo así para la soledad familiar, en la cual únicamente hay diferencias estadísticamente significativas para el grupo de calle.

En la Tabla 31, podemos observar las medias y desviaciones típicas en cada una de las subescalas de soledad tanto para nuestra muestra como para el baremo presentado por el autor en la validación de la escala. Hemos realizado un ANOVA mixto con un factor intra, sentimientos de soledad, compuesto por tres niveles: soledad emocional familiar, soledad 
emocional de pareja o romántica y soledad social; y un facto inter, el tipo de prostitución (calle, club y piso).

Tabla 31. Descriptivos de sentimientos de soledad en función del tipo de prostitución.

\begin{tabular}{|c|c|c|c|c|c|c|}
\hline & & \multicolumn{3}{|c|}{ Tipo de prostitución } & \multirow[b]{2}{*}{ Total } & \multirow[b]{2}{*}{ Baremo } \\
\hline & & Calle & Club & Piso & & \\
\hline & $\mathbf{N}$ & 21 & 33 & 92 & 146 & 116 \\
\hline $\begin{array}{c}\text { Soledad } \\
\text { emocional } \\
\text { familiar }\end{array}$ & $\begin{array}{c}\text { Media } \\
\text { (d.t.) } \\
\text { Prueba t } \\
\text { baremo }\end{array}$ & $\begin{array}{c}19.00 \\
(10.71) \\
\left(t_{(20)}=3.17, p=.005\right)\end{array}$ & $\begin{array}{c}14.55 \\
(7.43) \\
\left(\mathrm{t}_{(32)}=2.28, \mathrm{p}=.03\right)\end{array}$ & $\begin{array}{c}13.95 \\
(7.29) \\
\left(\mathrm{t}_{(91)}=3.09, \mathrm{p}=.03\right)\end{array}$ & $\begin{array}{l}14.81 \\
(8.03)\end{array}$ & $\begin{array}{l}11.6 \\
(7.6)\end{array}$ \\
\hline $\begin{array}{c}\text { Soledad } \\
\text { emocional de } \\
\text { pareja }\end{array}$ & $\begin{array}{c}\text { Media } \\
\text { (d.t.) } \\
\text { Prueba t } \\
\text { baremo }\end{array}$ & $\begin{array}{c}23.95 \\
(9.90) \\
\left(\mathrm{t}_{(20)}=4.23, \mathrm{p}=.000\right)\end{array}$ & $\begin{array}{c}21.02 \\
(8.09) \\
\left(t_{(32)}=6.49, p=.000\right)\end{array}$ & $\begin{array}{c}21.01 \\
(10.39) \\
\left(t_{(91)}=5.73, p=.000\right)\end{array}$ & $\begin{array}{l}22.10 \\
(9.89)\end{array}$ & $\begin{array}{l}14.8 \\
(9.6)\end{array}$ \\
\hline Soledad social & $\begin{array}{c}\text { Media } \\
\text { (d.t.) } \\
\text { Prueba t } \\
\text { baremo }\end{array}$ & $\begin{array}{c}20.95 \\
(11.06) \\
\left(\mathrm{t}_{(20)}=3.83, \mathrm{p}=.001\right)\end{array}$ & $\begin{array}{c}16.82 \\
(7.72) \\
\left(t_{(32)}=3.81, p=.001\right)\end{array}$ & $\begin{array}{c}16.21 \\
(8.10) \\
\left(t_{(91)}=5.35, p=.000\right)\end{array}$ & $\begin{array}{l}17.03 \\
(8.59)\end{array}$ & $\begin{array}{l}11.7 \\
(5.6)\end{array}$ \\
\hline Total & $\begin{array}{l}\text { Media } \\
\text { (d.t.) }\end{array}$ & $\begin{array}{c}21.30 \\
(10.56)\end{array}$ & $\begin{array}{l}18.43 \\
(7.75)\end{array}$ & $\begin{array}{l}17.06 \\
(8.59)\end{array}$ & $\begin{array}{l}17.98 \\
(8.84)\end{array}$ & \\
\hline
\end{tabular}

En primer lugar, no hemos encontrado diferencias significativas entre los diferentes tipos de prostitución $\left(\mathrm{F}_{(1,143)}=4.12, p=.02\right)$ en sus puntuaciones de soledad.

Pero sí que hemos encontrado diferencias significativas entre los tipos de soledad evaluados $\left(F_{(2,286)}=23.38, p=.000, \eta^{2}=.14\right)$, de forma que sienten mayor soledad de pareja o romántica que soledad social $(p=.000)$ y familiar $(p=.000)$, y no hemos encontrado diferencias significativas entre éstas últimas.

Finalmente, no hemos encontrado interacción entre los diferentes tipo de soledad y el tipo de prostitución $\left(\mathrm{F}_{(4,286)}=.72, \mathrm{p}=.58\right)$. 


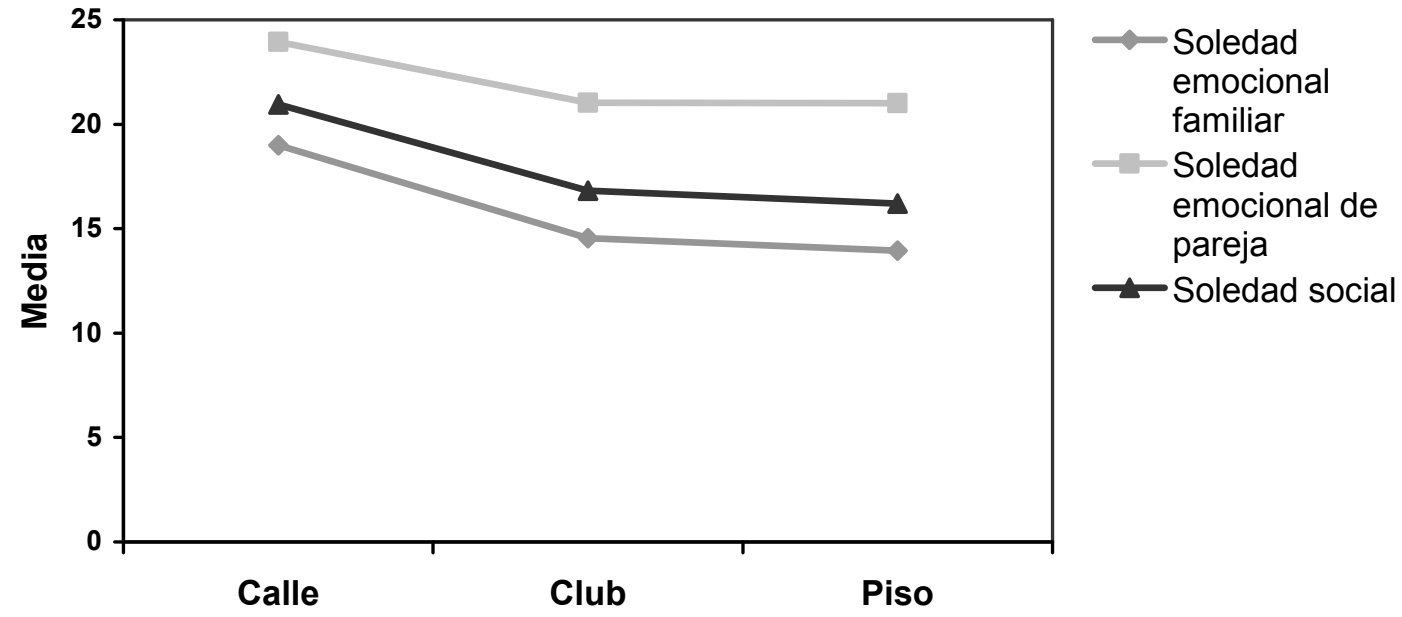

Figura 37 Sentimientos de soledad en función del tipo de prostitución

Como podemos observar, las personas que ejercen prostitución sienten altos niveles de soledad, tanto emocional como social, aunque los tres tipos de prostitución sienten en mayor medida soledad de pareja o romántica y en menor medida soledad familiar.

Para apoyar estos datos transcribimos a continuación algunos comentarios realizados por las personas entrevistadas en relación a los sentimientos de soledad y tristeza que sienten respecto a su familia, pareja y amistades.

"Yo a veces me siento triste me pongo una copa y venga, y venga... hombre yo...

tal vez uno se siente... porque está dejos de su país, de su hijo, de la familia que uno quiere, pero... yo me pongo la música, me pongo 2 ó 3 copas y venga yo me siento entonada y se me olvida un poco. Claro... echo en falta mi país, mi hijo, mi familia..." (Colombiana, trabajando en piso, 33 años)

"Hombre yo echo mucho de menos a mi familia, mis padres, mi hijo y a veces a una le apetece tener una pareja, con quien hablar, con quien contar las cosas, o un buen amigo" (Brasileña, trabajando en piso, 26 años)

Para terminar el apartado sobre las necesidades interpersonales básicas hemos evaluado el estado de satisfacción y depresión sexual de la muestra mediante dos subescalas. 
Hemos comparado tanto la media general en satisfacción y depresión sexual de nuestra muestra, como la media de cada uno de los grupos que la componen con la media poblacional que nos proporciona el baremo del autor de la escala para comprobar si nuestra muestra siente mayor o menor satisfacción y depresión sexual que la población general.

Tomando nuestra muestra, hemos obtenido diferencias significativas en las puntuaciones de satisfacción sexual al compararlo con el baremo. De manera que las personas que ejercen prostitución sienten mayor satisfacción sexual $\left(\mathrm{t}_{(145)}=4.33, \mathrm{p}=.000\right)$ que la población general. Al realizar la misma comparación en depresión sexual, hemos obtenido diferencias significativas entre la muestra y el baremo $\left(t_{(145)}=12.02, p=.000\right)$ de forma que las personas que ejercen prostitución sienten también mayor depresión sexual que el baremo.

Hemos comparado también cada uno de los grupos con el baremo (ver Figura 38), y no hemos encontrado diferencias significativas entre el baremo y el grupo de la calle en las puntuaciones en satisfacción sexual $\left(\mathrm{t}_{(20)}=.14, \mathrm{p}=.89\right)$. En cuanto a las puntuaciones en depresión sexual, si que hemos encontrado diferencias significativas entre las personas de la calle y el baremo $\left(\mathrm{t}{ }_{(20)}=5.55, \mathrm{p}=.000\right)$, de forma que las mujeres que ejercen en la calle sienten mayor depresión sexual que la población general.

En cuanto al grupo que ejerce prostitución en club, hemos encontrado que no hay diferencias significativas en satisfacción sexual al compararlo con el baremo $\left(t_{(32)}=.25\right.$, $\mathrm{p}=.80$ ). Pero sí que las hemos encontrado en depresión sexual ( $\left.t_{(32)}=6.78, p=.000\right)$, de forma que las mujeres que ejercen en club sienten mayor depresión sexual que la población general.

Finalmente, al comparar el baremo con el grupo de mujeres que ejerce en piso hemos encontrado diferencias significativas tanto en satisfacción sexual $\left(t_{(91)}=5.25, p=.000\right)$ como en depresión sexual $\left(t_{(91)}=8.53, p=.000\right)$, de forma que las personas que ejercen en piso sienten mayor satisfacción sexual y mayor depresión sexual en comparación con las personas del baremo. 

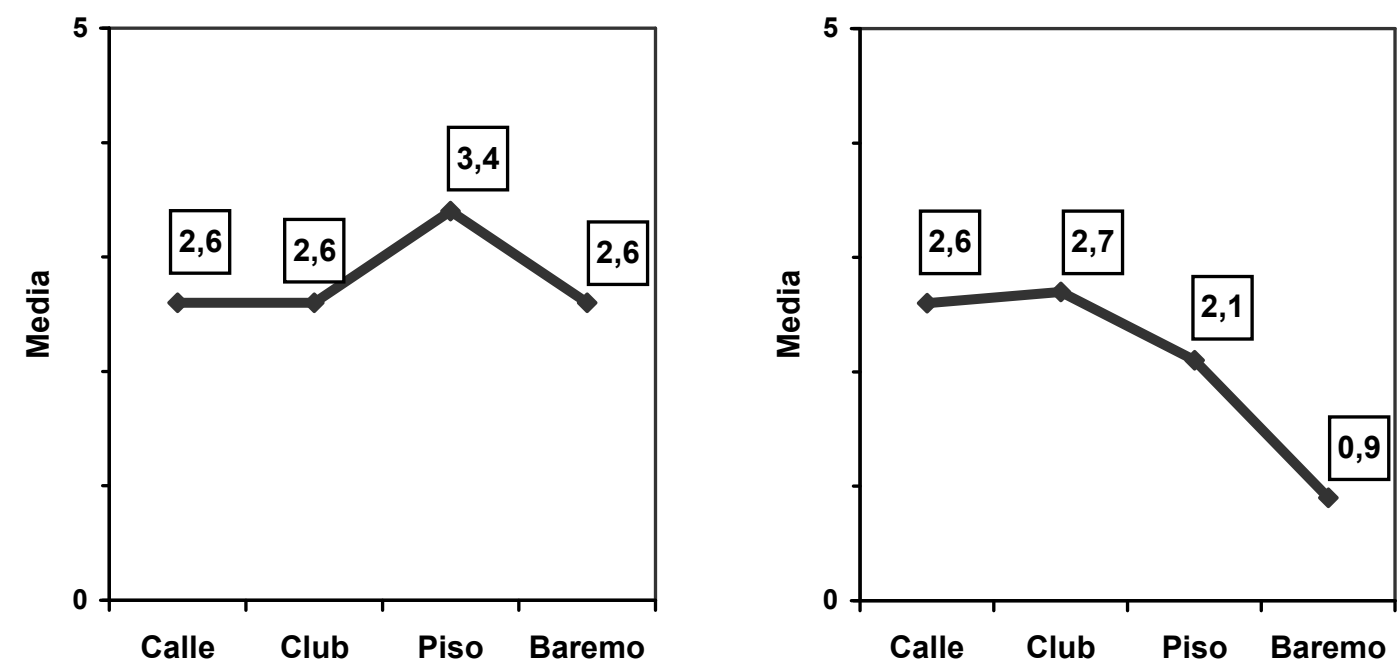

Figura 38. Puntuaciones medias en satisfacción sexual y depresión sexual en función del tipo de prostitución.

Hemos realizado un ANOVA mixto con un factor intra, necesidades sexuales, compuesto por dos niveles: satisfacción sexual y depresión sexual; y un facto inter, el tipo de prostitución (calle, club y piso), pero no hemos encontrado diferencias significativas entre los grupos $\left(F_{(2,143)}=1.20, p=.31\right)$ en las variables evaluadas, de forma que calle, club y piso no muestran diferencias significativas en satisfacción y depresión sexual. Tampoco hemos encontrado diferencias significativas entre los niveles de satisfacción y depresión sexual en la muestra en general $\left(F_{(1,143)}=1.88, p=.17\right)$. $Y$ finalmente tampoco hemos encontrado interacción significativa entre sus necesidades sexuales y el tipo de prostitución $\left(\mathrm{F}_{(2 \text {, }}\right.$ 143) $\left.=3.88, p=.02, \eta^{2}=.05\right)$.

Como vemos, nuestra muestra presenta un nivel de satisfacción sexual normal, incluso más alta que el resto de la población en el caso de las mujeres que trabajan en piso. Este resultado está relacionado con los datos encontrados anteriormente sobre placer sexual con el cliente, ya que las personas que trabajan en piso era el grupo que en mayor medida afirmaba sentir placer sexual con el cliente. Sin embargo encontramos también niveles altos de depresión sexual, mayores que la población general, esto quiere decir que nuestra muestra experimenta en mayor medida sentimientos de tristeza, infelicidad y depresión cuando piensa en su vida sexual que la población normal. 
"Con mi pareja he estado seis años, pero te puedes creer que hemos llegado a 3 meses sin tener relaciones sexuales porque estábamos más drogados que drogados, yo no se si él se la encontraba para mear, y yo... me miraba... y sabía que allí algo había, la verdad, te digo una cosa, no es que me de asco, me da miedo" (Española, trabajando en la calle, 36 años) 


\subsection{Calidad de vida}

Según la OMS (1994), la calidad de vida es la "percepción personal de un individuo de su situación en la vida, dentro del contexto cultural y de valores en que vive, y en relación con sus objetivos, expectativas, valores e intereses". En nuestro estudio hemos evaluado la calidad de vida mediante el WHOQOL BREF (WHOQOL Group, 1995) el cual produce un perfil de cuatro áreas: salud física, psicológica, social y ambiental.

Hemos comparado los resultados de nuestra muestra con el baremo de la escala utilizada compuesto por personas sanas y hemos encontrado diferencias significativas en todas las escalas, de forma que nuestra muestra presenta mejor salud física $\left(t_{(145)}=18.77\right.$, $\mathrm{p}=.000)$, mejor salud psicológica $\left(\mathrm{t}_{(145)}=8.73, \mathrm{p}=.000\right)$ y mejor salud ambiental $\left(\mathrm{t}_{(145)}=26.39\right.$, $p=.000)$ que el baremo, mientras que presenta peor salud social $\left(t_{(145)}=-28.60, p=.000\right)$.

Al comparar cada uno de los grupos que componen nuestra muestra con los baremos de las subescalas hemos encontrado el mismo patrón que al tomar la muestra en conjunto, exceptuando para las personas que trabajan en la calle. Las personas que trabajan en la calle presentan mejor salud ambiental, pero presentan peor salud social y no hay diferencias con la salud física y psicológica (ver Tabla 32).

Hemos realizado un ANOVA mixto para analizar las diferencias entre las subescalas de calidad de vida evaluadas y las interacciones entre estas variables y el tipo de prostitución (ver Tabla 32). Hemos definido un factor intra, la calidad de vida, compuesto por cuatro niveles: salud física, psicológica, social y ambiental; y un factor inter, el tipo de prostitución (calle, club y piso). 
Tabla 32. Descriptivos de calidad de vida en función del tipo de prostitución

\begin{tabular}{|c|c|c|c|c|c|c|}
\hline & & \multicolumn{3}{|c|}{ Tipo de prostitución } & \multirow[b]{2}{*}{ Total } & \multirow[b]{2}{*}{ Baremo } \\
\hline & & Calle & Club & Piso & & \\
\hline & $\mathbf{n}$ & 21 & 33 & 92 & 146 & $\begin{array}{c}\text { Muestra } \\
\text { Barcelona }\end{array}$ \\
\hline \multirow{4}{*}{ Salud física } & Media & 3.10 & 3.57 & 3.97 & 3.75 & \multirow{4}{*}{18.52} \\
\hline & (d.t.) & $(.93)$ & $(.66)$ & $(.55)$ & $(.71)$ & \\
\hline & Sumatorio & 21.67 & 25.00 & 27.76 & & \\
\hline & Prueba t & $\left(t_{(20)}=2.21, p=.04\right)$ & $\left(\mathrm{t}_{(32)}=8, \mathrm{p}=.000\right)$ & $\left(\mathrm{t}_{(91)}=22.95, \mathrm{p}=.000\right)$ & & \\
\hline \multirow{4}{*}{$\begin{array}{c}\text { Salud } \\
\text { psicológica }\end{array}$} & Media & 2.67 & 3.39 & 3.66 & 3.46 & \multirow{4}{*}{17.05} \\
\hline & (d.t.) & $(1.05)$ & $(.91)$ & $(.65)$ & $(.85)$ & \\
\hline & Sumatorio & 16.00 & 20.33 & 21.97 & & \\
\hline & Prueba t & $\left(\mathrm{t}_{(20)}=-.76, p=.46\right)$ & $\left(\mathrm{t}_{(32)}=3.45, \mathrm{p}=.002\right)$ & $\left(t_{(91)}=12, p=.000\right)$ & & \\
\hline \multirow{4}{*}{ Salud social } & Media & 2.83 & 3.02 & 3.47 & 3.27 & \multirow{4}{*}{16.95} \\
\hline & (d.t.) & $(1.26)$ & $(.93)$ & $(.92)$ & $(1.00)$ & \\
\hline & Sumatorio & 8.47 & 9.06 & 10.40 & & \\
\hline & Prueba t & $\left(t_{(20)}=-10.25, p=.000\right)$ & $\left(t_{(32)}=-16.28, p=.000\right)$ & $\left(\mathrm{t}_{(91)}=-22.77, \mathrm{p}=.000\right)$ & & \\
\hline \multirow{4}{*}{$\begin{array}{c}\text { Salud } \\
\text { ambiental }\end{array}$} & Media & 3.01 & 3.22 & 3.44 & 3.33 & \multirow{4}{*}{15.20} \\
\hline & (d.t.) & $(.76)$ & $(.68)$ & $(.59)$ & $(.66)$ & \\
\hline & Sumatorio & 24.10 & 25.79 & 27.54 & & \\
\hline & Prueba t & $\left(\mathrm{t}_{(20)}=6.72, \mathrm{p}=.000\right)$ & $\left(\mathrm{t}_{(32)}=11.12, \mathrm{p}=.000\right)$ & $\left(t_{(91)}=24.89, p=.000\right)$ & & \\
\hline \multirow{2}{*}{ Total } & Media & 2.90 & 3.30 & 3.63 & 3.45 & \\
\hline & (d.t.) & $(1.00)$ & $(.80)$ & $(.70)$ & $(.81)$ & \\
\hline
\end{tabular}

Hemos encontrado diferencias significativas en calidad de vida entre los diferentes tipos de prostitución $\left(F_{(2,143)}=12.59, p=.000, \eta^{2}=.15\right)$, de forma que las personas que ejercen en piso presentan mejor calidad de vida en comparación con las que trabajan en la calle $(p=.000)$, no encontrando diferencias significativas con el grupo de club (ver Figura 39).

Además, hemos encontrado que hay diferencias significativas entre las diferentes áreas de salud $\left(\mathrm{F}_{(3,141)}=14.24, \mathrm{p}=.000, \eta^{2}=.24\right)$, de forma que las personas entrevistadas presentan mejor salud física en comparación con la salud psicológica $(p=.000)$, la salud social $(p=.000)$ y la salud ambiental $(p=.000)$, no encontrando diferencias entre estas tres facetas de salud (ver Figura 39).

Por último, no hemos encontrado interacción significativa entre diferentes niveles de calidad de vida y los tipos de prostitución $\left(\mathrm{F}_{(6,429)}=2.64, \mathrm{p}=.02\right)$. 


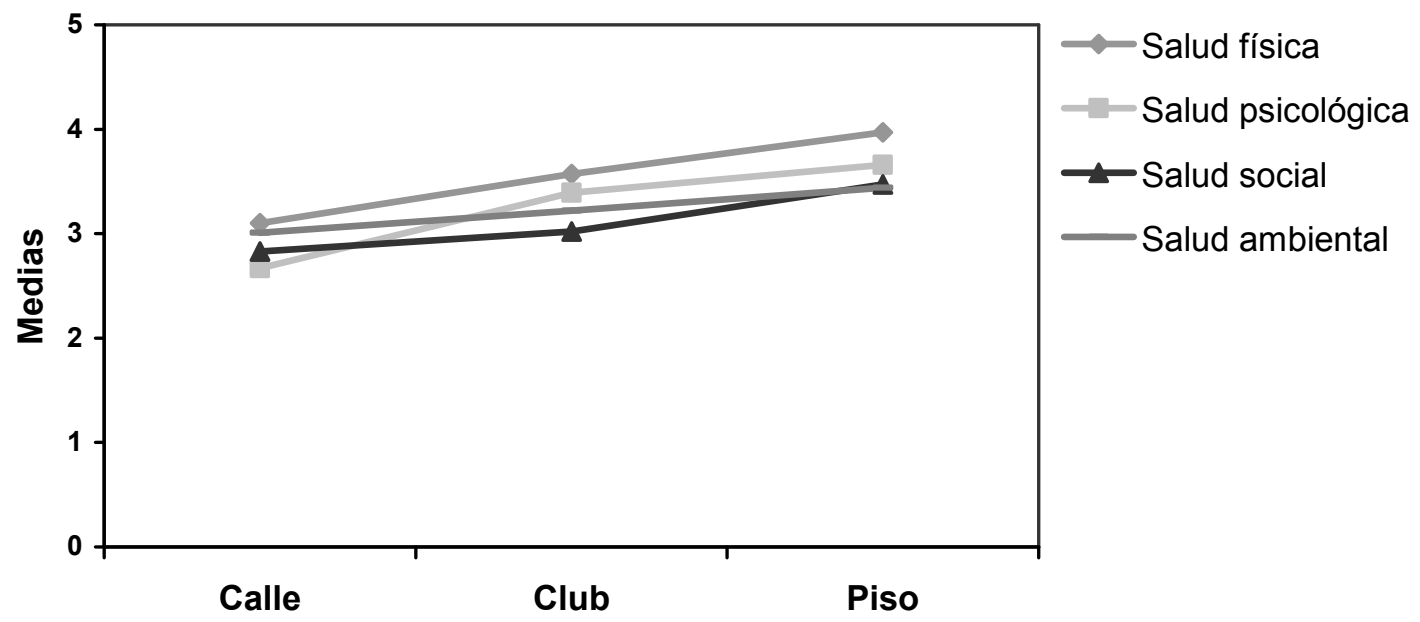

Figura 39. Dimensiones de la calidad de vida en función del tipo de prostitución

Como vemos este dato está relacionado con los resultados obtenidos en el apartado sobre necesidades interpersonales básicas, en este apartado encontramos que nuestra muestra siente una gran soledad emocional y social, lo cual corroboramos al encontrar que presentan peor salud social que la población general. En cuanto al resto de escalas nuestra muestra presenta buenos niveles de salud física, psicológica y ambiental. Y de nuevo son las prostitutas de la calle las que peor se encuentran en las cuatro áreas que componen la calidad de vida. 
7.4. Predictores de la calidad de vida de las personas que ejercen prostitución

En esta sección, estudiaremos una serie de variables que pueden explicar las diferencias en calidad de vida de las personas que ejercen prostitución. A partir de la bibliografía consultada sabemos que un buen estado de salud y una adecuada satisfacción de las necesidades interpersonales básicas (Pinedo y Martín, 2006; Weiss, 1982; WHOQOL group, 1994) tienen una influencia positiva sobre la calidad de vida. Por ello hemos seleccionado dos conjuntos de variables para explicar la calidad de vida, y son, (1) variables de salud relacionadas con la prostitución, y (2) variables relacionadas con las necesidades interpersonales básicas (soledad emocional familiar y de pareja, soledad social, satisfacción y depresión sexual).

Para analizar los predictores de la calidad de vida de las personas que ejercen prostitución hemos realizado diferentes análisis de regresión múltiple paso a paso considerando la calidad de vida como variable dependiente y como predictores las variables anteriormente mencionadas: variables de salud relacionadas con la prostitución y variables relacionadas con las necesidades interpersonales. En los análisis de regresión múltiple, hemos incluido estos dos grupos de variables por separado y no en conjunto en base a criterios metodológicos y teóricos. Hemos considerado que metodológicamente era más adecuado incluir las variables en dos grupos debido a que no tenemos un $\mathrm{n}$ suficiente para incluirlas todas en conjunto. $\mathrm{Y}$ en segundo lugar queremos comprobar que teóricamente las variables relacionadas con las necesidades interpersonales explican más calidad de vida que las variables de salud relacionadas con la prostitución.

En el primer conjunto de variables relacionadas con la salud incluimos consumo de drogas, VIH/SIDA, maltrato físico, psicológico y agresiones sexuales realizadas por el cliente durante el ejercicio de la prostitución, depresión, ansiedad y autoestima. Hemos considerado el consumo de drogas como una variable dicotómica, donde 0 es "No consume drogas" y 1 es "Sí consume drogas" a partir de la pregunta ¿Actualmente consumes algún tipo de droga? (pregunta número 53). De la misma forma el VIH/SIDA ha sido considerado una 
variable dicotómica donde 0 es "Seronegativa al VIH/SIDA" y 1 es "Seropositiva al VIH/SIDA" a partir de la pregunta ¿Eres seropositiva al virus del VIH/SIDA? (pregunta número 73). En la entrevista realizamos preguntas sobre la frecuencia con la que habían sufrido maltrato físico, psicológico y/o agresiones sexuales durante el ejercicio de la prostitución, y preguntamos por parte de qué persona/s lo habían sufrido (cliente, jefes/as, compañeras/os y pareja). En este análisis únicamente hemos tenido en cuenta los malos tratos y las agresiones que ha realizado el cliente ya que, hemos visto en el apartado anterior que es la persona que más agresiones comete contra este colectivo. Además, basándonos en la bibliografía consultada (Brents y Hausbeck, 2005; Church et al., 2001; Farley y Barkan, 1998; Raphael y Shapiro, 2004; Surrat et al., 2004; Wiliamson y Folaron, 2001) nos parece muy interesante conocer de qué forma influye en la calidad de vida los malos tratos físicos, psicológicos y las agresiones sexuales que reciben por parte de sus clientes. Las variables depresión, ansiedad y autoestima se obtienen a partir de las puntuaciones de las personas entrevistadas en las escalas que hemos usado para evaluar su salud mental.

El segundo conjunto de variables, relacionado con las necesidades interpersonales básicas, incluye las puntuaciones en las escalas de soledad emocional familiar, soledad emocional de pareja, soledad social, satisfacción sexual y depresión sexual.

Hemos utilizado como variable dependiente la puntuación media obtenida a partir de las cuatro subescalas que evalúan los diferentes tipos de salud (física, psicológica, social y ambiental), y posteriormente las puntuaciones medias obtenidas en cada una de las escalas del WHOQOL-BREF de la OMS, es decir, hemos realizado un análisis por separado para cada área de salud.

Por otra parte, como hemos comprobado en el apartado anterior, los perfiles de los tipos de prostitución son diferentes, ya que hay diferencias significativas en la calidad de vida entre las personas que ejercen prostitución en la calle y las que ejercen en club y piso, por ello consideramos el tipo de prostitución como variable moderadora de la relación entre los predictores señalados y la calidad de vida. Así, además de los análisis de regresión 
realizados con la muestra total, nos planteamos realizar análisis por separado para cada tipo de prostitución, pero no fue posible debido al tamaño muestral en el caso de la prostitución de exterior. Por ello, realizamos el análisis para la muestra de interior con el fin de comprobar si se repetían los resultados de la muestra global.

7.4.1. Predictores de salud relacionados con la prostitución que explican la calidad de vida.

En un primer momento hemos obtenido las correlaciones existentes entre las variables de salud relacionadas con la prostitución y la calidad de vida con el fin de determinar qué variables incluimos en el modelo de regresión (ver Tabla 33).

Como vemos en la Tabla 33, hay relaciones significativas entre todas las variables de salud y la calidad de vida. Como podríamos esperar consumir drogas, ser seropositiva al $\mathrm{VIH}$, haber recibido malos tratos físicos, psicológicos y agresiones sexuales por parte del cliente, tener síntomas de depresión y ansiedad se relacionan negativamente con la calidad de vida. Mientras que la autoestima se relaciona positivamente con la calidad de vida. 
Tabla 33. Matriz de correlaciones entre las variables de salud relacionadas con la prostitución y la calidad de vida de las personas que ejercen prostitución

\begin{tabular}{|c|c|c|c|c|c|c|c|c|c|}
\hline & $\begin{array}{l}\text { Calidad } \\
\text { de vida }\end{array}$ & $\begin{array}{l}\text { Consumo } \\
\text { de drogas }\end{array}$ & $\begin{array}{l}\text { VIH/ } \\
\text { SIDA }\end{array}$ & $\begin{array}{r}\text { Maltrato } \\
\text { físico } \\
\text { cliente }\end{array}$ & $\begin{array}{r}\text { Maltrato } \\
\text { psic. } \\
\text { cliente }\end{array}$ & $\begin{array}{r}\text { Agresión } \\
\text { sexual } \\
\text { cliente }\end{array}$ & Depresión & Ansiedad & Autoestima \\
\hline $\begin{array}{r}\text { Calidad de } \\
\text { vida }\end{array}$ & 1 & & & & & & & & \\
\hline $\begin{array}{r}\text { Consumo de } \\
\text { drogas }\end{array}$ & $-.34^{\star * *}$ & 1 & & & & & & & \\
\hline $\begin{array}{r}\mathrm{VIH} / \\
\text { SIDA }\end{array}$ & $-.33^{* * *}$ & $.27^{\star \star \star}$ & 1 & & & & & & \\
\hline $\begin{array}{r}\text { Maltrato físico } \\
\text { cliente }\end{array}$ & $-.24^{\star \star}$ & $.43^{\star \star *}$ & $.24^{\star *}$ & 1 & & & & & \\
\hline $\begin{array}{r}\text { Maltrato Psic. } \\
\text { cliente }\end{array}$ & $-.25^{\star \star}$ & $.26^{\star *}$ & .08 & $.63^{\star * *}$ & 1 & & & & \\
\hline $\begin{array}{l}\text { Agresiones } \\
\text { sex. cliente }\end{array}$ & $-.36^{* \star *}$ & $.28^{\star \star *}$ & .15 & $.55^{\star \star *}$ & $.36^{\star * *}$ & 1 & & & \\
\hline Depresión & $-.53^{\star * *}$ & $.35^{\star \star *}$ & $.25^{\star \star}$ & $.44^{\star * *}$ & $.42^{\star * *}$ & $.35^{\star * *}$ & 1 & & \\
\hline Ansiedad & $-.41^{* * *}$ & $.35^{\star \star \star}$ & $.25^{\star *}$ & $.37^{\star *}$ & $.36^{\star * *}$ & $.25^{\star \star}$ & $.77^{* \star *}$ & 1 & \\
\hline Autoestima & $.50^{\star \star *}$ & $-.30^{* * *}$ & $\begin{array}{c}- \\
.28^{\star * *}\end{array}$ & $-.25^{\star *}$ & $-.23^{* *}$ & $-.23^{* *}$ & $-.42^{\star \star \star}$ & $-.41^{* \star *}$ & 1 \\
\hline
\end{tabular}

A partir de los resultados de la matriz de correlaciones incluimos en el análisis de regresión todas las variables de salud ya que correlacionan significativamente con la calidad de vida $(\alpha=.01)$.

Realizado el análisis obtuvimos que en un primer paso entraba la depresión $\left(\mathrm{F}_{(1,140)}=\right.$ 53.59, p.000), y en el segundo la autoestima $\left(F_{(1,139)}=21.46\right.$, p.000). De manera que el modelo final resultante estaría formado por dos variables (ver Figura 40) que explican un $37 \%$ de la varianza de la calidad de vida $\left(F_{(2,139)}=41.44\right.$, p.000). La depresión entra en el modelo en sentido inverso de manera que un mayor número de síntomas depresivos se relacionan con una peor calidad de vida; mientras que la autoestima entra en sentido directo ya que un elevado nivel de autoestima se relaciona con mejor calidad de vida. 
PREDICTORES

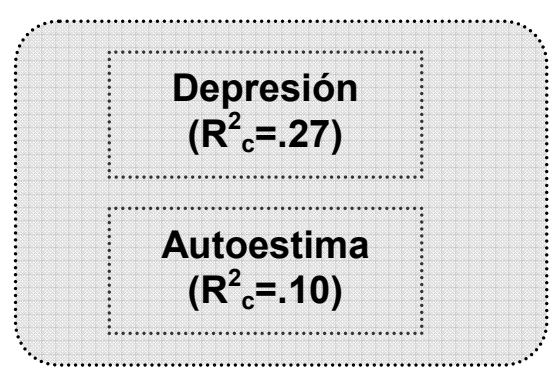

\section{CRITERIO}

$$
\beta=-.38^{* * *}
$$

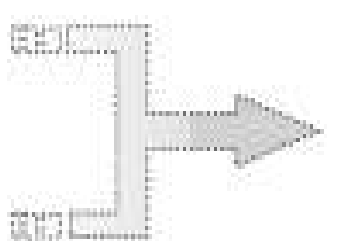

$\beta=.34^{\star * *}$

${ }^{* *} p<.01 ;{ }^{* * *} p<.001 ;$

Figura 40. Resumen del modelo de regresión lineal para la calidad de vida considerando las variables de salud relacionadas con la prostitución en la muestra general

A continuación vamos a analizar las variables que no han entrado en el modelo. Hemos encontrado que las variables agresiones sexuales del cliente $(p=.02)$, el VIH/SIDA $(p=.03)$ y el consumo de drogas $(p=.10)$ no entran en el modelo para explicar la calidad de vida debido a que usamos un alfa muy restrictivo. Sin embargo, la variable ansiedad (Índice de Tolerancia $=.39$ ) no entra en el modelo debido a que explica lo mismo que la variable depresión. Y finalmente, el maltrato físico y psicológico parece no ser importante en la explicación de la calidad de vida del colectivo de personas que ejercen prostitución.

Como hemos dicho al comienzo de este punto vamos a analizar de forma independiente las variables que explican la calidad de vida de las personas que ejercen prostitución de interior (en club y piso). En primer lugar (ver Tabla 34) presentamos las correlaciones existentes entre las diferentes variables relacionadas con la salud y la calidad de vida.

Para comenzar encontramos que únicamente, en este caso, las agresiones sexuales del cliente, la depresión, la ansiedad y la autoestima correlacionan significativamente con la calidad de vida $(\alpha=.01)$.

Es interesante comprobar que al eliminar del análisis a las personas que ejercen prostitución en la calle desaparecen las relaciones significativas de la calidad de vida con 
variables como el consumo de drogas, el VIH/SIDA y el maltrato físico y psicológico del cliente, por lo que probablemente el tipo de prostitución está moderando estas relaciones.

Tabla 34. Matriz de correlaciones entre las variables de salud relacionadas con la prostitución y la calidad de vida de las personas que ejercen prostitución de interior

\begin{tabular}{|c|c|c|c|c|c|c|c|c|c|}
\hline & $\begin{array}{c}\text { Calidad de } \\
\text { vida }\end{array}$ & $\begin{array}{l}\text { Consumo } \\
\text { de drogas }\end{array}$ & $\begin{array}{l}\text { VIH/ } \\
\text { SIDA }\end{array}$ & $\begin{array}{l}\text { Maltrato } \\
\text { físico } \\
\text { cliente }\end{array}$ & $\begin{array}{c}\text { Maltrato } \\
\text { psic. } \\
\text { cliente }\end{array}$ & $\begin{array}{l}\text { Agresión } \\
\text { sexual } \\
\text { cliente }\end{array}$ & Depresión & Ansiedad & Autoestima \\
\hline $\begin{array}{r}\text { Calidad de } \\
\text { vida }\end{array}$ & 1 & & & & & & & & \\
\hline $\begin{array}{r}\text { Consumo de } \\
\text { drogas }\end{array}$ & -.18 & 1 & & & & & & & \\
\hline $\begin{array}{l}\text { VIH/ } \\
\text { SIDA }\end{array}$ & .08 & -.08 & 1 & & & & & & \\
\hline $\begin{array}{r}\text { Maltrato } \\
\text { físico cliente }\end{array}$ & -.10 & .22 & .18 & 1 & & & & & \\
\hline $\begin{array}{r}\text { Maltrato Psic. } \\
\text { cliente }\end{array}$ & -.21 & .10 & -.02 & $.53^{\star \star \star}$ & 1 & & & & \\
\hline $\begin{array}{l}\text { Agresiones } \\
\text { sex. cliente }\end{array}$ & $-.31^{* \star *}$ & $-.23^{\star \star}$ & -.04 & $.52^{\star \star \star}$ & $.29^{\star \star \star}$ & 1 & & & \\
\hline Depresión & $-.46^{\star \star *}$ & .13 & -.10 & .22 & $.31^{\star \star \star}$ & $.27^{\star *}$ & 1 & & \\
\hline Ansiedad & $-.30^{\star * *}$ & .11 & -.04 & .21 & $.29^{\star \star \star}$ & .13 & $.74^{\star \star \star}$ & 1 & \\
\hline Autoestima & $.37^{\star \star \star}$ & -.10 & .00 & -.06 & -.11 & -.09 & $-.26^{\star \star}$ & $-.27^{* *}$ & 1 \\
\hline
\end{tabular}

En este caso las variables que se incluyeron en el análisis fueron: agresiones sexuales del cliente, depresión, ansiedad y autoestima. Como en el caso anterior, en un primer paso entró la depresión $\left(F_{(1,119)}=30.99, p=.000\right)$, y en el segundo la autoestima ( $F$ $(1,118)=11.43, p=.001)$. De manera que el modelo final resultante (ver Figura 41) está formado por dos variables que explican un $28 \%$ de la varianza de la calidad de vida $\left(\mathrm{F}_{(2,118)}=22.57\right.$, $p=.000$ ). Igual que en el caso anterior la depresión entra en el modelo en sentido inverso de manera que un mayor número de síntomas depresivos se relacionan con una peor calidad de vida; mientras que la autoestima entra en sentido directo ya que un elevado nivel de autoestima se relaciona con mejor calidad de vida. Por lo tanto, no hemos encontrado diferencias en las variables que explican la calidad de vida de las personas que ejercen prostitución en general y las personas que ejercen prostitución de interior. 
PREDICTORES

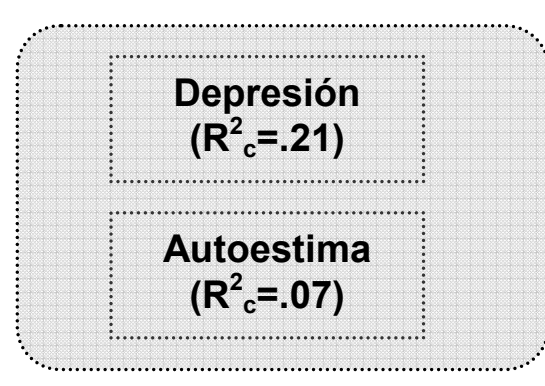

$\beta=-.38^{* * *}$

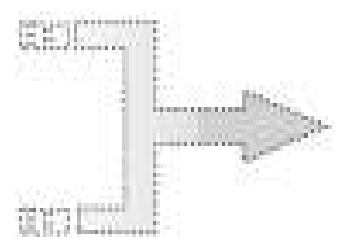

$\beta=.27^{* * *}$
CRITERIO

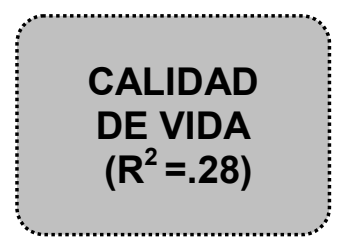

${ }^{* *} \mathrm{p}<.01 ;{ }^{* * *} \mathrm{p}<.001 ;$

Figura 41. Resumen del modelo de regresión lineal para la calidad de vida considerando las variables de salud relacionadas con la prostitución en las personas que ejercen prostitución de interior

En cuanto a las variables que no han entrado en el modelo, encontramos que la variable agresiones sexuales del cliente $(p=.01)$ no ha entrado debido a que hemos elegido un alfa muy restrictivo. Mientras que la variable ansiedad (Índice de Tolerancia=.45) no ha entrado debido a que comparte variabilidad con depresión, la cual entra en el primer paso.

7.4.2. Predictores relacionados con la salud y el mundo de la prostitución que explican las diferentes subescalas de calidad de vida

Como decíamos al comienzo de este punto, también vamos a analizar los factores que explican cada una de las subescalas que componen la medida de calidad de vida que hemos utilizado: salud física, salud psicológica, salud social y salud ambiental (Lucas, 1996).

Como en apartados anteriores, hemos obtenido la matriz de correlaciones de las diferentes variables de salud en el mundo de la prostitución con las diferentes subescalas de la calidad de vida para ver qué variables debemos incluir en cada uno de los análisis de regresión paso a paso.

En primer lugar vamos a comentar los resultados de la matriz de correlaciones obtenida a partir de la muestra general (ver Tabla 35). En cuanto a la salud física encontramos correlaciones significativas con todas las variables de salud, de manera que todas ellas entrarán en el análisis de regresión múltiple paso a paso. En cuanto a la salud psicológica, encontramos correlaciones significativas con todas las variables excepto con el 
maltrato físico y psicológico del cliente. En relación con la salud social, hemos encontrado correlaciones significativas con todas las variables excepto con el consumo de drogas, $\mathrm{VIH/SIDA} \mathrm{y} \mathrm{maltrato} \mathrm{físico} \mathrm{del} \mathrm{cliente.} \mathrm{Finalmente,} \mathrm{la} \mathrm{salud} \mathrm{ambiental} \mathrm{únicamente} \mathrm{muestra}$ correlaciones significativas con las variables agresiones sexuales del cliente, depresión y autoestima.

Todas las variables que muestran correlaciones significativas con cada uno de los tipos de salud (físico, psicológico, social y ambiental) muestran una relación inversa, exceptuando la autoestima que muestra correlaciones positivas.

Podemos destacar también que todos los indicadores de salud mental (depresión, ansiedad y autoestima) presentan correlaciones muy elevadas con cada una de las variables dependientes (salud física, psicológica, social y ambiental), excepto la ansiedad con la salud ambiental.

Tabla 35. Matriz de correlaciones entre las variables de salud relacionadas con la prostitución y las diferentes escalas de calidad de vida (salud física, psicológica, social y ambiental) en la muestra general

\begin{tabular}{|c|c|c|c|c|}
\hline & Salud Física & Salud Psicológica & Salud Social & Salud Ambiental \\
\hline Consumo de drogas & $-.38^{* \star *}$ & $-.34^{* * *}$ & -.19 & -.20 \\
\hline VIH/ SIDA & $-.44^{\star * *}$ & $-.29^{* \star *}$ & -.19 & -.18 \\
\hline Maltrato físico del cliente & $-.36^{\star \star \star}$ & -.23 & -.19 & -.05 \\
\hline Maltrato Psic. del cliente & $-.37^{* \star *}$ & -.18 & $-.27^{\star \star \star}$ & -.05 \\
\hline Agresiones sex. del cliente & $-.31^{* * *}$ & $-.38^{* * *}$ & $-.24^{* *}$ & $-.27^{* \star *}$ \\
\hline Depresión & $-.58^{\star \star \star}$ & $-.58^{\star \star *}$ & $-.34^{* \star *}$ & $-.26^{\star *}$ \\
\hline Ansiedad & $-.49^{* \star *}$ & $-.47^{* * *}$ & $-.27^{* \star *}$ & -.14 \\
\hline Autoestima & $.44^{\star \star \star}$ & $.47^{\star \star \star}$ & $.46^{\star \star \star}$ & $.36^{\star \star \star}$ \\
\hline
\end{tabular}

A continuación vamos a comentar la matriz de correlaciones obtenida en el subgrupo de personas que ejercen prostitución de interior (de club y de piso) (ver Tabla 36). En cuanto a la salud física hemos encontrado correlaciones significativas, con todas las variables excepto con consumo de drogas, VIH/SIDA y maltrato físico del cliente. En salud psicológica hemos encontrado relaciones significativas con las siguientes variables: agresiones sexuales del cliente, depresión, ansiedad y autoestima. En cuanto a la salud social se han encontrado relaciones significativas con la variable maltrato psicológico del 
cliente, depresión y autoestima. Finalmente, la salud ambiental presenta correlación significativa con las agresiones sexuales del cliente, la depresión y la autoestima.

De la misma forma que en el la tabla anterior, hemos encontrado que todas las variables con relaciones significativas lo hacen inversamente con cada uno de los tipos de salud que componen la calidad de vida, exceptuando la autoestima que se relaciona positivamente.

Otro aspecto importante a destacar al observar la matriz de correlaciones de la Tabla 36 es que las variables consumo de drogas, VIH/SIDA y maltrato físico del cliente dejan de tener correlaciones significativas cuando realizamos el análisis únicamente con las personas que ejercen prostitución de interior (piso y club). Como vemos en la tabla anterior estas variables tenían relaciones significativas con la salud física y la salud psicológica cuando hacemos referencia también a las personas que ejercen prostitución en la calle.

Tabla 36. Matriz de correlaciones entre las variables de salud relacionadas con la prostitución y las diferentes escalas de calidad de vida (salud física, psicológica, social y ambiental) en las personas que ejercen prostitución de interior

\begin{tabular}{|c|c|c|c|c|}
\hline & Salud Física & Salud Psicológica & Salud Social & Salud Ambiental \\
\hline Consumo de drogas & -.19 & -.17 & -.06 & -.16 \\
\hline VIH/ SIDA & -.09 & .13 & .16 & .10 \\
\hline Maltrato físico del cliente & -.22 & -.03 & -.12 & .02 \\
\hline Maltrato Psic. del cliente & $-.36^{* \star *}$ & -.10 & $-.26^{* *}$ & -.03 \\
\hline Agresiones sex. del cliente & $-.28^{\star *}$ & $-.32^{\star \star \star}$ & -.16 & $-.24^{\star *}$ \\
\hline Depresión & $-.48^{* * *}$ & $-.51^{* * *}$ & $-.25^{\star *}$ & $-.23^{* *}$ \\
\hline Ansiedad & $-.38^{* * *}$ & $-.37^{\star \star \star}$ & -.18 & -.07 \\
\hline Autoestima & $.26^{\star \star}$ & $.33^{* * *}$ & $.35^{\star * *}$ & $.30^{\star \star *}$ \\
\hline
\end{tabular}

${ }^{* *} \mathrm{p}<.01 ;{ }^{* * *} \mathrm{p}<.001 ; \mathrm{N}$ por lista $=121$

A continuación, basándonos en los resultados obtenidos en la matriz de correlaciones, vamos a comentar cada uno de los análisis de regresión múltiple paso a paso que hemos realizado para cada una de las subescalas de calidad de vida (física, psicológica, social y ambiental) para la muestra general y para las personas que ejercen prostitución de interior. 
- Predictores de salud física en la muestra general

A partir de los resultados de la matriz de correlaciones anteriormente comentada (ver Tabla 35) incluimos en el análisis de regresión paso a paso todas las variables de salud evaluadas.

Realizado este análisis encontramos que en un primer paso entraba la depresión ( $F$ $(1,140)=72.14, p=.000)$ y en el segundo el $\mathrm{VIH} / \operatorname{SIDA}\left(\mathrm{F}_{(1,139)}=23.48, \mathrm{p}=.000\right)$. De manera que el modelo final resultante estaría formado por dos variables (ver Figura 42) que explican un $43 \%$ de la varianza de la salud física en las personas que ejercen prostitución $\left(F_{(2,139)}=\right.$ 53.60, $p=.000$ ). Ambas variables entran en el modelo en sentido inverso de manera que un mayor número de síntomas depresivos y ser seropositiva al VIH/SIDA se relacionan con un peor estado de salud física.

PREDICTORES

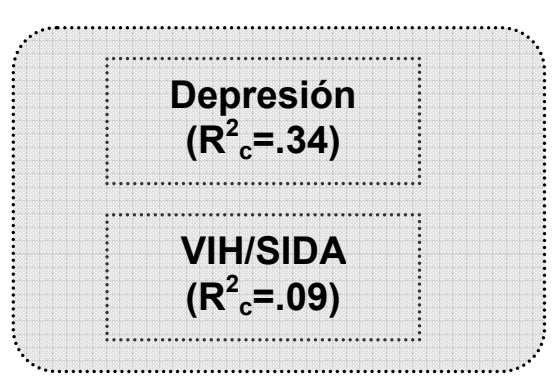

$\beta=-.50^{* * *}$

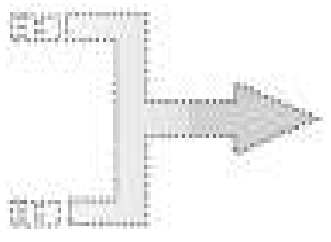

$\beta=-.32^{* * *}$

\section{CRITERIO}

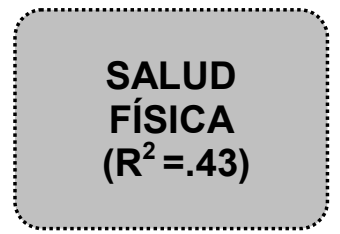

${ }^{* *} p<.01 ;{ }^{* * *} p<.001 ;$

Figura 42. Resumen del modelo de regresión lineal para la salud física considerando las variables de salud relacionadas con la prostitución en la muestra general

En cuanto al análisis de las variables que no han entrado en el modelo encontramos que la autoestima $(p=.01)$, el maltrato psicológico del cliente $(p=.02)$ y el consumo de drogas $(p=.04)$ no entran en el modelo debido a que hemos usado un alfa más restrictivo. Mientras que la ansiedad (Índice de Tolerancia $=.40$ ) no ha entrado en el modelo porque comparte variabilidad con la variable depresión, que entra en un primer paso. El maltrato físico y las agresiones sexuales del cliente parecen no ser factores explicativos de la salud física en la muestra de personas que ejercen prostitución. 
- Predictores de salud física en la muestra de prostitución de interior

Hemos realizado el análisis de regresión múltiple paso a paso con el grupo de personas que ejercen prostitución de interior a partir de las correlaciones significativas que hemos encontrado entre las variables analizadas (ver Tabla 36). Y encontramos que únicamente entra en el modelo la variable depresión $\left(F_{(1,119)}=74.73, p=.000\right)$, la cual explica un $22 \%$ de la varianza de la salud física (ver Figura 43) y entra en el modelo en sentido inverso, es decir, a mayor número de síntomas depresivos peor salud física. Como vemos el VIH/SIDA deja de ser un predictor de la salud física cuando retiramos del análisis a las personas que ejercen prostitución en la calle, ya que como vimos en el apartado anterior las personas que ejercen prostitución en la calle presentan el mayor porcentaje de seropositividad al VIH/SIDA. 
PREDICTORES

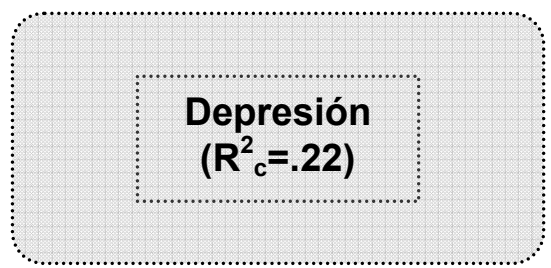

$$
\beta=-.48^{* * *}
$$

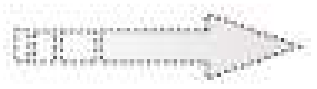

CRITERIO

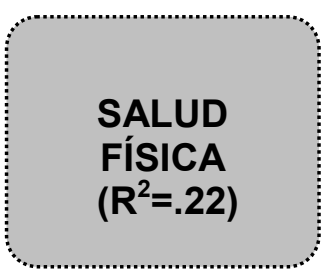

${ }^{* *} \mathrm{p}<.01 ;{ }^{* * *} \mathrm{p}<.001 ;$

Figura 43. Resumen del modelo de regresión lineal para la salud física considerando las variables de salud relacionadas con la prostitución en las personas que ejercen prostitución de interior

En cuanto a las variables que no han entrado en el modelo explicativo de la salud física en las personas que ejercen prostitución de interior, debemos destacar que de nuevo el maltrato psicológico $(p=.02)$ y las agresiones sexuales del cliente $(p=.05)$ no entran en el modelo de esta submuestra debido a que hemos elegido un alfa muy restrictivo. Mientras que, de nuevo la variable ansiedad (Índice de Tolerancia=.46), no entra porque explica lo mismo que la variable depresión. La autoestima parece no tener un gran poder explicativo en la salud física de las personas que ejercen prostitución de interior.

- Predictores de la salud psicológica en la muestra general

Las variables que se relacionaron significativamente con la salud psicológica (ver Tabla 35) fueron incluidas en el análisis de regresión paso a paso, y fueron: consumo de drogas, VIH/SIDA, agresiones sexuales del cliente, depresión, ansiedad y autoestima.

Realizado el análisis obtuvimos que en un primer paso entraba la depresión $\left(\mathrm{F}_{(1,140)}=\right.$ 69.52, $p=.000)$, en un segundo la autoestima $\left(F_{(1,139)}=14.86, p=.000\right)$, y en un tercero las agresiones sexuales del cliente $\left(F_{(1,138)}=6.74, p=.010\right)$. De manera que el modelo final resultante estaría formado por tres variables (ver Figura 44) que explican un $42 \%$ de la varianza de la salud psicológica $\left(\mathrm{F}_{(3,138)}=33.92, \mathrm{p}=.000\right)$. La depresión y las agresiones sexuales del cliente entran en sentido inverso, de manera que un mayor número de síntomas depresivos y un mayor número de agresiones sexuales del cliente se relacionan 
con un peor estado de salud psicológica. Mientras que la autoestima entra en sentido directo, un mayor nivel de autoestima se relaciona con mejor salud psicológica.

PREDICTORES

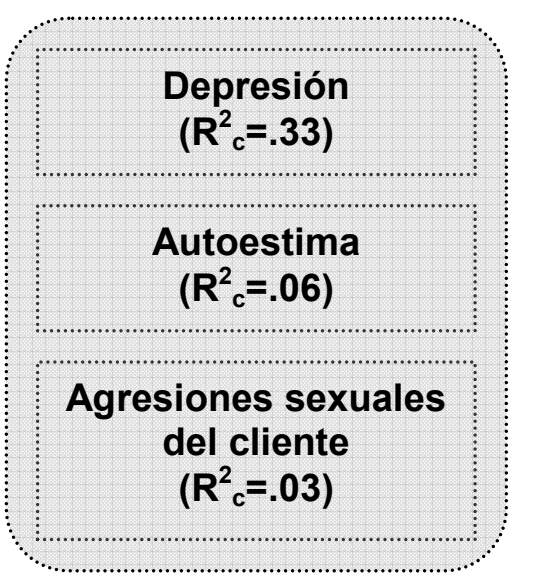

\section{CRITERIO}

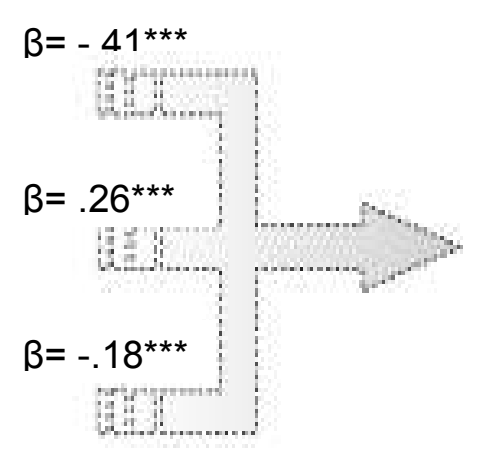

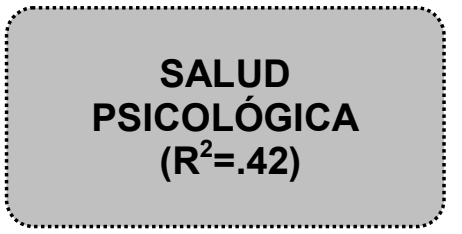

PSICOLÓGICA

$\left(R^{2}=.42\right)$

${ }^{* *} \mathrm{p}<.01 ;{ }^{* * *} \mathrm{p}<.001 ;$

Figura 44. Resumen del modelo de regresión lineal para la salud psicológica considerando las variables de salud relacionadas con la prostitución en la muestra general

En cuanto a las variables que no han entrado en el modelo explicativo de la salud psicológica, encontramos que la ansiedad (Índice de Tolerancia $=.39$ ) no entra en el modelo porque comparte variabilidad con la depresión, mientras que el consumo de drogas y el ser seropositiva al VIH/SIDA no son factores explicativos del estado de salud psicológica de las personas que ejercen prostitución.

- Predictores de la salud psicológica en la muestra de club y piso

Al analizar las variables explicativas de la salud psicológica partiendo de la matriz de correlaciones (ver Tabla 36) en las personas que ejercen prostitución de interior, obtuvimos que en un primer paso entraba la depresión $\left(F_{(1,119)}=42.76, p=.000\right)$ y en el segundo la autoestima $\left(F_{(1,118)}=7.30, p=.008\right)$. De esta manera el modelo final resultante estaría compuesto por dos variables (ver Figura 45) que explican un $30 \%$ de la varianza de la salud psicológica $\left(\mathrm{F}_{(2,118)}=26.16, p=.000\right)$. Como anteriormente hemos visto la depresión entra en sentido inverso y la autoestima en sentido directo, es decir, un menor número de síntomas 
depresivos y un mayor nivel de autoestima se relacionan con un mejor estado de salud psicológica.

Como vemos la variable agresiones sexuales del cliente deja de ser un factor explicativo de la salud psicológica cuando retiramos del análisis a las personas que ejercen prostitución en la calle. Este resultado puede deberse a que las personas que ejercen prostitución de interior no sufren agresiones sexuales con frecuencia por lo que no es una variable que influya o explique la salud psicológica de este subgrupo.

PREDICTORES

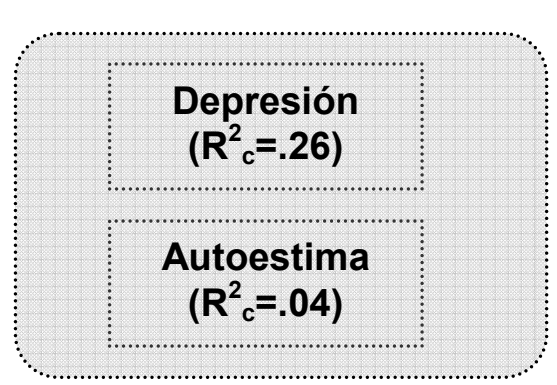

${ }^{* *} \mathrm{p}<.01 ;{ }^{* * *} \mathrm{p}<.001$
CRITERIO

$\beta=-.41^{* * *}$

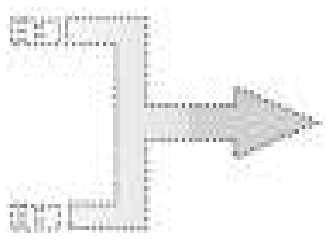

$\beta=.21^{* * *}$

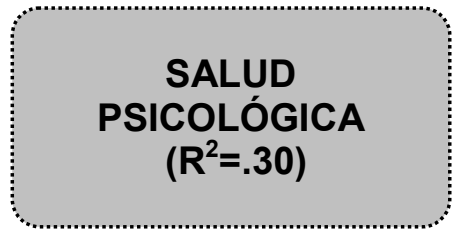

PSICOLÓGICA

$\left(R^{2}=.30\right)$

Figura 45. Resumen del modelo de regresión lineal para la salud psicológica considerando las variables de salud relacionadas con la prostitución en el subgrupo de personas que ejercen prostitución de interior

En primer lugar, las agresiones sexuales del cliente $(p=.02)$ no entran en el modelo explicativo porque hemos usado un alfa muy restrictivo. Sin embargo, la ansiedad no entra en el modelo explicativo de la salud psicológica en las personas que ejercen prostitución de interior porque comparte variabilidad con la depresión, que entra en primer lugar (Índice de Tolerancia $=.45)$.

- Predictores de la salud social en la muestra general

En relación a la salud social no hemos encontrado diferencias en las variables que entran en el modelo explicativo para la muestra general y para el subgrupo de personas que ejercen prostitución de interior, en ambos casos el modelo explicativo está compuesto por dos variables: la autoestima y el maltrato psicológico del cliente. 
Cuando realizamos el análisis para la muestra general la autoestima entra en un primer paso $\left(F_{(1,140)}=37.50, p=.000\right)$ y el maltrato psicológico del cliente en un segundo paso $\left(F_{(1,139)}=8.06, p=.005\right)$, de manera que el modelo explica un $25 \%$ de la varianza de la salud social $\left(F_{(2,139)}=23.73, p=.000\right)$ (ver Figura 46). La autoestima entra en sentido directo y el maltrato psicológico en sentido inverso, de manera que un mayor nivel de autoestima y un menor maltrato psicológico por parte del cliente se relaciona con mejor estado de salud social.

PREDICTORES

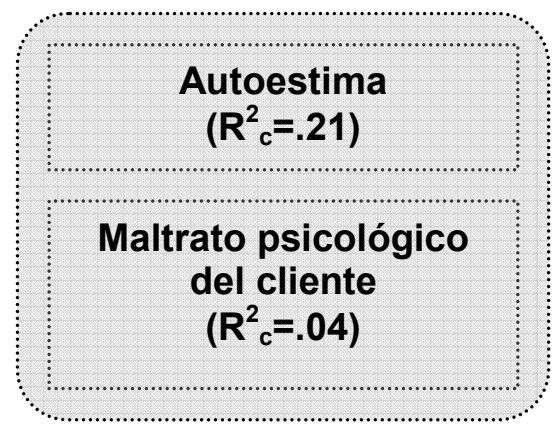

${ }^{* *} p<.01 ;{ }^{* * *} p<.001 ;$
CRITERIO

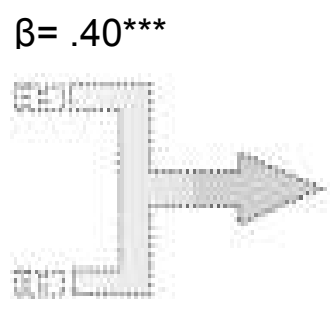

$\beta=-.22^{* * *}$
SALUD SOCIAL

$\left(R^{2}=.25\right)$

Figura 46. Resumen del modelo de regresión lineal para la salud social considerando las variables de salud y el mundo de la prostitución en la muestra general

En cuanto a las variables que no entran dentro del modelo explicativo de la salud social, encontramos que la depresión (Índice de Tolerancia=.71) y la ansiedad (Índice de Tolerancia $=.74)$ comparten variabilidad con la variable autoestima que entra en el modelo explicativo en el primer paso. Sin embargo las agresiones sexuales del cliente no parecen ser un predictor que explique la salud social.

- Predictores de salud social en la muestra de prostitución de interior

Como ya hemos comentado el modelo explicativo de la salud social para las personas que ejercen prostitución de interior es el mismo que para la muestra general (ver Figura 47), de manera que en un primer paso entra la autoestima $\left(F_{(1,119)}=16.25, p=.000\right)$ y 
en el segundo paso el maltrato psicológico del cliente $\left(F_{(1,118)}=10.94, p=.001\right)$, obteniendo un modelo explicativo con dos variables que explican el $19 \%$ de la varianza de la salud $\operatorname{social}\left(F_{(2,118)}=9.82, p=.000\right)$.

Como anteriormente hemos mencionado la autoestima entra en sentido directo y el maltrato psicológico del cliente en sentido inverso, por lo tanto un mayor nivel de autoestima y un menor nivel de maltrato psicológico del cliente se relaciona con un mejor estado de salud social.

PREDICTORES

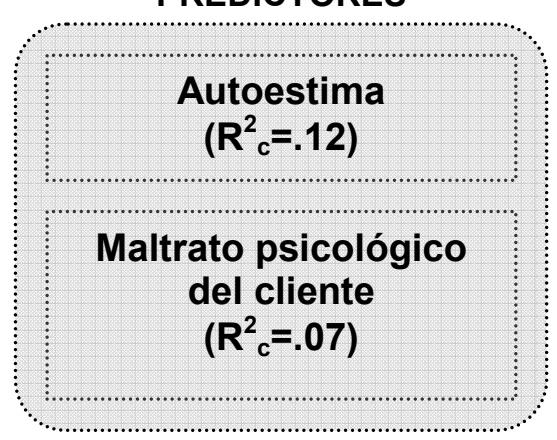

$\beta=.31^{* * *}$

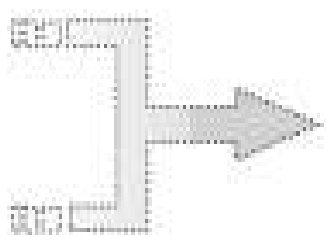

$\beta=-.28^{* * *}$

\section{CRITERIO}

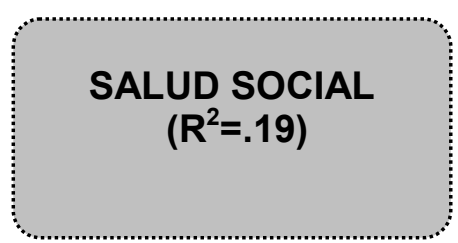

${ }^{* *} \mathrm{p}<.01 ;{ }^{* * *} \mathrm{p}<.001 ;$

Figura 47. Resumen del modelo de regresión lineal para la salud social considerando las variables de salud y el mundo de la prostitución en el subgrupo de personas que ejercen prostitución de interior

La variable depresión no entra en el modelo explicativo debido a que no parece ser importante en la explicación de la salud social.

\section{- Predictores de salud ambiental en la muestra general}

Finalmente, en relación con la salud ambiental, encontramos que tanto en el análisis con la muestra general como en el análisis con el subgrupo de mujeres que ejercen prostitución de interior el único predictor es la autoestima.

Para la muestra general la autoestima explica un $13 \%$ de la varianza de la salud ambiental $\left(F_{(1,140)}=7.68, p=.000\right)($ ver Figura 48). Esta variable entra en sentido directo de manera que a mayor autoestima mejor salud ambiental. 
PREDICTORES

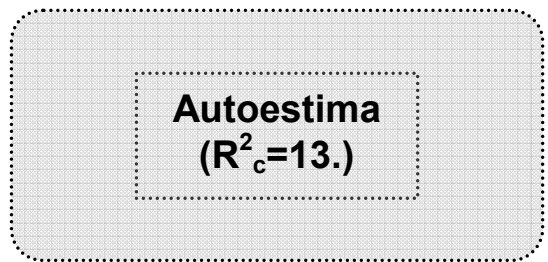

CRITERIO

$\beta=.36^{* * *}$

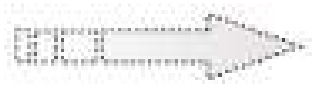

SALUD

AMBIENTAL

$\left(R^{2}=13.\right)$

${ }^{* *} \mathrm{p}<.01 ;{ }^{* * *} \mathrm{p}<.001 ;$

Figura 48. Resumen del modelo de regresión lineal para la salud ambiental considerando las variables de salud relacionadas con la prostitución en la muestra general

En cuanto a las variables que no entran en el modelo explicativo de la salud ambiental, tenemos en primero lugar las agresiones sexuales del cliente, la cual no entra porque hemos usado un alfa muy restrictivo $(p=.02)$. En segundo lugar no entra la depresión ya que no parece ser una variable importante en la explicación de la salud ambiental.

- Predictores de salud ambiental en la prostitución de interior

La autoestima es, de nuevo, la única variable explicativa del modelo de la salud ambiental para las personas que ejercen prostitución de interior. Esta variable explica un $9 \%$ de la salud ambiental $\left(F_{(1,119)}=12.07, p=.001\right)$ (ver Figura 49) y entra en sentido directo, de manera que a mayor autoestima mejor salud ambiental. 
PREDICTORES

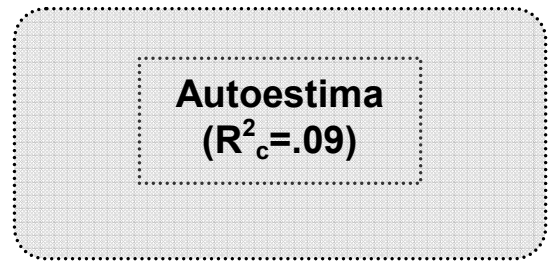

CRITERIO

$$
\beta=.30^{* * *}
$$

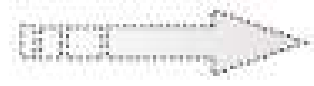

SALUD

AMBIENTAL

$\left(R^{2}=.09\right)$

${ }^{* *} p<.01 ;{ }^{* *} p<.001 ;$

Figura 49. Resumen del modelo de regresión lineal para la salud ambiental considerando las variables de salud relacionadas con la prostitución en las personas que ejercen prostitución de interior

En cuanto a las variables que no entran en el modelo explicativo de la salud ambiental, tenemos en primero lugar las agresiones sexuales del cliente, la cual no entra porque hemos usado un alfa muy restrictivo $(p=.02)$. En segundo lugar no entra la depresión ya que no parece ser una variable importante en la explicación de la salud ambiental.

7.4.3. Predictores relacionados con las necesidades interpersonales básicas que explican la calidad de vida

A continuación vamos a analizar en qué medida las necesidades interpersonales básicas explican la calidad de vida. Como hemos dicho anteriormente las variables que analizaremos son las siguientes: soledad emocional familiar, soledad emocional de pareja, soledad social, satisfacción sexual y depresión sexual.

A partir de la matriz de correlaciones (ver Tabla 37), comprobamos que todas las medidas de soledad correlacionan significativamente con la calidad de vida, y todas ellas, exceptuando la satisfacción sexual, en sentido negativo. De forma que una elevada soledad familiar, de pareja, social y la depresión sexual se relacionan con una peor calidad de vida, mientras que una mayor satisfacción sexual se relaciona con una mejor calidad de vida. 
Tabla 37. Matriz de correlaciones entre las variables de necesidades interpersonales básicas y calidad de vida en la muestra general

\begin{tabular}{|c|c|c|c|c|c|c|}
\hline & Calidad de vida & Soledad familiar & $\begin{array}{c}\text { Soledad de } \\
\text { pareja }\end{array}$ & $\begin{array}{c}\text { Soledad } \\
\text { social }\end{array}$ & $\begin{array}{c}\text { Satisfacción } \\
\text { sexual }\end{array}$ & Depresión sexual \\
\hline Calidad de vida & 1 & & & & & \\
\hline $\begin{array}{l}\text { Soledad } \\
\text { familiar }\end{array}$ & $-.52^{\star * *}$ & 1 & & & & \\
\hline $\begin{array}{c}\text { Soledad de } \\
\text { pareja }\end{array}$ & $-.28^{\star \star *}$ & $.28^{\star * *}$ & 1 & & & \\
\hline $\begin{array}{c}\text { Soledad } \\
\text { social }\end{array}$ & $-.54^{\star \star *}$ & $.50^{\star \star \star}$ & .07 & 1 & & \\
\hline $\begin{array}{c}\text { Satisfacción } \\
\text { sexual }\end{array}$ & $.54^{\star \star \star}$ & $-.35^{\star \star *}$ & $-.32^{\star \star \star}$ & $-.23^{\star \star \star}$ & 1 & \\
\hline $\begin{array}{c}\text { Depresión } \\
\text { sexual }\end{array}$ & $-.46^{\star \star \star}$ & $.31^{* \star *}$ & $.25^{\star \star \star}$ & .17 & $-.87^{* \star *}$ & 1 \\
\hline
\end{tabular}

Como hemos encontrado que todas las variables correlacionan significativamente con la calidad de vida, incluimos todas ellas en el análisis de regresión paso a paso.

Al realizar este análisis hemos encontrado que entran tres variables en el modelo. En un primer paso entra la soledad social $\left(F_{(1,144)}=58.63, p=.000\right)$, en el segundo la satisfacción sexual $\left(F_{(1,143)}=48.96, p=.000\right)$, y en el último la soledad emocional familiar $\left(F_{(1,142)}=9.56\right.$, $\mathrm{p}=.002)$.

El modelo final resultante está formado por tres variables (ver Figura 50) que explican un $49 \%$ de la varianza de la calidad de vida $\left(F_{(3,142)}=48.09, p=.000\right)$. La soledad social y familiar entran en el modelo en sentido inverso de manera que un mayor nivel de soledad social y familiar se relacionan con una peor calidad de vida; mientras que la satisfacción sexual entra en sentido directo ya que un buen estado de satisfacción sexual se relaciona con mejor calidad de vida. 
PREDICTORES

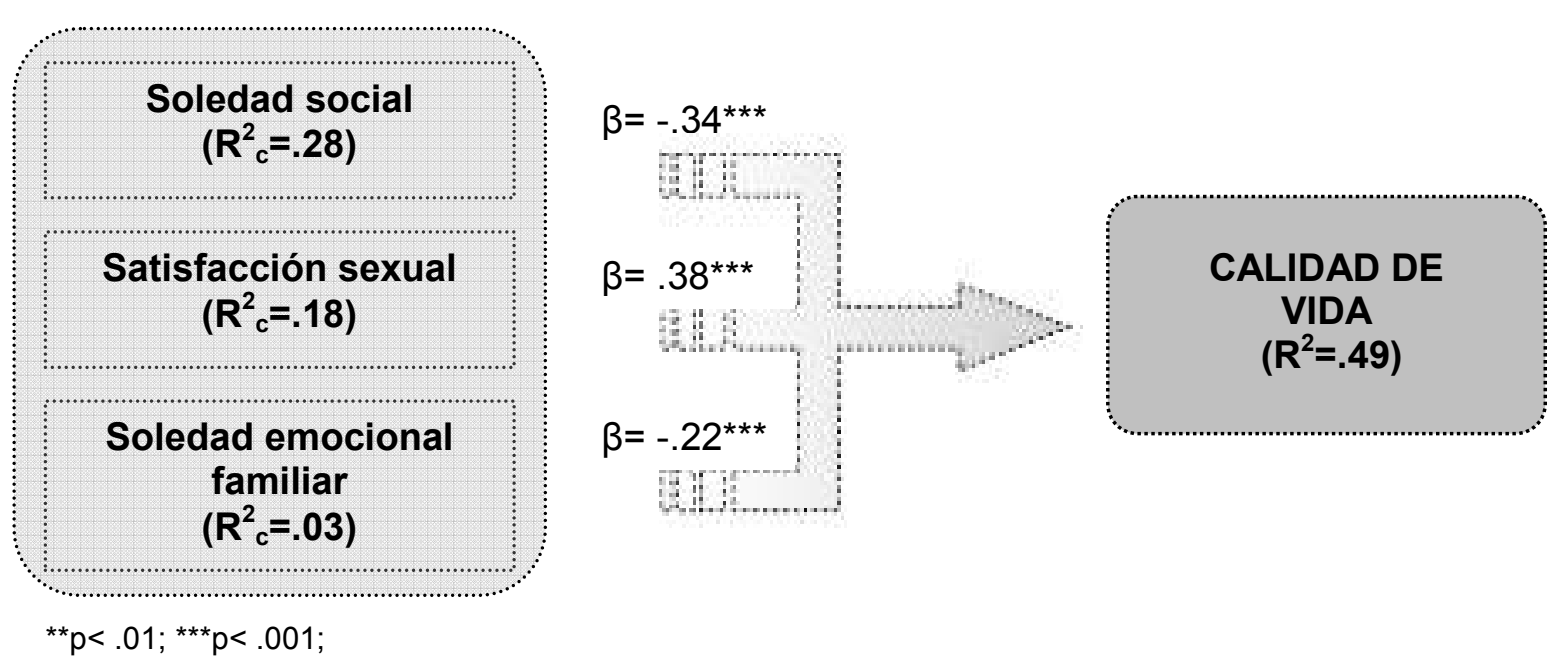

Figura 50. Resumen del modelo de regresión lineal para la calidad de vida considerando las variables de necesidades interpersonales básicas en la muestra general

A continuación vamos a analizar las variables que no han entrado en el modelo. La variable depresión sexual (Índice de Tolerancia $=.25$ ) no entra en el modelo debido a que comparte variabilidad con la satisfacción sexual que entra en un segundo paso, mientras que la soledad emocional de pareja no entra en el modelo porque parece no explicar significativamente la calidad de vida.

Como hemos dicho al comienzo de este punto vamos a analizar también las variables que explican la calidad de vida de las personas que ejercen prostitución de interior (en club y piso). En la Tabla 38 presentamos la matriz de correlaciones entre las necesidades interpersonales básicas y la calidad de vida.

Al eliminar del análisis a las personas que ejercen prostitución en la calle encontramos algunos cambios. Por ejemplo, la soledad emocional de pareja ya no correlaciona significativamente con la calidad de vida, por lo que no la incluiremos en el análisis de regresión múltiple paso a paso que realizaremos a continuación. 
Tabla 38. Matriz de correlaciones entre las variables de necesidades interpersonales básicas y calidad de vida en el subgrupo de personas que ejercen prostitución de interior

\begin{tabular}{|c|c|c|c|c|c|c|}
\hline & Calidad de vida & Soledad familiar & $\begin{array}{c}\text { Soledad de } \\
\text { pareja }\end{array}$ & $\begin{array}{l}\text { Soledad } \\
\text { social }\end{array}$ & $\begin{array}{c}\text { Satisfacción } \\
\text { sexual }\end{array}$ & Depresión sexual \\
\hline \multicolumn{7}{|l|}{ Calidad de vida } \\
\hline $\begin{array}{l}\text { Soledad } \\
\text { familiar }\end{array}$ & $-.36^{\star \star \star}$ & 1 & & & & \\
\hline $\begin{array}{c}\text { Soledad de } \\
\text { pareja }\end{array}$ & -.16 & .18 & 1 & & & \\
\hline $\begin{array}{l}\text { Soledad } \\
\text { social }\end{array}$ & $-.41^{\star \star \star}$ & $.41^{* * *}$ & -.06 & 1 & & \\
\hline $\begin{array}{c}\text { Satisfacción } \\
\text { sexual }\end{array}$ & $.53^{* \star *}$ & $-.31^{* \star *}$ & $-.34^{* * *}$ & -.16 & 1 & \\
\hline $\begin{array}{l}\text { Depresión } \\
\text { sexual }\end{array}$ & $-.40^{\star \star *}$ & $.23^{* * *}$ & .22 & .05 & $-.86^{\star \star *}$ & 1 \\
\hline
\end{tabular}

${ }^{* *} p<.01 ;{ }^{* * *} p<.001 ; \mathrm{N}$ por lista $=125$

A partir de la matriz de correlaciones hemos realizado un análisis de regresión múltiple paso a paso en el que hemos incluido las siguientes variables: soledad emocional familiar, soledad social, satisfacción sexual y depresión sexual.

Al realizar este análisis hemos encontrado que entran dos variables en el modelo. En un primer paso entra la satisfacción sexual $\left(\mathrm{F}_{(1,123)}=47.71, p=.000\right)$ y en un segundo paso entra la soledad social $\left(F_{(1,122)}=21.96, p=.000\right)$. El modelo explicativo resultante para las personas que ejercen prostitución de interior está formado por dos variables (ver Figura 51) que explican un $38 \%$ de la varianza de la calidad de vida $\left(F_{(2,122)}=38.90, p=.000\right)$. La satisfacción sexual entra en el modelo en sentido directo de manera que una mayor satisfacción sexual se relaciona con una mejor calidad de vida. Mientras que la soledad social entra en sentido inverso de manera que una mayor soledad social se relaciona con una peor calidad de vida.

Como vemos el modelo explicativo de la calidad de vida cambia cuando nos referimos a las personas que ejercen prostitución en general a cuando nos referimos al subgrupo de personas que ejercen prostitución de interior. En primer lugar la soledad emocional familiar deja de ser una variable explicativa del modelo cuando nos referimos a la prostitución de interior, por lo que parece ser un predictor relacionado con las personas que ejercen en la calle. También encontramos que cambia el orden de entrada de las otras dos 
variables, de manera que para las personas que ejercen prostitución de interior la satisfacción sexual explica más varianza de la calidad de vida que la soledad social.

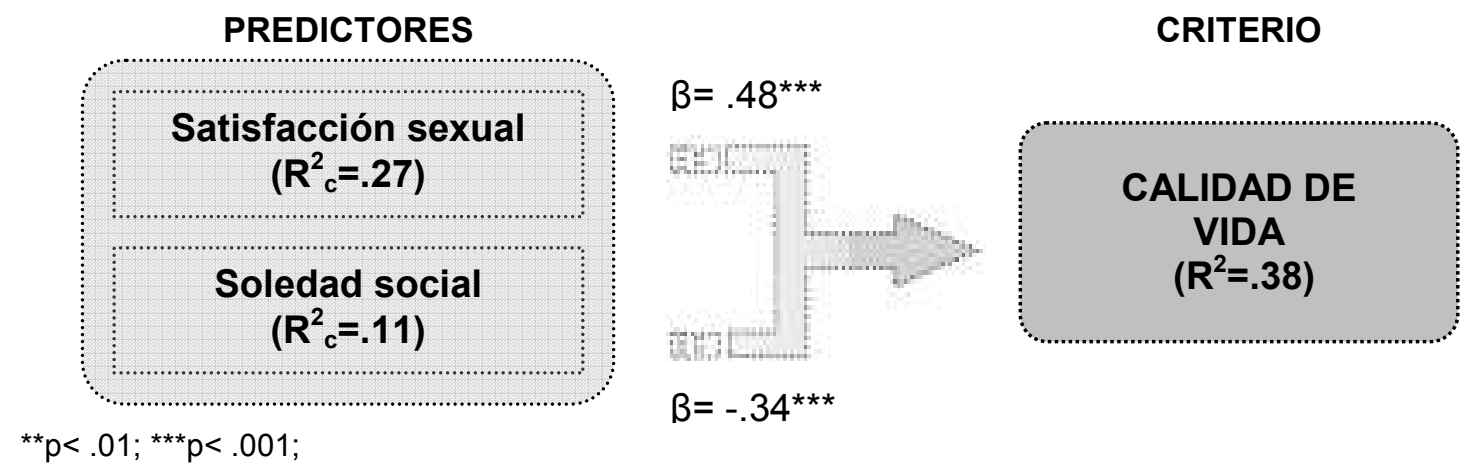

Figura 51. Resumen del modelo de regresión lineal para la calidad de vida considerando las variables de necesidades interpersonales básicas en el subgrupo de personas que ejercen prostitución de interior

En cuanto a las variables que no han entrado en el modelo, encontramos que la depresión sexual no entra (Índice de Tolerancia $=.25$ ) debido a que comparte varianza con la satisfacción sexual que entra en el primer paso. Tampoco entra la soledad familiar porque parece compartir variabilidad, en este caso, con la soledad social (Índice de Tolerancia = $.77)$.

7.4.4. Predictores relacionados con las necesidades interpersonales básicas que explican las diferentes subescalas de la calidad de vida

A continuación vamos a analizar los factores explicativos relacionados con las necesidades interpersonales básicas de cada una de las subescalas que componen la calidad de vida: salud física, psicológica, social y ambiental.

En primer lugar hemos obtenido la matriz de correlaciones entre las variables relacionadas con las necesidades interpersonales básicas y cada una de las subescalas de la calidad de vida para ver qué variables debemos incluir en cada uno de los modelos de regresión paso a paso. Vamos a realizar este análisis tanto con la muestra general como 
con el subgrupo de personas que ejercen prostitución de interior para ver las diferencias existentes entre ambos modelos explicativos.

En primer lugar vamos a comentar los resultados de la matriz de correlaciones en la muestra general (ver Tabla 39). En cuanto a la salud psicológica y social muestran relaciones significativas con todas las variables mientras que para la salud física y ambiental no encontramos relaciones significativas con soledad emocional de pareja.

Excepto en el caso de la satisfacción sexual el resto de variables presentan relaciones inversas con cada uno de las subescalas de calidad de vida. De manera que un mayor sentimiento de soledad familiar, de pareja y social y una mayor depresión sexual se relaciona con peor estado de salud física, psicológica, social y ambiental. Mientras que un buen estado de satisfacción sexual se relaciona con mejor estado de salud física, psicológica, social y ambiental.

También podemos destacar que, exceptuando la soledad de pareja que únicamente presenta relación significativa con la salud psicológica y social, el resto de variables presentan una correlación muy elevada todas las variables dependientes.

Tabla 39. Matriz de correlaciones entre las variables de necesidades interpersonales básicas y las diferentes escalas de calidad de vida en la muestra general

\begin{tabular}{|c|c|c|c|c|}
\hline & Salud Física & Salud Psicológica & Salud Social & Salud Ambiental \\
\hline Soledad familiar & $-.40^{\star \star \star}$ & $-.58^{* \star \star}$ & $-.43^{\star \star \star}$ & $-.37^{\star \star \star}$ \\
\hline Soledad de pareja & -.19 & $-.28^{* * *}$ & $-.27^{* * *}$ & -.21 \\
\hline Soledad social & $-.42^{\star \star \star}$ & $-.48^{* * *}$ & $-.61^{* * *}$ & $-.40^{\star \star \star}$ \\
\hline Satisfacción sexual & $.46^{\star \star \star}$ & $.45^{\star \star \star}$ & $.62^{\star \star \star}$ & $.37^{* * *}$ \\
\hline Depresión sexual & $-.43^{\star \star \star}$ & $-.38^{* * *}$ & $-.50^{* \star *}$ & $-.32^{\star \star \star}$ \\
\hline
\end{tabular}

${ }^{* *} p<.01 ;{ }^{* * *} p<.001 ; N$ por lista $=146$

A continuación vamos a analizar la matriz de correlaciones obtenida con el subgrupo de personas que ejercen prostitución de interior (ver Tabla 40), y como vemos todas las subescalas que componen la calidad de vida correlacionan significativamente y de forma elevada con todas las variables relacionadas con las necesidades interpersonales, excepto la soledad de pareja. La soledad emocional de pareja deja de tener relación con la salud 
física y ambiental cuando eliminamos del análisis a las personas que ejercen prostitución en la calle.

Al igual que con la muestra general todas las variables, excepto la satisfacción sexual, muestran una relación inversa con las subescalas de calidad de vida, de forma que una mayor soledad emocional familiar, de pareja, social y una mayor depresión sexual se relaciona con peor estado de salud física, psicológica, social y ambiental.

Tabla 40. Matriz de correlaciones entre las variables de necesidades interpersonales básicas y las diferentes escalas de calidad de vida en el subgrupo de personas que ejercen prostitución de interior

\begin{tabular}{|c|c|c|c|c|}
\hline & Salud Física & Salud Psicológica & Salud Social & Salud Ambiental \\
\hline Soledad familiar & $-.23^{* * *}$ & $-.45^{* * *}$ & $-.28^{* * *}$ & $-.23^{\star \star \star}$ \\
\hline Soledad de pareja & -.06 & -.17 & -.20 & -.12 \\
\hline Soledad social & $-.23^{* *}$ & $-.35^{* * *}$ & $-.50^{* * *}$ & $-.33^{\star * *}$ \\
\hline Satisfacción sexual & $.42^{* * *}$ & $.43^{\star \star *}$ & $.62^{\star \star \star}$ & $.35^{\star * *}$ \\
\hline Depresión sexual & $-.35^{\star * \star}$ & $-.31^{* * *}$ & $-.45^{\star \star \star}$ & $-.27^{\star \star \star}$ \\
\hline
\end{tabular}

- Predictores de salud física en la muestra

A partir de los resultados obtenidos en la matriz de correlaciones anteriormente comentada (ver Tabla 39) incluimos en el análisis de regresión paso a paso las siguientes variables: soledad emocional familiar, soledad social, satisfacción y depresión sexual.

Cuando realizamos el análisis para la muestra general la satisfacción sexual entra en un primer paso $\left(F_{(1,144)}=38.05, p=.000\right)$ y la soledad social en un segundo $\left(F_{(1,143)}=21.54\right.$, $p=.000$ ), de forma que obtuvimos un modelo explicativo (ver Figura 52) compuesto por dos variables que explican el $30 \%$ de la varianza de la salud física $\left(F_{(2,143)}=32.51, p=.000\right)$. La satisfacción sexual entra en sentido directo y la soledad social en inverso, de manera que una mayor satisfacción sexual y un menor nivel de soledad social se relacionan con un mejor estado de salud física en las personas que ejercen prostitución. 


\section{PREDICTORES}

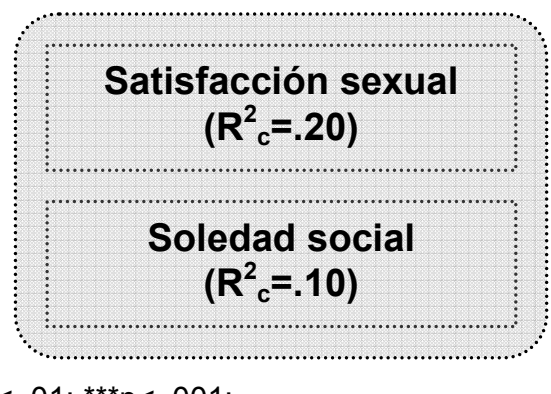

\section{CRITERIO}

$\beta=.38^{* * *}$

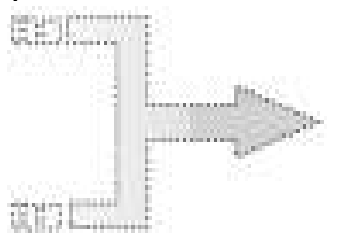

$\beta=-.33^{* * *}$

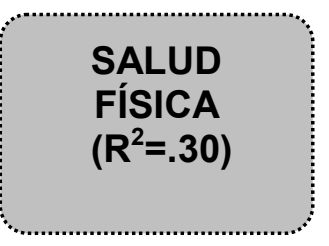

SALUD

$\left(\mathrm{R}^{2}=.30\right)$

${ }^{* *} p<.01 ;{ }^{* * *} p<.001$

Figura 52. Resumen del modelo de regresión lineal para la salud física considerando las variables relacionadas con las necesidades interpersonales básicas en la muestra general

En cuanto a las variables que no entran en el modelo explicativo de la salud física encontramos que ni la soledad emocional familiar (Índice de Tolerancia=.69), ni la depresión sexual (Índice de Tolerancia=.25) entran en el modelo debido a que explican lo mismo que la soledad social y la satisfacción sexual respectivamente.

- Predictores de salud física en las personas que ejercen prostitución de interior

Cuando hemos realizado el análisis de regresión múltiple paso a paso con el grupo de personas que ejercen prostitución de interior encontramos que únicamente entra una variable en el modelo explicativo: la satisfacción sexual $\left(F_{(1,123)}=27.04, p=.000\right)$, la cual explica un $18 \%$ de la varianza de la salud física (ver Figura 53) y entra en el modelo en sentido directo, es decir, una mayor satisfacción sexual se relaciona con un mejor estado de salud física.

Como vemos, la soledad social deja de ser un predictor de la salud física cuando hacemos referencia a la prostitución de interior. Es en el grupo de prostitución de calle donde la soledad social parece tener un poder explicativo de la salud física. 
PREDICTORES

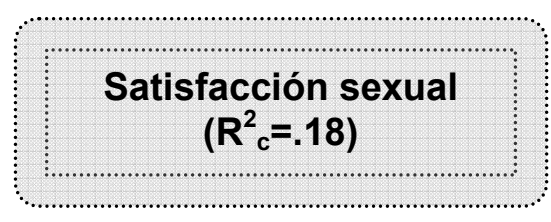

$\beta=.42^{* * *}$

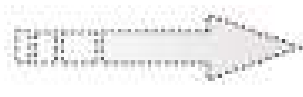

CRITERIO

SALUD

FÍSICA

$\left(R^{2}=.18\right)$

${ }^{* *} p<.01 ;{ }^{* * *} p<.001 ;$

Figura 53. Resumen del modelo de regresión lineal para la salud física considerando las variables relacionadas con las necesidades interpersonales básicas en el subgrupo de personas que ejercen prostitución de interior

En cuanto a las variables que no han entrado en el modelo encontramos que la soledad social $(p=.05)$ no entra porque usamos un criterio más restrictivo, la depresión sexual (Índice de Tolerancia=.26) no entra debido a que explica lo mismo que la satisfacción sexual y la soledad emocional familiar parece no ser importante en la explicación de la salud física.

- Predictores de salud psicológica en la muestra

Hemos incluido todas las variables de necesidades interpersonales básicas en el análisis de regresión múltiple ya que todas ellas se relacionaron significativamente con la salud psicológica.

Realizado el análisis obtuvimos que en un primer paso entraba la soledad emocional familiar $\left(F_{(1,144)}=73.21, p=.000\right)$, en un segundo la satisfacción sexual $\left(F_{(1,143)}=17.50\right.$, $p=.000)$, y en un tercero la soledad social $\left(F_{(1,142}=10.82, p=.001\right)$. De manera que el modelo final resultante estaría formado por tres variables (ver Figura 54 que explican un $44 \%$ de la varianza de la salud psicológica $\left(\mathrm{F}_{(3,142)}=38.90, \mathrm{p}=.000\right)$.

La soledad emocional familiar y la soledad social entran en el modelo en sentido inverso, de manera que mayores niveles de soledad familiar y social se relacionan con un peor estado de salud psicológica. Sin embargo, la satisfacción sexual se relaciona en sentido directo con la salud psicológica, ya que a mayor satisfacción sexual mejor nivel de salud psicológica. 
PREDICTORES

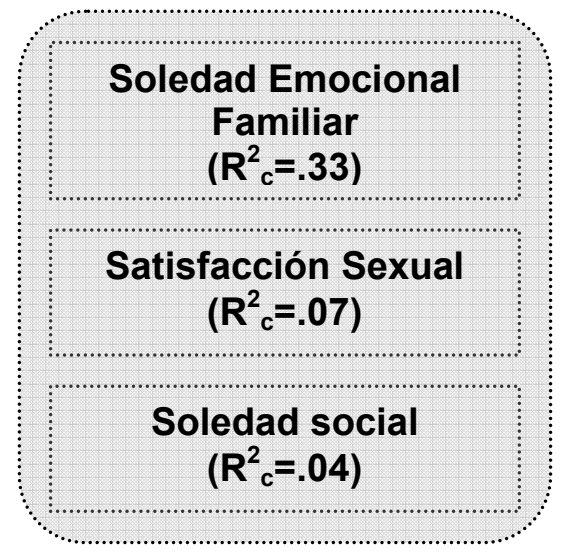

${ }^{* *} \mathrm{p}<.01 ;{ }^{* * *} \mathrm{p}<.001$
CRITERIO

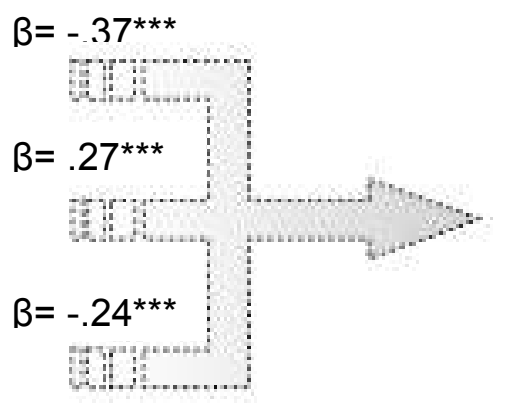

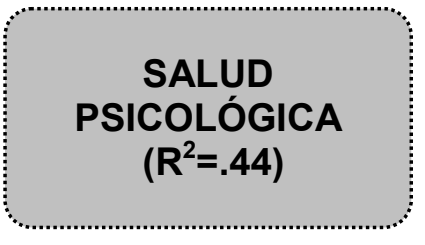

Figura 54. Resumen del modelo de regresión lineal para la salud psicológica considerando las variables relacionadas con las necesidades interpersonales básicas en la muestra general

En cuanto a las variables que no han entrado en el modelo, debemos destacar que la depresión sexual (Índice de Tolerancia=.25) no entra en el modelo debido a que explica lo mismo que la satisfacción sexual mientras que la soledad emocional de pareja no parece ser una variable que explique la salud psicológica de las personas que ejercen prostitución. 
- Predictores de salud psicológica en las personas que ejercen prostitución de interior

Para analizar las variables explicativas de la salud psicológica del subgrupo de personas que ejercen prostitución de interior incluimos en el análisis de regresión todas aquellas variables que correlacionaron significativamente con la salud psicológica, es decir, todas excepto la soledad emocional de pareja.

Obtuvimos que en un primer paso entraba la soledad emocional familiar $\left(F_{(1,123)}=\right.$ 31.03, $p=.000)$ y en el segundo la satisfacción sexual $\left(F_{(1,122)}=15.87, p=.000\right)$. De esta manera el modelo final resultante estaría compuesto por dos variables (ver Figura 55) que explican un $30 \%$ de la varianza de la salud psicológica $\left(F_{(2,122)}=25.33, p=.000\right)$. Como en los casos anteriores la soledad emocional familiar entra en sentido inverso mientras que la satisfacción sexual entra en sentido directo.

Como vemos, la variable soledad social vuelve a no tener poder explicativo cuando retiramos del análisis a las personas que ejercen prostitución en la calle. Se repite el mismo patrón que cuando analizamos los factores explicativos de la salud física.

\section{PREDICTORES}

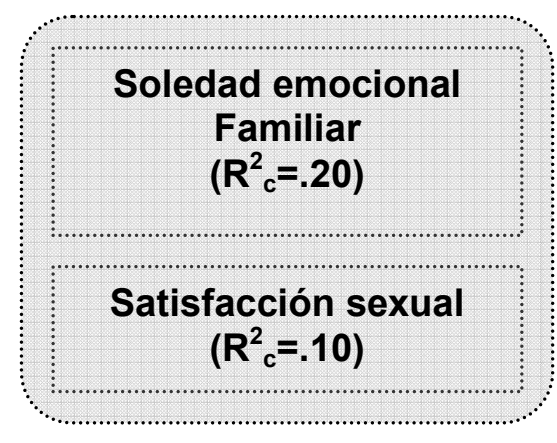

CRITERIO

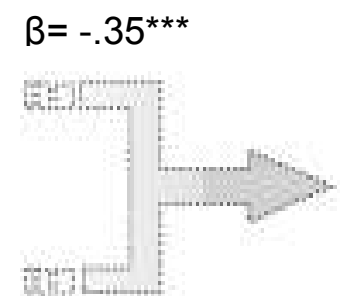

$\beta=.32^{* * *}$

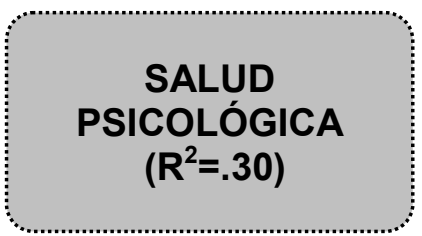

${ }^{* *} \mathrm{p}<.01 ;{ }^{* * *} \mathrm{p}<.001 ;$

Figura 55. Resumen del modelo de regresión lineal para la salud psicológica considerando las variables relacionadas con las necesidades interpersonales básicas en el subgrupo de personas que ejercen prostitución de interior

En cuanto a las variables que no entran en el modelo explicativo, encontramos que la soledad social no entra porque hemos usado un alfa muy restrictivo $(p=.03)$ y la depresión sexual (Índice de Tolerancia=.26) de nuevo explica lo mismo que la satisfacción sexual. 
- Predictores de salud social en la muestra

En relación a la salud social no hemos encontrado diferencias en las variables que entran en el modelo explicativo para la muestra general y para el subgrupo de personas que ejercen prostitución de interior, en ambos casos el modelo está compuesto por las variables satisfacción sexual y soledad social.

Cuando realizamos el análisis para la muestra general la satisfacción sexual entra en un primer paso $\left(F_{(1,144)}=90.93, p=.000\right)$ y la soledad social en un segundo paso $\left(F_{(1,143)}=\right.$ $85.00, p=.000$ ), de manera que el modelo explica el $61 \%$ de la varianza de la salud social $\left(F_{(2,143)}=114.48, p=.000\right)$ (ver Figura 56).

La satisfacción sexual entra en sentido directo y la soledad social en sentido inverso, de forma que una mayor satisfacción sexual y un menor sentimiento de soledad social se relacionan con una mejor salud social.

\section{PREDICTORES}

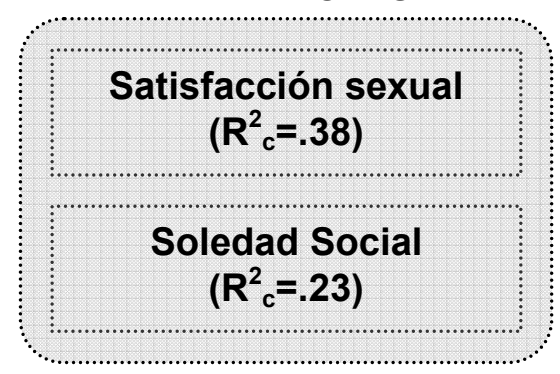

${ }^{* *} \mathrm{p}<.01 ;{ }^{* * *} \mathrm{p}<.001 ;$
CRITERIO

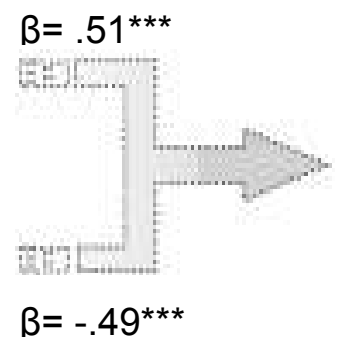

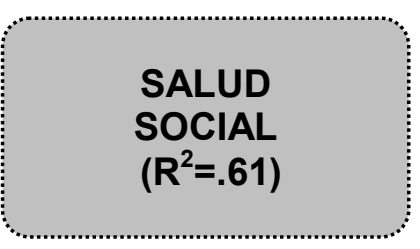

$\left(R^{2}=.61\right)$

Figura 56. Resumen del modelo de regresión lineal para la salud social considerando las variables relacionadas con las necesidades interpersonales básicas en la muestra general

En cuanto a las variables que no entran dentro del modelo explicativo de la salud social, encontramos que la soledad emocional familiar (Índice de Tolerancia=.69) no entra porque comparte variabilidad con la soledad social y la depresión sexual de nuevo comparte variabilidad con la satisfacción sexual (Índice de Tolerancia=.25), mientras que la soledad emocional de pareja no entra porque no parece tener poder explicativo en la salud social. 
- Predictores de salud social en las personas que ejercen prostitución de interior

Como ya hemos comentado el modelo explicativo de la salud social para las personas que ejercen prostitución de interior es el mismo que para la muestra general (ver Figura 57), de manera que en el primer paso entra la satisfacción sexual $\left(F_{(1,123)}=76.55\right.$, $p=.000)$, y en el segundo la soledad social $\left(F_{(1,122)}=46.31, p=.000\right)$, obteniendo un modelo explicativo con dos variables que explican el $55 \%$ de la varianza de la salud social. $\left(\mathrm{F}_{(2,122)}=\right.$ 75.53, $\mathrm{p}=.000$ ). Del mismo modo que con la muestra general, la satisfacción sexual entra en sentido directo y la soledad social en sentido inverso, de forma que una mayor satisfacción sexual y un menor sentimiento de soledad social se relacionan con una mejor salud social.

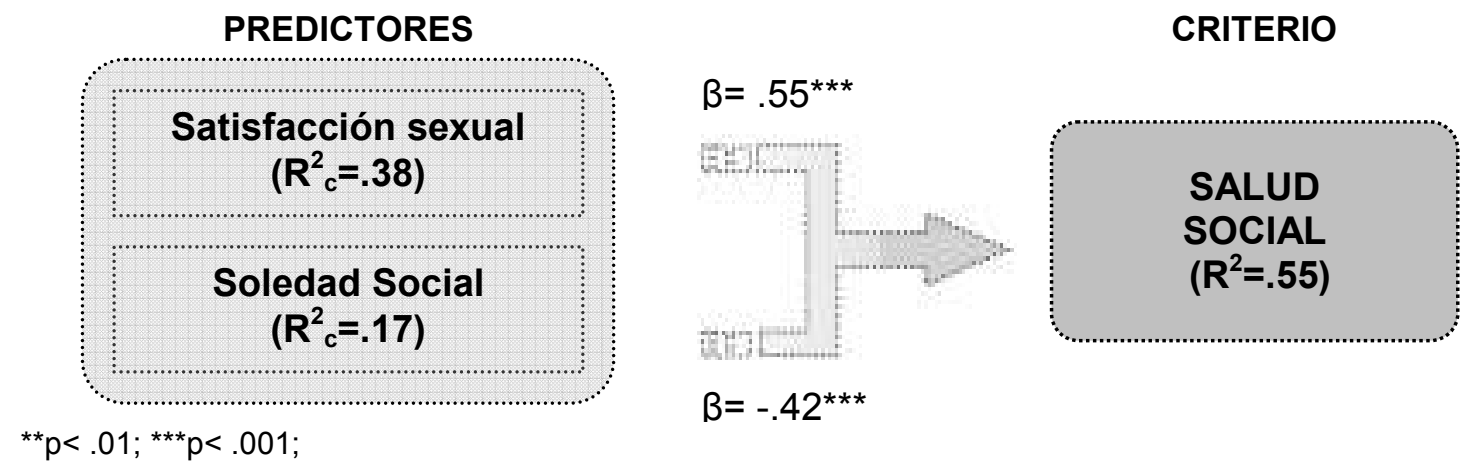

Figura 57. Resumen del modelo de regresión lineal para la salud social considerando las variables relacionadas con las necesidades interpersonales básicas en el subgrupo de personas que ejercen prostitución de interior

En cuanto a las variables que no entran en el modelo encontramos que tanto la soledad emocional familiar (Índice de Tolerancia=.77) como la depresión sexual (Índice de Tolerancia $=.25$ ) no entran en el modelo porque comparten variabilidad con la soledad social y la satisfacción sexual respectivamente.

- $\quad$ Predictores de salud ambiental en la muestra

Finalmente llegamos al análisis de las variables predictoras de la salud ambiental, y encontramos que tanto para la muestra general como para el subgrupo de prostitución de interior entran las mismas variables pero en orden diferente. 
Para la muestra general obtuvimos un modelo explicativo de la salud ambiental en el que entraba en el primer paso la soledad social $\left(F_{(1,144)}=26.76, p=.000\right)$, y en segundo paso la satisfacción sexual $\left(F_{(1,143)}=16.10, p=.000\right)$. Estas dos variables explicaban el $23 \%$ de la varianza de la salud ambiental $\left(F_{(2,143)}=22.83, p=.000\right)$ (ver Figura 58 ), donde la soledad social entraba en sentido inverso y la satisfacción sexual en sentido directo.
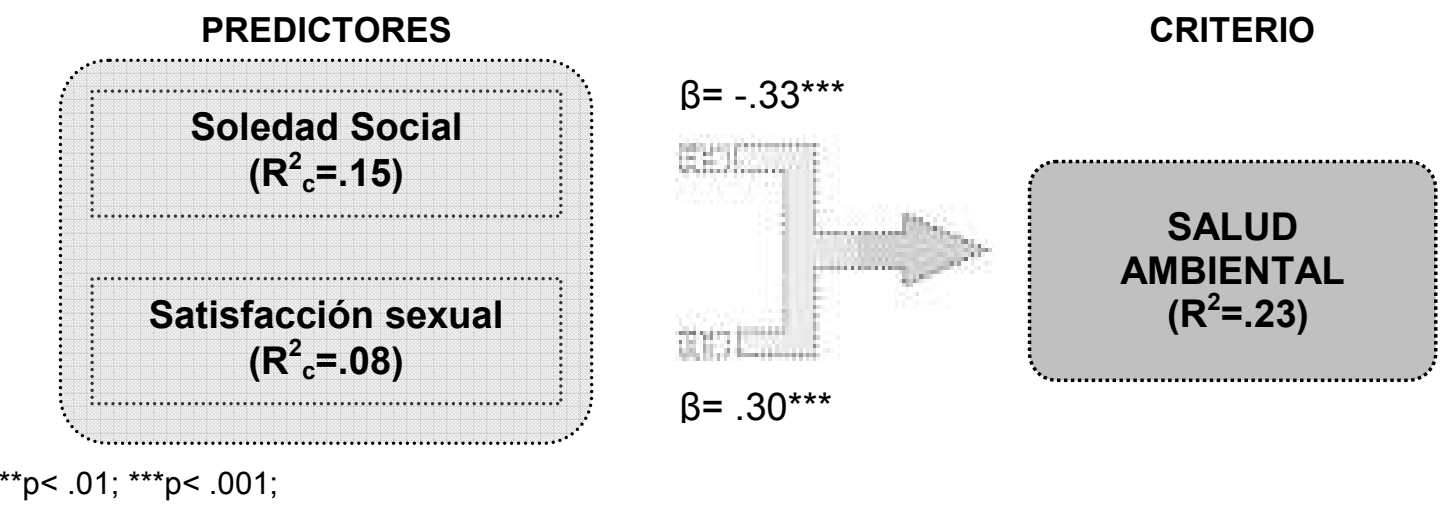

Figura 58. Resumen del modelo de regresión lineal para la salud ambiental considerando las variables relacionadas con las necesidades interpersonales básicas en la muestra general

En cuanto a las variables que no entran en el modelo encontramos de nuevo que tanto la soledad emocional familiar (Índice de Tolerancia=.69) como la depresión sexual (Índice de Tolerancia=.25) no entran en el modelo porque comparten variabilidad con la soledad social y la satisfacción sexual respectivamente.

- Predictores de salud ambiental en las personas que ejercen prostitución de interior

Con relación al modelo explicativo de la salud ambiental (ver Figura 59) en el subgrupo de personas que ejercen prostitución de interior obtuvimos un modelo compuesto por la satisfacción sexual en el primer paso $\left(F_{(1,123)}=17.25, p=.000\right)$ y la soledad social en el segundo $\left(F_{(1,122)}=11.94, p=.001\right)$. El modelo explica un $19 \%$ de la varianza de la salud ambiental $\left(F_{(2,122)}=15.36 p=.000\right)$, donde la satisfacción sexual entraba en sentido directo y la soledad social en sentido inverso. 
PREDICTORES

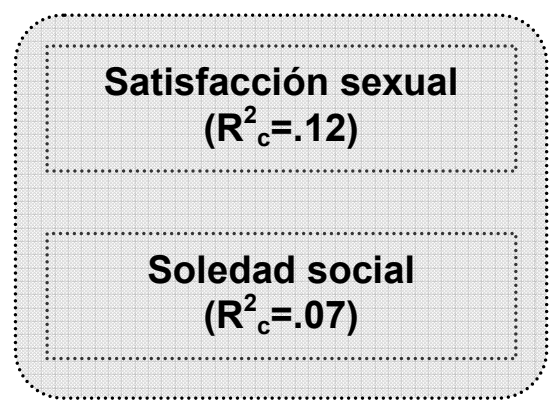

CRITERIO

$\beta=.31^{\star * *}$

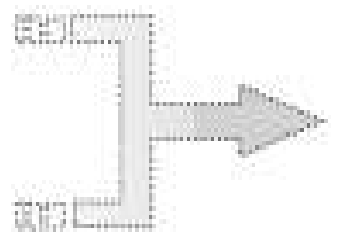

$\beta=-.28^{* * *}$

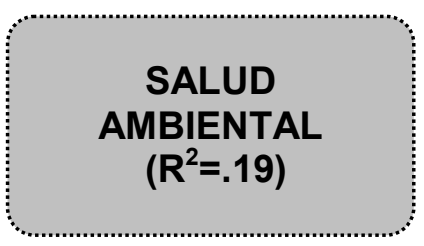

${ }^{* *} \mathrm{p}<.01 ;{ }^{* * *} \mathrm{p}<.001 ;$

Figura 59. Resumen del modelo de regresión lineal para la salud ambiental considerando las variables relacionadas con las necesidades interpersonales básicas en el subgrupo de personas que ejercen prostitución de interior

En cuanto a las variables que no entran en el modelo encontramos de nuevo que tanto la soledad emocional familiar (Índice de Tolerancia=.77) como la depresión sexual (Índice de Tolerancia=.25) no entran en el modelo porque comparten variabilidad con la soledad social y la satisfacción sexual respectivamente.

Finalmente vamos a presentar un resumen de las variables que han entrado en cada uno de los modelos explicativos de la calidad de vida y sus facetas para la muestra general (ver Tabla 41) y para la muestra de prostitución de interior (ver Tabla 42).

Los predictores relacionados con las necesidades interpersonales básicas explican un mayor porcentaje de las diferencias en calidad de vida que los predictores relacionados con la salud, tanto en el caso en que consideramos la muestra total como en el de la prostitución de interior. Si consideramos las diferentes facetas de la calidad de vida, esto es así principalmente en el caso de la dimensión de salud social, y esta misma tendencia se observa en el caso de la faceta de salud ambiental. Por el contrario, cuando consideramos la dimensión de salud física, los predictores relacionados con la salud (depresión y VIH/SIDA) explican porcentajes de varianza más elevados que los predictores relacionados con las necesidades interpersonales básicas. Si consideramos en esta dimensión las dos muestras analizadas, cabe destacar que cuando se analiza la prostitución de interior desaparece la variable VIH/SIDA, lo que indicaría que este aspecto es relevante para el 
caso de la prostitución de exterior, pero no en la de interior. Por último, en relación con la faceta de salud psicológica las diferencias son explicadas en la misma medida por factores de salud y de necesidades interpersonales en ambas muestras. Destacar, como en el caso anterior, que las agresiones sexuales que aparecen como predictor en la muestra global, desaparecen cuando se considera únicamente la prostitución de interior, por lo que podemos decir que este tipo de agresión es relevante en el caso de la prostitución de exterior.

Por último, destacar que los predictores de salud relacionados con la prostitución más relevantes, son los niveles de depresión y autoestima que aparecen sistemáticamente para explicar las diferentes dimensiones. Y, en relación con las necesidades interpersonales básicas, destacar la satisfacción sexual y la soledad social. Señalar que la soledad familiar figura como predictor de calidad de vida cuando se considera la muestra total y desaparece cuando nos referimos únicamente al grupo de interior. 
Tabla 41. Resumen de las variables explicativas de la calidad de vida y sus facetas en la muestra general de personas que ejercen prostitución

\begin{tabular}{|c|c|c|c|c|}
\hline & $\begin{array}{l}\text { Predictores } \\
\text { de salud }\end{array}$ & $\begin{array}{c}\text { \% Varianza } \\
\text { explicada }\end{array}$ & $\begin{array}{l}\text { Predictores } \\
\text { necesidades }\end{array}$ & $\begin{array}{c}\% \text { Varianza } \\
\text { explicada }\end{array}$ \\
\hline $\begin{array}{c}\text { CALIDAD DE } \\
\text { VIDA }\end{array}$ & $\begin{array}{l}\text { Depresión } \\
\text { Autoestima }\end{array}$ & $37 \%$ & $\begin{array}{l}\text { Soledad Social } \\
\text { Satisfac. Sexual } \\
\text { Soledad Familiar }\end{array}$ & $49 \%$ \\
\hline $\begin{array}{l}\text { SALUD } \\
\text { FÍSICA }\end{array}$ & $\begin{array}{l}\text { Depresión } \\
\text { VIH/SIDA }\end{array}$ & $43 \%$ & $\begin{array}{l}\text { Satisfac. Sexual } \\
\text { Soledad Social }\end{array}$ & $30 \%$ \\
\hline $\begin{array}{c}\text { SALUD } \\
\text { PSICOLÓGICA }\end{array}$ & $\begin{array}{c}\text { Depresión } \\
\text { Autoestima } \\
\text { Agres. Sexuales }\end{array}$ & $42 \%$ & $\begin{array}{l}\text { Soledad Familiar } \\
\text { Satisfac. Sexual } \\
\text { Soledad Social }\end{array}$ & $44 \%$ \\
\hline $\begin{array}{l}\text { SALUD } \\
\text { SOCIAL }\end{array}$ & $\begin{array}{c}\text { Autoestima } \\
\text { Agres. Psicológicas }\end{array}$ & $25 \%$ & $\begin{array}{l}\text { Satisfac. Sexual } \\
\text { Soledad Social }\end{array}$ & $61 \%$ \\
\hline $\begin{array}{c}\text { SALUD } \\
\text { AMBIENTAL }\end{array}$ & Autoestima & $13 \%$ & $\begin{array}{l}\text { Soledad Social } \\
\text { Satisfac. Sexual }\end{array}$ & $23 \%$ \\
\hline
\end{tabular}

Tabla 42. Resumen de las variables explicativas de la calidad de vida y sus facetas en las personas que ejercen prostitución de interior

\begin{tabular}{|c|c|c|c|c|}
\hline & $\begin{array}{l}\text { Predictores } \\
\text { de salud }\end{array}$ & $\begin{array}{l}\text { \% Varianza } \\
\text { explicada }\end{array}$ & $\begin{array}{l}\text { Predictores } \\
\text { necesidades }\end{array}$ & $\begin{array}{c}\text { \% Varianza } \\
\text { explicada }\end{array}$ \\
\hline $\begin{array}{c}\text { CALIDAD DE } \\
\text { VIDA }\end{array}$ & $\begin{array}{l}\text { Depresión } \\
\text { Autoestima }\end{array}$ & $28 \%$ & $\begin{array}{l}\text { Soledad Social } \\
\text { Satisfac. Sexual }\end{array}$ & $38 \%$ \\
\hline $\begin{array}{l}\text { SALUD } \\
\text { FÍSICA }\end{array}$ & Depresión & $22 \%$ & Satisfac. Sexual & $18 \%$ \\
\hline $\begin{array}{c}\text { SALUD } \\
\text { PSICOLÓGICA }\end{array}$ & $\begin{array}{l}\text { Depresión } \\
\text { Autoestima }\end{array}$ & $30 \%$ & $\begin{array}{l}\text { Soledad Familiar } \\
\text { Satisfac. Sexual }\end{array}$ & $30 \%$ \\
\hline $\begin{array}{l}\text { SALUD } \\
\text { SOCIAL }\end{array}$ & $\begin{array}{c}\text { Autoestima } \\
\text { Agres. Psicológicas }\end{array}$ & $19 \%$ & $\begin{array}{l}\text { Satisfac. Sexual } \\
\text { Soledad Social }\end{array}$ & $55 \%$ \\
\hline $\begin{array}{c}\text { SALUD } \\
\text { AMBIENTAL }\end{array}$ & Autoestima & $9 \%$ & $\begin{array}{l}\text { Satisfac. Sexual } \\
\text { Soledad Social }\end{array}$ & $19 \%$ \\
\hline
\end{tabular}




\section{CAPITULO 8: DISCUSIÓN}

La presentación de la discusión la articulamos en seis apartados. Comenzamos tratando de presentar los perfiles característicos que componen el fenómeno de la prostitución en la actualidad, seguimos presentando el estado de las necesidades interpersonales básicas y los niveles de calidad de vida de las personas que ejercen prostitutición, para terminar exponiendo los factores de salud relacionados con la prostitución y las necesidades interpersonales que explican los niveles calidad de vida de este colectivo, con el fin de identificar posibles factores en los que intervenir para mejorar su calidad de vida.

El quinto apartado hace referencia a las limitaciones detectadas en el desarrollo de este estudio. Y finalmente, el sexto apartado presenta las implicaciones de los resultados de esta Tesis Doctoral sobre la intervención dirigida a promover una mejora en la calidad de vida de este colectivo y sobre futuras investigaciones a llevar a cabo.

8.1. Perfil de las personas que ejercen prostitución en Castilla y León

En el primer objetivo de esta Tesis Doctoral nos planteamos "Describir un perfil de la prostitución en Castilla y León planteando las características específicas para cada tipo de prostitución".

Muchos son los autores que han afirmado la existencia de diferentes tipos o perfiles dentro del mundo de la prostitución, con nuevas características radicalmente diferenciadas (Agustín, 2001; Harcourt y Donovan, 2006; Medeiros, 2000; Ribeiro, Silva, Bessa y Sacramento, 2005; Shaver, 2005; Vandepitte, 2006; Vanwesenbeeck, 2001; Weitzer, 2005a). Nuestros resultados apoyan la existencia de grandes diferencias entre la denominada prostitución de exterior (calle) y la de interior (club y piso). Sobre todo hemos encontrado divergencia entre la prostitución de calle y la de piso, mientras que la de club se ha ido situando en un punto intermedio, aunque en general con mayores similitudes hacia la 
prostitución ejercida en pisos. Tanto nuestros datos como los consultados en otros estudios (Agustín, 2001, 2004, 2005; Fernández, 2004; Juliano, 2004a; Meneses-Falcón, 2003; Solana, 2003) dejan claro que el perfil dominante en la actualidad es la persona inmigrante que ejerce prostitución de interior (club o piso), mientras que el perfil de persona española que ejerce en la calle es minoritario, tendente a desaparecer y compuesto fundamentalmente por drogodependientes (Barahona, 2001; CIMTM, 2003; MenesesFalcón, 2003; Potterat, 1998).

Los principales cambios que ha sufrido el fenómeno de la prostitución en los últimos diez años son: el aumento del sector, el volumen del mercado ha aumentado a través de la inmigración y las nuevas fórmulas comerciales como internet y los macroclubes (Agustín, 2005; López y Pinedo, 2007); la extranjerización, entre el $80 \%$ y el $90 \%$ del colectivo son extranjeras (Agustín, 2001, 2004, 2005; Fernández, 2004; Juliano, 2004a; Meneses-Falcón, 2003; Solana, 2003); y la dispersión en la ubicación de los locales, la prostitución de calle y los clubes de ciudad tienden a desaparecer y son sustituidos por pisos, de forma paralela se abren macro clubes en régimen de plaza en las carreteras que unen importantes núcleos de población (Agustín, 2001; Emakunde, 2001; Ibbitson, 2002; López y Pinedo, 2007; Salas, 2004). Los resultados de nuestra muestra han encontrado y apoyan la aparición de éstas nuevas características (un $77 \%$ son extranjeras, un $63 \%$ ejerce prostitución en pisos de relax y sólo un $14.4 \%$ ejerce en la calle).

Como hemos visto a partir de nuestros resultados y de otros estudios realizados, tanto en España como en otros países (Alonso, 2001; APRAM, 1997, ASE-PSIKÉ, 1998; Barahona, 2001; Barnard, 1992, 1993; Brussa, 1999; CIMTM, 2003; Cwikel, Ilan y Chudakov, 2003; Diputación de Palencia, 2008; Emakunde, 2001; Fernández, 2004; Jordan, 2005; López y Pinedo, 2007; Medeiros, 2000; Perkins, 1991; McKeganey, 2006; Pons, 1992; Pinedo y Martín, 2006; Ribeiro et al., 2005; Solana, 2003; Vandepitte, 2006), la prostitución es ejercida fundamentalmente por mujeres, aunque no podemos olvidar el grupo de varones, transexuales y travestis que, cada día con más presencia, realizan esta actividad, 
constituyéndose como un nuevo perfil dentro del mundo de la prostitución (Anhel et al., 2006; Belza et al., 2000; Pelucio, 2005a, 2006a; Reback et al., 2006).

Las personas que ejercen prostitución es un colectivo que se inicia en la actividad siendo jóvenes pero prácticamente la totalidad lo hacen siendo mayores de edad, y se mantienen en ella durante un periodo variable de tiempo dependiendo de sus necesidades económicas. Además, como también se ha encontrado en otros estudios, la mayoría del colectivo ejerce esta actividad como única fuente de ingresos (CIMTM, 2003; Cwikel, Ilan y Chudakov, 2003; López y Pinedo, 2007; Pinedo y Martín, 2006).

Hemos encontrado que un porcentaje mínimo de las personas entrevistadas han sido obligadas por una tercera persona a ejercer esta actividad (Agustín, 2001; Alonso, 2001; Juliano, 2002, 2004a; López y Mestre, 2006; Osborne, 2004; Pheterson, 1990, 1992; Pinedo y Martín, 2006). Sabemos que el delito de explotación sexual existe aunque consideramos que con una frecuencia menor de la que se cree. También es posible que nuestros datos estén sesgados por la distribución de nacionalidades, con un mayor porcentaje de latinoamericanas, ya que algunos autores (CIMTM, 2003) han señalado que las personas de esta nacionalidad son más libres y están menos coaccionadas que sus compañeras africanas y de Europa del Este, las cuales se ven sometidas con mayor frecuencia a extorsión y explotación sexual. A partir de los datos y el conocimiento del fenómeno creemos que los delitos cometidos contra este colectivo son más sutiles que los delitos relacionados con la trata con fines de explotación sexual. Hemos detectado que se da con mayor frecuencia el tráfico de personas y abusos relacionados con las condiciones en las que se ejerce esta actividad. Ser víctima de un delito de tráfico de personas conlleva pagar una cantidad abusiva en concepto de gastos directos e indirectos del viaje migratorio (billetes de avión, dinero que se debe presentar en extranjería para entrar en el país, etc.). Estas personas contraen una elevada deuda que empeora su ya grave situación económica por lo que en ocasiones ejercer prostitución es una forma de acceso a mayores y más rápidos ingresos con los que pagar esta deuda. En estos casos las personas no son coaccionadas mediante fuerza o engaño de una tercera persona, pero sus circunstancias 
insostenibles requieren soluciones desesperadas y la prostitución pasa a ser una opción económica más rápida.

Otras circunstancias abusivas y que en algunos estudios han sido definidas como formas de violencia (CIMTM, 2001; López y Mestre, 2006; Sanders, 2005; Shaver, 2005; Solana, 2003; Vandepitte, 2006; Vanwesenbeeck, 2001), son las relacionadas con las condiciones en las que se ejerce prostitución y que se dan en todos los tipos de prostitución. Nos referimos fundamentalmente a las largas jornadas laborales, a la inexistencia de días de descanso y vacaciones, a la falta de derechos laborales como el paro, baja por enfermedad o jubilación, etc. A pesar de que cada tipo de prostitución se lleva a cabo en determinadas circunstancias, hemos comprobado que en general la actividad no se lleva a cabo en condiciones adecuadas y que las personas entrevistadas se muestran insatisfechas con el ejercicio de la prostitución. De hecho la muestra entrevistada reconoce tener muchas necesidades, en concreto afirman necesitar más información sobre ETS, la legalización de la prostitución como una actividad laboral, alternativas laborales, ayudas sanitarias y más higiene en el lugar de trabajo.

La legalización de la prostitución ha sido y es un tema debatido por todos los gobiernos a nivel internacional, y si nos centramos en Europa y España hemos encontrado diferentes opciones políticas para el mismo fenómeno (López y Mestre, 2006; Di Nicola et al., 2005). Al igual que nosotros, otros estudios (Lim, 1998, 2004; López y Mestre, 2006; López y Pinedo, 2007; Mestre, 2004) han encontrado que las propias personas que ejercen prostitución prefieren la legalización como opción legislativa más adecuada. La legalización de la prostitución para obtener derechos sociales y laborales parece ser una de las necesidades más importantes de este colectivo. Como hemos visto en nuestros resultados las condiciones en las que se ejerce prostitución son en ocasiones abusivas (trabajan muchas horas, no tienen vacaciones, ni días de descanso, ni baja por enfermedad remunerados, etc.) por lo que es lógico que vean como una necesidad prioritaria conseguir derechos sociales y laborales que regulen y las protejan ante situaciones abusivas. 
Pasamos a continuación a comentar sus relaciones familiares y sociales. En cuanto a sus relaciones familiares hemos encontrado, como en la mayoría de los estudios consultados (Alonso, 2001; Emakunde, 2001; Diputación de Palencia, 2008; Fernández, 2004; López y Pinedo, 2007; Pinedo y Martín, 2007; Pons, 1992; Solana, 2003), que las personas que ejercen prostitución son fundamentalmente personas solteras y sin pareja (80.1\%). Esta circunstancia, no tener pareja, es una de las situaciones de riesgo que según Weiss $(1973,1982)$ puede provocar la aparición del sentimiento de soledad, en concreto la soledad romántica o de pareja. Y así lo hemos encontrado, este colectivo siente una gran soledad, y en concreto una gran soledad de pareja.

Pero, aunque son personas sin pareja, hemos encontrado que un porcentaje importante de ellas tienen hijos/as (58.2\%), como lo avalan también otros estudios consultados (APRAM, 1997; ASE-PSIKÉ, 1998; Cáritas de Zaragoza, 1996; Defensor del Pueblo Andaluz, 2002; Diputación de Palencia, 2008; Emakunde, 2001; López y Pinedo, 2007; Pons, 1992). El hecho de tener hijos/as siendo solteras implica que en muchos casos las cargas económicas familiares dependen únicamente de ellas, más aún cuando una parte del colectivo (35.3\%) afirma que el padre de sus hijos/as no se hizo responsable de ellos/as. Esta falta de responsabilidad paterna, ya no sólo en el cuidado y crianza de los/as hijos/as sino también en su mantenimiento económico, es otro factor que carga de mayores responsabilidades económicas a estas mujeres. Es especialmente importante destacar que estos padres no sólo no se han hecho cargo de sus responsabilidades paternas sino que en algunos casos han sido maltratadores o han abusado sexualmente de sus parejas (24\%), siendo este uno de los motivos por los que estas mujeres terminaron sus relaciones con los padres de sus hijos/as. Si a esto le añadimos que son personas con antecedentes laborales precarios (un $54.8 \%$ han realizado trabajos sin cualificación y un $21.9 \%$ no tenían ningún tipo de trabajo), que se han endeudado para migrar, etc. vemos que hay diferentes factores que se unen creando unas necesidades económicas importantes en este colectivo y que como hemos visto influyen en su entrada en la prostitución. 
En cuanto a sus relaciones sociales hemos encontrado también graves carencias (un $52 \%$ afirma no tener ninguna amistad dentro del mundo de la prostitución, entorno al $50 \%$ de las personas de club y piso tiene a sus amistades en sus países de origen, y un $50 \%$ de las españolas afirman que sus amistades más íntimas han muerto), las cuales según varios estudios se deben al hecho de ser inmigrantes y a la exclusión social en la que vive este colectivo (Agustín, 2001; Juliano, 2002; López y Mestre, 2006; Perkins, 1991; Pheterson, 1990; Sanders, 2005; Savitz y Rosen, 1988; Vanwesenbeeck, 2001). De hecho, hemos encontrado una baja satisfacción con estos vínculos y una alta soledad social en las personas entrevistadas, pero consideramos, como veremos más adelante, que las razones son diferentes para cada tipo de prostitución.

En relación con las conductas de autocuidado y el estado de salud física de las personas que ejercen prostitución, hemos encontrado, en consonancia con otros estudios (Cwikel et al., 2003; Jeal y Salisbury, 2004), que un 45\% del colectivo no acude a los servicios sociosanitarios públicos existentes en España, debido, en la mayoría de las ocasiones (66.6\%), a no disponer de tarjeta sanitaria. El no disponer de esta tarjeta se debe en la mayoría de los casos a que la persona se encuentra ilegalmente y tiene miedo a empadronarse y ser localizada y deportada a su país. Pero aunque no acuden a los servicios sanitarios públicos prácticamente la totalidad de la muestra (91.1\%) afirma realizar reconocimientos médicos periódicos, por lo que son atendidas en otro tipo de servicios como son las clínicas privadas, las ONGs y asociaciones que trabajan con este colectivo. Podemos concluir que este colectivo se preocupa por su salud física y busca vías alternativas donde ser atendidas sanitariamente.

En cuanto al consumo de drogas, aspecto muy vinculado al mundo de la prostitución en los años 80 y 90, hemos encontrado al igual que otros estudios (ACLAD Valladolid, 1997; CIMTM, 2003; Diputación de Palencia, 2008; Brewis y Linstead, 2000; Cwikel, Ilan, Chudakov, 2003; López y Pinedo, 2007; Ribeiro y Sacramento, 2005; Sanders, 2005; Vanwesenbeeck, 2001), que en la actualidad no se da con frecuencia. El tabaco y el alcohol han sido las sustancias que con mayor frecuencia se consumen diariamente en la muestra 
entrevistada (un $34.9 \%$ y un $2.7 \%$ respectivamente), mientras que la cocaína y el hachís se consumen esporádicamente (un $6.2 \%$ consume cocaína y un $4.8 \%$ consume hachís o cannabis diariamente) y asociado a momentos de ocio o con determinados clientes que pagan para que ellas consuman drogas también. Como vemos en la actualidad el consumo de drogas no se da con la frecuencia que se daba hace dos décadas, donde la prostitución se vinculaba directamente con el consumo de drogas. La mayoría de las personas entrevistadas han comentado la necesidad de cuidar su salud porque tienen hijos/as y familiares que dependen de ellas y de sus ingresos, y si cayesen enfermas o se enganchasen a drogas no podrían mantenerles.

También hemos analizado la sexualidad de las personas que ejercen prostitución, la cual se encuentra rodeada de estereotipos, y hemos encontrado que las personas que ejercen prostitución se inician en general más precozmente en las relaciones sexuales coitales en comparación con la población general, aunque creemos que este dato se ve influido por el grupo de personas que ejercen prostitución de exterior ya que son las que mayor precocidad sexual muestran. Pero en relación a la promiscuidad sexual hemos encontrado que nuestra muestra presenta un menor número de parejas sexuales en comparación con la población general.

En cuanto al uso de métodos anticonceptivos o de barrera hemos encontrado datos similares a otros estudios los cuales afirman que las personas que ejercen prostitución están muy concienciadas y se protegen en sus relaciones sexuales comerciales aunque no ocurre lo mismo en sus relaciones de pareja lo que puede conllevar embarazos no deseados, abortos y enfermedades de transmisión sexual(Albert et al., 1998; Belza et al., 2000; Day y Ward, 2004; Jackson et al., 2005; McKeganey y Barnard, 1996; Sánchez et al., 2003; Vanwesenbeeck, 2001; Ward et al., 1999; Ward et al., 2004; Warr y Piett, 1999). De hecho, hemos encontrado que las mujeres entrevistadas que han tenido hijos/as han sido madres a edades muy tempranas (19.25 años). A partir de nuestra experiencia en el trabajo de campo creemos que nuestra muestra considera el uso del preservativo no sólo como una forma de prevenir enfermedades y embarazos sino también como un dispositivo que permite separar 
el sexo comercial del privado y distanciarse del cliente. También consideramos que la totalidad de la muestra afirma usar el preservativo en sus relaciones sexuales comerciales porque hemos hecho referencia a las relaciones sexuales que conllevan penetración vaginal y/o anal, las cuales son las que mayores riesgos conllevan cuando se llevan a cabo sin protección. Pero creemos que si hiciéramos referencia a conductas sexuales consideradas de menor riesgo, como el sexo oral, el uso del preservativo bajaría considerablemente. De hecho, sabemos que, como han encontrado también en otros estudios, muchas personas que ejercen prostitución no los usan en este tipo de prácticas sexuales porque afirman que perderían muchos clientes y por consiguiente ingresos económicos (Diputación de Palencia, 2008; Jackson et al., 2005; López y Pinedo, 2008; Rao et al., 2001).

Para finalizar el análisis sobre la sexualidad y la salud sexual de las personas que ejercen prostitución hemos encontrado que la gran mayoría de las personas entrevistadas (70\%) afirman haber disfrutado sexualmente en alguna o en bastantes ocasiones en sus relaciones sexuales comerciales. Es un hecho general que las personas que ejercen prostitución disfruten de algunas de sus relaciones sexuales comerciales, aunque hemos encontrado gran variabilidad respecto a este hecho. Algunas personas han comentado que prefieren no permitirse disfrutar con el cliente porque pueden perder el control de la situación, mientras que otras afirman que prefieren disfrutar sexualmente si se da la situación. Creemos que en este aspecto hay diferencias entre las mujeres que ejercen prostitución y los hombres, travestis y transexuales, ya que este último grupo parece, en mayor medida, disfrutar sexualmente con los clientes. Este dato ha sido apoyado por otros estudios y en ocasiones se ha relacionado con un mayor número de conductas de riesgo (Anhel et al., 2006; Pelucio, 2005a, 2005b; Weitzer, 2005a), parece que bajar la barrera que separa el sexo-comercial-no placentero asociado al uso de preservativo del sexo-privadoplacentero sin preservativo puede llevar a la persona a asumir un mayor número de conductas de riesgo con los clientes. Esta circunstancia se relaciona con lo anteriormente comentado sobre la mayor desprotección existente con las parejas, parece que hay una asociación entre uso del preservativo-sexo comercial-no disfrute sexual, de manera que 
cuando alguno de estos elementos se modifica (sexo privado o disfrute sexual) el uso del preservativo puede verse alterado.

En relación con su salud psicológica hemos evaluado sus síntomas de depresión, de ansiedad y su nivel de autoestima, y hemos encontrado que nuestra muestra, al igual que otros estudios (De Schampheleire, 1990) presenta mayor número de síntomas depresivos que la población general. En cuanto a sus niveles de ansiedad no hemos encontrado diferencias con el baremo poblacional por lo que presentan niveles normales de ansiedad, al igual que sus niveles de autoestima los cuales son superiores a la población general. Vemos que su salud psicológica presenta únicamente un elevado número de síntomas depresivos, pero no sienten ansiedad ni presentan una baja autoestima. Creemos que estos síntomas depresivos se encuentran relacionados con los sentimientos de soledad derivados de su condición de inmigrante (tener lejos a la familia y amigos, echar de menos su país, etc.) y de la situación de relativo aislamiento en el que ejercen prostitución (gran movilidad, vivir en los lugares donde ejercen prostitución, sin apenas tiempo de ocio, etc.)

En cuanto a la violencia sufrida durante el ejercicio de la prostitución, aspecto muy vinculado a esta actividad en diferentes trabajos consultados (Church et al., 2001; Kurtz et al., 2004; McKeganey y Barnard, 1996; Perkins, 1991; Sanders, 2005; Shaver, 2005; Surrat et al., 2004; SWOP-USA, 2007; Ribeiro y Sacramento, 2005; Vanwesenbeeck, 2001; Weitzer, 2005a) hemos encontrado que las personas que ejercen violencia física, psicológica y sexual en mayor medida sobre este colectivo son los clientes, seguidos de las propias parejas de las personas que ejercen prostitución. Como hemos visto, aunque se da con una baja frecuencia, los clientes y las parejas de las personas entrevistadas son los que agreden tanto física como psicológica y sexualmente a las personas que ejercen prostitución. Durante las entrevistas se han comentado también la existencia de episodios esporádicos de humillaciones y discriminaciones por parte de vecinos o de gente de la calle por el hecho de ser inmigrante, es decir, episodios racistas. 


\subsubsection{Prostitución de exterior}

Como hemos visto en el marco teórico y en nuestros resultados las personas que ejercen prostitución en la calle son las que presentan peores condiciones en todos los apartados estudiados (ACLAD Valladolid, 1997; APRAM, 1997; Barnard, 1992, 1993; Cáritas de Zaragoza, 2006; McKeganey, 2006; Meneses-Falcón, 2003; Pinedo y Martín, 2007).

En primer lugar, encontramos que un porcentaje importante de las personas que ejercen en la calle son españolas (57\%), de las cuales en su mayoría son mujeres $(71.4 \%)$, aunque encontramos también un porcentaje alto de transexuales/travestis (28.6\%), más que en otros tipos de prostitución.

Hemos encontrado que se trata de un colectivo con escasa formación académica, la mayoría de ellas tienen un nivel de primaria. Esta circunstancia las dificulta acceder al mercado laboral de manera que son el grupo que presentan mayor precariedad laboral ya que tienen un mayor porcentaje de personas que nunca han realizado trabajos remunerados o que han realizado trabajos no cualificados. Como en otros estudios (ACLAD Valladolid, 1997; APRAM, 1997; Barnard, 1992, 1993; Cáritas de Zaragoza, 2006; McKeganey, 2006; Meneses-Falcón, 2003) hemos encontrado que la causa más frecuente por la que el grupo que ejerce en la calle afirma comenzar a ejercer prostitución es la de costearse su adicción a las drogas. Esta circunstancia, como veremos más adelante, va a llevar asociada un peor estado de salud y peores condiciones en el ejercicio de la prostitución.

En cuanto a las condiciones en las que ejercen prostitución, las personas que ejercen en exterior suelen cobrar su actividad en función del tipo de servicio sexual que demanda el cliente. Debido a las características de la prostitución en la calle (los clientes se captan en la calle, los servicios se realizan en el coche del cliente en lugares públicos, etc.) prima la rapidez de la transacción, por lo que cobrar por servicio en vez de por tiempo facilita este aspecto. Además es el tipo de prostitución donde se pueden encontrar los precios más bajos, dadas las circunstancias en las que se da el servicio y la rapidez. 
Son las que presentan mayor libertad de horarios ya que no dependen ni de un club ni de las normas de un piso. Puede ser que esta libertad se vea reflejada en que son las que menor número de horas permanecen en la calle ejerciendo prostitución, aunque siguen realizando largas jornadas laborales, sin embargo, son las que mayor número de clientes tienen. Así, aunque presentan los precios más bajos del mercado obtienen ingresos similares al resto de tipos de prostitución.

Hemos encontrado que en la calle no se da en un porcentaje muy elevado de movilidad. Probablemente las que afirman cambiar de lugar para ejercer prostitución son el pequeño grupo de transexuales e inmigrantes que hemos encontrado en las calles. Mientras que las españolas drogodependientes no cambian de lugar para ejercer la actividad.

Las malas condiciones en las que se ejerce prostitución en la calle (estar a la intemperie, precios bajos, pasar muchas horas en la calle, realizar los servicios en el coche del cliente, etc.) pueden influir en la baja satisfacción que este grupo muestra con el ejercicio de la actividad. Por ello consideran importantes cada una de las necesidades planteadas en la entrevista, afirmando en mayor medida que las de interior la necesidad de protección en el lugar de trabajo. Esta última necesidad cobra especial importancia en este tipo de prostitución ya que son las más vulnerables a sufrir episodios de violencia, como ha sido constatado también en otros estudios (Baker et al., 2003; Barnard et al., 2002; Brents y Hausbeck, 2005; Church et al., 2001; Farley, 1998; Potterat et al., 1998; Raphael y Shapiro, 2003; Ribeiro y Sacramento, 2005; Romans et al., 2001; Sanders, 2005; Ward et al., 1999).

En cuanto a sus relaciones familiares y sociales hemos encontrado que, al igual que otros estudios (Agustín, 2001; ASE-PSIKÉ, 1997; Bindman, 2004; Diputación de Palencia, 2008; Juliano, 2002; Junco, 2003; Medeiros, 2000; Pheterson, 1996; Pons, 1992; Sanders, 2004, 2005; Warr y Piett, 1999; Weitzer, 2005a), las personas que ejercen prostitución de exterior tienen una red familiar y social más desestructurada y con vínculos más distantes que en la prostitución de interior. Como hemos visto el hecho de ser drogodependiente influye en gran medida en las relaciones sociofamiliares minando los vínculos existentes y desestructurando las relaciones. Hemos encontrado que estas personas tienen a sus 
familias de origen en la misma ciudad en la que viven, esta circunstancia facilitaría el contacto familiar, pero no es así debido a la desestructuración familiar ya comentada.

Esta desestructuración familiar se repite en sus relaciones con sus hijos/as ya que la mayoría de ellos viven con los abuelos/as o se encuentran tutelados por los servicios sociales, es decir, algunas de estas mujeres han perdido la tutela de sus hijos/as debido probablemente a su drogodependencia.

En relación con sus relaciones sociales, hemos encontrado que las personas que ejercen prostitución de exterior afirman en mayor medida que el resto de grupos que sus amistades más íntimas han muerto. Dado que nuestra muestra es joven la causa de la muerte prematura de sus amistades puede ser el consumo de drogas o los factores asociados al mismo (VIH/SIDA, sobredosis, etc.).

En resumen, las personas que ejercen prostitución de exterior, es decir, fundamentalmente personas españolas con problemas de drogodependencias, aunque viven cerca de sus familiares no mantienen un contacto frecuente y satisfactorio debido al hecho de consumir drogas y los factores asociados a éste (ejercer prostitución, delincuencia, etc.). Es lógico, por tanto, que ante estas circunstancias muestren una baja satisfacción con sus relaciones familiares y sociales.

Pasamos a continuación a comentar el estado de salud de este colectivo, ampliamente estudiado desde los inicios de la epidemia del SIDA, cuando se les señaló como grupo de riesgo de enfermedades como el VIH/SIDA (Church et al., 2001; Day y Ward, 2004; Ibbitson, 2002; Medeiros, 2000; Vanwesenbeeck, 2001).

En relación a su salud física y al igual que otros estudios (Baker et al., 2003, 2004; Barnard, 1992; Brewis y Linstead, 2000; El-Bassel et al., 1997; López y Pinedo, 2007; McKeganey y Barnard, 1996; Meneses-Falcón, 2003; Pinedo y Martín, 2006; Ribeiro y Sacramento, 2005; Sanders, 2005; Surrat et al., 2004; Vanwesenbeeck, 2001) nuestros datos muestran que las personas que ejercen prostitución de exterior presentan importantes problemas de consumo de drogas que conllevan otros problemas de salud. En concreto este grupo presenta el mayor porcentaje de consumo de drogas y un tiempo más prolongado de 
consumo respecto a las personas que ejercen prostitución de interior. Además es en el único grupo en el que hemos encontrado consumo de heroína por vía parenteral, siendo la vía de infección por VIH/SIDA en este colectivo. También hemos encontrado que en la mayoría de los casos había un policonsumo ya que también consumían cocaína, hachís, tabaco y alcohol.

En cuanto a su sexualidad y salud sexual, aspectos muy estereotipados en el mundo de la prostitución, hemos encontrado que de nuevo el grupo de personas que ejerce en la calle presenta la peor situación. Este grupo presenta mayor precocidad sexual tanto en sus primeras relaciones sexuales sin penetración como con penetración, tanto al compararlas con la población general como con sus compañeras de interior. Además también presentan un mayor número de parejas sexuales que las personas que ejercen prostitución de interior, aunque no parecen ser más promiscuas que la población general.

En el caso de las mujeres que ejercen en la calle hemos encontrado que tienen el mayor índice de embarazos no deseados, los cuales parecen deberse a las relaciones sexuales privadas desprotegidas. Dado que son embarazos no deseados es lógico que encontremos como consecuencia que este grupo de personas presente el mayor índice de abortos en comparación con las mujeres que ejercen en interior, tanto antes como durante el ejercicio de la prostitución.

Hemos encontrado también, como en otros estudios (McKeganey y Barnard, 1996; Surrat et al., 2004; Uribe-Salas et al., 2003; Ward et al., 1999, 2004; Williamson y Folaron, 2001; Wolfers, 2000), que las personas que ejercen prostitución en la calle han sufrido alguna ETS en mayor medida que la prostitución de interior. Este dato puede deberse a que estas personas no se protegen adecuadamente en sus relaciones sexuales de pareja, ejercen prostitución en peores condiciones higiénicas y/o a que son usuarias de drogas inyectables, que como sabemos hay determinadas enfermedades de transmisión sexual que también pueden contagiarse mediante el intercambio de jeringuillas, como el caso del VIH/SIDA o la hepatitis (ACLAD Valladolid, 1997; APRAM, 1997; McKeganey y Barnard, 1996; Surrat et al., 2004; Uribe-Salas et al., 2003; War y Piett, 1999). En resumen, las 
personas que ejercen prostitución de calle vuelven a ser el tipo de prostitución con mayores problemas de salud, en este caso salud sexual, mostrando mayor porcentaje de ETS y seropositividad al $\mathrm{VIH}$.

Al analizar su estado de salud mental hemos encontrado, al igual que otros estudios realizados con este tipo de prostitución (El-Bassel et al, 1997; O'Sullivan et al., 1996), que en el pasado han sido diagnosticadas de ansiedad y/o depresión en mayor medida que sus compañeras de interior. De hecho muestran en la actualidad mayores síntomas de depresión y ansiedad que la población general y también respecto a sus compañeras de interior. Se han dado diferentes explicaciones a estos mismos resultados y se asocian especialmente al consumo de drogas, a factores relacionados con el mismo o a las condiciones en las que se ejerce prostitución en la calle.

Hemos analizado también su nivel de autoestima y hemos encontrado de nuevo que presentan las puntuaciones más bajas en comparación con las prostitutas de interior, aunque al compararlo con el baremo encontramos un nivel medio, que aunque necesitaría una mejora, no es extremadamente bajo. Si consideramos las características que hemos encontrado de las personas que ejercen prostitución de exterior parece normal que muestren los niveles más bajos de autoestima, puesto que son las que ejercen prostitución en peores condiciones y las que peor estado de salud muestran.

Al igual que otros estudios (Agustín, 2001; Church et al., 2001; Kurtz et al., 2004; McKeganey y Barnard, 1996; Perkins, 1991; Pheterson, 2000; Sanders, 2005; Shaver, 2005; Surrat et al., 2004; SWOP-USA, 2007; Ribeiro y Sacramento, 2005; Vanwesenbeeck, 2001; Weitzer, 2005a) las personas entrevistadas que ejercen en la calle sufren el mayor número de episodios de violencia física, psicológica y sexual en comparación con las personas que ejercen prostitución de interior. Sufren violencia por parte de los clientes, de sus parejas e incluso de sus propias compañeras ya que como hemos comentado las condiciones en las que ejercen prostitución las sitúa en una situación de mayor vulnerabilidad a episodios de violencia. 


\subsubsection{Prostitución de interior}

Como hemos dicho anteriormente el grupo de personas que ejercen prostitución de interior presentan características diferenciadas al grupo de personas que ejercen en exterior, muchas de las cuales se ven determinadas por el hecho de que la mayoría de estas personas son inmigrantes (83\%), donde la nacionalidad principal es la latinoamericana, seguida de la de Europa del Este, la africana y la oriental. Es un grupo compuesto en su mayoría $(87 \%)$ por mujeres aunque encontramos un pequeño grupo de travestis/transexuales (11\%) y hombres (3\%), como vemos únicamente encontramos prostitución masculina en interior.

Su nivel académico no es bajo, se trata de un colectivo con formación académica. Hemos encontrado que un porcentaje importante tiene como mínimo educación secundaria o formación profesional (50\%), incluso algunas de ellas tienen estudios universitarios (15\%), siguen estudiando o están ahorrando para costearse sus estudios. De manera que, en este caso, una escasa formación académica no parece ser una causa de entrada en la prostitución. Sin embargo, sí que hemos encontrado que son personas con antecedentes laborales precarios, es decir, la mayoría no han desempeñado trabajos cualificados o ni siquiera han tenido un trabajo remunerado anteriormente. Puede ser que el hecho de ser mujer y vivir en países en desarrollo haya dificultado a estas personas insertarse en el mercado laboral adecuadamente, de manera que han tenido que recurrir a la migración y al ejercicio de la prostitución para conseguir los recursos económicos que necesitan. De hecho al estudiar las causas por las que comenzaron a ejercer esta actividad hemos encontrado como en otros estudios que en la prostitución de interior priman los aspectos económicos (CIMTM, 2003; Elias at al., 1998; Harcourt y Donovan, 2005; Jessen, 2004; Jordan, 2005; Juliano, 2004a). Las personas migrantes que ejercen prostitución presentan una serie de necesidades económicas que favorecen la entrada en la prostitución y están íntimamente relacionadas con el género y la migración. 
En cuanto a las condiciones en las que se ejerce la actividad hemos encontrado que en prostitución de interior la actividad se cobra en función del tiempo, es decir, el cliente paga por un tiempo determinado en el cual se contratan una serie de servicios sexuales específicos. Las características de los pisos y los clubes facilitan que los clientes puedan contratar servicios más largos ya que se desarrollan dentro de una habitación con más intimidad y mejores condiciones higiénicas. Además la prostitución de interior tiene los precios más altos del mercado, siendo especialmente altos los de piso. Esto es así porque es el único tipo de prostitución donde las ganancias de cada servicio se comparten con los/as dueños/as del piso, por lo que los precios deben ser más elevados.

En relación a los horarios y el número de clientes atendidos diariamente, ambos factores muy relacionados con las ganancias económicas, hemos encontrado que las personas que ejercen prostitución en pisos de relax son las que mayor número de horas (17.7 horas) se encuentran en los pisos esperando la llegada de clientes, en algunos casos hasta 24 horas. Pero, aunque realizan un menor número de servicios sexuales por día obtienen ingresos similares al resto ya que los precios son más altos. En este punto hemos encontrado diferencias con las personas que ejercen en club, ya que éstas últimas trabajan menos horas pero atienden a un número similar de clientes, obteniendo por tanto ingresos similares. Dado que en los clubes deben respetar horarios de apertura y cierre al público las personas que ejercen en ellos presentan un horario más reducido que las de piso, aunque siguen realizando largas jornadas laborales.

Al igual que en otros estudios (Agustín, 2001; CIMTM, 2003; Diputación de Palencia, 2008; Fernández, 2004; López y Pinedo, 2007; Sanders, 2005; van der Helm, 2004) hemos encontrado que las personas que ejercen prostitución de interior presentan una gran movilidad, es decir, cambian con frecuencia de lugar donde ejercen prostitución (44\%). La frecuencia de esta movilidad se da con mayor frecuencia en régimen de plaza, es decir, cambian de lugar para ejercer prostitución cada 21 días. Ésta forma de organización de la actividad ha sido detectada en otros estudios (Diputación de Palencia, 2008; Fernández, 2004; López y Pinedo, 2007; Solana, 2003) y ha surgido con la llegada de personas 
inmigrantes al ejercicio de la prostitución como una forma de rentabilizar la actividad tanto para los dueños de los locales como para las propias personas que ejercen la actividad, pero como veremos, la movilidad conlleva ventajas e inconvenientes. Por un lado implica ser la novedad en los locales donde trabajan, por lo que suelen tener más clientes y con ello más ganancias; por otro lado, y sobre todo las personas que se encuentran ilegalmente en el país, cambian continuamente de ciudad para evadir las redadas policiales. En cuanto a los inconvenientes, la movilidad provoca desarraigo, nunca establecen una red de apoyo social, ni conocen los recursos disponibles de cada ciudad, por lo que ante un problema suelen estar más desprotegidas y aisladas. También supone un problema para la intervención y realización de estudios con este colectivo, ya que la realidad de hoy es muy cambiante y puede no ser igual que la realidad de dentro de unos meses o años. Hemos encontrado mayor movilidad entre las personas que ejercen en piso que en club, probablemente porque nuestra muestra se compone en mayor medida por personas que ejercen en club de ciudad que personas que ejercen en club de carretera.

Como reflejan nuestros resultados y han encontrado otros estudios (Cwikel et al., 2003) las condiciones en las que las personas de pisos y clubes ejercen prostitución no son las más adecuadas (trabajan muchas horas al día, cambian con frecuencia de lugar para ejercer, etc.) esto puede influir en la baja satisfacción que hemos encontrado con el ejercicio de la prostitución. Pero aún siendo bajo el grado de satisfacción en todos los tipos de prostitución, las personas que ejercen en piso muestran mayor grado de satisfacción que el resto de grupos.

Pasamos a continuación a comentar las relaciones familiares y sociales de las personas que ejercen prostitución de interior, y dado que la mayoría son personas inmigrantes analizaremos también en qué medida estas relaciones se ven marcadas por el proceso migratorio. Como afirman otros estudios (Agustín, 2001; López y Pinedo, 2007; Medeiros, 2001; Solana, 2003) las familias de origen de las personas extranjeras que hemos entrevistado se encuentran fundamentalmente en sus países, por lo que no pueden mantener un contacto directo con ellos/as. Esto conlleva que la unidad de convivencia de las 
extranjeras esté compuesta principalmente por amistades u otras personas que ejercen prostitución.

También hemos encontrado un rasgo distintivo en las personas que ejercen en piso, éstas en mayor medida que sus compañeras de club y calle viven con sus hijos/as (68\%). El hecho de ejercer prostitución en un piso, donde los horarios pueden ser flexibles, es compatible con la crianza y cuidado de los/as hijos/as ya que éstas mujeres puede compatibilizar sus horarios con sus responsabilidades. Sin embargo, trabajar en un club no permite disponer de tal flexibilidad ya que los horarios y la localización de los clubes son fijos. Debido a esta circunstancia las personas que ejercen en piso presentan un mejor estado de sus necesidades interpersonales básicas, en concreto menor soledad emocional familiar ya que tienen contacto directo con su familia creada.

En cuanto a sus relaciones sociales hemos encontrado también que un número importante de las personas que ejercen prostitución de interior tiene a sus amistades más íntimas en sus países de origen (50\%), debido a que como hemos visto son inmigrantes en su mayoría.

En resumen, dado que la red familiar y social de las personas que ejercen prostitución de interior, es decir las extranjeras, se encuentran en sus países de origen, es lógico pensar que sus relaciones no sean satisfactorias puesto que no pueden mantener un contacto personal frecuente y deben limitarse a una relación telefónica. Normalmente las personas extranjeras no desvelan a sus familiares y amigos el origen de sus ingresos económicos, dado que están muy lejos es improbable que conozcan la actividad que realizan. Esto ayuda a mantener intactos estos vínculos y que no se deterioren, ya que muchas personas son rechazadas por sus familias y amistades al descubrir que están ejerciendo prostitución.

En cuanto a su salud, y al igual que otros estudios, hemos encontrado un buen estado de salud de las personas que ejercen prostitución de interior (Belza et al., 2000; Day y Ward, 2004; McKeganey y Barnard, 1996; Medeiros, 2000; Sanchez et al., 2003; Sanders, 2005; Solana, 2003; Surrat et al., 2004; Vanwesenbeeck, 2001; Ward et al., 2004; Ward et 
al., 1999; Uribe y Hernández, 2000; Uribe-Salas et al., 2003; Warr y Piett, 1999). Son las que en un menor porcentaje consumen drogas y como se ha encontrado en otros estudios (Cwikel et al., 2003), las sustancias consumidas con mayor frecuencia son el tabaco y el alcohol, seguidas de hachís y cocaína. Consumen tabaco durante las largas horas de espera de clientes, el alcohol y el hachís se consume mayormente en ambiente festivo, mientras que la cocaína es consumida en ocasiones con el cliente, el cual en muchos casos paga para que ellas consuman con él como parte del servicio.

Parece que las personas que ejercen prostitución de interior no se inician precozmente en las relaciones sexuales, de hecho se inician más tarde que sus compañeras que ejercen en exterior y que la población general. Además tampoco presentan promiscuidad sexual ya que tienen un menor número de parejas sexuales en comparación, de nuevo, con las personas que ejercen en la calle y que la población general.

Como hemos visto, parecen desprotegerse en sus relaciones sexuales privadas (Belza et al., 2000; Cwikel et al., 2003; Day y Ward, 2004; McKeganey y Barnard, 1996; Vanwesenbeeck, 2001; Warr y Piett, 1999), de hecho, hemos encontrado que las mujeres que ejercen en club presentan un alto porcentaje de embarazos antes de ejercer prostitución, los cuales se han dado a edades tempranas. Sin embargo, presentan un menor número de interrupciones de embarazos, es decir, las personas que ejercen prostitución de interior, especialmente las de club, tienen un mayor número de embarazos pero éstos no son interrumpidos, por lo que como ya hemos comentado, puede ser un factor que influya en su entrada en la prostitución puesto que soportan importantes cargas familiares.

Al analizar el número de personas que han sufrido en alguna ocasión una ETS y/o son seropositivas al VIH hemos encontrado, al igual que otros estudios (Belza et al., 2000; Cwikel et al., 2003; Day y Ward, 2004; Medeiros, 2000; Sanchez et al., 2003; Sanders, 2005; Solana, 2003; Surrat et al., 2004; Vanwesenbeeck, 2001; Ward et al., 2004; Ward, Day y Weber, 1999; Uribe y Hernández, 2000; Uribe-Salas et al., 2003; Warr y Piett, 1999; Williamson y Folaron, 2001; Wolfers, 2000) que las personas que ejercen prostitución de 
interior son las que presentan menores tasas de infección. Es decir, este tipo de prostitución vuelve a ser el que presenta mejores condiciones de salud.

En cuanto a su salud mental, al igual que se ha encontrado en otros estudios (Fernández, 2004; Shaver, 2005; Weitzer, 2005a), las personas que ejercen prostitución de interior presentan en menor medida un diagnóstico de depresión y/o ansiedad en el pasado, y presentan mejor estado de salud mental en la actualidad en comparación con sus compañeras que ejercen en la calle. Pero debemos destacar que aún siendo las que mejores condiciones de salud presentan éstas no son adecuadas ya que hemos encontrado un mayor número de síntomas depresivos que la población general, los cuales pueden estar relacionados con el hecho de ser inmigrantes y/o ejercer prostitución. En cuanto a sus niveles de autoestima, hemos encontrado que son elevados, los cuales son similares a los de la población general.

Finalmente, en relación a los episodios de violencia sufridos durante el ejercicio de la prostitución, hemos encontrado que se dan de forma infrecuente en la prostitución de interior. La mayoría de personas que ejercen prostitución en club o en piso afirman no haber sufrido violencia física, psicológica o sexual nunca o en una ocasión. En resumen, la violencia dentro de la prostitución de interior es baja debido fundamentalmente a que cuentan con mayores medidas de seguridad, no trabajan solas, usan cámaras de grabación, cuentan con personal de seguridad, etc. 
8.2. Estado de las necesidades interpersonales básicas de las personas que ejercen prostitución

Como segundo objetivo de esta Tesis Doctoral nos hemos planteado "Analizar el grado en el que este colectivo satisface sus necesidades interpersonales básicas (necesidades emocionales, sociales y sexuales), en primer lugar para la muestra general y después para cada uno de los tipos de prostitución.".

Como hemos visto en el marco teórico las personas tenemos una serie de necesidades de vinculación emocional y social que debemos satisfacer adecuadamente ya que influyen en nuestro estado de salud. Dado que el $77 \%$ de las personas entrevistadas son inmigrantes (tienen lejos a familia y amigos, tienen diferencias culturales y lingüísticas, etc.) y dadas las condiciones en las que ejercen prostitución (vivir en un club o piso, largas jornadas laborales, la discriminación social y el estigma, etc.), las circunstancias en las que vive el colectivo no favorecen el contacto y las relaciones personales por lo que encuentran dificultades para cubrir sus necesidades interpersonales básicas.

Hemos evaluado en primer lugar las necesidades emocionales familiares y románticas o de pareja y las necesidades sociales. Como cabía esperar, al comparar sus puntuaciones con el baremo de población general en cada una de las subescalas de soledad evaluadas hemos encontrado que las personas que ejercen prostitución presentan mayores niveles de soledad emocional y social. Como vemos hay una insatisfacción con sus relaciones interpersonales, dato que se encuentra en consonancia con la baja satisfacción con el contacto sociofamiliar que hemos hallado. En general nuestra muestra presenta una baja calidad de sus relaciones interpersonales, la cual puede influir negativamente en su estado de salud y calidad de vida.

No hemos encontrado diferencias entre las personas que ejercen en exterior e interior en ninguna de las escalas evaluadas, aunque creemos que las causas de estos elevados niveles de soledad pueden ser diferentes para cada uno de los tipos de prostitución. Las personas que ejercen prostitución de exterior presentan un perfil muy 
característico, tienen a sus familiares cerca pero las relaciones son malas o inexistentes y sus hijos/as viven con los abuelos o en los servicios sociales. Todos estos factores están relacionados con su drogodependencia y el estilo de vida asociado a ella (ejercer prostitución en la calle, vivir en albergues o no tener casa, delincuencia, etc.) y dificultan la satisfacción de sus necesidades emocionales y sociales. El grupo que ejerce prostitución en la calle y son drogodependientes es el más rechazado y excluido por la sociedad por lo que tiene grandes dificultades para cubrir sus necesidades interpersonales.

Sin embargo, las personas que ejercen prostitución de interior, al ser en su mayoría inmigrantes, tienen a sus familiares e hijos/as en otros países. Creemos que en este caso la insatisfacción con sus relaciones familiares se ven influidas por la distancia en la que se mantienen, por la imposibilidad de tener un contacto directo, no porque las relaciones sean malas o nulas. De hecho la gran mayoría ha emigrado y ejerce prostitución para ayudar económicamente a sus familiares e hijos/as. En muchos casos estas relaciones siguen siendo buenas porque han ocultado el ejercicio de la prostitución, dado que sus familiares están en otro país sería muy difícil que se enterasen del origen real de sus ingresos, este hecho facilita que las relaciones familiares se mantengan fuertes y no haya un rechazo familiar o social hacia la persona que ejerce prostitución. Es paradójico el hecho de que estas personas migren y ejerzan prostitución, con el esfuerzo que esto conlleva, para ayudar económicamente a sus familias, pero a la vez tengan que vivir una doble vida para ocultar el origen de sus ingresos. Vivir en una mentira continua, con el estrés y malestar que esto conlleva, para evitar ser rechaza por los familiares a los que están ayudando económicamente.

Pero uno de los datos más interesantes que hemos encontrado en nuestros datos es la alta soledad emocional romántica o de pareja que presenta el colectivo, la cual es mayor que la soledad emocional familiar o social. Parece que las personas que ejercen prostitución tienen graves problemas para cubrir satisfactoriamente sus necesidades románticas o de pareja. Nos referimos en concreto a la necesidad de compartir y mostrar pensamientos y sentimientos íntimos, a la necesidad de recibir apoyo y ánimo de la propia pareja. Dado que 
la mayoría de las personas que hemos entrevistado dice no tener pareja es lógico que tengan dificultades para cubrir satisfactoriamente estas necesidades. Pero ¿Por qué las personas que ejercen prostitución no tienen pareja? Creemos que ambas situaciones se relacionan en varios sentidos. En primer lugar, un porcentaje importante de las mujeres entrevistadas tienen hijos/as a su cargo pero no tienen el apoyo económico del padre. Esta circunstancia puede facilitar la entrada en la prostitución a aquellas personas que sin la ayuda de una pareja deben soportar importantes cargas económico-familiares, es decir, el no tener una pareja que apoye económicamente puede facilitar el ejercicio de la prostitución. $Y$ en segundo lugar, hay muchas personas que afirman no querer tener una relación de pareja mientras están realizando esta actividad. Para ellas tener pareja mientras están ejerciendo prostitución las generaría problemas, tanto si se lo ocultan como si no lo hacen. Si lo ocultan deberán llevar una doble vida que generará una constante preocupación, culpa y estrés; mientras que si no lo ocultan piensan que el hombre que lo acepta no las puede querer lo suficiente y lo único que puede querer es su dinero. De manera que muchas prefieren no tener pareja mientras ejercen prostitución pero el hecho de no tenerla genera problemas como la aparición del sentimiento de soledad romántica o de pareja.

Hemos encontrado también elevados niveles de soledad social en el colectivo, y de forma similar a lo comentado para la soledad familiar, creemos que hay factores comunes y específicos para la prostitución de exterior y la de interior que determinan estos resultados. Por un lado, el hecho de ejercer prostitución y las condiciones en las que se realiza puede dificultar el contacto social tanto por el estigma que la actividad conlleva como la imposibilidad de encontrar horas de ocio en las que relacionarse. Además, cada grupo presenta sus propios factores que explican estos altos niveles de soledad social. En el grupo de calle, un grupo importante de personas (53\%) afirma que sus amistades más íntimas han muerto luego han perdido a alguna persona que componían su principal red de apoyo social. Dado que el colectivo al que nos referimos es joven, sus amistades también lo serían, por lo que estas muertes prematuras probablemente se relacionen con el hecho de que estas personas también eran drogodependientes (e.g. muerte por sobredosis, VIH/SIDA, etc.). En 
cuanto al grupo de prostitución de interior, donde la mayoría son inmigrantes, en torno a la mitad del grupo afirma tener a sus amistades más íntimas en sus países de origen, por lo que obviamente el contacto social es escaso debido a la distancia. Solamente un pequeño grupo (37\%) afirma tener alguna amistad íntima en la misma ciudad donde vive. Como vemos este grupo sufre el aislamiento relacionado con el ejercicio de la prostitución y el desarraigo de ser inmigrantes.

Pasamos finalmente a comentar la última de las necesidades interpersonales definidas por López (2008), las necesidades sexuales. Para ello hemos evaluado no sólo su satisfacción sexual sino también su nivel de depresión sexual y como esperábamos hemos encontrado resultados generalizables a toda la muestra, sin grandes diferencias entre las personas que ejercen en exterior y en interior. Como otros estudios (Diputación de Palencia, 2008; Medeiros, 2000; Perkins, 1991; Pheterson, 2000; Pinedo, 2008; Savitz y Rosen, 1988; Warr y Piett, 1999; Weitzer, 2005a) hemos encontrado que nuestra muestra presenta buenos niveles en satisfacción sexual, pero también altos niveles en depresión sexual. Parece que al analizar estos resultados en función del tipo de prostitución encontramos que la alta satisfacción sexual de la muestra total se ve influida por las puntuaciones de las personas que ejercen en piso, ya que el resto de tipos de prostitución no presenta diferencias con el baremo al analizarlos de forma separada. Mientras, en relación a la depresión sexual, todos los tipos de prostitución presentan puntuaciones mayores que el baremo poblacional. Estos datos pueden parecer contradictorios pero como ya hemos visto en la definición de las variables hacen referencia a conceptos diferentes.

En primer lugar, creemos que muestran un buen nivel de satisfacción sexual ya que su mecánica sexual (deseo, excitación y orgasmo) funciona correctamente, son personas jóvenes, sin problemas de salud que disponen de las características fisiológicas adecuadas para poder disfrutar de su vida sexual. Además, aunque no tienen pareja, hemos visto que la gran mayoría afirma sentir placer en alguna o varias ocasiones en sus relaciones sexuales comerciales, por lo que dicen sentirse satisfechas con su vida sexual. Otros estudios (Agustín, 2001; Perkins, 1991; Pheterson, 2000; Pinedo, 2008; Savitz y Rosen, 1988; Warr y 
Piett, 1999; Weitzer, 2005a) han encontrado que las personas que ejercen prostitución son sexualmente más comunicativas y poseen la capacidad de separar el sexo comercial del privado, aspectos que pueden facilitar una mayor satisfacción sexual. Aunque toda la muestra presenta buenos niveles de satisfacción sexual, hemos visto que las personas que ejercen en piso los presentan aún mejores. Este resultado puede relacionarse con las mejores condiciones de salud y de ejercicio de la prostitución que presentan las personas que ejercen en piso, además este grupo vive en mayor medida con sus parejas, circunstancia que puede facilitar una vida sexual más satisfactoria ya que pueden obtener placer tanto con sus parejas como con sus clientes.

Sin embargo, hemos visto que presentan elevados niveles de depresión sexual, aspecto más psicoafectivo que fisiológico. Parece que la muestra en su totalidad muestra sentimientos de tristeza e infelicidad cuando recuerdan determinados aspectos o episodios de su vida sexual. La explicación que nosotros hemos encontrado a estos resultados hace referencia a la naturaleza misma de la prostitución, es decir, es posible que las circunstancias a las que se enfrentan en el ejercicio de esta actividad (clientes borrachos, maleducados, desaseados, etc.) las lleve a sentir tales sentimientos respecto a su vida sexual. Otra posible explicación podría relacionarse con el hecho de haber sufrido abusos sexuales en su vida como lo han señalado otros autores (Vanwesenbeeck, 2001), pero desde nuestros datos únicamente conocemos las agresiones sexuales ocurridas durante el ejercicio de la prostitución, suceso que aunque poco frecuente podría influir negativamente en la vida sexual de una persona llevándola a vivir este tipo de sentimientos negativos hacia su vida sexual.

Dado que la depresión sexual se relaciona con aspectos más psicoafectivos que fisiológicos el hecho de carecer de pareja y de presentar un elevado nivel de soledad romántica, puede hacer que lleve a estas personas a considerar su vida sexual deprimente en cuanto a que carece de aspectos como la afectividad, el cariño, el romanticismo, etc. Un cliente puede llegar a satisfacer las necesidades sexuales fisiológicas de una persona que 
ejerce prostitución si se dan las condiciones adecuadas pero es improbable que satisfaga necesidades de carácter más afectivo y emocional relacionadas con la sexualidad en pareja. 
8.3. Nivel de calidad de vida de las personas que ejercen prostitución

En el tercer objetivo de esta Tesis Doctoral nos hemos planteado "Analizar la calidad de vida de este colectivo en cada una de sus dimensiones (salud física, psicológica, social y ambiental), en primer lugar para la muestra general y después para cada uno de los tipos de prostitución".

Antes de comentar los resultados encontrados tenemos que tener en cuenta que el tipo de medida que hemos utilizado para evaluar la calidad de vida de este colectivo es de carácter subjetivo por lo que hemos medido su satisfacción con las diferentes facetas vitales que componen la calidad de vida. Además, como ya hemos explicado en el marco teórico, auque las necesidades son universales sus satisfactores están influidos por la cultura. Dado que nuestra muestra está compuesta en su mayoría por personas de otras nacionalidades y culturas debemos tener en cuenta que habrá diferencias culturales que influyan en su satisfacción con los determinados aspectos que componen la calidad de vida. Es decir, podemos encontrar que se sienten satisfechas con determinados aspectos de la calidad de vida con los cuales nosotros no lo estaríamos, y viceversa. Además su satisfacción personal con su calidad de vida se verá influida por las condiciones en las que vivían en sus respectivos países ya que si éstas eran especialmente malas un mínimo cambio en ellas puede hacer que estas personas se sientan satisfechas con su calidad de vida actual aunque no sea objetivamente adecuada.

En primer lugar hemos encontrado que no tienen peor salud física, psicológica y ambiental que el baremo poblacional, pero sí peor salud social. Al realizar el análisis comparativo para los diferentes tipos de prostitución hemos encontrado la misma tendencia en el caso de la prostitución de interior, mientras que la prostitución de exterior no presenta mejor salud física ni psicológica que el baremo sino similar. En resumen, este colectivo presenta niveles adecuados de salud en todas las escalas exceptuando la salud social que es menor al baremo. No hemos encontrado estudios que evaluasen la calidad de vida de este colectivo como tal, pero algunos trabajos han encontrado como nosotros niveles 
adecuados de salud física y psicológica (Fernández, 2004; Romans, 2001; Shaver, 2005; Weitzer, 2005a) pero importantes carencias sociales (Harcourt y Donovan, 2005; Juliano, 2002; Pheterson, 2000; Solana, 2003). Estos datos concuerdan con los anteriormente comentados sobre las necesidades interpersonales, en ambos casos vemos que los aspectos sociales son los que más afectados se encuentran en el colectivo de personas que ejercen prostitución.

Al comparar la calidad de vida entre los diferentes tipos de prostitución hemos encontrado, como en otros estudios (Brents y Hausbeck, 2005; Church et al., 2001; ElBassel et al., 1997; Farley y Barkan, 1998; Raphael y Shapiro, 2004; Surrat et al., 2004; Williamson y Folaron, 2001) que de nuevo las mujeres que ejercen en interior, especialmente las de piso, presentan mejor calidad de vida que las que ejercen en exterior, aunque los niveles encontrados en prostitución de exterior son similares a los de la población general, es decir, son adecuados.

Hemos encontrado que el colectivo presenta un nivel de salud física especialmente bueno, este dato puede deberse a que la mayoría de la muestra es joven y no tiene problemas de salud (e.g. dolores físicos, tratamientos médicos, energía diaria, etc.) por lo que sienten altos niveles de satisfacción con su estado de salud física.

Como hemos visto el nivel de salud psicológica es superior a la población general en el caso de la prostitución de interior y similar en el caso de la prostitución de exterior, por lo que presentan buenos niveles de salud psicológica. Estos datos pueden parecer contrarios a los niveles de depresión que hemos hallado en todos los tipos de prostitución. Pero si consideramos el tipo de preguntas con las que hemos evaluado este tipo de salud (e.g. satisfacción vital, sentido de la vida, capacidad de concentración, aceptación de su apariencia física, etc.) vemos que se trata de una medida más amplia de salud psicológica, que no sólo se refiere al malestar psicológico. Dado que es una muestra joven, con muchas metas en sus vidas y que gracias a ellas sus familias salen adelante económicamente, creemos que es lógico que se sientan satisfechas con estos aspectos que componen su salud psicológica. Creemos que, como hemos visto en el marco teórico (Booth, 1995; 
DiTomaso y Spinner, 1997; Fisher y Phillips, 1982; Peplau y Perlman, 1982; Weiss, 1973, 1982) los altos niveles de depresión que hemos encontrado se relacionan con los sentimientos de soledad emocional y social que presenta la muestra, de manera que influyen más negativamente en la salud social de las entrevistadas y no tanto en su salud psicológica.

Sin embargo, los bajos niveles de salud social que hemos encontrado, se encuentran en consonancia con los resultados encontrados en el apartado anterior sobre las necesidades interpersonales básicas, donde hemos visto que la muestra de personas que ejercen prostitución no satisface adecuadamente sus necesidades emocionales y sociales. Como ya hemos comentado anteriormente, factores relacionados con la inmigración y con el ejercicio de la prostitución influyen negativamente en la satisfacción de las necesidades relacionales de nuestra muestra y esto interviene negativamente en la salud de las personas, en concreto en su salud social.

Finalmente, hemos encontrado buenos niveles de salud ambiental en comparación con el baremo poblacional. Si consideramos el tipo de preguntas que hemos utilizado para evaluar este tipo de salud parece que las personas entrevistadas se sienten satisfechas con las condiciones ambientales en las que viven, con el dinero del que disponen, con la forma de transporte que utilizan, etc. Dado que la mayoría del colectivo proviene de países en desarrollo donde las condiciones vitales son duras parece lógico que se sientan satisfechas con las condiciones en las que viven en España, aunque estas no sean adecuadas en la mayoría de los casos. Como sabemos este colectivo realiza esta actividad por motivos económicos y hemos encontrado que tienen ingresos medios-altos, por lo que parece lógico que se encuentren satisfechas con ellos. Creemos que el tema económico es el que influye en mayor medida en su satisfacción con la salud ambiental ya que como hemos visto en el marco teórico muchos son los autores que señalan las motivaciones económicas para la realización de esta actividad (CIMTM, 2003; Elias et al., 1998; Harcourt y Donovan, 2005; Jordan, 2005). En resumen, si su meta es ganar dinero con esta actividad y así lo consiguen es lógico que se encuentren satisfechas. 
En resumen, somos seres sociales y por tanto tenemos unas necesidades de vinculación emocional y social necesarias para nuestro correcto desarrollo. A partir de los datos obtenidos en este estudio podemos afirmar que el área social es el más afectado en el colectivo de personas que ejercen prostitución, presentan insatisfacción con el contacto sociofamiliar, presentan altos niveles de soledad emocional y social, y presentan una baja salud social. 
8.4. Factores explicativos de la calidad de vida de las personas que ejercen prostitución

En cuanto al cuarto y último objetivo de esta Tesis Doctoral nos hemos propuesto "Plantear una posible explicación a las diferencias en calidad de vida y en todas sus facetas de las personas que ejercen prostitución a partir de variables de salud relacionadas con la prostitución y variables relacionadas con las necesidades interpersonales, para establecer pautas de intervención que mejoren la calidad de vida de este colectivo. En primer lugar para la muestra general y después para cada uno de los tipos de prostitución".

8.4.1. Factores de salud relacionados con la prostitución explicativos de la calidad de vida en las personas que ejercen prostitución

En primer lugar, hemos encontrado que factores relacionados con la salud psicológica, como la depresión y la autoestima, contribuyen a la explicación de la calidad de vida de las personas que ejercen prostitución, tanto en interior como en exterior. Estos dos indicadores hacen referencia al bienestar emocional de la persona, y parece que para las personas que ejercen prostitución esta área sería una de las más influyentes en su calidad de vida.

Al explicar las diferentes facetas de la calidad de vida para cada uno de los tipos de prostitución hemos encontrado, como esperábamos, que el VIH/SIDA y las agresiones sexuales del cliente son factores explicativos que se asocian al grupo de personas que ejercen prostitución de exterior (Belza et al., 2000; Day y Ward, 2004; McKeganey y Barnard, 1996; Sánchez et al., 2003; Surrat et al., 2004; Vanwesenbeeck, 2001; Ward et al., 2004). Mientras que factores como la depresión y la autoestima son factores explicativos generales para el colectivo de personas que ejercen prostitución.

Pasamos a continuación a analizar los factores explicativos de cada una de las facetas que componen la calidad de vida para cada uno de los tipos de prostitución. En 
cuanto a la salud física de la muestra hemos encontrado que la depresión y ser seropositiva al VIH/SIDA son los factores explicativos más importantes. Mientras que para la prostitución de interior únicamente es la depresión, lo cual nos demuestra que el VIH/SIDA es un factor explicativo específico de la prostitución de exterior.

En la salud psicológica también hemos encontrado un modelo explicativo diferente para cada tipo de prostitución. Mientras que para la muestra general factores como la depresión, la autoestima y las agresiones sexuales del cliente contribuyen a explicar la salud psicológica, para las personas que ejercen prostitución de interior únicamente son explicativas la depresión y la autoestima. Parece por tanto que las agresiones sexuales del cliente son un factor explicativo específico de las personas que ejercen en exterior.

En cuanto a los factores explicativos de la salud social hemos encontrado que la autoestima y el maltrato psicológico del cliente son importantes para la muestra en general, no encontrando diferencias entre la prostitución de interior y exterior. En contra de lo esperado el maltrato psicológico también es una variable explicativa para el grupo de prostitución de interior. Como hemos visto en el apartado anterior las personas entrevistadas presentan bajos niveles de salud social, la única faceta de la calidad de vida donde muestran puntuaciones bajas. Es interesante ver cómo el maltrato psicológico explica este tipo de salud, de hecho puede estar relacionado con el estigma y discriminación que sufre este colectivo, como otros autores han señalado en sus estudios (Agustín, 2001; Baker et al., 2004; Bindman y Doezema, 1997; Elias et al., 1989; Juliano, 2004a; López y Mestre, 2006; Medeiros, 2000; Pheterson, 1990, 2000; Perkins, 1991; Sanders, 2006; Shaver, 2005; Vandepitte, 2006; Weitzer, 2005a; Wolfers, 1999). Los prejuicios, el estigma y la discriminación social se traducen en muchas ocasiones en insultos y humillaciones por el hecho de ser inmigrante, ser drogodependiente o ejercer prostitución, y así lo reflejan las transcripciones que hemos reflejado en el apartado de Resultados.

Finalmente, tampoco hemos encontrado diferencias en los factores explicativos de la salud ambiental para la prostitución de interior y la de exterior. En ambos casos la autoestima es el factor que más contribuye a su explicación. 
Podemos resumir que la depresión y la autoestima, indicadores de bienestar emocional, son las variables de salud más importantes en la explicación de la calidad de vida y sus facetas en las personas que ejercen prostitución, tanto de interior como de exterior. Estos resultados son especialmente interesantes debido a su gran valor práctico, ya que son aspectos en los que se puede intervenir para mejorar la calidad de vida de este colectivo. También debemos destacar que ser seropositiva al VIH y sufrir agresiones sexuales son variables explicativas específicas del colectivo de personas que ejercen prostitución de exterior, y deben ser tenidas en cuenta si pretendemos intervenir con este colectivo.

8.4.2. Factores relacionados con las necesidades interpersonales básicas explicativos de la calidad de vida en las personas que ejercen prostitución

Como esperábamos y apoyando la evidencia empírica consultada (Brehm, 1985; DiTomaso y Spinner, 1997; López, 1995, 2008; Maslow, 1954; Ochaíta y Espinosa, 2004) las necesidades interpersonales básicas explican una importante variabilidad de la calidad de vida y de cada una de las facetas que la componen, más aún, en la mayoría de los casos, que las variables de salud relacionadas con la prostitución. Con estos datos demostramos la importancia de tomar en cuenta el marco de las necesidades interpersonales básicas si queremos intervenir en la mejora de la calidad de vida de las personas que ejercen prostitución.

Antes de pasar a comentar cada uno de los datos obtenidos en la explicación de la calidad de vida y sus facetas en las personas que ejercen prostitución tenemos que hacer mención a la importancia de la soledad romántica o de pareja en la explicación de la calidad de vida. Como hemos visto en el apartado anterior las personas que ejercen prostitución en general presentan niveles muy altos de soledad romántica o de pareja. Debido a que presenta resultados muy homogéneos en toda la muestra y las pruebas estadísticas utilizadas se basan en la explicación de la variabilidad a partir también de la variabilidad, 
este factor no ha entrado en ninguno de los modelos explicativos de la calidad de vida ni de cada una de sus facetas. Dado que no ha entrado en ninguno de los modelos explicativos podemos pensar que no es importante en la explicación de la calidad de vida o en las facetas que la componen, pero creemos que por el contrario es una de las variables que mayor importancia tienen ya que toda la muestra presenta niveles elevados de este tipo de soledad. De hecho consideramos que debe ser tenida en cuenta en toda intervención dirigida a la mejora de la calidad de vida de este colectivo, ya que como vemos presenta graves dificultades para cubrir adecuadamente esta necesidad interpersonal.

Algo similar ocurre con la variable depresión sexual, la cual presenta puntuaciones muy altas en la muestra total, pero no entra en los modelos explicativos de la calidad de vida. En este caso, no entra porque comparte variabilidad con la satisfacción sexual de manera que ambas variables parecen explicar lo mismo. Aún así debemos considerar la importancia de esta variable ya que en general las personas entrevistadas presentan elevados niveles de depresión sexual, lo que nos indica que algo va mal en las necesidades sexuales de las personas que ejercen prostitución.

Hemos encontrado que todas las necesidades interpersonales básicas (soledad social, satisfacción sexual y soledad emocional familiar) son importantes factores explicativos de la calidad de vida de las personas que ejercen prostitución, aunque la soledad familiar deja de ser importante cuando eliminamos del análisis a las personas que ejercen prostitución de exterior. Este resultado puede apoyar los datos comentados en el apartado anterior donde explicábamos que aunque la muestra en general presenta puntuaciones altas en soledad emocional familiar las causas de esta soledad son diferentes para cada tipo de prostitución, ya que para el grupo de exterior las relaciones familiares eran insatisfactorias porque eran inexistentes o nulas debido a su drogodependencia mientras que para el grupo de interior sus relaciones eran insatisfactorias porque se mantenían en la distancia. De manera que para el grupo de calle la soledad familiar influye negativamente en su calidad de vida porque realmente no cuenta con ese apoyo familiar, mientras que para el 
grupo de interior no influye negativamente porque sí que pueden contar con este apoyo dado que las relaciones familiares son buenas.

En la explicación de la salud física hemos encontrado diferencias entre la prostitución de exterior y la de interior. En la explicación de la salud física de la muestra general hemos encontrado que la satisfacción sexual y la soledad social son factores importantes. Mientras que para la prostitución de interior únicamente encontramos la satisfacción sexual. Parece ser que la soledad social es un factor explicativo específico de la salud física de las personas que ejercen prostitución de exterior.

En cuanto a la salud psicológica, hemos encontrado de nuevo diferencias entre ambos tipos de prostitución. Para la muestra general la soledad familiar, la satisfacción sexual y la soledad social son variables importantes en la explicación de la calidad de vida. Mientras que para las personas que ejercen prostitución de interior sólo son importantes las variables soledad familiar y satisfacción sexual. De nuevo la soledad social parece ser una variable explicativa especialmente importante para el grupo de personas que ejercen prostitución de exterior.

Sin embargo, el modelo explicativo de la salud social no presenta diferencias entre los tipos de prostitución. En este caso la satisfacción sexual y la soledad social son las variables que contribuyen a explicar la salud social. Como era de esperar la soledad social influye de forma negativa en la salud social. Es lógico que tanto la satisfacción sexual como la soledad social sean importantes indicadores de la salud social ya que esta medida evalúa apoyo social, relaciones interpersonales y vida sexual. Dado que la salud social es la que presenta menores niveles en la muestra general deberemos tener en cuenta estas variables para poder intervenir en ellas.

Finalmente, en la explicación de la salud ambiental hemos encontrado que entran las mismas variables para ambos tipos de prostitución pero entran en orden diferente. Para la muestra general la soledad social y la satisfacción sexual son las variables que explican la salud ambiental, sin embargo para el grupo de prostitución de interior estas variables cambian de orden, en primer lugar está la satisfacción sexual y en segundo lugar la soledad 
social. De nuevo vemos que la soledad social se asocia con el grupo de personas que ejerce prostitución en la calle.

En resumen, vemos que la satisfacción sexual y la soledad social son las necesidades interpersonales que en mayor medida explican la calidad de vida y sus facetas en las personas que ejercen prostitución. Como hemos visto las personas que ejercen prostitución presentan buenos niveles de satisfacción sexual, especialmente las personas que ejercen prostitución de interior, por lo que parece lógico que presenten también buenos niveles de calidad de vida.

En conclusión, aunque ambos grupos de variables, las variables relacionadas con la salud y con las necesidades interpersonales, son importantes en la explicación de la calidad de vida de las personas que ejercen prostitución, hemos encontrado, como esperábamos, que los factores relacionados con las necesidades interpersonales (49\%) son más importantes que los factores de salud relacionados con la prostitución (37\%).

En cuanto a la explicación de cada una de las facetas que componen la calidad de vida, hemos encontrado que todas ellas, exceptuando la salud física, se explican mejor por variables relacionadas con las necesidades interpersonales que por variables de salud relacionadas con la prostitución. Parece lógico que la salud física de las personas que ejercen prostitución se explique en mayor medida por aspectos como ser seropositiva al V/H/SIDA y tener depresión (43\%), que por variables relacionadas con el contacto interpersonal como es la soledad social y la satisfacción sexual (30\%). En relación a la salud psicológica, aunque las necesidades interpersonales (soledad familiar y social y satisfacción sexual) la expliquen en mayor medida (44\%), vemos que no hay grandes diferencias con el porcentaje explicado por las variables de salud (42\%), ya que en éstas últimas hemos incluido algunas variables relacionadas con el bienestar psicológico como la depresión y la autoestima. Pero debemos destacar el alto porcentaje de salud social que es explicado por factores como la satisfacción sexual y la soledad social $(61 \%)$ en comparación con las variables de salud (25\%) como la autoestima y las agresiones psicológicas. Es lógico que los sentimientos de soledad social y la falta de apoyo social expliquen en gran medida la 
salud social de las personas que ejercen prostitución. Como hemos visto anteriormente, es un colectivo que siente una gran soledad social en comparación con la población general luego puede influir negativamente en su calidad de vida. Finalmente, la salud ambiental es explicada mayormente por las necesidades interpersonales (23\%) en comparación con los factores de salud relacionados con la prostitución (13\%).

Hemos encontrado el mismo patrón en la explicación de la calidad de vida y sus facetas cuando nos hemos referido únicamente a las personas que ejercen prostitución de interior, es decir, las necesidades interpersonales básicas explican mejor la calidad de vida y sus facetas $(38 \%)$ que los factores de salud relacionados con la prostitución (28\%), exceptuando la salud física que se explica mejor a partir de éstos últimos. También hemos encontrado que hay factores que se relacionan especialmente con la explicación de la calidad de vida de las personas que ejercen prostitución de exterior como son el VIH/SIDA, las agresiones sexuales, la soledad familiar y la soledad social. 
8.5. Problemas metodológicos en el estudio de la prostitución

Los problemas metodológicos que recogemos en este apartado son aquellos que pueden limitar la generalización de los resultados y que derivan de la técnica de muestreo, las características de los participantes y del contexto de la investigación, la recogida de la información y del tipo de análisis empleados.

En primer lugar vamos a hacer una breve referencia a las dificultades metodológicas que otros autores (Agustín, 2001; Jessen, 2004; Medeiros, 2000; Pheterson, 1990; Sanders, 2006; Shaver, 2005; Vandepitte, 2006; Vanwesenbeeck, 2001; Weitzer, 2005b) han detectado en la investigación sobre el fenómeno de la prostitución y creemos que hemos superado en nuestro estudio. Consideramos que hemos accedido a una muestra representativa del colectivo en Castilla y León y que, aunque no ha sido seleccionada aleatoriamente, los criterios seguidos para escogerla nos han asegurado una representatividad muestral adecuada para el colectivo al que nos dirigimos. Hemos accedido a la muestra mediante el contacto directo con el colectivo, sin necesidad de mediadores ni seleccionándola únicamente en instituciones que las atienden. Gracias a esta estrategia hemos superado algunas de las dificultades y sesgos asociados al contexto en el que se desarrolla el estudio como por ejemplo conseguir la confianza de las personas encargadas de los locales a los que hemos accedido y de las personas a las que hemos entrevistado. Nos hemos integrado completamente en el mundo de la prostitución en Castilla y León lo que nos ha permitido acceder a información privilegiada, objetiva y útil que nos ayudará a desarrollar pautas de intervención con este colectivo. Aún así consideramos que el grupo de personas que ejercen prostitución en clubes puede mostrar algún sesgo ya que está compuesto fundamentalmente por personas que ejercen en club de ciudad, cuando en la realidad hay un mayor número de personas ejerciendo en club de carretera.

También consideramos que el tamaño de los grupos en función de la nacionalidad es muy diferente pudiendo reflejar mayoritariamente la realidad latinoamericana, aunque por otra parte refleja fielmente la proporción de las distintas nacionalidades existente en la 
prostitución en Castilla y León. Otro aspecto relacionado con la nacionalidad es que hemos clasificado a las personas entrevistadas en dos grandes grupos personas españolas y extranjeras, de manera que el grupo de las extranjeras pueden contener amplias variaciones culturales que pueden influir en sus conductas y percepción de salud. Probablemente podamos encontrar diferencias entre las personas latinoamericanas, las africanas, las de Europa del este o las asiáticas, de manera que la generalización de los datos en este sentido debe ser tomada con cautela.

Existe una gran controversia sobre qué tipo de medida es más adecuada en la medición de la calidad de vida, si de tipo objetivo o subjetivo. Dado que los indicadores de calidad de vida están influidos por la cultura y en nuestro estudio contamos con representación cultural variada posiblemente deberíamos haber usado una medida objetiva de calidad de vida junto con la subjetiva para ver cuales son sus condiciones objetivas de salud.

Realizar estudios de este tipo con personas que realizan actividades estigmatizadas puede facilitar que conformen sus respuestas a lo que se espera socialmente de ellas, es decir, que contesten con deseabilidad social. Obviamente es muy difícil saber en qué grado estas personas están sesgando sus respuestas por la deseabilidad social, tanto más cuando es un proceso en gran medida inconsciente. Pero consideramos que hemos minimizado en gran medida este aspecto debido a la metodología que hemos seguido. La confianza que hemos alcanzado con las personas encargadas de los locales y el hecho de no juzgar nunca su actividad y preocuparnos únicamente por su estado de salud ha facilitado que estas personas se mostrasen confiadas para poder responder de forma sincera.

En cuanto al análisis de datos, hemos utilizado los baremos poblacionales que el autor de cada escala proporciona para tener un punto de referencia o estándar con el que comparar a las personas que ejercen prostitución, pero consideramos que estas comparaciones deben ser tomadas con cautela ya que pueden no ser un criterio adecuado. Hemos decidido realizar este tipo de comparaciones debido a la dificultad de encontrar un 
grupo control equiparado en todas sus características excepto en el ejercicio de la prostitución.

Hemos decidido realizar análisis comparativos a partir de las recomendaciones que otros autores han dado sobre la necesidad de distinguir entre prostitución de interior y exterior, pero en nuestro caso debemos tener en cuenta que existe otra variable que se confunde con el tipo de prostitución y es la nacionalidad. De esta manera, la prostitución de exterior se solapa con la nacionalidad española y la prostitución de interior con la nacionalidad extranjera.

En relación al análisis de datos, podríamos haber realizado el análisis de regresión múltiple paso por paso incluyendo todas las variables en el modelo, sin distinguir entre variables interpersonales básicas y variables de salud relacionadas con prostitución, pero debido a razones teóricas y metodológicas hemos decidido realizarlos por separado en estos dos grupos de variables. En cuanto a los motivos teóricos, consideramos que es importante comprobar si las necesidades interpersonales explican mejor la calidad de vida que las variables de salud; y en cuanto a los motivos metodológicos, debido al tamaño muestral no podemos realizar el análisis con todas las variables por lo que hemos tenido que dividirlas en dos grupos en función de criterios teóricos. Esta limitación se extiende al caso de la puntuación de exterior, donde no hemos podido realizar el análisis por separado debido al reducido número de casos del que disponemos.

Finalmente, la naturaleza de los datos aportados es correlacional, lo cual restringe cualquier inferencia de tipo causal aunque creemos que nuestros resultados aportan importantes líneas de intervención prácticas. 


\subsection{Implicaciones prácticas}

Creemos que esta Tesis Doctoral no sólo supone un avance en el conocimiento de las características de la vida cotidiana e interpersonal de estas personas, un tema siempre olvidado, sino que también tiene una gran utilidad práctica a la hora de diseñar e implementar intervenciones dirigidas a mejorar las condiciones en las que vive este colectivo. Hemos diseñado este trabajo de investigación con el objetivo de aportar líneas de actuación dirigidas a mejorar las condiciones laborales, el estado de salud y, en resumen, la calidad de vida de las personas que se encuentran ejerciendo prostitución en Castilla y León. Nuestro objetivo no es aportar soluciones para erradicar o abolir la prostitución sino que hemos adoptado una perspectiva preventiva y de reducción de los daños que puede causar el ejercicio de la prostitución o las condiciones en las que se ejerce. Aún así, antes de comentar nuestras propuestas de intervención queremos hacer una breve referencia sobre el tratamiento que se da, en la actualidad, al fenómeno de la prostitución.

Como hemos visto España sigue una perspectiva abolicionista por lo que su objetivo último es hacer desaparecer la prostitución. Pero son muy pocos los esfuerzos por poner en marcha medidas que faciliten la salida de estas personas del mundo de la prostitución y olvidan establecer medidas para evitar la entrada en esta actividad.

Cuando se han analizado las causas de entrada en la prostitución se han distinguido entre causas próximas y lejanas. Entre las principales causas cercanas se ha señalado la pobreza o urgente necesidad económica, pero poca atención se presta a las causas lejanas o factores que generan esta necesidad económica, fundamentalmente la desigualdad de género y la económica. Siempre que exista desigualdad habrá personas dispuestas a vender servicios sexuales para poder acceder a los recursos o bienes que necesita. Como hemos visto en nuestros datos, en la actualidad la prostitución está fuertemente vinculada con el hecho de ser mujer, pobre e inmigrante, por lo que se deberían poner en marcha medidas dirigidas a minimizar las diferencias entre los países ricos y los pobres. Ya que cuando hay pobreza las mujeres son las que en primer lugar la sienten, y cuando no hay 
muchas más opciones la prostitución pasa al primer plano. También sería interesante que los gobiernos estudien acciones jurídicas dirigidas a prevenir por un lado que miles de migrantes se endeuden con las redes de tráfico de personas, y por otro, que muchas de las personas que migran se queden ilegalmente en el país. El endeudamiento y la ilegalidad son dos factores que llevan a muchas personas a tener que ejercer prostitución para poder ganar el dinero que necesitan.

En cuanto a las medidas que los gobiernos ponen en marcha para facilitar la salida de estas personas del mundo de la prostitución son prácticamente inexistentes. En comunidades autónomas como Cataluña se han establecido ayudas económicas durante un periodo de tiempo limitado para facilitar la inserción social y laboral de aquellas personas que quieren dejar la prostitución. Pero estas medidas suelen ser ineficaces porque son económicamente escasas y como hemos visto estas mujeres tienen importantes necesidades económicas. Además en torno a la mitad de este colectivo se encuentra ilegalmente en el país por lo que no pueden beneficiarse de este tipo de ayudas o alternativas, ya que ser ilegal te cierra la puerta a todo tipo de ayudas.

Pero dado que nuestro objetivo es proporcionar líneas de intervención eficaces que mejoren las condiciones de vida, la salud y la calidad de vida de las personas que ejercen prostitución pasamos a comentarlas a continuación. En este apartado aportamos algunas sugerencias para paliar todos aquellos aspectos negativos que hemos detectado en este estudio y para mejorar su calidad de vida.

Cuando las diferentes instituciones públicas se plantean la intervención con personas que ejercen prostitución suelen dirigir sus esfuerzos a la prevención de enfermedades de transmisión sexual, al uso consistente del preservativo, a la prevención de consumo de drogas o a la detención de redes de explotación sexual. Pero hemos visto que los principales problemas que presenta este colectivo en la actualidad se relacionan con las malas condiciones en las que ejercen prostitución y las carencias de tipo afectivo y social (Agustín, 2001; Pheterson, 2000; Sanders, 2005; Vanwesenbeeck, 2001) como depresión, soledad emocional y social, depresión sexual y baja salud social. 


\subsubsection{Propuestas de intervención}

A continuación aportamos algunas sugerencias para la intervención con el colectivo de personas que ejercen prostitución. Todas ellas dirigidas a mejorar las condiciones en las que viven y su calidad de vida.

Existe en la actualidad un debate sobre el tipo de atención sociosanitaria que debe recibir el colectivo de personas que ejercen prostitución. Por una parte encontramos partidarios que defienden la existencia de servicios específicos que atiendan las necesidades concretas de este colectivo, mientras que otros apoyan la integración total de estas personas en la red social y sanitaria pública como el resto de la población (Alexander, 1999; Ballester, Perelló y Vecina, 2005; Belda, 2004; Bindman y Doezema, 1997; Emakunde, 2001; Fernández, 2005). Obviamente ambas posturas tienen ventajas y desventajas. En cuanto a la principal ventaja de los servicios específicos, es que proporcionarían un acceso más directo, rápido y especializado al colectivo; mientras que la principal ventaja de la integración de este colectivo en la red sociosanitaria pública es que proporcionaría mayor integración del colectivo, el cual se encuentra excluido socialmente. En cuanto a las principales desventajas, en el caso los servicios específicos es que podrían generar la segregación de estas personas; mientras que en el caso de la integración en los servicios públicos es que el acceso a estos servicios puede verse dificultado por la desconfianza de las personas ilegales, por el desconocimiento existente de las vías de acceso, y por el miedo a ser juzgado y mal tratado por el hecho de ser inmigrantes y ejercer prostitución.

A partir de nuestros datos y la experiencia adquirida en el trabajo diario con este colectivo creemos que son necesarios ambos enfoques. Por una parte, la existencia de servicios específicos que trabajen en la detección, información y atención de este grupo de personas, ya que factores como la ilegalidad, la movilidad, el aislamiento en pisos y clubes, etc. dificultan la disponibilidad de información necesaria para acceder a los servicios sociosanitarios públicos. De manera que empadronarse, tramitar la tarjeta sanitaria, conocer 
tu propio centro de salud, ó pedir una cita, pueden ser tareas especialmente difíciles para población inmigrante, que no conoce la ciudad e incluso puede no conocer el idioma. Por ello un servicio específico e integral podría atender la falta de información y las carencias que presenta el colectivo. Pero no se debería olvidar que, otra labor importante de este tipo de servicios es tratar de integrar a este colectivo en la red sociosanitaria normalizada, es decir, el objetivo último ha de ser la integración del colectivo.

A continuación exponemos las propuestas de intervención que a partir de nuestro estudio consideramos más importantes:

1. Promoción de servicios de apoyo integral a las personas que ejercen prostitución para mejorar sus condiciones de cida, su salud y calidad de vida.

Este tipo de servicios deberían tener las siguientes características: (a) confidencialidad y anonimato del servicio: debido al estigma asociado a esta actividad y a la ilegalidad, muchas de las personas que ejercen esta actividad guardan celosamente su identidad por el miedo constante a ser descubiertas o deportadas; (b) sin necesidad de documentación ni tarjeta sanitaria, debemos asegurar que no sea necesario disponer de la documentación en regla para ser atendida en este tipo de servicios ya que si no dejaremos fuera de toda atención al colectivo que más necesita este tipo de servicios, las personas ilegales; (c) gratuidad del servicio, asegurar que todos los servicios prestados son gratuitos o con costes mínimos, ya que muchas personas no se hacen reconocimientos médicos si éstos tienen un coste económico; y (d) partir de una perspectiva transcultural, las personas que ejercen prostitución vienen con un bagaje cultural, religioso, político, etc. diferente y diverso y es necesaria la adaptación a la diversidad por parte de los profesionales que las atienden. Conociendo sus miedos, prejuicios, costumbres, etc. será más fácil educar en la salud. Y deberían incluir los siguientes servicios:

- Contacto y acercamiento directo al colectivo: debido a las características del colectivo, la atención debe comenzar a través de unidades móviles que acudan a 
las zonas o locales donde se ejerce prostitución, cuya labor es contactar e informar de los servicios que se encuentran a disposición del colectivo.

- Atención sanitaria y prevención de riesgos: compuesta por atención médica general; atención ginecológica completa (pruebas de ETS, detección precoz de cáncer de cuello de útero, prescripción de métodos anticonceptivos, etc.), prevención de consumo de sustancias etc. Para la prevención de riesgos en el ejercicio de la prostitución es necesario, no sólo formar en el uso adecuado del preservativo y la prevención de enfermedades de transmisión sexual, sino también debemos tener en cuenta otro tipo de conductas perjudiciales para su salud. Nos referimos a los excesivos lavados vaginales y anales, el uso de óvulos vaginales y otros medicamentos sin prescripción médica, la hormonación e inyección de silicona sin supervisión médica de los travestis y transexuales, etc. Además se informará de los recursos y servicios existentes y se derivará a la red normalizada cuando sea necesario.

- Atención psicológica: Como hemos visto las personas que ejercen prostitución presentan un alto número de síntomas depresivos y una gran soledad. Se debe tener en cuenta este tipo de problemática a la hora de intervenir con este colectivo para detectar precozmente la aparición de esta sintomatología y proporcionar el apoyo necesario. Desde el área de atención psicológica se deberán llevar a cabo también sesiones de counselling tanto antes como después de la realización de las pruebas de detección del VIH/SIDA.

- Atención social y jurídica: este colectivo presenta una gran problemática social asociada al hecho de ser inmigrantes. Tienen una gran desinformación sobre los servicios existentes, la legislación española y sus derechos. De manera que necesitan asesoramiento para realizar tareas como empadronarse, tramitar la tarjeta sanitaria, acceder a ayudas sociales, legalizar su situación, reunificar a sus familiares, realizar denuncias sobre abusos, etc. 
2. Intervención a nivel social: como hemos visto el colectivo de personas que ejercen prostitución sufren un gran aislamiento, discriminación y exclusión social. Para poder minimizar esta problemática de tipo social también se pueden llevar a cabo actuaciones dirigidas hacia la sociedad en general, como la sensibilización respecto a la problemática de este colectivo.

- Hacer llegar a la sociedad información objetiva sobre este colectivo para intentar cambiar actitudes negativas y estereotipos que fomentan la discriminación y el rechazo hacia estas mujeres. Los medios de comunicación podrían ser un medio para transmitir este tipo de información libre de prejuicios además de fomentar el debate social sobre esta problemática.

- Sensibilizar a los profesionales (policía, médicos, psicólogos, trabajadores sociales, etc.) que trabajan con este colectivo para mejorar el tipo de atención que les prestan y para que tomen en cuenta una perspectiva transcultural.

3. Integración a nivel laboral: En determinados casos hay personas que ejercen prostitución que demandan otras alternativas de trabajo, por lo que es necesario proporcionar formación complementaria y asesoramiento en búsqueda de empleo. Es necesario promocionar la organización de actividades formativas becadas económicamente para aquellas personas que ejercen prostitución, de manera que puedan disponer de unos ingresos económicos mientras llevan a cabo su formación. Es necesario también facilitar la contratación laboral de estas personas mediante la creación de empresas de inserción sociolaboral que faciliten el primer paso de entrada al mundo laboral normalizado. Pero no podemos olvidar al grupo de personas que no desean cambiar de actividad y por lo tanto tienen otras necesidades a nivel laboral como es la regulación de las condiciones en las que se ejerce la actividad. Se deberían mejorar las condiciones en las que vive este colectivo (e.g. normalización de horarios, disponibilidad de tiempo de ocio y descanso, etc.) y facilitar el contacto social y el descanso. Además, una regulación de la actividad podría dignificarla al proporcionar una serie de derechos sociales y laborales para las personas que la ejercen. 
4. Área de investigación: una intervención social eficaz debe basarse en el conocimiento objetivo de la realidad a la que se dirige, de manera que es necesaria una investigación continua que detecte los problemas emergentes o los cambios de perfil existentes de manera que pueda adaptarse la intervención con la investigación. A continuación exponemos una relación de los temas de investigación que deben ser llevados a cabo con prioridad. 
8.6.2. Propuestas de investigación futuras

- Estudio en profundidad de las causas y condiciones migratorias de las personas provenientes de países en desarrollo. Análisis comparativo entre migrantes que ejercen prostitución y migrantes que realizan otras actividades económicas. Con el objetivo de ver si hay diferencias que puedan explicar la entrada en la prostitución (mayores necesidades económicas en el país de origen, mayor endeudamiento con redes de tráfico de personas, etc.). Estudiar las dinámicas de reclutamiento, socialización, vigilancia, explotación, coerción y tráfico de personas para proporcionar un modelo de las relaciones de poder que experimentan las personas que ejercen prostitución, que van desde la dominación extrema a aquellos que no experimentan ningún tipo de explotación o coerción.

- Investigación sobre las causas lejanas que favorecen la entrada en la prostitución. La investigación necesita dirigirse a las políticas de género y temas sociales como la feminización de la pobreza, la violencia, el abuso doméstico, etc.

- Análisis en profundidad del tipo de conductas de riesgo y los motivos por los que se desprotegen las personas que ejercen prostitución tanto en sus relaciones comerciales como en sus relaciones privadas. Con el objetivo de comprobar en qué medida se desprotegen con el cliente y con la pareja, ya que hemos detectado un alto número de accidentes con el preservativo en relaciones sexuales con el cliente y un bajo nivel de protección en relaciones sexuales con la pareja.

- Estudio de la influencia que tiene el tiempo ejerciendo prostitución sobre la salud y calidad de vida de las personas que ejercen prostitución. Es probable que a mayor tiempo ejerciendo prostitución determinados aspectos relacionados con la salud, como la depresión, la soledad emocional y social, empeoren. Dado que estos aspectos se relacionan con un mayor número de conductas de riesgo, éstas podrían aumentar también con el paso del tiempo ejerciendo prostitución. 
- Estudio comparativo de las necesidades interpersonales básicas entre migrantes que ejercen prostitución y migrantes que no la ejercen. Con el objetivo de comprobar en qué medida los altos niveles de soledad se deben al proceso migratorio o al ejercicio de la prostitución. Se ha detectado un síndrome característico de las personas inmigrantes, el Síndrome de Ulises, caracterizado por síntomas que fácilmente pueden ser confundidos con la depresión y vienen provocados por el desarraigo y los cambios producidos por el viaje migratorio.

- Analizar qué características presenta el grupo de personas que ejercen prostitución y no presentan soledad romántica o de pareja. Con el objetivo de conocer los factores que influyen en que una persona que ejerce esta actividad cubra satisfactoriamente su necesidad emocional romántica o de pareja.

- Analizar qué factores explican los altos niveles de depresión sexual que presenta nuestra muestra. Analizar si se trata de factores relacionados con el ejercicio de la prostitución y las situaciones a las que se tienen que enfrentar durante el ejercicio de la misma, o si se relaciona con episodios de violencia sexual sufridos en algún momento de su etapa evolutiva.

- Estudio del colectivo de hombres, transexuales y travestis que ejercen prostitución y cada vez es más numeroso. Dado que son un colectivo desconocido y se han detectado importantes conductas de riesgo y problemas de salud es necesario el estudio de su estilo de vida y su estado de salud biopsicosocial. Analizar qué características diferenciales presentan con el colectivo de mujeres biológicas que ejercen prostitución.

- Estudio del colectivo de personas que compran servicios sexuales. Estudio en profundidad de sus características, sus motivaciones, sus necesidades y en especial de su baja percepción de riesgo, ya que la mayoría de las personas que ejercen prostitución a las que hemos entrevistado coinciden en afirmar que son los clientes quienes solicitan e incluso pagan más dinero por tener relaciones sexuales desprotegidas. 


\section{CAPITULO IX: CONCLUSIONES}

¿) Hemos detectado la existencia de dos perfiles diferenciados en el mundo de la prostitución en Castilla y León en base al lugar donde realizan esta actividad: la prostitución de exterior (calle) y de interior (clubes y pisos). Cada uno de los tipos de prostitución presenta una serie de características propias que deben ser tenidas en cuenta a la hora de intervenir con cada uno de ellos.

En la actualidad, el perfil mayoritario de las personas que ejercen prostitución está compuesto por mujeres jóvenes inmigrantes provenientes de países en vías de desarrollo que ejercen prostitución de interior fundamentalmente. En general las personas que ejercen prostitución en Castilla y León no parecen estar obligadas por terceras personas para ejercer prostitución pero si lo están por las graves carencias económicas en que viven y la dificultad para acceder a otras opciones rentables. Por ello, el motivo principal por el que las personas comienzan a ejercer prostitución es la grave situación económica en la que se encuentran. Esta situación de gran necesidad les puede llevar a aceptar condiciones laborales abusivas, por lo que ven como una necesidad prioritaria la legalización de la prostitución para conseguir derechos sociales y laborales. En su mayoría son personas solteras, con poco contacto sociofamiliar, que pasan muchas horas ejerciendo prostitución y viven en el mismo lugar donde la realizan. Por tanto se trata de un grupo de personas que se encuentran solas y tienen pocas posibilidades para establecer vínculos emocionales y sociales estables. Es un colectivo que se preocupa por su salud realizando reconocimientos médicos periódicos. No sufren episodios de violencia con frecuencia durante el ejercicio de la prostitución aunque suelen ser los clientes quienes llevan a cabo estas agresiones. 
Usan consistentemente los preservativos en sus relaciones comerciales no siendo así en sus relaciones privadas. En cuanto a su estado de salud mental presentan un elevado nivel de síntomas depresivos pero no presentan problemas de ansiedad y tienen una buena autoestima.

\& Las personas que ejercen prostitución de exterior (calle) son las que presentan el peor estado de salud y las peores condiciones en el ejercicio de la prostitución. Como veremos muchos de los estereotipos que se han asociado a la prostitución en general provienen de las características de la prostitución de calle. Son personas con bajo nivel académico que ejercen prostitución para costearse su adicción a las drogas. El hecho de ser drogodependientes conllevará graves problemas en el resto de sus facetas vitales, como por ejemplo una importante desestructuración familiar y social que las lleva a la exclusión absoluta. Presentan las peores condiciones en el ejercicio de la prostitución (ejercen en la calle expuestas a extremas condiciones climatológicas, sin adecuadas condiciones higiénicas, sin protección, con los precios más bajos, etc.). Presentan mayores problemas de salud como embarazos no deseados, abortos voluntarios, enfermedades de transmisión sexual, mayor tasa de infección por VIH/SIDA y mayores problemas de salud mental, tanto en el pasado como en la actualidad.

Las personas que ejercen prostitución de interior (club y piso) son el grupo mayoritario en la actualidad y presentan características radicalmente distintas al grupo de exterior, relacionadas principalmente con el hecho de ser inmigrantes provenientes de países en vías de desarrollo. Tienen un buen nivel académico pero una precaria historia laboral como consecuencia del hecho de ser mujer o transexual/travesti y por las condiciones de pobreza de sus países de origen. Presentan mejores condiciones de ejercicio de la prostitución en cuanto a que la realizan en lugares cerrados, más protegidas y con mayor higiene. 
Pero también presentan aspectos negativos como el gran número de horas que se encuentran ejerciendo esta actividad, la falta de tiempo de descanso y ocio y la alta movilidad. Debido a su condición de inmigrantes tienen a sus redes sociofamiliares en sus países de origen por lo que no se sienten muy satisfechas con el tipo de contacto que mantienen. Presentan un mejor estado de salud, no consumen drogas, tampoco son víctimas de episodios de violencia, usan de forma adecuada el preservativo con el cliente y presentan un menor número de abortos, enfermedades de transmisión sexual e infecciones por VIH/SIDA. Pero parecen no usar consistentemente el preservativo con sus parejas o relaciones sexuales privadas de manera que tienen un alto número de embarazos que llevan a término por lo que estos hijos/as pueden ser una causa de sus problemas económicos. En cuanto a su salud mental presentan un alto número de síntomas de depresión, que pueden estar propiciados por la soledad asociada al hecho de ser inmigrantes o a las condiciones en las que ejercer prostitución.

Las personas que ejercen prostitución tienen graves dificultades para cubrir satisfactoriamente sus necesidades interpersonales básicas. Parecen tener especial dificultad para satisfacer su necesidad de compartir y mostrar pensamientos y sentimientos íntimos y de recibir apoyo y ánimo de la propia pareja, aspecto que puede verse influido por el hecho de no tener pareja. También presentan altos niveles de depresión sexual, es decir, presentan sentimientos de tristeza e infelicidad cuando recuerdan determinados aspectos o episodios de su vida sexual. Del mismo modo, hemos encontrado elevados niveles de soledad social y soledad familiar debido al aislamiento en el que viven y a la exclusión social que soportan asociada al ejercicio de la prostitución. El único aspecto que parece ser cubierto satisfactoriamente es su nivel de satisfacción sexual, que es incluso superior a la población general. 
\& Las personas que ejercen prostitución presentan un buen nivel de salud física, psicológica y ambiental pero un bajo nivel de salud social, pero es especialmente bueno en las personas que ejercen prostitución de interior. De nuevo el área social es el que mayor problemática presenta en el colectivo de personas que ejercen prostitución, sienten poco apoyo social y tienen una baja calidad en sus relaciones interpersonales. Ser inmigrantes, drogodependientes o las condiciones en las que ejercen prostitución son factores asociados a un mayor aislamiento y exclusión social.

¿ Las necesidades interpersonales básicas explican mejor la calidad de vida que los factores de salud relacionados con la prostitución. En concreto, las dimensiones de bienestar emocional (depresión y autoestima) y relaciones interpersonales (soledad social y satisfacción sexual) son los factores explicativos de la calidad de vida de las personas que ejercen prostitución. Para el grupo de personas que ejercen prostitución de calle hemos detectado un factor específico que explican su calidad de vida y está relacionado con sus relaciones interpersonales y es la soledad familiar.

E) EI VIH/SIDA y las agresiones sexuales son factores explicativos de la salud física y psicológica, respectivamente, de las personas que ejercen prostitución de exterior, pero no de la prostitución de interior. Para el grupo de exterior ser seropositiva/o al VIH/SIDA es un factor explicativo de su salud física ya que presentan altas tasas de infección debido al consumo de drogas por vía parenteral. 
Este grupo presenta también las condiciones más inseguras en el ejercicio de la actividad por lo que las agresiones sexuales durante el ejercicio de la misma explican su salud psicológica.

\&) La soledad social es un factor explicativo especifico de la salud física, psicológica y ambiental de las personas que ejercen prostitución de exterior. Aunque todo el colectivo de personas que ejercen prostitución siente altos niveles de soledad social, éstos son más influyentes en la explicación de la salud física, psicológica y ambiental del grupo de personas que ejercen en la calle.

¿) Las intervenciones dirigidas al colectivo de personas que ejercen prostitución deberían dirigirse a cambiar las condiciones en las que ejercen prostitución, a paliar sus sentimientos de soledad y mejorar su salud social.

\& Las personas que ejercen prostitución se ven rodeadas por multitud de estereotipos que facilitan la aparición del estigma, su marginación y su exclusión social. Pero a partir de nuestros datos hemos rebatido muchos de estos estereotipos:

- No son personas incultas sin ningún tipo de formación.

- $\quad$ No son menores de edad víctimas de coacciones y engaños.

- No son víctimas indefensas de mafias de explotación sexual. En todo caso pueden ser vistas como víctimas de una sociedad machista, de la pobreza, etc.

- No son un foco de infección de enfermedades de transmisión sexual.

- No son personas despreocupadas por su salud.

- No son víctimas de elevados episodios de violencia durante el ejercicio de la prostitución.

- No son personas promiscuas, ni frígidas o incapaces de sentir placer sexual. 


\section{REFERENCIAS BIBLIOGRÁFICAS

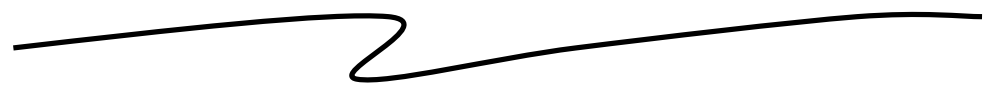

ACLAD Valladolid (1997). Estudio sobre la mujer prostituta y drogodependiente en la ciudad de Valladolid. Manuscrito no publicado.

Agredano, A. (2005). Aprender a ver la realidad de la trata de mujeres desde una perspectiva de los derechos humanos. Comunicación presentada en el I Congreso Internacional y Virtual Prostitución: comercio de personas sin fronteras. Universidad de Islas Baleares.

Agustín, L. M. (2001). Trabajar en la industria del sexo, y otros tópicos migratorios. San Sebastián: Hirugaren Prentsa.

Agustín, L. M. (2004). Lo no hablado: deseos, sentimientos y la búsqueda de "pasárselo bien”. En R. Osborne (Ed.), Trabajador@s del sexo. Barcelona: Bellaterra.

Agustín, L. M. (2005). La familia española, la industria del sexo y las migrantes. Comunicación presentada en el I Congreso Internacional y Virtual Prostitución: comercio de personas sin fronteras. Universidad de Islas Baleares.

Albert, A.E., Warner, D.L. y Hatcher, R.A. (1998). Facilitating condom use with clients during commercial sex in Nevada's legal Brothels. American Journal of Public Health, 88 (4), 643-646.

Alexander, P. (1999). Health care for sex workers should go beyond STD care. Research for sex work, 2, 14-15. http://www.nswp.org/r4sw/ (06 Octubre 2003).

Alonso, F. J. (2001). Aproximación a la realidad de la prostitución femenina en la provincia de Salamanca. Excmo. Ayuntamiento de Salamanca y Excma. Diputación Provincial de Salamanca.

Andía, B. (2006). Homofobia y crímenes de odio. Boletín del programa de diversidad sexual ILGA http://www.runa.org.pe/divsexual/informes/homofobia.htm\#top (7 Enero 2008). 
Anhel, E., Teixeira, C., Marilac, L. Y Costa, N. (2006). Travestis profissionais do sexo e HIVIAIDS: $\quad$ conhecimento, opinioes e http://www.cedeplar.ufmg.br/seminarios/seminario_diamantina/2006/D06A012.pdf (20 Enero 2008)

APRAM (1997). Situación de la prostitución en Valladolid. Excmo. Ayuntamiento de Valladolid. Manuscrito no publicado.

ASE-PSIKÉ (1998) Estudio sobre la prostitución femenina en Castilla y León. Junta de Castilla y León: Consejería de Sanidad y Bienestar Social.

Baker, L.M., Case, P. y Policicchio, D.L. (2003). General health problems of inner-city sex workers: a pilot study. Journal of the Medical Library Association, 91 (1), 67-71.

Baker, L.M., Wilson, F.L. y Winebarger, A.M. (2004). An exploratory study of the health problems, stigmatization, life satisfaction, and literacy skills of urban, street-level sex workers. Women \& Health, 39 (2), 83-96.

Baltazar, M.C., Rivera, L., Cruz, A. y Hernández, C. A. (2005). Prevalencia de infecciones de transmisión sexual y factores de riesgo concomitantes en sexo servidoras de Cuautla, Morelos. Ginecología y obstetricia de México, 73, 36-47.

Ballester, L., Perelló, J. y Vecina, C. (2005). Bases para un programa de autonomía personal y social de trabajadoras del sexo en situaciones de riesgo. Comunicación presentada en el I Congreso Internacional y Virtual Prostitución: comercio de personas sin fronteras. Universidad de Islas Baleares.

Barahona, M. J. (2001). Tipología de la prostitución femenina en la Comunidad de Madrid. Madrid: Dirección General de la Mujer.

Barnard, M. (1992). Working in the dark: researching female prostitution. En H. Roberts (Ed.) Women's health matters. London: Routlege

Barnard, M. (1993). Violence and vulnerability: conditions of work for street working prostitutes. Sociology of Health and IIIness, 15 (1), 5-14. 
Barnard, M. Hart, G., Church, S. (2002). Client violence against prostitute women working from street and off-street locations: a three city comparison. Violence research programme, ESRC.

Bartholomew, K. y Horowitz, L.M. (1991). Attachment styles among young adults: A test of a four category model. Journal of personality and social psychology, 61 (2), 226-244.

Belda, J. et al. (2004). Análisis temporal de la prostitución femenina que acude al CIPS de Alicante (1997-2003). Póster presentado al Congreso de SEISIDA Mujer, VIH y SIDA. Madrid.

Belza, M. J. (2004). Prevalencia de VIH, HTLV-I y HTLV-II en pacientes de consultas de enfermedades de transmisión sexual, 1998-2002. Póster presentado al Congreso de SEISIDA Mujer, VIH y SIDA. Madrid.

Belza, M.J., Llácer, A., Mora, R., de la Fuente, L., Castilla, Noguer, L. y Cañellas,S. (2000). Características sociales y conductas de riesgo para el $\mathrm{VIH}$ en un grupo de travestis y transexuales masculinos que ejercen la prostitución en la calle. Gaceta Sanitaria, 13 (5), 330-337.

Benner, P. (1985). Quality of life: a phenomenological perspective on explanation, prediction, and understanding in nursing science. Advances in Nursing Science, Special Issue: Quality of Life, 8, 1-14.

Bindman, J. (2004). Trabajadoras/es del sexo, condiciones laborales y derechos humanos: problemas "típicos” y protección atípica. En R. Osborne (Ed.), Trabajador@s del sexo. Barcelona: Bellaterra.

Bindman, J., y Doezema, J. (1997) Redefining Prostitution as Sex Work on the International Agenda. www.walnet.org/csis/papers/redefining.html (10 Junio 1999)

Boletín Oficial del Parlamento de Navarra (1999). B. O. P. N. № 151 de marzo de 1999. http://www.parlamento-navarra.es/castellano/boletines/1999/03marzo.asp (15 Abril 2004).

Booth, R. (1995). Importance of Understanding Loneliness. http://www.diabetichelp.com/mmlonely.txt (24 Febrero 2004) 
Bowlby, J. (1976). El vínculo afectivo. Buenos Aires: Editorial Paidós.

Bowlby, J. (1976). La separación afectiva. Buenos Aires: Editorial Paidós.

Bowlby, J. (1986). Los vínculos afectivos. Madrid: Morata.

Bowling, A. (1997). Measuring Health. A Review of Quality of Life Measurement Scales. (2 ${ }^{\text {nd }}$ ed.). Buckingham-Philadelphia: Open University Press.

Brehm, S.S. (1985). Intimate Relationships. USA: Random House, Inc.

Brents, B.G. y Hausbeck, K. (2005). Violence and legalized brothel prostitution in Nevada. Examining safety, risk, and prostitution policy. Journal of Interpersonal Violence. 20 (3), 270-295.

Brewis, J. y Linstead, S. (2000a). The worst thing is the screwing (1): Consumption and the management of identity in sex work. Gender, work and organization, 7 (2), 84-97.

Brewis, J. y Linstead, S. (2000b). The worst thing is the screwing (2): Context and career in sex work. Gender, work and organization, 7 (3), 168-180.

Brown, L. y Laird, R. (s.f.). Review of instruments assessing health-related quality of life. Tulane University. http://www.popcouncil.org/pdfs/horizons/appendix_d.pdf (12 Enero 2005)

Brussa, L. (1999). Migrant sex workers in Europe. Denying rights is an obstacle to proper care. Research for sex work, 2, 8-9. http://www.nswp.org/r4sw/ (06 Octubre 2003)

Burns, D.D. (2001). Autoestima en 10 días. Diez pasos para vencer la depresión, desarrollar la autoestima y descubrir el secreto de la alegría. Editorial Paidós.

Butcher, K. (2003). Confusion between prostitution and sex trafficking. Health and Human rights. The Lancet, 361, 1983.

Cacciopo, J.T., Hawkley, L.C., Crawford, L.E., Ernst, J.M., Burleson, M.H., Kowaleski, R.B., Malarkey, W.B., Cauter, E.V. y Bernston, G.G. (2002). Loneliness and health: potential mechanism. Psychosomatic Medicine, 64, 407-417.

Camejo, M.I., Mata, G. Y Díaz, M. (2003). Prevalencia de hepatitis B, hepatitis C y sífilis en trabajadoras sexuales de Venezuela. Revista de Saúde Pública, 37 (3), 339-344. 
Carcedo, R. J. (2005). Necesidades sociales, emocionales y sexuales de los presos. Estudio en un centro penitenciario. Tesis doctoral no publicada. Facultad de psicología. Universidad de Salamanca.

Cáritas de Zaragoza (1996). La prostitución en la calle. Estudio sobre los procesos de marginación e inserción de las mujeres que se acercan al centro de acogida FOGARAL de Cáritas Diocesana de Zaragoza. Manuscrito no publicado.

Carnelley, K.B., Pietromonaco, P.R. y Jaffe, K. (2006). Depression, working models of others, and relationship functioning. Journal of personality and social psychology, 66 (1), 127-140.

Carter, K.H., Harry, B.P., Jeune, M. y Nicholson, D. (1997). Percepción de riesgo, comportamientos riesgosos y seroprevalencia del VIH en trabajadoras sexuales de Georgetown, Guyana. Revista Panameña de Salud Pública, 2(4), 238-246.

Caufield, M. (2000). Empowered sex workers: Do they exist? Research for sex work, 3, 1718. http://www.nswp.org/r4sw/ (06 Octubre 2003)

Chetwynd, J. y Plumridge, L. (1993). Clients of female sex workers: A pilot study. Christchurch, Department of Community Health and General Practice, School of Medicine.

Church, S., Henderson, M., Barnard, M. y Hart, G. (2001). Violence by clients towards female prostitutes in different work settings: questionnaire survey. London: BMJ Journals, 322, 524-525.

CIMTM (2003). Informe sobre el tráfico de mujeres y la prostitución en la Comunidad de Madrid. Dirección general de la mujer. Madrid: EC Gráfica.

Colectivo Hetaira (s.f.). Por los derechos de las prostitutas. Madrid. http://www.colectivohetaira.org (12 junio 2005)

Consejo General de la Abogacía Española (2005). El nuevo reglamento de extranjería y el proceso de normalización laboral. Valladolid: Lex Nova.

Covre, P. (2004) ¿De prostitutas a sex workers? En R. Osborne (Ed.), Trabajador@s del sexo. Barcelona: Bellaterra. 
Cusick, L. (2002). Youth Prostitution: A literature Review. Child Abuse Review, 11, 230-251.

Cwikel, J., Ilan, L. Y Chudakov, B. (2003). Women brothel workers and occupational health risk. Journal of Epidemiology and Community Health, 57, 809-815.

Davis, C.M. (1998). Handbook of sexuality-related measures. Thousand Oaks: Sage Publications.

Day, S. y Ward, H. (2004). Sex work, mobility and health in Europe. London: Kegan Paul Limited.

Deci, E. y Ryan, R. (2000). Self-determination theory and the facilitation of intrinsic motivation, social development, and well-being. American Psychologist, 55, 78-88.

De Jong, J. y Van Tilburg, T. (1999). Manual of the loneliness scale. Faculty of social sciences. Vrije Universiteit Amsterdam. (Copia obtenida del autor).

De Schampheleire, D. (1990). MMPI characteristics of professional prostitutes: A crosscultural replication. Journal of Personality Assesment, 54 (1 y 2), 343-350.

Defensor del pueblo Andaluz (2002). La prostitución realidad y políticas de intervención pública en Andalucía. BOPA, 302. 07-05-2002. http://www.defensorand.es/informes/ie-prostitucion.htm (24 Agosto 2003)

Defensora del Pueblo de la Comunidad Foral de Navarra (2005). Derechos humanos y prostitución

en

Navarra.

http://www.defensornavarra.com/site/index.php?/es/publicaciones/informes_especiale s (Marzo 2005)

Derogatis, L. R. (1994). SCL-90-R Cuestionario de 90 síntomas. Madrid: TEA Ediciones.

Di Nicola, A., Orfano, I., Cauduro, A. y Conci, N. (2005).Study on nacional legislation on prostitution and the trafficking in women and children. Università degli studi di Trento y Università Católica del Sacro Cuore. Parlamento Europeo.

Diputación de Palencia (2008). Variables sociodemográficas de mujeres en riesgo de exclusión social. Departamento de Servicios Sociales de la Diputación de Palencia. 
DiTomaso, E. y Spinner, B. (1993). The development and initial validation of the social and emotional loneliness scale for adults (SELSA). Personality and Individual Differences, $1(14), 127-134$.

DiTomaso, E. y Spinner, B. (1997). Social and emotional loneliness: a re-examination of Weiss typology of loneliness. Personality and Individual Differences, 3 (22), 417-427.

DiTomaso, E., Brannen, C. y Best, L.A. (2004) Measurement and validity characteristics of the short version of the social and emotional loneliness scale for adults. Educational and Psychological Measurement, 1 (64), 99-119.

DiTomaso, E., Brannen, C., Ross, L. y Burgess, M. (2003). Attachment styles, social skills and loneliness in young adults. Personality and Individual Differences, 35, 303-312.

Doezema, J. (2004). ¡A crecer! La infantilización de las mujeres en los debates sobre "tráfico de mujeres". En R. Osborne (Ed.), Trabajador@s del sexo. Barcelona: Bellaterra.

El-Bassel, N., Schilling, R.F., Irwin, K.L., Faruque, S., Gilbert, L., Von Bargen, J., Serrano, Y. y Edlin, B.R. (1997). Sex trading and psychological distress among women recruited from the streets of Harlem. American Journal of Public Health, 87 (1), 66-70.

Elias, J., Bullough, V.L., Elias, V. \& Brewer, G. (1998). Prostitution: on whores, hustlers, and Johns. Nueva York: Prometheus Books.

Emakunde (2001). La prostitución ejercida por mujeres en la C.A.E. Instituto Vasco de la Mujer.

Faquhar, M. (1995). Definitions of quality of life: a taxonomy. Journal of Advanced Nursing, $22,502-8$.

Farley, M. y Barkan, H. (1998). Prostitution, Violence against women, and posttraumatic stress disorder. Women \& Health, 27 (3), 37-49.

Feeney, J. y Noller, P. (1996). Adult attachment. California: SAGE Publications.

Felce, D. y Perry, J. (1995). Quality of life: it's Definition and Measurement. Research in Developmental Disabilities, 1 (16) , 51-74. 
Fernández, J. (2000). El travestismo: ¿Ruptura de las identidades sexuales, reforzamiento de los procesos de generización o identidad paradójica?. Tesis doctoral no publicada, Universidad de Buenos Aires. Argentina.

Fernández, J. (2005). Una aproximación al empleo de las redes de acción en el ámbito europeo: el caso TAMPEP. Comunicación presentada en el I Congreso Internacional y Virtual Prostitución: comercio de personas sin fronteras. Universidad de Islas Baleares.

Fernández, M. J. (2004). Prostitución, inmigración y salud: perfil de las trabajadoras sexuales de Avilés (Asturias). Gobierno del Principado de Asturias. Consejería de Vivienda y Bienestar Social. Oviedo: KRK Ediciones.

Fernández, M. J. (2005). Prostitución, inmigración y salud: perfil de las mujeres que ejercen prostitución en Avilés (Asturias). Comunicación presentada en el l Congreso Internacional y Virtual Prostitución: comercio de personas sin fronteras. Universidad de Islas Baleares.

Fernández, M. J. (2005a). Prostitución, inmigración y salud: estrés psicosocial de las mujeres que ejercen prostitución en Avilés (Asturias). Comunicación presentada en el I Congreso Internacional y Virtual Prostitución: comercio de personas sin fronteras. Universidad de Islas Baleares.

Fernández, N. (2006). Salud psicológica y variables personales de las personas transexuales. Trabajo de grado no publicado, Universidad de Salamanca. España.

Fernández-Ballesteros, R. (1993). The construct of Quality of Life among the elderly. In E. Beregi, I.A. Gergely and K. Rajzi (Eds). Recent advances in Aging and Science. Milán: Mondussi Ed.

Fernández-Ballesteros, R. (1998). Quality of life: The differential conditions. Psychology in Spain, 1 (2), 57-65.

Fernández-Ballesteros, R. y Maciá, A. (1993). Calidad de vida en la vejez. Intervención social, 5 (2), 77-94. 
Fischer, C.S. y Phillips, S.L. (1982). Who is alone? Social characteristics of people with small networks. En L.A. Peplau y D. Perlman (Ed.), Loneliness: a sourcebook of current theory, research and therapy. Nueva York: John Wiley and sons.

Fitness, J. (2006). Emotion and cognition in close relationships. En P. Noller y J. Feeney, Close relationships: Functions, forms and processes. Great Britain: Psychology press.

Fraley, R.C. y Shaver, P.R. (2000). Adult romantic attachment: theoretical developments, emerging controversies, and unanswered questions. Review of General Psychology, $4(2), 132-154$.

Garaizabal, C. (2004) ONG y derechos humanos: la experiencia de Hetaira. En R. Osborne (Ed.),Trabajador@s del sexo. Barcelona: Bellaterra.

Gómez, E., Peri, J. M., Andrés, S. Y de Pablo, J. (2001). Trastorno de la identidad sexual: aspectos epidemiológicos, sociodemográficos, psiquiátricos y evolutivos. Cuadernos de medicina psicosomática y psiquiatría de enlace. 58, 76-83.

Gómez, J. (1997). Avances en sexología. Bilbao: Universidad del País Vasco.

Gómez-Vela, M. (S.f.). Calidad de vida. Evolución del concepto y su influencia en la investigación y la práctica. Instituto Universitario de Integración en la Comunidad, Facultad de Psicología, Universidad de Salamanca. http://www3.usal.es/ inico/investigacion/invesinico/calidad.htm (05 Mayo 2005)

González de Rivera, J.L., y cols. (2002). Manual SCL-90-R Cuestionario de 90 síntomas. Leonard R. Derogatis. Versión española. Madrid: TEA Ediciones.

Gorter, A., Sandiford, P., Segura, Z. y Villabella, C. (1999). Improved health care for sex workers. A voucher programme for female sex workers in Nicaragua. Research for sex work, 2, 11-13. http://www.nswp.org/r4sw/ (06 Octubre 2003)

Guasch, O. y Visuales, O. (2003). Sexualidades. Diversidad y control social. Barcelona: Ediciones Bellaterra. 
Gutiérrez-Cortines, M., Pinedo, R. y Martín, M. (2006). Estudio de la prostitución en Valladolid. Concejalía de Acción Social. Excmo. Ayuntamiento de Valladolid. Manuscrito no publicado.

Harcourt, C., y Donovan, B. (2005). The many faces of sex work. Sexually Transmitted Infections, 81, 201-206

Hazan, C, Campa, M. y Gur-Yaish, N. (2006). Attachment across the lifespan. En P. Noller y J. Feeney, Close relationships: Functions, forms and processes. Great Britain: Psychology press.

Hazan, C. y Shaver, P. (1987). Romantic love conceptualizad as an attachment process. Journal of Personality and Social Psychology, 52, 511-524.

Herrera, M. (2000). Detrás del telón... Entre lo imaginario y lo real. Estudio cualitativo sobre mujeres en prostitución. Tesis no publicada. Universidad de Costa Rica.

Ibbitson, M. (2002). Out of the sauna: sexual health promotion with 'off street' sex workers. Journal of epidemiology and community health, 56, 903-904.

Informe ILGA (2007). Asesinatos de gays y transexuales en México y Brasil. ILGA http://noticiasgay.info/2007/07/13/informe-ilga-asesinato-de-gays-y-transexuales-enmexico-y-brasil/ (7 Enero 2008)

INE (2006). España en cifras. http://www.ine.es (22 noviembre 2007).

Informe de la Guardia Civil (2002). Tráfico de seres humanos. Informe general de situación centrado en la explotación sexual. Unidad Técnica de Policía Judicial-EMUME Central.

http://www.malostratos.org/images/pdf/INFORME\%20EXPLOTACION\%20SEXU\%20 GU\%20CIVIL\%202002.pdf (12 Noviembre 2004).

Informe Durex $2005 \quad$ (2006). Global sex survey 2005. http://www.durex.com/es/gss2005results.asp?intMenuOpen=9 (Enero 2007). Instituto de la mujer (2003). IV Plan de Igualdad de Oportunidades entre Mujeres y Hombres (2003-2006). http://www.mtas.es/mujer/piom.htm (24 Octubre 2004). 
IV Conferencia Mundial sobre la Mujer (1995). Declaración y Plataforma de Acción de Beijing. http://www.onu.org/temas/mujer/Beijing5/beijing5.htm (23 Enero 2005).

Jackson, L.A., Sowinski, B., Bennet, C. Y Ryan, D. (2005). Female sex trade workers, condoms and the public-private divide. En J. T. Parsons, Contemporary research on sex work (Ed.), NY: Harworth Press.

Jeal, N. Y Salisbury, C. (2004). Self-reported experiences of health services among female street-based prostitutes: a cross-sectional survey. British Journal of General Practice, $54,515-519$.

Jordan, J. (2005). The sex industry in New Zealand: A literature review. Wellington: Ministry of Justice.

Jessen, L. (2004). Prostitution seen as violence against women. En S. Day y H. Ward (Ed.), Sex work, mobility and health in Europe. London: Kegan Paul Limited.

Juliano, D. (2002). La prostitución: el espejo oscuro. Barcelona. Icaria.

Juliano, D. (2004a). Excluidas y marginales. Una aproximación antropológica. Madrid: Grupo Anaya.

Juliano, D. (2004b). El peso de la discriminación: debates teóricos y fundamentaciones. En R. Osborne (Ed.), Trabajador@s del sexo. Barcelona: Bellaterra.

Junco, C. (2003). Prostitución de calle y precariedad. Materiales de Reflexión. http://www.cgt.es/modules.php?name=Downloads\&d_op=viewdownload\&cid=11. $\quad(25$ Enero 2005)

Kaplan, B.H. (1975). An epilogue: toward further research and health, in Kaplan and J.C. Cassel (Eds.) Family and Health: An Epidemiological Approach. Chapel Hill, NC: University of North Carolina, Institute for Research and Social Science.

Kempadoo, K. (s.f.). Una reconceptualización de la prostitución. http://www.lolapress.org/artspanish/kemps9.htm (5 Diciembre 2005)

Kontula, A. (s.f. ). Sex worker's relationship to sexual pleasure. Manuscrito sin publicar.

Kurtz, S.P., Surratt, H.L., Iniardi, J.A. y Kiley, M.C. (2004). Sex work and date violence. Violence against women, 10 (4), 357-385. 
Lamb, K.L., Brodie, D.A. y Roberts, K. (1988). Physical fitness and health-related fitness as indicators of a positive health state. Health Promotion, 3, 171-182.

Larose, S, Guay, F. y Boivin, M. (2002). Attachment, social support, and loneliness in young adulthood: a test of two models. Personality and social psychology bulletin, 28 (5), 684-693.

Le Meur, Y. (2005). El mercado transnacional del sexo. Comunicación presentada en el I Congreso Internacional y Virtual Prostitución: comercio de personas sin fronteras. Universidad de Islas Baleares.

Lee, J.A. (1988). Love-styles. En R.J. Sternberg y M. Barnes (Eds.), The psychology of love. New Haven: Yale University Press.

Lerner, M. (1973). Conceptualization of health and well-being. Health Services Research, 8, 6-12.

Lim L. (1998). The Sex Sector: The Economic and Social Bases of Prostitution in Southeast Asia. Ginebra: Oficina Internacional del Trabajo.

Lim, L. (2004). El sector del sexo: la contribución económica de una industria. En R. Osborne (Ed.),Trabajador@s del sexo. Barcelona: Bellaterra.

Lombroso, C. y Ferrero, G. (1893). La donna delincuente: la prostituta e la donna normale. Roma: Roux.

Lopata, H.Z., Heineman, G.D. y Baum, J. (1982). Loneliness: antecedents and coping strategies in the lives of widows. En L.A. Peplau y D. Perlman (Ed.), Loneliness: a sourcebook of current theory, research and therapy. Nueva York: John Wiley and sons.

López, A. y Becoña, E. (2006). Dependencia de la cocaína y psicopatología a través del SCL-90-R. Revista de Psicopatología y Psicología Clínica, 11 (1), 13-20.

López, F. (1995). Necesidades de la infancia y protección infantil. Fundamentación teórica, clasificación y criterios educativos. Vol. 1. Madrid: Sistema de Atención Social a la Infancia (SASI). Ministerio de Asuntos Sociales. 
López, F. (1997). Afecto y sexualidad. En J. Gómez (Ed.), Avances en sexología. Bilbao: Universidad del País Vasco.

López, F. (2004). Género y sexualidad. En E. Barberá y I. Martínez-Benlloch (Coord.), Psicología y género. Madrid: Pearson Educación.

López, F. (2008). Necesidades de la infancia y la adolescencia. Madrid: Pirámide.

López, F., Etxebarría, I., Fuentes, M.J., y Ortiz, M.J. (1999). Desarrollo afectivo y social. Madrid: Ediciones pirámide.

López, F. y Pinedo, R. (2007). La mujer que ejerce prostitución en Castilla y León. Observatorio de Género de Castilla y León. Junta de Castilla y León. Manuscrito sin publicar.

López, M. y Mestre, R. (2006). Trabajo sexual. Reconocer derechos. Valencia: Ediciones la Burbuja.

Lucas, R. (1996). WHOQOL-BREF Versión Barcelona. División de salud mental. Ginebra: Organización Mundial de la Salud.

Luengo, J. (2005). Reglamentación de la prostitución en la España del primer tercio del siglo XX. Comunicación presentada en el I Congreso Internacional y Virtual Prostitución: comercio de personas sin fronteras. Universidad de Islas Baleares.

Luengo, J. (2005). Teorización en torno a la feminidad de las prostitutas. Comunicación presentada en el I Congreso Internacional y Virtual Prostitución: comercio de personas sin fronteras. Universidad de Islas Baleares.

Mahon, N.E., Yarcheski, A. y Yarcheski, T.J. (2004). Social support and positive health practices in early adolescents. Clinical nursing research, 13 (3), 216-236.

Maslow, A. H. (1954). Motivación y Personalidad. Madrid: Ediciones Díaz de Santos.

Max-neef, M., Elizalde, A. y Hopenhayn, M. (1986). Desarrollo a escala humana. Uppsala: Fundación Dag Hammarskjöld.

Max-Neef, Manfred (1993), Desarrollo a Escala Humana: Conceptos, Aplicaciones y Reflexiones. Barcelona: Icaria 
McKeganey, N. (2006). Street prostitution in Scotland: The views of working women. Drugs: education, prevention and policy, 13 (2), 151-166.

McKeganey, N. and Barnard, M. (1996) Sex Work on the Streets: Prostitutes and Their Clients. Milton Keynes: Open University Press.

Medeiros, R. P. (2000). Hablan las putas: sobre prácticas sexuales, preservativos y SIDA en el mundo de la prostitución. Barcelona: Virus Editorial.

Melrose, M. (2002). Labour pains: some considerations on the dificultéis of researching juvenile prostitution. Internacional Journal of Social Research Methodology, 5 (4), 333-351.

Meneses-Falcón, C. (2003).Perfil de la prostitución callejera. Análisis de una muestra de personas atendida por APRAMP. Madrid: Universidad Pontificia de Comillas.

Meroño, M. (2005). Hacer la calle. Comunicación presentada en el / Congreso Internacional y Virtual Prostitución: comercio de personas sin fronteras. Universidad de Islas Baleares.

Meroño, M. (2005). Mujer sin red. Comunicación presentada en el I Congreso Internacional y Virtual Prostitución: comercio de personas sin fronteras. Universidad de Islas Baleares.

Mestre, R. (2004). Las caras de la prostitución en el estado español: entre la ley de extranjería y el código penal. En R. Osborne (Ed.), Trabajador@s del sexo. Barcelona: Bellaterra.

Metzenrath, S. (1998). In touch with the needs of sex workers. Research for sex work, 1, 1113. http://www.nswp.org/r4sw/ (06 Octubre 2003)

Monteros, S. (2005). Elementos para el debate sobre la legislación española en materia de protección de las víctimas del tráfico de personas con fines de explotación sexual. Ponencia presentada en el I Congreso Internacional y Virtual Prostitución: comercio de personas sin fronteras. Universidad de Islas Baleares.

Montomery, R. (1999). There aren't even any written materials in the clinic to read. Research for sex work, 2, 2-5. http://www.nswp.org/r4sw/ (06 Octubre 2003). 
Moreno, L. y Kerrigan, D. (2000).HIV prevention strategies among female sex workers in the Dominican Republic. Research for sex work, 3, 8-10. http://www.nswp.org/r4sw/ (06 Octubre 2003).

Nadal, A. (2005). Prostitución en un juzgado de peligrosidad y rehabilitación social. Comunicación presentada en el I Congreso Internacional y Virtual Prostitución: comercio de personas sin fronteras. Universidad de Islas Baleares.

Noller, P. y Feeney, J. (2006). Close relationships: Functions, forms and processes. Great Britain: Psychology press.

Noller, P. (2006). Marital relationships. En P. Noller y J. Feeney, Close relationships: Functions, forms and processes. Great Britain: Psychology press.

Núñez, F. (1995). Mujeres Públicas. Historia de la Prostitución en España. Historia de la España Sorprendente. Temas de Hoy. SA.

Nzambi, K. (1999). Integrating services within existing Ministry of Health Institutions. Research for sex work, 2, 16-17. http://www.nswp.org/r4sw/ (06 Octubre 2003).

O'Sullivan, D.M., Zuckerman, M. y Kraft, M. (1996). The personality of prostitutes. Journal of Personality and Individual Differences, 21 (3), 445-448.

Ochaíta, E. y Espinosa, M.A. (2004). Hacia una teoría de las necesidades infantiles y adolescentes. UNICEF. Aravaca: McGraw Hill.

Ojer, D. (2005). Variables asociadas a la interrupción voluntaria del embarazo (IVE) en mujeres que ejercen prostitución en Asturias. Comunicación presentada en el I Congreso Internacional y Virtual Prostitución: comercio de personas sin fronteras. Universidad de Islas Baleares.

Ortí, M.J. (2005). Prostitución de calle y otros contextos. Comunicación presentada en el I Congreso Internacional y Virtual Prostitución: comercio de personas sin fronteras. Universidad de Islas Baleares.

Osborne, R. (2004). Trabajador@s del sexo. Barcelona: Bellaterra.

Oso, L. y Ulloa, M. (2001), Tráfico e inmigración femenina desde la voz de las mujeres inmigrantes, en Elena Bonelli y Marcela Ulloa (Eds.) (2001), Tráfico e inmigración de 
mujeres en España. Colombianas y ecuatorianas en los servicios domésticos y sexuales. Madrid: ACSUR-Las Segovias.

Parrón, N. (2005). ...Y el mal que la acompaña. Ponencia presentada en el / Congreso Internacional y Virtual Prostitución: comercio de personas sin fronteras. Universidad e Islas Baleares.

Pelúcio, L. (2005a). Sexualidade, genero e masculinidade no mundo dos t-lovers, a construçao da identidade de um grupo de homens que se relacionam com travestis. Comunicación presentana en el XII Congreso Brasileiro de sociologia http://64.233.161.104/search?=cache:DwjxuL8ino0J:damazo.groobyforums.com/files/ tlovers.doc+Corpo+metamorfose+e+identidades+\%E2\%80\%93+de+Alana+Elisa+Sta r\&hl=pt-BR\&gl=br\&ct=clnk\&cd=1 (20 Abril 2006)

Pelúcio, L. (2005b). Na noite nem todos os gatos sao pardos. Notas sobre a prostituiçao travesti. Cadernos Pagu, 25, 217-248.

Pelúcio, L. (2006a). O Gênero na Carne: sexualidade, corporalidade e Pessoa - uma etnografia entre travestis Paulistas. En Grossi, Miriam P. \& Schwade, Elisete. (Eds.). Política e Cotidiano: estudos antropológicos sobre gênero, família e sexualidade. Florianópolis/SC: Nova Letra.

Pelúcio, L. (2006b). Soropositividade, Pressão e Depressão: da Vida Nervosa das Travestis Vivendo com HIVIAids. En Seminário Internacional Fazendo Gênero VII, Florianóplois.

Peplau, L.A. y Perlman, D. (1982). Loneliness. A sourcebook of current theory, research and therapy. Nueva York: John Wiley and sons.

Perkins, R. (1991). Working girls: prostitutes, their life and social control. Tesis no publicada. University of Canberra, Australian Institute of Criminology. www.aic.gov.au/publications/lcj/working/ch4-4.html (15 Marzo 2005)

Pheterson, G. (1990). The category 'prostitute' in scientific inquiry. The Journal of Sex Research, 27, (3), 397-407.

Pheterson, G. (1992). Nosotras las putas. Madrid: Talasa. 
Pheterson, G. (2000). El prisma de la prostitución. Ediciones Talasa. Madrid.

Pinedo, R. (2005). Salud y calidad de vida en las mujeres que ejercen prostitución: estudio cualitativo. Comunicación presentada en el I Congreso Internacional y Virtual Prostitución: comercio de personas sin fronteras. Univerisidad de Islas Baleares.

Pinedo, R. (2005). Salud y calidad de vida en las mujeres que ejercen prostitución: estudio cuantitativo. Comunicación presentada en el I Congreso Internacional y Virtual Prostitución: comercio de personas sin fronteras. Univerisidad de Islas Baleares.

Pinedo, R. y Martín, J. M. (2006). Calidad de vida y necesidades interpersonales de las mujeres que ejercen prostitución: estudio cualitativo. Sexología integral. 3 (4), 193200.

Pinedo, R. (2008a). Condiciones sociales y laborales de las mujeres inmigrantes que ejercen la prostitución en Castilla y León. En J.A. Valero y M. Tejedor (Eds.), La educación social ante los nuevos retos de la inmigración y los servicios sociales. Universidad de Valladolid: Gerencia de los Servicios Sociales.

Pinedo, R. (2008b). Salud sexual de las personas que ejercen prostitución. Comunicación oral presentada en el $X$ Congreso Español de Sexología y IV Encuentro Iberoamericano de profesionales de la sexología.

Pinillos, J.L. (1982). Los prejuicios y la sociedad contemporánea. Cuenta y razón, 5, 15-25. http://www.cuentayrazon.org/revista/pdf/005/Num005_002.pdf (10 Abril 2007)

Pons, I. (1992). Condiciones de vida de las prostitutas en Asturias. Principado de Asturias.

Pons, I. (2004). Más allá de los moralismos: prostitución y ciencias sociales. En R. Osborne (Ed.),Trabajador@s del sexo. Barcelona: Bellaterra.

Potterat, J.J., Rothenberg, R.B., Muth, S.Q., Darrow, W.W. y Phillips-Plummer, L. (1998). Pathways to prostitution: The chronology of sexual and drug abuse milestones. The Journal of Sex Research, 35 (4), 333-240.

Potterat, J.J., Brewer, D.D., Muth, S.Q., Rothenberg, R.B., Woodhouse, D.E., Muth, J.B., Stities, H.K. y Brody, S. (2004). Mortality in a long-term open cohort of prostitute women. American Journal of Epidemiology, 159 (8), 778-785. 
Prostitution Research. (1999). Swedish Law on Prostitution. http://www.prostitutionresearch.com/swedish.html (13 Marzo 2004)

Rao V., Gupta I., Lokshin M. y Jana S. (2001). Sex workers and the cost of safe sex: the compensating differential for condom use among Calcutta prostitutes. Journal of Development Economics, 71, (2), 585-603.

Raphael, J. y Shapiro, D.L. (2004). Violence in indoor and outdoor prostitution venues. Violence against women, 10 (2), 126-139.

Ratiff, E.A. (2000). Empowerment for sex workers? Notes from the Philippines. Research for sex work, 3, 12-14. http://www.nswp.org/r4sw/ (06 Octubre 2003).

Reback, C.J., Lombardi, E.L., Simon, P.A. y Frye, D.M. (2005). HIV seroprevalence and risk behaviors among transgendered women who exchanged sex comparison with those who do not. Journal of Psychology and Human Sexuality. 17, 5-22.

Reforma del Código Penal (2003). Delitos de prostitución. http://www.boschonline.net/Novedades/Legislacion/Otrosdocs/cp0203.html (15 Marzo 2007).

Ribeiro, M., Silva, M.C., Bessa, F. y Sacramento, O. (2005). Prostituiçao abrigada em clubes (zonas fronteiriças do Minho e Trás-os-Montes). Prácticas, riscos e saúde. Lisboa: Comissao para a Igualdade e para os Dereitos das Mulheres.

Ribeiro, M. y Sacramento, O. (2005). Violence against prostitutes. Findings of research in the spanish-portuguese frontier region. European Journal of Women's Studies, 12 (1), $61-81$

Rivera, C. (s.f.) La prostitución como fenómeno social regulado por los estados. Una perspectiva histórica de los diversos sistemas en el s. XX. http://www.cajpe.org.pe/rij/bases/nuevdh/dh2/ceci.htm (06 Julio 2005).

Rodríguez, M.A. (2005). Enfermedades prevalentes y percepción de la salud en la prostitución femenina en España. Ponencia presentada en el I Congreso Internacional y Virtual Prostitución: comercio de personas sin fronteras. Univerisidad de Islas Baleares. 
Rodríguez, N. (2005). Mujeres en Prostitución. Cuerpos fuera de lugar. Ponencia presentada en el I Congreso Internacional y Virtual Prostitución: comercio de personas sin fronteras. Univerisidad de Islas Baleares.

Romans, S.E., Potter, K., Martín, J. Y Herbison, P. (2001). The mental and physical health of female sex workers: a comparative study. Australian and New Zealand Journal of Psychiatry. 35. 75-80.

Rosenberg, M. (1989). Society and the adolescent Self-image. Revised edition. Middletown, CT: Wesleyan University Press.

Rubenstein, C.M. y Shaver, P. (1982). The experience of loneliness. En L.A. Peplau y D. Perlman (Eds.), Loneliness: a sourcebook of current theory, research and therapy. Nueva York: John Wiley and sons.

Salas, A. (2004). El año que trafiqué con mujeres. Madrid: Temas de hoy.

Sanchez, J., Campos, P., Curtois, B., Gutierrez, L., Carrillo, C., Alarcon, J., Gotuzzo, E., Hughes, J.,Watts, D., Hillier, S., Buchanan, K., y Colmes, K. (2003). Prevention of sexually transmitted diseases (STDs) in female sex workers. American Sexually Transmitted Diseases. 30 (4), 273-279.

Sanders, E. (2006). Researching prostitution: The methodological challenges of researching sex work in Thailand. http://www.leeds.ac.uk/genderstudies/events/epapers/epaper6\%20Erin\%20Sanders.pdf (23 Julio 2006).

Sanders, T. (2004). A continuum of risk? The management of health, physical and emotional risks by female sex workers. Sociology of Health \& Illness, 26 (5), 1-18.

Sanders, T. (2005). Sex work. A risky business. Devon: Willan Publishing.

Sanders, T. (2006). Sexing up the subject: Methodological nuances in the female sex industry. Sexualities, 9 (4), 471-490.

Saunders, P. (2005). Traffic violations. Determining the meaning of violence in sexual trafficking versus sex work. Journal of Interpersonal Violence, 20 (3), 343-360.

Savitz, L. y Rosen, L. (1988). The sexuality of prostitutes: sexual enjoyment reported by "streetwalkers". The journal of sex research, 24, 200-208. 
Shaver, F.M. (2005). Sex work research. Methodological and ethical challenges. Journal of Interpersonal Violence, 20 (3), 296-319.

Simpson, J.A. y Rholes, W.S. (1998). Attachment theory and close relationships. Nueva York: The Guilford Press.

Simpson, J.A. y Tran, S. (2006). The needs, benefits, and perils of close relationships. En P. Noller y J. Feeney, Close relationships: Functions, forms and processes. Great Britain: Psychology press.

Sirgy, J. M. (2002). Psychology of quality of life. Dordrecht: Kluwer Academic Publishers.

Snell, W.E. (1995). The Multidimensional Sexual Self-Concept Questionnaire. En C.M. Davis, Handbook of sexuality-related measures. Thousand Oaks: Sage Publications.

Sobo, E.J. (1995). Finance, romance, social support, and condom use among impoverished inner-city women. Human Organization, 54 (2), 115-128.

Solana, J. L. (2003). Prostitución, tráfico e inmigración de mujeres. Granada: Editorial Comares

$\begin{array}{lllll}\text { Solidaridad.net (2007). La } & \text { La } & \text { en }\end{array}$ (http://www.solidaridad.net/noticias.php?not=4646 (16 Julio 2007)

Sternberg, R.J. y Barner, M. (1988). The psychology of love. New Haven: Yale University Press.

Steverink, N. y Lindenberg, S. (2006). Which social needs are important for subjective wellbeing? What happens to them with aging?, Psychology and Aging, 21, 281-290.

Surrat, H.L., Inciardi, J.A., Kurtz, S.P. y Kiley, M.C. (2004). Sex work and drug use in a subcultura of violence. Crime \& delinquency, 50 (1), 43-59.

SWOP-USA (2007). International Day to End Violence Against Sex Workers. http://www.swopusa.org/dec17/locations.htm (27 Enero 2008).

Tep, M. y Ek, S. (2000). Vietnamese sex workers in Cambodia. Research for sex work, 3, 20. http://www.nswp.org/r4sw/ (06 Octubre 2003).

Touzé,A., de San josé, S.,Coursaget, P., Almirall, M.R., Palacio, V.,Meijer, C., Kornegay, J. y Bosch, F.X. (2001). Prevalence of anti-human papillomavirus type 16,18,31 and 58 
particles in women in the general population and in prostitutes. Journal of Clinical Microbiology, 39 (12), 4344-4348.

Uribe, P., y Hernández, G. (2000). Sexo comercial e infecciones de transmisión sexual (ITS) en la ciudad de México. Consejo Nacional de la lucha contra el SIDA, 23, 203-219.

Uribe-Salas, F., Conde-González, C.J., Juárez-Figeroa, L. Y Hernández-Castellanos, A. (2003). Sociodemographic Dynamics and sexually transmitted infections in female sex workers at the mexican-guatemalan border. Sexually transmitted diseases, 30 (3), 266-271.

Van den Borne, F. (2003). I am not a prostitute: Discords in targeted HIVIAIDS prevention interventions in urban and trading centers in Malawi. http://www.hsph.harvard.edu/takemi/RP214.pdf (15 Enero 2004)

Van der Helm, T. (2004). Mobility in prostitution, the impact of policy and the implications for health: a case study from The Netherlands. En S. Day y H. Ward (Ed.), Sex work, mobility and health in Europe. London: Kegan Paul Limited.

Van Doorninck, M. y Timmerman, P. (2005). Declaración de los derechos de las/os trabajadoras/es del sexo. International Committee on the Rights of Sex Workers in Europe. http://www.sexworkeurope.org/ (12 Julio 2005).

Vandepitte, J. et al. (2006). Estimates of the number of female sex workers in different regions of the World. Sexually Transmitted Infections, 82, 18-25.

Vanwesenbeeck, I. (2001). Another decade of social scientific work on sex work: A review of research 1990-2000. Annual Review of sex research. 12, 242-289.

Vazquez, A.J., Jimenez, R. y Vazquez-Morejón R. (2004). Escala de autoestima de Rosenberg: fiabilidad y validez en población clínica española. Apuntes de Psicología, $22(2), 247-255$.

Vecina, C. (2005). Explotación sexual de mujeres inmigrantes en Mallorca. Comunicación presentada en el I Congreso Internacional y Virtual Prostitución: comercio de personas sin fronteras. Universidad de Islas Baleares. 
Verdugo, M.A. (2006). Cómo mejorar la calidad de vida de las personas con discapacidad. Instrumentos y estrategias de evaluación. Salamanca: Amarú Ediciones.

Wahba, M. A., Bridwell, L. G. (1976). Maslow reconsidered: A review of research on the need hierarchy theory. Organizational Behavior and Human Performance, 15, 212240.

Ward, H., Day, S., Green, A., Cooper, K. y Weber, J. (2004). Declining prevalence of STI in the London sex industry, 1985 to 2002. Sexually Transmitted Infections, 80, 374-378.

Ward, H., Day, S. Y Weber, J. (1999). Risky business: health and safety in the sex industry over a 9 year period. Sexually transmitted infections, 75, 340-343.

Warr, D.J. y Pyett, P.M. (1999). Difficult relations: sex work, love and intimacy. Sociology of Health \& IIInes. 21 (3), 290-309.

Weiss, R. S. (1973). Loneliness: The experience of emotional and social isolation. Massachusetts: MIT Press.

Weiss, R.S. (1982). Issues in the study of loneliness. En L. Peplau y D. Perlman (Eds.), Loneliness: a sourcebook of current theory, research and therapy. Nueva York: John Wiley and sons.

Weitzer, D. (2005a). New directions in research on prostitution. Crime, Law \& Change. 43, 211-235.

Weitzer, D. (2005b).Flawed Theory and Method in studies of prostitution. Violence against women, $11(7)$, 934-949.

West, J. (2000). Extended review. Reworking sex work. Work, Employment and Society, 14 (2), 395-399.

WHOQOL Group (1994). Development of the WHOQOL: Rationale and current status. International Journal of Mental Health. 23, 24-56.

WHOQOL Group (1995). Measuring quality of life: the development of the world Health Organization Quality of Life Instrument (WHOQOL). Geneva: World Health Organization. 
Wijers, M. y Chew, L. (1997). Trafficking in women. Force labour \& Slavery like practices. STV. Utrech.

Wijers, M. (2001). Política de la Unión Europea sobre el tráfico de mujeres. En Mariagrazia Rossili (Ed.), Políticas de genero en la Unión Europea. Madrid: Narcea.

Williamson, C. y Folaron, G. (2001). Violence, risk and survival strategies of street prostitution. Western Journal of Nursing Research, 23 (5), 463-475.

Wolfers, I. (1999). Appropiate health services for sex workers. Research for sex work, 2, 1-3. http://www.nswp.org/r4sw/ (06 Octubre 2003).

Wolfers, I. (2000). Empowerment of sex workers \& HIV prevention. Research for sex work, 3, 1-3. http://www.nswp.org/r4sw/ (06 Octubre 2003).

Woods, W.J., Binson, D., Mayne, T.J., Rebchook, G.M. (2001). Facilities and HIV prevention in bathhouse and sex club environments. The Journal of Sex Research, 38 (1), 68-74.

World Health Organization (1958). The first ten years. The Health Organization. Geneva: World Health Organization.

World Health Organization (1994). Quality of life assessment. An annotated bibliography. Geneva: Division of Mental Health, World Health Organization. 


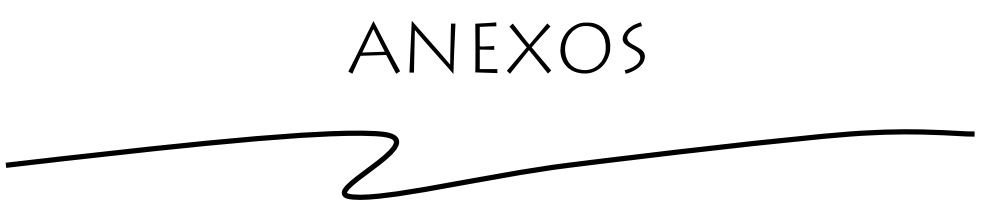




\section{Variables sociodemográficas y relacionadas con el ejercicio de la prostitución}

1 Clave:

2 Género: 1. Mujer.

2. Varón.

3. Transexual (De hombre a mujer)

3 ¿Qué edad tienes?

$4 \quad$ ¿Cuál es tu nacionalidad? $\quad 1 . \quad$ Española

2. Extranjera

1. Africanas.

2. Europeas del Este.

3. Latinoamericanas.

4. Chinas.

5. Unión Europea.

6. Otras

6 ¿Hasta qué edad asististe a la escuela?

$7 \quad$ ¿Qué nivel de estudios has alcanzado?

1. No sabe ni leer ni escribir (en su idioma)

2. Primaria.

3. Secundaria.

4. Módulos/FP.

5. Estudios Universitarios.

8 ¿Qué profesión tenías antes de ejercer prostitución?

$9 \quad$ ¿Actualmente trabajas en otro trabajo? $\quad 1$. Sí.

10 ¿Recibes algún tipo de ayuda social?

2. No

¿Cuál es tú media de ingresos económicos mensuales? (€/mes)

11. Prostitución

12. Otros trabajos

13. Ayudas

14.Total

15 ¿Qué edad tenías cuando te prostituiste la primera vez? 


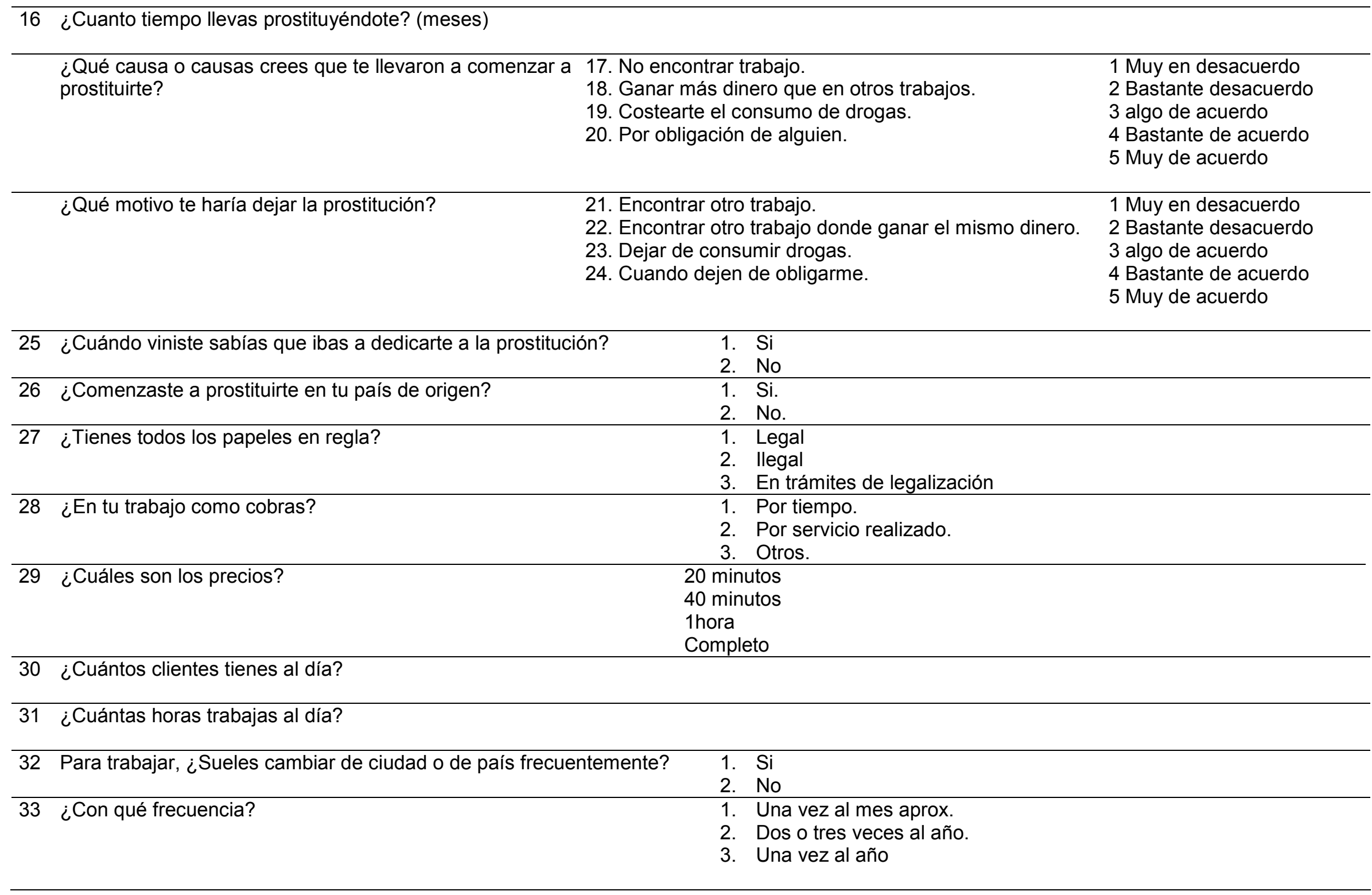




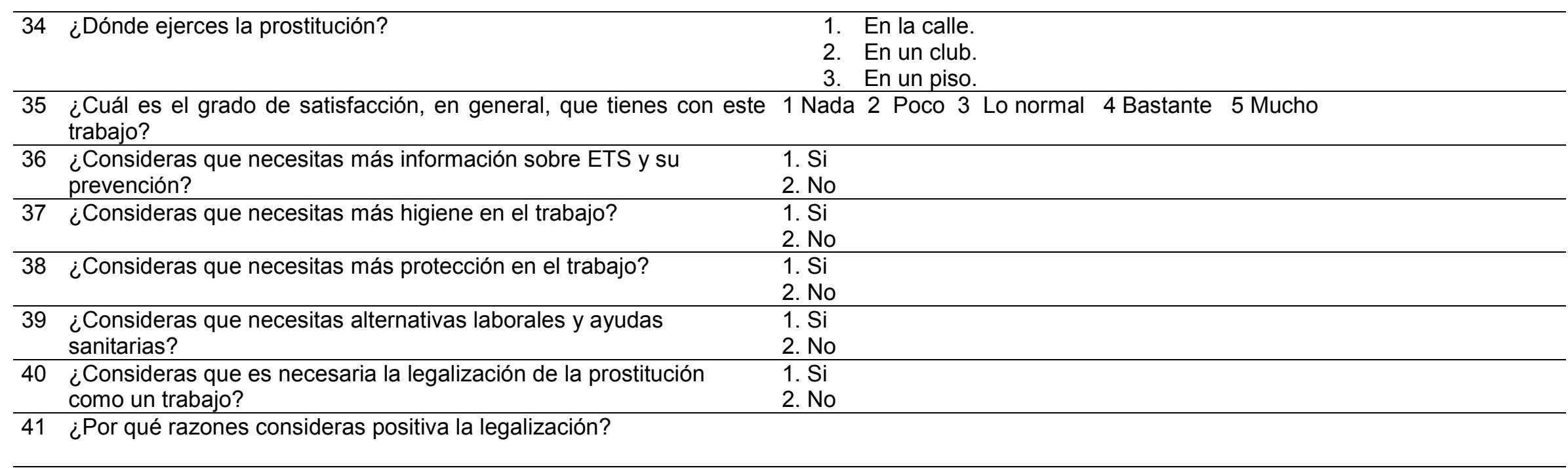

\section{Vida familiar y social}

\begin{tabular}{|c|c|}
\hline 42 Estado civil & $\begin{array}{l}\text { 1. Soltera (Sin pareja o con parejas de menos de } 6 \text { meses sigue en 19) } \\
\text { 2. Casada } \\
\text { 3. Separada/divorciada } \\
\text { 4. Viuda } \\
\text { 5. Pareja estable. (de más de } 6 \text { meses) }\end{array}$ \\
\hline 43 ¿Con qué personas convives? & $\begin{array}{l}\text { 1. Con mi pareja } \\
\text { 2. Con mi familia de origen (padres, hermanos, etc.) } \\
\text { 3. Amigos/as } \\
\text { 4. Iguales (otras mujeres que ejercen prostitución) } \\
\text { 5. Sola }\end{array}$ \\
\hline 44 ¿Cuántos hijos/as tienes? & \\
\hline 45 ¿Con quién viven tus hijos/as? & $\begin{array}{l}\text { 1. Conmigo } \\
\text { 2. Conmigo y el padre } \\
\text { 3. Con los abuelos } \\
\text { 4. En los servicios sociales }\end{array}$ \\
\hline $\begin{array}{l}46 \text { ¿El padre se hizo cargo de sus responsabilidades económicas en } \\
\text { cuanto a ese niño/a? }\end{array}$ & $\begin{array}{ll}\text { 1. } & \mathrm{Si} \\
\text { 2. } & \text { No }\end{array}$ \\
\hline
\end{tabular}


1. Separación debida a malos tratos y abusos.

2. Separación debida a una/s infidelidad/es.

48 ¿Dónde se encuentra tu familia de origen? (Padres, hermanos, etc.)

3. Separación debida a que la pareja se acabó por otros motivos.

1. En mi ciudad.

2. En otra ciudad.

49 ¿Dónde se encuentran tus amigos/as más íntimos?

3. En otro país.

50 ¿Tienes alguna amiga íntima en el lugar de trabajo o que hayas

1. En la misma

donde vivo yo.

3. En otro país. conocido en el lugar de trabajo?

1. $\mathrm{Si}$

51 ¿Estás satisfecha/o con el tipo y frecuencia de contacto que 1 Nada 2 Un poco 3 Lo normal 4 Bastante 5 Mucho mantienes con tu familia de origen?

52 ¿Estás satisfecha con la frecuencia y el tipo de contacto que 1 Nada 2 Un poco 3 Lo normal 4 Bastante 5 Mucho mantienes con tus hijos/as?

53 ¿Estás satisfecha/o con el tipo y frecuencia de contacto que mantienes con tus amistades más íntimas?

54 ¿Estás satisfecha con el tipo de relación y frecuencia de contacto 1 Nada 2 Un poco 3 Lo normal 4 Bastante 5 Mucho que mantienes con tus compañeras/os de trabajo?

\section{Estado de salud física, psicológica y sexual}

\begin{tabular}{|c|c|c|c|}
\hline 55 & ¿Acudes a los servicios sociosanitarios públicos? & $\begin{array}{ll}\text { 1. Sí } \\
\text { 2. No }\end{array}$ & \\
\hline 56 & ¿Por qué razón no acudes a este tipo de servicios? & & \\
\hline 57 & ¿Te haces reconocimientos médicos? & $\begin{array}{ll}\text { 1. } & \mathrm{Si} \\
\text { 2. } & \mathrm{No}\end{array}$ & \\
\hline & ¿Con qué frecuencia? & $\begin{array}{l}\text { 1. Cada } 3 \text { meses o menos } \\
\text { 2. Cada } 6 \text { meses más o menos. } \\
\text { 3. Uno al año. }\end{array}$ & \\
\hline 59 & ¿Actualmente consumes algún tipo de droga? & $\begin{array}{ll}\text { 1. } & \mathrm{Si} \\
\text { 2. } & \text { No } \\
\end{array}$ & \\
\hline 60 & ¿Cuántos años llevas consumiendo o has consumido? & & \\
\hline 61 & $\begin{array}{l}\text { 0. Nunca } \\
\text { 1. } 1 \text { ó } 2 \text { veces al año. } \\
\text { 2. } 1 \text { ó } 2 \text { veces al mes. } \\
\text { 3. } 1 \text { ó } 2 \text { veces por semana. } \\
\text { 4. Diariamente }\end{array}$ & 64 Tabaco & $\begin{array}{l}\text { 0. Nunca } \\
\text { 1. } 1 \text { ó } 2 \text { veces al año. } \\
\text { 2. } 1 \text { ó } 2 \text { veces al mes. } \\
\text { 3. } 1 \text { ó } 2 \text { veces por semana. } \\
\text { 4. Diariamente }\end{array}$ \\
\hline
\end{tabular}


1. 1 ó 2 veces al año.

1. 1 ó 2 veces al año.

2. 1 ó 2 veces al mes.

2. 1 ó 2 veces al mes.

3. 1 ó 2 veces por semana.

3. 1 ó 2 veces por semana.

4. Diariamente

4. Diariamente

63 Hachís, Marihuana

0 . Nunca

1. 1 ó 2 veces al año.

2. 1 ó 2 veces al mes.

3. 1 ó 2 veces por semana.

4. Diariamente

\begin{tabular}{|c|c|c|c|}
\hline & 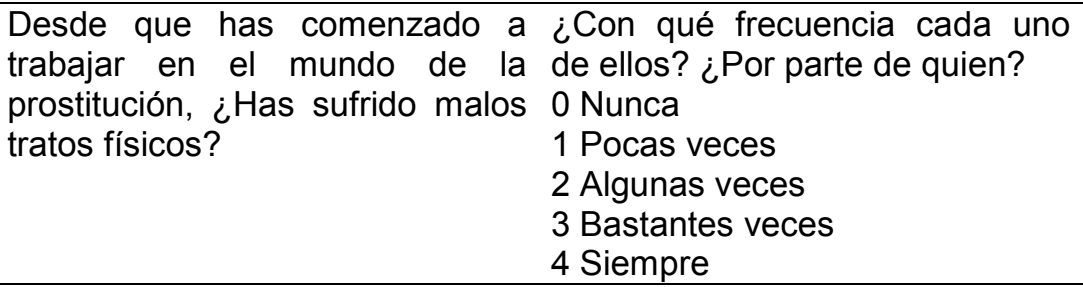 & $\begin{array}{l}\text { Patadas, golpes, empujones, } \\
\text { agresiones con armas... }\end{array}$ & $\begin{array}{l}\text { 64. El cliente } \\
\text { 65. Mi jefa/e. } \\
\text { 66. Compañeras. } \\
\text { 67. Mi pareja. } \\
\text { 68. Mi familia. } \\
\text { 69. Vecinos y/o amigos. } \\
\text { 70. Policía. }\end{array}$ \\
\hline 71 & \multicolumn{3}{|l|}{$\begin{array}{l}\text { ¿A qué edad mantuviste tus primeras actividades sexuales } \\
\text { consentidas? (Actividades sexuales sin penetración) }\end{array}$} \\
\hline 72 & \multicolumn{3}{|l|}{$\begin{array}{l}\text { ¿A qué edad mantuviste tu primera relación sexual coital, con } \\
\text { penetración, vaginal o anal, consentida? }\end{array}$} \\
\hline 73 & \multicolumn{3}{|l|}{$\begin{array}{l}\text { ¿Cuántas parejas sexuales has tenido hasta comenzar a } \\
\text { prostituirte? }\end{array}$} \\
\hline 74 & ¿Usas algún método anticonceptivo? & $\begin{array}{ll}\text { 1. } & \mathrm{Si} \\
\text { 2. } & \text { No } \\
\end{array}$ & \\
\hline 75 & ¿Cuándo usas preservativo (masculino o femenino)? & $\begin{array}{l}\text { 1. Siempre, en todas las } \\
\text { 2. Sólo con mi cliente. }\end{array}$ & es. \\
\hline 76 & $\begin{array}{l}\text { ¿Tuviste algún embarazo (a término) antes de entrar en el mundo de } \\
\text { la prostitución? }\end{array}$ & $\begin{array}{ll}\text { 1. Sí } \\
\text { 2. No }\end{array}$ & \\
\hline 77 & ¿El embarazo fue deseado? ¿Buscabas tener ese hijo o hija? & $\begin{array}{ll}\text { 1. } & \text { Si } \\
\text { 2. } & \text { No }\end{array}$ & \\
\hline 78 & \multicolumn{3}{|l|}{ ¿A qué edad has tenido tu primer embarazo? } \\
\hline 79 & \multicolumn{3}{|l|}{$\begin{array}{l}\text { ¿Tuviste algún aborto provocado, antes de entrar en el mundo de la } \\
\text { prostitución? ¿Cuántos? }\end{array}$} \\
\hline 80 & \multicolumn{3}{|l|}{$\begin{array}{l}\text { ¿Has tenido algún aborto provocado durante el ejercicio de la } \\
\text { prostitución? ¿Cuántos? }\end{array}$} \\
\hline
\end{tabular}




\begin{tabular}{|c|c|c|c|}
\hline 81 & ¿Has tenido alguna enfermedad de transmisión sexual? & $\begin{array}{ll}\text { 1. Sí } \\
\text { 2. No }\end{array}$ & \\
\hline 82 & ¿Conoces tu estado serológico frente al VIH/SIDA? & $\begin{array}{l}\text { 1. Soy seronegativa } \\
\text { 2. Soy seropositiva }\end{array}$ & \\
\hline & 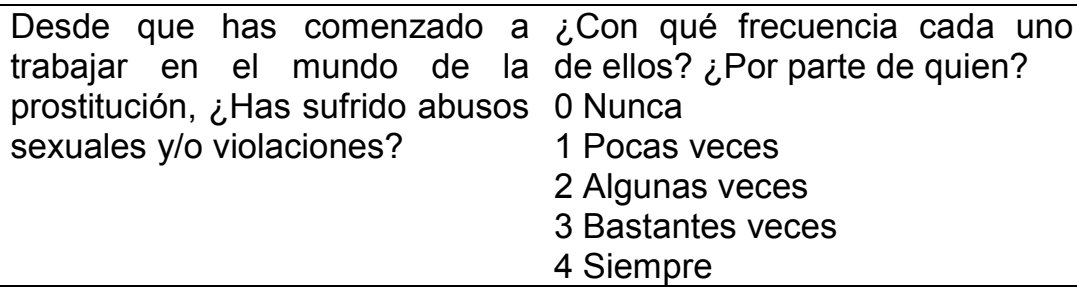 & $\begin{array}{l}\text { Caricias, pellizcos, besos, etc. no } \\
\text { deseados, obligarte a realizar } \\
\text { conductas sexuales vejatorias } \\
\text { (humillantes) }\end{array}$ & $\begin{array}{l}83 \text { El cliente } \\
84 \text { Mi jefa/e. } \\
85 \text { Compañeras. } \\
86 \text { Mi pareja. } \\
87 \text { Mi familia. } \\
88 \text { Vecinos y/o amigos. } \\
89 \text { Policía. }\end{array}$ \\
\hline 90 & $\begin{array}{l}\text { ¿Alguna vez has sentido excitación sexual o placer sexual, con } \\
\text { alguno de tus clientes? }\end{array}$ & $\begin{array}{l}\text { 1. Si, alguna vez. } \\
\text { 2. Si, bastantes veces. } \\
\text { 3. Ninguna vez. }\end{array}$ & \\
\hline
\end{tabular}

\section{Salud psicológica (Depresión, Ansiedad y Autoestima)}

\begin{tabular}{|c|c|c|}
\hline $\begin{array}{l}\text { Lea } \\
\text { uste }\end{array}$ & $\begin{array}{l}\text { entamente la lista que presentamos en las páginas siguien } \\
\text { e ha pasado en las últimas semanas, incluyendo el día de } \\
0 \text { si no ha tenido esa molestia en absoluto. } \\
1 \text { Si la ha tenido un poco presente. } \\
2 \text { si la ha tenido moderadamente. } \\
3 \text { si la ha tenido bastante. } \\
4 \text { si la ha tenido mucho o extremadamente. }\end{array}$ & \\
\hline 91 & Pérdida de peso o de placer sexual & 01234 \\
\hline 92 & Sentirse baja de energías o decaída & 01234 \\
\hline 93 & Pensamientos suicidas, o ideas de acabar con su vida & 01234 \\
\hline 94 & Llorar fácilmente & 01234 \\
\hline 95 & La sensación de estar atrapada o como encerrada & 01234 \\
\hline 96 & Culparse a sí misma de todo lo que pasa & 01234 \\
\hline 97 & Sentirse sola & 01234 \\
\hline 98 & Sentirse triste & 01234 \\
\hline 99 & Preocuparse demasiado por todo & 01234 \\
\hline 100 & No sentir interés por nada & 01234 \\
\hline 101 & Sentirse desesperanzada con respecto al futuro & 01234 \\
\hline 102 & Sentir que todo requiere un gran esfuerzo & 01234 \\
\hline
\end{tabular}




\section{Necesidades interpersonales básicas}

En estas páginas encontrarás una serie de afirmaciones que deberás responder individualmente acerca de tus relaciones sociales. Por favor, léelas atentamente e indica el grado en el cual estás de acuerdo o en desacuerdo con cada una de ellas aplicándotelas a ti mismo/a, usando una escala de 7 puntos para contestar cada una de las afirmaciones.

Por favor, tómate un momento para pensar sobre cómo fueron las relaciones con tu pareja, tu familia y tus amigos durante el año pasado. Marca el número que mejor refleja el grado con el cual cada una de las siguientes frases describe tus pensamientos y sentimientos del año pasado. Por favor, intenta responder cada una de las frases.

"Durante el año pasado..."

$\begin{array}{llllll}1 \text { Muy en } & 2 \text { Bastante en } & 3 \text { Algo en } & 4 \text { Intermedio } & 5 \text { Algo de acuerdo } & 6 \text { Bastante de acuerdo }\end{array}$

desacuerdo desacuerdo

132 me sentí solo/a cuando estaba con mi familia

133 me sentí parte de un grupo de amigos/as.

134 tuve una pareja con la que mostraba la mayoría de mis pensamientos y sentimientos íntimos.

\begin{tabular}{ll} 
& 1234567 \\
\hline & 1234567 \\
\hline & 1234567 \\
\hline 1234567 \\
1234567 \\
1234567 \\
1234567 \\
1234567 \\
1234567 \\
1234567 \\
1234567 \\
1234567 \\
1234567 \\
1234567 \\
1234567
\end{tabular}

no hubo nadie en mi familia con el que podía contar para buscar apoyo y ánimo, aunque lo deseaba

mis amigos comprendían mis razones y argumentos.

137 tuve una pareja o un esposo/a que me dio el apoyo y ánimo que necesité.

138 no tuve un/a amigo/a con el que compartir mis puntos de vista aunque lo deseaba.

139 me sentí unido/a a mi familia.

140 pude contar con la ayuda de mis amigos/as.

141 desee tener una relación de pareja más satisfactoria.

142 me sentí parte de mi familia.

143 mi familia realmente se preocupó de mí.

144 no tuve un amigo/a que me comprendiera, aunque lo deseaba.

145 tuve una pareja a cuya felicidad he contribuido.

146 tuve insatisfecha mi necesidad de tener una relación de pareja íntima.

1234567

Satisfacción y depresión sexual

A continuación vas a ver una serie de afirmaciones sobre la vida sexual de las personas. Piensa en tu vida sexual durante los últimos 6 meses y di

en qué grado te identificas con cada frase que aparece a continuación.

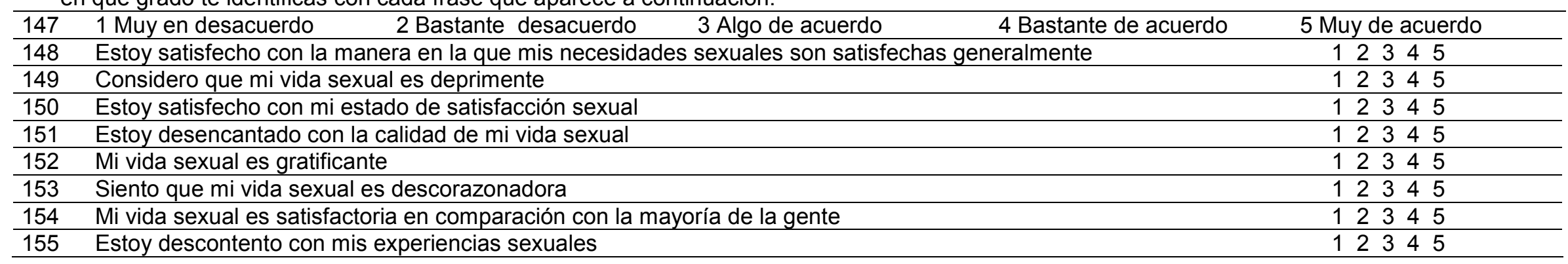




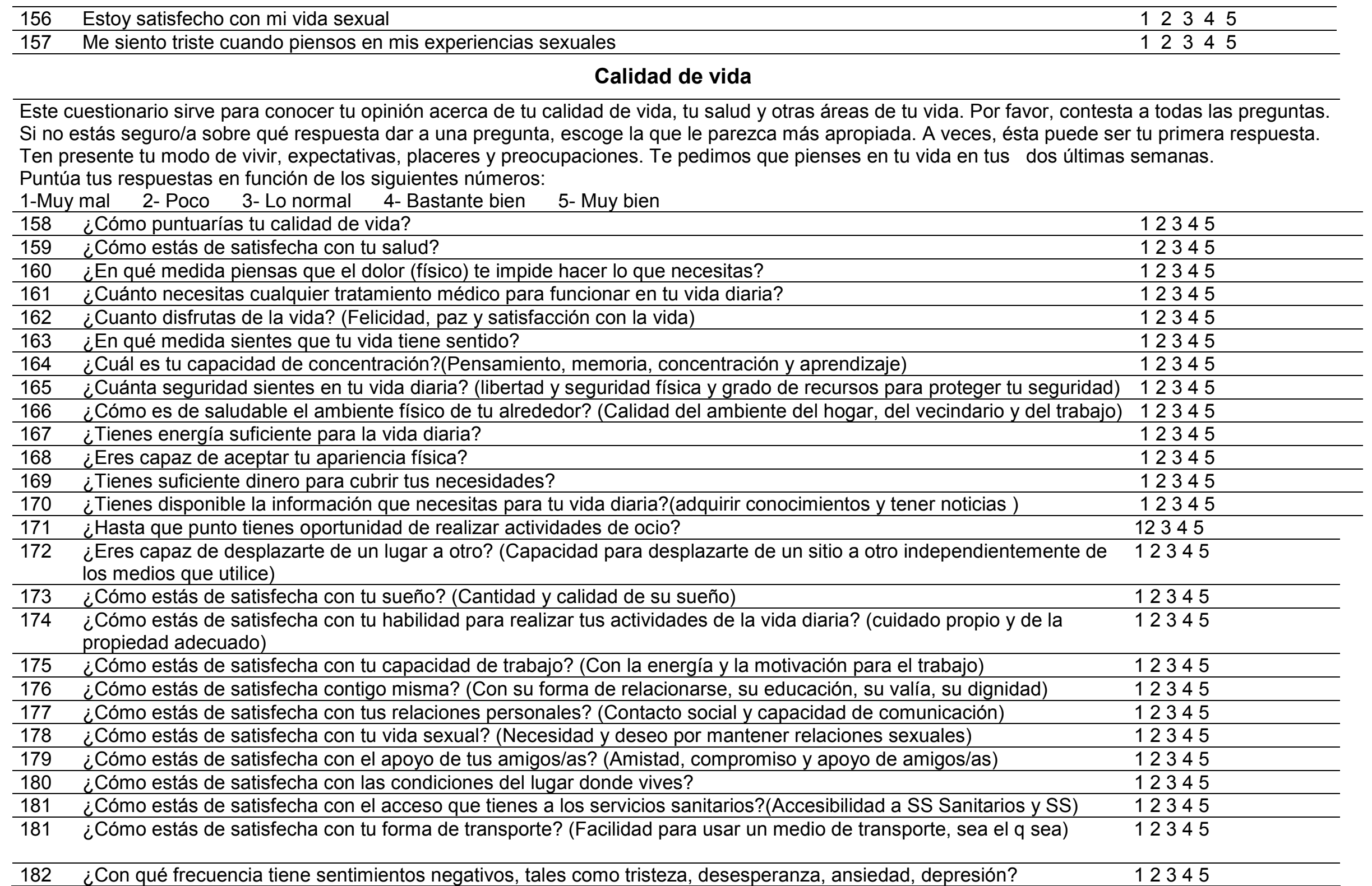


